Synthèses

\title{
Transformations agricoles et agroalimentaires
}

\section{Entre écologie et capitalisme}

Gilles Allaire, Benoit Daviron, coordinateurs
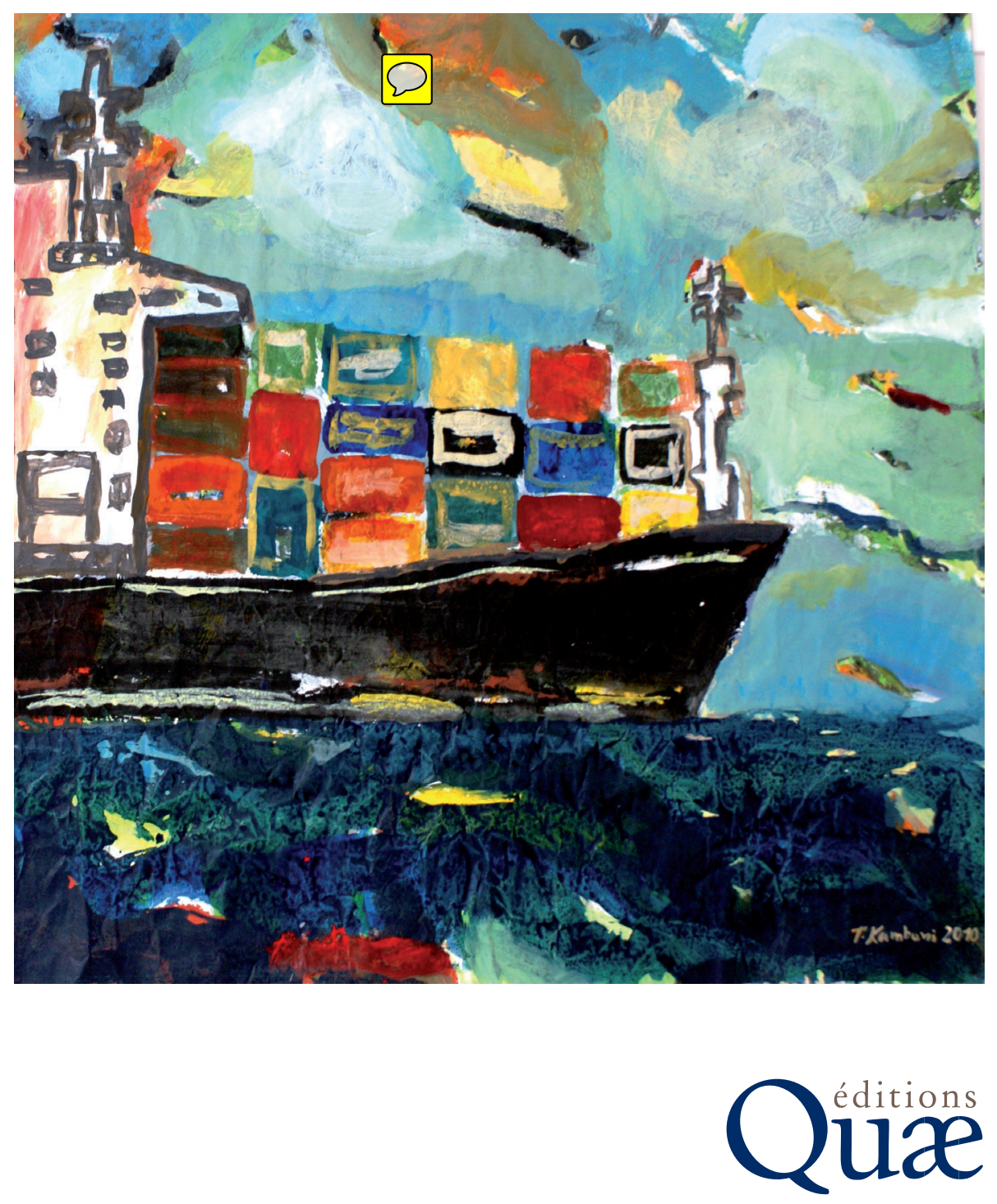



\section{Transformations agricoles et agroalimentaires}

Entre écologie et capitalisme

Gilles Allaire et Benoit Daviron, coordinateurs 


\section{Remerciements}

Cet ouvrage cherche à rendre compte de l'évolution des analyses et des perspectives conduites dans le champ de l'institutionnalisme et portant sur le secteur agroalimentaire depuis la parution de l'ouvrage La grande transformation de l'agriculture publié en 1995 sous la coordination de Gilles Allaire et Robert Boyer. La plupart des chapitres qu'il inclut sont issus de communications présentées lors d'un séminaire organisé à Montpellier en juin 2014 sous l'intitulé « Renouveler les approches institutionnalistes sur l'agriculture et l'alimentation : La "grande transformation" 20 ans après ». Cet ouvrage et le séminaire de 2014 ont bénéficié du soutien financier du Cirad et de l'Inra. Nous remercions les responsables de ces organismes qui ont accepté de soutenir ce projet, en particulier Paule Moustier, Paul Colonna et Éric Cahuzac, ainsi que toutes les personnes qui ont participé à ce séminaire et à son organisation scientifique. Nous remercions aussi Pascale Morin pour son aide dans l'organisation matérielle de celui-ci.

Nous remercions Laure Cordesse, Antoine Doré (Inra, UMR Agir) et Gaël Plumecocq (Inra, UMR Agir) pour la traduction de l'anglais vers le français de différents chapitres. Signalons par ailleurs que les traductions de citations en langue étrangère dans les autres chapitres ont été effectuées par les auteurs (sauf mentions contraires).

Nous remercions enfin Françoise Réolon et Yann Lézénès pour la grande qualité du travail d'édition.

Nous remercions Laure Cordesse et Véronique Brill pour leur aide dans la révision de la version finale des épreuves et pour leur soutien méritoire durant toute la poursuite de ce projet.

Gilles Allaire, Benoit Daviron 


\section{Table des matières}

Introduction

Industrialisation et socialisation de l'agriculture

G. Allaire, B. DAVIRON

Partie I. LA QUestion AgRAire

DANS UNE PERSPECTIVE ÉCOLOGIQUE, GÉOPOLITIQUE ET HISTORIQUE

1. Transitions socio-métaboliques globales

F. KRAUSMANN, M. FisCHER-KoWALSKI

2. Capitalocène : une histoire conjointe du système Terre et des systèmes Monde

C. BONNEUIL, J.-B. FRESSOZ

3. Énergie, biomasse, hégémonie : une histoire longue des transformations des agricultures

B. DAVIRON, G. ALLAIRE

4. La Chine, le nouveau stockeur en dernier ressort après les États-Unis ?

F. CourleuX, J.-N. Depeyrot

5. La renaissance de l'agriculture japonaise ?

D. H. WHITTAKER, R. SCOLLAY

6. Coévolution des pratiques agricoles et du mode d'usage de l'eau à Almeria (Andalousie)

A. BUCHS, V. BOISVERT

7. La race bovine Holstein, institution de la modernisation de l'agriculture entre bien marchand et bien commun

J. LABATUT, G. TESNIÈRE

PARTIE II. LES TRAITS ORIGINAUX DES AGRICULTURES ET DES SYSTÈMES ALIMENTAIRES DANS LES SOCIÉTÉS DU XXI ${ }^{\mathrm{e}}$ SIÈCLE

8. La bioéconomie : vers une nouvelle organisation des systèmes agricoles et industriels ?

P. COLONNA, E. VALCESCHINI

9. Transition du régime agro-industriel européen vers la bioéconomie :

life sciences versus agroécologie

L. LEVIDOW, N. BÉFORT, M. NIEDDU, F.-D. VIVIEN 
10. L'agriculture biologique en France, entre projet critique et conventionnalisation

T. Poméon, E. FoullzeuX, S. Lemeilleur, A. Loconto

11. La sécurité sanitaire des aliments : un nouveau modèle de régulation européen

L. SAULAIS, E. VALCESCHINI

12. La nouvelle autocratie agroalimentaire

L. BUSCH

13. Libéralisation des marchés laitiers et différenciation régionale des régimes de concurrence

M. DERVILLÉ

14. Les organisations agricoles dans la Russie de Vladimir Poutine : une lecture commonsienne

P. GROUIEZ

15. Investissements fonciers à grande échelle et financiarisation de l'agriculture : une analyse par les filières agrofinancières

A. Ducastel, W. AnseEUW

\section{PARTIE III. DiVERsité, HYBRIDATION ET RENOUVELLEMENT DES APPROCHES INSTITUTIONNALISTES}

16. Les analyses en termes de «food regime » : une relecture

J. WILKINSON, D. GOODMAN

17. Théorie de la régulation et transformations de l'agriculture : nouveaux enjeux, nouvelles perspectives de recherche?

J.-M. TOUZARD, P. LABARTHE

18. Régime de connaissances et régulation sectorielle en agriculture

C. LAURENT, P. LANDEL

19. Le paquet de cigarettes neutre : des dangers de l'intelligence en sciences sociales

F. COCHOY

20. L'économie des conventions dans les études agroalimentaires anglophones : filiations avec l'école française, circulation et nouvelles perspectives

E. Cheyns, S. Ponte

21. L'ambivalence de la socialisation de l'agriculture

G. ALLAIRE

Références bibliographiques

Liste des auteurs 


\title{
Introduction
}

\section{Industrialisation et socialisation de l'agriculture}

\author{
G. Allaire, B. Daviron
}

\begin{abstract}
À l'heure des robots et du numérique, la terre (habitat, agriculture, paysage, planète) et la nourriture (du corps et de l'âme) sont parmi les préoccupations majeures dans les espaces médiatiques et politiques. L'industrie et les promesses d'abondance avaient peut-être fait oublier qu'elles sont au fondement des sociétés humaines. La crise alimentaire de 2008, qui a secoué plusieurs continents, a rappelé aux gouvernements l'enjeu de la sécurité alimentaire. Après des décennies d'abondance et une baisse tendancielle du prix des produits agricoles de base, de nouvelles fictions économiques, de la bioéconomie aux circuits courts, qui au-delà des médias paraissent influencer les milieux financiers, ont conduit à un retour de la question de la valeur de la terre et de l'agriculture en ces différentes composantes. La question de la santé, qui va avec celle des droits humains, prend également une place élargie, tant dans les politiques publiques (dont la recherche) que dans la production de normes alimentaires. Enfin, des mouvements sociaux transnationaux se sont emparés de la question de l'avenir de l'agriculture et de l'alimentation et de celle de la «bonne vie » (Monni et Pallottino, 2015).
\end{abstract}

Pour contribuer à cette réflexion sur notre avenir, celui de la terre et de la nourriture, cet ouvrage propose de prendre un large recul pour rendre compte de ce que nous appellerons la socialisation de l'agriculture, c'est-à-dire les modalités de son gouvernement tant par les politiques agricoles que par l'organisation des marchés ${ }^{1}$ dans un cadre national et international ; ce processus s'étend de la fin du XIX ${ }^{\mathrm{e}}$ siècle à la période actuelle, sous des formes historiques très diverses dans le temps et dans l'espace. Cette question est traitée dans l'ouvrage en mobilisant trois temporalités. La première est celle de la planète. La seconde celle des façons dont l'humanité, à différents stades de développement, mobilise matériaux et énergie sous la forme de régimes socioécologiques ou métaboliques successifs. L'industrialisation de l'agriculture s'inscrit dans le cadre d'un changement de régime avec l'utilisation de la biomasse fossile (charbon, pétrole). La troisième est celle du capitalisme, avec la

1. Il ne s'agit pas des marchés locaux à la Braudel, gérés par les villes et les marchands, mais des marchés intégrés à la sphère capitaliste au niveau national et international, marchés régis par des normes professionnelles établies à partir de la fin du XIX ${ }^{\mathrm{e}}$ siècle dans le cadre des politiques agricoles nationales, tant en Amérique qu'en Europe. Sur la distinction, sur la longue période, des régimes de marché, voir Allaire et Daviron (2006). 
succession des systèmes hégémoniques d'organisation du monde qui est considérée dans les premiers chapitres (ce qui n'exclut pas de multiples polarités). Les chapitres suivants embrassent le $\mathrm{xx}^{\mathrm{e}}$ siècle, porteur d'une série de processus de transformation de l'agriculture et de l'alimentation que l'on peut rassembler autour de trois tendances : la normalisation pour ce qui concerne la définition des produits et des marchés ; l'individualisation, pour ce qui concerne tant l'organisation sociale de la production que les formes de consommation ; l'industrialisation, c'est-à-dire l'utilisation croissante de l'énergie fossile, pour ce qui concerne le type de ressources mobilisées. L'accent est mis sur les transformations depuis les années 1970 et sur les dynamiques contemporaines en ce début de $\mathrm{XxI}^{\mathrm{e}}$ siècle.

\section{$\rightarrow$ Retour sur les lectures régulationniste et conventionnaliste de la grande transformation de l'agriculture et de l'alimentation}

Cet ouvrage réunit des recherches récentes réalisées par des auteurs de différents pays, économistes, sociologues, historiens et agronomes ${ }^{2}$. Sa particularité est d'offrir un prolongement, à vingt ans d'écart, à un précédent ouvrage collectif, La grande transformation de l'agriculture, publié en 1995 sous la direction de Gilles Allaire et Robert Boyer (1995). Cet ouvrage avait permis de réunir les travaux se rattachant aux approches régulationniste et conventionnaliste qui étudiaient l'agriculture et l'agroalimentaire et de proposer un agenda de recherche prometteur. Vingt ans après, qu'est-il advenu de ce programme ${ }^{3}$ ?

L'ouvrage de 1995 visait à appréhender la place de l'agriculture et de l'alimentation dans la période fordiste (qui démarre, pour l'agriculture, dans les années 1930 aux États-Unis et dans les années 1950 en France), et à rendre compte des crises et des recompositions de « l'agriculture du fordisme », c'est-à-dire des transformations alors en cours depuis une décennie (période faisant suite à la crise des années 1970). Les politiques agricoles que l'on peut associer au fordisme (le New deal aux ÉtatsUnis, la politique agricole gaulliste des années 1960 en France, la PAC définie en 1958, etc.), qui stabilisent les marchés agricoles et investissent fortement dans la recherche-développement et la formation, ont étendu le mouvement de socialisation de l'agriculture, d'une part en réglementant l'accès aux marchés, d'autre part en favorisant l'investissement privé (plutôt que collectif), ce qu'on appelle la « modernisation de l'agriculture ». La croissance importante de la production agricole

2. Les approches théoriques mobilisées dans l'ouvrage s'inscrivent dans plusieurs traditions institutionnalistes, la théorie de la régulation (chapitre 17), enrichie par la référence à l'institutionnalisme de John Commons (chapitres 6, 13, 14 et 21) et aux travaux d'Elinor Ostrom (chapitres 7 et 21), l'économie des conventions (chapitres 5, 6, 10 et 20) et la sociologie économique et politique (avec des approches originales, chapitres 12 et 19$)$.

3. Cette question a motivé l'organisation du colloque « La grande transformation de l'agriculture vingt ans après », qui s'est tenu les 16 et 17 juin 2014 à Montpellier SupAgro. Une majeure partie des chapitres de cet ouvrage est dérivée de communications présentées à ce colloque. Ce dernier a également inspiré la publication d'un dossier sur l'agriculture dans la Revue de la régulation $(2016,2): \mathrm{http} / / /$ regulation.revues. org/ ainsi que dans la Revue française de socio-économie (2017). 
mise en marché qui en a résulté est à attribuer à cette dynamique d'investissement et à un régime d'accumulation intensive (Bertrand, 1980). L'ouvrage de 1995, comme le souligne Wilkinson (1997), a posé la question de la « crise structurelle » de l'agriculture du fordisme, en mettant l'accent sur ses causes internes (crise des dispositifs de régulation sectoriels, des politiques agricoles, de l'agriculture familiale, du système de distribution et des modes de consommation alimentaires, etc.), se traduisant notamment dans des crises de qualité et des crises professionnelles.

Bien que l'analyse ait alors essentiellement porté sur la trajectoire de l'agriculture française, dans le contexte européen ${ }^{4}$, cet ouvrage a pu servir de référence pour l'étude d'autres situations locales car il proposait une approche régulationniste dans un cadre sectoriel. La notion de "régulation sectorielle », avec la notion de " régulation territoriale » apparaissaient comme une innovation des années 1990 au sein de la théorie de la régulation (Boyer et Saillard, 1995). L'ouvrage de 1995 appelait lui-même à des comparaisons entre secteurs et entre contextes nationaux.

Ce programme de travail se heurtait cependant à plusieurs difficultés, tenant notamment à la notion de régulation sectorielle elle-même. Robert Boyer (1990, 2015 : 136-138) a consacré la conceptualisation de la notion de régulation sectorielle à partir de l'analyse du cas du secteur viticole (Bartoli et Boulet, 1990), et cette référence est reprise dans la quasi-totalité des monographies sectorielles se référant à la théorie de la régulation. De ce point de vue, la notion de secteur est peu différente de la notion, classique en économie rurale, de filière et renvoie à l'émergence, dans la longue durée, d'institutions et d'organisations spécifiques identifiant des marchés particuliers (le vin, le lait, le sucre, etc.).

Une perspective différente était toutefois proposée par les premiers articles visant à traiter la question agraire avec une perspective régulationniste, l'un en anglais concernant l'agriculture des États-Unis, l'autre en français, concernant l'agriculture française, parus au même moment (Kenney et al., 1989 ; Allaire, 1988b). Ces articles s'intéressaient à la place de l'agriculture dans le modèle de développement fordiste, en considérant que la dynamique économique générale détermine largement la structure de l'agriculture, les formes de propriété, de production et de travail. Ici, la régulation sectorielle renvoie à un champ économique et politique que circonscrivent les politiques agricoles et les crises que connaît l'agriculture s'inscrivent dans la dynamique du capitalisme. Selon cette perspective, le sens de la notion de secteur se rapproche de celui qu'elle a dans l'analyse des politiques publiques (Muller, 1984, 1990) et renvoie tant à la définition d'un statut social de l'agriculteur qu'à des politiques économiques structurelles particulières. Dans la conception de la science politique, les « référentiels sectoriels » sont en correspondance avec un « référentiel global » qui, dans un contexte donné, correspond aux représentations qui orientent les politiques. D’une façon analogue, un régime d'accumulation et un

4. L'ouvrage de 1995 ignorait les recherches anglo-saxonnes qui, à la même période, faisaient également référence à la théorie de la régulation ou à l'économie des conventions ou qui, plus généralement, s'intéressaient aux rapports entre agriculture et capitalisme (pour un tour d'horizon, voir Buttel, 2001). Cette absence de dialogue a perduré comme le montrent les chapitres 17 (théorie de la régulation) et 20 (économie des conventions), en lien cependant avec un certain essoufflement de ces approches appliquées au domaine agroalimentaire tant dans le monde francophone qu'anglophone, jusqu'à un renouvellement récent sans lequel le présent ouvrage n'aurait pas existé. 
mode de régulation sectoriels s'inscrivent dans un modèle général de développement (pour reprendre les concepts de la théorie de la régulation). Dans cette perspective, des comparaisons internationales ou historiques concernant l'agriculture ou les systèmes alimentaires sont nécessairement des comparaisons des formes de capitalismes. C'est là une des ambitions du présent ouvrage. Les autres difficultés pour développer un programme de recherches prolongeant l'ouvrage de 1995 à partir du cadre régulationniste ou conventionnaliste des années 1990 tiennent d'une part à la difficulté de positionnner l'analyse au niveau de l'économie monde et d'autre part de la positionner au niveau de la planète, c'est-à-dire en considérant les rapports des sociétés à la nature. Nous allons maintenant présenter ces deux questions.

\section{La difficulté à se situer au niveau du système Monde}

Pour se situer au niveau du système monde la notion de « régime international » de la théorie de la régulation ne suffit pas (Mistral, 1982, 1986 ; Vidal, 2002). La focalisation de la théorie de la régulation sur le niveau national, y compris dans l'analyse des variétés du capitalisme, tend à minorer les forces transnationales, du moins avant que soit développée l'analyse du capitlaisme financier. Mais, plus généralement, les écoles hétérodoxes françaises se sont peu intéressées aux empires et il est finalement frappant de constater que les travaux de Braudel (1979) les ont peu inspirées, mais à l'inverse ont été investis par des chercheurs des pays qui ont eu un pouvoir hégémonique sur le monde : Pays-Bas, Royaume-Uni, États-Unis. Cela concerne en particulier l'agriculture, à quelques exceptions près (Bertrand et al., 1985 ; Tubiana, 1984).

À la même époque que les premiers travaux régulationnistes sur l'agriculture, des auteurs anglo-saxons, en mettant en avant le concept de «food regimes » (régimes agroalimentaires), ont eu d'emblée une ambition globale. Cette approche a été introduite par Harriet Friedmann et Philip McMichael (1989) $)^{5}$ qui se proposaient « d'explorer le rôle de l'agriculture dans le développement de l'économie mondiale capitaliste et dans la trajectoire du système des États ». À partir d' « une perspective d'histoire mondiale », ils montrent que la relation historique entre " agriculture » et « industrie » a été «fluide et mondiale ». Le concept de food regime est proposé pour « lier les relations internationales de production et de consommation alimentaire aux formes d'accumulation que l'on peut distinguer à différentes périodes de transformations du capitalisme depuis $1870 »$ (Ibid. : 95). Les auteurs ont repris à Aglietta l'opposition entre accumulation extensive et accumulation intensive pour opposer les deux premiers food regimes décrits correspondant aux hégémonies anglaise, puis américaine. À l'origine, cette approche répond à une insatisfaction concernant la façon dont est prise en charge la question agraire par les analyses contemporaines du capitalisme (Friedmann et al., 2016). Cette notion est maintenant connue en France, en particulier les débats actuels pour caractériser les forces configurant un troisième régime ; plusieurs des chapitres de cet ouvrage y font d'ailleurs référence, Jean-Marc Touzard et Pierre Labarthe proposant un rapprochement

5. Pour un tour d'horizon récent de l'histoire de la notion de food regimes, de son utilisation et des débats en cours, voir l'article de Henry Bernstein et les réponses de Harriet Friedmann et Philip McMichael dans le numéro de mai 2016 du Journal of Peasant Studies. 
avec les travaux régulationnistes (chapitre 17) ${ }^{6}$. L'approche en termes de food regime, qui a l'intérêt de poser un niveau d'analyse globale, a fait l'objet de critiques de différents points de vue concernant la façon dont s'organise la domination d'un food regime ou son caractère hégémonique. La critique de David Goodman et John Wilkinson (chapitre 16) conteste la notion d'hégémonie et souligne la variété des trajectoires selon les parties du monde et la continuité du jeu des facteurs spécifiques dans celles-ci à travers les régimes successifs. Si on admet un système des États régis par des relations hégémoniques, les candidats à l'hégémonie restent longtemps dans cette position, avec leurs cartes spécifiques ; ce qui conduit à la diversité géopolitique. À titre d'exemple, l'Allemagne a su profiter, de longue date, de son industrie chimique, qui lui permet aujourd'hui de conquérir des positions dans le champ de la bioéconomie.

L'exploitation dite familiale, c'est-à-dire insérée dans le marché mais n'employant pas ou peu de salariés, s'est imposée au cours du siècle passé partout où on l'a laissé faire, c'est-à-dire sauf dans les pays communistes et dans quelques pays où les grands propriétaires fonciers ont réussi politiquement à bloquer toute réforme agraire. Là où la compétition était ouverte, elle a vaincu les grandes unités capitalistes (sauf peut-être pour quelques produits comme le palmier ou le caoutchouc). Cette agriculture dite familiale $^{7}$ (Bosc et al., 2014) est généralement considérée comme la forme dominante sur la planète en des aspects très variés. La norme politique de l'agriculture familiale est liée aux politiques agricoles nationales qui ont émergé aux États-Unis et dans l'Europe du Nord à la fin du XIX ${ }^{\mathrm{e}}$ siècle. D'une certaine façon, cette norme fait partie du food regime américain ; elle a d'ailleurs été promue activement en Europe de l'Est après la Première Guerre mondiale et en Asie après la seconde (Révolution verte). Mais, conceptuellement floue, cette notion masque la grande diversité des formes d'organisation des activités agricoles, comme par exemple l'agriculture urbaine, qui partout se développe sous des formes complètement renouvelées, ou le processus d'individualisation du travail (Nicourt, 2013) dans les exploitations européennes et américaines. Sur le plan politique, elle fait obstacle à « l'agriculture paysanne » promue par les mouvements sociaux contestant l'impératif de croissance agricole.

Du point de vue des formes de production, les formes collectives de gestion des ressources et des marchés locaux, sous des formes infiniment variées selon les contextes nationaux et locaux, jouent de tout temps un rôle essentiel. Le passage de formes locales (communautaires) de gouvernement à des formes professionnelles participe de la sectorisation de l'agriculture moderne. Aujourd'hui, de vastes systèmes de ressources relèvent d'un gouvernement qui associe la puissance publique (à travers la recherche-développement qui a un caractère international), des firmes (dont les coopératives) et des organisations professionnelles agricoles (à titre d'exemple, pour l'eau, voir chapitre 6 ; pour les ressources génétiques animales, voir chapitre 7). Ces formes hybrides de gouvernement des ressources se transforment selon les formes sociales que prend la technique, avec la libéralisation des politiques agricoles nationales.

6. Voir également son usage, pour discuter de l'évolution de la place de l'Afrique dans les marchés internationaux, par Daviron (2008).

7. Elle repose de fait sur des personnes, femmes et hommes (aussi enfants et vieillards), qui s'inscrivent à la fois dans une économie domestique, d'entreprise, de marché et dans des communautés familiales, de voisinage, de genre, de race et professionnelles. 


\section{La question du rapport de la société à la nature}

La question du rapport de la société à la nature (ou du métabolisme social, dans les termes du chapitre 1) est restée à la marge, tant de la théorie de la régulation que de l'économie des conventions. Comme le constatent Durand et Cahen-Fourot (2016), l'intégration de la question environnementale et écologique à la théorie de la régulation reste un chantier largement ouvert. Les premiers travaux en France ont été conduits à Lille (Rousseau, 2002 ; Zuindeau, 2001) sur les rapports entre environnement et industries et au Royaume-Uni (par exemple Drummond et Marsden, 1995 ; Gibbs, 1996) en rapport avec la question du développement durable. Ils ont en général plaidé pour un élargissement du corpus régulationniste. Ainsi, il a été développé par une école de géographie régulationniste une « théorie de la régulation environnementale » (notamment dans la revue Geoforum) qui a eu une notoriété limitée (notamment en France), mais qui a encore ses défenseurs parmi les auteurs régulationnistes (par exemple Chester, 2010). La question environnementale, dans ces premiers travaux, tourne, pourrait-on dire, autour de la notion de développement durable, qui à la fois s'institutionnalise dans les années 1990, suite au Rapport Bruntland de 1987, et reste une valeur contestataire qui alimente les sciences sociales critiques.

L'institutionnalisation du développement durable correspond, dans les termes de Muller (2010a), à un changement du référentiel des politiques publiques, repérable à l'échelle internationale depuis le début des années 2000, c'est-à-dire du discours global qui lie les référentiels d'action publique sectoriels. Cette institutionnalisation est traçable dans les politiques des firmes (responsabilité sociale de l'entreprise), dans les «bonnes pratiques » agricoles, dans les standards de qualité et dans les discours politiques. Néanmoins, il a été également argumenté que les formes institutionnelles classiques de la théorie de la régulation conviennent mieux qu'un cadre institutionnel séparé, pour rendre compte de la consommation d'énergie par exemple ${ }^{8}$. Pour Robert Boyer, dans leur majorité, les auteurs régulationnistes (français) ont préféré considérer la régulation environnementale à l'instar des « dispositifs institutionnels sectoriels ». Les « dispositifs institutionnels environnementaux » prennent des formes différentes selon les domaines d'application et se déploient à différentes échelles, infra et supranationales, avec un rôle propre des États dans leur mise en œuvre. Leur diversité s'inscrit dans la diversité des capitalismes nationaux (Douai et Montalban, 2012). Ainsi, pour Boyer, ces dispositifs sont « la projection des formes institutionnelles sur l'espace des relations économie/environnement » (Boyer, 2015 : 162). Le parallèle peut être fait avec le débat dans l'économie des conventions sur l'existence d'une « cité verte » (proposée par Bruno Latour) venant s'ajouter aux six « cités » (domestique, marchande, industrielle, civique, inspirée, de l'opinion) distinguées par Boltanski et Thévenot (1991). Elle n'a finalement pas trouvé sa place dans cet édifice, notamment parce que l'écologie n'est pas une philosophie politique et que fonder une cité verte sur la « deep ecology » ne s'est pas révélé pertinent.

Becker et Raza (2000), dans un texte se démarquant des analyses d'Alain Lipietz (1995) au motif qu'elles séparent la théorie de la régulation de l'écologie politique,

8. Mattew Huber (2013) met en rapport le recours au pétrole avec le rapport salarial fordiste. Sur ce point, voir également le chapitre 2. 
proposent au contraire de les intégrer, tant pour des raisons théoriques que politiques. Pour ces auteurs, le rapport social à la nature régule « l'accès à l'environnement physique et les modalités de son utilisation pour les activités de production et de reproduction » (Becker et Raza, 2000 : 11). Ils s'appuient sur la conception d'O'Connor (1998), qui voit dans la nature une des trois conditions de la production sur lesquelles se fonde l'accumulation capitaliste - les deux autres étant la force de travail et les ressources communes (infrastructures physiques et sociales) -, et ils soulignent que ces conditions sont l'objet de luttes politiques entre le capital et les autres forces. La nature ne peut être alors conçue comme extérieure au monde social (nous pensons pour notre part que la réciproque est également vraie), "par conséquent, la dynamique expansionniste capitaliste dépend de l'appropriation permanente du monde matériel, créant ainsi la nature non seulement par le biais de nouvelles ressources, mais en conditionnant les environnements humains aux nécessités du procès de valorisation du capital »(Becker et Raza, 2000 : 14). Ils illustrent leur propos à partir de la biodiversité en montrant « comment les relations sociales à la nature interagissent avec l'actuel procès de colonisation de la biodiversité, dont [ils] pensent qu'il peut constituer un aspect central d'un nouveau régime d'accumulation » (Ibid. : 5). Nous reviendrons sur ce point, mais nous faisons nôtre cette perspective d'économie écologique.

Ce nouvel ouvrage collectif vise à explorer les évolutions intervenues depuis vingt ans. Depuis les années 1990, le contexte international a connu d'importants changements qui s'inscrivent dans un contexte général de transformation politique et culturelle des modes de gouvernement, fréquemment appelé néolibéralisme, et qui ne sont intelligibles que dans un contexte transnational. Par rapport à l'ouvrage de 1995, les perspectives théorique et temporelle ont été élargies, ainsi que la focale, en considérant les agricultures du monde dans leur diversité et en même temps les forces de transformation qui sont à l'œuvre ${ }^{9}$. Nous allons maintenant présenter les principaux résultats sous plusieurs angles : les forces transnationales en ce début de siècle, la question de l'hégémonie, les nouvelles frontières technologiques et finalement la perspective d'une économie générale et écologique.

\section{" Capitalisme début de siècle, les forces transnationales}

Les années de rupture sont les années 1990, après la chute du mur de Berlin (1989). Elles ont vu : la consécration d'un processus de réforme libérale des politiques avec la fin de l'Uruguay Round et la création de l'Organisation mondiale du commerce (1994), puis l'entrée de la Chine à l'OMC (2001) ; des crises financières à répétition

9. Nous suivons en cela les conseils de Karl Kautsky qui, dans son célèbre ouvrage La question agraire, soulignait l'importance de bien distinguer «états » et " tendances » et écrivait : "Le théoricien doit rechercher les tendances générales de l'évolution sociale ; le politique pratique doit partir des états particuliers qu'il trouve devant lui. Les tendances de l'évolution sociale, aussi celles de l'évolution agricole, sont dans tous les pays civilisés essentiellement les mêmes, mais les états qu'elles ont créés sont extrêmement différents dans les divers pays, et même dans les diverses parties d'un même pays, en raison des différences de situation géographique, de climat, de configuration du sol, du passé historique et, par suite, de puissance des différentes classes sociales » (Kautsky, $1900: v)$. 
(Mexique en 1994, pays asiatiques en 1997, Russie et Brésil en 1998) ; la signature d'une série d'accords internationaux sur l'accès aux ressources naturelles, en particulier les ressources génétiques, et plus largement une transnationalisation des normes.

Après la crise des années 1970, depuis les années 1980, s’est enclenché un processus de libéralisation des politiques agricoles qui s'est poursuivi jusqu'à aujourd'hui, bien que la croissance du commerce international ait connu un ralentissement après la crise de 2008. Cette libéralisation constitue une rupture tant du point de vue du commerce que des régimes de régulation sectorielle. Au-delà des modifications tarifaires, il s'agit de réformes des politiques agricoles nationales, avec une réduction du domaine public (dont les systèmes de connaissance, chapitre 18) et du poids des corporatismes sectoriels (avec néanmoins de fortes résistances).

Le processus de libéralisation des politiques économiques nationales accompagne l'internationalisation des circuits de valeur et la financiarisation. Comme l'écrit Cédric Durand (2014 : 7) :

«La financiarisation n'est pas un épiphénomène. Elle touche au cœur de l'organisation du capitalisme contemporain, car le capital fictif a pris une place centrale dans le procès général d'accumulation du capital. Ce capital fictif, qui s'incarne sous forme de créances, d'actions et de produits financiers divers dont le poids dans nos économies s'est considérablement accru, représente des prétentions sur les richesses à produire. »

Cette financiarisation du capitalisme peut se lire dans des transformations qui concernent la production, les services, le salariat, le gouvernement des entreprises, les comportements des ménages ou les formes de management public. Toutefois, comme le développent Antoine Ducastel et Ward Anseeuw dans le chapitre 15, « la financiarisation n'est pas le processus englobant et homogénéisant parfois décrit ».

La financiarisation en soi n'est pas un phénomène nouveau concernant l'agriculture. Les marchés à terme de produits agricoles ont une longue histoire ; la financiarisation de la propriété des industries agricoles et alimentaires se développe depuis plusieurs décennies ; quant à la financiarisation de l'agriculture paysanne, elle s'est développée avec l'accès au crédit. Cependant, on observe des phénomènes nouveaux. À la suite de la crise financière de 2008, l'industrie financière s'est « engagée dans la quête "d'actifs alternatifs" qui ne soient pas corrélés avec les marchés boursiers et qui puissent constituer une protection contre l'inflation »; il s'agit notamment de fonds d'investissement spécialisés dans le foncier agricole, comme ceux étudiés dans le chapitre 15. L'étude d'Antoine Ducastel et Ward Anseeuw met en évidence toute « la chaîne d'intermédiaires - investisseurs, gestionnaires d'actif, consultants, administrations nationales et locales, agriculteurs - engagés en interaction dans le cadrage et la mise en ouvre de cette financiarisation du foncier », qu'ils appellent une « filière agrofinancière ». Les institutions financières impliquées mettent en œuvre une double opération de titrisation et de délégation de la gestion des fonds agricoles acquis. Il s'agit d'un cadre (une formule d'investissement) permettant de fonder la rémunération des capitaux investis dans une ou plusieurs entreprises agricoles (détenues sous forme d'actions) sur la rentabilité financière et sur la « rentabilité sociale » de l'entreprise, capitalisée par diverses formes de certification. Une pluralité de facteurs, architecture entrepreneuriale et fiscale, systèmes d'information sur les impacts environnementaux et sociaux, pratiques et procédures d'évaluation, est à considérer « pour comprendre le codage sous-jacent propre à ce produit financier ». 
Les normes sont l'enjeu de négociations internationales, qu'il s'agisse des normes sanitaires (chapitre 11), de l'agriculture biologique, dont se sont emparées les multinationales de la distribution, ou des normes dites de durabilité. Or l'OMC ne se révèle pas à cet égard un cadre efficace. Il faut souligner le rôle des multinationales et des mouvements sociaux transnationaux ( $v s$ celui des syndicats sectoriels nationaux dans la période antérieure) dans le vaste marché des normes ${ }^{10}$. Le caractère transnational du processus de normalisation correspond à l'internationalisation des marchés en amont et en aval de l'agriculture. À côté de la réglementation, selon Laure Saulais et Egizio Valceschini (chapitre 11), « trois grands types de normes encadrent l'activité des acteurs économiques des filières agroalimentaires à l'échelle internationale : i) les normes privées de producteurs (producteurs primaires ou transformateurs du secteur agroalimentaire), individuelles ou collective ; ii) les normes privées de clients (transformateurs ou distributeurs); iii) les normes "systèmes" collectives ». La multiplication des forums internationaux multipartites de normalisation des normes (Allaire et Sylvander, 2011; Alphandery et al., 2012 ; Daviron et Vagneron, 2012 ; Cheyns et al., 2016) ne conduit pas cependant à un effacement des États, qui restent maîtres du système légal.

Ce qui a été appelé pour l'agriculture le «tournant qualité » correspond à un changement plus général de la logique de standardisation, que l'on peut rapporter à la diffusion de " conceptions de contrôle » ${ }^{11}$ fondées sur l'individualisation des activités sociales et des croyances, par rapport aux cadres domestique, communautaire, professionnel et sectoriel. Cette nouvelle logique, transnationale et transectorielle, étudiée par Lawrence Busch dans le chapitre 12, est celle du "tripartite standard regime », notion qualifiant une « triple transformation, qui relie (1) les standards, (2) les certifications et (3) les accréditations (Loconto et al., 2012)». Ce « régime tripartite de standardisation » établit « un système de gouvernance privée mondial qui se prolonge bien au-delà des entreprises individuelles ». Ainsi, « une énorme bureaucratie internationale composée d'organismes de normalisation, d'entreprises de certification, d'organismes d'accréditation, de développeurs de mesures, de collecteurs et d'analyseurs de données a été mise en place afin de créer des marchés mondiaux » (chapitre 12). Il régit la valorisation du capital financier et du capital intangible (chapitre 21). Ce régime tripartite, qui se déploie dans tous les domaines, y compris la finance, mobilise une grande partie des institutions de recherche et renforce la technostructure du capital. En analysant le développement historique du régime de standardisation tripartite, Lawrence Busch montre que celui-ci généralise (hors de

10. Dans cette introduction et dans l'ouvrage, les termes «normes » et «standard » sont équivalents, en accord avec l'usage de plus en plus fréquent dans les sciences sociales, quoique le français distingue les deux termes.

11. Cette notion est introduite dans le chapitre 21. Pour White (1992), la recherche du contrôle de son environnement est inhérente à toute « identité » qui émerge dans l'organisation sociale. Dans la sociologie économique de Fligstein (1996), les conceptions de contrôle sont une des institutions régissant les marchés, qui structurent la compréhension du fonctionnement et du positionnement d'un marché qu'en ont les participants. Il s'agit ici, plus généralement, des représentations des hiérarchies qualitatives entre firmes, régions, produits, métiers et statuts, personnes et connaissances, qui structurent les activités économiques, politiques et civiles. La même expression est utilisée par des marxistes néo-gramsciens pour désigner des stratégies de long terme concernant les rapports de travail, l'ordre « économique et l'ordre politique, en résonance avec les intérêts particuliers de groupes sociaux ou de classes. Ce sont des cadres de pensée et d'action » (van Apeldoorn, 2004 : 155). 
la firme fordiste) le taylorisme et donc le travail dépendant ; mais, plus que d'une uniformisation des normes matérielles, il s'agit d'une normalisation des procédures, dont les impacts sont structurels. C'est ce que, d'une certaine façon, montre Franck Cochoy dans le chapitre 19 à propos du conflit entre industrie cigarettière et puissance publique sur le théâtre médiatique que constituent les inscriptions sur un paquet de cigarette ; chacun de ces acteurs sait que ces messages ont peu d'effet immédiat, ce qui compte c'est l'impact à long terme sur les représentations et les comportements.

L'analyse de ce nouveau régime peut être conduite pour différents types de normes, par exemple le commerce équitable, les normes faisant référence au développement durable ou à l'agriculture biologique. Ainsi, le chapitre 10 consacré à l'agriculture biologique $(\mathrm{AB})$ en France, écrit par Thomas Poméon et al., analyse la normalisation de l'AB (on parle de « conventionnalisation » du marché des produits biologiques) et s'intéresse aux réactions critiques des acteurs du secteur, qui passent également par le système des marques pour différencier des projets.

L'extension du nouveau régime de standardisation modifie les rapports de force entre les acteurs concernant le gouvernement des marchés. Cela passe par des crises structurelles des dispositifs de régulation, sectoriels et régionaux, existants, qui peuvent être analysées à plusieurs échelles. Dans le cas particulier de la restructuration de la production et des marchés laitiers en France avec la fin de la politique européenne de quotas laitiers, Marie Dervillé, dans le chapitre 13, étudie au niveau de systèmes productifs locaux les arrangements institutionnels (appelés « modèles de concurrence ») qui permettent la séparation des marchés et les conditions de résilience ou d'entrée en crise de ceux-ci, dans un contexte de changement de l'environnement concurrentiel (voir aussi Dervillé et Allaire, 2014a).

\section{"Un monde sans hégémonie?}

La possibilité d'une transposition de la notion d'hégémonie du niveau national au niveau international a été défendue à la suite de Kinderlberger (1973) par de nombreux auteurs comme Wallerstein (1983a) et Arrighi (1994) ${ }^{12}$. L'hégémonie s'illustre par la création et le contrôle d'un certain nombre d'institutions internationales. Elle s'exprime aussi dans le domaine des idées par la promotion de normes portant tant sur les façons de produire ou de consommer que sur les modes d'organisation des entreprises ou des politiques publiques. L'adhésion aux normes portée par l'hégémon garantit une certaine convergence des dynamiques et une certaine prédictibilité du futur. L'influence dans le domaine intellectuel et culturel permet en outre de présenter l'action de l'hégémon comme étant en conformité avec l'intérêt global. Selon ces auteurs, c'est l'existence d'un pays hégémonique à l'échelle

12. «Le concept "d'hégémonie mondiale" adopté ici [...] fait spécifiquement référence au pouvoir d'un État d'exercer des fonctions de direction et de gouvernance sur un système d'États souverains. En principe, ce pouvoir peut inclure la gestion quotidienne des institutions d'un tel système à un moment donné. Historiquement cependant, le gouvernement d'un système d'États souverains a toujours impliqué une certaine capacité d'action transformative, qui a changé le mode de fonctionnement du système d'une façon fondamentale. Ce pouvoir est quelque chose de plus et de différent de la "domination" pure et simple. C'est le pouvoir de la domination renforcé par l'exercice de la "direction intellectuelle et morale" » (Arrighi, $1994: 29$ ) 
mondiale qui permettrait d'expliquer les périodes de stabilité dans les relations internationales et l'accumulation capitaliste. C'est aussi le déclin des positions hégémoniques, sous l'effet de la concurrence d'autres pays dans le domaine économique et militaire, qui expliquerait les crises. Depuis le XVII ${ }^{\mathrm{e}}$ siècle, se seraient ainsi succédé les Provinces-Unies, le Royaume-Uni et les États-Unis au titre d'hégémon, chacun des inter-règnes étant marqué par l'instabilité économique, politique et militaire.

Aujourd'hui, alors que l'affaiblissement de la position des États-Unis semble patent ${ }^{13}$, certains considèrent que nous sommes en phase de transition entre deux situations hégémoniques (la Chine apparaissant de plus en plus comme prétendant à la succession, voir chapitre 4), tandis que d'autres affirment que la notion même d'hégémonie a perdu de son sens dans le domaine des relations internationales du fait de l'affaiblissement des États et des organisations interétatiques et, à l'inverse, du renforcement de l'influence des multinationales et des organisations non gouvernementales. La notion de gouvernance globale ou transnationale joue ici un rôle central (voir Overbeek et al., 2010 pour un état du débat).

C'est la deuxième lecture qui l'emporte dans les travaux utilisant la notion de food regime pour caractériser la situation présente dans le domaine agricole et alimentaire. De nombreux auteurs s'inscrivant dans ce courant, McMichael (2013) en tête, défendent l'idée qu'aurait émergé un "corporate food regime » caractérisé par le rôle des grandes entreprises gouvernant un système alimentaire mondial. Cela est toutefois contesté, y compris par Harriet Friedmann qui considère la place politique des mouvements sociaux dans une situation de crise du régime (Friedmann, 2005a).

Dans le chapitre 16, John Wilkinson et David Goodman vont plus loin en remettant en cause, pour toute période, l'idée d'un food regime hégémonique. Ils écrivent :

« Nous pensons qu'il est plus exact historiquement et plus éclairant analytiquement de considérer une pluralité d'ordres alimentaires régionaux qui partagent, de manière croissante, des frontières scientifique et technologique similaires et des arrangements institutionnels communs plutôt que de conserver les concepts d'hégémonie et de "régime agroalimentaire international" ».

Dans le cadre de cette introduction, nous ne trancherons pas le débat. Nous nous contenterons de rappeler un certain nombre de faits saillants qui ont marqué les marchés agricoles au cours des dernières années.

La fragmentation du marché mondial des principaux produits agricoles en marché nationaux - spécificité du « court $\mathrm{xx}^{\mathrm{e}}$ siècle »(1914-1989, selon Hobsbawm, 1994) - a été grandement remise en cause par les plans d'ajustement structurel et les accords de l'OMC. Les marchés internationaux ont en grande partie perdu le rôle d'écluse qu'ils jouaient entre des marchés nationaux stabilisés. L'unification (ou la réunification) du marché mondial n'est toutefois que partielle car elle ne concerne pas des pays aussi importants que l'Inde ou la Chine ayant maintenu des politiques de régulation du marché national dans le cadre de leur stratégie de

13. Le déclin des États-Unis prend de multiples formes : désindustrialisation au profit de la Chine, recentrage de l'économie illustré dans le domaine énergétique par l'exploitation des gaz de schiste, mais aussi explosion des circuits courts, crise financière, difficultés à la mise en place d'une politique de réduction des inégalités, tendance au retrait (Obama) et à l'isolationnisme (Trump). 
sécurité alimentaire. Elle ne concerne pas non plus les pays où la consommation alimentaire porte prioritairement sur des produits «non échangeables » (au sens de l'économie internationale) comme le mil, les bananes plantains, l'igname ou encore le fonio, autrement dit nombre de pays africains. Elle est en outre rapidement remise en cause, lors des flambées des prix, par des pays exportateurs comme l'Argentine qui impose taxes et contingentement aux exportations pour freiner la hausse des prix à la consommation.

La géographie des échanges a été bouleversée au cours des vingt dernières années avec, d'une part, le basculement de la demande d'importation de l'Europe vers l'Asie et, d'autre part, la diminution de la part de marché contrôlée par l'Union européenne et les États-Unis au profit, principalement, des pays qui, autrefois alliés au sein du groupe de Cairns, militaient en faveur de la libéralisation des échanges (principalement les anciens dominions anglais et les pays d'Amérique latine et d'Asie du Sud-Est).

Les oligopoles coopératifs d'État qui, après la guerre et jusqu'aux années 1980, régulaient, dans un contexte de surproduction structurelle, un certain nombre de marchés de produits agricoles ont disparu. Aucun dispositif de coopération ne s'y est substitué, en particulier pour une gestion stabilisatrice des stocks mondiaux. Certes, comme l'expliquent Frédéric Courleux et Jean-Noël Depeyrot dans le chapitre 4, la Chine détient aujourd'hui une part des stocks mondiaux de céréales suffisante pour jouer un tel rôle, mais elle ne l'a pas endossé à ce jour. Les marchés à terme qui fixent les prix internationaux des produits agricoles (Chicago, New York, Londres) ont connu, au début des années 2000, une arrivée massive de capitaux spéculatifs. Cette arrivée est une manifestation claire du mouvement de financiarisation des économies, qui, si l'on en croit Arrighi (1994, 2007), accompagne et signale systématiquement le déclin d'une puissance hégémonique.

La demande non alimentaire de produits agricoles s'est fortement accrue sous l'effet des politiques de soutien aux agrocarburants de l'Union européenne et des ÉtatsUnis. En France, les volumes de matières grasses végétales utilisées pour la production d'agrocarburant sont équivalents à ceux de la consommation humaine (Daviron 2014). Aux États-Unis, l'utilisation de maïs pour la production d'éthanol est supérieure à son usage en aliment pour le bétail. Fortement questionnés sur leurs impacts environnementaux directs et indirects, les agrocarburants n'auront peutêtre pas l'avenir brillant qui leur était annoncé. Ils n'en resteront pas moins le signal avancé de la recherche par les pays de l'OCDE d'une substitution des ressources fossiles par de la biomasse que le projet de la bioéconomie (voir chapitres 8 et 9) entend bien approfondir et généraliser.

Ces différents facteurs (demande asiatique, agrocarburant, absence de coopération sur les marchés, financiarisation) expliquent la flambée des prix que les marchés de produits agricoles ont connue en 2007-2008. Depuis, la tension est redescendue bien que les prix soient restés à un niveau sensiblement supérieur à celui du début des années 2000. Il semble que se soit opéré un renversement de la tendance d'évolution des prix agricoles. L'instabilité des marchés de produits de base s'est diffusée de manière hétérogène aux marchés domestiques (Daviron et Douillet, 2013). Cette crise a aussi révélé l'impuissance des organisations internationales (HLPE, 2011). Malgré la multiplication des initiatives internationales ayant suivi 
la flambée ${ }^{14}$, les principaux déterminants de la crise n'ont pas été supprimés. Tous les éléments sont donc toujours en place pour qu'une telle flambée se répète.

Dans les pays ou les régions où elle a lieu, comme dans l'Union européenne ou en Amérique latine, la diffusion de l'instabilité des marchés de base a deux conséquences ; d'une part, les producteurs agricoles, les firmes alimentaires et de la distribution recherchent une couverture du risque financier, renforçant ainsi la financiarisation de l'économie agricole ; d'autre part, ils cherchent à échapper à cet espace de concurrence, en développant des normes volontaires et des arrangements contractuels. C'est une des raisons du développement actuel de l'AB et des circuits courts dans les pays du Nord, et des labels commerce équitable au Sud. Dans ce contexte, se multiplient ce que van der Ploeg appelle les «marchés nichés » (nested markets), c'est-à-dire des marchés qui peuvent se développer à côté, ou plutôt à l'abri (nested signifiant imbriqué ou intégré), des marchés de masse gérés par les multinationales («empires ») et dans lesquels est remis en cause le fossé séparant agriculteurs et consommateurs : « la distance [est remplacée] par la proximité, l'artificiel par la fraîcheur, l'anonymat par l'identité et l'authenticité, la standardisation par la diversité et l'inégalité par l'équité » (van der Ploeg et al., 2012). Différents exemples étudiés dans les chapitres de cet ouvrage, à commencer par celui de l'agriculture biologique, montrent l'importance de l'analyse des institutions qui séparent et qui lient construction des marchés et valorisation, précisément pour rendre intelligible le système des marchés.

\section{W Nouvelles frontières de valorisation du capital}

La transnationalisation néolibérale s'accompagne d'une révolution technologique, centrée sur le traitement des signaux, la numérisation, la robotisation, la bioinformatique et les sciences intégratives. Elle constitue de nouvelles frontières pour la valorisation du capital.

Les auteurs du premier chapitre supposent que les NTIC (nouvelles technologies de l'information et de la communication) jouent un rôle dans un infléchissement du régime métabolique global, à partir de la fin du $\mathrm{xx}^{\mathrm{e}}$ siècle, en permettant une meilleure efficacité énergétique des dispositifs techniques. Julie Labatut et Germain Tesnière dans le chapitre 7, en étudiant l'histoire de la vache Holstein et les évolutions actuelles du contrôle des ressources génétiques animales dans le contexte du développement de la bio-informatique et, notamment dans les années 2010, de la génomique, décrivent une restructuration des activités de sélection animale permettant une exploitation renforcée du vivant. Parallèlement, les accords internationaux qui ont suivi la Convention de Rio sur la biodiversité de 1992 ont affirmé la propriété commune des communautés paysannes sur les ressources génétiques végétales, tout en renforçant de l'autre (dans

14. Réforme du Comité de la sécurité alimentaire mondiale, création d'un nouveau dispositif de coordination entre les différentes agences des Nations unies, lancement d'une « Initiative sur la sécurité alimentaire » par le G8 et d'un « Plan d'action sur la volatilité des prix des produits alimentaires et l'agriculture mondiale » par le G20, création d'un Système d'information sur les marchés agricoles (Amis) doté d'un Forum de réponse rapide. 
le cadre du système des brevets) les capacités des multinationales biotechnologiques à poursuivre la colonisation du vivant (Thomas, 2015). Cette question, soulevée également dans le chapitre 2, est en filigrane des chapitres sur la bioéconomie (chapitres 8 et 9) ; les auteurs du chapitre 9 (Levidow et al.) opposent deux conceptions, la première s'inscrivant dans la perspective d'une exploitation plus poussée de la biodiversité (soutenue par une idéologie scientiste pour laquelle il s'agit là d'un devoir moral), la seconde dans la perspective d'une " agroécologie » correspondant à une logique de subsistance et de bonne vie, plutôt que de profit.

Les nouvelles technologies permettent de nombreuses transformations des systèmes techniques, par exemple dans l'utilisation de l'eau pour l'irrigation en individualisant les accès et en adaptant les débits à la mesure des besoins (chapitre 6). Arnaud Buchs et Valérie Boisvert, dans ce chapitre sur l'agriculture à Almeria (Andalousie), analysent le «mode d'usage de l'eau » sous deux volets : un volet économique, relatif à l'ajustement de l'offre et des usages finaux, qui « comprend l'ensemble des normes techniques relatives au type de mobilisation, au traitement, à l'approvisionnement, à la répartition sectorielle et aux usages finaux des ressources produites »; un volet institutionnel qui identifie « qui a le droit de mobiliser les ressources, et selon quelles conditions et modalités ». L'analyse historique permet ici de mettre en évidence deux caractéristiques du modèle almérien : il relève d'une « production sociale de la nature » justifiée par le dogme de l'efficacité technique, et d'un compromis social mettant en congruence une logique marchande au niveau de l'agriculteur, une logique communautaire portée par les associations d'irrigants et une logique planificatrice-hiérarchique portée par les autorités publiques.

Dans l'optique néolibérale, le déploiement des nouvelles technologies repose sur un développement des droits de propriété intellectuelle privatifs et des standards de qualité, qui conditionnent la valorisation du capital financier et du capital intangible (chapitre 21). Cette optique est combattue par d'autres conceptions du contrôle, mettant au contraire en avant les capacités collectives de contrôle de l'avenir qu'offre le développement d'échanges citoyens, l'organisation de coopératives locales et de procédures participatives (sur ce dernier point, voir le chapitre 10).

Considérant de façon globale les utilisations de la biomasse et les systèmes de production à l'échelle planétaire, les auteurs du chapitre 3 doutent que la révolution numérique ait, du moins aujourd'hui, un effet macroscopique visible. À l'échelle du monde, il ne semble pas qu'on assiste à une crise de l'industrialisation de l'agriculture, à l'heure où, aux États-Unis et en Chine, se multiplient les fermes de plusieurs dizaines de milliers de vaches, où la mécanisation décolle en Afrique, où se perfectionnent les techniques de mobilisation et d'utilisation des ressources en eau, où s'industrialisent les filières de production de biocarburants, bloquant des modèles locaux d'autonomie énergétique, où le saumon sauvage n'est plus qu'une infime partie de la consommation mondiale et les ports de la côte norvégienne sont devenus des parcs à hors-bords. Si les années 1990 sont bien celles d'une crise structurelle de l'agriculture du fordisme, reposant sur des politiques nationales, et du début de la fin de l'hégémonie américaine, du point de vue plus global de l'industrialisation de l'agriculture et des modes de consommation associés reposant sur une consommation intensive d'énergie, assiste-t-on à une crise du modèle ou au contraire aux effets en retour de sa diffusion? Ces effets concernent tant la production de 
déchets, comme les gaz à effets de serre, les déchets plastiques, etc., d'un côté, que les réactions (du saumon bio aux réserves naturelles en passant par l'agriculture urbaine), de l'autre. L'orientation dominante, avec la poursuite de la colonisation de la nature, reste une utilisation intensive des ressources.

\section{" Vers une économie générale et écologique}

Les systèmes socioéconomiques dépendent d'un flux continu de matériaux et d'énergie pour se reproduire et se maintenir ; la notion de métabolisme socioécologique (chapitre 1) assimile cette dépendance au métabolisme biologique des organismes vivants. Ici, la notion de métabolisme associe la nature aux formes de production et de consommation, la nature étant socialement définie par ces dernières (en termes de ressources et d'accès). L'accroissement du métabolisme social est un processus de « colonisation de la nature » (Baccini et Brunner, 1991 ; FischerKowalski et Haberl, 1993). Les systèmes socioéconomiques ne se juxtaposent pas pour former un seul système, il y a des échanges entre eux. La comptabilité des flux de matières et d'énergie étendue à ces échanges met en lumière, au long du développement historique, des échanges écologiquement inégaux entre régions du monde et entre groupes sociaux (chapitres 2 et 3 ).

La thermodynamique apporte un cadre (non suffisant) pour l'analyse du métabolisme énergétique. À cet égard, l'ouvrage de Nicholas Georgescu-Roegen, The Entropy Law and the Economic Process (1971), cherche à montrer que la croissance économique est un épuisement et une dégradation irréversible de l'énergie et des ressources minières (application du second principe de la thermodynamique selon lequel l'entropie d'un système clôt ne peut que croître) à partir du moment où les sociétés sont sorties du cadre de l'économie solaire ${ }^{15}$. D'autres travaux, plus récents, s'appuyant sur le fait que les structures organisées de la société sont des structures instables, dissipatrices d'énergie, mettent en lumière une dynamique complexe des crises des régimes métaboliques. Selon le troisième principe de la thermodynamique, la taille de ses structures tend à s'accroître, ce qui conduit à la menace de crises plus globales. Ces analyses (dont on trouvera des références dans les chapitres 2 et 3) amènent à militer pour la tempérance en matière de croissance économique.

Georges Bataille, dans un article de 1933 («La notion de dépense »), voit lui dans l'utilitarisme un principe qui fausse l'analyse économique : «Il n'existe en effet aucun moyen correct, étant donné l'ensemble plus ou moins divergent des conceptions actuelles, qui permette de définir ce qui est utile aux hommes » (Bataille, 1967 : 25). Il y a, selon nous (chapitre 3), dans la philosophie de Bataille une autre source d'inspiration pour penser le métabolisme des sociétés. Pour lui, la dynamique de la vie et de l'humanité est dans une logique de consumation de l'énergie plus que de consommation, il propose une «économie générale » qui ne concerne pas tant la question de la production que celle de l'excédent d'énergie, la « part maudite ». Il illustre son analyse par différents aperçus historiques de la façon dont les civilisations ont pris en charge cette dépense et par la logique de l'accumulation capitaliste. Les monuments

15. Sur les caractéristiques de l'économie solaire (avant l'industrialisation), voir le chapitre 3. 
religieux, l'art, les sacrifices, les épices, les armes, les guerres et les krachs financiers sont des manifestations de cette part maudite. Il y a un décalage entre des situations locales, dans lesquelles s'exercent des pressions sur les ressources, et le mouvement général de l'énergie. L'épuisement de certaines ressources (dans un contexte d'échange inégal) et les restructurations qui peuvent en résulter peuvent s'analyser dans le cadre de l'économie générale que nous propose Bataille, c'est-à-dire une économie de la dépense, sous toutes ses formes. La science économique utilitariste ne peut avoir d'autre credo que celui de la croissance des besoins. Si la question est de rompre avec l'utilitarisme, son implication politique est celle de la recherche de la bonne vie, la part des anges et des Bacchus plutôt que du maudit.

C'est autour du thème de la décroissance que débouchent les travaux plus récents portant sur le métabolisme social. Fridolin Krausmann et Marina Fischer-Kowalski écrivent en conclusion du chapitre 1 :

«Finalement, la société doit reconnaître que la croissance matérielle rencontre des limites et qu'il est d'autant plus important de découpler la qualité de la vie humaine de l'utilisation de matière et d'énergie. Ceci ne pourra survenir au moyen des seules technologies, mais nécessitera des changements sociétaux plus profonds. »

Personne n'a de recette en la matière, mais on peut chercher à mettre en lumières les formes historiques du métabolisme social. Pour Christophe Bonneuil et JeanBaptiste Fressoz (chapitre 2), «parler de Capitalocène plutôt que d'Anthropocène [...] signale en particulier que l'échange écologique inégal est bien un facteur explicatif majeur de la genèse conjointe des asymétries de richesses propres à la dynamique historique du capitalisme et de l'essor des impacts humains à l'origine du déraillement géologique de la planète dans l'Anthropocène ».

Il existe d'autres sources d'inspiration des courants en faveur de la décroissance (Durand et Légé, 2012), notamment la littérature critique du développement (Illich, Latouche, etc.), qui voit dans celui-ci une croyance occidentale qui a été imposée aux dépens des autres cultures. Ce qui est en cause est l'impératif de la croissance ou, selon l'expression d'Hirschman (1970), la « tension » de l'économie qu'impose le raisonnement économique. Des auteurs radicaux marxistes voient cette tension comme l'expression de l'essence du capitalisme, ce que Marx a appelé le « fétichisme de la marchandise ». Ici, la marchandise dans le circuit capitaliste a deux valeurs, celle liée à son usage et celle qui est au principe de l'échange capitaliste (A-M-A), c'est-à-dire de la valorisation du capital. Le processus capitaliste de création de la valeur, devenu autonome, façonne lui-même les besoins en créant toujours plus de marchés, par des dispositifs (au sens de Foucault), qu'Illich appelle des « monopoles radicaux » (chapitre 21). Selon les marxistes qui ont épousé la cause écologique (libertaires), les changements profonds pour renverser la logique des choses sont à attendre de la fin du capitalisme (qui n'a pas toujours gouverné l'humanité).

Selon nous, il ne faudrait pas évacuer de l'analyse le mouvement de la critique sociale et l'existence d'aspirations à la bonne vie qui empreignent la vie sociale (formes de solidarité), y compris dans l'organisation des marchés. La question de la décroissance n'est pas directement l'objet de cet ouvrage. Cependant, à travers nombre de sujets et de situations qui sont abordés à partir d'analyses empiriques, deux discours sont mis en évidence : un qui vise à rendre les techniques plus raisonnables et plus efficaces à la fois, sans toutefois inverser la logique d'intensification ; l'autre qui entend rompre avec 
l'impératif de la production pour la production, visée prêtée à l'agroécologie par ses défenseurs les plus radicaux. Ces alternatives se retrouvent dans les différentes propositions défendues dans les débats en cours sur la réforme des politiques agricoles, comme le montre ici le cas du Japon étudié par Hugh Whitttaker et Robert Scollay (chapitre 5).

\section{W Conclusion}

Si l'objectif d'une «transition écologique et énergétique », dont l'agriculture est un élément déterminant, est devenu politiquement correct et l'objet de nombreuses prises de position, celles-ci s'opposent sur les voies à privilégier et sur le sens profond de cette transition. La notion de transition a un usage polymorphe et renvoie à une diversité de transformations sociales dans différents contextes géopolitiques. Mais elle a désormais un usage principalement normatif, plusieurs programmes étant en compétition. Elle est utilisée pour désigner des objectifs politiques, mais tend alors à rabattre la complexité des phénomènes sur des questions techniques. Les questions sociales, quant à elles, si elles sont présentes dans le débat, ne sont que rarement explicitement intégrées dans la conception des transitions. Un travail critique est nécessaire.

Le débat sur l'impératif de la croissance a même pénétré les instances d'orientation de la recherche agronomique. Ainsi, par exemple, le Comité de la recherche agricole auprès de la Commission européenne met en évidence, dans un récent exercice de prospective, une nouvelle conjoncture intellectuelle et politique, dans laquelle au paradigme productiviste s'oppose un paradigme de la "suffisance ». Est introduite l'idée que la productivité en soi n'est peut-être pas un objectif raisonnable. Ce rapport (Freibauer et al., 2011) distingue deux grands récits, l'un centré sur la productivité (avec des investissements massifs en R\&D et la suppression de "barrières au marché », c'est-à-dire plus de concurrence et de droits de propriété intellectuelle) et l'autre sur la «suffisance ». Ce qui est significatif est la reconnaissance par le Scar (Standing Committe on Agricultural Research) d'un récit (et donc d'un possible scénario) qui considère que l'enjeu pour l'avenir n'est pas une intensification accrue, mais des changements d'ordre institutionnel.

Le consensus intellectuel actuel pour dénoncer les dégâts du productivisme ne va pas jusqu'au renoncement à l'impératif de la croissance. Il est amoindri par un appel au réalisme invoquant la croissance des besoins alimentaires et des autres utilisations de la biomasse, qui est l'argument de la technostructure pour conserver son pouvoir. Cet argument est celui du «péril imminent » pour justifier un non-changement ou un changement qui n'en est pas un ${ }^{16}$. Mais que penser alors des alternatives (circuits de proximité, agricultures se référant à l'agroécologie, etc.) ? Plus nous sommes intelligents, comme le dit Franck Cochoy à propos du paquet de cigarette neutre (chapitre 19), plus nous développerons de bons arguments pour en montrer l'inanité ou l'inefficacité, mais comme il le dit aussi, se référant à une leçon d'Hirschman que nous retiendrons aussi, ce n'est pas une raison pour ne pas essayer !

16. Sur la rhétorique « réactionnaire » ou « progressiste », voir Hirschman (1991), cité dans le chapitre 21. 
Une perspective raisonnable fondée sur la suffisance de la production agricole (avec des stocks correctement gérés), certes utopique, laisserait leur place au thé, au café, aux épices, aux vignes et aux prairies fleuries, comme contribution (modeste) à la part maudite, mais devrait être associée à celle d'une réduction des inégalités et d'une extension des droits sociaux (droit à l'alimentation). Elle met en question le rôle des connaissances et la responsabilité sociale de la science.

Cet ouvrage ouvre des pistes dans trois directions : i) une optique d'histoire globale et de longue période, de l'écologie aux structures sociales ; ii) une approche institutionnaliste faisant une place importante à l'écologie ; iii) un aperçu large, quoiqu'incomplet, sur l'organisation des capitalismes et la diversité des agricultures (des chapitres traitent spécifiquement de la Chine, du Japon, des États-Unis, de l'Afrique du Sud, de l'Andalousie, de la Russie, d'autres de l'organisation de monde et des échanges internationaux, à différentes périodes de l'histoire).

Il est organisé en trois parties. La première revient sur la question agraire en la resituant dans une perspective écologique, géopolitique et historique. La seconde partie rend compte de diverses transformations récentes des agricultures et des systèmes alimentaires dans différentes régions du monde. Enfin, la dernière rassemble des chapitres offrant une illustration de la diversité et de l'évolution des approches institutionnalistes mobilisées pour l'étude de l'agriculture. 


\section{Partie I \\ La question agraire dans une perspective écologique, géopolitique et historique}





\title{
Chapitre 1 \\ Transitions socio-métaboliques globales
}

\author{
F. Krausmann, M. Fischer-Kowalski
}

La plupart des recherches socio-écologiques de long terme analysent les interrelations dynamiques entre écosystèmes et sociétés dans des contextes très localisés. Pourtant, les changements technologiques et le développement économique au niveau global ont des impacts significatifs sur les interactions nature-société ayant lieu dans des contextes régionaux spécifiques. Il est donc fondamental de comprendre comment des systèmes socio-écologiques locaux et régionaux sont insérés dans des processus opérant à un niveau plus large (Haberl et al., 2006). Dans ce chapitre ${ }^{1}$, nous analysons l'évolution des interactions nature-société associées à l'industrialisation, en mettant l'accent sur la manière dont les changements technologiques ont bouleversé les relations entre la société et son environnement naturel. Nous visons ainsi une meilleure compréhension des contraintes que l'environnement impose au développement socioéconomique et de l'importance de la technologie, à la fois dans sa capacité à réduire ou à éliminer ces contraintes, et à altérer l'environnement naturel.

Pour parvenir à cette compréhension socioécologique du phénomène d'industrialisation, nous nous appuyons sur les concepts de métabolisme sociétal et de « colonisation de la nature » (Baccini et Brunner, 1991 ; Fischer-Kowalski et Haberl, 1997a). L'utilisation de la notion de métabolisme dans le cadre d'une analyse socioéconomique date de Karl Marx qui voulait ainsi souligner le besoin qu'ont les humains d'obtenir leurs moyens de subsistance par un échange avec la nature, dans le cadre d'un processus socialement organisé et impliquant du travail (FischerKowalski, 1998 ; Singh et al., 2010). Ce concept a depuis été affiné, utilisé dans des travaux quantitatifs menés dans le cadre d'analyses comptables macroéconomiques, et historiquement spécifié : ce n'est pas seulement « l'être humain », dont le métabolisme est dépendant de la nature et a un impact sur elle, mais plutôt les différentes formes de production sociale et de consommation.

L'énergie est une composante essentielle du métabolisme d'une société. Sa disponibilité joue un rôle crucial dans la définition des relations avec la nature, en limitant la capacité des êtres humains à extraire, à transporter et à transformer des ressources. La question de cette disponibilité pour la société, ainsi que des sources à partir desquelles elle peut être obtenue, est donc fondamentale, non seulement pour les

1. Ce chapitre est une traduction d'un chapitre de l'ouvrage Long Term Socio-Ecological Research: Studies in Society-Nature Interactions Accros Spatial and Temporal Scales (Singh S.J., Haberl H., Chertow M., Mirt M., Schmid M., dir.), Springer, 2012. Nous remercions les auteurs et les éditions Springer d'avoir accepté cette réédition. 
relations que les sociétés entretiennent avec la nature, mais aussi pour les relations qui structurent les sociétés elles-mêmes. Il est ainsi possible de distinguer différents grands « régimes socio-métaboliques » qui sont apparus au cours de l'histoire de l'humanité, ainsi que des phases de transition, généralement présentées comme des « révolutions » : la Révolution néolithique, par laquelle est désignée la transition du régime de chasseurs-cueilleurs vers la société agraire, et la Révolution industrielle, qui désigne la transition de la société agraire vers le régime industriel (Sieferle, 2003).

Nous nous concentrons ici sur cette seconde transition, toujours en cours au niveau mondial. Ainsi, bien que le phénomène décrit ne soit pas particulièrement nouveau, nous tenterons de montrer que le recours à une perspective socioécologique élargie permet de renouveler les manières d'observer et de comprendre les changements technologiques à l'œuvre. En prenant en compte non seulement les acteurs humains et leurs relations, mais également les conditions et les conséquences naturelles de leurs activités, il est possible de parvenir à comprendre les besoins, les limites et les relations causales, et de les décrire en termes quantitatifs, ce qui permet d'éviter de rendre compte de ces processus en termes de progrès ou de déclin. Les récits construits sur l'idée de progrès ou de déclin reposent tous deux sur une compréhension de la nature à partir d'une interprétation magique (au moins implicitement) plutôt que sur une interprétation réaliste et fondée sur les sciences de la nature. À l'aphorisme « la foi peut déplacer des montagnes », il pourra alors être répondu en termes plus réalistes : «C'est bien possible, mais cela nécessitera énormément d'énergie. »

\section{" Les relations société-nature avant la Révolution industrielle : le métabolisme des sociétés agraires}

Le métabolisme des sociétés préindustrielles est basé sur l'usage de la biomasse, et donc sur la capacité des plantes à utiliser l'énergie solaire, via la photosynthèse, pour créer de la matière à partir de dioxyde de carbone $\left(\mathrm{CO}_{2}\right)$, d'eau et de composés minéraux. La biomasse fournit, sous la forme de nourriture, l'énergie nécessaire à l'existence des êtres humains et de leurs animaux qui peuvent ensuite la convertir en travail. La combustion (du bois par exemple) fournit la chaleur nécessaire aux foyers et à diverses activités manufacturières (travail du métal par exemple). Elle fournit aussi l'éclairage.

L'impossibilité de convertir l'énergie thermique en énergie mécanique (avant l'invention de la machine à vapeur) limite fortement la disponibilité en énergie mécanique. Les énergies hydraulique et éolienne jouent ainsi un rôle important, bien que quantitativement secondaire. Avant la Révolution industrielle, la biomasse fournit $99 \%$ de toute l'énergie primaire. La majeure partie de la biomasse est utilisée pour nourrir les gens et leurs animaux. La part de la biomasse utilisée comme bois de chauffage varie selon les régions en fonction des forêts disponibles et des conditions climatiques. Enfin, une part réduite de la biomasse est destinée à des usages non énergétiques (habitat, habillement, outillage...).

En utilisant de la biomasse, les humains mobilisent des flux d'énergie renouvelable. Dans une économie agraire, la nature est transformée de façon à générer des 
bénéfices sociaux sous la forme d'un accroissement de la quantité de biomasse utilisable. L'historien de l'environnement Rolf Peter Sieferle (2001) décrit les sociétés agraires comme des « systèmes d'énergie solaire contrôlée ». Au niveau global, ces systèmes d'énergie solaire contrôlée caractérisent les relations hommes-nature qui ont prévalu dans la plupart des sociétés humaines jusqu'au $\mathrm{xxI}^{\mathrm{e}}$ siècle. C'est ce que nous définissons comme «le régime socio-métabolique agraire ». Les nombreuses déclinaisons locales de ce régime, générées par les facteurs biogéographiques et sociaux, possèdent des caractéristiques communes qui permettent de le distinguer d'autres régimes socio-métaboliques (comme celui des « chasseurs-cueilleurs » ou le « régime industriel») : la production d'énergie utilisable est basée sur une transformation contrôlée des écosystèmes dans le but d'accroître leur rendement en biomasse utilisable. Du travail est investi dans l'aménagement des écosystèmes et accroît leur productivité. Pour que cette forme de subsistance soit durable, il faut que les activités agraires aient un rendement énergétique net positif (taux de retour énergétique, $\mathrm{TRE}^{2}$ ) : la quantité d'énergie-biomasse produite doit être significativement plus importante que la quantité d'énergie dépensée sous la forme de travail humain. Le TRE de l'Europe centrale avant la période d'industrialisation était de 10 pour 1 (Leach, 1976 ; Krausmann, 2004). Le surplus d'énergie pouvait être redistribué vers les secteurs non agraires de la société, pour fournir nourriture et matériaux de chauffage aux urbains et à ceux ne prenant pas part aux activités agricoles, ainsi que pour nourrir les animaux servant au transport.

Plus le surplus est important et plus les structures sociales peuvent se complexifier. Le surplus n'atteint cependant jamais des niveaux particulièrement élevés, le travail de dix fermes domestiques est nécessaire pour subvenir aux besoins d'un ou de deux foyers supplémentaires (de propriétaires fonciers, d'artisans ou de fonctionnaires). Dans un tel régime, l'augmentation de la demande en nourriture, qui est généralement provoquée par une augmentation de la population, implique de consacrer de nouvelles terres à l'agriculture - ce qui peut nécessiter l'appropriation de nouveaux territoires. Lorsque la terre est rare et le territoire limité, une solution de dernier recours consiste à intensifier l'usage de l'espace en y appliquant une plus grande quantité de travail dans le but d'accroître les rendements. Cependant, à mesure que cette intensification s'opère, la production par heure de travail diminue jusqu'à atteindre une limite physique au-delà de laquelle le processus d'intensification n'apporte plus rien. Lorsque cette limite est atteinte, la totalité de la population est mise au travail (enfants compris) tout en souffrant du manque de ressources essentielles. Cette logique, étudiée par l'anthropologue Esther Boserup (1965, 1981), limite donc fondamentalement le développement des sociétés agraires : la croissance mène inexorablement à une stagnation des ressources énergétiques et matérielles par habitant, voire à leur diminution, en dépit de tous les progrès faits en matière de technique agricole.

Les contraintes liées au transport ajoutent une limite supplémentaire à la croissance. Dans ces sociétés, le transport terrestre repose sur le travail animal ou humain, coûteux en énergie (alors même que la biomasse a une densité énergétique faible) et, pour les matières premières pondéreuses, rentable seulement sur de courtes distances. La

2. Sur le concept de TRE (EROI en anglais), voir Hall et al. (1986 : 28). 
biomasse étant une matière première dispersée dans l'espace et à faible densité énergétique, elle est particulièrement affectée par les contraintes de transports. Elle ne peut être déplacée sur de longues distances que lorsque des voies navigables existent. Dans le régime agraire, la croissance des villes est très contrainte et n'est possible qu'à la proximité de voies d'eau ou de côtes dotées d'arrière-pays fertiles. Les seules sources d'énergie mécanique étant le travail physique des hommes et des animaux, le vent et l'eau, la productivité du travail demeure faible ${ }^{3}$. Ainsi, le niveau, la structure et la différenciation spatiale du métabolisme sociétal, en reposant sur le système de l'énergie solaire contrôlée, sont sujets à de fortes limites. Les différences régionales tiennent essentiellement aux possibilités d'élevage et aux conditions climatiques ${ }^{4}$.

Bien que les sociétés agraires aient la capacité d'être énergétiquement soutenables (usage de flux renouvelables plutôt que des ressources épuisables), leur régime repose sur une transformation massive de la nature qui génère certains risques et problèmes environnementaux. Dans la plupart des cas, le développement de l'agriculture s'est fait au prix de déforestations : ainsi, par exemple, seule une petite partie de l'Angleterre était encore boisée avant la Révolution industrielle et, en Europe centrale, plus de $50 \%$ des forêts ont été rasées entre 900 et 1900 (Bork et al., 1998 ; Darby, 1956). Les changements dans les usages des sols impliquent aussi des changements dans les cycles de l'eau et des nutriments (azote, phosphore), dégradant souvent la qualité des sols et provoquant leur érosion. La transformation des écosystèmes change la faune et la flore, et le déplacement des plantes, des animaux et des parasites effectué par les hommes peut avoir de nombreux effets pervers (Crosby, 1986). La proximité avec les animaux encourage le développement de parasites et de maladies tandis que, dans les villes, l'air et l'eau deviennent pollués. Cependant, ces problèmes restent localisés. De plus, ils sont très fréquemment déclenchés par des processus naturels comme des phénomènes climatiques extrêmes. Les politiques cherchant à éviter ces problèmes s'appuient sur la diversification, plutôt que sur la spécialisation, et sur la sous-exploitation des ressources disponibles (Müller-Herold et Sieferle, 1997).

Toutefois, un facteur déterminant pour la durabilité des sociétés agraires réside dans leur capacité à maintenir un équilibre entre les niveaux de population et de fertilité des sols, et à stabiliser ainsi les rendements agricoles sur le long terme. Les règles culturelles (et légales) permettaient de réguler la croissance des populations, notamment à travers les restrictions pour les mariages et les tabous sexuels, caractéristiques des sociétés agraires (Harris et Ross, 1987). Stabiliser, sans parler d'augmenter, la production alimentaire par habitant dans le cadre d'une agriculture entièrement dépendante de moyens de production locaux et biologiques est une tâche très difficile qui n'a pas toujours été couronnée de succès : dégradation des sols, désertification et, dans certains cas, effondrement de la structure sociale ont souvent résulté des

3. Il faut imaginer qu'avec 2000 travailleurs pour bâtir les pyramides, les pharaons disposaient d'une capacité productive légèrement supérieure à celle d'un travailleur contemporain utilisant une machine pour construire une route.

4. Les sociétés pastorales dotées d'un grand nombre d'animaux par habitant connaissent les meilleurs taux de conversion de la biomasse. Les sociétés dont les moyens de subsistance dépendent majoritairement du travail humain physique et des régimes alimentaires basés sur la culture des plantes (comme les sociétés du Sud et du Sud-Est asiatique qui cultivent massivement le riz) connaissent les taux de conversions les plus faibles. 
tentatives ratées pour contrôler le système agricole ou d'un déséquilibre entre niveau de population et capacité du système agraire (Diamond, 2005 ; Tainter, 1988). Le système de rotation triennale, fréquemment utilisé en Europe centrale au début du $\mathrm{XIX}^{\mathrm{e}}$ siècle, parvenait à assurer l'apport d'éléments nutritifs pour les plantes au moyen d'un système de rotation complexe et intensif en travail incluant jachère, collecte et épandage de fumier, et transferts de nourriture des forêts et des prairies vers des terres arables (Mazoyer et al., 2006 ; Cusso et al., 2006 ; Krausmann, 2004).

\section{" La phase charbonnière des transitions métaboliques ou la success story anglaise depuis le milieu du xvı" siècle}

$\mathrm{Au} \mathrm{XVII}{ }^{\mathrm{e}}$ siècle, se développe en Angleterre un nouveau système énergétique basé sur une utilisation massive du charbon. Cette transition énergétique se caractérise par le passage d'une utilisation de ressources à faible densité énergétique - la biomasse renouvelable - à l'exploitation d'une ressource à forte densité énergétique - le charbon dont les "dépôts » se sont constitués au cours des ères géologiques passées (Smil, 2003). Connu de longue date, le charbon est initialement exclusivement utilisé pour le chauffage des villes, en remplacement du bois, incapable de satisfaire leurs besoins croissants. En Angleterre, du charbon est disponible à proximité des villes ou facilement transportable à bas prix par voie d'eau. Des centres d'industrie manufacturière très peuplés émergent aussi parce que, dès le XVII ${ }^{\mathrm{e}}$ siècle, les grands propriétaires fonciers anglais se rendent compte qu'il est plus rentable d'utiliser leurs terres pour la production de matières premières pour l'industrie textile que pour produire des denrées alimentaires à destination des populations rurales qu'ils considèrent comme superflues.

En 1800, les habitants d'Angleterre utilisent déjà $900 \mathrm{~kg}$ de charbon par an (voir figure 1.1a). Cela constitue un modèle de développement radicalement nouveau et promis à un grand avenir, comme l'ascension rapide de l'Angleterre allait le prouver. En 1800, l'Angleterre réalise $90 \%$ de l'extraction mondiale de charbon dont une part non négligeable est exportée vers les autres pays européens qui, à leur tour, commencent à découvrir les bénéfices d'une économie carbonée. Pourtant, en termes quantitatifs, les États-Unis, le Japon ainsi qu'une grande partie de l'Europe demeurent, jusqu'au milieu du $\mathrm{XIX}^{\mathrm{e}}$ siècle, assez largement dépendants d'un régime socio-métabolique agraire, et donc de la biomasse comme source de matières premières et d'énergie. Ce n'est qu'à partir de 1850 que l'Allemagne, la France et les États-Unis commencent véritablement leur transition énergétique, c'est-à-dire accroissent leur consommation de charbon par habitant (figure 1.1a). En 1900, plus de $70 \%$ des extractions mondiales de charbon étaient le fait de quatre pays : l'Angleterre, la France, l'Allemagne et les États-Unis. Dans le reste du monde, seuls quelques centres urbains industriels sont touchés par cette transition. En effet, les pays européens déjà entrés dans une phase d'industrialisation ont tout intérêt à utiliser le colonialisme pour empêcher les autres régions du monde de suivre la voie du développement industriel, afin qu'ils continuent à assurer la production de biens alimentaires et de matières premières bon marché, et qu'ils servent de marché secondaire pour écouler leur production industrielle. 

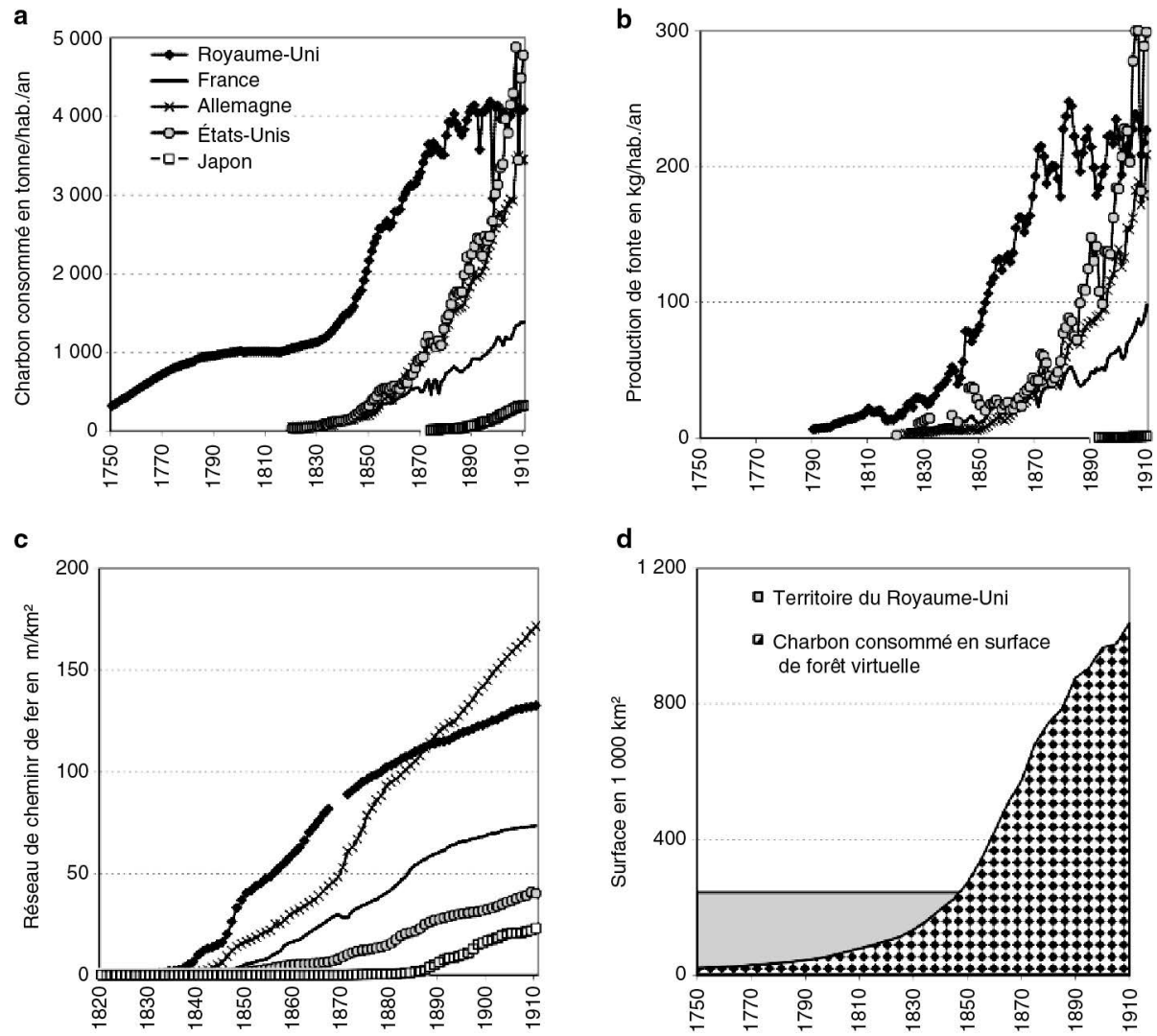

Figure 1.1. Évolution de l'utilisation du charbon (a), de la fonte brute (b) et des réseaux ferrés (c) dans certains pays entre 1750-1830 et 1910.

Utilisation du charbon en termes d'équivalent de forêt virtuelle au Royaume-Uni.

Calculs effectués par les auteurs à partir de Mitchell (2003), Maddison (2008), Schandl et Krausmann (2007).

La Révolution industrielle et la prédominance d'un nouveau système énergétique sont étroitement liées à l'établissement d'un nouveau complexe technologique caractérisé par des interactions nombreuses et l'existence de boucles de rétroactions positives entre l'exploitation du charbon, la machine à vapeur, la production de fer et d'acier, et le chemin de fer (Grübler, 1998 : 207). La machine à vapeur a d'abord été utilisée pour pomper l'eau et a ainsi permis d'accéder à du charbon profondément enfoui, ainsi que de réduire les coûts d'extraction. Son utilisation a alors favorisé l'accroissement de la production de fer et, à partir de 1870, d'acier de haute qualité. Ces grandes quantités de fer (et plus tard d'acier), ainsi que le développement des machines à vapeur ont rendu possible une révolution dans les transports, notamment du chemin de fer et des bateaux à vapeur.

Le développement de la consommation de charbon, de la production de fonte brute et des réseaux de chemin de fer, au cours du XIX ${ }^{\mathrm{e}}$ siècle, témoigne de l'avance du Royaume-Uni (figure 1.1), ainsi que du rattrapage qu'opèrent un peu plus tard 
l'Allemagne ou les États-Unis. Entre 1840 et 1860, des réseaux de chemin de fer sont construits dans de nombreux pays. Combinés aux bateaux à vapeur, ils rendent possible, pour la première fois dans l'histoire de l'humanité, l'échange à longue distance entre des populations produisant des biens alimentaires et celles, de taille croissante, nécessitant ces biens alimentaires, car engagées dans la production industrielle. Désormais, la croissance des villes ne connaît plus de limite.

Les machines à vapeur convertissent l'énergie thermique en énergie mécanique, ce qui permet d'accroître formidablement la puissance disponible par rapport au régime métabolique précédent. Ces changements radicaux dans les capacités d'extraire, de transporter, de transformer et de consommer de la matière donnent lieu à une nouvelle forme de métabolisme sociétal : en plus de la biomasse, d'énormes quantités de charbon, de matériaux de construction et de minerai sont extraites. Au RoyaumeUni, par exemple, l'utilisation de matériaux passe de 60 à 400 millions de tonnes par an entre 1750 et 1900 . Durant cette période, l'utilisation de matière et d'énergie augmente plus rapidement que la population. Pour la première fois dans l'histoire, la demande pour du travail non agricole croît rapidement : les performances des vastes équipements mus par l'énergie tirée du charbon génèrent un fort besoin en maind'œuvre pour la production manufacturière. Durant cette phase, l'accroissement de consommation de matière et d'énergie par habitant ne se traduit pas par une amélioration du niveau de vie des masses, mais bénéficie d'abord à l'expansion de l'industrie et des exportations. L'environnement des citadins, lui, se dégrade.

Dans son étude globale de l'histoire environnementale au $\mathrm{xx}^{\mathrm{e}}$ siècle, John McNeill fait référence à Charles Dickens pour décrire cette phase comme la période Coketown (McNeill, 2000 : 296). Celle-ci est caractérisée par des villes industrielles en expansion peuplées de cheminées avec leurs fumées âcres, leurs cours d'eau pollués, leurs sinistres quartiers de pauvres et d'ouvriers. L'utilisation croissante de matière et d'énergie s'accompagne d'un accroissement d'émissions de gaz toxiques, d'effluents et de déchets, générant de nouveaux types de problèmes environnementaux et dégradant la qualité de la vie, particulièrement dans les centres urbains industriels densément peuplés. Au cours de cette période, les pollutions de l'air et de l'eau, de même que les problèmes d'hygiène et de santé afférents deviennent transrégionaux. Des mesures telles que la construction de cheminées plus hautes ou de réseaux de canaux permettent de disperser et de diluer certains polluants, mais ne font que diminuer leur impact local.

La phase charbonnière du développement est une première étape vers l'émancipation du système énergétique vis-à-vis de l'espace, repoussant un peu plus loin les limites de la croissance économique. Rolf Peter Sieferle (2001) a évoqué cette idée en parlant de «forêts souterraines ». Il a montré que, dès 1850, l'énergie (en termes de valeur calorique) dégagée par le charbon brûlé chaque année au Royaume-Uni était équivalente à celle produite par une forêt virtuelle de la taille du pays entier, et à quatre fois cette surface en 1900 (voir figure 1.1d).

Pour autant, le charbon n'émancipe pas de toutes les contraintes prévalant dans le système énergétique solaire. Les humains restent en effet totalement dépendants de la biomasse pour leur alimentation. Le début de l'industrialisation est marqué par un accroissement de la population (en Angleterre, elle double entre 1750 et 1900), principalement employée (y compris les femmes et les enfants) dans les secteurs non 
agricoles de l'économie. L'accès à une énergie inanimée toujours plus abondante n'a donc pas remplacé le travail humain, mais a au contraire alimenté sa demande. De même, les réseaux ferrés n'ont pas remplacé les animaux de traits : le maillage ferroviaire et l'intensification du fret de marchandise et du transport des hommes ont nécessité plus d'animaux de traits (chevaux surtout) pour assurer la distribution locale et le transport régional. Alors que le charbon a continué de remplacer le bois de chauffage, la construction de voies ferrées et l'industrie papetière naissante ont nécessité toujours plus de bois. Paradoxalement, la transformation du système énergétique s'accompagne donc d'un accroissement de la demande en biomasse pour nourrir hommes et bêtes, ainsi que pour alimenter en matières premières les nouvelles industries. Dans le même temps, il n'a plus été possible d'étendre les terres cultivables et les moyens pour augmenter les rendements se sont avérés limités, notamment par manque chronique d'engrais. Bien que le guano, le salpêtre chilien ou le superphosphate soient utilisés de plus en plus intensément à partir de la fin du XIX ${ }^{\mathrm{e}}$ siècle, les volumes restent faibles et limités à certaines cultures (oranges, tabac). Les apports de nutriments aux plantes reposent donc toujours sur des ressources internes aux exploitations agricoles (fumier, légumineuses, etc.). Ainsi, les limites fondamentales de l'agriculture traditionnelles demeurent, en dépit de certaines innovations biologiques (nouvelles variétés ou pratiques culturales). En Angleterre par exemple, où ces innovations ont été mises en place précocement, elles ont été suivies d'une stagnation des rendements du blé nécessitant, au cours du XIX ${ }^{\mathrm{e}}$ siècle, l'importation des denrées alimentaires des colonies d'outre-mer, de Russie ou des États-Unis (Krausmann et al., 2008b).

Dans ce dernier pays, entre 1850 et 1920, plus de 100 millions d'hectares de terres de très bonne qualité sont appropriés dans le Midwest, après l'expulsion violente des populations indigènes (Cunfer, 2005). Les sols des Grandes Plaines, très riches en nutriments, permettent alors d'obtenir des rendements élevés avec peu de travail, générant une productivité du travail extraordinairement forte. Une petite population rurale peut ainsi nourrir celle des côtes américaines, et même exporter une partie de la production vers l'Europe. Aux alentours de 1880, les États-Unis exportent déjà plus de 4 millions de tonnes de céréales, permettant de subvenir aux besoins nutritifs de plus de 20 millions de personnes (Krausmann et Cunfer, 2009).

Ce développement est aussi étroitement lié à celui des grappes technologiques de l'ère Coketown, puisqu'il dépend de l'expansion des réseaux ferrés et du bateau à vapeur, de l'approvisionnement en charbon des populations vivant dans des plaines peu boisées mais au climat rigoureux, et enfin de l'accès à des équipements en acier permettant la mécanisation de l'activité agricole.

\section{" Pétrole et voiture : la success story américaine à partir de 1900}

Durant la phase suivante d'industrialisation, les États-Unis ne doivent pas seulement leur position de leader à leur forte productivité agricole, mais aussi à une autre ressource : le pétrole. Avec la découverte d'importants gisements à Spindletop au Texas, l'utilisation du pétrole explose à partir de 1900 : en l'espace de trente ans, la 
production pétrolière américaine passe de moins de 10 millions à 140 millions de tonnes par an, pour atteindre plus de 1,2 million de tonnes de pétrole par habitant et par an avant la crise économique des années 1930. Tout comme l'Angleterre avec le charbon, les États-Unis dominent le secteur de la production du pétrole durant toute la première moitié du $\mathrm{xx}^{\mathrm{e}}$ siècle, ce n'est qu'après la Seconde Guerre mondiale que l'exploitation des réserves énormes du Moyen-Orient évince les États-Unis de leur position dominante sur le marché mondial.

Le pétrole possède une densité énergétique supérieure à celle du charbon, coûte moins cher à exploiter, et, avec les bonnes infrastructures, peut être facilement transporté à moindre coût. De toutes les options possibles, le pétrole apparaît donc comme une source d'énergie idéale. Cependant, à la différence du charbon, les réserves de pétrole (mais aussi de gaz naturel) sont distribuées très inégalement sur la planète. Les pays industrialisés européens, qui avaient été si prospères jusqu'à présent, ne possèdent qu'une petite partie des réserves exploitables et doivent d'abord s'équiper d'infrastructures de distribution intensives en capital (tel que les pipelines, les pétroliers et les raffineries) pour pouvoir utiliser cette ressource. Une partie des profits issus de la production industrielle européenne se concentre ainsi dans d'autres parties du monde (et, initialement, notamment aux États-Unis). Ainsi, l'utilisation du pétrole redistribue les rapports de pouvoirs au niveau mondial.

L'utilisation du pétrole comme nouvelle source d'énergie s'est accompagnée de l'émergence d'un nouveau complexe technologique. McNeill a qualifié cette combinaison entre moteur à combustion, automobile et avion, industrie (pétro-chimique) et électricité de Motown cluster en référence au centre de l'industrie automobile des États-Unis (la motor town Detroit) (McNeill, 2000 : 297). L'individualisation et l'accélération des transports des hommes et des marchandises que provoque l'arrivée du moteur à combustion interne ont déclenché une nouvelle révolution des transports. De plus, l'électricité, une nouvelle forme d'énergie universellement utilisable, permet la mécanisation de nombreux processus technologiques via le moteur électrique. Mais le charbon, de même que la biomasse lors de la première phase, n'est pas complètement remplacé et continue de servir de base à la production d'acier et pour la production d'énergie thermique. Néanmoins, la consommation de charbon, qui atteint son plus haut niveau historique aux États-Unis en 1920 et dans les pays européens quelques décennies plus tard, n'a cessé de décroître depuis. Inversement, il n'a fallu que quelques décennies pour que le pétrole représente la moitié du flux d'énergie mondial (figure 1.2).

Le contexte économique qui a permis l'établissement d'un nouveau système énergétique aux États-Unis est constitué d'une combinaison d'énergie bon marché, de production à la chaîne et de croissance des revenus du travail. C'est ce que la littérature appelle le fordisme et qui a annoncé l'ère de la production et de la consom-

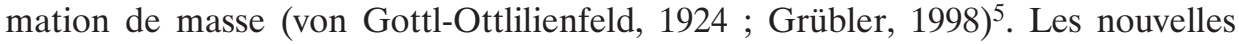
technologies ont ainsi trouvé des applications dans des biens de grande consommation, de sorte que, désormais, les ménages atteignent des niveaux élevés de consommation d'énergie et de matière, avec un accroissement spectaculaire de leur

5. La notion de fordisme a aussi été largement utilisée et débattue dans les travaux régulationnistes français (voir par exemple Coriat, 1979) à partir d'un texte de Gramsci de 1929. 

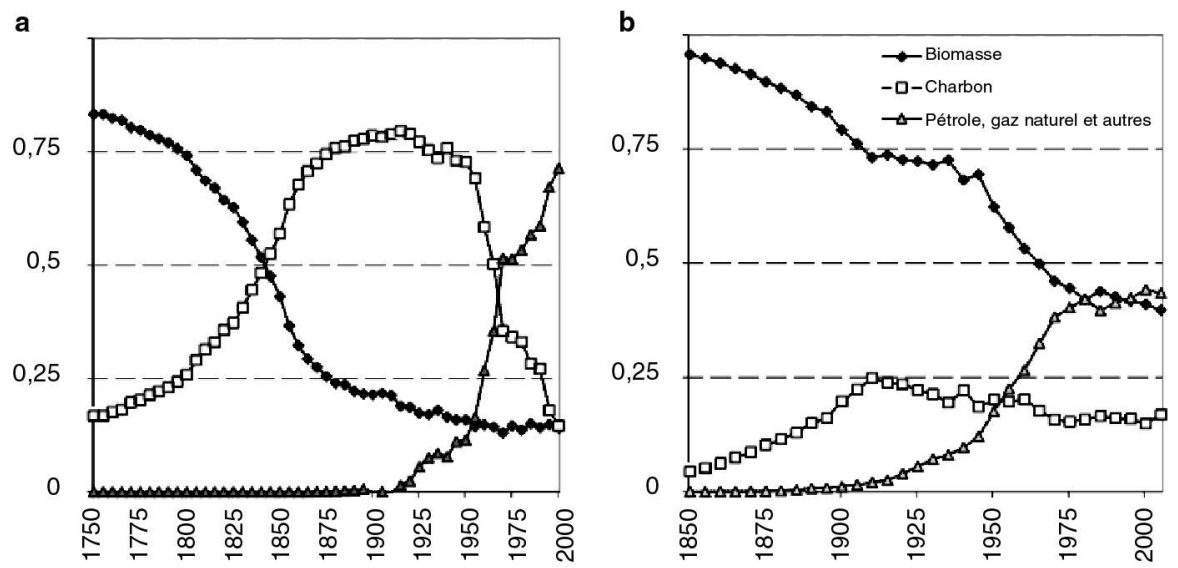

Figure 1.2. Établissement d'une nouvelle forme d'énergie (a) au Royaume-Uni (17502000) et (b) dans le monde entier (1850-2005).

Ces schémas présentent les parts dans la production d'énergie primaire de la biomasse (nourriture ou combustible), du charbon et du pétrole/gaz naturel (y compris autres formes d'énergies).

Données à partir de Schandl et Krausmann (2007), Krausmann et al. (2009), Podobnik (1999) et IEA (2007).

bien-être matériel. L'automobile, le chauffage central, les équipements électriques domestiques et la viande, produits intensifs en matière et en énergie, constituent les produits phares de cette période. En quelques décennies, ces produits deviennent très abordables pour toutes les couches sociales de la société. L'ensemble de leur consommation augmente donc, donnant naissance à l'american way of life. En Europe et au Japon, cette dynamique s'impose au lendemain de la Seconde Guerre mondiale (en partie du fait de l'aide américaine), causant un doublement de la consommation par habitant de matière et d'énergie (et des pollutions et déchets correspondants) en l'espace de vingt-cinq ans. Pour décrire cette croissance sans précédent du métabolisme sociétal, l'historien de l'environnement Christian Pfister parle de «syndrome des années 1950 ». Pfister montre qu'entre la Seconde Guerre mondiale et la première crise pétrolière, les rapports nature-société se sont fondamentalement modifiés (Pfister, 2003). Ce nouveau régime socio-métabolique s'appuie sur trois « forces » : la rapide baisse des prix relatifs de l'énergie, ce qui réduit son importance dans les coûts de production; des investissements publics dans la construction de réseaux électriques, de transports et de pipelines ${ }^{6}$; une nouvelle forme de gouvernement (l'État providence) garantissant des revenus du plus grand nombre (Lutz, 1989)7 ${ }^{7}$ En Europe, ce régime socio-métabolique est impulsé par la reconstruction après la Seconde Guerre mondiale. Au total, le « syndrome des années 1950 » permet un rattrapage des niveaux de développement et une diffusion de l'american way of life dans les pays de l'Europe de l'Ouest, au Canada, en Australie et au Japon. Initialement, le reste du monde demeure à l'écart.

6. Dans les années 1930, la politique du New Deal permet la construction d'un million de kilomètres d'autoroutes et de 77000 ponts aux États-Unis. À partir de 1956, avec l'aide du Federal Highway Aid Program, le pays a été maillé d'un vaste réseau autoroutier.

7. Sur ce point, voir le chapitre 21 et, en français, sur la genèse de l'État providence, Ewald (1986). 
La voiture est le plus important des facteurs de transformation du métabolisme sociétal du $\mathrm{Xx}^{\mathrm{e}}$ siècle. Elle fonde les bases d'une nouvelle révolution des transports : avec plusieurs milliers de mètres par $\mathrm{km}^{2}$, le réseau routier est plusieurs fois plus dense que le réseau ferroviaire ; les animaux de trait, moyen de distribution indispensable pour les réseaux de transports centralisés, deviennent superflus. Après la Seconde Guerre mondiale, les pays industrialisés voient leurs flottes de véhicules augmenter rapidement. Dès 1970, chaque pays européen a entre 250 et 350 véhicules pour 1000 habitants (et au moins deux fois plus aux États-Unis - voir figure 1.3.). Les voitures bon marché permettent, pour la première fois, un accès généralisé au transport individuel. La production automobile devient ainsi le premier secteur industriel, fondamental pour que ce nouveau régime puisse s'établir. Ce système de transport génère directement ou indirectement d'énormes flux de matière et d'énergie (Freund et Martin, 1993) : en moyenne, 30 tonnes de matériaux sont requis pour produire une voiture. Aux États-Unis, dans les années 1990, 10 à $30 \%$ des métaux et les deux tiers du caoutchouc étaient utilisés dans l'industrie automobile. De plus, chaque kilomètre d'autoroute nécessite en moyenne 40000 tonnes de ciment, d'acier, de sable et de graviers, et les réseaux routiers prennent 10 à 15 fois plus d'espace que les voies ferrées. Au cours de cette phase, le transport surpasse l'industrie comme premier secteur consommateur direct d'énergie. La consommation de carburant devient, avec le chauffage, le facteur le plus important dans la consommation d'énergie des pays industrialisés.

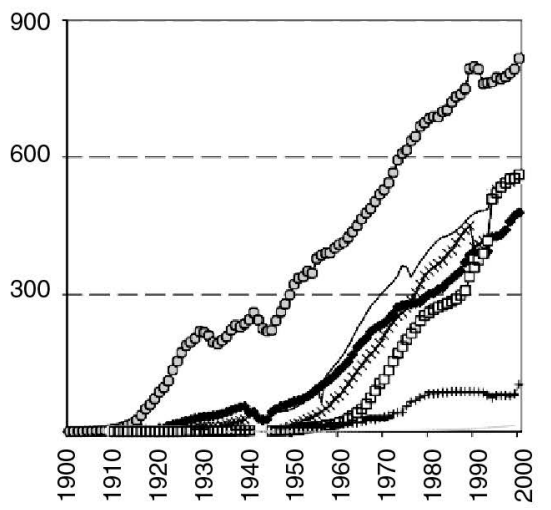

b

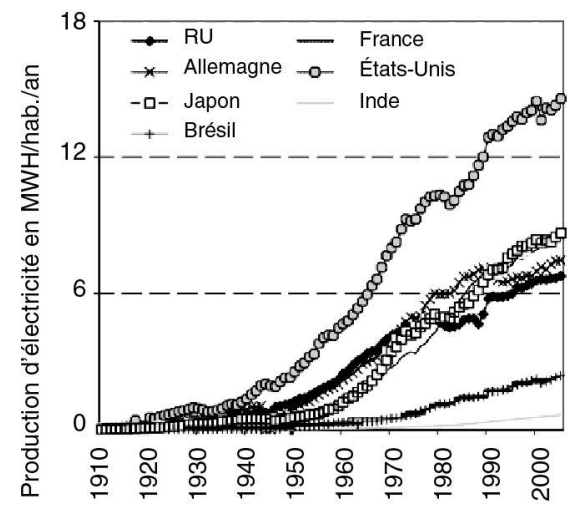

Figure 1.3. Stock de véhicules (a) et production électrique (b) au $\mathrm{xx}^{\mathrm{e}}$ siècle. Données calculées par les auteurs, à partir de Mitchell (2003) et Maddison (2008).

La production d'électricité ne dépend pas d'une source primaire particulière. Elle a d'abord été produite à partir de ressources hydriques, puis dans des centrales thermiques fonctionnant au charbon, au pétrole, au gaz naturel, avec des déchets, ou, à partir des années 1960, dans des centrales nucléaires. L'électrification de masse est devenue, $\mathrm{au} \mathrm{Xx}^{\mathrm{e}}$ siècle, un prérequis fondamental pour le développement industriel et un niveau de vie élevé. L'augmentation constante de la demande en électricité accompagne la croissance économique. Actuellement, chaque pays industrialisé consomme en moyenne 8 à $10 \mathrm{MKh}$ par habitant et par an, sauf aux États-Unis où 
la consommation est double (voir figure 1.3). La production d'électricité nécessite d'importantes quantités d'énergie car $60 \%$ d'énergie primaire est perdue dans les processus de génération et de transmission. Dans les pays industrialisés, 20 à $25 \%$ de l'énergie primaire consommée est utilisée dans la production électrique. En fonction des ressources dont ils disposent, ces pays choisissent différentes voies de production : hydroélectrique (Autriche, Suède), nucléaire (France), plus fréquemment à partir du charbon (spécifiquement pour les pays nouvellement industrialisés comme la Chine ou l'Inde). Les deux tiers de la production mondiale de charbon sont ainsi utilisés dans des centrales thermiques. Chacune de ces technologies a des impacts négatifs spécifiques sur l'environnement : l'hydroélectricité représente une perturbation dans le fonctionnement des écosystèmes ; les centrales thermiques contribuent aux émissions de $\mathrm{CO}_{2}$; l'énergie nucléaire implique de nombreux risques (voir les incidents de Three Miles Island en 1979 aux États-Unis et de Tchernobyl en 1986 en Ukraine) et continue de poser des problèmes de stockage des déchets radioactifs. Aujourd'hui ${ }^{8}$, environ $15 \%$ de l'électricité est d'origine nucléaire et $56 \%$ de celle-ci est produite par trois pays (les États-Unis, la France et le Japon).

L'électricité est universelle, facilement utilisable et permet l'éclairage, le chauffage ou l'accomplissement de tâches mécaniques. Les moteurs électriques permettent la mécanisation de processus complexes. Ils ont révolutionné les activités domestiques à travers la diffusion d'équipements comme les machines à laver, les lave-vaisselle ou les aspirateurs, et ont rendu les processus de production industrielle indépendants du travail physique humain. Finalement, les transistors et les puces d'ordinateurs ont donné lieu à la révolution des technologies de l'information et de la communication (téléphone, télévision et technologies informatiques) ${ }^{9}$.

\section{- Les limites des transformations industrielles depuis les années 1970}

Au début des années 1970, aux États-Unis, sur la base d'un modèle complexe simulant les interrelations globales entre dynamiques sociétales et économiques et leurs causes et conséquences naturelles, est publié un rapport au titre provoquant : The Limits to Growth (Meadows et al., 1972, traduit en français par « Halte à la croissance ? »). La vraisemblance des résultats est éprouvée quelques années plus tard avec le premier choc pétrolier : en réaction à la guerre israélo-arabe de 1973, les pays de l'Opep réduisent leur production de pétrole, ce qui entraîne un accroissement du prix du baril de 3 à 5 dollars. D'autres crises pétrolières suivent en 1979 et 1990 (première et seconde Guerres du Golfe). De leur côté, les États-Unis atteignent, en 1970-1971, le peak oil, c'est-à-dire le niveau maximum d'extraction de pétrole

8. C'est-à-dire vers 2010, ce chapitre a été écrit avant l'accident nucléaire majeur de Fukushima (Japon) du 11 mars 2011.

9. Note des coordinateurs : la partie s'intitulant « la Révolution verte» (pages 354-355 de l'original) a été supprimée car traitée par ailleurs (chapitre 3). Les auteurs y soulignent que, grâce à son agriculture extrêmement productive, les États-Unis ont réussi à compenser au cours du XIX ${ }^{\mathrm{e}}$ siècle les faiblesses du modèle anglais (l'insuffisance de la production alimentaire relativement à la densité et à la croissance de la population) ; puis, avec le pétrole, un nouveau modèle agricole est apparu. 
domestique, ce qu'avait annoncé M.K. Hubbert dès 1956 (Deffeyes, 2001). Ils deviennent dès lors importateurs nets de pétrole alors que les guerres coûteuses menées au Moyen-Orient n'ont pas vraiment permis de sécuriser leurs approvisionnements pétroliers. Enfin, le nucléaire, pourtant soutenu par des investissements massifs, n'a pas tenu ses promesses. L'énergie nucléaire s'est en effet révélée plus chère et plus longue à développer que prévu. Elle a également été remise en cause suite aux accidents de Three Miles Island (1979), de Tchernobyl (1986) et de Fukushima (2011).

Un ensemble de mesures a été mis en œuvre à travers le monde pour réduire à la fois l'utilisation de pétrole et l'accroissement de la consommation d'énergie. Une chute brutale (mais brève) de l'utilisation d'énergie et de matériaux dans les pays industrialisés (voir figures 1.4a et 1.4b), suivie d'un arrêt de la croissance de la consommation par habitant ont ainsi eu lieu après 1973. Au cours des trois décennies suivantes, les dépenses en matière et en énergie des pays industrialisés se sont stabilisées à un niveau relativement élevé, mais les niveaux de consommation de l'Europe et du Japon ont arrêté de converger vers le niveau américain demeuré deux fois supérieur. Le Japon a initié une réorientation de son industrie automobile vers la production de véhicules plus petits et consommant moins d'énergie. L'industrie automobile américaine, au contraire, a continué d'adhérer à cette dynamique d'utilisation intensive des ressources, jusqu'à son effondrement lors de la crise de 2008.

Les années 1970 peuvent être considérées comme le début de la fin du régime sociométabolique américain fondé sur un usage gaspilleur des ressources naturelles. Parallèlement, émerge un nouveau régime basé sur les NTIC (nouvelles technologies de l'information et de la communication), permettant potentiellement de satisfaire les besoins humains en utilisant moins de ressources.

$\mathrm{Au}$ cours de la seconde phase de la transition métabolique mondiale des cent dernières années, les flux de matière extraits par les humains ont augmenté de 8 à 60 millions de tonnes par an, et la consommation d'énergie primaire a augmenté de 50 et $480 \mathrm{EJ} /$ an (figure 1.4c, 1.4d). Le quadruplement de la population mondiale explique en partie que le métabolisme sociétal soit devenu si important. La croissance de la consommation par habitant dans les pays industrialisés a cependant joué un rôle très important dans cette augmentation. La transition métabolique a également conduit à diversifier les matériaux utilisés ${ }^{10}$.

Le métabolisme industriel a engendré de nombreux problèmes, y compris au niveau mondial, et a conduit à une domination de la nature par les humains à un niveau jamais atteint. Au début du XxI ${ }^{\mathrm{e}}$ siècle, aucun écosystème n'échappe à l'influence de l'homme et de nombreuses espèces et écosystèmes ont disparu ou sont menacés d'extinction (Millenium Ecosystem Assessment, 2005). Pour certains problèmes environnementaux, comme les cas de pollutions classiques dont l'industrialisation est la cause principale, des solutions technologiques peuvent exister : installation de dispositifs de recyclage des déchets, usage de filtres pour éliminer ou neutraliser certaines substances toxiques, processus de décomposition, etc. La résolution du problème de

10. Les équipements électroniques (comme les ordinateurs ou les téléphones portables) peuvent inclure jusqu'à soixante types de métaux différents. Dans la plupart des cas, étant donné la petite taille de ces composants, leur recyclage est impossible (Hilty, 2008 : 168). 

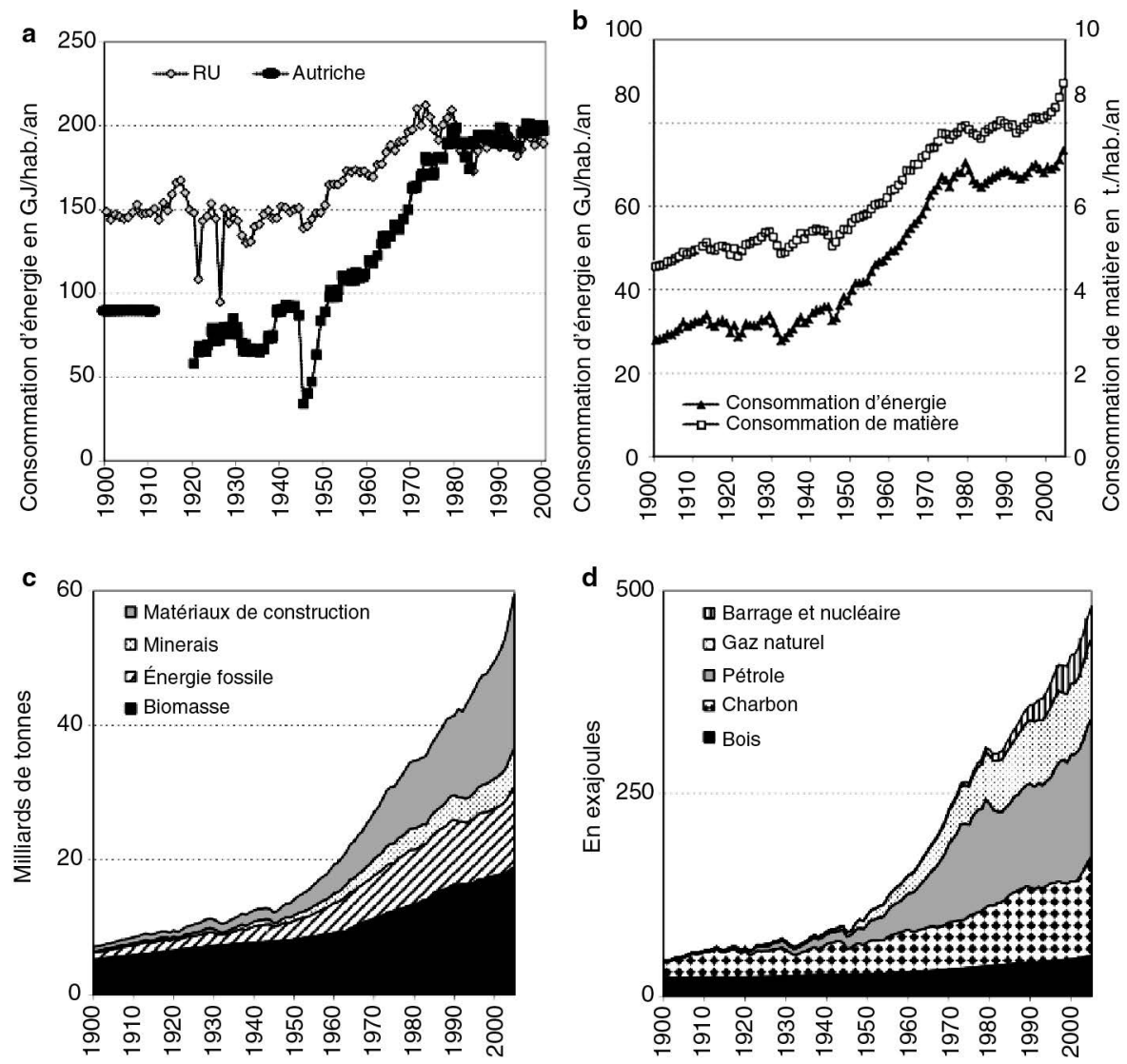

Figure 1.4. Développement du métabolisme sociétal global. (a) Consommation d'énergie par habitant au Royaume-Uni et en Autriche, (b) consommation mondiale d'énergie et de matériaux par habitant, (c) consommation mondiale de matériaux, et (d) consommation mondiale d'énergie primaire par ressource.

Données basées sur Krausmann et al. (2008b, 2009).

trou dans la couche d'ozone illustre cette possibilité : cinq années seulement après sa découverte en 1985, le bannissement des chlorofluorocarbones était déjà acté et mis en ouvre au niveau international. Depuis, le trou dans la couche d'ozone a lentement diminué. De cette manière, avec le développement de nouvelles politiques environnementales, certains problèmes environnementaux majeurs ont pu être contenus ou évités. Cependant, ces politiques seules ne peuvent constituer des solutions à certains problèmes fondamentaux causés par la transition métabolique.

Les flux de matière générés par les activités humaines ont atteint un niveau qui est comparable au volume de matière converti par les processus biogéochimiques naturels de la planète : on estime ainsi qu'au début du XXI ${ }^{\mathrm{e}}$ siècle l'humanité s'approprie annuellement environ $30 \%$ de la biomasse nouvellement produite (production primaire nette) et donc une grande partie des moyens d'existence de tous les organismes hétérotrophes (Haberl et al., 2007). De même, les émissions de nitrogène 
d'origine anthropiques ont plus contribué à la fixation de l'azote dans les écosystèmes terrestres que tous les mécanismes naturels (Galloway et al., 2008). Certains scientifiques qualifient cette période de domination des écosystèmes par l'activité humaine d'ère de l'Anthropocène (Steffen et al., 2007) (voir chapitre 2).

Tout cela survient à une époque où à peine un milliard de gens vivent selon un profil métabolique industriel, alors que les cinq milliards restant y aspirent en vivant, en partie, dans des conditions d'extrême pauvreté. Le tableau 1.1 montre les différences qui existent entre les profils socio-métaboliques de différents pays et met en évidence le couplage entre le revenu (mesuré en PIB par habitant) et la consommation de ressources.

Les États-Unis n'ont pas été les seuls à ignorer les signaux du début des années 1970. Les autres pays industrialisés ne les ont pas vus non plus. Il n'a pas été possible de remplacer la logique de consommation intensive de ressources du régime industriel par une nouvelle logique métabolique que serait censée porter une société de l'information et de la communication. Au contraire, les NTIC sont simplement venues s'ajouter au système existant. En ce sens, a été manquée l'opportunité de montrer aux pays émergents qu'un nouveau modèle de développement économique et technologique pouvait offrir une bonne qualité de vie à un coût écologique bien plus faible. Désormais, la dynamique des relations société-nature menace de conduire à des crises majeures si ce n'est à des catastrophes.

Tableau 1.1. Profils socio-métaboliques en 2000.

\begin{tabular}{|c|c|c|c|c|c|c|c|}
\hline & $\begin{array}{l}\text { PIB par } \\
\text { habitant } \\
\text { (revenu) }\end{array}$ & $\begin{array}{c}\text { Consommation } \\
\text { de matériaux }\end{array}$ & $\begin{array}{c}\text { Consommation } \\
\text { d'énergie }\end{array}$ & $\begin{array}{c}\text { Émissions } \\
\text { de } \mathrm{CO} 2\end{array}$ & $\begin{array}{c}\text { Consom- } \\
\text { mation } \\
\text { d'électricité }\end{array}$ & $\begin{array}{l}\text { Véhicules } \\
\text { à moteur }\end{array}$ & $\begin{array}{l}\text { Empreinte } \\
\text { écologique }\end{array}$ \\
\hline & \$/hab./an & t/hab./an & GJ/hab./an & tC/hab./an & GJ/hab./an & $\begin{array}{l}\text { Pour } \\
1000 \\
\text { hab. }\end{array}$ & $\mathrm{Ha} / \mathbf{a n}$ \\
\hline États-Unis & 31618 & 28 & 440 & 5,6 & 52 & 761 & 9,6 \\
\hline Japon & 23804 & 16 & 202 & 2,5 & 31 & 551 & 4,4 \\
\hline France & 23735 & 17 & 252 & 1,6 & 29 & 548 & 5,6 \\
\hline Allemagne & 23391 & 20 & 225 & 2,7 & 25 & 553 & 4,5 \\
\hline Royaume-Uni & 22560 & 12 & 214 & 2,6 & 24 & 418 & 5,6 \\
\hline Corée & 14010 & 15 & 208 & 2,5 & 20 & 223 & 4,1 \\
\hline Argentine & 11012 & 22 & 227 & 1,0 & 9 & 204 & 2,3 \\
\hline Mexique & 8231 & 15 & 117 & 1,0 & 7 & 144 & 2,6 \\
\hline Brésil & 6646 & 16 & 139 & 0,5 & 8 & 92 & 2,1 \\
\hline Chine & 3491 & 7 & 55 & 0,6 & 4 & 10 & 1,6 \\
\hline Inde & 2234 & 6 & 37 & 0,3 & 2 & 11 & 0,8 \\
\hline
\end{tabular}

Sources : The World Bank Group (2007) pour le PIB en dollars constants pour l'année 2000, ajusté en parité de pouvoir d'achat ; Krausmann et al. (2008a) pour les consommations d'énergie et de matériaux; Marland et al. (2007) pour les émissions de $\mathrm{CO}_{2}$; IEA (2007) pour la consommation électrique ; United Nations Departments of Economic and Social Affairs (2004) pour le stock de véhicules à moteur; Global Footprint Network (2006) pour l'empreinte écologique. 
Si le processus de rattrapage dans lequel les deux tiers de la population mondiale se trouvent engagés implique d'atteindre le niveau de métabolisme des pays industrialisés, alors les extractions de ressources tripleront d'ici 2050. Fournir suffisamment de nourriture à une population en croissance et de plus en plus riche nécessitera d'accroître la pression sur les rares écosystèmes encore préservés et d'utiliser les sols cultivés de manière plus intensive. Un tel développement nécessitera forcément un retour au charbon (EIA, 2010). Cette tendance, qui semble déjà amorcée au niveau mondial, sera très coûteuse et pourra même mener à une catastrophe climatique. Pour ce qui concerne les eaux douces et les réserves d'eau potables, la situation dans de nombreuses régions du globe est déjà désespérée, avec un futur suspendu à la menace du changement climatique. Concernant d'autres ressources, comme les métaux précieux, la concurrence deviendra telle qu'elle accroîtra les risques de conflits armés. Le monde se trouve actuellement sur ce chemin de développement - autant que sur celui d'une crise économique mondiale qui pourrait renverser cette tendance.

Le Protocole de Kyoto a visé à amorcer ce changement de tendance, avec les mesures de restriction d'émissions de $\mathrm{CO}_{2}$, principal rejet du métabolisme industriel. Le $\mathrm{CO}_{2}$ (avec d'autres gaz à effet de serre) est responsable d'une altération sans précédent des cycles biogéochimiques avec de graves conséquences sur le système climatique mondial. La croissance des émissions de ces gaz est une conséquence directe de la combustion des énergies fossiles. Actuellement, 8 Giga tonnes (Gt) de carbone sont émises chaque année dans le monde, ce qui représente une moyenne de 1,5 tonne par habitant. La figure 1.5 représente la progression des émissions de $\mathrm{CO}_{2}$ dans certains pays industrialisés et en développement. L'évolution des émissions reflète étroitement les différentes phases de la transition métabolique globale. Le taux d'émission de l'Angleterre en 1750, début de la Révolution industrielle, était de 0,25 t de carbone par habitant et par

a

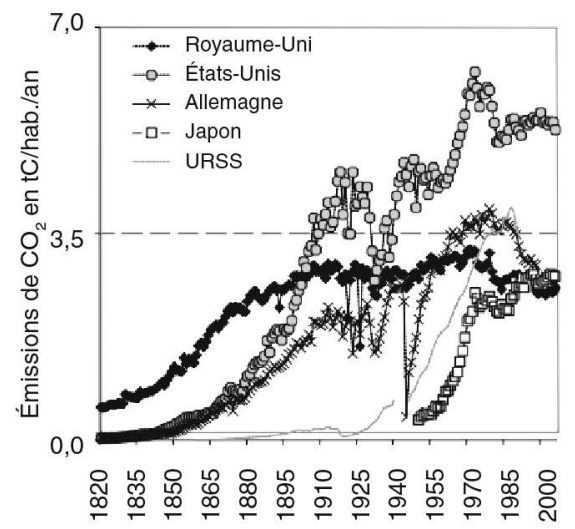

b

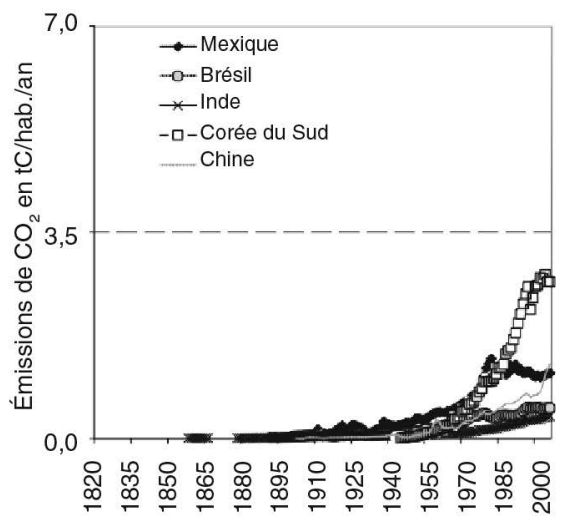

Figure 1.5. Émissions de $\mathrm{CO}_{2}$ résultant de la combustion des énergies fossiles et de la production de ciment pour certains pays industrialisés (a) et du Sud (b).

Données en tonnes de carbone (C) par habitant et par an, basées sur Marland et al. (2007) pour les émissions de $\mathrm{CO}_{2}$ et Maddison (2008) pour la population. 
an. Ce taux double une première fois pour atteindre $0,5 \mathrm{t} / \mathrm{hab}$./an en 1800 et une deuxième fois à $1 \mathrm{t} / \mathrm{hab}$./an en 1850. Les autres pays européens et les États-Unis suivent la même trajectoire après 1850 . Une autre course au rattrapage a eu lieu au milieu du $\mathrm{Xx}^{\mathrm{e}}$ siècle, lorsque les nations qui voulaient s'industrialiser en Europe (l'URSS), en Asie (le Japon, puis la Corée du Sud) et en Amérique latine (le Mexique) ont fortement augmenté leurs émissions de $\mathrm{CO}_{2}$ en l'espace de deux ou trois décennies. Pour la grande majorité des autres pays, cependant, ce processus n'était pas encore survenu; au début du XXI ${ }^{\mathrm{e}}$ siècle, de grandes économies comme l'Inde ou le Brésil continuent d'avoir des taux d'émission inférieurs à $0,5 \mathrm{t} / \mathrm{hab}$./ an. Aujourd'hui, un pays industrialisé émet en moyenne 3,5 t/hab./an, alors que tous les autres pays émettent en moyenne 0,5 t/hab./an. Respecter les objectifs de garder le réchauffement climatique sous les deux degrés d'augmentation nécessiterait de réduire les émissions moyennes à 1,3 t/hab./an (IPCC, 2007) ${ }^{11}$.

\section{W Conclusion}

Au début du XXI ${ }^{\mathrm{e}}$ siècle, coexistent des conceptions très différentes sur les manières de résoudre la crise écologique mondiale (dans certains cas, l'existence même de cette crise est contestée). Il y a ceux qui placent tous leurs espoirs dans la technologie en pensant qu'elle permettrait de continuer à suivre le chemin de la croissance économique que nous avons suivi jusqu'à présent. Ainsi, comme par le passé, des solutions technologiques « en fin de chaîne », comme la géo-ingénierie, permettraient de régler le problème du changement climatique (IPCC, 2005). D'autres comptent sur les gains d'efficacité permettant d'économiser de l'énergie et de la matière dans les processus de production, ce qui devrait déconnecter le métabolisme sociétal de la croissance économique (Weizsäcker et al., 1995). Il serait ainsi possible de conserver une croissance économique tout en réduisant son impact sur le climat et sur l'environnement, en adoptant un mode de vie basé sur une consommation réduite ainsi que sur l'utilisation de sources énergétiques décarbonées (énergie solaire, éolienne ou nucléaire). Enfin, d'autres remettent plus radicalement en cause le paradigme de la croissance (décroissance) et en appellent à un nouveau modèle de société assurant les conditions biophysiques compatibles avec une population mondiale croissante sur le long terme (Jackson, 2009).

Une perspective socioécologique de long terme ne permet pas de trancher clairement ces débats, mais fournit quelques pistes. Il est en effet évident que la forte demande des sociétés industrielles en énergie et en matière est structurellement déterminée et ne peut être réduite à un usage plus frugal des ressources. Dans le régime sociométabolique industriel, le développement économique et le métabolisme sont étroitement liés, et les gains de productivité générés (parfois énormes) n’ont jamais permis de réduire le métabolisme, mais l'ont au contraire toujours augmenté (Ayres et Warr, 2009). Une perspective historique montre que des solutions ont souvent été trouvées par le passé, mais que ces solutions ont généré de nouveaux problèmes.

11. Les émissions de la Chine (7,6 t/hab./an en 2013) donnent une idée de l'ampleur de l'effort à accomplir. 
Finalement, la société doit reconnaître que la croissance matérielle rencontre des limites et qu'il est d'autant plus important de découpler la qualité de la vie humaine de l'utilisation de matière et d'énergie. Ceci ne pourra survenir au moyen des seules technologies, mais nécessitera des changements sociétaux plus profonds. Ceux qui militent pour le concept de développement durable croient qu'il serait sage d'organiser de manière proactive ces changements.

Traduit de l'anglais par Gaël Plumecocq. 


\section{Chapitre 2 \\ Capitalocène : une histoire conjointe du système Terre et des systèmes Monde

\author{
C. Bonneuil, J.-B. Fressoz
}

$\mathrm{Si}$, selon le mot de Frederic Jameson (2003), il est plus facile « d'imaginer la fin du monde que celle du capitalisme ", c'est que ce dernier est devenu coextensif à la Terre. Les trois derniers siècles se caractérisent par une accumulation extraordinaire de capital : en dépit de guerres destructrices, ce dernier s'est accru d'un facteur

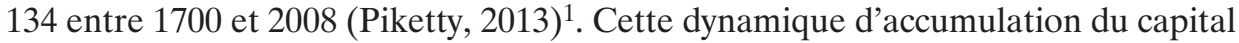
a sécrété une «seconde nature » faite de routes, de plantations, de chemins de fer, de mines, de pipelines, de forages, de centrales électriques, de marchés à terme et de porte-conteneurs, de places financières et de banques structurant les flux de matière, d'énergie, de marchandises et de capitaux à l'échelle du globe. Bien plus qu'un « anthropos » indifférencié et considéré sous l'angle principalement démographique, c'est cette technostructure orientée vers le profit qui a fait basculer le système Terre dans «l'Anthropocène ». Le changement de régime géologique est le fait de «l'âge du capital » (Hobsbawm, 1968) bien plus que le fait de «l'âge de l'homme » dont nous rebattent les récits dominants.

L'enjeu de ce chapitre ${ }^{2}$ est d'articuler l'histoire de l'économie-monde chère à Fernand Braudel et les transformations du système Terre, d'une façon qui éclaire à la fois l'histoire du capitalisme et la genèse de l'Anthropocène. Marx voyait dans le capitalisme un dispositif d'autoproduction de l'argent (la formule ArgentMarchandise-Argent+) résultant d'un mode de production visant non plus la fabrication d'objets d'usage mais celle de marchandises vendues afin d'accroître le capital. Celui-ci devient un "sujet automate » au détriment de la liberté humaine et de l'intégrité de la Terre. Dans cette lignée, bien des auteurs marxistes ont analysé les dégradations écologiques comme une rupture métabolique propre à la logique intrinsèque du capitalisme (Foster et al., 2010). Ils ont décrit l'incapacité du capitalisme à

1. Calcul effectué en dollars 1990 constants à partir des données de Piketty (2013: 739) : http://piketty. pse.ens.fr/files/capital21c/pdf/supp/TS12.4.pdf (consulté le 22 octobre 2016). D'un point de vue marxiste, c'est la richesse - dont le capital proprement dit n'est qu'une fraction - qui est ici comptabilisée.

2. Note des éditeurs : ce chapitre est une réédition d'un chapitre d'un ouvrage publié aux éditions du Seuil, L'événement anthropocène. La Terre, l'histoire et nous, qui a été ajouté à la deuxième édition en 2016. Nous remercions les auteurs et les éditions du Seuil d'avoir accepté cette réédition. Le texte a été légèrement revu sur la forme par les auteurs et la présentation des références bibliographiques modifiée (avec l'aide d'Arnaud Buchs que nous remercions), en raison du format du présent ouvrage. 
reproduire non seulement le travailleur, mais aussi l'environnement, comme sa « seconde contradiction » (O'Connor, 1988). La mobilisation du monde par le capitalisme a pris des formes extrêmement diversifiées selon les lieux et les temps. D'un point de vue environnemental, le capitalisme agraire et rentier prévalant encore dans les campagnes européennes du XIX ${ }^{\mathrm{e}}$ siècle et reposant sur la fertilité différentielle des sols (et donc sur leur relatif entretien) n'a que peu à voir avec le capitalisme fossile, minier et pétrolier déployant ses forages à travers le monde au rythme de l'épuisement des ressources.

Aussi, au lieu des grands universaux de « l'espèce humaine » ou du « capital », ce chapitre propose de considérer comme agents historiques de l'Anthropocène les métabolismes successifs engendrés par les «systèmes Monde » depuis un quart de millénaire (voir chapitre 1). Revenons un instant sur la notion de système Monde. Celle-ci s'est développée à la suite des travaux de Fernand Braudel et d'Immanuel Wallerstein $(1985$; 2006) pour saisir historiquement la globalisation de l'économie et la perpétuation d'inégalités économiques entre régions du monde. Quatre cycles d'accumulation, quatre systèmes Monde ont été distingués depuis le $\mathrm{XV}^{\mathrm{e}}$ siècle, centrés sur quatre puissances hégémoniques successives : les cités italiennes (qui financèrent l'expansion vers l'Amérique), la Hollande, la Grande-Bretagne (de la fin du XVIII ${ }^{\mathrm{e}}$ siècle au début du XX ${ }^{\mathrm{e}}$ siècle), puis les États-Unis (au Xx $\mathrm{x}^{\mathrm{e}}$ siècle). Pour les historiens de l'Anthropocène, la notion de système Monde possède le double avantage d'être à la fois historique et dynamique, et d'être suffisamment systémique et globale pour ouvrir un dialogue constructif avec les sciences, elles aussi systémiques et globales, du système Terre (Hornborg et Crumley, 2006). Face à un système Terre transformé, nous n'avons plus un « anthropos » indifférencié, mais plutôt des systèmes historiques de domination organisant chacun de façon distincte les flux de matière, d'énergie, de marchandises et de capitaux à l'échelle globale ${ }^{3}$. Comme le souligne Wallerstein, ces systèmes sont structurellement inégalitaires : les nations hégémoniques accumulent du capital, garantissent un certain niveau de vie aux classes moyennes, maintiennent ce faisant l'ordre social en leur sein, et financent leurs infrastructures, l'éducation, la santé, la mobilité et l'innovation. Ces États et, surtout, les entreprises qu'ils protègent ont le pouvoir économique et la force militaire pour prélever à bon prix dans les pays périphériques des matières premières, y exploiter si nécessaire une main-d'œuvre peu coûteuse, y écouler des marchandises démodées et polluer leurs environnements.

La notion de système Monde est actuellement revisitée à l'aune des flux de matière et d'énergie, de la thermodynamique et de l'empreinte écologique (Hornborg, 2014 ; Foster et Holleman, 2014). Ces travaux font apparaître des écologies-monde (Moore, 2015) successivement co-engendrées par chaque phase de l'histoire de l'économie-monde. Ils démontrent également que la prospérité des pays riches s'est construite au moyen d'un accaparement des bienfaits de la Terre et d'une externalisation des dégâts environnementaux, par le biais de phénomènes de dépossession et d' «échange inégal ». Dans Le Capital, Marx notait déjà que la position économiquement asservie de l'Irlande faisait que « l'Angleterre, [en lui faisant produire

3. Concernant plus spécifiquement la géopolitique des flux impliquant la biomasse présente et fossile (charbon, pétrole, gaz), selon les hégémonies hollandaise, anglaise et américaine, voir le chapitre suivant. 
blé, laine et bétail pour ses besoins] a indirectement exporté le sol de l'Irlande, sans même concéder à ses cultivateurs ne fussent que les moyens de remplacer les éléments constituants du sol » (Marx, 1973 [1867] : 141). Prolongeant l'idée de Rosa Luxemburg, David Harvey a suggéré que le capitalisme, pour soutenir un régime d'exploitation salarial dans les pays du centre, a besoin de s'approprier de façon récurrente du travail humain et des productions naturelles initialement vierges de rapports marchands (Harvey, 2010). Cette asymétrie se réalise soit par prédation (appropriation par dépossession), soit par un échange inégal en termes de travail incorporé 4 .

Une seconde dimension de l'échange inégal suscite un intérêt croissant de la part des historiens et des écologues : l'échange écologique inégal. L'échange est dit écologiquement inégal lorsque des territoires de la périphérie exportent des produits à forte valeur d'usage écologique contre des produits qui ont une moindre valeur d'usage écologique. Cette valeur écologique peut se mesurer en hectares nécessaires à la production de différents services écosystémiques, en « empreinte écologique $»^{5}$, en quantité d'énergie incorporée ou "émergie" dans les échanges internationaux ${ }^{6}$, en quantité de matière ${ }^{7}$, en entropie ${ }^{8}$, ou en déchets et nuisances générées. Par exemple, en partant de l'analyse thermodynamique de l'économie de GeorgescuRoegen, André Gunder Frank et Immanuel Wallerstein ont envisagé le système Monde comme une structure dissipative ${ }^{9}$. À chacune de leurs phases, les systèmes productifs et d'échanges génèrent de l'entropie vers le système Terre et répartissent cette entropie d'une façon inégale sur la planète (Wallerstein, 1983b ; Frank, 2006 : 304). Cette nouvelle comptabilité des hectares incorporés, de l'énergie incorporée, des émissions de gaz à effet de serre incorporées, de l'entropie générée ou de la matière (eau, biomasse, minerais, etc.) incorporée dans les échanges économiques

4. Depuis les travaux de R. Prebisch, A. Emmanuel et S. Amin, l'échange inégal se caractérise par la dégradation des termes de l'échange pour un pays de la périphérie du système Monde, c'est-à-dire par le fait qu'il faille exporter de plus en plus de biens (typiquement des matières premières) pour pouvoir obtenir la même quantité de biens importés (typiquement des biens industriels) et que le nombre d'heures de travail ainsi échangées soit de plus en plus inégal.

5. Le biologiste suédois Georg Borgström introduit dans les années 1960 la notion d'« hectares fantômes » comme les hectares incorporés dans les produits importés. Cette approche va influencer l'historien de la révolution industrielle Kenneth Pomeranz (ci-après), ainsi que William Rees et Mathis Wackernagel (1996) qui ont développé l'«empreinte écologique » comme nouvel indicateur de soutenabilité. Pour la méthode et les résultats récents, voir http://www.footprintnetwork.org (consulté le 22 octobre 2016).

6. Proposée par le grand écologue H.T. Odum, l'« émergie » estime le travail des écosystèmes incorporé dans un produit et est mesurée au moyen de l'énergie ayant été mobilisée par les processus écologiques ayant concouru à ce produit.

7. Les spécialistes de la «Material and Energy Flow Analysis » mesurent les échanges mondiaux selon leur masse (en tonnes) ou leur contenu énergétique. Voir l'article pionnier des chercheurs de l'Institut für Soziale Ecologie à Vienne (Fischer-Kowalski et Haberl, 1997b) (voir chapitre 1).

8. Selon la loi de l'entropie, toute entreprise économique transforme des ressources naturelles (de basse entropie) en produits et déchets à plus haute entropie, et présente donc un coût entropique toujours supérieur à son produit. Dans le cas du système Terre qui est un système ouvert, une partie de cette entropie est réduite par le monde vivant qui reconstitue une matière plus ordonnée (néguentropie) en utilisant l'énergie du soleil (photosynthèse). Le passage à une économie fossile dissipant l'énergie libre des stocks souterrains plus vite qu'elle ne se reconstitue annuellement dans la biosphère apparaît bien comme un marqueur entropique de l'Anthropocène. En suivant cette lecture on peut considérer le système Monde comme une structure dissipative (Georgescu-Roegen, 1971).

9. Sur ce point, voir le chapitre 3. 
mondiaux suscite un foisonnement de nouvelles méthodes et de séries statistiques qui offrent une compréhension neuve, rematérialisée, de l'histoire des sociétés en éclairant leur métabolisme et les écologies-monde successives qu'elles produisent et dans lesquelles elles s'insèrent. Depuis deux siècles, le décollage des pays industriels a généré une grande divergence de revenus avec les populations des pays pauvres : les $20 \%$ les plus pauvres de la planète obtenaient 4,7 \% du revenu mondial en 1820, mais seulement 2,2 \% en 1992 (Bourguignon et Morrisson, 2002). Existe-t-il un lien entre cette histoire des inégalités entre humains et l'histoire des altérations écologiques de l'Anthropocène ?

\section{$\rightarrow$ Le basculement dans l'Anthropocène : une lecture globale}

Le récit standard de l'Anthropocène fabrique une histoire très européo-centrée où le dérèglement global serait un effet secondaire d'une vague européenne d'innovations tirant le monde vers la croissance. Penser l'Anthropocène comme un capitalocène oblige à reconsidérer la pertinence de ce point de départ et à en proposer une lecture plus globale. Si c'est effectivement au début XIX ${ }^{\mathrm{e}}$ siècle, avec l'entrée dans l'ère industrielle, que l'ensemble du système Terre est altéré et que l'humanité devient une force géologique et non plus seulement biologique, faire débuter l'Anthropocène autour de 1800 occulte le fait essentiel que le capitalisme industriel a été intensément préparé par le « capitalisme marchand » depuis le $\mathrm{XVI}^{\mathrm{e}}$ siècle, $\mathrm{y}$ compris dans son rapport destructeur à la nature. Parler de capitalocène signale que l'Anthropocène n'est pas sorti tout armé du cerveau de James Watt, de la machine à vapeur et du charbon, mais d'un long processus historique de mise en relation économique du monde, d'exploitation des hommes et du globe, remontant au XVI ${ }^{\mathrm{e}}$ siècle et qui a rendu possible l'industrialisation ${ }^{10}$.

La révolution industrielle prend place dans un monde déjà capitaliste et globalisé. Jusque loin dans le $\mathrm{XIX}^{\mathrm{e}}$ siècle, le capitalisme britannique est beaucoup plus marchand, globalisé et extraverti qu'une histoire focalisée sur la production pourrait le laisser croire. La finance, la gestion de la dette publique et le commerce international génèrent des fortunes bien plus importantes que les mines ou l'industrie textile. C'est un assemblage d'aristocrates, de banquiers et de commerçants qui façonne l'impérialisme britannique et la globalisation économique des XVIII ${ }^{\mathrm{e}}$ et XIX ${ }^{\mathrm{e}}$ siècles.

Cette classe de gentlemen capitalists acquiert un poids politique prééminent car elle finance les guerres contre la France et pour l'hégémonie globale. Ces dernières ont pour objet principal la domination de l'espace commercial atlantique : la guerre de succession d'Autriche, la guerre de Sept ans et la guerre d'Amérique. Le financement de la guerre et de la dette publique (qui en 1815 en Angleterre atteint deux fois le $\mathrm{PNB}$ ) reposait sur les revenus du commerce global. D'où la centralité pour l'État

10. Ce néologisme nous est venu lors la préparation de l'édition anglaise de notre ouvrage (Bonneuil et Fressoz, 2013), en même temps qu'elle a été proposée par Jason Moore (2015) et d'autres penseurs éco-marxistes. 
britannique de l'East India Company qui canalise le tribut indien, du Navigation Act qui promeut l'activité d'import-export de Londres et des revenus « invisibles » du commerce maritime et de l'assurance. L'importance du capitalisme marchand et financier pour l'État britannique se lit dans les grandes orientations politiques du $\mathrm{XIX}^{\mathrm{e}}$ siècle : le libre-échange tout d'abord, qui fait de Londres l'entrepôt du monde, et la réduction des dépenses publiques ensuite qui, au prix d'une augmentation de la misère, permettait de renforcer la livre sterling (retour au gold standard en 1819) et donc aux gentlemen capitalists d'exporter leurs capitaux à travers le globe (Cain et Hopkins, 1986 ; Darwin, 2009 : 112).

Le commerce transatlantique fut sans nul doute « l'étincelle » (Hobsbawm, 1968: 48) qui déclencha la révolution industrielle. Sa valeur quadruple au cours du XVIII ${ }^{\mathrm{e}}$ siècle et il représente alors les deux tiers du commerce anglais. Londres devient la plaque tournante du commerce mondial, l'activité de ré-export $(85 \%$ du tabac et $95 \%$ du café sont ainsi réexportés en Europe dans les années 1770) payant pour les importations des matières premières d'Europe du Nord : bois, goudron, potasse, à savoir des matières représentant des « surfaces fantômes » extrêmement importantes (Deane et Cole, 1967 : 87). Par exemple, en 1810, la Grande-Bretagne importait des pays baltes et d'Amérique du Nord des cendres alcalines, issues de la combustion de bois, pour son industrie du savon et du verre. Ces cendres équivalaient à 25 millions de mètres cubes de bois par an, c'est-à-dire bien plus que la production annuelle de bois britannique ${ }^{11}$.

À cela s'ajoutent les revenus invisibles (c'est-à-dire ne passant pas par les douanes anglaises) de la traite négrière, de l'or brésilien, de l'argent mexicain ${ }^{12}$ et du commerce multilatéral assuré par la marine commerciale britannique. La révolution commerciale transatlantique stimule la construction navale et donc en retour l'industrie métallurgique. Le cuivre pour la marine fournit un marché décisif aux mines des Cornouailles, un secteur crucial pour les débuts de la machine à vapeur (Inikori, 2002). Elle accélère également le développement des institutions financières, l'usage des lettres de change et du crédit commercial permettant la croissance de la masse monétaire ; elle explique le développement de l'assurance maritime (la Lloyds est fondée en 1688) et de l'assurance incendie (les premières compagnies, la Phoenix et la Sun Fire, sont créées pour couvrir les risques liés au raffinage du sucre à Londres). Le commerce colonial crée les milieux bancaires de Bristol, Glasgow et Liverpool (les familles Heywood et Leyland) centraux pour le financement des manufactures dans ces régions industrielles (Inikori, 2002). Enfin et surtout, il assure une demande en produits manufacturés déterminante pour le décollage de l'industrie anglaise à la fin du XVIII ${ }^{\mathrm{e}}$ siècle. Cette demande exponentielle est tirée par l'explosion démographique en Amérique du Nord, dont la population blanche passe de 300000 en 1700 à 6 millions en 1800. En 1784, les produits textiles représentaient $57 \%$ des exportations britanniques, $82 \%$ en 1800 (Crouzet, 1980). En 1801, l'Amérique absorbe $60 \%$ de la production textile du Lancashire (Crafts, 1985 : 143). Ce marché en expansion permanente explique les efforts de productivité et la mécanisation rapide du coton à partir de 1760 .

11. Merci à Paul Warde sur ce point.

12. L'or brésilien représente des sommes aussi importantes selon François Crouzet (1990) que le commerce international formel anglais. 
La centralité du commerce transatlantique dans la révolution industrielle renvoie à celle des esclaves africains qui constituent le pivot fondamental d'un système Monde alors dominé par la Grande-Bretagne. Premièrement, les revenus de la traite, qui ont suscité tant de débats parmi les historiens, sont actuellement réévalués à la hausse : Joseph Inikori estime à $50 \%$ le taux de profit des meilleurs négriers à la fin du XVIII ${ }^{\mathrm{e}}$ siècle (Morgan, 2000). Les profits de la traite représentent environ $40 \%$ de l'investissement commercial et industriel britannique après 1750 (Solow, 1985). Deuxièmement, le sucre produit par des esclaves représente, de loin, le commerce le plus lucratif. Au début du XIX ${ }^{\mathrm{e}}$ siècle, les colonies britanniques en produisent 177000 tonnes par an contre 33000 pour les colonies françaises amputées de Saint-Domingue (Richards, 2003 : 455). La consommation anglaise passe de 1 à 25 livres par personne et par an au cours du XVIII ${ }^{\mathrm{e}}$ siècle et fournit un apport important en calories (4\% en 1800) augmentant la productivité des travailleurs britanniques (auquel il faudrait ajouter le riz). Troisièmement, le coton, produit dans le Sud esclavagiste, constitue bien sûr l'aliment principal de l'industrie textile. Quatrièmement, les produits agricoles d'Amérique du Nord et les morues de Newfoundland sont importés par les îles Caraibes, vouées aux monocultures d'exportation, pour nourrir les esclaves. Ce marché considérable (jusqu'au début du XIX ${ }^{\mathrm{e}}$ siècle, le nombre d'Africains traversant l'Atlantique est supérieur à celui des Européens) solvabilise les colonies blanches et leur permet en retour d'acheter les produits manufacturés britanniques. En somme, à la fin du XVIII ${ }^{\mathrm{e}}$ siècle, la traite négrière et le système de la plantation esclavagiste constituent le socle d'un système Monde avec des économies satellites entièrement organisées par les besoins économiques de la puissance britannique.

La nature fondamentalement globale du phénomène trop simplement appelé « révolution industrielle » peut également être saisie par les capacités productives des espaces mis en relation. L'historien Kenneth Pomeranz a entrepris, dans Une grande divergence, d'expliquer pourquoi l'Angleterre, et non la région chinoise du delta du Yangzi, a pris la voie de l'industrialisation (Pomeranz, 2010). En 1750, ces deux sociétés présentaient un niveau de « développement » économique et technologique à peu près équivalent et étaient confrontées à des pressions analogues sur leurs ressources en terre et en bois. En Angleterre, le prix du bois de chauffe est multiplié par 8 entre 1500 et 1630 et le couvert forestier ne représentait que 5 à $10 \%$ de la surface du pays à la fin du XVIII ${ }^{\mathrm{e}}$ siècle. Les plaintes sur l'épuisement des sols s'intensifient sans que l'usage du trèfle (rotation du Norfolk) ne résolve le problème.

Selon Pomeranz, une double « contingence » favorable explique la voie anglaise. Premièrement : la disponibilité du charbon. Les mines anglaises sont relativement faciles à exploiter et proches des centres de consommation, alors qu'en Chine elles se trouvent à plus de $1500 \mathrm{~km}$ de Shanghai. Deuxièmement : la situation impériale de l'Angleterre qui lui permet de drainer des ressources cruciales à son développement industriel. En 1830, le sucre (antillais) équivaut à 600000 hectares de bonnes terres à céréales, le coton (américain) à 9,3 millions d'hectares de pâturages à ovins et le bois (d'Amérique et de mer Baltique) à plus de 400000 hectares de forêts. Au total, sans compter le charbon, on atteint ainsi plus de 10 millions d'hectares fantômes (l'équivalent des deux tiers de la surface agricole utile cumulée de l'Angleterre et du Pays de Galles) nourrissant les machines et les travailleurs anglais. À ce calcul, il conviendrait d'ajouter les hectares de terre et d'océan assurant la capture, grâce 
à la photosynthèse, du $\mathrm{CO}_{2}$ dont la Grande-Bretagne émet $80 \%$ des émissions mondiales en 1825 (Malm, 2015).

En outre, comme l'a montré Alf Hornborg (2013), l'échange est bien écologiquement inégal : en 1850, en échangeant 1000 livres sterling de textile manufacturé à Manchester contre 1000 livres de coton brut américain, l'Angleterre était gagnante à $46 \%$ en termes de travail incorporé (échange inégal) et à $6000 \%$ en termes d'hectares incorporés, se libérant ainsi de la contrainte de produire autant de fibres qui entreraient en concurrence avec les autres besoins en grains, bois et fourrages. Le cas du delta du Yangzi témoigne également de l'importance de ce type d'asymétries pour l'industrialisation britannique. Le delta de la rivière des perles importait $\mathrm{au} \mathrm{XVIII}{ }^{\mathrm{e}}$ siècle d'immenses quantités de biens primaires et de coton brut du haut Yangzi et de la Chine du Nord. Mais, à l'inverse des régions périphériques du système Monde atlantique, ces régions se tournent $\mathrm{au} \mathrm{XVIII}{ }^{\mathrm{e}}$ siècle vers la production textile, privant le delta de débouchés pour sa production et de matières premières bon marché. Le monde économique chinois, davantage homogène que l'espace impérial atlantique, ne permit pas l'accumulation écologique et capitalistique assurant le décollage industriel britannique. La mécanisation et la machine à vapeur ne prennent sens qu'au sein d'un espace transatlantique différencié permettant l'afflux de produits agricoles et forestiers à bon marché. Sans l'empire, la révolution industrielle aurait été physiquement impossible. Werner Sombart voyait dans la pénurie de bois due à la déforestation et dans l'épuisement des sols européens « la menace d'une fin du capitalisme », voire de la « culture européenne » vers 1800 (Sombart, 1928 : 1137-1153). Sans aller jusque-là, Pomeranz (2010 : 332) écrit qu'« en l'absence de la double aubaine du charbon et des colonies, la Grande-Bretagne se serait trouvée confrontée à une impasse écologique sans issue interne apparente ».

Si l'externalisation de la contrainte environnementale soulagea la Grande-Bretagne, elle bouleversa les écologies de la périphérie. La disponibilité d'immenses espaces « vides », grâce à l'élimination de $90 \%$ de la population amérindienne de 1492 à 1700, initia un rapport à l'environnement beaucoup plus prédateur qu'en Europe. Par exemple, la culture du tabac épuisait les terres si rapidement (après trois ou quatre récoltes seulement) qu'au cours du XVIII ${ }^{\mathrm{e}}$ siècle sa production dut se déplacer du Maryland et de Virginie vers les Appalaches (Merchant, 2002 : 49). La transformation des Caraïbes en monoculture sucrière entraîna déforestation, érosion et épuisement des sols (Richards, 2003 : 459 ; Beinart et Hughes, 2007 : 36-39). Les plantations de canne à sucre introduisirent la malaria dans l'espace tropical américain : les récipients en terre cuite nécessaires pour sécher les molasses multipliaient les points d'eau stagnante et s'avérèrent d'excellents incubateurs pour les moustiques A. Aegypti, importés d'Afrique et porteurs de malaria (McNeill, 1999). Quant aux fabuleuses mines d'argent du Mexique et du Pérou, elles furent épuisées en quelques décennies, laissant des environnements intensément pollués : 200000 tonnes de mercure y furent consommées jusqu'en 1900, l'essentiel partant en vapeur dans l'atmosphère (Nriagu, 1994). On pourrait encore mentionner la quasiextinction du castor, du bison américain ou de la baleine boréale à la fin du XIX $\mathrm{X}^{\mathrm{e}}$ siècle, en lien d'ailleurs avec l'industrialisation, le cuir de bison fournissant d'excellentes courroies de transmission et l'huile de baleine un excellent lubrifiant pour les mécaniques de la révolution industrielle (Richards, 2003 : 612 ; McNeill, 2001 : 238). 
En 1999, la Commission mondiale africaine pour la vérité, les réparations et le rapatriement demanda le paiement par les puissances occidentales de 777 milliards de dollars pour indemniser l'Afrique du trafic d'esclaves et des richesses pillées pendant la période coloniale ${ }^{13}$. Quelle que soit la valeur de ce chiffre, il ne rendra jamais compte du fait que l'Occident est « redevable » de l'Afrique, mais aussi de l'Amérique et de l'Asie, pour son essor industriel. Ce dernier et donc l'entrée dans l'Anthropocène furent rendus possibles par l'échange écologique inégal avec ces régions aux XVIII ${ }^{\mathrm{e}}$ et $\mathrm{XIX}^{\mathrm{e}}$ siècles.

\section{" L'écologie-monde du système Monde britannique}

La seconde moitié du XIX ${ }^{\mathrm{e}}$ siècle voit le développement de deux phénomènes étroitement liés : d'un côté, se mettent en place les infrastructures de la globalisation économique, de l'autre, un écart économique massif se creuse entre l'Europe et l'Amérique du Nord d'une part, et l'Asie de l'autre.

Le système Monde alors centré sur la Grande-Bretagne repose sur une écologiemonde inégalitaire : le charbon, en accroissant drastiquement les capacités productives des pays industriels, amplifie d'autant la demande de matières organiques provenant du monde tropical. En outre, dans le dernier tiers du XIX ${ }^{\mathrm{e}}$ siècle, les pays industrialisés entrent dans un nouveau cycle d'accumulation du capital lié à la seconde révolution industrielle : chimie organique, électricité, puis automobile. S'ils sont globalement indépendants en énergie et en fer (Bairoch, 1999), les techniques au fondement de leur prospérité dépendaient de certains produits clé provenant des pays périphériques : des minerais comme l'étain de Malaisie pour l'industrie agroalimentaire (boîtes de conserve) ainsi que pour les barils de pétrole, ou le cuivre des Andes et du Congo pour l'électrification ; et des produits végétaux ou animaux tels l'huile de baleine ou les oléagineux tropicaux pour l'éclairage et la lubrification des machines, la gutta-percha pour le réseau télégraphique ; le caoutchouc pour l'industrie mécanique (courroies de transmission, joints d'étanchéité pour les machines à vapeur...), puis pour l'automobile (Tully, 2009). De même, le maintien de la fertilité des sols européens et américains repose sur l'extraction du guano du Pérou, de la Bolivie et du Chili (dont les réserves seront épuisées en quelques décennies), ainsi que du phosphate de Tunisie, du Maroc et d'Algérie (Foster et Clarck, 2009). Avant la Première Guerre mondiale, les pays riches importent déjà $41 \%$ de leur consommation de phosphate, soit 2,9 millions de tonnes par an (Bairoch, 1999 : 99). Malgré ces apports, la productivité agricole stagne dans les deux derniers tiers du XIX ${ }^{\mathrm{e}}$ siècle au Royaume-Uni, qui pour nourrir sa population au moindre coût importe en 1900 plus de $60 \%$ de son alimentation contre $15 \%$ en 1850 (Schandl et Krausmann, 2007 : 110). Les hectares fantômes qui nourrissent les Britanniques sont aussi nombreux que la surface agricole du pays (ibid.). Si la Grande Bretagne exporte du charbon et des biens industriels, elle est, entre 1850 et 1939, importatrice de minerais (déficit de 12 millions de tonnes à la veille de la Première Guerre

13. Site de la BBC (20/08/1999) : «Trillions Demanded in Slavery Reparations » : http://news.bbc. co.uk/2/hi/africa/424984.stm (consulté le 22 octobre 2016). 
mondiale) et surtout de biomasse (le déficit passe de 5 millions de tonnes en 1855 à plus de 30 millions de tonnes à la fin des années 1930) (Schandl et Schulz, 2002). Aucun autre pays industriel n'a alors un modèle de développement aussi dépendant de la biomasse du reste du monde. Ces éléments relativisent grandement la thèse de Paul Bairoch selon laquelle les pays industrialisés n'auraient guère eu besoin des produits des pays périphériques avant 1940.

Cette écologie-monde inégalitaire est liée à un capitalisme très extraverti. L'économie se financiarise et se mondialise dans le cadre d'un système monétaire international stable basé sur la livre sterling (et donc sur l'étalon or). La responsabilité limitée - le Company Act anglais de 1862, réforme des sociétés anonymes de 1867 en France, loi allemande de 1892 instaurant les sociétés à responsabilité limitée $(\mathrm{GmbH})$ (Guinnane et al., 2008) - rend l'actionnariat moins risqué, en particulier pour des entreprises opérant hors du territoire national. La généralisation de la cotation en bourse fluidifie encore les rouages du capitalisme financier. Cette stabilisation juridique du capital privé entraîne son déplacement massif de l'État vers les entreprises. En 1860, les bons du trésor britannique représentaient la moitié de la capitalisation londonienne et moins de $5 \%$ en 1914.

Le capital financier européen s'oriente massivement vers des investissements outremer. En 1913, $40 \%$ de la richesse nationale française est constituée de valeurs mobilières, dont près de la moitié est investie à l'étranger (Berger, 2003 : 26). Entre 1870 et 1913, la Grande-Bretagne investit chaque année 4,5\% de son PNB à l'étranger. En 1913, ces actifs (3,8 milliards de livres) représentent $40 \%$ de la richesse nationale (Cairncross, 1953 : 104) et la moitié de tous les investissements directs à l'étranger (IDE). Ces capitaux jouent un rôle central dans l'Anthropocène : la Grande-Bretagne projette le capitalisme fossile sur le monde entier ${ }^{14}$. En 1913, les chemins de fer étrangers représentent $40 \%$ des IDE britanniques. Suivent les mines (plus de mille compagnies minières sont cotées au London Stock Exchange en 1898), des compagnies de gaz d'éclairage, d'adduction d'eau et des plantations tropicales (Darwin, 2009 : 112-120). Ces investissements sont très rémunérateurs. L'investissement britannique à l'étranger s'auto-entretient : entre 1870 et 1914, ses revenus $(5,3 \%$ du PNB) excèdent la valeur des capitaux qui s'exportent $(4,5 \% \mathrm{du}$ PNB) (Ferguson, 2004 : 245). C'est ainsi que la Grande-Bretagne peut compenser une balance commerciale largement déficitaire, attirer les matières premières dont elle a besoin et maintenir la livre sterling comme pilier du système monétaire international.

Ce capitalisme financier s'incarne dans des dispositifs techniques, très émetteurs de $\mathrm{CO}_{2}$, qui réorganisent les flux de matière, d'énergie et de marchandises à l'échelle mondiale. Canaux transcontinentaux, chemins de fer, bateaux à vapeur, docks, silos à grain et lignes télégraphiques fabriquent une seconde nature à l'échelle de la planète, pénétrant à l'intérieur des pays périphériques et les arrimant à l'économiemonde. Ces réseaux réduisent le coût de la coordination et renforcent la puissance des firmes géantes dévolues à leur gestion.

14. Seulement $6 \%$ de ces investissements se font en Europe, $45 \%$ dans le monde anglo-saxon, $20 \%$ en Amérique latine, $16 \%$ en Asie et $13 \%$ en Afrique. 
Alors qu'il fallait six mois pour se rendre de Londres à Calcutta au XVIII ${ }^{\mathrm{e}}$ siècle, il ne faut plus que deux semaines à la fin du XIX ${ }^{\mathrm{e}}$ siècle. Le prix du transport maritime chute fortement. La flotte marchande mondiale passe de 9 à 35 millions de tonnes entre 1850 et 1900, dont $60 \%$ sous pavillon britannique. Cette hégémonie anglaise est favorisée par l'exportation massive (25\% de sa production) de charbon : les navires britanniques sont alors les seuls à pouvoir naviguer les cales pleines dans les deux sens de leur périple.

Le réseau télégraphique mondial est également mis en place par des firmes majoritairement anglaises. Il permet de mieux gouverner les empires et d'améliorer la rapidité et la fiabilité de l'information commerciale ce qui, en retour, rend plus rentable le commerce de pondéreux où une différence de prix marginale peut jouer un grand rôle dans la profitabilité (Headrick, 1988). De manière corrélative, le dernier tiers du XIX ${ }^{\mathrm{e}}$ siècle voit la mise en place d'un marché mondial. Les prix convergent : en 1870, le blé était vendu $57 \%$ plus cher à Liverpool qu'à Chicago, la différente tombe à $15 \%$ en 1914 (Berger, 2003 : 18).

Le réseau ferroviaire mondial, qui passe de 100000 à 1000000 de kilomètres entre 1860 et 1920 (Darwin, 2009 : 115), est financé principalement sur capitaux privés, souvent britanniques. Par exemple, en 1860, la firme de construction ferroviaire Peto, Brassey and Betts emploie 100000 employés sur cinq continents et édifie des lignes de la Russie à l'Amérique du Sud en passant par le Canada et l'Algérie (Linder, 1994). À la fin du XIX ${ }^{\mathrm{e}}$ siècle, les investissements directs à l'étranger sont comme magnétisés par les ressources minérales et agricoles. En Afrique, comme en Amérique du Sud et en Asie, les chemins de fer sont systématiquement associés à l'extraction minière ou au transport des pondéreux agricoles pour le marché international : drainage du cuivre et du guano au Pérou et au Chili, drainage du coton en Inde, du café au Brésil, de la viande en Argentine, monoculture de la banane en Amérique centrale ou de l'arachide au Sénégal, etc. Les pays périphériques n'offrent pas seulement des matières premières mais aussi des travailleurs bon marché : travailleurs « engagés » des mines et des plantations en état de quasiservitude, coolies chinois fuyant la guerre civile causée par les guerres de l'opium et la révolte des Taiping, exploités sur les chantiers ferroviaires du monde entier (Northrup, 1995).

Les infrastructures placent les pays du tiers-monde dans une situation de spécialisation et de dépendance économique. Des pays entiers peuvent dorénavant être étranglés par la coupure du crédit qui prépare l'asservissement économique ou politique. Comme l'a montré Tim Mitchell pour le cas du pétrole, la hiérarchie dans le système Monde passe par une répartition soigneusement choisie des dispositifs techniques : forer des puits de pétrole sans établir de moyens de stockage et de raffinage assure la mise en dépendance des pays producteurs. La seconde nature du capitalisme a précipité l'intégration des régions périphériques dans le système Monde, ainsi que la désintégration des économies précapitalistes transformées en périphérie « sous-développée ». Les États postcoloniaux du $\mathrm{Xx}^{\mathrm{e}}$ siècle ont hérité de ces infrastructures, rendant difficile un développement plus harmonieux de leur économie.

C'est lors de la mise en place d'un marché mondial qu'entre 1850 et 1900 s'opère un grand renversement : la famine disparaît définitivement de l'Europe occidentale et 
se propage de façon dévastatrice dans le monde colonial. Deux séries de famines, entre 1876 et 1898, liées à un épisode climatique El Niño causèrent entre 30 et 50 millions de morts à travers le monde, principalement en Chine et en Inde. Or jamais ces deux pays n'avaient connu un tel désastre. Des sécheresses similaires en Chine au XVIII ${ }^{\mathrm{e}}$ siècle avaient été gérées de manière satisfaisante par l'empire Qing grâce à des systèmes de greniers impériaux, de transports de longue distance par le grand canal reliant Chine du Nord et Chine du Sud, et des distributions de grains dans l'urgence. Pour comprendre l'impact humain de cet épisode climatique, il faut donc chercher d'autres explications que naturelles : la vulnérabilité des sociétés indiennes et chinoises avait pour cause, en amont, la dislocation des systèmes de résilience et de secours. La Chine sortait des deux guerres de l'opium et de la terrible guerre civile des Taiping (due en grande partie à l'affaiblissement de l'empire du Milieu sous les coups de boutoir du colonialisme européen). Quant à l'Inde, la gestion du pouvoir britannique visait à augmenter ses exportations agricoles malgré la famine. Ainsi ce grand désastre doit-il se comprendre comme le croisement d'un accident climatique régulier et assez banal, de la construction du marché global des céréales centré sur Londres et Chicago (les récoltes indiennes étaient déjà acquises par l'entremise des marchés à terme) et enfin de la dislocation des sociétés asiatiques sous le coup du colonialisme (Davis, 2003). Ainsi, en pleine période de famine, l'Inde consacre une partie de plus en plus importante de son agriculture à l'exportation : jute, coton, indigo, mais aussi blé et riz à destination du marché mondial. Les exportations de riz en particulier passent de moins 700000 tonnes à plus d'1,5 million de tonnes au cours du dernier tiers du XIX ${ }^{\mathrm{e}}$ siècle $^{15}$.

Les conséquences écologiques de la seconde révolution industrielle dans les pays périphériques sont également dramatiques. L'arbre à gutta-percha disparaît dès 1856 de Singapour, puis de nombreuses îles de Malaisie (Tully, 2009). À la fin du XIX ${ }^{\mathrm{e}}$ siècle, la ruée vers le caoutchouc s'empare de l'Amazonie, causant massacres d'Indiens et déforestation. Au début du $\mathrm{xx}^{\mathrm{e}}$ siècle, l'hévéa est transféré du Brésil vers la Malaisie, le Sri Lanka, Sumatra, puis au Liberia où des compagnies anglaises et américaines (Hoppum, Goodyear, Firestone...) établissent d'immenses plantations. Ces dernières mettent à bas plusieurs millions d'hectares de forêts, causant l'épuisement du sol et l'introduction de la malaria (Tucker, 2000). Dans les années 1920 au Congo, le développement des plantations de caoutchouc, de l'exploitation minière et des chemins de fer provoque une première dissémination régionale du virus VIH (Faria et al., 2014).

C'est ainsi que, dans le dernier tiers du XIX ${ }^{\mathrm{e}}$ siècle, naît le «sous-développement ». Les écarts économiques massifs entre l'Europe et l'Amérique du Nord d'un côté, et l'Asie de l'autre se creusent à cette époque. Entre 1800 et 1913, le revenu par habitant des Européens augmente de $222 \%$, celui des Africains de $9 \%$ et celui des Asiatiques de $1 \%$ seulement (Bairoch, 1985).

Le dernier tiers du $\mathrm{XIX}^{\mathrm{e}}$ siècle et le début du $\mathrm{XX}^{\mathrm{e}}$ siècle voient enfin émerger des puissances rivales qui bousculent l'hégémonie britannique, les États-Unis au premier chef, mais aussi l'Allemagne, la France, puis le Japon. La montée de la compétition

15. Palgrave Historical Statistics (2013), tableau C17 : http://www.palgraveconnect.com (consulté le 22 octobre 2016). 
accélère les projets impériaux : les puissances européennes contrôlent politiquement $35 \%$ de la surface terrestre en 1800, $67 \%$ en 1878 et pas moins de $85 \%$ en 1914 (Arrighi, 2010 : 54). L'empire joue un rôle central dans le développement économique mondial car il permet de maintenir à flot le système Monde britannique. L'Inde en particulier, qui devient le premier importateur de produits britanniques, constitue alors un immense marché captif. Sans l'Asie, qui générait $73 \%$ du crédit commercial de la Grande-Bretagne en 1910, celle-ci aurait été obligée d'abandonner le libre-échange avec ses partenaires commerciaux (les États-Unis, les dominions blancs, l'Allemagne et la France) qui auraient par conséquent perdu leurs débouchés et ralenti leur croissance économique. L'économie mondiale se serait alors fragmentée en blocs commerciaux autarciques, à l'instar ce qui s'est passé lors de la crise économique de 1929 (Arrighi, 2010 : 271 ; Davis, 2003 : 324-326).

\section{" L'écologie-monde inégale de la grande accélération}

Après deux guerres mondiales et une grande dépression économique, le monde entre après 1945 dans une croissance historiquement exceptionnelle qui marque la «grande accélération » de l'Anthropocène. Une caractéristique clé de cette croissance est sa folle consommation, autant d'énergie que de matière. Alors qu'il avait suffi de $+1,7 \%$ par an de consommation d'énergie fossile pour une croissance mondiale de $2,13 \%$ par an dans la première moitié du $x^{\mathrm{e}}$ siècle, il en faut $+4,48 \%$ par an (sans l'uranium) entre 1945 et 1973 pour une croissance annuelle de 4,18\%. Entre 1950 et 1970, la population est multipliée par 1,46, le PIB mondial par 2,6, la consommation de minerais et de produits miniers pour l'industrie par 3,08, celle des matériaux de construction par $2,94^{16}$. Seule la consommation de biomasse augmente moins vite que la croissance économique, du fait de la substitution de ressources minérales à la biomasse pour la construction, de produits pétroliers à l'énergie animale et à la fertilisation en agriculture, et de produits de synthèse aux colorants et aux fibres textiles agricoles. On assiste donc à la mondialisation du basculement d'une économie organique à une économie fossile. Le nombre d'humains qui passent d'un métabolisme de société agraire (consommation d'environ 65 gigajoules par personne et par an) à un métabolisme industriel basé sur les énergies fossiles (223 gigajoules par personne et par an) croît de $30 \%$ de la population mondiale en 1950 à $50 \%$ en 2000 (FischerKowalski et al., 2014 ; voir aussi chapitre 1). La "grande accélération » n'est donc pas un phénomène uniforme d'accélération de la croissance, mais un changement qualitatif de mode de vie et de métabolisme qui arrime une croissance mondiale forte à une croissance encore plus forte d'énergie fossile (et notamment du pétrole qui supplante le charbon) et de ressources minérales, et représente ainsi une perte d'efficacité matière et énergie de l'économie mondiale.

Ce processus est aussi géographiquement et socialement inégal, façonné par la dynamique d'un système Monde à présent dominé par les États-Unis en contexte

16. Pour le PIB et la population, séries Maddison : http://www.ggdc.net/maddison/maddison-project/ home.htm (consulté le 16 janvier 2017) ; pour les consommations de matière et d'énergie, données de l'Institute of Social Ecology: http:/www.uni-klu.ac.at/socec/downloads/Online_data_global_flows_ update_2011.xls (consulté le 16 janvier 2017). 
de Guerre froide. Au sortir de la guerre, la puissance américaine est en effet à son apogée. Alors que l'économie européenne est ruinée, le produit national brut des États-Unis a plus que quadruplé depuis 1939 et le pays détient d'immenses stocks de devises. À la fin des années 1940, les États-Unis assurent $60 \%$ de la production industrielle mondiale, produisent près de $60 \%$ du pétrole mondial (et en consomment autant) et pèsent un tiers du PIB mondial, alors que la Grande-Bretagne, à son apogée en 1870, ne pesait que $9 \%$ du PIB mondial (Chase-Dunn et al., 2005).

À la sortie de la guerre, le gouvernement des États-Unis est soucieux de créer les conditions favorables à l'expansion de leur économie et à la croissance du camp occidental. C'est dans ce contexte que s'instaure un nouvel ordre économique international fondé sur le libre-échange et la croissance : accords de Bretton Woods instituant le dollar comme monnaie mondiale en 1944, Gatt (General Agreement on Tariffs and Trade) libéralisant le commerce en 1947 (l'agriculture faisant exception), plan Marshall, point 4 de la doctrine Truman sur l'aide au développement, etc. Cet ordre mondial permet de trouver des débouchés à la gigantesque production industrielle et agroalimentaire états-unienne, et assure plein emploi et pacification sociale après la grande grève de 1946. Il vise aussi à stabiliser socialement le camp occidental en le faisant entrer dans la croissance. Le compromis social fordiste et consumériste est alors considéré comme le meilleur rempart contre le communisme (Aglietta, 1997 ; Linnér, 2003). Il s'agit également de « développer » le tiersmonde pour éviter son basculement dans le communisme tout en sécurisant, pour les États-Unis et leurs alliés industrialisés, des matières premières à bas prix. Dans les années 1950 et 1960, une gigantesque exploitation des ressources naturelles et humaines permet au bloc de l'Est de faire bonne figure dans la course aux armements, à l'espace, à la production, mais aussi à la consommation qui n'est pas le moindre des terrains d'affrontements de la Guerre froide. Pour distancer le camp communiste, l'OCDE (héritière du plan Marshall) constitue le bras stratégique des politiques de croissance du camp occidental.

La fabrique de l'abondance en Europe et au Japon et la Pax Americana passent par un produit clé, le pétrole, auquel $10 \%$ du plan Marshall est consacré. Cette aide en pétrole enrichit largement les majors états-uniennes (Standard Oil, Caltex, Socony-Vacuum Oil...) à qui les trois quarts du pétrole financé par le plan Marshall est acheté à des prix supérieurs au cours mondial (Painter, 1984 : 362-363). Mais elle est aussi une arme géopolitique majeure en dévitalisant les forces ouvrières communisantes européennes liées au charbon et en dopant la croissance des alliés occidentaux. L'Union soviétique de son côté ne sut pas faire couler à flots les énergies fossiles chez ses alliés, ponctionnant au contraire les ressources de l'Europe de l'Est. Le pétrole transforme également l'agriculture européenne qui adopte tracteurs, engrais chimiques et pesticides. Ce «petro-farming » devient énergétiquement déficitaire : le taux de retour énergétique de l'agriculture (nombre de calories alimentaires obtenues par calorie utilisée pour les produire) chute de 12,6 en 1826 à 2,1 en 1981 en Angleterre, de 3 en 1929 à 0,7 en 1970 en France, et même à 0,64 aux États-Unis et au Danemark en $2005^{17}$. Alors qu'à l'âge des empires, l'Europe était importatrice de grains, de viande et d'oléagineux, après 1945, s'instaure un

17. Données de Bayliss-Smith, 1982 ; Schulman, 1978 ; Heller et Keoleian, 2000 ; Markunsen et Ostergard, 2013 (d'où une certaine disparité). 
nouveau « food regime $»^{18}$ mondial. Grâce au pétrole pas cher et aux aides à l'exportation (Public Law 480 états-unienne en 1954), les agricultures des pays industriels deviennent exportatrices de produits agroalimentaires, et notamment de céréales, vers le tiers-monde. Cette transformation favorise l'exode rural et un coût du travail faible dans les pays du Sud cherchant les voies de l'industrialisation, tandis que les multinationales agro-industrielles conquièrent le monde et changent les habitudes alimentaires.

Le succès géopolitique et économique de la Pax Americana croissanciste n'a d'égal que l'énormité de son empreinte écologique, pesant sur la planète entière. L'indicateur d'empreinte écologique humaine globale ${ }^{19}$ passe de l'équivalent de $63 \%$ de la capacité bioproductive terrestre en 1961 à $97 \%$ en 1975 (aujourd'hui plus de $150 \%$, soit une consommation de 1,5 planète par an). Les importations de matière, mesurées en tonnes et en agrégeant tous les produits (minéraux, énergétiques, biomasse, matériaux de construction ou biens manufacturés), ont augmenté de 7,59\% par an entre 1950 et 1970 dans les pays industriels occidentaux (Schaffartzik et al., 2014). Presque autosuffisants en fer, en cuivre et en bauxite dans la première moitié du $\mathrm{Xx}^{\mathrm{e}}$ siècle, ces pays présentent en 1970 un solde négatif de $85 \mathrm{Mt}$ de fer, 2,9 Mt de cuivre et de 4,1 Mt pour la bauxite (Bairoch, 1999 : 97, 102-103). Au total, comptabilisées en tonnes, les importations des pays occidentaux grimpent de 299 millions de tonnes en 1950 à 1282 millions de tonnes en 1970 (Schaffartzik et al., 2014).

Si l'on considère l'évolution de la balance des échanges de matière (figure 2.1) entre les différentes parties du monde, il apparaît que la différence écologique essentielle entre système communiste et capitaliste réside dans le fait que le camp communiste exploite et dégrade surtout son propre environnement pour son développement, alors que les pays industriels occidentaux construisent leur croissance sur un gigantesque drainage des ressources minérales et renouvelables du reste du monde non communiste, qui lui se vide de sa matière et de son énergie de haute qualité.

La mise en œuvre de ce colossal drainage de matières extraites dans les régions périphériques du système Monde fait l'objet d'une attention toute stratégique des dirigeants états-uniens. Dès mai 1945, le secrétaire à l'Intérieur écrit à Roosevelt : « Il est essentiel de concrétiser la déclaration de la Charte atlantique, en assurant l'égal accès de toutes les nations [occidentales] aux matières premières du monde » (cité par Linnér, 2003 : 29). Dans la continuité des logiques de ravitaillement de guerre, l'accès à des ressources cruciales comme l'uranium, le caoutchouc ou l'aluminium (ingrédient clé de l'aviation moderne) devient alors affaire d'État avec des politiques énergiques de sécurisation de l'accès à ces ressources, du pétrole vénézuélien ou moyen-oriental au manganèse indien en passant par l'uranium congolais. Alors que leur montée en puissance économique entre 1870 et 1940 s'était largement construite sur l'utilisation intensive de leurs ressources domestiques (bois, charbon, pétrole, fer, cuivre, eau, etc.), les États-Unis passent après-guerre

\footnotetext{
18. Sur les trois «food regimes » qui se sont succédé dans le monde depuis 1870, voir Friedmann (2005a). 19. Cet indicateur est basé sur une estimation de la surface de terre ou d'océan nécessaire pour produire les ressources consommées et absorber les déchets (et notamment les gaz à effet de serre) d'une population donnée. Cette surface est mesurée en " hectares bioproductifs ", calculés en tenant compte des fonctionnements des différents milieux du globe. Données de Global Footprint Network : http://www. footprintnetwork.org (consulté le 22 octobre 2016).
} 


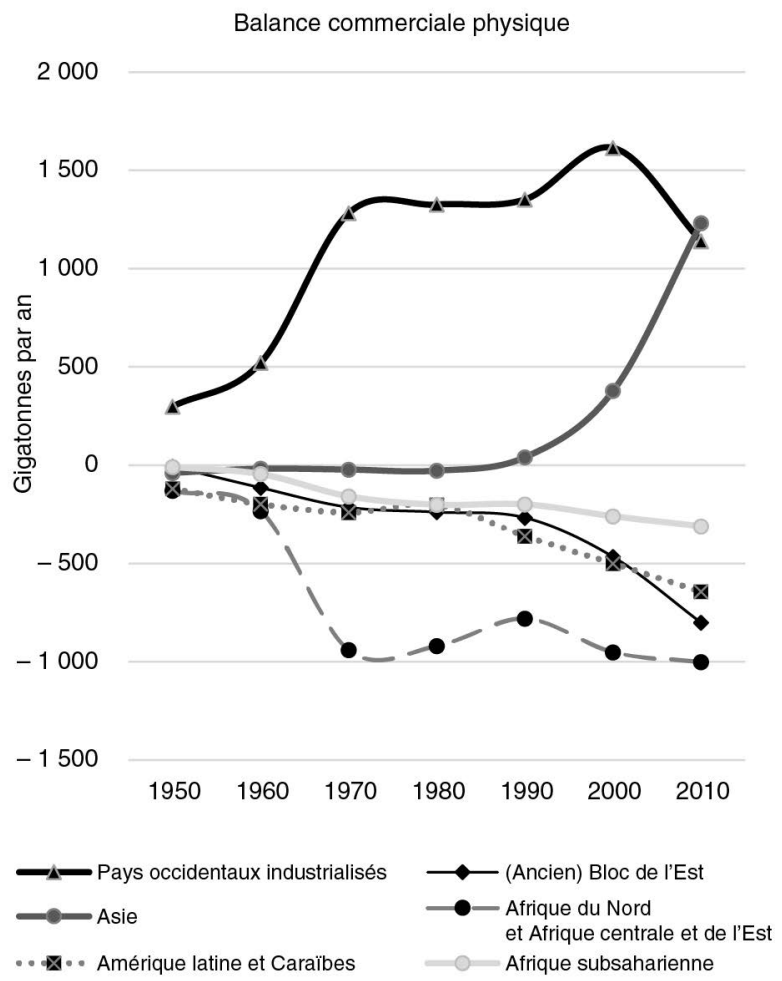

Figure 2.1. Balance matière de six grands groupes de pays depuis 1950 .

Graphique établi à partir des données de Schaffartzik et al. (2014).

d'un statut d'exportateur net à celui d'importateur net de matières premières et d'énergie : les rapports parlementaires, les commissions (Commission Paley, 19511952) et les think tanks (Resources for the Future) proposent alors de mobiliser les ressources mondiales pour sécuriser l'Occident tout en préservant les ressources américaines pour le futur.

Les États-Unis soutiennent le mouvement de décolonisation comme un moyen de sécuriser leurs approvisionnements grâce à un accès direct aux ressources sans médiation des puissances coloniales européennes. Ils initient la Conférence scientifique des Nations unies sur l'utilisation et la conservation des ressources naturelles (UNSCCUR, 1949). Les représentants de 49 pays y prônent l'inventaire et l'« usage rationnel » des ressources naturelles de la planète, inexplorées ou sousutilisées faute de technologies suffisantes, ou, plus rarement, jugées surexploitées par défaut de savoirs scientifiques. Les États-Unis et les experts occidentaux des Nations unies s'érigent ainsi en maîtres des ressources mondiales et gardiens de leur «bon usage » (Robertson, 2008; Mahrane et Bonneuil, 2014). Et les multinationales états-uniennes jouent un rôle prépondérant dans la réorganisation du métabolisme mondial. Disposant d'une avance de savoir-faire (notamment autour des technologies pétrolières, atomiques et chimiques, mais aussi en techniques de marketing) et de solides réseaux dans la Pax Americana, les entreprises états-uniennes 
se globalisent à la faveur de la guerre et de la Guerre froide. Durant la Seconde Guerre mondiale, l'armée américaine s'était déployée sur tous les continents, entraînant avec elle les grandes entreprises prestataires. La construction de bases militaires représente à elle seule 2,5 milliards de dollars de contrats, dont profitent Morrison-Knudsen, Bechtel, Brown \& Root... À cela s'ajoutent les énormes besoins en approvisionnement alimentaire et pétrolier, en logistique, etc. Ces entreprises développent des capacités à se projeter dans le monde, à produire à grande échelle ainsi que des connexions avec les décideurs militaires et politiques qui vont les transformer en grandes multinationales après la guerre. Elles établissent dans le monde entier des bases militaires, des installations pétrolières, des pipelines, des barrages, des installations pétrochimiques, des équipements nucléaires, des mines et des usines de ciment, d'engrais, de pesticides et de produits agroalimentaires (Linder, 1994 : 126). Entre 1945 et 1965, les entreprises américaines réalisent à elles seules $85 \%$ des nouveaux investissements directs à l'étranger du monde (Jones, 2005 : 88).

Cette prise de contrôle permet un accès aux ressources mondiales dans des conditions plus que favorables. Alors que, selon Paul Bairoch, les termes de l'échange s'étaient améliorés pour les pays du tiers-monde entre la fin du XIX ${ }^{\mathrm{e}}$ siècle et 1939 , le phénomène marquant d'après-guerre est la nette dégradation des termes de l'échange des «pays en voie de développement » exportateurs de produits primaires et importateurs de biens manufacturés : près de -20\% de 1950 à 1972. Cette dégradation ne cessa qu'avec le choc pétrolier de 1973 pour les pays pétroliers, mais se poursuivit jusqu'aux années 1990 pour les pays exportateurs de matières premières agricoles ou minières (Bairoch, 1999 : 161). La croissance économique et le modèle social des pays occidentaux n'auraient pu se construire sans cet échange inégal. Des économistes ont récemment démontré que les deux tiers de la croissance des pays industriels sont dus au simple accroissement de l'utilisation d'énergie fossile, le « progrès techniques » n'expliquant que le tiers restant (Giraud et Kahraman, 2014). Les revenus des États et leur capacité à financer l'investissement et la redistribution sociale reposent aussi sur le pétrole. En 1971, lorsque les compagnies conviennent avec l'Opep de faire passer le prix du baril de 2 à 3 dollars, au même moment, les produits raffinés se vendaient 13 dollars en Europe, dont $60 \%$ de taxes par le pays consommateur. Ce qui veut dire que les États européens touchaient sur chaque baril de pétrole trois fois plus que les pays de l'Opep.

Cet échange économiquement inégal est aussi un échange écologiquement inégal. Parmi les trois vastes pays riches en ressources, l'empreinte écologique de l'URSS atteint $100 \%$ de sa biocapacité domestique en 1973, la Chine atteint ce chiffre en 1970 (et ne cesse de monter depuis, atteignant $256 \%$ en 2009). D’un autre côté, tandis que l'empreinte écologique des États-Unis atteint déjà $176 \%$ en $1973^{20}$, à la même date, la Grande-Bretagne est à $377 \%$, la France à $141 \%$, l'Allemagne fédérale à $292 \%$ et le Japon à $576 \%$, alors même que nombre de pays d'Afrique, d'Asie et d'Amérique latine sont sous un ratio de $50 \%$. On voit à quel point le formidable endettement écologique des pays industriels occidentaux est bien le moteur de la « grande accélération » engagée en 1945-1973. Ceux-ci, et ce sera la

20. Les séries statistiques sur l'empreinte des différents pays sont tirées de Global Footprint Network, 2014. National Footprint Accounts 1961-2010, édition 2012 : http://www.footprintnetwork.org (consulté le 22 octobre 2016). 
clé de la Guerre froide, vident littéralement le reste du monde de sa matière et de son énergie de haute qualité. Assis sur ces ressources à bon marché, ils entrent dans un modèle insoutenable de développement. Leurs émissions massives de polluants et de gaz à effets de serre reviennent au bout du compte à s'approprier les fonctionnements écosystémiques réparateurs du reste du monde. La « grande accélération » apparaît ainsi comme le creusement d'un écart écologique entre des pays occidentaux qui génèrent beaucoup de richesses sans soumettre leur territoire à des impacts excessifs et le reste du monde dont l'économie pèse d'une lourde empreinte sur le territoire.

Le Mali et la Bolivie doivent ainsi aujourd'hui extraire vingt fois plus de matière de leur territoire que les États-Unis pour fabriquer un dollar de PIB, l'Inde et la Chine dix fois plus ${ }^{21}$. Cet échange écologique inégal est bien illustré par l'histoire des forêts pendant la grande accélération. Depuis la dernière glaciation, 10 millions de kilomètres carrés de couvert forestier (43 fois la Grande-Bretagne) ont été perdus dans le monde, dont la moitié au seul $\mathrm{xx}^{\mathrm{e}}$ siècle, réduisant les capacités planétaires de capture du dioxyde de carbone, accentuant le risque de dérèglement climatique majeur et transformant aussi la pédologie et la pluviométrie des régions concernées (McNeill, 2001 : 312). Mais, alors que les XVII ${ }^{\mathrm{e}}$ et XVIII ${ }^{\mathrm{e}}$ siècles connurent une forte déforestation en Europe de l'Ouest (et jusqu'en 1920 aux États-Unis), on assiste au $\mathrm{XX}^{\mathrm{e}}$ siècle, et surtout depuis 1945, à un accroissement du couvert forestier ouest-européen et à un quasi-maintien de la forêt états-unienne : cela signifie que les 5 millions d'hectares de forêts perdus au $\mathrm{xx}^{\mathrm{e}}$ siècle l'ont été dans les pays économiquement les plus pauvres (Tucker, 2000 ; Williams, 2002, 2008), tout en générant des produits forestiers et agricoles largement consommés en Europe et aux États-Unis, qui dans le même temps amélioraient la qualité écologique de leur territoire.

\section{"Conclusion}

Parler de capitalocène plutôt que d'Anthropocène possède de multiples effets heuristiques et explicatifs. Cela signale en particulier que l'échange écologique inégal est bien un facteur explicatif majeur de la genèse conjointe des asymétries de richesses propres à la dynamique historique du capitalisme et de l'essor des impacts humains à l'origine du déraillement géologique de la planète dans l'Anthropocène. Une histoire rematérialisée et écologisée du capitalisme apparaît comme le partenaire indispensable des sciences du système Terre pour appréhender notre nouvelle époque 22 .

21. Voir le portail materialflows.net (consulté le 22 octobre 2016).

22. Une telle histoire devrait se poursuivre pour analyser les transformations du système Monde depuis les années 1970, après les chocs pétroliers et l'âge du pétrole bon marché, à l'âge de la financiarisation du capitalisme, de la révolution néolibérale et néo-conservatrice comme tentative de maintien de l'hégémonie américaine, du problématique « découplage » des économies industrielles occidentales, de la montée de la Chine comme centre potentiel d'un nouveau système Monde en concurrence encore larvée avec les États-Unis, des flux énormes de déchets toxiques et électroniques vers les pays pauvres, et des tensions géopolitiques accrues sur les ressources et l'atmosphère... On trouvera quelques éléments en ce sens dans Harvey (2010), Moore (2015), Jorgenson et Clark (2012), Jorgenson (2012). 
À l'heure où des millions de pauvres sont affectés par le dérèglement climatique et viennent grossir le flot des migrants, cette lecture écologique de l'histoire des systèmes Monde revêt des enjeux de géopolitique et de justice environnementale considérables. Juste avant le sommet de la Terre de Rio (1992), en pleine négociation de la Convention Climat, deux écologistes indiens émirent l'idée d'une dette historique des pays riches en matière écologique (Agarwal et Narain, 1991). Ils proposaient d'attribuer à chaque habitant de la planète un droit à émettre tenant compte des émissions passées de ses concitoyens. Un haut dirigeant chinois affirmait en 2009 que « la crise climatique résulte d'un modèle de développement économique très inégal qui s'est propagé au cours des deux derniers siècles, permettant aux pays riches d'aujourd'hui d'atteindre les niveaux de revenus qui sont les leurs, en partie parce qu'ils n'ont pas pris en compte les dégâts environnementaux qui menacent aujourd'hui la vie et les modes de vie des autres » (Zukang, 2009 : vii) ${ }^{23}$.

C'est en réponse à ce type d'instrumentalisation de la notion de "responsabilité commune mais différenciée » que certains historiens, tels Dipesh Chakrabarty (2014 : 123-124), cherchent à déconnecter l'histoire du capitalisme de celle de l'Anthropocène. Pour lui, « c'est grâce aux pauvres (c'est-à-dire grâce au fait que le développement est inégal et injuste) que nous ne rejetons pas des quantités encore supérieures de gaz à effet de serre dans la biosphère [...] Ceux qui lient le changement climatique exclusivement à des origines historiques, ou à la formation des inégalités de richesses dans le monde moderne soulèvent des questions pertinentes sur les inégalités historiques ", mais non pertinentes pour éclairer la genèse historique du nouvel état de la Terre qu'est l'Anthropocène. On peut s'étonner qu'après avoir annoncé, à l'âge de l'Anthropocène, la rencontre de l'histoire humaine et de l'histoire de la Terre, Chakrabarty postule à présent une séparation, une « indifférence » réciproque, entre l'histoire des dominations et des inégalités entre humains et celle des perturbations écologiques et géologiques infligées à la Terre. Ce paradoxe lui permet de conclure que « d'un point de vue logique, la crise climatique n'est pas en soi le résultat des inégalités économiques » (2014:124). Si l'argument semble «logique » d'un point de vue statique (les plus pauvres n'ont-ils pas une empreinte écologique plus faible ?), il est par contre historiquement très problématique. Comme nous l'avons montré dans ce chapitre, le modèle de développement industriel et son métabolisme en matière et en énergie qui a altéré la trajectoire géologique de notre Terre est inséparable de l'histoire des systèmes Monde capitalistes, de l'échange écologique inégal, du colonialisme et de l'impérialisme, de l'exploitation et du sous-développement.

23. Sha Zukang était alors en charge des affaires économiques à l’ONU. 


\title{
Chapitre 3 \\ Énergie, biomasse, \\ hégémonie : une histoire longue des transformations des agricultures
}

\author{
B. Daviron, G. Allaire
}

\section{- Trois temporalités pour lire les transformations contemporaines des agricultures}

Pour voir l'avenir, il faut prendre du recul. Pour ouvrir une discussion sur l'avenir de l'agriculture et de l'alimentation, ce chapitre propose de reconsidérer l'industrialisation de l'agriculture et de l'alimentation dans une triple perspective temporelle : celle d'une "économie générale » qui inscrit l'histoire des sociétés dans celle de la nature et de la vie comme un processus global, celle des régimes socioécologiques (ou métaboliques) qui se succèdent dans l'histoire de l'humanité et celle des configurations hégémoniques de l'économie monde qui se succèdent dans l'histoire du capitalisme. Nous voudrions montrer qu'il ne s'agit pas là d'une ambition démesurée.

Notre premier point d'ancrage est la proposition de Georges Bataille d'une économie de la « dépense », en totale rupture avec les conceptions utilitaristes dominantes. Son analyse anticipe certains résultats qui ont été établis par la thermodynamique, résultats qui permettent d'ailleurs de préciser la perspective d'une « économie générale » et ses implications concernant les sociétés humaines.

Les analyses de la base matérielle des sociétés humaines, de leurs sources de matières et d'énergie, constituent notre seconde référence. Ces analyses, base de tout un courant de l'économie écologique, sont illustrées par les travaux de l'Institut d'écologie sociale de Vienne (voir chapitre 1).

Enfin, ce chapitre s'inscrit dans l'abondante littérature, produite à la suite des travaux fondateurs de Fernand Braudel (1979), d'Immanuel Wallerstein (2006) ou de Giovanni Arrighi (1994), proposant d'analyser le monde comme un ensemble hiérarchisé avec un centre et des périphéries, et l'histoire mondiale comme une succession de configurations hégémoniques. Dans la suite du chapitre 2, qui a montré que les hégémonies successives ont reposé sur des échanges écologiquement inégaux, 
selon des mécanismes différents dans chaque cas, ce chapitre ambitionne de montrer que des modalités particulières de production et d'utilisation de la biomasse peuvent être associées aux différentes configurations hégémoniques qui se sont succédées depuis le $\mathrm{XVI}^{\mathrm{e}}$ siècle : Provinces-Unies, Royaume-Uni et, enfin, États-Unis.

Les trois premières parties de ce chapitre sont organisées autour de chacune des trois perspectives considérées. Une quatrième partie s'intéresse aux transformations en cours dans le domaine de l'agriculture, et plus largement des sources et des usages de la biomasse.

\section{" L’économie générale : «part maudite » et dissipation d'énergie}

Au-delà de la longue durée historique et de la mise en évidence de régimes métaboliques historiques, quelques rares auteurs invitent à considérer une perspective radicalement plus large en plaçant la vie et les sociétés humaines dans la dynamique du cosmos. Dans « La part maudite » (1949), l'écrivain et philosophe Georges Bataille reprend l'idée, déjà développée en 1932 dans « La notion de dépense », que le vivant (au fil des âges) comme les sociétés humaines (au fil des siècles) s'approprient un flux croissant d'énergie. Le développement des formes de la vie, avec l'apparition de la reproduction sexuée, des végétaux, puis des herbivores, puis des carnivores, puis de l'humanité, et la complexification des formes de vie, permet à l'ensemble du vivant de mobiliser et de dépenser toujours plus d'énergie. Il ne s'agit pas d'une analogie entre le développement de la vie sur terre et celui de l'humanité, mais d'une continuité, qui conduit Bataille à une « économie générale » (Bataille, 1967).

L'activité humaine, quelles que soient les fins que les hommes y assignent, peut être vue comme le prolongement de l'activité générale du vivant, définie ici comme appropriation du flux d'énergie reçu par la terre : "Au-delà de nos fins immédiates, son œuvre [celle de l'humanité] en effet, poursuit l'accomplissement inutile et infini de l'univers » (Bataille, 1967 : 49). Sans (semble-t-il) en avoir connaissance, Bataille rejoint la caractérisation du vivant qui s'impose peu à peu au cours des années 1920 à partir de travaux d'auteurs comme Lotka selon qui la sélection naturelle favorise les espèces les plus efficientes dans la capture de l'énergie nécessaire à leur préservation (Lotka, 1922). Bataille étend cette vision du vivant aux affaires humaines ${ }^{1}$.

Ainsi, peuvent s'interpréter les passages des sociétés du stade chasseurs-cueilleurs au stade agraire, puis industriel. La maîtrise du feu est la première grande innovation qui accroît substantiellement la dépense d'énergie par les sociétés humaines (Crosby, 2006). L'apparition de l'agriculture (au néolithique) et des techniques de conservation des aliments accroît à son tour substantiellement la dépense d'énergie

1. Cette idée a été reprise d'une autre façon par Ilya Prigogine avec la notion de structure dissipative. Pour une discussion récente de la transposition de la perspective de Lotka et Prigogine aux affaires humaines, voir Adams (1975) et, pour une version française relativement accessible, Roddier (2012). 
par les sociétés humaines, bien que les conséquences de cette transition soient plus qu'ambivalentes sur le plan social ${ }^{2}$.

À partir des révolutions techniques industrielles, c'est-à-dire l'exploitation du charbon puis du pétrole, la dépense de quantités toujours croissantes d'énergie prend la forme d'une accumulation du capital physique. Mais, comme le souligne M. Guillaume (1988: 105) :

«Cette réponse ne peut être que provisoire : la société humaine "outillée" devient un ensemble capable de capter des quantités de plus en plus élevées d'énergie, qu'elle doit donc gaspiller (les guerres massives par exemple) ou réinvestir. Un tel système ne peut que rencontrer rapidement des limites, d'autant plus que ses composantes ne se développent pas de façon nécessairement cohérente entre elles. »

Selon Guillaume, il manque à l'analyse de Bataille la notion d'entropie. Ainsi, pour Guillaume (1988: 105) :

«C'est aussi faute de tenir compte de l'entropie que Bataille a sous-estimé la capacité du monde industriel de repousser les limites de son développement. Que font, en effet, les sociétés post-industrielles? Elles mettent en ordre les pratiques (bureaucratiques) et les signes (information et communication). Cette mise en ordre - c'est le second principe de la thermodynamique - absorbe beaucoup d'énergie et contribue à gaspiller son excès. Il faut donc généraliser la notion de dépense à celle de dépense bureaucratique et communicationnelle ».

Cette forme de « dépense » n'apparaît pas avec les « sociétés post-industrielles ». Pour ne prendre qu'un exemple, on peut citer la bureaucratie qui permettait une gestion centralisée de l'agriculture dans l'Empire du Milieu. Néanmoins, la capacité à dissiper l'énergie sous la forme de la normalisation et de la bureaucratie a explosé au cours du dernier siècle (ce dont rendent compte les chapitres 12 et 21).

Bataille va plus loin que les biologistes ou les physiciens en affirmant que les organismes vivants disposent très généralement d'un excès d'énergie et que cet excès doit être d'une façon ou d'une autre dépensé :

« L'organisme vivant, dans la situation que déterminent les jeux de l'énergie à la surface du globe, reçoit en principe plus d'énergie qu'il n'est nécessaire au maintien de la vie : l'énergie (la richesse) excédante peut être utilisée à la croissance d'un système (par exemple d'un organisme); si le système ne peut croître, ou si l'excédent ne peut être en entier absorbé dans sa croissance, il faut nécessairement le perdre sans profit, le dépenser, volontiers ou non, glorieusement ou sinon de façon catastrophique » (Bataille, $1967: 49$ ).

La question alors posée aux sociétés humaines est celle de l'utilisation de cet excédent. Ce qu'apporte Bataille, c'est la qualification de l'excédent d'énergie comme une « part maudite », qui ne peut s'échanger selon les lois de l'économie classique, quid pro quo, et doit être «sacrifiée » pour que l'organisme retrouve un équilibre fonctionnel, et ceci durant toute sa durée de vie. Si elle n'est pas stockée pour un temps (notamment sous forme de capital productif), l'énergie excédentaire doit être

2. Comme le montrent les travaux des archéologues sur la base d'une analyse des squelettes et des dentitions, cette transition s'est souvent accompagnée d'une dégradation de la situation sanitaire des populations (voir par exemple Larsen, 2006 ; Mummert et al., 2011). Cette dégradation est liée d'une part à une forte augmentation de la pression parasitaire provoquée par la sédentarisation et l'augmentation de la densité de population, d'autre part à la réduction de la diversité alimentaire, cause de diverses carences. Se développent alors des inégalités sur la base de l'accès aux ressources alimentaires. 
dépensée, « consumée en pure perte ». Le jeu, la fête, le sacrifice, l'érotisme, comme la valeur accordée aux futilités, en sont des façons.

Deux points de la théorie thermodynamique généralement admise aujourd'hui permettent de mieux comprendre et de prolonger l'œuvre de Bataille : la notion de «structure dissipatrice d'énergie », selon l'expression d'Ilya Prigogine (1969), qui rend compte de structures dont l'existence tient à un échange permanent d'énergie et de matière, et parfois d'informations, avec leur environnement, et le troisième principe selon lequel l'évolution des structures dissipatrice va dans le sens d'une maximisation du flux d'énergie qui les traverse, autrement dit d'une production toujours plus grande d'entropie ou une dissipation toujours plus grande d'énergie, jusqu'au déséquilibre suivi de l'effondrement.

La thèse de Bataille - celle d'un monde vivant condamné à trouver les moyens de dissiper l'excédent d'énergie, qui serait aussi le lot des sociétés - ne signifie pas que les hommes vivraient dans l'abondance ! L'abondance, comme l'a montré Sahlins (1976), est d'ailleurs une notion culturelle, civilisationnelle. Les «structures dissipatrices » à considérer ne sont pas les humains en tant qu'organismes biologiques et spirituels, mais les sociétés humaines considérées avec leur territoire et leur métabolisme ${ }^{3}$, ou en d'autres termes en tant qu'écosystèmes. Une société dispose de ressources limitées par le territoire contrôlé (biomasse, travail humain ou animal et techniques), et à la fois produit des ressources nouvelles et une population nouvelle par sa dynamique, son métabolisme. Aussi, pour les sociétés humaines, se pose toujours la question de l'équilibre entre population et ressources ${ }^{4}$. Comme nous l'apprennent les anthropologues, le contrôle des ressources passe par un contrôle de la démographie via, entre autres, un usage très fréquent de l'infanticide (sur ce thème voir Sahlins, 1976 ; Wilkinson, 1973 ; Clark, 2007 ; Bataille, 1967 : 123), comme forme de sacrifice de la « part maudite », au même titre que les guerres et les migrations.

En accord avec le troisième principe de la thermodynamique, la taille et la complexité des sociétés, structures dissipatrices d'énergie, n'a cessé de croître pour recouvrir aujourd'hui une économie et une société mondialisées. C'est précisément cette question qui enflamme Bataille lorsqu'il écrit « La part maudite » en 1949, après la déflagration de la Seconde Guerre mondiale ; il prend alors position pour la « coexistence pacifique » en vue d'œuvrer à supprimer la pauvreté par le développement, contre la perspective de la Guerre froide (la part maudite passant dans la course à l'armement) qui, en maintenant le sous-développement, n'évitera pas de nouvelles explosions.

Pour notre propos, il est frappant de constater que Bataille mentionne dans son texte les « jeux de l'énergie à la surface du globe » au moment même où la société qui l'entoure et sa propre vie matérielle dépendent de plus en plus de l'énergie tirée des profondeurs du globe ! Cette exploitation des ressources fossiles, en offrant aux humains - ou plutôt à certains humains - une énergie abondante et bon marché, crée une rupture radicale dans l'histoire humaine. Cette rupture est au cour des

3. La notion de métabolisme est élargie de l'organisme biologique à la société. On ne trouve pas directement le terme chez Bataille, mais on le trouve chez Marx et les théoriciens de l'économie écologique (chapitre 1).

4. Sur la question de la limite énergétique à la croissance des sociétés agraires, voir le chapitre 1. 
travaux d'économie écologique sur le métabolisme socio-écologique des nations industrielles que nous abordons maintenant.

\section{" Économie écologique et métabolisme socioécologique}

L'économie écologique prend ses racines au XIX ${ }^{\mathrm{e}}$ siècle chez quelques penseurs russes (Martínez-Alier, 1987), mais son développement est lié aux inquiétudes sur les limites de la croissance de la fin des années 1960. L'économie écologique, du moins sa partie la plus originale, se distingue de l'économie de l'environnement mainstream par son souci de relier sciences naturelles et sciences sociales (Spash, 1999). Il s'agit là encore d'une perspective d'économie générale, quoique moins générale que celle proposée par Bataille. Cette approche met l'accent sur :

- l'impossibilité d'une croissance infinie du fait des limites physiques de la planète, ce qui la rapproche des mouvements favorables à la décroissance ;

- l'incommensurabilité des valeurs, autrement dit l'impossibilité de tout convertir en valeur monétaire et de définir de façon purement objective un prix « écologiquement correct » ou des compensations financières (Martínez-Alier et Muradian, 2015);

- le lien entre enjeux distributifs et enjeux écologiques, créé par la capacité qu'ont les acteurs dominants de rejeter l'extraction de ressources - et ses " externalités négatives »-vers les catégories sociales les plus faibles (Martínez-Alier, 2014);

- la distinction entre oikonomia et chremastistika tels que ces termes sont définis par Aristote : oikonomia signifie la fourniture de ressources matérielles à l'oikos, la famille élargie, alors que la chrématistique est l'art d'étudier les marchés pour faire de l'argent (Daly et al., 1994).

En bref, l'économie écologique, du moins sa partie la plus originale, se distingue de l'économie de l'environnement mainstream par son souci de relier sciences naturelles et sciences sociales.

Parmi les sources de matière et d'énergie que l'humanité utilise pour se nourrir, se vêtir, se déplacer ou encore s'abriter (mais aussi construire des palais et faire la guerre), la biomasse occupe une place à la fois essentielle et très particulière. La biomasse rassemble tous les types de matières organiques.

Comme l'explique Wrigley (2010), pendant la plus grande partie de son histoire, l'homme a dépendu de la biomasse non seulement pour la fourniture d'aliments, mais aussi comme source quasi unique de matières premières et d'énergie. La biomasse apporte le combustible, les fibres et les peaux pour s'habiller, une bonne partie des matériaux nécessaires pour se loger ou encore, via les animaux et les hommes eux-mêmes, l'essentiel de l'énergie mécanique. Elle joue aussi un rôle essentiel dans l'entretien de la fertilité des sols. Enfin, la biomasse fournit la majeure partie des matières premières et l'énergie thermique (charbon de bois) nécessaires au travail de la plupart des artisans : menuisier, verrier, forgeron, cordonnier, brasseur, chapelier, etc. 
Le rôle de la biomasse dans les affaires humaines est bouleversé par le développement de l'utilisation des énergies fossiles à partir du XVIII ${ }^{\mathrm{e}}$ siècle. Les sociétés européennes, puis le reste du monde, basculent alors d'une économie (ou métabolisme) qui peut être qualifiée de «solaire » à une économie « minière ${ }^{5}$. Le propre d'une économie minière, caractéristique de la Révolution industrielle et de ses suites, est de tirer l'essentiel de ses ressources de l'exploitation du sous-sol. L'énergie est le domaine où le basculement est le plus manifeste. En quelques décennies, le charbon, puis le pétrole et le gaz naturel (plus marginalement l'uranium) s'imposent comme la source quasi unique d'énergie (Kander et al., 2014). Mais la fourniture des matériaux s'en trouve elle aussi bouleversée avec le remplacement de produits issus de la biomasse par des produits de synthèse ou des dérivés de minerais que l'énergie abondante permet d'extraire et de traiter. Ressources fossiles, le charbon, le pétrole ou le gaz n'en restent pas moins de la biomasse. Sieferle utilise, à propos de ces ressources, l'expression très imagée de «forêt souterraine » (Sieferle, 2001). Il s'agit toutefois d'une biomasse qui ne se renouvelle pas (du moins pas à une vitesse pertinente pour l'histoire humaine). Pour les humains, son stock est donc fini et n'est pas lié au flux d'énergie solaire.

En explorant l'émergence du régime métabolique industriel et les manières dont développement économique, croissance démographique, usage des ressources et changements environnementaux sont inter-reliés, Krausmann et Fischer-Kowalski montrent comment le passage d'un système " énergie solaire » à un système « énergie fossile » a permis de séparer le système énergétique de l'utilisation des terres et d'abolir les limites à la croissance économique (chapitre 1). Cette transition métabolique a rendu possible une croissance démographique sans précédent et une augmentation massive de la consommation de matière et d'énergie par habitant

Rappelant que toute accumulation suppose un échange inégal, Hornborg utilise cette notion pour désigner un transfert asymétrique de matière et/ou d'énergie grâce auquel la capacité productive d'un groupe est augmentée au détriment d'un autre (Hornborg, 2003 : 8). Défendant la nécessité de maintenir une distinction entre la dimension matérielle/biophysique et la dimension culturelle/sémiotique de l'échange, Hornborg note :

«L'histoire de la consommation montre clairement que la première condition pour l'accumulation est qu'il existe une demande culturelle pour la marchandise en question. [...] Mais, contrairement à l'économie mainstream, nous devons reconnaître qu'une seconde condition pour l'accumulation réside dans l'organisation matérielle de la production. C'est cette dimension biophysique du processus économique que la préoccupation des économistes mainstream pour l'utilité néglige, et cela a été le dénominateur commun de nombreuses remises en cause de cette préoccupation de Karl Marx à l'économie écologique [en passant par Georges Bataille]. Proposer une telle remise en cause est une tâche essentielle qui

5. En utilisant les termes de «solaire » et «minier », nous trahissons quelque peu les écrits de Wrigley qui parle lui de sociétés « organiques » et «minérales ». Or, le charbon et le pétrole peuvent être considérés comme étant du domaine de l'organique puisque issus de la transformation de biomasse. L'utilisation du terme « minier », pour caractériser des économies faisant massivement usage du charbon et du pétrole mais aussi de nombreux minéraux, résout la question. Par ailleurs, l'usage du terme « solaire », au lieu de " organique ", permet de rendre compte à la fois de l'importance de la biomasse, produite de manière directe ou indirecte par le rayonnement solaire, comme source de matière et d'énergie, et de l'utilisation du vent et des courants d'eau, produits indirects du rayonnement solaire, comme source d'énergie. 
suppose de reconnaître la dimension biophysique sans vouloir en faire le fondement de la valeur» (Hornborg, 2012: 13).

Hornborg s'appuie sur les travaux de Bunker (1985) qui propose d'analyser l'échange inégal en termes d'extraction et, pour traiter de la situation des pays dits « en développement », de compléter la notion de «mode de production » par celle de « mode d'extraction ». Pour lui, toute production s'exerce par la transformation de matière et d'énergie préalablement extraites d'un lieu particulier :

« Cette matière et cette énergie qui circulent au travers du système productif sont partiellement et temporairement conservées dans une forme utile qui favorise une organisation sociale de plus en plus complexe et un renforcement de la capacité productive de l'environnement physique. À l'inverse, la perte d'énergie et de matière dans le territoire d'où elles sont extraites, et les perturbations du système social et des systèmes vivants naturels simplifient de façon croissante l'organisation sociale et son environnement naturel en réduisant à la fois le flux d'énergie et son utilisation » (Bunker, $1985: 13$ ).

On retrouve ici l'idée des structures dissipatives dont la pérennité suppose un apport permanent d'énergie en provenance de leur environnement, mais aussi l'exportation continue d'entropie vers ce même environnement, cet apport se faisant par le transfert de ce que Bunker appelle les «marchandises extractives ». L'échange inégal permet l'existence comme structures dissipatrices tant du centre que de la périphérie ; le transfert de richesses vers le centre lui permet d'accumuler du capital et un niveau de consommation dissipateur d'entropie, tandis que la structure dissipatrice périphérique certes se maintient, mais par un appauvrissement de son territoire (et à terme la migration de sa population).

L'idée qu'il ne peut y avoir accumulation sans extraction (transfert de matière et d'énergie d'une région à une autre) souligne l'importance des fronts pionniers dans l'histoire longue du capitalisme. Par « fronts pionniers », on entend généralement les espaces caractérisés ou par la mise en culture de terres précédemment non cultivées ou par l'exploitation de biomasse « naturelle » (non anthropogénique).

Dans le premier cas, les fronts pionniers ne représentent pas seulement un processus d'extension spatiale, il s'agit aussi d'une intensification de l'exploitation (colonisation) de la nature. Ils renvoient aux processus de colonisation de la nature telle que la définissent Fischer-Kowalski et Haberl :

« Pour alimenter leur métabolisme, les sociétés transforment les systèmes naturels de façon à ce qu'ils tendent à maximiser leur utilité sociale. Les écosystèmes naturels sont remplacés par des écosystèmes agricoles (prés, champs) conçus de façon à ce qu'ils produisent le plus possible de biomasse utile ou ils sont convertis en espaces construits. Les animaux sont domestiqués ; le code génétique des espèces est modifié de façon à accroître leur résistance aux maladies, aux pesticides ou aux produits pharmaceutiques. Ces interactions entre le système social et le système naturel ne peuvent être interprétées en termes d'échanges métaboliques de matières et d'énergie. Elles ont un tout autre caractère. En référence au mot «colonus », qui désigne en latin le paysan, nous appelons « colonisation » ce mode d'intervention sur les systèmes naturels et nous désignons par ce terme l'ensemble des activités humaines qui changent délibérément d'importants paramètres des systèmes naturels et qui les maintiennent activement dans un état différent de celui qui prévaudrait en l'absence de telles interventions » (Fischer-Kowalski et Haberl, 1998 : 575). 
La deuxième situation de front pionnier renvoie en premier lieu aux ressources extractives que Bunker étudie (forêts « naturelles », animaux « sauvages », produits de la mer, etc.). Nous ajouterons à cette biomasse présente la biomasse passée et fossilisée que constituent le charbon, le pétrole et le gaz naturel.

L'histoire du capitalisme depuis le $\mathrm{XVI}^{\mathrm{e}}$ siècle $^{6}$ peut ainsi être présentée comme l'histoire d'un front pionnier. Son point de départ est l'Europe de l'Ouest et il s'étend initialement tant à l'Ouest qu'à l'Est (Pologne, Ukraine, Roumanie, Russie...). L'avancée de cette grande frontière s'accélère encore après 1750 en raison de la poussée démographique et du développement des réseaux de transport et de communication (McNeill, 1992). Le monde entier y est alors intégré. Au cours du XVIII ${ }^{\mathrm{e}}$ siècle, avec le développement de l'utilisation du charbon, l'Angleterre ouvre pour l'Europe une nouvelle frontière, celle de l'exploitation des énergies fossiles, une frontière verticale et non plus horizontale, pour exploiter une autre biomasse lointaine, venant cette fois d'elsewhen (d'autrefois) et non plus d'elsewhere (d'autre part) selon la formule de Catton (1982: 41).

La notion de front pionnier a été très fréquemment utilisée et longuement débattue par les historiens, en particulier dans les travaux consacrés aux États-Unis sous le terme de «frontière », et l'essentiel du débat a porté, à la suite du texte fondateur de Frederick Jackson Turner (1893), sur le rôle de la frontière dans la formation des institutions politiques ou la trajectoire économique des pays concernés (voir Barbier, 2011, pour une synthèse récente). Mais l'existence d'un front pionnier mondial, démarrant aux alentours de 1500, et son rôle dans la prospérité de l'Europe sont au cœur de l'ouvrage de Walter Prescott Webb intitulé « la grande frontière » (Webb, 1964). Il écrit :

«Quel était le caractère essentiel de la frontière ? Il s'agissait intrinsèquement d'un vaste ensemble de richesse sans propriétaire. Ce flux de richesse soudain, continu et croissant sans fin a provoqué dans la Métropole [expression utilisée par Webb pour désigner l'Europe] un boom économique que le monde n'avait jamais connu avant et ne verra probablement plus jamais. Ce boom a commencé quand Christophe Colomb est revenu de son premier voyage, il a crû lentement, puis a continué de plus en plus vite jusqu'à ce que la frontière qui l'alimentait soit arrivée à sa fin. Si l'on considère que la frontière s'est fermée en 1890 ou 1900, on peut estimer que le boom a duré à peu près 400 ans » (Webb, 1964 : 13).

Notre analyse s'inscrit dans le prolongement de celle de Webb en l'élargissant toutefois de deux façons. D'une part, elle considère que la «grande frontière » n'a pas concerné que la seule Néo-Europe ${ }^{7}$. Elle prend en compte un espace plus important et y inclut divers territoires des zones tropicales, mais aussi de l'Eurasie (la Sibérie ou les steppes d'Asie centrale par exemple). En outre, en incluant la biomasse fossile, elle prend en compte l'existence d'une frontière interne à l'Europe (et plus tard à bien d'autres régions du monde). Ce double élargissement spatial nous conduit aussi à considérer que la logique de la frontière ne s'est pas arrêtée en 1900 et qu'elle est encore largement d'actualité.

6. La dynamique de «colonisation » européenne peut être considérée comme plus précoce, si l'on y inclut la Reconquista espagnole et les croisades menées par les chevaliers teutoniques, ou encore les grands défrichements menés entre le $\mathrm{XI}^{\mathrm{e}}$ et le XIII ${ }^{\mathrm{e}}$ siècle.

7. L'expression, fort pratique, de Néo-Europe a été proposée par Alfred Crosby pour désigner les pays ayant bénéficié des migrations européennes au XIX ${ }^{\mathrm{e}}$ siècle (principalement l'Amérique " tempérée », l'Australie, la Nouvelle-Zélande et l'Afrique du Sud) (Crosby, 1973). 


\section{" Hégémonies}

Ce chapitre s'inscrit dans la lignée des analyses menées, dans le monde anglosaxon, en termes de food regime. Ces analyses, qui ambitionnent de « lier les relations internationales de production et de consommation alimentaires aux formes d'accumulation que l'on peut distinguer à différentes périodes des transformations du capitalisme depuis $1870 »$ (Friedmann et McMichael, 1989 : 95), retiennent une périodisation de l'histoire calée sur la succession des configurations hégémoniques. Ont ainsi été décrits :

- un premier régime (1870-1930) centré sur le Royaume-Uni, et caractérisé par des importations de produits tropicaux en provenance des colonies, et des importations de grains de base et de produits animaux issus des dominions britanniques ;

- puis un second régime (1950-1970) dans lequel les États-Unis jouent un rôle central grâce à leur part de marché, à l'utilisation massive de l'aide alimentaire et à l'exportation du modèle agro-industriel intensif (facteurs relativisés par John Wilkinson et David Goodman dans le chapitre 16).

Notre analyse se distingue toutefois des travaux conduits selon l'approche food regime de trois façons :

La première s'intéresse à la biomasse, ses sources et ses usages. La spécialisation de l'agriculture, et des espaces ruraux, sur la seule production alimentaire est une particularité $\mathrm{du} \mathrm{xx}^{\mathrm{e}}$ siècle étroitement liée à l'utilisation massive d'énergie fossile, et il est fort probable que l'avenir remette en cause cette spécialisation de l'agriculture sur l'alimentation (voir chapitre 9).

La seconde s'intéresse au rôle de la biomasse dans le métabolisme socio-écologique des hégémons. Nous nous intéressons non seulement à la contribution de l'agriculture et de la biomasse à l'accumulation du capital, mais aussi aux échanges de matières et d'énergie dont dépend toute société humaine. Nous rejoignons ici les travaux de Moore $(2003,2010)$ qui propose de substituer, à la notion d'économie monde, celle d'écologie monde.

La troisième différence est une lecture plus longue. Remonter jusqu'à l'hégémonie des Provinces-Unies, avant la Révolution industrielle, nous donne la possibilité de comprendre les conditions de l'hégémonie dans un monde sans énergie fossile, mais aussi de mieux comprendre la spécificité et la précarité de ce que nous vivons depuis deux siècles, et les enjeux actuels concernant le secteur agricole.

\section{Provinces-Unies}

À la fin du $\mathrm{XVI}^{\mathrm{e}}$ siècle, début du XVII ${ }^{\mathrm{e}}$ siècle, les Provinces-Unies, qui se sont libérées du joug des Hasbourgs, constituent une puissance économique et militaire sans rival. Une de leurs spécificités est l'abondance de la population urbaine, situation précoce en Europe, mis à part dans les Flandres et sur la côte méditerranéenne. En 1675, $42 \%$ de la population des Provinces-Unies habite en ville, $60 \%$ dans la province de Hollande, dont 200000 dans la seule ville d'Amsterdam À la même époque, le taux d'urbanisation de l'Angleterre tourne autour de $15 \%$, celui de la France de $12 \%$. 
Sur le plan local, les Provinces-Unies disposent de deux ressources originales sur lesquelles s'appuie partiellement leur métabolisme socio-écologique :

- une agriculture spécialisée autour des productions animales (produits laitiers surtout), des fibres textiles (lin) et du tabac. Une bonne partie des techniques alors mises en œuvre, usages des légumineuses par exemple, proviennent des Flandres proches, où elles ont vu le jour dès le Moyen Âge, à l'époque de la grandeur de Gand, Bruges et Anvers (Slicher Van Bath, 1963 : 71);

- l'exploitation de la tourbe, qui remplace le bois pour la fourniture de l'énergie thermique, permet l'existence de nombreuses activités consommatrices d'énergie : ferronnerie, brasserie, briqueterie, raffinerie, teinturerie, etc. (De Decker, 2015).

Mais, surtout, les Provinces-Unies fondent leur métabolisme et leur richesse sur la mobilisation, par la création de marchés, de la biomasse lointaine. Elles introduisent, selon Moore, une véritable rupture dans l'histoire longue des fronts pionniers d'Eurasie :

«Les fronts pionniers de recherche de marchandises ont remplacé les fronts pionniers de recherche de ressources. L'expansion mondiale s'est substituée à l'expansion régionale comme réponse aux pressions socio-écologiques. Et là où autrefois l'expansion réduisait les tensions générées par la pression démographique, un capitalisme en pleine ascension a renversé la logique » (Moore, $2010: 35$ )

Cette capacité à mobiliser des ressources lointaines repose sur la maîtrise remarquable du complexe bois/eau/vent, qui caractérise ce que Mumford appelle la phase éotechnique (« l'aurore des techniques ») (Mumford, $1934: 110)$, et se matérialise sous la forme de moulins, de canaux et de bateaux à voile. On estime que la flotte des Provinces-Unies, au milieu du XVII ${ }^{\mathrm{e}}$ siècle, est équivalente à la totalité des flottes des autres pays européens. Les Provinces-Unies disposent à la fois d'une grande capacité de transport, mais aussi de coûts très bas, ce qui leur permet d'être en quasi-monopole pour le commerce de produits pondéreux, le bulk trade (grain, bois, sel, poisson, lin, chanvre, goudron, etc.).

Les exportations de grains de la Baltique atteignent un pic au milieu du XVII ${ }^{\mathrm{e}}$ siècle et les Provinces-Unies en contrôlent $80 \%$ à $90 \%$ (van Tielhof, 2002 : 73). Amsterdam est le centre de ce marché, la bourse d'Amsterdam permettant de centraliser et de diffuser l'information sur les quantités et les prix. Si la moitié des grains de la Baltique livrés à Amsterdam est réexportée vers le Sud de l'Europe, l'autre moitié sert à nourrir toutes les Provinces-Unies, villes et campagnes. Au milieu du XVII ${ }^{\mathrm{e}}$ siècle, les importations de grains nourrissaient plus de la moitié du million d'habitants vivant dans les provinces de Hollande, d'Utrecht, de Friesland et de Groningen (de Vries, $1974: 172)^{8}$.

Mais les grains ne sont pas les seuls produits du commerce hollandais. Pêché en mer Baltique, en mer du Nord et plus tard dans l'Atlantique Nord, le poisson (hareng) est abondamment réexporté (80 \% d'après de Vries et van der Woude, 1997 : 251) jusqu'en Pologne. De la Baltique encore, et de Scandinavie, viennent le bois et les produits forestiers (poix et goudrons, cendre et potasse) indispensables pour la construction, mais aussi et surtout pour l'industrie navale si performante. Il y a aussi

8. De Vries se fonde sur une consommation par habitant de $200 \mathrm{~kg}$ par an, ce qui l'amène a estimé la population nourrie par les importations à 600000 personnes. 
la laine importée d'Angleterre ou d'Espagne et le lin de Russie qui approvisionnent une industrie textile exportatrice. Il faut ajouter les fourrures - omniprésentes dans les costumes des élites européennes de l'époque - en provenance des forêts finlandaises ou russes. Enfin, last but not least du point de vue de l'accumulation capitaliste, il y a les épices. Les Hollandais ont réussi, au milieu du XVII ${ }^{\mathrm{e}}$ siècle, à déplacer les Portugais de la position de force qu'ils détenaient dans l'océan indien.

La position hégémonique des Provinces-Unies est mise à mal (Arrighi, 1994) par la concurrence que lui opposent la France et l'Angleterre à partir de la deuxième moitié du XVII ${ }^{\mathrm{e}}$ siècle. Si les Hollandais jouent un rôle fondateur dans le développement des plantations de canne à sucre dans le Nord du Brésil qu'ils contrôlent alors, ils sont ensuite évincés de cette activité. Le plein développement des plantations esclavagistes aux Amériques devient une affaire de Français et d'Anglais et fait partie de leurs politiques mercantilistes. Ce mode radicalement nouveau de commerce de biomasse à longue distance - nouveau dans le sens où il s'accompagne d'un contrôle direct du territoire fournisseur et de la création ex nihilo d'exploitations fondées sur de la main-d'œuvre allogène, les esclaves africains - ne peut guère être associé à une configuration hégémonique. Il est plutôt le produit d'une de ces phases de fragmentation du commerce qui accompagnent les transitions hégémoniques. Le sucre, malgré ce qu'a pu en dire Wallerstein (1974 : 44), n'est pas, même à la fin du XVIII ${ }^{\mathrm{e}}$ siècle, un complément essentiel de l'alimentation européenne ${ }^{9}$. Le sucre est encore au XVIII ${ }^{\mathrm{e}}$ siècle une épice, sans doute essentielle pour l'accumulation du capital, mais sans grande importance pour le métabolisme socioécologique des pays européens. Il n'en sera pas de même au siècle suivant.

\section{Royaume-Uni}

Comme nous l'avons déjà mentionné, la Révolution industrielle, sur laquelle se fonde le statut d'hégémon du Royaume-Uni, s'accompagne d'un changement radical de son métabolisme socioécologique (Krausmann et al., 2008 ; Sieferle ; 2001 ; Wrigley, 2010). Le charbon, biomasse fossile, s'impose progressivement au cours des XVII ${ }^{\mathrm{e}}$ et $\mathrm{XVIII}^{\mathrm{e}}$ siècles. Son abondance permet de multiplier par quatre la consommation d'énergie par habitant entre 1650 et 1850 . À cette dernière date, la part du charbon représente $90 \%$ de la consommation énergétique du pays (Warde, 2007).

Mais, durant la phase d'hégémonie anglaise, l'exploitation de l'énergie fossile s'accompagne d'une utilisation accrue de biomasse lointaine. Jusqu'en 1850, c'est d'abord de la biomasse non alimentaire qui est importée en quantités très fortement croissantes. Les fibres textiles, à commencer par le coton, et les teintures sont les premières concernées. En 1845, les matières premières représentent en valeur les deux tiers des importations de biomasse, les fibres à elles seules $36 \%$ et les teintures $7 \%$ (Davis, 1979).

L'abolition des Corns Laws en 1846 change la situation. Durant les décennies qui suivent, le Royaume-Uni augmente considérablement ses importations de produits

9. En Angleterre, les importations de sucre par habitant et par an passent de $1 \mathrm{~kg}$ à $10 \mathrm{~kg}$ entre 1700 et 1800 , soit, à cette dernière date, une contribution de $4 \%$ des besoins nutritionnels. En France, seulement $1 \mathrm{~kg}$ par personne et par an est importé à la fin du XVIII ${ }^{\mathrm{e}}$ siècle (Sieferle, 2001 : 98). 
alimentaires. Juste avant la Première Guerre mondiale, le pays se trouve, pour son approvisionnement en biomasse, dans une position de "dépendance extérieure » extrême et inégalée depuis. À côté des matières premières destinées à l'industrie (coton, laine, lin, matières grasses, caoutchouc, etc.), le blé, la viande, le beurre, les fruits sont importés massivement. En 1913, les importations représentent $58 \%$ des calories alimentaires consommées dans le pays (Board of Trade, 1917) et supposent l'exploitation d'une surface de terre équivalente à la totalité des surfaces cultivées dans le Royaume-Uni (Krausmann et al., 2008).

L'agriculture anglaise se recentre alors sur les productions animales et développe la sélection génétique des animaux (moutons, bovins et chevaux) dans la suite des travaux de Robert Bakewell (1725-1795), considéré comme le premier éleveur ayant utilisé des méthodes rationnelles de sélection pour le bétail (Vissac, 2002). Dans le même temps, l'agriculture s'ouvre aux achats d'intrants pour l'alimentation animale et la fertilisation. L'intensification de l'agriculture anglaise repose donc tant sur les avancées dans la « colonisation de la nature », avec la rationalisation de la sélection animale, que sur l'achat d'intrants (en partie importés). L'agriculture anglaise initie alors la désintégration de l'agriculture et de l'élevage et remet en cause une caractéristique originale, et historiquement profondément ancrée, du monde rural ouest-européen.

Si le Royaume-Uni importe autant, c'est aussi qu'il bénéficie d'une offre abondante. L'utilisation de la machine à vapeur comme source d'énergie mécanique pour le transport joue ici un rôle essentiel. C'est la première fois dans l'histoire de l'humanité qu'une source d'énergie alternative aux muscles (animaux ou humains) est disponible pour le transport terrestre. Soudain, la mobilisation en grande quantité de biomasse lointaine devient possible, y compris à l'intérieur des continents. Le bouleversement des conditions de transport ne concerne pas que les produits. Les coûts de migration s'en trouvent aussi profondément réduits, ce qui génère des déplacements massifs de populations européennes et asiatiques, et s'accompagne d'un changement profond des modalités de gouvernement du travail. Aux engagés européens du XVI ${ }^{\mathrm{e}}$ et $\mathrm{XVII}^{\mathrm{e}}$ siècles, à qui le voyage était payé en échange d'une obligation de travail de plusieurs années, ont été substitués les esclaves africains au XVIII ${ }^{\mathrm{e}}$ siècle, puis à ceux-ci des engagés asiatiques, principalement indiens (indentured labor). Le XIX ${ }^{\mathrm{e}}$ siècle se distingue par l'existence d'une migration massive de travailleurs « libres », une première dans l'histoire du capitalisme (McNeill, 1992 : 55).

S'ouvre, avec le développement du chemin de fer, ce qui peut être considéré comme la période d'apogée des fronts pionniers continentaux. La colonisation par des migrants européens de territoires précédemment exploités par des chasseurscueilleurs ou des pasteurs a lieu au même moment dans la grande prairie nordaméricaine, dans la steppe à l'Est de la Russie, dans le veld Sud-Africain, dans la pampa argentine, dans le busch australien, dans la plaine manchoue ou dans la mata atlantica brésilienne.

Les pays lointains ne sont pas les seuls à approvisionner le Royaume-Uni. En Europe, plusieurs pays y contribuent ; les pays méditerranéens pour le vin ou les oranges et, plus lourd de conséquences pour l'avenir de l'agriculture européenne, le Danemark et les Pays Bas qui se spécialisent au profit du Royaume-Uni dans la production de beurre et de viande de porc en détournant (si l'on peut dire) une 
partie du flux de céréales et d'oléagineux originaires des pays lointains. Se développe, dans ces derniers pays, une version radicalisée de la stratégie de spécialisation dans les productions animales, et de la désintégration de l'agriculture et de l'élevage déjà conçue par les agriculteurs anglais au cours du XIX ${ }^{\mathrm{e}}$ siècle.

\section{États-Unis}

Produit de l'expansion anglaise - le plus grand des pays néo-européens selon l'expression de Crosby -, les États-Unis acquièrent au cours du XIX ${ }^{\mathrm{e}}$ siècle, grâce au chemin de fer et à l'immigration, une dimension continentale, et donc une population, un stock de ressources et un marché sans équivalent dans les pays européens (à l'exception de la Russie). Au xx ${ }^{\mathrm{e}}$ siècle, ces caractéristiques lui fourniront les bases de son hégémonie.

Mais, durant les premières décennies du $\mathrm{xx}^{\mathrm{e}}$ siècle, l'agriculture américaine est confrontée à une double crise agricole : crise de la production et crise des débouchés. Avec la fin du front pionnier, durant la dernière décennie du XIX ${ }^{\mathrm{e}}$ siècle selon Turner, la logique d'exploitation minière de la fertilité des sols - qui s'est imposée lorsque les réserves de terre «vierge » paraissaient illimitées - rencontre ses limites. La production agricole par habitant baisse fortement à partir de 1900. À partir de la même date, les exportations agricoles stagnent (alors que l'économie du pays s'est construite sur elles) et les importations s'envolent. Au cours des années 1920, la balance commerciale agricole devient déficitaire (voir figure 3.1). Enfin, à la fin de cette décennie, les rendements de l'ensemble du pays tendent à baisser alors que

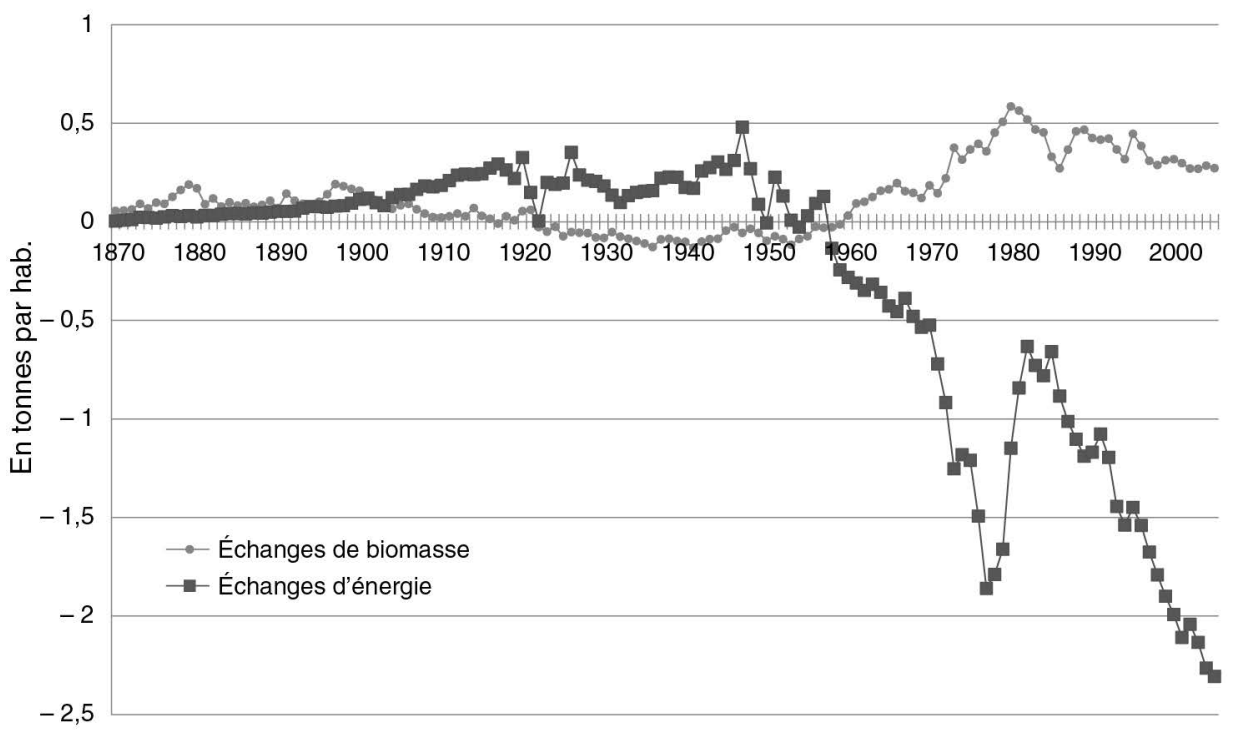

Figure 3.1. États-Unis : solde des échanges de biomasse et d'énergie fossile par habitant, 1870-2005.

Sources : d'après Gierlinger et Krausmann (2012). 
sont apparus de nouveaux concurrents, où les fronts pionniers ont démarré plus tardivement, comme en Argentine ou en Australie.

Parallèlement, les débouchés pour les produits agricoles se ferment à partir de la Première Guerre mondiale. Celle-ci a appris à tous les belligérants européens les dangers que fait courir une trop grande dépendance vis-à-vis d'un approvisionnement lointain. Après la crise des années 1930 et la Seconde Guerre mondiale, vient s'ajouter, à l'objectif de sécurité nationale, le souci premier, dans les politiques économiques de l'Europe et de l'Amérique du Nord, de lutter contre le chômage et la surproduction avec des politiques régulatrices. La participation aux échanges extérieurs devient clairement subordonnée au plein-emploi des facteurs et à la stabilité des marchés intérieurs (Block, 1977 ; Ruggie, 1982). Dans le domaine agricole, l'autosuffisance devient ainsi progressivement la norme même si cet objectif est parfois inatteignable (comme au Japon, chapitre 5) ou s'il s'exprime dans un cadre impérial (comme en France entre 1930 et 1957) ou régional (comme en Europe après 1957).

Or, très tôt, dans le contexte de la rivalité croissante des prétendants à l'hégémonie (l'Allemagne en particulier), l'exploitation du charbon n'est plus pensée comme un moyen d'aller chercher de la biomasse toujours plus loin, mais d'y substituer des produits de synthèse. La chimie allemande, qui se construit sur la production de teintures (Hohenberg, 1967), investit progressivement les différentes branches de matériaux (plastiques, fibres, caoutchouc) et, point essentiel, la fabrication d'engrais azotés (Smil, 2001). Le développement de la chimie permet simultanément une réduction de la variété des usages de la biomasse et un accroissement de la capacité de production dans un territoire donné. Le basculement général vers l'économie nationale autocentrée trouve ici sa base matérielle, au moins du point de vue de la biomasse. À la condition de contrôler des réserves de charbon, et bientôt de pétrole (et quelques autres réserves minières pour l'obtention de phosphore et de potassium), un pays semble pouvoir connaître une croissance illimitée de la production agricole. L'autosuffisance en biomasse devient dès lors possible, d'autant plus que, grâce au développement des produits de synthèse et à la possibilité de transformer l'énergie thermique en énergie mécanique, l'agriculture est désormais dédiée dans sa quasi-totalité à l'alimentation des humains.

Dans ce contexte, la sortie de la crise pour l'agriculture américaine passe par un changement radical des façons de produire et de consommer. Côté production, la solution se trouve dans la pleine intégration de l'agriculture dans l'économie minière. L'adoption du tracteur - particulièrement bien adapté au degré élevé de mécanisation que connaît l'agriculture américaine dès le milieu du XIX ${ }^{\mathrm{e}}$ siècle en raison de la pénurie de main-d'œuvre - et l'utilisation, d'une part, d'engrais de synthèse, couplée à la diffusion de variétés améliorées et des hybrides, et, d'autre part, de pesticides permettent, à partir de 1940, une envolée de la productivité du travail et des rendements (voir figure 3.2). Contrairement à la sélection animale qui a démarré en Europe sous le contrôle des éleveurs, se créent aux États-Unis des entreprises semencières distinctes des agriculteurs (Lewontin et Berlan, 1990 ; voir aussi chapitre 16). Côté offre, c'est aussi le développement d'une production animale fondée sur la consommation de céréales et de soja. Le modèle agricole qui s'impose alors aux États-Unis doit ainsi être vu comme une hybridation entre les innovations ayant répondu, à la fin du $\mathrm{XIX}^{\mathrm{e}}$ siècle et au début du $\mathrm{XX}^{\mathrm{e}}$ siècle, aux 
contraintes de l'agriculture américaine (mécanisation, puis motorisation pour faire face au manque de main-d'œuvre) et celles ayant répondu aux contraintes de l'agriculture ouest-européenne (spécialisation dans les productions animales à partir de grains achetés, de fait importés dans le cas de l'Europe). Côté consommation, c'est le développement de la consommation de produits animaux et de l'aide alimentaire interne qui permettra, dans un premier temps, de lever la menace de la surproduction, alors que l'adoption généralisée de stratégies d'autosuffisance nationale réduit les débouchés internationaux (Daviron, 2008).

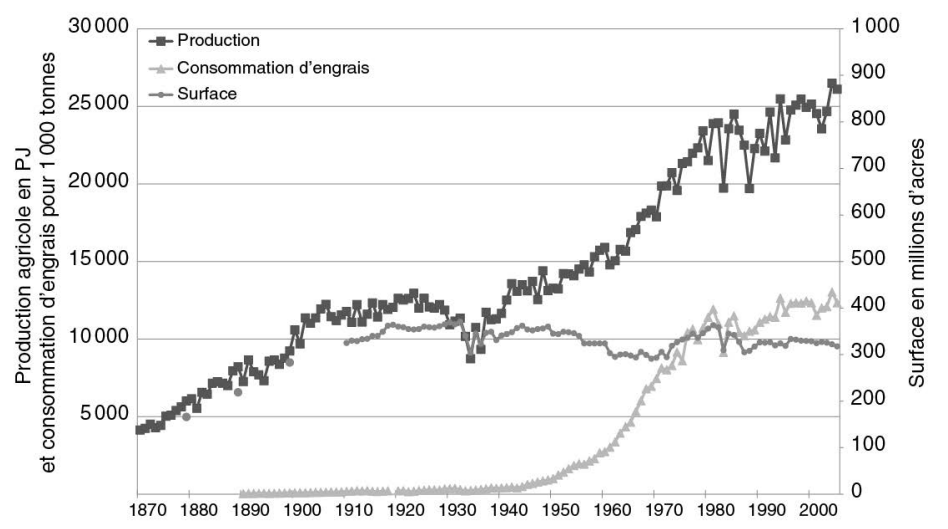

Figure 3.2. États-Unis : production agricole (en PJoules), surface cultivée (en millions d'acres) et consommation d'engrais (en milliers de tonnes), 1870-2005.

Sources : d'après United States Bureau of the Census, 1976 (surface) ; USDA, diverses années (consommation d'engrais); Gierlinger et Krausmann, 2012 (production agricole).

La sortie de crise passe aussi par la mise en place d'une politique très interventionniste (protection aux frontières, stockage, aides directes, etc.) visant à stabiliser les revenus agricoles et à garantir des débouchés croissants.

Cet ensemble de «solutions », à la fois techniques et institutionnelles, est adopté par les pays européens après la Seconde Guerre mondiale. Son volet technique et la norme de l'autosuffisance sont aussi adoptés par nombre de pays en développement dans le cadre de la dite "Révolution verte », bien que nombre d'entre eux, engagés dans des stratégies volontaristes d'industrialisation, taxent plutôt qu'ils ne soutiennent leur agriculture.

Le chapitre agricole du Gatt, seul dispositif de réglementation des politiques commerciales instauré après la guerre, entérine et autorise les politiques interventionnistes (Daviron et Voituriez, 2006). Il donne une très grande latitude dans l'utilisation des barrières non tarifaires et des subventions à l'exportation. Les dérogations accordées aux États-Unis en 1955 ne feront que confirmer cette situation d'exception pour l'agriculture. De fait, jusqu'à la conclusion de l'Uruguay Round, tous les instruments ou presque étaient « légalement » autorisés pour garantir la protection des agricultures nationales (voir Hopkins et Puchala, 1980 ; Cohn, 1993).

La division internationale du travail entre pays exportateurs de biomasse et pays exportateurs de biens industriels, qui prévalait à l'époque de l'hégémonie anglaise, 
est bien morte. Les échanges agricoles ne croissent que très faiblement, bien plus faiblement que les échanges des autres produits. Les marchés de produits agricoles acquièrent un caractère résiduel où ne s'échangent qu'excédent et déficit.

À partir des années 1960, les États-Unis renouent toutefois avec un solde excédentaire de leurs échanges de biomasse. De ce point de vue, ils se distinguent nettement des hégémons précédents (Pays-Bas, Royaume-Uni). Ce retour à l'excédent s'appuie, jusqu'aux années 1970, sur deux courants majeurs d'exportations, d'une part l'aide alimentaire (qui représente une part essentielle des exportations de blé et d'huile), d'autre part l'alimentation animale (maïs, soja) principalement destinée à l'Europe et au Japon. Mais l'excédent dans les échanges de biomasse s'accompagne, à l'année près, de l'apparition d'un déficit dans les échanges d'énergie fossile (voir figure 3.1). La frontière verticale s'est clairement substituée à la frontière horizontale.

\section{Après l'hégémonie... et après le pétrole?}

Les États-Unis ont-ils d'ores et déjà perdu leur position hégémonique ? Cette question a beaucoup agité les esprits durant les années 1970-1980 et le début des années 1980, dans le contexte du premier choc pétrolier, de la (re)montée de l'Europe et du Japon, et de la défaite américaine au Vietnam. L'ouvrage de Keohane, After Hegemony, publié en 1984 considère la chose comme acquise. Il s'agissait de s'interroger sur les conditions de stabilité des relations internationales dans un monde posthégémonique. La chute du mur de Berlin et l'effondrement du bloc soviétique qui l'a suivie ont toutefois relégué cette perspective. En effet, ces événements ont souvent été lus comme une victoire des États-Unis et l'avènement d'un monde unipolaire. La « mise au pas » des pays dits « en développement », acquise dans les années 1990 lors de la résolution de la crise de la dette, la suprématie américaine dans le domaine des technologies de l'information et de la communication, ou encore la libéralisation des échanges promue par l'OMC semblaient confirmer cette victoire.

Mais, au cours des dernières années, la tonalité du débat a de nouveau changé. Les déboires militaires des États-Unis se sont accumulés tandis que la part de la Chine dans la production manufacturière mondiale a dépassé celle des États-Unis. Le déclin de l'hégémonie américaine est de nouveau annoncé. Pour Arrighi, c'est ainsi qu'il faut interpréter la financiarisation de l'économie américaine qui ne ferait que répéter ce qu'ont connu, dans leur propre phase de déclin, les Provinces-Unies et le Royaume-Uni (Arrighi, 2005).

Quelles évolutions peut-on lire dans le rapport à la biomasse ? Peut-on dès à présent constater l'émergence d'un nouveau modèle de production et de consommation de cette biomasse sur laquelle pourrait se fonder une nouvelle configuration hégémonique?

Il est certainement trop tôt pour considérer que la Chine pourra assurément s'imposer comme puissance hégémonique et y chercher un nouveau rapport à la biomasse. D'autre part, cela n'a guère de sens d'éliminer les États nations de l'analyse et de considérer, comme McMichael (2005, 2012) et bien d'autres auteurs après 
lui (Burch et Lawrence 2009 ; Holt Giménez et Shattuck, 2011 ; Sage, 2013), que s'est constitué un corporate food regime - un régime agroalimentaire des firmes - ne reposant donc que sur les seules multinationales. De son côté, Friedmann (2005a) préfère parler d'un «corporate-environmental food regime », en soulignant le poids des questions environnementales, ce qui renvoie au rôle des États dans la mise en œuvre des conventions internationales, et au rôle des mouvements sociaux. Pour l'heure, nous ne pouvons que rendre compte d'un certain nombre de transformations sans prétendre rendre compte de l'existence d'un nouveau modèle stabilisé.

Le premier constat qui peut être fait concerne les politiques agricoles. Celles-ci ont été profondément remises en cause à la fois par les négociations de l'OMC et par les programmes d'ajustement structurel qu'ont connus les pays dits « en développement ». Les deux dernières décennies ont ainsi favorisé une certaine convergence, vers des niveaux faibles, des soutiens à l'agriculture entre pays « développés » et «pays en développement ». Au Brésil, en Inde et en Chine - où à la fin des années 1980 l'agriculture était encore taxée -, le niveau de soutien tend à se rapprocher, voire à dépasser, le niveau de soutien en Europe et aux États-Unis où il a sensiblement baissé.

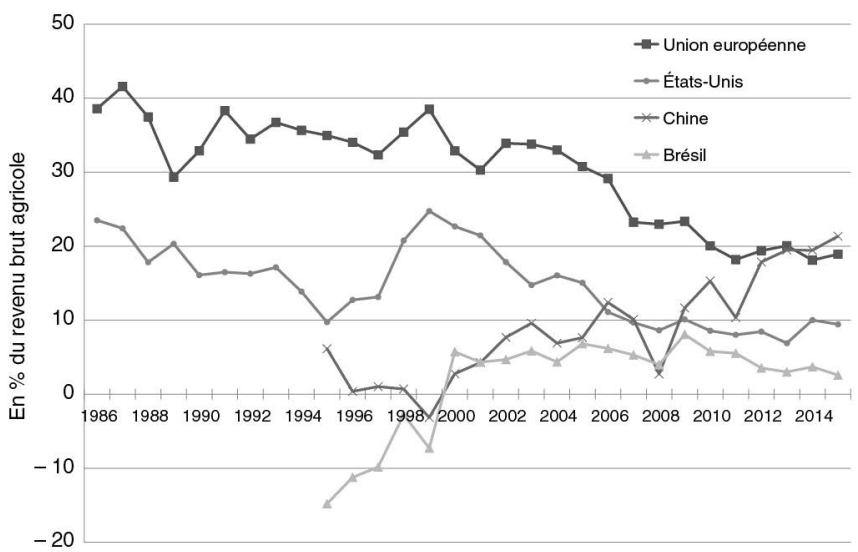

Figure 3.3. Équivalents subventions à la production agricole, calculés par l'OCDE, 19862015 (en \% du revenu brut agricole).

Sources : OCDE, http://stats.oecd.org/viewhtml.aspx?QueryId=70965\&vh=0000\&vf=0\&l\&il=\&lan $\mathrm{g}=$ en (consulté le 21 octobre 2016).

La réunification du marché mondial est cependant loin d'être aboutie, du moins en ce qui concerne la formation des prix. En effet, si dans un pays comme la France, comme dans le reste de l'Union européenne, les prix des produits agricoles fluctuent désormais, et pour la première fois depuis plusieurs générations, en lien avec les prix internationaux, il n'en est pas de même en Chine et en Inde. La flambée des prix internationaux des céréales en 2007-2008 a ainsi été transmise aux marchés européens, mais n'a guère affecté les prix intérieurs en Chine et en Inde, qui conservent un objectif d'autosuffisance en céréales et continuent d'utiliser les marchés internationaux comme moyen de stabiliser les prix intérieurs, en y exportant les excédents ou en en important leur déficit suivant l'état de la récolte. 
Cette relative continuité des stratégies d'autosuffisance de l'Inde ou de la Chine n'empêche pas la poursuite - voire l'accélération depuis la crise financière de 2008 du basculement vers l'Asie de la demande mondiale d'importation de produits agricoles (Daviron et Douillet, 2013). Les trois dernières décennies ont vu l'Europe perdre la place centrale qu'elle occupait depuis plusieurs siècles dans la demande d'importation de produits agricoles. L'Europe représente aujourd'hui moins de $20 \%$ des importations mondiales quand la part de l'Asie dépasse les $40 \%$. Car si la Chine et l'Inde conservent leur objectif d'autosuffisance pour les céréales, elles ont renoncé à un tel objectif pour les oléo-protéagineux et, dans le cas de la Chine, pour la quasi-totalité de la biomasse non alimentaire (coton, caoutchouc, bois...). La Chine est devenue, en à peine plus d'une décennie, le premier pays importateur de graines de soja (64\% des importations mondiales), de coton (42\%), de laine ( $45 \%$ ) ou de caoutchouc (28\%). Mais l'existence, soulignée plus haut, d'un soutien croissant accordé à l'agriculture et la persistance de la stratégie d'autosuffisance interdisent de considérer que la Chine, bien qu'elle soit devenue à son tour l'atelier du monde, soit engagée sur une trajectoire similaire à celle du Royaume-Uni au $\mathrm{XIX}^{\mathrm{e}}$ siècle en ce qui concerne son approvisionnement en biomasse.

Les modalités de production et de consommation de biomasse demeurent, elles, relativement inchangées. Du point de vue des usages de la biomasse, l'heure n'est pas encore aux grands bouleversements malgré les promesses de renoncement aux énergies fossiles faites par nos gouvernements. Dans les domaines agricole, agroalimentaire et agrochimique, ces promesses prennent aujourd'hui le nom de nombreux projets de recherche et d'investissement menés sous l'étendard de la « bioéconomie » (voir chapitres 8 et 9). Mais, pour l'heure, les carburants pour véhicules automobiles sont le seul secteur où ces promesses se sont déjà traduites en actes tant au Brésil qu'aux États-Unis et dans l'UE. Chez les deux derniers, elle a donné lieu à des politiques offrant une garantie de débouché, venues partiellement remplacer les mesures démantelées suite aux accords de l'OMC.

Réalisée à la marge, la substitution de carburants tirés du raffinage du pétrole par de l'éthanol ou du diester n'en a pas moins suscité une très forte demande de matières premières agricoles (maïs et graines oléagineuses en particulier) qui ont contribué à la flambée des prix internationaux des produits alimentaires de 20072008 (HLPE, 2011). Cela donne une idée des conséquences que pourrait avoir sur la sécurité alimentaire mondiale une politique volontariste de substitution des ressources fossiles par de la biomasse. L'industrie chimique, qui a joué un rôle si important dans l'émergence du modèle agricole du $\mathrm{xx}^{\mathrm{e}}$ siècle, voit dans la biomasse un nouveau gisement de matières premières, à l'égal de ce qu'ont été le charbon et le pétrole, avec le risque d'y voir transposée la même logique minière. Certes, si la bioéconomie devient un moyen pour « colocaliser les activités de production et de transformation dans un objectif de durabilité », comme le voient Paul Colonna et Egizio Valceschini (chapitre 9), on peut penser que l'échange écologique inégal pourrait être réduit ; toutefois, cette perspective apparaît encore comme une utopie.

Du côté de l'offre de biomasse, il faut d'abord constater qu'aux États-Unis (voir figure 3.2 plus haut) comme en Europe (voir figure 3.4) la croissance de la production agricole a été cassée au cours des années 1980 suite à la diminution des soutiens. Mais l'intensification s'est poursuivie, comme en atteste par exemple l'évolution 
du rendement de la culture du maïs aux États-Unis qui a continué d'augmenter au même rythme depuis 1970 (+1,5\% par an). À l'échelle du monde, il n'y a pas à proprement parler de crise de l'agriculture de la chimie. Certes, il existe des crises sectorielles liées à l'instabilité des prix, comme en Europe dans le secteur laitier depuis la fin des quotas laitiers (chapitre 13), mais ce sont des crises de compétitivité qui résultent de la radicalisation du «modèle américain » (des fermes, des élevages et des machines toujours plus grandes) ou de sa diffusion à de nouvelles zones. Il s'agit plus d'une compétition acharnée entre champions du modèle que d'une mise en cause du modèle.

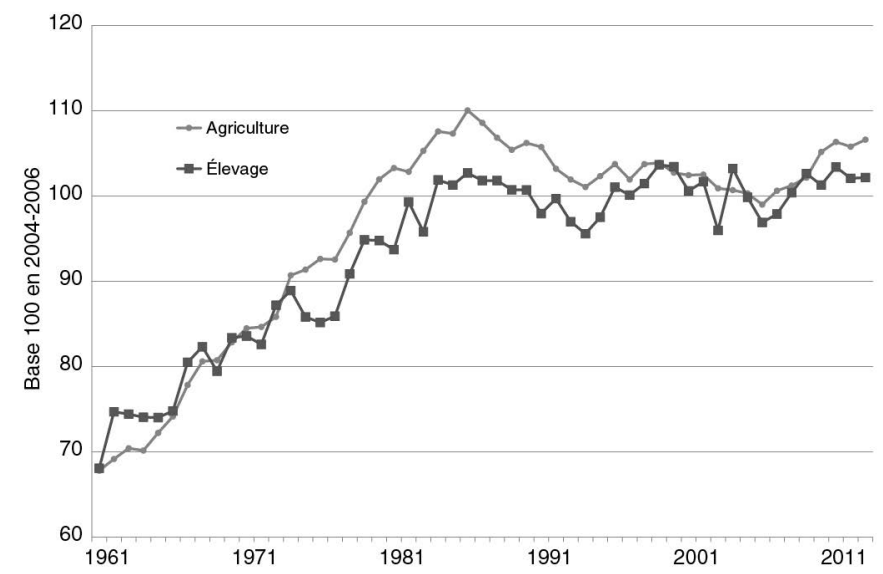

Figure 3.4. Indice de la production de l'agriculture et de l'élevage en Europe de l'Ouest, 1960-2013.

Sources : FAOStat.

Cette diffusion prend parfois l'allure de fronts pionniers caractérisés par le fait qu'il ne s'agit pas, le plus souvent, de la mise en culture de territoires précédemment exploités par des populations de chasseurs-cueilleurs (cela existe encore comme en Indonésie) ou de pasteurs, mais plutôt d'une réaffectation de terres déjà colonisées avec une valorisation accrue du foncier. Nous nous trouvons plutôt face à un deuxième passage d'un mouvement de colonisation commencé un ou deux siècles plus tôt. De fait, comme Turner le décrivait déjà il y a plus d'un siècle, les fronts pionniers se caractérisent le plus souvent par une succession de colonisations dans laquelle le trappeur est déplacé par l'éleveur qui est lui-même déplacé par l'agriculteur (Turner, 1893). C'est à ce type de succession que nous serions confrontés à l'échelle du monde.

Parallèlement, l'exploitation ou la colonisation plus en profondeur du vivant se poursuit avec les OGM, pas ceux qui permettent d'utiliser l'herbicide de Monsanto (qui paraît avoir fait son temps), mais ceux qui produisent des molécules utilisées comme médicament, et avec la génomique qui, en l'espace de quelques années, a bouleversé la sélection animale (chapitre 7) et la biologie médicale.

Certes, cette radicalisation et la diffusion de l'agriculture de la chimie sont toutefois de plus en plus contestées pour leurs conséquences environnementales et sociales. 
Cela donne lieu à une multitude d'initiatives et de projets cherchant à « verdir » le modèle («agriculture raisonnée »), notamment par des innovations visant à réduire la pression des polluants (lutte « intégrée ») ou améliorant l'efficacité dans l'usage des ressources naturelles (voir l'exemple de l'eau, chapitre 6), ou à en proposer des alternatives plus ou moins radicales (agroécologie, agriculture biologique, permaculture, etc.). Les stratégies individuelles de verdissement du modèle ne conduisent pas à une réduction globale des pressions du fait de l'extension des systèmes de production intensifs (paradoxe de Jevons). Parmi les alternatives recensées, l'agriculture biologique occupe une superficie croissante en Europe et Amérique du Nord, néanmoins il a pu être montré (par une étude de cas en France) que ce mode de production utilise indirectement des sous-produits de l'agriculture chimique (intrants organiques et stocks de phosphore dans les sols notamment) (Nesme et al., 2016). Aussi, la question : l'AB peut-elle nourrir le monde ? peut sérieusement être posée aujourd'hui (Reganold et Wachter, 2016), en revanche la réponse est loin d'être évidente et suscite bien d'autres questions (Allaire, 2016).

L'émergence des nouveaux modèles dont il vient d'être question repose en outre sur un foisonnement de nouvelles normes et de labels visant à promouvoir ces alternatives auprès des consommateurs $(\mathrm{AB})$ ou plus simplement à neutraliser la critique du modèle (standards de durabilité type RSPO). Différents chapitres de cet ouvrage traitent de ces évolutions (voir entre autres les chapitres 10,11, 12 et 21). Toutefois, ces initiatives ne changent pas vraiment la logique de la production de biomasse à l'œuvre depuis le milieu du $\mathrm{XX}^{\mathrm{e}}$ siècle parce que leur emprise demeure bien faible à l'échelle du monde ou parce qu'elles s'en accommodent.

\section{W Conclusion}

L'histoire de l'humanité s'inscrit dans la continuité de l'histoire du cosmos et de la terre, et ne peut échapper aux lois de la thermodynamique. Structures dissipatives, les sociétés humaines se sont succédées en mobilisant des quantités croissantes d'énergie et de matière.

Pendant la majeure partie de l'histoire humaine, cette énergie et ces matières ont été essentiellement fournies par le rayonnement solaire immédiat via la biomasse et, de manière complémentaire, le vent et les cours d'eau. Comme le montre l'hégémonie des Provinces-Unies au XVII ${ }^{\mathrm{e}}$ siècle, la richesse et la puissance reposaient sur «l'heureuse combinaison » de ces ressources, autrement dit sur la capacité d'utiliser vents et cours d'eau pour mobiliser à son profit le maximum de biomasse proche et lointaine. Mais, avec les Provinces-Unies, cette mobilisation a pu aussi reposer sur la création de multiples marchés, plus ou moins lointains et étendus. Telle est la rupture sur laquelle se fonde leur hégémonie.

La Révolution industrielle, en exploitant les gigantesques stocks de charbon, de pétrole et de gaz naturel accumulés dans le sous-sol, a prodigieusement augmenté la quantité d'énergie mobilisée par les sociétés et avec elle leur complexité. Elle donne naissance à deux configurations hégémoniques - le Royaume-Uni et les États-Unis - dont le rapport à la biomasse se distingue nettement. L'hégémonie du 
Royaume-Uni s'accompagne d'une division internationale du travail dans laquelle l'ensemble de la planète est mobilisé pour approvisionner des marchés mondiaux de biomasse centrés sur l'Europe. La croissance de la production de biomasse est horizontale, basée sur de multiples fronts pionniers, portée par le développement du chemin de fer et des migrations massives.

L'hégémonie des États-Unis se traduit par un bouleversement radical de la place de l'agriculture dans le métabolisme socioécologique. Spécialisée sur la fourniture d'aliments, l'agriculture, de pourvoyeuse d'énergie comme elle l'avait toujours été dans l'histoire humaine, en devient au contraire consommatrice. Parallèlement, la division internationale du travail du XIx ${ }^{e}$ siècle est remise en cause par la généralisation des stratégies d'autosuffisance que permet l'utilisation d'énergie fossile dans la production agricole.

Depuis deux décennies, ces modalités de production et d'utilisation de la biomasse sont doublement contestées. Elles l'ont d'abord été par la remise en cause, dans le cadre de l'OMC, des politiques de protection des marchés agricoles. Plus récemment et de manière croissance, ces modalités sont remises en cause du point de vue de leurs conséquences environnementales. Néanmoins, ces critiques n'ont pour l'instant aucunement "révolutionné » le métabolisme des sociétés industrielles.

Bataille (1967) analyse ce processus et accuse l'excès d'énergie, la part maudite, d'être à l'origine du drame humain : guerre, accumulation industrielle, bureaucratie. Mais, comme nous l'avons dit, Bataille ignore la notion d'entropie et le fait que toute maximisation de la dissipation énergétique se traduit inévitablement par la maximisation de la production d'entropie. Dans notre monde, les déchets, sous toutes leurs formes matérielles, (nucléaires, $\mathrm{CO}_{2}$, azote actif, résidus de pesticide, etc.), constituent, à côté de la chaleur, la forme très concrète que prend cette entropie. Leur production, en excès au regard de la capacité d'absorption des divers puits à déchets (océans, atmosphère, nappes phréatiques, etc.) et des cycles du vivant, est aujourd'hui l'autre part maudite avec laquelle nos sociétés doivent composer. 



\title{
Chapitre 4 \\ La Chine, le nouveau stockeur en dernier ressort après les États-Unis ?
}

\author{
F. Courleux, J.-N. Depeyrot
}

La sécurité alimentaire de la population chinoise constitue un enjeu économique et social crucial pour l'Empire du Milieu. En dépit d'une politique agricole ambitieuse pour développer la production domestique, les perspectives d'augmentation de la demande alimentaire chinoise laissent envisager un recours croissant aux importations dans les années à venir, alors que la Chine est aujourd'hui quasiment autosuffisante en céréales et importe principalement du soja. Compte tenu de l'étroitesse des marchés internationaux, le recours croissant de la Chine à ces marchés aura un impact décisif sur le niveau et la volatilité des prix mondiaux. Si la Chine a développé une stratégie de sécurité alimentaire très ambitieuse via des investissements dans la production agricole au-delà de ses frontières, il n'en reste pas moins qu'elle semble également ne pas laisser aux seuls importateurs privés chinois et aux négociants internationaux la gestion de sa participation au commerce international. Outre les droits aux frontières et autres quotas d'importation, elle dispose de capacités de stockage public suffisamment conséquentes (officiellement de 250 millions de tonnes fin 2014) pour jouer le rôle de "stockeur mondial en dernier ressort » tel qu'ont pu le jouer par le passé les États-Unis. Le niveau des stocks publics chinois est un sujet sensible et établir leur valeur soulève des difficultés au moins aussi importantes que le sont les enjeux autour de leur divulgation, compte tenu des réactions potentielles des agents économiques (Schwoob, 2015). Les chiffres publiés à ce sujet par le Conseil international des céréales, la FAO (Food and Agriculture Organization of the United Nations) ou l'USDA (United States Department of Agriculture) sont ainsi parfois considérés comme discutables, il n'en reste pas moins que ce sont ceux qui sont repris pour constituer les bilans de fin de campagne, indicateurs phares pour la formation des prix.

Dans la première partie de ce chapitre, nous rassemblons les principaux éléments sur l'évolution de la politique agricole chinoise depuis la grave famine de la fin des années 1950. Bien que la Chine se soit résolument engagée au cours de la dernière décennie dans une stratégie d'importations d'huiles et de protéines végétales, l'accroissement important de la production de céréales lui a permis de rester, pour l'heure, peu dépendante des importations en matière de céréales (riz, blé, maïs). Dans la deuxième partie, nous reviendrons sur le concept de «stockeur en dernier ressort » tel que joué par les États-Unis depuis les années 1930 jusqu'aux années 1980. Les outils mobilisés, les conditions nécessaires, ainsi que les limites 
rencontrées, qui ont remis en cause le leadership américain en matière de régulation des échanges internationaux, seront développés. À partir d'une analyse des fondamentaux des marchés des céréales depuis un peu moins d'une décennie, nous illustrerons le fait que la loi de King est toujours d'actualité - de petites variations de quantité causent toujours d'importantes variations de prix - pour en arriver à la conclusion que la Chine, via sa politique domestique, dispose aujourd'hui des moyens pour jouer un rôle de stabilisateur mondial des marchés agricoles. Au-delà de la faisabilité technique, cette troisième partie propose également une discussion quant aux conditions et aux motivations que pourrait avoir la Chine à endosser ce rôle de stockeur en dernier ressort.

\section{" Les politiques agricoles et alimentaires en Chine : de l'autosuffisance à la maîtrise de la dépendance}

Rappelons d'abord que la constitution de stocks publics de céréales représente une politique à la fois ancienne et forte de l'Empire du Milieu, afin d'assurer l'alimentation d'une population historiquement nombreuse (Kuhn et Pouch, 2010). La gestion d'importants stocks régionaux de céréales fut une des priorités de l'État chinois dès le $\mathrm{XVII}^{\mathrm{e}}$ siècle (Will, 1983), avec toutes les difficultés qu'elle pouvait rencontrer en termes de logistiques (transports et conservation des grains) et de réactivité aux déterminants des marchés, avec le double objectif de la sécurité alimentaire et de la stabilisation des prix.

La République populaire de Chine a voulu bâtir son développement à partir du secteur agricole, notamment par la collectivisation massive des terres, avec la mise en place en 1955 de près d'un million de coopératives « semi-socialistes » où subsistait la propriété du sol. Dans ces coopératives, regroupant aussi les activités de dépôt et de crédit, l'agriculture est néanmoins vouée, dès le départ, à financer le développement de l'industrie, les dépôts étant largement supérieurs aux crédits octroyés (Dumont, 1957). Ces coopératives ont ensuite été fédérées en « coopératives socialistes » à partir de 1957 - la propriété du sol étant alors conférée à la collectivité - avant d'intégrer le système des communes populaires dans le cadre du Grand Bond en avant. Ces communes populaires se verront alors confier un monopole d'achat et de commercialisation des céréales, toujours dans le but de favoriser et de développer le secteur industriel grâce à des prix d'achats aux producteurs inférieurs aux cours internationaux. La désorganisation totale liée à la mise en place de ce système complexe a joué un grand rôle dans la grande famine qui frappa la Chine entre 1958 et 1962. La conjugaison de choix techniques parfois irrationnels, d'une programmation des objectifs de production irréaliste et de l'accaparement des actifs agricoles au profit du développement d'une petite industrie rurale impacta lourdement la production : la sécurité alimentaire a été sacrifiée. L'ampleur du désastre poussera le gouvernement chinois à infléchir rapidement ses positions et à prendre des décisions plus pragmatiques. En 1962, Dumont constate une baisse de la mobilisation des travailleurs agricoles sur les corvées non agricoles et que de nombreux lopins de terres ont été attribués aux agriculteurs sous gestion privée, ceux-ci étant même autorisés à vendre leur surplus de production (Dumont, 1964). 
Malgré l'infléchissement de la doctrine de collectivisation, le système des communes populaires perdurera jusqu'en 1979. La priorité de cette économie dirigée reste centrée sur la production de céréales, à des prix toujours inférieurs aux échanges internationaux, pour favoriser l'émergence du secteur industriel.

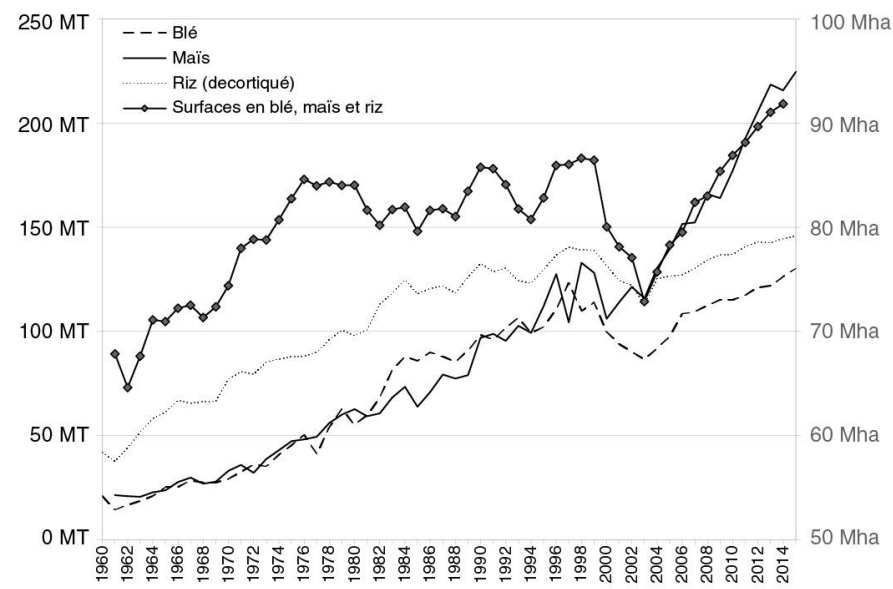

Figure 4.1. Production agricole chinoise de céréales : blé, maïs et riz.

Source : auteurs, d'après les données de la FAO et de l'USDA.

À la suite des réformes de 1962, la production de céréales en Chine connaît une croissance forte, avec $+16 \%$ par an pour le blé et le maïs entre 1962 et 1979, et $+7,5 \%$ par an pour la production de riz (figure 4.1). Les surfaces cultivées en blé, maïs et riz progressent de $30 \%$ sur la même période. Cette croissance de la production, mais aussi le recours à quelques importations permettent de répondre à l'accroissement de la demande tout en autorisant la reconstitution de stocks de report importants, devenus d'autant plus stratégiques après le désastre de 1958-1962.

En 1979, la Chine entame une période de profondes réformes, le système des communes populaires est démantelé et les marchés sont peu à peu libéralisés. La décollectivisation des terres est opérée : les agriculteurs peuvent désormais disposer de baux d'exploitation de trente ans, et bénéficient de plus en plus d'autonomie et de responsabilité dans le choix de leurs productions. Dans le même temps, les prix garantis des produits agricoles sont revalorisés pour se rapprocher progressivement, dans les années 1990, des cours internationaux. Selon Yang (2005), le processus de libéralisation de la commercialisation des céréales permet ainsi que plus du tiers de la production intérieure de céréales soit échangé directement sur le marché intérieur en 1995.

L'autonomie croissante des producteurs entraîne un ajustement des surfaces cultivées en faveur du développement des cultures commerciales plus intensives en main-d'œuvre au détriment des céréales : arbres fruitiers, légumes, arachides, betteraves. Après avoir culminé à 84,3 millions d'hectares en 1978, les surfaces cultivées en blé, maïs et riz vont ainsi reculer de $4 \%$ entre 1979 et 1987 . Le progrès technique et la diffusion des intrants permettent de compenser ces retraits - la production 
continuant à progresser rapidement (figure 4.1) - et d'approvisionner les stocks de report qui atteignent ainsi plus de $90 \%$ du volume de la consommation chinoise de blé et de maïs à la fin des années 1990.

En 1995, l'objectif d'autosuffisance alimentaire de couvrir $95 \%$ des besoins nationaux en grains est réaffirmé, et le gouvernement réintroduit le système d'approvisionnement obligatoire : les gouverneurs provinciaux sont responsables de l'autosuffisance en céréales de leur province (Yang, 2005). Parallèlement, le gouvernement chinois met en place des prix minimums garantis incitatifs sur le blé (1998), le riz et le maïs (1999). Ces incitations portent leurs fruits et la relance de la production se traduit même par des excédents en céréales au début des années 2000.

En parallèle, la rapide croissance économique de la Chine depuis 1995 a permis une nette amélioration du niveau de vie se traduisant par l'augmentation des aliments carnés dans le régime alimentaire (Chaumet et Pouch, 2012). Cette évolution du régime alimentaire entraîne un accroissement des importations de protéines végétales destinées à l'alimentation animale : le solde commercial du soja s'effondre, et la Chine devient rapidement le premier importateur mondial de soja et doit renoncer à l'autosuffisance en soja (Chaumet, 2012). S'agissant des céréales, bien que leur utilisation dans l'alimentation animale soit passée de 70 millions de tonnes en 1985 à 160 millions de tonnes en 2005 (Aubert, 2008), l'augmentation de la production a conduit à maintenir les importations à un niveau réduit (7 millions de tonnes en 2013) au regard de sa production (475 millions de tonnes en 2013, soit plus de $20 \%$ de la production mondiale). Toutefois, si la Chine se voit contrainte de renoncer à l'autosuffisance protéique, elle développe une stratégie de sécurisation et de maîtrise de ses approvisionnements extérieurs, notamment par des prises de positions à l'étranger dans les filières de production et de transformation animales (filière porcine avec Smithfield, investissement dans des usines de poudre de lait, etc.), la prise de contrôle de terres agricoles (70 opérations recensées pour plus de 2,1 millions d'hectares destinés à la production alimentaire ${ }^{1}$ ) ou encore des contrats d'approvisionnements sur longue période (engagement pour 2 millions de tonnes de maïs avec l'Ukraine en 2013).

L'autosuffisance alimentaire reste ainsi un objectif majeur des dirigeants chinois, réaffirmé notamment dans le douzième Plan quinquennal 2011-2015 (Chaumet, 2013), mais, compte tenu des tendances de consommation et de l'urbanisation croissante consommatrice de terres agricoles, celle-ci paraît s'éloigner de plus en plus. Pour autant, les efforts et l'ampleur des politiques agricoles chinoises montrent que la Chine est loin de négliger ce secteur : d'une autosuffisance globale devenue inatteignable, la Chine passe ainsi à une stratégie de sécurisation et de maîtrise de sa dépendance. En outre, l'activisme du gouvernement chinois vis-à-vis de son secteur agricole s'inscrit également dans une visée de rééquilibrage économique entre les zones urbaines et rurales chinoises, ou tout du moins une tentative d'endiguement du creusement des inégalités entre villes et campagnes, défi réaffirmé par les autorités chinoises en mars 2013 lors du bilan de la période 2007-2012. Les enjeux de ce triple défi (modernisation de l'agriculture, amélioration de la situation socioéconomique des producteurs et rénovation des infrastructures) sont tels que l'on

1. Land Matrix, 2015. Land Matrix, http://www.landmatrix.org/ (consulté le 19 octobre 2016). 
considère qu'ils pourraient menacer tout à la fois la croissance économique générale et la stabilité sociale et politique du pays. Dans les zones rurales les plus défavorisées en 2012, le revenu moyen annuel par habitant était jusqu'à 25 fois plus faible que le revenu urbain moyen. Le sentiment de pauvreté du monde rural est encore accentué par le fait que ce sont les migrants ruraux, soit 260 millions de personnes et $20 \%$ de la population totale chinoise, qui représentent la majorité de la population pauvre urbaine (Colin, 2012). Ces inégalités sont sources d'instabilités politiques majeures, à tel point qu'en 2010, il y aurait eu officiellement 187000 événements de protestations paysannes recensés par l'Académie chinoise des sciences sociales (Woo, 2012; Colin, 2012).

L'objectif d'autosuffisance alimentaire en Chine se concentre ainsi sur les céréales qui sont soutenues par une importante politique de régulation interne de prix minimums à un niveau relativement élevé, via des protections douanières et du stockage public. Toute importation est soumise à quotas, principalement accordés aux entreprises d'État. En 2012, les quotas d'importation s'élevaient à 9,6 millions de tonnes de blé et 7,2 millions de tonnes de maïs. L'octroi de ces quotas varie et dépend des conditions de marché, et notamment de l'état des stocks qu'ils soient privés ou publics. La gestion des stocks publics de céréales est assurée par l'administration d'État, Sinograin, complétée par une trentaine de filiales. Sinograin, créé en 2000, était doté en 2012 de 23000 employés, et disposait de 338 centres de stockage en propre répartis à travers la Chine et de plus de 1000 centres agréés au total, pour une capacité estimée à 250 millions de tonnes. Le gouvernement chinois a d'ailleurs annoncé mi-juin 2015 un plan quinquennal de modernisation des infrastructures et un accroissement des capacités de stockage de 50 millions de tonnes. Sinograin est ainsi chargé des achats de céréales aux prix minimums garantis fixés chaque année par l'État, et de la gestion et de la revente des stocks sur des places de marché spécifiques, notamment à Zhengzhou pour le blé et à Dalian pour le maïs. En fin de campagne 2014, on estime ainsi que les stocks chinois rassembleraient 75 millions de tonnes de blé, soit $35 \%$ des réserves mondiales, 82 millions de tonnes de maïs, soit plus de $40 \%$ des stocks mondiaux, et 47 millions de tonnes de riz (46\% des stocks mondiaux), ce qui fait de la Chine, de loin, le premier stockeur mondial. La comparaison des prix de marché intérieurs, qui peuvent fluctuer au-dessus du prix minimum, avec les cours mondiaux montre l'efficacité de cette politique de stabilisation et de maîtrise de la volatilité (figure 4.2).

Parallèlement à ce soutien à la production par les prix, le gouvernement chinois a mis en place, depuis 2002, d'importantes mesures de subvention aux intrants : l'achat de semences de qualité a été soutenu à hauteur de 3 milliards de dollars en 2012, et l'achat d'engrais et de pesticides pour un montant de 17,1 milliards de dollars en 2012 (OCDE, 2013). En outre, des aides directes ont également été introduites à partir de 2004 dans le but de favoriser l'investissement dans l'agriculture et l'amélioration de la productivité (OCDE, 2005). Le soutien public aux producteurs a ainsi progressé, atteignant $15 \%$ des recettes agricoles en 2012 et se rapprochant ainsi de la moyenne des pays de l'OCDE ${ }^{2}$. Mais, si les soutiens directs aux agriculteurs continuent de s'accroître, l'essentiel de la politique agricole chinoise transite

2. En cherchant à prendre en compte la sous-évaluation du yuan, Butault et al. (2012) portent même ce chiffre à $17 \%$ pour 2010. 


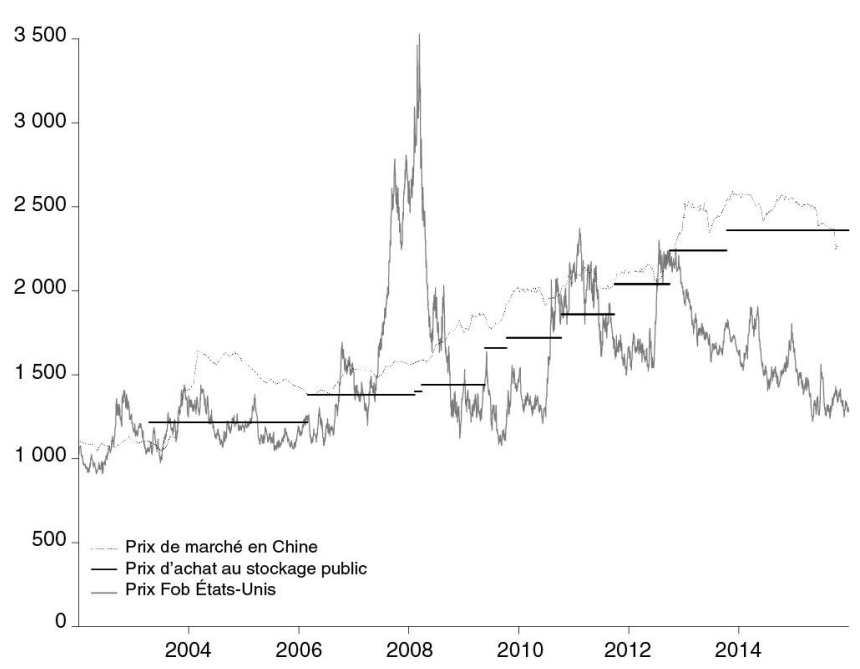

Figure 4.2. Prix de soutien et prix de marché du blé en Chine.

Sources : auteurs, inspirés par Gale (2013).

Sources des données : IGC, BCE, FAO, USDA et GNGOIC.

par la politique de soutien des prix domestiques, qui représentait $57 \%$ des soutiens totaux à l'agriculture en 2012. En définitive, le soutien à la production semble avoir porté ses fruits puisque la Chine est, depuis 2005, le premier producteur mondial de céréales, avec, pour l'année 2014, 126 millions de tonnes (Mt) de blé, 216 Mt de maïs et 224 Mt de riz.

Forte de ce succès, la politique chinoise n'en reste pas moins appelée à connaître certains ajustements pour faire face au repli généralisé des marchés internationaux observé depuis 2014. La croissance des importations de substitut aux céréales pour l'alimentation animale et l'accumulation de stocks de maïs au-delà des besoins de sécurité alimentaire conduisent en effet les autorités chinoises à modifier la politique de soutien au maïs. À partir de la campagne 2016, les importations de drèches de brasserie sont davantage taxées et le prix intérieur du maïs est abaissé afin de conserver aux droits de douane à $65 \%$ leur caractère dissuasif. Une aide contra cyclique (deficiency payment) est mise en place pour compenser la baisse des prix du maïs, qui doit permettre de maintenir un niveau de revenu équivalent aux producteurs et de réduire la sole consacrée au maïs de $10 \%$ à l'horizon 2020 (Li, 2016). Cet ajustement de la politique de soutien devrait se traduire par une augmentation de la production de soja et un renforcement de la compétitivité des élevages chinois tout en garantissant un haut niveau de sécurité alimentaire.

Depuis le début des années 2000, la Chine développe ainsi une politique agricole ambitieuse de soutien à la production de céréales, par des aides directes, mais surtout par une politique efficace de stabilisation de son marché intérieur à un niveau de prix élevé pour le riz et le blé. La politique agricole chinoise est marquée par une forte capacité d'adaptation traduisant un pragmatisme réel dans la recherche de solutions pour atteindre des objectifs ambitieux. Ces mesures l'ont ainsi amenée au premier rang mondial en termes de consommation, de production et de stockage 
de céréales. On relèvera d'ailleurs le paradoxe, du point de vue de la théorie économique, qui veut que le pays que l'on qualifie « d'atelier du monde », au vu du développement de son industrie manufacturière, soit aussi le plus grand pays agricole et celui où les prix des principaux produits agricoles sont les plus élevés au monde. Paradoxe qui devrait amener à renouveler certaines approches de l'économie du développement et certaines théories sur la spécialisation productive résultant de l'intégration commerciale.

\title{
W Le rôle de stockeur en dernier ressort dans les échanges internationaux de céréales
}

\begin{abstract}
À l'instar de la Chine, l'intervention publique reste la règle en matière agricole dans la quasi-totalité des pays. La crise de 2007-2008 et la forte volatilité des prix internationaux observée depuis se sont même traduites par un renforcement des politiques agricoles nationales. On présente parfois les négociations du Gatt (General Agreement on Tarrifs and Trade) du cycle de l'Uruguay entamé en 1986 comme la première tentative de vouloir traiter dans un cadre multilatéral les questions de commerce agricole. Mais ce serait passer sous silence la période 1930-1980 où de nombreux pays ont cherché à relancer les échanges internationaux de matières premières, et parmi elles les matières premières agricoles, par la mise en place d'accords sur les principaux produits de base (Gilbert, 1996). La recension de ces négociations montre quelques traits communs, celui qui retient particulièrement notre attention est le fait qu'ils sont souvent portés diplomatiquement par un ou quelques pays exportateurs (Gordon-Ashworth, 1984).
\end{abstract}

Dans le cas du blé, pas moins de huit accords internationaux ont été signés entre 1933 et 1971. Les États-Unis, premier producteur et exportateur de céréales sur la période, disposaient alors d'un leadership sur ces accords. Dans un contexte de croissance des rendements, il s'agissait surtout de désengorger des marchés internationaux plombés par les surplus. L'accord le plus ambitieux, celui de 1949 renouvelé quatre fois jusqu'en 1966, prévoyait des engagements d'achat et de vente sur plusieurs années représentant jusqu'à deux tiers des échanges internationaux à des prix compris dans une fourchette assez étroite. Surtout, il engageait les trois pays exportateurs de l'époque, les États-Unis, le Canada et l'Australie, à disposer de stocks stabilisateurs conséquents. Ces dispositions étaient autant de garanties données aux pays importateurs que l'accroissement des échanges dans ce cadre sécuriserait leur approvisionnement. Les programmes d'aide alimentaire extérieure, qui furent intégrés aux négociations lors de l'accord de 1967, constituaient également des moyens d'écoulement des produits et de recrutement de nouveaux pays consommateurs. Engagés dans cette recherche de stabilisation des marchés internationaux, les principaux protagonistes cherchaient alors à mettre en cohérence leur politique agricole intérieure. En particulier, les États-Unis mobilisaient pleinement le stockage public et des programmes de jachères obligatoires pour retirer des terres de la production. La figure 4.3 montre ainsi l'ampleur de ces programmes de jachères : dans les années 1960, ils approchaient les 70 millions d'acres, une surface correspondant à 28 millions d'hectares, soit plus de deux fois la superficie des terres arables en France. 


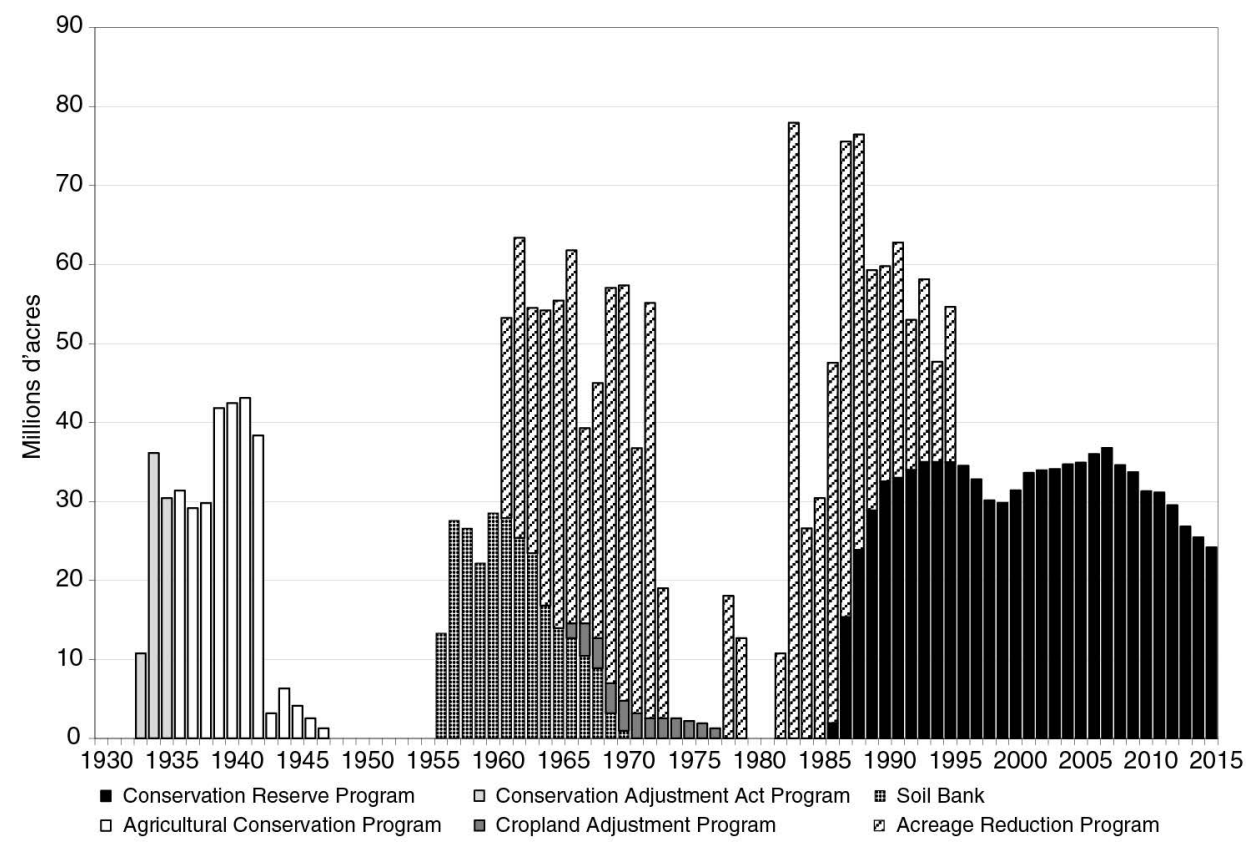

Figure 4.3. Terres mises en jachère aux États-Unis entre 1933 et 2015, par programme. Sources : auteurs, d'après Lubowski et al., 2006, mise à jour d'après des données de l'USDA.

Le soutien des prix et la régulation de l'offre constitueront ainsi « les principes de base de l'intervention des pouvoirs publics aux États-Unis dans le secteur agricole de 1933 à 1996 », et le prix de soutien américain devient alors « un prix d'orientation pour le cours mondial des produits pour lesquels les États-Unis détiennent une part considérable de ce marché (blé, maïs, soja, coton) » (Devienne et al., 2005). De la sorte, les États-Unis ont joué le rôle de «stockeur en dernier ressort » (Boussard et $a l .$, 2008) ou « d'offreur résiduel » indispensable pour porter l'accord (Losch, 2007). Le principal enseignement de cette période et de l'activisme des États-Unis pour développer les échanges doit être vu dans la relation entre la stabilisation des prix et l'ouverture commerciale. S'il est vrai que l'accroissement des échanges permet de diminuer les effets déstabilisateurs de chocs dits exogènes (Boussard et al, 2013), comme des événements climatiques extrêmes, force est de constater qu'à l'aune des faits historiques la causalité entre ouverture et stabilisation est inversée : c'est la stabilisation des prix internationaux par le «stockeur en dernier ressort » qui a permis l'ouverture commerciale.

À peine le huitième accord était-il signé en 1971 que le système d'accords internationaux sur le blé commençait à connaître des difficultés qui se révéleront insurmontables pour le «stockeur en dernier ressort » de l'époque. On peut arrêter la période de début des tensions avec la flambée des prix des matières premières de 1973-1974, que l'on attribue parfois aux conséquences du premier choc pétrolier, lequel, dans les faits, fut postérieur à la hausse des prix des céréales. L'étincelle fut la conclusion, en dehors de l'accord, de plusieurs contrats de commercialisation sur 
du blé américain à destination de l'URSS par différents négociants internationaux qui, faute d'avoir eu connaissance des démarches de leurs homologues, s'étaient engagés sur des volumes pressentis, au total, supérieurs à la récolte à venir. De la sorte, le «stockeur en dernier ressort » s'est lui-même mis en défaut pour ses clients réguliers. En outre, bien que le soja ne fût concerné par aucun engagement international, l'annonce d'un embargo sur les exportations américaines de ce produit en mai 1973, dans l'intention de faire baisser les prix intérieurs, contribua à affaiblir la crédibilité des États-Unis à porter ces accords. Enfin, en 1979, le leadership en matière de commerce des céréales se heurta également à la politique étrangère américaine, au moment de la mise en place par les États-Unis d'un embargo sur les céréales à destination de l'URSS suite à l'invasion de l'Afghanistan.

Les accords sur le blé ne survécurent donc pas à la décennie 1970 en dépit d'une dernière tentative menée par l'administration Carter entre 1978 et 1980 qui proposa, en vain, un système de stockage multilatéral financé par les pays développés (Bertrand et Delorme, 2007). Il faut également rappeler que l'accord sur le blé fut également déstabilisé par l'opposition croissante aux accords sur les produits de base, dans un contexte où les visées émancipatrices des 77 pays en développement cherchant, via la Cnuced (Conférence des Nations unies sur le commerce et le développement) et la Conférence de Nairobi en 1976, à instaurer le NOEI (Nouvel ordre économique international) dans lequel les accords sur les produits de base constituaient un instrument économique susceptible de renverser la détérioration des termes de l'échange, à l'instar de l'Opep pour le pétrole (Lines, 2007).

Pour autant, la fin des accords sur le blé ne signa pas immédiatement l'abandon de la stratégie du «stockeur en dernier ressort » par les États-Unis. L'alternative développée fut, dans cette période de marchés déprimés, de chercher à régler le problème à la source en renforçant le programme de stockage public et, surtout, en augmentant les mesures de mise en jachère obligatoire. Ainsi en 1983, près du quart de la surface agricole américaine n'est pas cultivé dans l'objectif de rééquilibrer le marché intérieur et, compte tenu du poids de l'agriculture américaine, le marché international (figure 4.3).

La remise en cause finale de cette politique de «stockeur en dernier ressort » jouée au niveau mondial par le principal exportateur de céréales fut, de fait, consécutive à la stratégie non coopérative déployée par l'Argentine et surtout par l'Europe, fraîchement devenue exportatrice, qui gagnèrent des parts de marché dans les échanges internationaux grâce et aux dépens des États-Unis. On peut en effet avancer que le fait que la Communauté européenne devienne exportatrice nette de blé en 1981 et exporte davantage de blé que les États-Unis en 1984 et 1985 a sonné le glas du leadership américain. Il est d'ailleurs à remarquer que les fameuses montagnes de blé dans les stocks communautaires étaient finalement assez limitées et qu'au regard de sa production, les stocks de report européens sont toujours restés très stables et assez bas (figure 4.4), bien en dessous de la moyenne mondiale. On ne peut donc pas vraiment dire que l'Europe, forte de sa Politique agricole commune, ait cherché à tenir le rôle de stockeur en dernier ressort dont, par son fait, elle avait découragé les États-Unis. Au contraire, deux stratégies opposées vont s'affronter en vain. D'un côté de l'Atlantique, le budget communautaire est mis à rude épreuve pour subventionner des exportations, de l'autre, on paie les agriculteurs pour mettre en 
jachère leurs champs et on remplit les stocks publics afin d'espérer faire remonter les cours mondiaux. D'un côté de l'Atlantique, les stocks publics sont l'étape intermédiaire avant l'exportation subventionnée automatique, de l'autre, on préfère faire varier les stocks pour tamponner un marché international en proie à une instabilité structurelle.

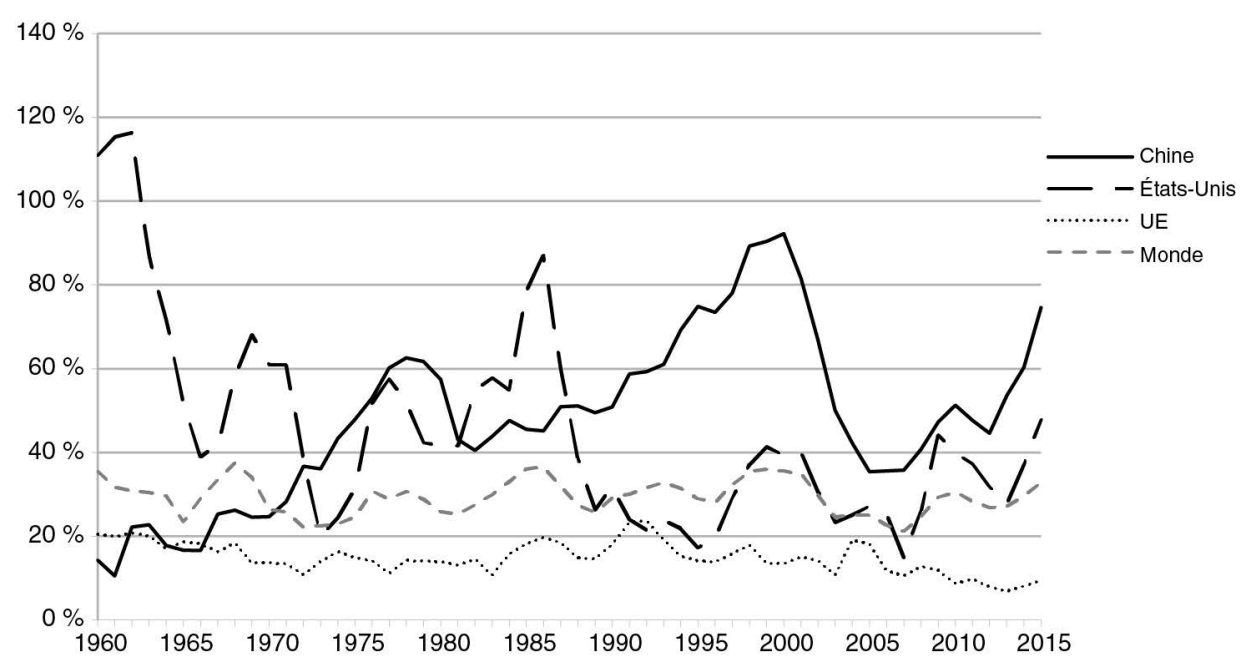

Figure 4.4. Blé : ratio stocks de fin de campagne/production nationale.

Sources : auteurs, d'après les données de l'USDA et de l'IGC.

Cette divergence de vue et d'action entre l'exportateur historique aux vastes plaines et le nouveau venu, pour qui le marché international n'est que le moyen de stabiliser les prix intérieurs, ne put que faire des étincelles. La suite est connue : l'Europe fit la sourde oreille aux tentatives de conciliations entamées dès le début des années 1980, si bien que la mèche fut réellement allumée dès lors que la pression politique interne face à un budget agricole communautaire en dehors de tout contrôle se conjugua à la pression politique internationale qui, à elle seule, n'avait pu faire plier un lobby agricole européen très influent. À partir de cette période, sur les sujets agricoles, le calendrier multilatéral et l'agenda communautaire se confondirent : il s'agissait de réformer la $\mathrm{PAC}$ et de mettre en place une discipline internationale en matière de soutien à l'agriculture. Le coup d'envoi fut donné à la conférence du Gatt de Punta del Este en 1986 qui lança le cycle de négociation de l'Uruguay. Il s'acheva par les accords de Marrakech en 1994 qui arrêtèrent l'accord agricole définissant les règles à respecter en matière de soutien à l'agriculture et instaurant l'OMC (Organisation mondiale du commerce). Entre temps, l'accord de Blair House entre Américains et Européens et la réforme de la PAC adoptée en 1992 avaient établi les principes à suivre en matière agricole pour les deux partenaires.

La discipline de l'OMC en matière agricole se centra sur l'accès aux marchés (les droits de douane sont plafonnés et convertis en taxe proportionnelle aux prix), sur le soutien interne (le soutien par les prix doit être remplacé par des subventions directes ayant le moins d'effet distorsif possible sur les échanges) et sur les 
subventions à l'exportation (qui doivent être baissées). Le principal objectif du cycle de négociation de l'Uruguay était d'imposer une réforme de la PAC visant à réduire ses impacts déflationnistes sur les marchés internationaux. Concrètement, l'instauration d'une jachère obligatoire (au taux fixe de $15 \%$ de la surface arable), ainsi que la baisse des prix d'intervention, compensée partiellement par des aides de moins en moins incitatives à la production, devaient permettre de faire baisser la production et de limiter le recours aux subventions à l'exportation.

Mais au demeurant, si l'on a cherché à limiter la portée de politiques agricoles nationales qui avaient pu se traduire par des stratégies non coopératives vis-à-vis du «stockeur en dernier ressort», la discipline agricole de l'OMC a également mis à bas cette fonction centrale de "stockeur en dernier ressort ». Dans le contexte idéologique des années 1990, tournant le dos à l'expérience américaine en matière de régulation du marché des céréales, on s'en est remis aux vertus stabilisatrices des marchés : la confrontation des offres et des demandes devait conduire à l'équilibre de marché.

Les critiques émises lors des flambées de prix de 2007-2008 et de 2010 à l'égard de plusieurs pays ayant limité leurs exportations ont d'ailleurs révélé les limites du cadre de l'OMC en matière agricole : aucune disposition ne prévoyait d'encadrer ce type de pratiques. Ceci est d'autant plus troublant que la réduction des barrières à l'importation est, au contraire, au cœur des objectifs de la gouvernance mondiale des politiques agricoles depuis la fin des années 1980. Quels présupposés cette asymétrie dans le traitement des barrières commerciales révèlent-ils ? En premier lieu, elle manifeste que l'objectif du cadre de l'OMC était principalement de sortir les marchés internationaux de la déprime dans laquelle les politiques nationales non coopératives la maintenaient. De plus, elle traduit une représentation largement partagée où le progrès technique devait permettre la poursuite de la tendance à la baisse des prix agricoles, sorte de loi d'airain d'un monde sans rareté. Enfin, on peut y voir la croyance dans l'autorégulation et l'efficience des marchés laissés à eux-mêmes sans égards vis-à-vis des causes structurelles de la volatilité des marchés agricoles.

Au sujet des politiques de stockage, l'accord agricole de 1994 prévoit de réduire l'outil à son acception la plus étroite. Les seules aides au stockage public qui ne sont pas soumises à réduction sont celles qui doivent répondre à la triple condition de ne pas apporter un soutien des prix aux producteurs, que les stocks répondent à un objectif de sécurité alimentaire et que les achats soient faits au prix de marché. C'est d'ailleurs cette vision très corsetée de l'utilisation du stockage public que l'Inde et les pays du G33 cherchent à faire modifier depuis la préparation de la Conférence ministérielle de l'OMC à Bali en décembre 2013 (Berthelot et Galtier, 2014).

La crise agricole de 2007-2008 et la forte volatilité des prix internationaux observée depuis agissent donc comme un révélateur des limites de la discipline de l'accord agricole de l'OMC. Restreindre les politiques non coopératives est nécessaire mais non suffisant, compte tenu de la volatilité structurelle des marchés agricoles laissés à eux-mêmes, ainsi que des coûts et des sources d'inefficacité qu'elle induit pour l'ensemble de l'économie. Si, en théorie, le meilleur remède à des prix hauts est des prix hauts dans la mesure où ils stimulent la production et conduisent à l'ajustement, dans la pratique, pour un gouvernement confronté à une flambée de prix, « la 
non-intervention n'est pas une politique crédible » (Galtier, 2012). Cette déclinaison du principe de réalité implique donc de penser la coopération entre pays et la coordination entre politiques nationales afin de prévenir des situations dans lesquelles la gestion de l'urgence l'emporterait, à juste titre pour l'essentiel, sur toutes considérations et engagements internationaux.

La relation entre stabilité des prix internationaux et ouverture commerciale est complexe. D'un côté, l'ouverture commerciale permet, grâce aux échanges, d'atténuer les impacts localisés d'un incident climatique. De l'autre, l'ouverture commerciale n'est possible que si chaque pays a suffisamment confiance dans les échanges internationaux pour assurer son approvisionnement à un prix relativement stable. Pour enclencher et maintenir ce cercle vertueux positif en termes de sécurité alimentaire et pour qu'il puisse permettre une spécialisation productive intelligente, vu que la non-intervention n'est pas crédible, cela suppose un cadre de coopération où un ou plusieurs pays supportent le rôle de «stockeur en dernier ressort ». Compte tenu de l'importance de sa politique agricole et de son rang, que ce soient en termes de production ou de consommation, la Chine peut-elle tenir ce rôle?

\section{W La Chine comme nouveau stockeur en dernier ressort?}

L'examen de la politique agricole chinoise a permis d'établir quelques ordres de grandeurs sur la production, la consommation et le stockage de l'Empire du Milieu. Afin d'apporter des éléments de réponse à la question posée, nous proposons de rapporter ces chiffres à ceux de la volatilité des cours mondiaux, et plus précisément à la valeur du stock de fin de campagne que nous considérons comme la variable centrale pour expliquer les tensions sur les marchés. Cette analyse nous permettra de voir si la Chine dispose ou non de la capacité d'intervention nécessaire. Mais, si elle le pouvait, pourquoi le voudrait-elle ? Une seconde sous-partie discutera des motivations que la Chine aurait à endosser le costume de stockeur en dernier ressort.

Depuis 2007, les cours des céréales sont entrées dans une période d'instabilité inédite. Les nombreuses analyses produites pour tenter d'expliquer le comportement des prix internationaux ont listé les différentes causes sous-jacentes. Certaines ont au mieux tenté de les classer par ordre d'importance, mais aucune ne s'est hasardée à attribuer un poids respectif à chacun des facteurs (Trostle, 2008). Parmi ces facteurs, le niveau des stocks de report a souvent été mis en avant : la perspective de leur faible niveau à l'issue de la campagne 2007-2008 a été considérée comme un des principaux facteurs. Il convient de préciser que les stocks de report ne se limitent pas aux seuls stocks détenus par des institutions publiques. De plus, ce concept découle de la saisonnalité de la production de céréales (une récolte par hémisphère et par an, avec une prédominance de l'hémisphère nord), il correspond aux quantités disponibles à la veille de la prochaine récolte, celles à même d'assurer la soudure entre les récoltes.

Les graphiques de la figure 4.5 montrent les ratios des stocks de report rapportés à la consommation mondiale, respectivement pour le blé et le maïs : en 2007-2008, ils avaient atteint $21 \%$ pour le blé et $15 \%$ pour le maïs, renouant avec les niveaux les plus bas des années 1970. 
Ratio annuel stocks/consommation mondiale : blé

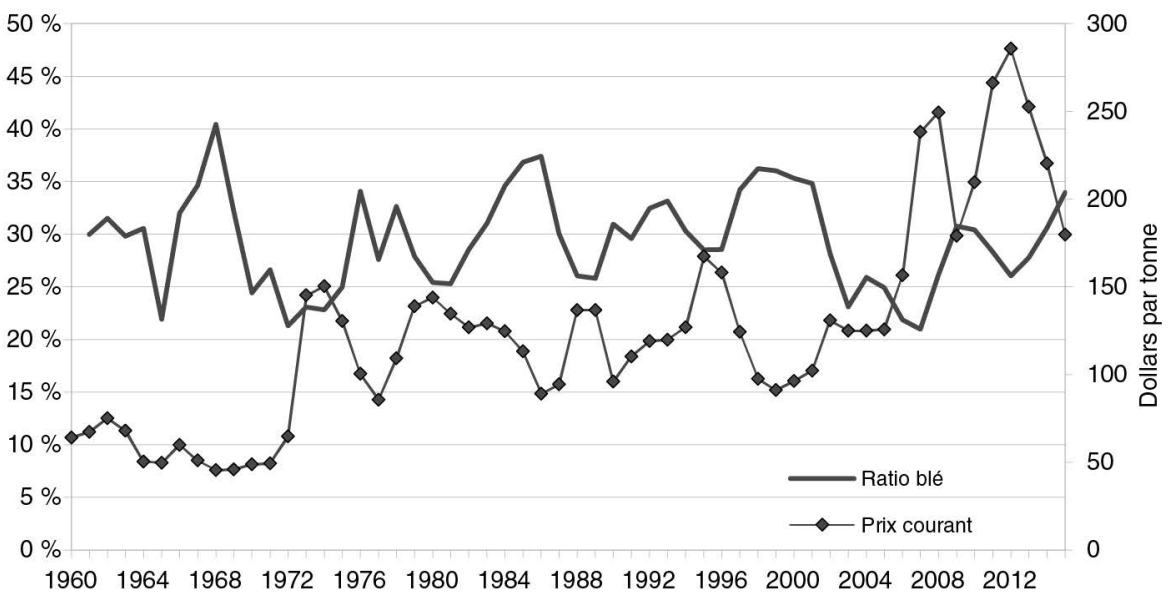

Ratio annuel stocks/consommation mondiale : maïs

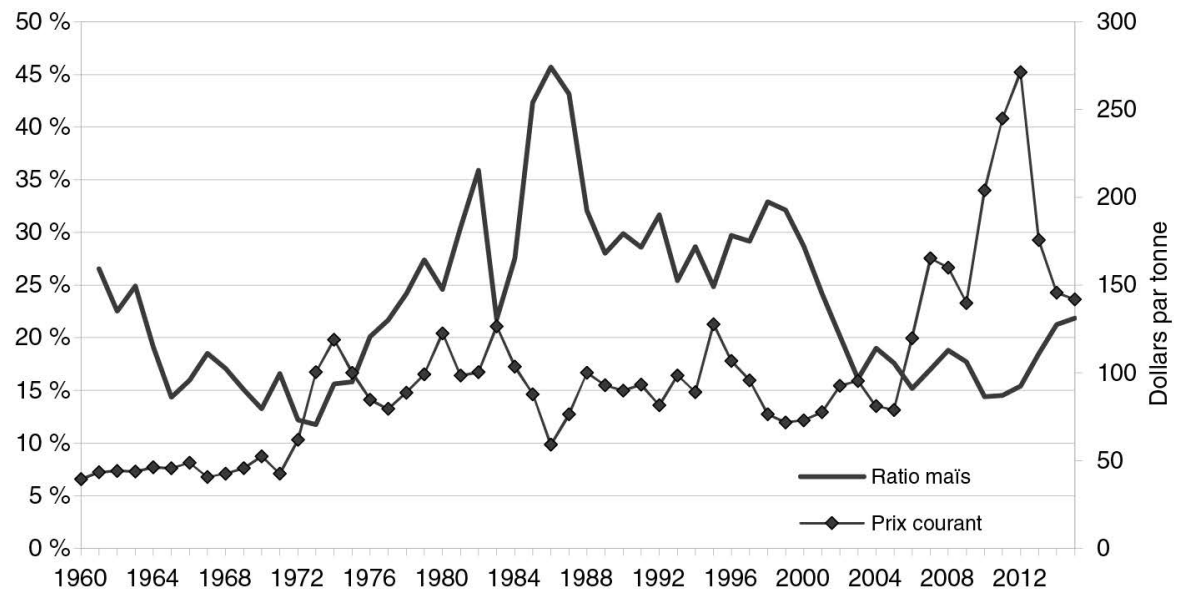

Figure 4.5. Ratio annuel stocks/consommation mondiale : (a) blé et (b) maïs.

Toutefois, il faut également remarquer que ce niveau était déjà quasiment atteint depuis 2004 sans qu'aucune hausse de prix significative n'ait été observée alors. De plus, le niveau interroge également : tout ce passe comme si, pour le blé, à $20 \%$ de stocks/consommation, soit 70 jours de marge pour assurer la soudure, on considère que la pénurie est proche, alors qu'à $30 \%$, soit 110 jours, c'est le sentiment de réserves pléthoriques qui l'emporte. La baisse des prix de 2009, consécutive notamment à une très bonne récolte, a en effet relevé cet indicateur au-dessus des $30 \%$. Ainsi, tout ce passe comme si, autour d'un pivot à $25 \%$ de stocks/ consommation, quelques dizaines de millions de tonnes en plus ou en moins suffisaient à faire basculer les prix d'un côté ou d'un autre : pour une production mondiale de céréales (hors riz) estimée à environ 2 milliards de tonnes, l'ordre de grandeur est de 100 millions de tonnes. La loi de King, malgré ses trois siècles, 
n'a jamais été autant d'actualité : un léger différentiel entre la production et la consommation est susceptible de conduire à des variations des prix très importantes.

En regardant de plus près le ratio stocks/consommation (figure 4.6), on constate tout de même une rupture dans la relation entre cet indicateur phare et le prix moyen annuel. Cela donne à penser que nous serions entrés dans un nouveau régime de prix depuis 2007 : il existe toujours une relation assez régulière entre le niveau de prix et le ratio stock de report sur consommation, mais celle-ci n'est plus la même depuis 2007 (Couharde et al., 2012).
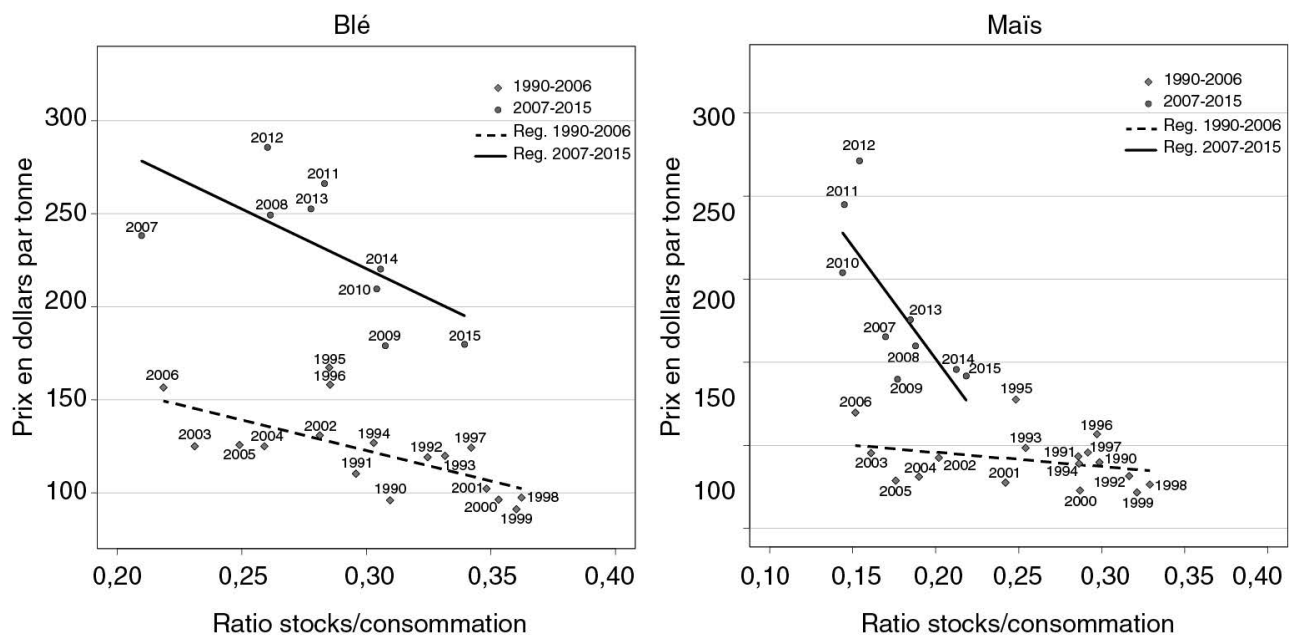

Figure 4.6. Relation entre niveau de prix et ratio stocks de report/consommation pour le blé et le maïs.

Sources : auteurs, d'après les données de l'USDA et de l'IGC.

Des paramètres tels que l'augmentation des coûts du pétrole et des engrais ou la dépréciation du dollar expliquent une partie du décalage, mais ils paraissent insuffisants pour expliquer le passage d'un prix international inférieur aux coûts de production de la plupart des zones agricoles à un prix qui reste au-dessus des coûts des producteurs même les moins compétitifs, mais pourtant nécessaires pour satisfaire la demande. Peut-on invoquer, comme Orléan (2004), qu'il faille parfois aller chercher des explications à la formation des prix dans des conventions, des représentations partagées entre acteurs ? On serait donc passé d'un univers d'abondance, où il était normal que les prix baissent, du fait du progrès technique, en deçà des coûts complets marginaux à une situation où la crise de 2007-2008 aurait resensibilisé les agents économiques, privés comme publics, à un risque de tensions sur les approvisionnements consécutif au changement climatique et aux perspectives sociodémographiques. Faut-il y voir également une conséquence de la financiarisation des marchés agricoles à l'œuvre depuis le milieu des années 2000 (pour une caractérisation du phénomène, voir Lecocq et Courleux, 2011) ? Ce phénomène peut-il être invoqué pour expliquer cette nouvelle relation par la connexion croissante entre les différents marchés financiers dans un contexte d'abondance de liquidités ? 
Difficile de conclure sur les causes de ce nouveau régime, et par conséquent difficile de savoir s'il est durable ou si une autre rupture se profile. On peut seulement constater que l'attrait des marchés financiers de matières premières agricoles pour les acteurs financiers semble marquer le pas : les effets de réputation et une moindre rentabilité ont incité plusieurs acteurs financiers à se retirer, et l'intérêt initial d'utiliser cette classe d'actifs dans des stratégies de différenciation de portefeuille s'estompe avec l'augmentation des corrélations entre les prix des matières premières et les autres actifs (Guilleminot et al., 2013).

En outre, l'augmentation des prix des céréales observée depuis 2007 s'est traduite par une augmentation de la production conséquente, de l'ordre de $30 \%$ entre 2006 et 2015. Le renforcement des politiques agricoles, les programmes de subvention aux intrants et les investissements dans les infrastructures pour limiter les gaspillages n'y sont pas non plus étrangers. Les récoltes records s'enchaînent et les prix connaissent depuis 2013 un tassement sensible.

La conjoncture actuelle des prix des céréales, qu'elle remette ou non en cause le nouveau régime de prix, amène à s'interroger sur la fonction de stockeur en dernier ressort. Considérant que, « dans la quasi-totalité des cas, les fluctuations sont indésirables pour la société, les pertes des moins favorisés dépassant en général les avantages des bénéficiaires » (Boussard, 1987), la question des stocks, au sens large, et de leurs effets stabilisateurs ou déstabilisateurs continue de se poser. Plus précisément, à l'aune de son poids en matière de production et de consommation de céréales, et compte tenu des infrastructures de stockage public qu'elle a développées, la Chine dispose certainement des capacités nécessaires pour remplir cette fonction. Pour autant, au-delà d'une hypothétique faisabilité technique, il convient de considérer les motivations qui l'amèneraient à exercer ce rôle, ainsi que les conditions à réunir s'agissant des stratégies des autres acteurs.

Afin de discuter de ces motivations, nous distinguerons ici trois dimensions : la première relève de l'efficacité de la politique agricole chinoise et de son acceptabilité aux yeux du concert des nations ; la deuxième repose sur l'idée que jouer ce rôle de stockeur en dernier ressort peut être pour la Chine l'un des moyens d'exercer sa volonté de puissance sur la scène internationale en usant de son poids croissant dans l'économie mondiale ; enfin, la troisième renvoie aux conditions d'exercice de ce rôle qui peut difficilement faire face à des politiques non coopératives de la part des autres États.

Les renforcements progressifs de sa politique agricole ont permis à la Chine de limiter l'exposition de sa population et de son économie à la forte volatilité des prix observée depuis 2007. Cette stabilité relative des prix intérieurs chinois s'explique notamment par la confiance des acteurs économiques dans la capacité de Sinograin à répondre à la demande en cas de tensions sur l'offre. Mais, aussi importants que soient les stocks de régulation, ils peuvent toujours être mis en défaut en cas d'incidents climatiques importants, voire répétés. Dit autrement, il n'est pas possible d'être parfaitement isolé des fluctuations des cours internationaux. Et ce d'autant plus qu'en dépit de sa volonté de contrôler sa dépendance aux importations, il y a tout lieu de penser que les évolutions démographiques et socioéconomiques de la Chine conduiront à un recours croissant aux échanges internationaux pour assurer son approvisionnement. Apparaît alors une motivation importante à revêtir 
le costume de stockeur en dernier ressort : exporter sa stabilisation domestique tendrait à limiter le risque de se faire prendre en défaut dans ses propres frontières. Et ceci peut paraître d'autant plus accessible pour un acteur dont la production de céréales excède le volume total des échanges internationaux (autour de $350 \mathrm{Mt}$ en 2014-2015, riz inclus).

Assumer le rôle de stockeur en dernier ressort présenterait également l'opportunité d'offrir une nouvelle perspective à la gouvernance des politiques agricoles embourbée dans le cycle de Doha à l'OMC. La baisse des cours internationaux qui se confirme depuis 2013 va en effet se traduire par une augmentation des niveaux de soutien agricole, que ce soient dans les pays qui soutiennent via des aides directes variables selon les prix ou dans ceux qui déconnectent leurs prix intérieurs des cours internationaux par des mesures aux frontières. La Chine, dont le niveau de soutien exprimé en valeur absolue est déjà le plus important compte tenu de la taille de son secteur agricole (Butault et al., 2012), sera également concernée par cette hausse qui, comme pour d'autres, l'amènera à se rapprocher, voire à dépasser les engagements pris lors de son adhésion à l'OMC.

On pourrait avancer que l'Empire du Milieu aurait intérêt à empêcher la baisse des prix internationaux pour rester dans les clous de ses engagements commerciaux. Mais, concrètement, quel pays souhaiterait attaquer la Chine devant l'organe de règlement des différends de l'OMC pour sa politique agricole sans risquer d'enclencher une remise en cause totale de la discipline agricole actuelle de l'OMC et par là entériner l'échec du cycle de Doha ? Et quel risque la Chine prendrait-elle à ne pas appliquer les réformes imposées sur le fondement de règles dont la légitimité s'érode avec les débats sur la non-neutralité des aides directes ou sur l'impossibilité actuelle de considérer les aides au stockage, pourtant répandue, autrement que comme des politiques à proscrire (Berthelot et Galtier, 2014) ? Il faut d'ailleurs remarquer que, si l'Inde a pris le leadership de la fronde à l'OMC pour requalifier les politiques de stockage, la discrétion de la Chine, en retrait mais bien présente dans le G33, peut aussi se traduire comme une stratégie visant à ne pas relégitimer un ensemble de règles discutables. Et donc, inversement, on peut penser qu'une nouvelle discipline collective s'agissant des politiques agricoles nationales ne pourra émerger, pour être véritablement effective, sans être centrée sur les réalités économiques agricoles et alimentaires du ou des quelques pays souhaitant assumer ce leadership.

Le développement économique que connaît la Chine depuis les années 1980 restera vraisemblablement inégalé dans l'histoire de par sa rapidité et son ampleur. Le poids croissant de l'économie chinoise dans l'économie mondiale s'accompagne de l'ambition de figurer au rang des grandes puissances, notamment sur le plan diplomatique. Par la doctrine politique du « rêve chinois », la Chine souhaite affirmer son statut de grande puissance et annonce vouloir faire émerger un nouveau type de relations internationales plus équilibrées (Duchâtel, 2013). Cette volonté de participer activement à la conduite du monde devrait continuer de s'exprimer vis-à-vis du secteur des matières agricoles. Comptant historiquement parmi les premières politiques macroéconomiques, les politiques agricoles, via leur impact sur les prix alimentaires et donc l'inflation/déflation, pourraient être mis à profit dans des stratégies de résorption des déséquilibres macroéconomiques, voire de sortie de déflation, dès lors qu'elles pourraient être orchestrées par un acteur aussi majeur que la Chine. 
L'importante activité diplomatique entre pays du Sud-Est asiatique, notamment au sein de l'Asean+3 (Association des nations de l'Asie du Sud-Est), peut être vue comme traduisant l'affirmation d'une stratégie de leadership de la part de la Chine s'agissant de la stabilisation des prix internationaux du riz. En effet, l'Apterr (Asean Plus Three Emergency Rice Reserve) a vu son action sensiblement renforcée suite à la crise de 2007-2008 : ce dispositif d'échange d'information sur les stocks des différents pays prévoit également que chaque État membre distingue, parmi ses propres réserves, une quantité qui pourra être mise à disposition de ses partenaires en cas d'urgence (Belesky, 2014 ; Cadilhon et Milleman, 2011). Bien que les volumes promis aux situations d'urgence soient limités et que des risques de reniement persistent toujours, la transparence sur les stocks et la confiance réciproque, bâties via cette coopération entre les principaux pays producteurs et consommateurs de riz, peuvent être avancées pour expliquer la stabilité des cours du riz, produit qui a échappé aux répliques de 2010 et 2012 qui ont fortement touchées les prix des autres céréales (Dawe et Timmer, 2012).

Enfin, comme l'a montré la remise en cause de l'action des États-Unis comme régulateur mondial des marchés des céréales au début des années 1980, le stockeur en dernier ressort doit pouvoir compter sur la coopération des autres partenaires, ou tout du moins ne doit pas compter des adversaires qui jouent sciemment contre lui. Dans le contexte de ce début de $\mathrm{XxI}^{\mathrm{e}}$ siècle, marqué à la fois par une vigoureuse augmentation de la production dans un contexte de prix internationaux beaucoup plus favorables et par la multiplication des incidents climatiques consécutifs au réchauffement climatique, un type de mesure semble devoir être particulièrement exploré, concernant les politiques de promotion de biocarburants. Elles devraient, notamment pour les nouvelles usines, intégrer des mécanismes d'évitement ou d'effacement qui prendraient directement en compte les prix des matières premières agricoles afin de ne pas contribuer à rendre la demande encore plus inélastique. Des mécanismes de ce type existent déjà aux États-Unis et au Brésil (Claquin et $a l ., 2015)$, mais pourraient être approfondis et généralisés quitte à dédommager les industriels pour la sous-utilisation temporaire des capacités de production.

\section{Conclusion}

Premier producteur, premier consommateur et premier stockeur de céréales au niveau mondial, la Chine a progressivement rééquilibré sa politique économique en faveur de l'agriculture pour maintenir des objectifs d'auto-approvisionnement élevés en céréales, préférant par ailleurs maîtriser sa dépendance en protéine végétale. La géopolitique des accords sur le blé montre le rôle central de stockeur en dernier ressort qu'ont joué les États-Unis des années 1930 aux années 1980 avant la mise en œuvre de l'accord agricole de l'OMC. La stabilité garantie par le leadership américain en matière de régulation du marché international a contribué au développement des échanges. À l'inverse, après une période de prix historiquement élevés depuis la crise de 2007-2008, la perspective d'un retournement de conjoncture laisse craindre une nouvelle séquence de jeu non coopératif entre des pays qui ne voudront pas remettre en cause leurs politiques agricoles nouvellement renforcées. La Chine 
paraît être un des candidats sérieux au rôle de nouveau stockeur en dernier ressort, et ce d'autant plus compte tenu de la nouvelle doctrine politique du " rêve chinois ", par laquelle la Chine réaffirme son statut de grande puissance, et vise un nouveau type de relations internationales plus équilibrées. Cela supposerait, contrairement à l'expérience des accords sur le blé, que les autres partenaires commerciaux ne jouent pas contre cette stratégie. Nous pensons que le prochain mode de régulation des échanges internationaux qui établira une discipline collective crédible en matière de politiques agricoles nationales ou régionales ne pourra se construire sans assumer le besoin de disposer, par produit, d'un ou de plusieurs pays œuvrant en tant que stockeur en dernier ressort. 


\section{Chapitre 5 \\ La renaissance de l'agriculture japonaise ?

\author{
D. H. WhitTaker, R. Scollay
}

Ce chapitre ${ }^{1}$ étudie le régime de l'agriculture japonaise après la Seconde Guerre mondiale, les bouleversements qu'il connaît aujourd'hui et ses futurs possibles. Il décrit tout d'abord l'érosion du régime agricole de l'après-guerre, puis les transformations que subissent actuellement l'agriculture et la politique agricole japonaises, et, en troisième lieu, en référence à Allaire et Boyer (1995, Introduction), les multiples projets en compétition pour construire un nouveau régime.

La transition a, dans un certain sens, été retardée par le changement de générations, mais à présent elle s'accélère. Cette accélération a été déclenchée par l'annonce, par le Premier ministre Kan en 2010, d'une participation du Japon aux négociations du TPP (Trans-Pacific Partnership ou Partenariat trans-pacifique). Les coopératives agricoles (JA) se sont alors immédiatement mobilisées pour exprimer leur opposition, mais ce tollé a conduit à une attention nouvelle de la société japonaise vis-à-vis de l'agriculture et des politiques agricoles. Cela a débouché sur une attaque en règle contre ce qui a été décrit comme la défense d'intérêts acquis et le cantonnement du pays dans une situation d'otage de son passé. C'est sur cette base que le Premier ministre Abe a pu introduire un ensemble de réformes, dont la réforme des coopératives agricoles (JA) elles-mêmes, bien que celles-ci aient constitué historiquement un des socles du Parti libéral démocrate (LDP) de ce même Premier ministre.

Ces réformes peuvent être vues comme l'expression de l'adhésion croissante du Japon au néolibéralisme. Mais ce n'est pas seulement un exemple du renforcement de la cité marchande au détriment de la cité industrielle (Boltanski et Thévenot, 1991). Ainsi, le slogan « une agriculture forte » du Premier ministre Abe (c'est-àdire une agriculture capable à la fois de résister à une croissance des importations et de fournir un nouveau secteur d'exportation) recouvre de multiples propositions. Il existe aussi des récits alternatifs à celui de «l'agriculture forte » qui sont plus proches des cités domestique et civique de Boltanski et Thévenot, des discours eux aussi tournés vers l'avenir mais défendant une vision plus personnalisée, d'autres produits et formes de qualité, et un mode de vie moins marchandisé.

Nous essaierons de donner du sens à cette profusion de propositions. Nous examinerons tout d'abord l'agriculture et la politique agricole de l'après-guerre, et leur rôle dans

1. Ce chapitre reprend des éléments publiés dans D.H. Whittaker, R. Scollay, J. Gilbert, 2013. «TPP and the Future of Food Policy in Japan ». Working Paper series 13-01, Auckland, New Zealand Asia Institute, document lui-même issu des recherches financées par Fonterra, New Zealand. 
le «miracle » économique japonais, puis nous observerons comment le statu quo a pu perdurer bien que l'environnement ait changé, en particulier durant l'Uruguay Round, ce qui a eu pour effet de prolonger de deux décennies le régime de l'après-guerre.

Notre principal centre d'intérêt, cependant, est la situation de l'agriculture et des politiques agricoles depuis 2010, les débats en cours et les différents projets de changement. De nouveaux acteurs pénètrent à présent le monde agricole, avec des ambitions diverses. Les représentants des cités industrielles et marchandes se bousculent pour se positionner, tandis que les réseaux alternatifs qui rejettent en partie ces cités ont connu un écho favorable dans l'opinion. L'agriculture japonaise de 2030 sera très différente de celle de 2010. Avec ou sans le «big bang » du TPP, il y aura une nouvelle vie, même si personne ne sait encore clairement à quoi elle ressemblera.

\section{H Le système de l'avant et de l'après-guerre}

Le Japon est à la fois conforme et non conforme aux modèles dualistes des économistes. L'agriculture a effectivement fourni les ressources en capital et en travail pour la croissance du secteur industriel, ainsi que la nourriture des villes en expansion. Mais, dans les premières décennies qui ont suivi la restauration Meiji en 1868, c'est plutôt dans les campagnes que dans les villes qu'a eu lieu la croissance économique.

En fait, beaucoup de fermes familiales ont combiné leur revenu agricole à un revenu tiré de la sériciculture, et de la filature et du tissage de la soie, brouillant ainsi la ligne de partage supposée entre agriculture et industrie (Francks, 1999 ; Smith, 1989). De plus, bien que de nouveaux fronts pionniers agricoles aient été ouverts sur Hokkaido, et plus tard dans les colonies japonaises d'outre-mer, la production s'est surtout accrue grâce aux gains de productivité des exploitations existantes plutôt que suite à l'expansion territoriale - une sorte de « Révolution verte » basée sur des technologies nationales. Ces changements ont eu lieu dans le contexte de petites unités agricoles, qui combinent souvent plusieurs sources de revenu (ibid.).

Dans les années 1930 et 1940, environ $70 \%$ des exploitations familiales exploitaient moins d'une acre de terre. Ces petites exploitations, souvent pauvres et précaires, ont vu leur dépendance vis-à-vis des grands propriétaires s'accentuer. Selon Fukutake (1989), l'agriculture japonaise était alors caractérisée par la petite taille des exploitations familiales, où le travail est principalement effectué à la main, et le système des grands propriétaires, avec la moitié des terres arables louées à des fermiers. « La réforme agraire consécutive à la guerre », note-il, « a libéré l'agriculture d'au moins la seconde de ses caractéristiques majeures » (ibid. : 92). Les forces d'occupation d'après-guerre ont en effet mis en œuvre ce que le général MacArthur prétendait être la réforme la plus ambitieuse - et réussie - depuis celle que les frères romains Gracchus avaient organisée au II ${ }^{\mathrm{e}}$ siècle av. J.-C. ${ }^{2}$. Près de 2 millions d'hectares ont été distribués aux fermiers lors de cette réforme, ce qui a maintenu inchangé la première caractéristique de l'agriculture japonaise : la petite taille des exploitations. En 1952,

2. Dore (1959) voit cela plus en termes de forces sociales locales et de ressources libérées par l'Occupation, mais son évaluation des réformes est globalement positive, autant en termes de démocratisation que de progrès de la cohésion sociale. 
la loi sur les terres agricoles (Agricutural Land Law) a sanctuarisé le modèle des petits exploitants-propriétaires en instaurant des restrictions strictes sur la propriété agricole pour toute personne extérieure au secteur.

Les forces d'occupation voyaient également dans les coopératives agricoles un outil de démocratisation, le pendant rural des syndicats ouvriers dans les villes. Mais, dans l'immédiat après-guerre, la collecte et la distribution de nourriture était une priorité absolue, et elle s'est imposée rapidement comme priorité numéro un. Sur la suggestion du ministère de l'Agriculture, de la forêt et de la pêche (Ministry of Agriculture, Forests and Fisheries, MAFF), les associations agricoles datant de l'époque de la guerre ont été ressuscitées. Presque 14000 coopératives ont été rapidement instituées, en même temps que des organisations départementales et nationales. Fonctionnant en principe « de bas en haut », beaucoup se sont retrouvées en difficultés financières et ont été restructurées, entraînant un renforcement du fonctionnement « du haut vers le bas ». Les coopératives ont été utilisées pour contrer les organisations rurales plus radicales, contribuant ainsi à la formation du «triangle de fer » du Japon de l'après-guerre. Des tentatives de contrôle du prix du riz ont aussi préparé le terrain aux interventions gouvernementales à venir.

La Loi basique sur l'agriculture de 1961 a cherché à promouvoir la modernisation et la mécanisation, ainsi que des gains de productivité, au travers du regroupement d'exploitations, mais sans la volonté politique de revenir sur la réforme agraire. Le ministre du MAFF Agaki déclarait en 1964 : « le temps est venu de reformer le système de fermage et de permettre aux fermiers d'accroître leurs activités. Nous devrions autoriser une corporation publique à acheter, vendre ou louer des terres aux fermiers qui voudraient agrandir la taille de leur exploitation » (cité par Yamashita, 2008a). Le débat a apparemment fait rage au sein du MAFF, et un texte de loi fut rédigé et présenté deux fois, mais rejeté les deux fois.

Les petites exploitations ont alors rapidement adopté la mécanisation et amélioré leur productivité, bénéficiant de généreuses subventions pour acheter des équipements et des engrais auprès d'un secteur industriel en plein essor (Dore, 1978). Fukutake (1989 : 93) remarque :

« Dès le milieu des années 1960, le Japon était un des premiers pays en ce qui concerne la puissance disponible par acre de terre cultivée, une statistique reflétant un investissement excessif, résultant lui-même de la taille minuscule des exploitations soulignée précédemment comme une caractéristique cruciale des exploitations agricoles familiales au Japon, défaut auquel à ce jour on n'a pas trouvé de solution. Le coût de la mécanisation, associé aux augmentations des prix des engrais et des pesticides chimiques, a, de fait, représenté un frein pour les revenus agricoles malgré l'amélioration des rendements. »

Dans le même temps, la relocalisation des usines quittant les centres urbains pour s'installer à la campagne a offert de plus en plus d'opportunité de revenus complémentaires. En 1970, les agriculteurs à plein temps ne représentaient plus que $16 \%$ du total des agriculteurs, ceux dont le revenu était principalement agricole $34 \%$ et ceux dont le revenu était principalement non agricole $51 \%$. Tandis qu'en France les politiques agricoles se concentraient sur les agriculteurs à plein temps ou bénéficiant de revenu principalement agricole, favorisant ainsi une augmentation continue de la taille des exploitations, le Japon a choisi un autre chemin pendant les années fastes de l'après-guerre (Yamashita, 2009). 
Les subventions à la production de riz ont aussi incité les agriculteurs à continuer à produire du riz même en petites quantités. Les coopératives (JA) n'avaient pas particulièrement intérêt à voir diminuer le nombre de petits agriculteurs, ni à privilégier les fermiers à plein temps. Tous pouvaient en être membres ou quasimembres et utiliser leurs services, et tous contribuaient à leur expansion économique et politique. Leur banque, Norinchukin, bénéficiait des dépôts des membres et du paiement anticipé des subventions pour le riz, sommes qu'elles pouvaient placer avec profit sur les marchés financiers. Par ailleurs, les agriculteurs achetaient les intrants et les machines aux coopératives JA grâce à des prêts contractés auprès de Norinchukin. Enfin, les surcoûts de production étaient absorbés par le gouvernement, c'est-à-dire in fine par le contribuable (salarié).

Dans les années 1970, la surproduction de riz, associée au ralentissement de la consommation nationale, a conduit à une politique de diversification basée sur le contrôle des surfaces cultivées et sur des subventions aux agriculteurs produisant d'autres produits que du riz. Les surfaces concernées ont ainsi augmenté régulièrement au rythme de la diminution de la consommation de riz. En 2012, environ 1,1 million d'hectares, soit $40 \%$ des terres rizicoles, étaient concernés par la politique de diversification ${ }^{3}$.

\section{"Repli ou retranchement}

Le Japon a abordé les années 1980 en bien meilleure forme que la plupart des autres pays industrialisés. Les accords avec les syndicats ouvriers sur les hausses de salaires avaient permis de contrôler rapidement l'inflation, et les produits manufacturés japonais inondaient les marchés mondiaux. Les coûts croissants du soutien au monde rural n'étaient pas vraiment un problème aux yeux de la nombreuse classe moyenne urbaine. Au contraire, celle-ci valorisait la qualité de ses produits, soutenait son usage contrôlé des pesticides et des polluants, et appréciait la variété croissante de produits que leurs revenus en augmentation leur permettaient d'acheter plus régulièrement. La politique gouvernementale et l'action des coopératives avaient favorisé la standardisation (Allaire et Wolf, 2004) sur le modèle de la « cité industrielle », mais des marchés importants pour des produits de qualité spécifiques existaient aussi, par exemple dans les rayons alimentaires des grands magasins (ou dans les restaurants et chez les traiteurs).

Cependant, quelques voix commençaient à se faire entendre contre le « triple fardeau » du Japon : les surplus agricoles, les prix élevés au consommateur et les dépenses publiques croissantes, typiques d'un pays développé. À partir de 1980, Keidaren - la fédération des syndicats patronaux - a commencé à réclamer des réformes du secteur agricole et sa libéralisation. Les États-Unis avaient fait pression pour que le Japon libéralise le marché du bœuf et des agrumes pendant les négociations du Tokyo Round du Gatt (General Agreement on Tariffs and Trade) en 1978-1979, et Keidaren craignait des représailles contre le secteur manufacturier (Yoshumatsu, 1998). Elle mit en place un comité sur les politiques agricoles, réclama l'accès à de la nourriture importée meilleur marché pour les usines de transformation

3. Une révolution symbolique a lieu en 2011 quand les ménages ont dépensé plus en pain qu'en riz, signe d'un changement radical de régime alimentaire et de style de vie (source : Asahi shinbun, 16 août 2012). 
alimentaire de ses membres, critiqua l'augmentation des subventions agricoles et commença à réclamer la révision de tout le système de contrôle alimentaire ${ }^{4}$.

JA riposta en instaurant un boycott des produits des industriels partisans des réformes et le MAFF fit pression sur Keidaren pour qu'elle adoucisse un peu ses analyses. La pression des États-Unis fut en revanche plus dure à infléchir. Dans le cadre de l'accord de l'Uruguay Round, le Japon fut contraint, en 1991, de renoncer aux quotas sur le bœuf et les oranges. Aux élections de 1989, après l'annonce de ces mesures, le Parti libéral démocratique (LDP) perdit sa majorité à la chambre haute à cause du vote de protestation du milieu rural $^{5}$, ce qui initia une période d'instabilité politique qui eut des répercussions importantes sur la politique agricole. On était aussi à la veille de l'éclatement de la bulle financière au Japon et de la période connue sous le nom des décennies perdues. Que l'on soit d'accord ou pas avec cette appellation, elle décrit assez bien l'agriculture japonaise et les politiques agricoles dans les années 1990 et 2000.

Le véritable enjeu était bien sûr le riz. Le Japon était d'accord pour réduire de $30 \%$ l'ensemble des subventions domestiques à l'agriculture entre 1986 et 2006, mais refusait obstinément de convertir les mesures de protection du riz en tarifs douaniers. Les officiels déclarèrent même : « Nous n'autoriserons jamais le moindre grain de riz à entrer au Japon. » Un compromis fut néanmoins trouvé en 1994 sous la forme d'un accord qui donnait un accès minimum garanti. En outre, la Loi de contrôle des produits de base fut remplacée par la Loi de contrôle de l'alimentation en 1994. Les représentants politiques du monde rural et le MAFF eurent cependant du mal à obtenir les fonds exceptionnels qu'ils réclamaient et qu'ils considéraient comme nécessaires pour préparer les campagnes de libéralisation commerciale. Une grande partie des 6 milliards de yens (plus 1,2 milliard pour des travaux dans les villes rurales) qu'ils réussirent à obtenir furent en fait investi dans des travaux publics, dont certains d'une utilité très discutable et sans grand rapport avec l'agriculture. Comme le note Aurelia George Mulgan (2006 : 90) :

«Étant donné l'opportunisme fiscal du MAFF, l'URAA (Uruguay Round Agreements Act) n'a pas joué un grand rôle pour empêcher l'expansion de la politique japonaise de soutien et de protection à l'agriculture. En réalité, il s'est accompagné d'une augmentation plutôt que d'une diminution du volume de subventions attribuées au secteur. L'objectif de maximiser les interventions du MAFF s'est en outre traduit par l'ampleur des fonds dilapidés dans des travaux publics inutiles. »

Bien que le niveau de soutien aux prix des produits agricoles japonais ait diminué de plus d'un tiers entre le milieu des années 1980 et le milieu des années 2000, le soutien à la production, mesuré par l'OCDE sous la forme d'équivalent subvention à la production (ESP) et incluant donc les aides directes, s'est effectivement peu réduit. Selon les données de l'OCDE, le soutien, mesuré en pourcentage du revenu agricole, est passé de $66 \%$ en 1986 à un peu moins de $50 \%$ en 2006, faisant du Japon le cinquième pays de l'OCDE en termes d'aide à l'agriculture (OCDE, 2006a). Pour d'autres auteurs, le soutien à l'agriculture serait plus important encore (Shogenji, 2010 ; Yamashita, 2008b).

4. En 1980, le budget du MAFF représentait 8,5\% des dépenses publiques. $65 \%$ de ce budget était consacré à des subventions, principalement destinées à la riziculture (Yoshimatsu, $1998: 340$ ).

5. Ces votes comptent plus que les votes urbains car la carte électorale n'a pas évolué au rythme de l'urbanisation et parce que JA était capable de mobiliser les non-agriculteurs autant que les agriculteurs. 


\section{W Le déclin de l'agriculture japonaise}

Malgré ces soutiens, les difficultés du monde rural se sont accumulées. Les transferts et les mesures palliatives adoptés pour ranimer l'agriculture japonaise n'ont pas pu endiguer, ni même masquer, un déclin irrésistible. Ainsi :

- la production agricole japonaise a perdu près d'un tiers de sa valeur entre le milieu des années 1980 et 2009 ;

- le nombre de fermes « commerciales »- celles de plus de 0,3 hectare réalisant un chiffre d'affaires de plus 500000 yens par an - a aussi été en constante diminution. En 1990, les fermes commerciales étaient deux fois plus nombreuses que les fermes non commerciales. En 2010, le nombre de fermes non commerciales était 1,4 fois plus élevé que celui des fermes commerciales (MAFF, 2010a);

- alors que le nombre de foyers vivant exclusivement d'un revenu agricole à temps plein est resté relativement stable sur la période 1990-2010 - entre 0,42 et 0,48 million -, le nombre de foyers travaillant à temps partiel dans l'agriculture mais ayant un revenu principalement agricole (exploitation dite " type 1 ») et ceux travaillant à temps partiel avec un revenu principalement non agricole (exploitation dite «type 2 ») ont en revanche diminué de plus de la moitié. Cette évolution est, dans certains cas, le résultat de conversion d'exploitations à temps partiel vers des exploitations à temps complet, au moment du départ à la retraite des employés non agricoles ;

- le vieillissement des agriculteurs à temps complet s'est accéléré. En 2010, moins de $15 \%$ d'entre eux avaient moins de 65 ans (Yamashita, 2008b), tandis que plus de $48 \%$ étaient âgés de plus de 70 ans et $31 \%$ avaient plus de 75 ans (figure 5.1). En revanche, seulement $35 \%$ avaient entre 55 et 69 ans, et, surtout, moins de $7 \%$ entre 20 et 39 ans ;

- les emplois hors agriculture auxquels pouvaient autrefois avoir accès les fermiers de type 1 et 2 ont disparu, à la faveur de la relocalisation offshore des manufactures, des fusions administratives et des restrictions dans l'emploi public rural. Les possibilités de revenus complémentaires pour les enfants reprenant l'exploitation sont ainsi devenues très limitées. De fait, beaucoup de ménages agricoles, quel que soit le type, n'ont pas de successeur (MAAF, 2011a);

- la surface totale cultivée a diminué en partie à cause d'un zonage laxiste (figure 5.2). Ainsi, «bien que 1,1 million d'hectares de terres cultivables aient été créés par des travaux publics ou d'autres moyens, quelque 2,6 millions d'hectares agricoles - plus de $40 \%$ des 6,09 millions d'hectares cultivés en 1961 - ont disparu après avoir été abandonnés ou convertis en terrains constructibles ou destinés à d'autres usages. Cela représente environ la surface que le Japon consacre aujourd'hui à la culture du riz » (Yamashita, 2008b). De leur côté, les agriculteurs âgés refusent de vendre ou de louer leurs terres à d'autres agriculteurs par peur de rater une meilleure opportunité, comme en vendant à des constructeurs de centres commerciaux, qui font désormais partie du paysage «normal » de la vie rurale. Ce refus de vendre est encore renforcé par l'existence d'avantages fiscaux liés à la possession d'une terre agricole 6 .

6. Une règle de base souvent mentionnée est le taux d'imposition 10/5/3 : un employé est imposé sur l'ensemble de ses revenus, un travailleur indépendant sur la moitié et un agriculteur sur moins d'un tiers. 


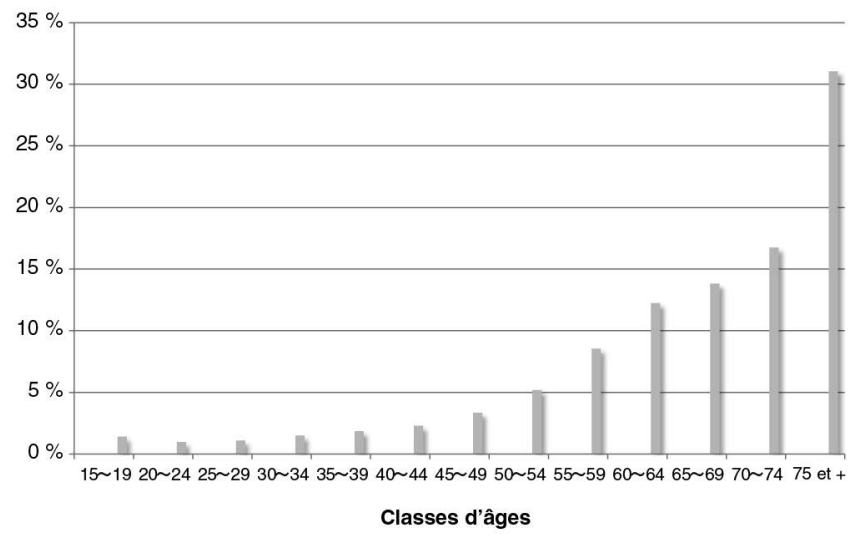

Figure 5.1. Répartition par classe d'âge des agriculteurs travaillant dans des fermes commerciales, 2010.

Sources : MAFF, 2011b.

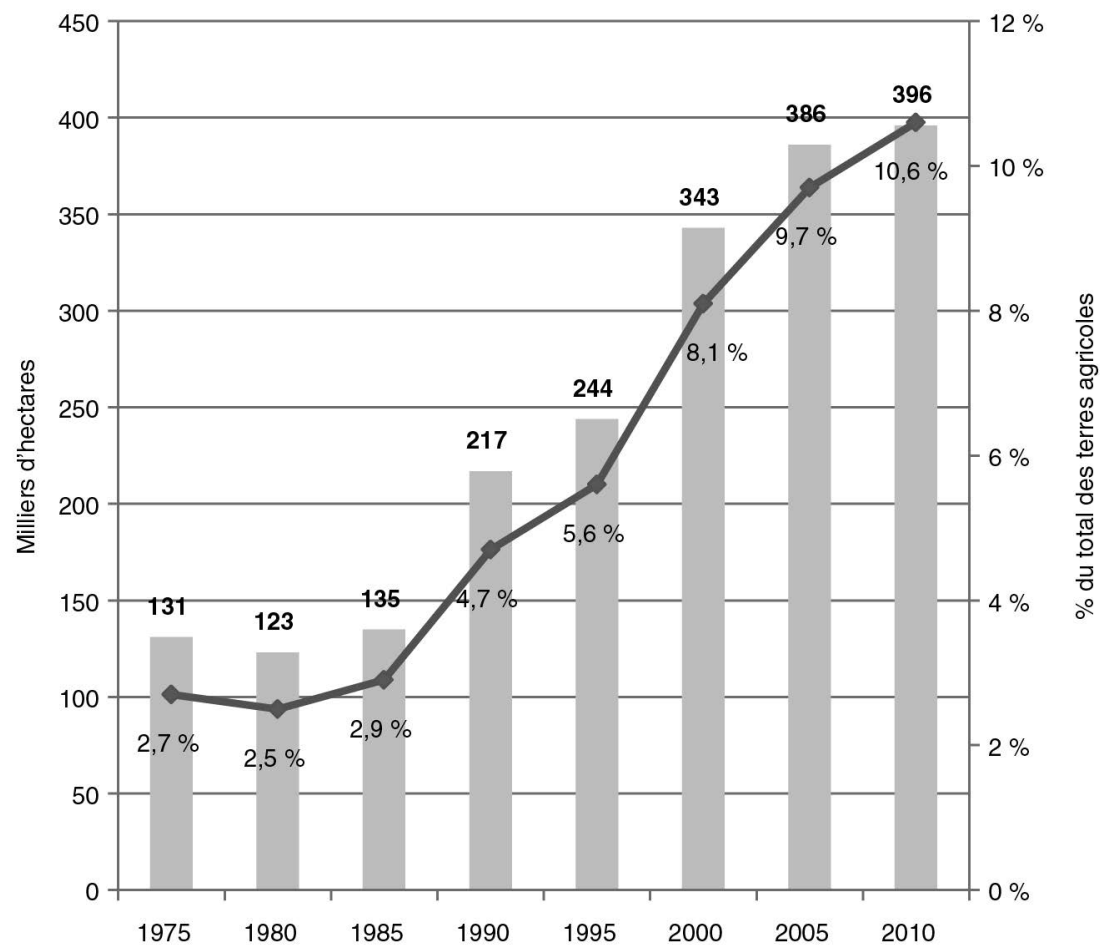

Figure 5.2. Surface de terres agricoles abandonnées (en milliers d'hectares et en \% du total des terres agricoles), 1975-2010.

Sources : MAFF, 2011c. 
Le vieillissement des agriculteurs et l'augmentation des surfaces abandonnées auraient pu donner l'opportunité d'effectuer une redistribution des terres dans le sens d'un agrandissement des exploitations, mais, en 2010, le modèle d'aprèsguerre (et d'avant-guerre) prévalait toujours. Plus de $55 \%$ des exploitations faisaient moins d'un hectare, et plus de $80 \%$ moins de deux hectares (figure 5.3). $14 \%$ des terres étaient détenues par des exploitations de moins d'un hectare, et $30 \%$ par des exploitations de moins de deux hectares. Il n'y a qu'à Hokkaido que les exploitations étaient plus grandes : les exploitations de plus de 15 hectares représentaient $87 \%$ des terres en 2010, contre $15 \%$ dans le reste du Japon (figure 5.4).

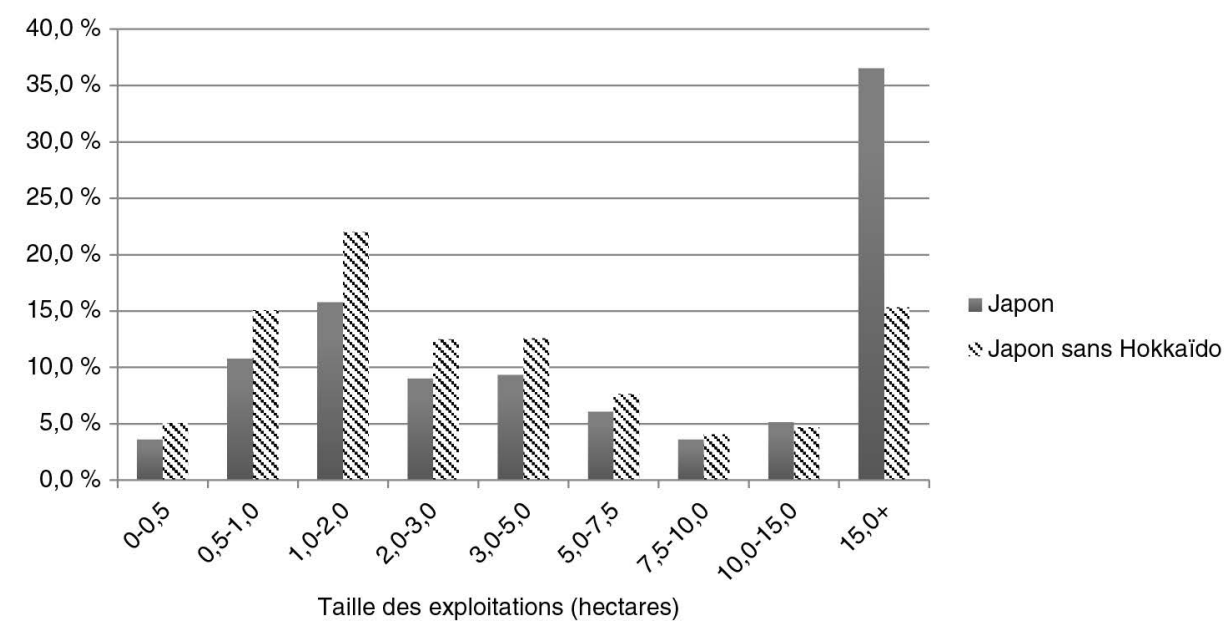

Figure 5.3. Répartition des exploitations par taille (en \% du total), 2010.

Sources : MAFF, 2010b.

Le revenu net, le revenu brut et le revenu disponible étaient fonction de la taille de l'exploitation. Un foyer moyen sur une unité de moins d'un hectare avait un revenu agricole négatif. Il dépendait donc des revenus complémentaires et des subventions gouvernementales pour obtenir un revenu brut et un revenu disponible positif. En revanche, la proportion de revenu complémentaire déclinait quand la taille de l'exploitation augmentait. La partie principale $(79 \%)$ du revenu des «exploitants entrepreneurs » provenait de l'agriculture, alors que cette partie est très faible pour les exploitants « demi-entrepreneurs » ou à temps partiel ${ }^{7}$. Il faut toutefois noter que, bien que les agriculteurs à plein temps aient eu des fermes plus grandes, le revenu des agriculteurs à temps partiel était plus important que celui des agriculteurs à plein temps, ce qui met en évidence l'avantage de ce style de vie (figure 5.5). Les données d'enquête faisaient d'ailleurs apparaître que le nombre de foyers agricoles dépendant des seuls revenus agricoles pour leurs moyens d'existence était assez faible, sans doute guère plus de 400000.

7. Ces différentes catégories sont similaires, mais pas tout à fait identiques, aux types 1 et 2 vus plus haut. 


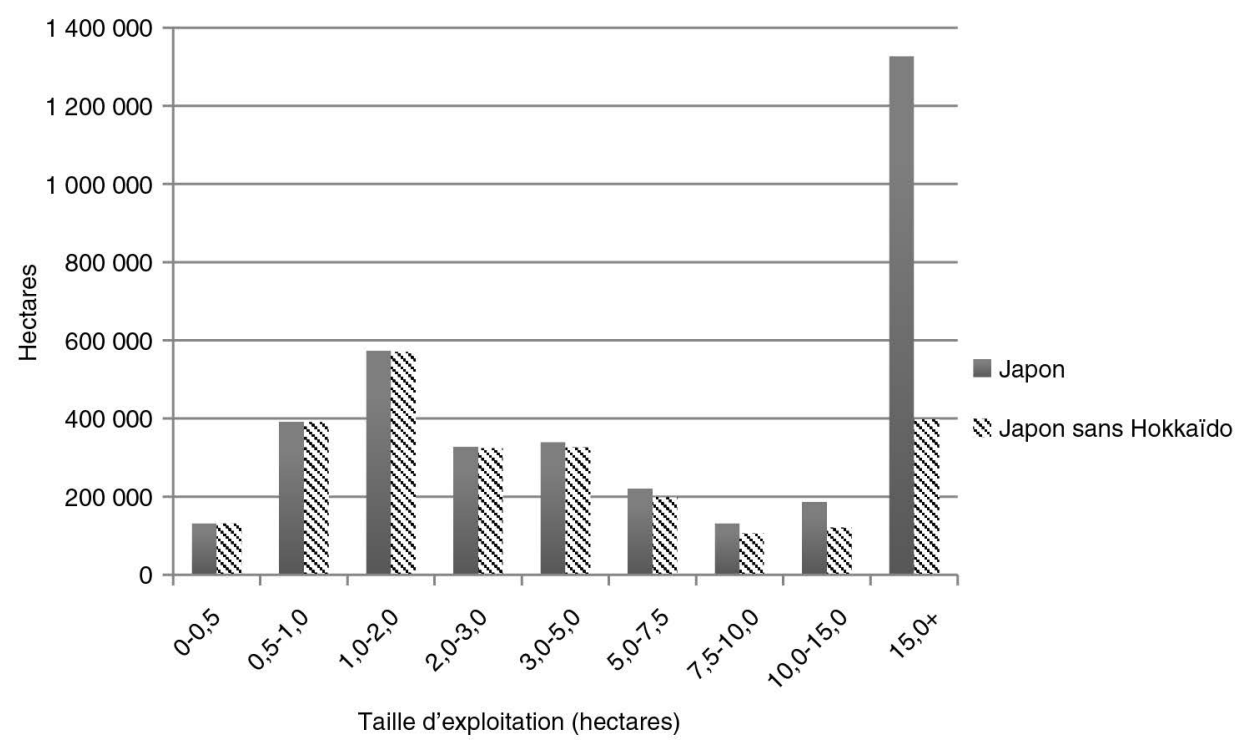

Figure 5.4. Surface totale de terre cultivée par taille d'exploitation, 2010.

Sources : MAFF, 2010b.

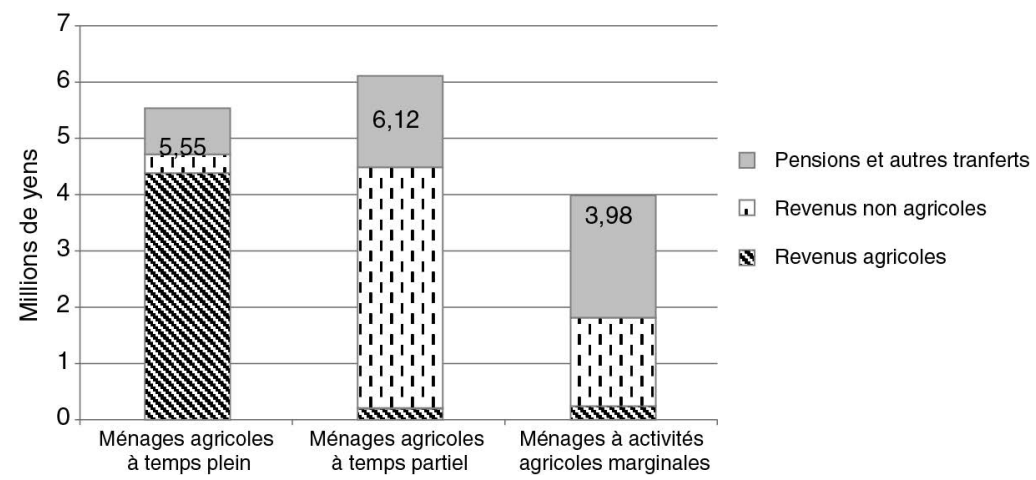

Figure 5.5. Sources de revenus des ménages agricoles.

Sources : MAFF, 2011a.

Bien sûr, des différences existaient selon la production des exploitations. Ainsi, la situation des exploitations pratiquant des cultures fortement utilisatrice de sol, comme la riziculture, se distinguait nettement de celle des exploitations pratiquant des cultures très intensives comme l'horticulture. Ces dernières paraissaient en bien meilleur état d'un point de vue commercial. Leur compétitivité étant garantie par la périssabilité des produits et la proximité des marchés, elles pouvaient attirer des capitaux et des jeunes travailleurs.

Une comparaison rapide de deux secteurs qui semblent très différents - le riz et les produits laitiers - montrera qu'en réalité la production de produits laitiers 
rencontrait - et rencontre encore - un grand nombre de problèmes normalement associés à la riziculture.

En 2010, 72 \% des exploitations commerciales agricoles cultivaient des rizières. La riziculture n'était pas seulement le cour symbolique de l'agriculture japonaise, c'était encore réellement son noyau dur. Cela n'a pas n'empêché que la part du riz dans la valeur totale des productions agricoles japonaises ait chuté de $50 \%$ en 1955 à légèrement moins de $20 \%$ en 2009. En effet, la consommation per capita a pratiquement été divisée par deux entre 1961 et 2010. Depuis 1970, des politiques de promotion de cultures alternatives au riz ont été appliquées pour éviter la surproduction de riz, qui aurait autrement résulté de la réponse des agriculteurs aux prix du riz maintenus à un haut niveau.

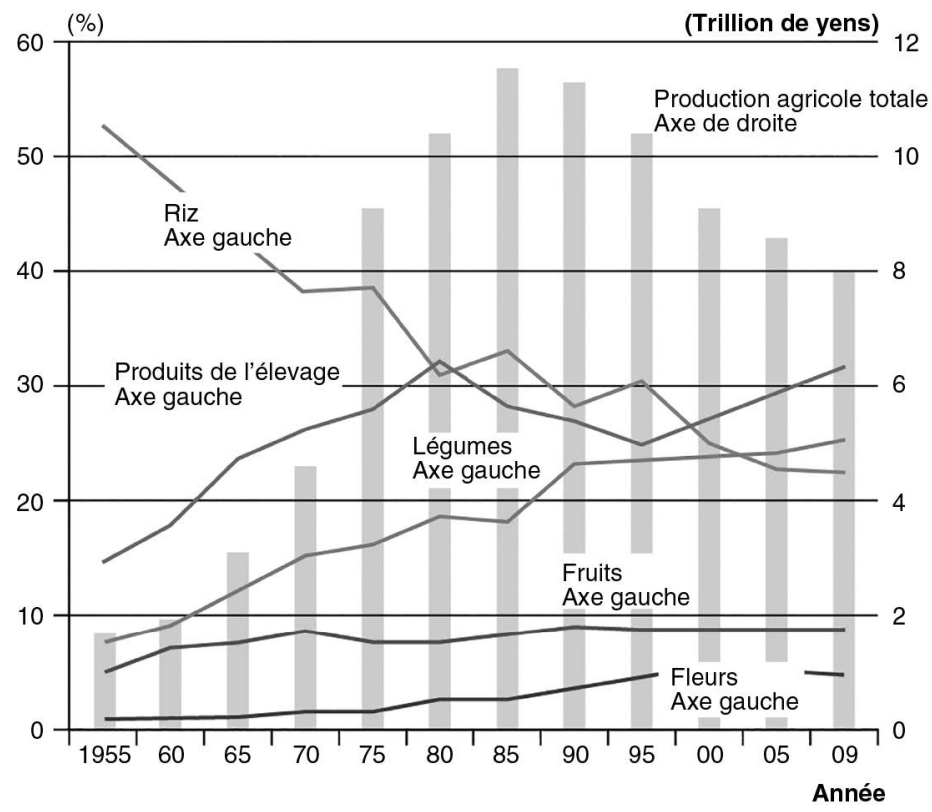

Figure 5.6. Valeur de la production agricole et part des principaux produits, 1955-2009. Source : Kawashima (2011 : 99), à partir des données MAFF, Seisan nōgyō shotoku tōkei, diverses années.

Bien qu'il ait mis en place un programme de stabilisation des revenus agricoles en 1998, le LDP annonça en 2008 que les aides allaient dorénavant se concentrer sur les agriculteurs «professionnels ». Ceci ouvrit une brèche que le parti d'opposition, le Parti démocratique du Japon (DPJ), exploita en promettant des aides au revenu agricole pour tous les agriculteurs, sans distinction de taille, qu'ils soient agriculteurs à plein temps ou à temps partiel. Le DPJ accéda au pouvoir en 2009 et appliqua cette politique, au début comme un programme pilote pour les riziculteurs, puis en l'étendant aux producteurs de blé, d'orge, de soja, de sucre et de pomme de terre à amidon ${ }^{8}$.

8. Dans le cadre de cette politique, les agriculteurs recevaient un paiement fixe de 15000 yens par dixième d'ha de riz planté dans le but de combler l'écart entre un coût de production de référence estimé à 13700 yens pour $60 \mathrm{~kg}$ et un prix de vente de référence de 12000 yens. Un paiement complémentaire pouvait être alloué si le prix moyen aux producteurs descendait en dessous du prix de référence. 
Quand les mesures de protection du riz furent finalement converties en droits de douane, ceux-ci furent fixés à 341 yens par kg. Compte tenu des prix en vigueur en 2012, ce montant correspondait à un droit ad valorem de $534 \%$ sur le riz californien, de $800 \%$ sur le riz thailandais et de $1082 \%$ sur le riz vietnamien. Dans le cadre des engagements pris à l'OMC, des petites quantités de riz étaient cependant importées par l'Agence alimentaire du MAFF avec des droits de douane nuls. Évidemment, les importations commerciales de riz ont été minimales tandis que de petites quantités ont été exportées. La menace d'une libéralisation dans le cadre du TPP était donc bien réelle.

Le débat national sur la réforme agricole et la libéralisation des échanges n'a guère abordé le cas des produits laitiers, sans doute parce que les producteurs de lait sont peu nombreux (20 000 contre 1,6 million de riziculteurs). De plus, le nombre de producteurs était en déclin continu du fait de l'augmentation du nombre de vaches par exploitation et du rendement par vache. À première vue, le secteur des produits laitiers semblait réussir mais, pourtant, beaucoup des problèmes rencontrés par les riziculteurs touchaient aussi les producteurs de lait.

Depuis le milieu des années 1990, la production nationale de lait cru a diminué, passant de 8,5 à 7,5 millions de tonnes ${ }^{9}$. Le secteur était partagé en deux, avec un peu plus de la moitié du lait produit sur Hokkaido, dans des unités de presque 70 vaches en moyenne, destiné prioritairement $(76 \%)$ à la transformation, et un petit peu moins de la moitié dans le reste du Japon, dans des unités de 35 vaches en moyenne, principalement $(88 \%)$ destiné à la consommation sans transformation. Le déclin observé depuis les années 1990 correspond à une diminution notable de la production en dehors d'Hokkaido, qui reflète la diminution de la consommation de lait sous forme de boisson. Cette division du secteur en deux parties, avec des coûts de production significativement moindres sur Hokkaido que dans le reste du pays, était maintenue grâce à des quotas de production régionaux accordés aux associations régionales membres de l'Association japonaise des produits laitiers, ainsi qu'à une subvention au lait destiné à la transformation, qui compensait la différence de prix par rapport au lait à boire. Un accord stipulait que le lait d'Hokkaido pouvait cependant être utilisé comme boisson sur Honshu, pour des raisons sanitaires comme cela s'est produit après les désastres de Tokohu et Fukushima. Environ 4 millions de tonnes de produits laitiers par an (base équivalent lait) étaient importées au Japon. Destinés à la transformation, ils étaient sujets à des tarifs et des quotas par tarifs.

Si une expansion de la production doit advenir quelque part, ce sera sur Hokkaido, mais rares sont ceux qui croient possible un développement significatif. Les acteurs industriels mettent en avant les incertitudes qui freinent les investissements. Or plus la taille de l'exploitation augmente, plus les risques sont importants. Une des incertitudes concerne la volatilité des prix de l'alimentation animale, vu qu'une grande quantité provient de l'importation ${ }^{10}$. Les différentes sortes d'aides gouvernementales sont elles aussi appelées à se réduire. De fait, beaucoup des problèmes liés au vieillissement des exploitants et à leur succession sont les mêmes dans le secteur

9. Les données sur le secteur laitier proviennent de Alic (2012) et de Hokkaido shitei seinyū seisansha dantai et Hokuren (2012).

10. Les aliments du bétail représentent $30 \%$ des coûts de production à Hokkaido. Cette part est plus importante dans le reste du Japon. 
du riz et dans le secteur des produits laitiers, même dans les grandes exploitations d'Hokkaido (voir Nōrin suisan chōkikin'yu kyōkai, 2005). Il n'est donc pas surprenant que les producteurs aient fait du lobbying pour que les mesures de stabilisation du revenu agricole s'appliquent aussi aux producteurs laitiers (Kobayashi, 2011).

\section{$\downarrow$ Des réponses politiques incohérentes et une nouvelle menace extérieure}

Autrefois, le Japon semblait offrir un modèle de développement intéressant pour les pays à exploitations agricoles de petite taille n'ayant pas connu la révolution agricole. Mais le Japon a ensuite rencontré les problèmes communs à tous les pays développés et, sous certains aspects, de manière encore plus aiguë du fait de ses structures propres. Le déclin de l'agriculture a été si intense que plus personne ne s'est opposé à une réforme, du moins ouvertement, mais avec des projets et des calendriers très différents.

Ainsi, les partisans d'un changement progressif et ceux d'un changement radical ont des visions totalement différentes. Jusqu'à 2013, le camp des premiers était en position de force. Constitué du «triangle de fer » des politiciens de l'électorat rural - surtout membres du LDP -, du MAFF et des JA, ainsi que des universitaires liés à eux, ils menaient leurs politiques à l'abri du regard du public, en vertu d'un environnement réglementaire complexe et d'un manque général d'intérêt pour la question agricole. Coupes budgétaires mises à part, leurs scénarios et leurs plans de réforme progressives n'étaient guère menaçants, car ils concernaient un monde avec lequel les outsiders (les urbains) avaient peu de relations directes.

La révision de la Loi de base sur l'agriculture, en 1999, s'inscrit dans cette perspective de réformes progressives. La nouvelle mouture de la loi reconnaît que la politique doit être nuancée en fonction des besoins locaux, ceux des villages de montagnes étant très différents de ceux des villages proches des villes. Elle reconnaît aussi un rôle aux collectivités locales dans l'élaboration et la mise en œuvre des politiques. Malheureusement, ce programme fut mis à mal par la fusion des collectivités locales également initiée en 1999. Leur nombre fut presque divisé par deux, de 3250 à 1750 . En outre, les fusions furent plus importantes en zones rurales, de même que les pertes d'emploi dans les services agricoles. La capacité des collectivités à engager des politiques localement différenciées fut donc amoindrie au moment même où de nouvelles demandes leur étaient adressées (Shogenji, 2010).

Le Plan de base pour l'agriculture de 2000 réaffirmait l'objectif d'augmenter le niveau d'autosuffisance alimentaire, mesuré sur une base d'apport calorique, de 40 à $45 \%$ à l'horizon 2010, sans toutefois de mesures réalistes pour atteindre ce but et en maintenant les politiques de diversifications. Il incluait aussi la promotion de l'industrie « sextaire » (rokuji sangyo - industrie primaire $\times$ industrie secondaire $\times$ industrie tertiaire) renforcée par une nouvelle loi passée en 2011. Cela signifiait établir un lien entre la production agricole (industrie primaire), la transformation (industrie secondaire), et la commercialisation et le marketing, y compris vers l'international (industrie tertiaire), mais dans une logique allant de la production vers 
la consommation plutôt que l'inverse. Présenté comme une sortie de crise pour les villages agricoles, ce projet était cohérent étant donnée la multiplication des sources de revenus qui résultait de l'augmentation du nombre d'agriculteurs à temps partiel. Des propositions visant à accroître la taille des exploitations étaient aussi avancées, mais surtout par les organisations agricoles locales. Enfin, la multifonctionnalité de l'agriculture était évoquée (MAFF, 2010b). Cette approche gradualiste avait toutefois peu d'impact sur le déclin de l'agriculture japonaise. Shogenji (2010) souligne ainsi la poursuite d'une «triple détérioration »: de la politique agricole, de la production agricole et des villages ruraux.

C'est à ce moment que fut placée une bombe à retardement. En octobre 2010, le Premier ministre Kan annonça que le Japon envisageait sérieusement de participer au TPP (Trans-Pacific Partnership, Partenariat trans-pacifique en français ${ }^{11}$ ). Les opposants à ce traité réagirent immédiatement. Particulièrement présents au JA et au MAFF, ils produisirent nombre de publications remplies de déclarations faisant sensation, démontrant que la participation au TPP ne détruirait pas seulement l'agriculture japonaise, mais aussi l'identité même du Japon, dont les racines seraient paysannes. De nombreuses publications furent rapidement éditées (voir Nobunkyō, 2010) regroupant des avis allant du scepticisme à l'opposition catégorique. Une pétition anti-TPP recueillit 11 millions de signatures. Le MAFF publia des calculs basés sur les données du GTAP (Global Trade Analysis Project) qui annonçaient que l'adoption du TPP se traduirait par la destruction de la moitié de la production agricole japonaise et de $90 \%$ de la production de riz (Honma, 2012).

Bien que moins rapides à se mobiliser, les partisans d'une réforme radicale finirent toutefois par faire entendre leurs voix. Ils construisirent leur propre modèle, toujours sur la base des données du GTAP, mais avec d'autres hypothèses. Leurs analyses et leur discours mettaient en avant le fait que la participation au TPP ne serait pas entièrement négative pour l'agriculture, et dénonçaient en revanche la prise en otage du futur économique et politique du Japon par le lobby agricole. Ils affirmaient que c'était le modèle politique défendu par le lobby agricole qui risquait de détruire l'agriculture japonaise, que, si les réformes agricoles étaient menées à bien, le Japon deviendrait un exportateur non négligeable de produits agricoles, et enfin que le moyen le plus efficace de mettre en place les réformes nécessaires était la participation au TPP. Le titre de l'ouvrage d'Asakawa (2012), « Le Japon va devenir la plus puissante des nations agricoles du monde grâce au TPP », donne un exemple faisant sensation, pour ne pas dire extravagant, de cette manière de voir.

Le débat sur l'agriculture sortit ainsi des marges du débat public, du domaine réservé de quelques obscurs spécialistes et d'ardents défenseurs des intérêts acquis, pour devenir, dans des médias d'audience populaire, un sujet sur lequel beaucoup de gens donnaient leur point de vue selon des perspectives très variées. Une des raisons était que les intérêts du secteur agricole n'étaient pas les seuls en jeu. Une autre raison était que l'opinion publique redécouvrait les problèmes rencontrés par le secteur agricole et la possibilité que ce secteur ne soit plus un

11. Comme son nom l'indique, cet accord vise à renforcer l'intégration économique trans-pacifique entre, d'une part, les États-Unis et ses partenaires de l'Alena (Canada et Mexique), et d'autre part les pays riches en ressources que sont l'Australie, la Nouvelle-Zélande, le Chili, le Pérou, Singapour, la Malaisie, le Viêt-Nam et le Brunei. Les négociations ont été lancées en mars 2010. 
gouffre à ressources immuable mais puisse au contraire se convertir en une partie dynamique de l'avenir du Japon.

C'était la position du Premier ministre Abe. À la suite de sa victoire en décembre 2012 aux élections de la chambre basse, le gouvernement Abe prit la décision de participer aux négociations du TPP. Abe présenta cela comme un élément clef de la « troisième flèche » de la stratégie de renouveau économique, connue à présent sous le nom de « Abenomiques », qui visait à restaurer la puissance et la vitalité économique du Japon. Les deux « premières flèches » étaient, respectivement, l'expansion monétaire et l'incitation fiscale, la « troisième flèche » consistait, elle, en un " pack de croissance » visant à encourager la croissance en stimulant l'investissement privé au moyen d'une série de mesures, dont une déréglementation étendue et une internationalisation accrue de l'économie à travers le TPP et d'autres initiatives commerciales (Aso, 2013).

Le TPP étant présenté comme un élément d'une stratégie globale de revitalisation de l'économie japonaise, les ministres du gouvernement Abe cherchèrent à déplacer le fond du débat sur les implications du TPP pour l'agriculture japonaise. Un HautCommissariat à la vitalisation de l'agriculture, de la forêt, de la pêche et des régions rurales fut mis en place en 2013 , avec la tâche d'élaborer une stratégie permettant de : - doubler le revenu des agriculteurs et des ruraux en dix ans ;

- doubler les exportations agricoles pour atteindre 1 milliard de yens en 2020 ;

- réduire dans les dix ans les coûts de production de $40 \%$ ans au moyen d'un agrandissement des exploitations avec l'aide d'un organisme de médiation des terres agricoles (créé à cet effet dans chaque préfecture);

- doubler le nombre de nouveaux agriculteurs, et d'augmenter à 50000 en dix ans le nombre d'exploitations agricoles commerciales (Sakuyama, 2014).

La volonté de traiter l'agriculture comme un secteur industriel s'exprima au sein du MAFF par la création d'une division de l'industrie alimentaire (shokuryo sangyo kyoku). Cette création émettait d'une part un signal clair en direction des réformateurs du ministère et montrait d'autre part que le pilotage de la réforme s'effectuait à l'extérieur du ministère, dans le bureau même du Premier ministre.

En février 2015, fort d'une nouvelle victoire électorale, l'administration Abe lança un premier assaut contre « la forteresse JA ». L'opinion générale pensait pourtant que cela n'arriverait jamais. Avec presque 10 millions de membres - dont plus de « membres associés » (non engagés dans l'agriculture) que d'agriculteurs - JA représentait un pouvoir électoral crucial. Mais JA apparaissait aussi comme plus dédié à la défense des intérêts acquis qu'à la promotion de changements favorables à l'agriculture.

En fait, l'agriculture n'était plus l'activité majeure de la plupart des 700 coopératives. Une enquête de 2014 portant sur 482 coopératives montrait ainsi que :

- pour les deux tiers d'entre elles, moins de $10 \%$ de leurs prêts étaient destinés à l'agriculture ;

- les profits liés aux ventes de produits agricoles étaient plus importants que ceux liés à d'autres produits pour seulement neuf d'entre elles (Shukan daiyamondo, 29 novembre 2014 : 68-75);

- la majorité d'entre elles perdaient de l'argent sur leurs activités agricoles et compensaient ces pertes par des activités non agricoles, en particulier financières ; 
- ces profits s'étaient eux-mêmes amenuisés au fur et à mesure que les retraités retiraient leurs économies et transmettaient leurs actifs à leurs enfants urbains. Les fonds de la mutuelle d'assurance-vie des JA avaient de ce fait baissé de $35 \%$ entre 2001 et 2011 (ibid.).

La politique d'Abe imposait les changements suivants à JA :

- d'ici à 2019, l'organisation syndicale centrale (Zenchü) devait devenir une entreprise distincte (une shadan hojin) et perdre ses fonctions de supervision des coopératives individuelles ;

- ses fonctions d'audit devaient être externalisées, les coopératives individuelles pouvant dès lors choisir d'autres auditeurs si elles le désiraient ;

- les coopératives individuelles n'avaient plus à payer de cotisation à Zenchü (environ 8 milliards de yens par an $)^{12}$;

- la branche entrepreneuriale de JA (Zenno) devrait être reformée pour une entrée en bourse ${ }^{13}$;

- la majorité des directeurs des coopératives devaient être des exploitants agricoles professionnels.

L'intention clairement affichée était donc de donner plus de poids aux coopératives individuelles, de leur offrir de nouveaux choix en faisant jouer la concurrence et d'encourager l'initiative locale.

Ces propositions sont à mettre en lien avec un plan visant à abolir la politique de diversification et de réduction des surfaces cultivées. Les changements apportés au JA ont toutefois été, inévitablement, le résultat d'un compromis. Le bruit a couru qu'on avait donné le choix à JA entre des changements concernant les conditions d'adhésion et des changements concernant les fonctions de l'organisation, et que JA avait choisi la deuxième option ${ }^{14}$. Il y avait assez d'ambiguité dans ces mesures pour que certains observateurs doutent de leur capacité à apporter de réels changements, mais il y avait aussi la menace de mesures beaucoup plus ambitieuses si les premières restaient sans effets.

Les décisions radicales prises en février 2015 furent mises en place à la fin d'une période où l'attitude adoptée par le Japon dans le cadre des négociations du TPP faisait sérieusement douter les observateurs extérieurs de la volonté du gouvernement Abe de mener à bien cet élément de la «troisième flèche » des Abenomiques. Dans les négociations du TPP, le Japon s'était montré acharné à la défense des « cinq produits sacrés » que sont le riz, le blé, le bœuf et le porc, les produits laitiers et le sucre. À l'heure où nous écrivons, le résultat à attendre de ces négociations est encore loin d'être clair. Le Japon se rapproche toutefois peu à peu d'une position dans laquelle la protection douanière du riz, du blé et du porc serait réduite mais pas éliminée, avec des mécanismes de sauvegarde qui autoriseraient cette protection

12. La suppression de ces versements privait Zenno des fonds nécessaires au lobbying mais bénéficiait aux coopératives individuelles et aux agriculteurs. La décision était donc une manœuvre politique bien calculée (Nikkei shimbun, 12 février 2015).

13. Si Zenno était transformée en entreprise par action, elle deviendrait la septième plus grande entreprise de commerce du Japon, compte tenu d'un chiffre d'affaires de 5 milliards de yens en 2013 (Shykan daymondo, 20 novembre 2014 : 52). Norinchukin Bank et le Fonds mutualiste de JA deviendraient les deuxièmes entreprises dans, respectivement, le secteur bancaire et le secteur des assurances-vies.

14. Nikkei shimbun, 10 février 2015. 
à être relevée aux niveaux antérieurs si les volumes d'importation dépassent une certaine quantité.

Quels que soient les résultats du TPP, la menace ou la possibilité d'un tel accord ont attiré l'attention du public sur l'agriculture japonaise, et suscité et approfondi les propositions pour le changement. Cinq années de fièvre, ayant débuté par une violente offensive contre le TPP, ont ironiquement ouvert la porte au changement bien plus rapidement que quiconque aurait pu l'imaginer au début. À partir d'une situation dans laquelle l'agriculture était sur la défensive, un nouveau discours a émergé pour promouvoir une « agriculture forte » dynamisée par de nouveaux entrants et de nouveaux investisseurs poursuivant leurs propres objectifs. C'est vers ce discours que nous nous tournons à présent.

\section{Quel genre de renouveau?}

Derrière la façade apparemment immuable que présente le Japon aux négociations du TPP, de nombreuses transformations sont à l'œuvre dans l'agriculture japonaise. La nouvelle Loi agricole de 2009 a initié un processus de réforme des conditions d'accès à l'activité agricole. Ce processus s'est fortement accéléré en 2014 quand l'Organisme de médiation des terres agricoles (couramment appelée la Banque agricole) a acquis le rôle d'intermédiaire entre ceux qui veulent louer des terres agricoles et ceux qui veulent en mettre à disposition. Les durées de bail ont été simultanément étendues de 20 à 50 ans.

Les entreprises de la grande distribution s'étaient déjà préparées à une ouverture accrue de l'activité agricole. L'enseigne Aeon, qui possède 1500 magasins de détail dans tout le pays, a annoncé qu'en 2015 la proportion de légumes vendus sous sa propre marque passerait de 4 à $20 \%$, ces légumes étant issus d'exploitations directement gérées par l'enseigne ou d'exploitations sous contrat. Elle a également annoncé que les exploitations détenues en propre auraient en moyenne 15 ha et formeraient un total d'au moins $500 \mathrm{ha}^{15}$. Selon ces annonces, Aeon deviendrait le premier exploitant agricole du pays. Seven \& I Holdings a aussi annoncé qu'elle triplerait la quantité de fruits et légumes qu'elle vend sous sa propre marque avec de nouveaux des produits provenant de ses propres exploitations ou d'exploitation sous contrat. La chaîne d'épiceries Lawson a adopté une approche légèrement différente. Elle envisagerait de renforcer ses liens avec de grands producteurs agricoles, considérant que, au Japon, les entreprises extérieures au secteur agricole ont de piètres résultats quand elles se lancent directement dans l'agriculture.

De leur côté, les institutions financières se sont précipitées pour procurer les fonds nécessaires aux nouveaux investissements dans l'agriculture. Les banques nationales, tout comme les banques régionales, ont créé des fonds pour des projets dans l'industrie «sextaire ». À la recherche de meilleurs rendements que celui des bons du trésor japonais, des compagnies d'assurance-vie japonaises ont également annoncé 
leur intention d'investir dans des secteurs « de croissance », y compris l'agriculture ${ }^{16}$. JA elle-même a commencé à passer des accords avec des compagnies non agricoles pour développer ses activités dans la production agricole, la transformation, la logistique et la restauration ${ }^{17}$.

Les grandes compagnies industrielles se sont elles aussi hâtées de mettre en place des départements agricoles. Cela concerne en particulier la quasi-totalité des grandes compagnies électroniques, qui voient dans la gestion des données en temps réel et les systèmes de contrôle automatisés une nouvelle frontière d'activité. Elles espèrent mobiliser le concept de «ferme des technologies de l'information » (IT farming) pour construire une industrie d'exportation. C'est en partie l'intérêt manifesté par Google, Amazon, Microsoft et Phillips pour le secteur agricole qui a déclenché ce mouvement. La baisse spectaculaire du coût d'utilisation des données agricoles stockées sur le cloud fait espérer une amélioration de l'efficacité et de la stabilité de la gestion des exploitations. Environ cinquante grandes entreprises du secteur des technologies de l'information participent à un projet dédié à « la prochaine génération d'agriculture » et porté conjointement par Nippon Keidanren et JA. De son côté, Toyota a mis au point sa méthode kaizen pour le riz dans le but de réduire de $25 \%$ les coûts en intrants et de $5 \%$ au moins le coût en travail (tout en offrant des salaires comparables à ceux du secteur industriel), et donc d'abaisser les coûts de production du riz à 100 yens le kilo. Elle l'a expérimentée sur ses propres terres et créé une filiale pour diffuser ses méthodes ${ }^{18}$.

Ceci n'a pas eu lieu qu'au Japon. À Dà Lat, au Viêt-Nam, les compagnies japonaises ont renforcé leur présence au moyen d'accords locaux pour augmenter la qualité et la productivité des produits agricoles, en vendant les produits avec un label de qualité japonais dans le supermarché Aeon Mall de Hô-Chi-Minh ville ou en les exportant vers Hong Kong ou le Japon ${ }^{19}$. Il y a de plus en plus d'opportunités pour ce type d'affaire en raison des nombreuses inquiétudes concernant la sûreté des produits alimentaires, en particulier de ceux venant de Chine. Toyota Tsusho, la filiale de négoce de Toyota, est partie prenante de l'opération de Dà Lat, et d'autres grandes compagnies de négoce japonaises sont impliquées dans d'autres parties du monde.

Le gouvernement a mis en place des prêts et des incitations fiscales pour attirer les jeunes dans l'agriculture. Ces mesures n'ont eu d'abord aucune efficacité, le problème principal demeurant celui de la formation (Kobari, 2012). En réponse à ce problème, des structures d'appui ont été créées, et des formations initiales et continues ont été mises en place pour aider ceux souhaitant devenir exploitant ou salarié agricole. Beaucoup de couples dotés d'une formation universitaire cherchent à devenir des exploitants agricoles propriétaires dans le but de changer leur vie et celle de leurs enfants. Les universités sont aussi confrontées à de plus en plus de candidats pour les études agricoles, ce qui les oblige à renforcer leur département d'agriculture et à acheter de nouvelles terres agricoles ${ }^{20}$.

16. Les banques privées autres que JA ne représentaient que $15 \%$ du financement de l'agriculture en mars 2015. Nikkei shimbun, 27 janvier 2014, 31 janvier 2015, 3 mars 2015.

17. Shükan daiyamondo, 29 novembre 2014.

18. Nikkei shimbun, 5 avril 2014, 25 janvier 2015.

19. Nikkei shimbun, 5 mars 2015.

20. Nikkei Weekly, 4 juin 2012. 
Comme on le voit, l'agriculture apparaît maintenant comme une nouvelle industrie dotée d'un potentiel de croissance. Les chaînes de valeur agricoles sont en cours de réforme, avec ou sans JA, et se développent à l'international. Une partie des idées proviennent de l'étranger. L'expérience française, combinant remembrement des terres et maintien du statut familial des exploitations agricoles, a ainsi attiré l'attention japonaise. Mais ce sont les Pays-Bas qui attirent le plus d'attention, en particulier des entreprises extérieures au milieu agricole. Harada (2011) souligne que, malgré sa petite taille, la Hollande exporte pour 80 milliards de dollars de produits agricoles : si la Hollande peut le faire, pourquoi pas le Japon?

Ce nouveau discours est celui de « l'agriculture forte »- une agriculture sur le pied de guerre et non pas sur la défensive. Les initiatives soutenant ce discours sont mises en avant. Elles vont dans le sens d'un alignement renforcé de l'agriculture sur le secteur industriel et d'une internationalisation accrue, en capitalisant, d'une part, sur la popularité de la cuisine japonaise à l'étranger, d'autre part, sur la réputation de qualité et de sûreté acquise par l'industrie manufacturière.

Mais il existe aussi un autre discours porté par ceux regardant l'agriculture comme un nouveau projet favorable à l'environnement et aux personnes, un projet centré sur le local et non sur le modèle industriel. Il est apparu dans les médias dominants après le triple désastre du 11 mars 2011 (tremblement de terre, tsunami, accident nucléaire) avant d'être marginalisé par le discours de l'agriculture forte lié à l'Abenomics. Cet autre discours circule néanmoins dans les réseaux sociaux qui relient les producteurs régionaux avec les restaurants cools et les consommateurs des grandes villes, et au sein des circuits de commercialisations des produits de terroirs et des produits sans ou avec peu de pesticides. On le retrouve aussi chez ceux promouvant le retour à la terre. Ce discours se construit en partie en rejet du discours dominant.

Allaire et Wolf (2004) distinguent trois logiques (ou mythes) d'innovation qu'ils appellent standardisation, décomposition et identité. La standardisation, une logique linéaire associée à l'industrialisation, a, ces dernières années, laissé la place aux deux autres logiques porteuses de différenciation et, de fait, de qualité. La logique de la décomposition est basée sur une approche réductionniste. Elle s'appuie sur des bases de données informationnelles qui, d'une part, rendent compte dans le détail de l'évolution du comportement des consommateurs et, d'autre part, fournissent des informations sur la composition et les attributs des produits qui peuvent être utilisés pour proposer rapidement des produits nouveaux et différenciés. La logique de l'identité, au contraire, «valorise les origines, les modalités particulières de production ou les engagements religieux, éthiques ou politiques. Les concepts intégrateurs de tradition, de communauté ou de territoire sont mobilisés [...] les produits identitaires font référence à une esthétique de l'élégance naturelle qui s'oppose à la standardisation des produits industriels » (Allaire et Wolf, 2004 : 444).

Au Japon, à côté de ces deux logiques de différenciations, existe une logique de néo-standardisation. La petite agriculture de l'après-guerre, bien que hautement mécanisée, insérée dans le dispositif de collecte et de distribution des JA, n'était pas totalement standardisée, du moins pas au regard de la logique industrielle du toyotisme. C'est ce qui est maintenant en train de se passer avec le regroupement des petites exploitations en unités plus grandes de 10 à 15 ha - encore petites au regard des standards internationaux - et l'application des concepts d'organisation 
industrielle, tel que la très symbolique approche kaizen de Toyota (amélioration constante).

En même temps que la logique de différentiation, opère une logique d'intensification. Les technologies de l'information et les méthodes du big data sont appliquées à des usines horticoles. L'industrie des suppléments alimentaires est aussi en pleine expansion. Et la logique identitaire s'exprime dans les réseaux de restaurants et de bars, comme nous l'avons souligné. Ces deux logiques inhibent la logique de décomposition. Fujimoto (2006) affirme que la compétitivité de l'industrie japonaise est construite sur une logique intégrale et ne s'accommode que difficilement de la logique modulaire, particulièrement dans le secteur des technologies de l'information. Whittaker et al. (2016) défendent l'idée selon laquelle le récent renouveau de plusieurs grandes entreprises industrielles repose sur des technologies intégratives, réduisant l'usage des technologies modulaires ou les mobilisant comme composantes de systèmes plus larges. Il est possible que la même logique soit appliquée aux produits issus de l'agriculture et aux technologies associées, par exemple dans le domaine des biotechnologies.

Selon la théorie des conventions, le prix est la mesure courante de la valeur s'il n'y a pas d'incertitude sur la qualité. Dans ce cas, les différences de prix reflètent les différences de qualité. Mais si les prix ne peuvent pas refléter à eux seuls la qualité, d'autres conventions de qualité doivent être établies, impliquant des formes de coordination domestique, industrielle ou civique (Ponte et Gibbons, 2005). De fait, l'importance croissante des autres conventions de qualité générée par le «tournant de la qualité » dans le domaine alimentaire conduit à une coexistence conflictuelle de multiples formes de coordination (Allaire et Boyer, 1995, Introduction). Tel est le cas pour le Japon. Il y a toujours multiplicité des formes de coordination et des conventions, mais la forme dominante industrielle-marchande laisse la place à la diversité, avec d'un côté des formes industrielles-marchandes intensifiées, de l'autre des formes domestique, et dans les deux des éléments de convention civique.

Dans sa version intensifiée, la forme industrielle-marchande fait appel au label « fait au Japon » dont la force a été construite par les entreprises industrielles. Alors qu'elles cherchent à exploiter cette force, les nouvelles entreprises de l'agrobusiness qui exportent vers l'Asie et ailleurs devront faire face à des imitateurs, y compris frauduleux, qui affaibliront la valeur de leur marque. Elles devront trouver de nouvelles façons de signaler la qualité qu'elles affirment avoir, et cela supposera de nouveaux investissements et la construction de nouvelles alliances. La coordination domestique, utilisée par ceux opposés à la logique industrielle-marchande intensive, ne pose pas les mêmes problèmes car les réseaux de coordination sont interpersonnels et directs. Mais ces caractéristiques peuvent les empêcher de s'étendre. Dans les deux cas, ils existent de nombreux sujets non abordés par les nouveaux discours, en particulier par celui de « l'agriculture forte ». Il y a aussi de nombreux manques dans notre capacité à quantifier les changements proposés par ces discours. Les décideurs politiques et ceux engagés dans la construction d'une nouvelle agriculture pour le Japon pourraient réduire leur temps d'apprentissage en s'intéressant aux recherches induites par la publication de La grande transformation de l'agriculture il y a vingt ans (Allaire et Boyer, 1995) et aux textes réunis dans cet ouvrage.

Traduit de l'anglais par Laure Cordesse 



\title{
Chapitre 6 \\ Coévolution des pratiques agricoles et du mode d'usage de l'eau à Almeria (Andalousie)
}

\author{
A. Buchs, V. BOISVERT
}

En se référant au cadre analytique du « mode d'usage de l'eau » local comme traceur des dynamiques d'aménagement et des changements agraires, ce chapitre retrace l'évolution du modèle agricole du Campo de Dalías (province d'Almeria, Andalousie) fondé sur une agriculture «forcée ». Aujourd'hui dévolu à la production horticole sous serres orientée vers l'export, ce modèle repose sur une nature entièrement façonnée par la technique visant à l'émanciper de la saisonnalité et de la disponibilité des ressources naturelles.

La domestication de l'eau a été initialement motivée par des objectifs politiques : l'occupation d'un espace hostile déserté par les populations grâce à la mobilisation des ressources en eau et à l'édification de réseaux d'irrigation. Cet exemple est emblématique des aspirations technicistes de l'ère franquiste qui, dans ce cas, ont transformé un quasi-désert en périmètre irrigué. Par la suite, l'enjeu est devenu essentiellement économique : entretenir le modèle d'agriculture intensive d'exportation extrêmement rentable. L'analyse historique du modèle agricole almérien permet de montrer en quoi il est autochtone (Roux, 2010) et idiosyncrasique, puisqu'il se distingue à la fois des grands récits relatifs aux mutations du secteur agricole et des systèmes avec lesquels il est en concurrence directe, en particulier les serres hollandaises. Il s'illustre à différents égards : sa forte composante technique présente un caractère hybride, les innovations technologiques se mariant aux savoirs paysans anciens, et, contre la tendance franquiste, il repose sur une structure familiale et des parcelles de petite taille.

La grille de lecture théorique mobilisée, au croisement de l'institutionnalisme historique et de l'institutionnalisme sociologique, permet de coupler une perspective diachronique, visant la compréhension des changements de modes d'usage de l'eau agricole, et une perspective synchronique à même de dessiner les contours du modèle agricole local, en insistant sur la figure qui est en son centre : l'agriculteur. Nous nous appuyons sur la typologie des transactions de John R. Commons pour rendre compte de l'influence du dogme de l'efficacité technique dans l'orientation des processus de coordination.

Premièrement, nous retraçons la genèse et l'évolution du modèle almérien en détaillant les phases d'un mode d'usage de l'eau particulier, ainsi que les mutations des 
pratiques agricoles locales. Deuxièmement, deux caractéristiques du modèle agricole local sont soulignées : la prédominance de la technique couplée à la logique marchande ; et les tensions dynamiques entre les agriculteurs individuels atomisés, les différentes formes de collectif dans lesquelles ils sont impliqués et l'État.

\section{" Une approche historique : le mode d'usage de l'eau comme traceur}

Dans la logique de l'articulation dynamique d'un régime d'accumulation et d'un mode de régulation (Boyer et Saillard, 2002), le mode d'usage relève de deux volets respectivement liés aux pratiques et aux règles ${ }^{1}$.

D’une part, l'étude du volet économique revient à identifier comment sont mobilisées les ressources : il est relatif à l'ajustement de l'offre et des usages finaux (de consommation ou non) des ressources produites. Il comprend l'ensemble des normes techniques relatives au type de mobilisation, au traitement, à l'approvisionnement, à la répartition sectorielle et aux usages finaux des ressources produites. D'autre part, l'analyse du volet institutionnel a pour objet d'identifier qui a le droit de mobiliser les ressources, et selon quelles conditions et modalités. Il porte sur les normes sociales relatives aux droits de disposition sur les ressources primaires et sur les ressources produites, et permet de renseigner les modes d'allocation des ressources produites (marché, gestion communautaire, délégation de service, etc.).

Le volet institutionnel habilite et contraint (Commons, 2005 [1934]) le volet économique qui, en retour, conforte ou non le volet institutionnel via les pratiques. L'identification de régularités dans l'articulation dynamique des deux volets et l'analyse des périodes de crise permettent de définir les différents états et étapes du mode d'usage.

\section{La colonisation interne :}

\section{genèse d'un mode d'usage de l'eau agricole particulier}

L'influence du mouvement régénérationniste a été déterminante pour l'évolution des usages de l'eau. Un projet militaro-géographique de mobilisation des ressources naturelles a été élaboré afin d'assurer la modernisation et la renaissance de l'Espagne, alors touchée par une crise à la fois politique (disparition en 1898 de l'empire colonial), économique (grande dépression) et sociale (opposition farouche à l'ordre ancien). Il est associé à la figure emblématique de Joaquín Costa (1846-1911), intellectuel espagnol dont la « solution hydrologique » constitue le fondement de la croissance nécessaire aux réformes sociales et à l'émancipation culturelle. Pour assurer la « colonisation interne » de l'Espagne (Marié, 1999) face aux contraintes climatiques et hydrologiques, Costa s'engage à « refaire la géographie de la patrie » : "si dans d'autres pays il est suffisant pour l'Homme d'aider la Nature, ici il est nécessaire de

1. Pour une présentation détaillée du mode d'usage de l'eau, voir Buchs (2014, 2016). 
faire plus, il est nécessaire de la créer » (1911). Cette recomposition territoriale doit s'accompagner d'un changement d'échelle dans la gestion de l'eau, confiée à l'État, afin de transcender les intérêts locaux (caciquisme).

La mise en place du projet régénérationniste commence dans les années 1920 , notamment sous la dictature de Primo de Rivera. Néanmoins, il faut attendre 1933 et le Plan nacional de obras hidráulicas coordonné par Lorenzo Pardo pour faire entrer l'Espagne dans l'ère de la planification hydraulique (Clarimont, 2006). Ce projet s'appuie sur de nouvelles règles apparues dès 1866 consolidant l'interventionnisme, en faveur de l'administration centrale et instituant un domaine public hydraulique comprenant l'ensemble des ressources (sans les eaux souterraines) dont l'utilisation est soumise à l'octroi de concessions (régime de propriété publique). Cette période est également marquée par l'émergence d'un nouveau découpage territorial avec la création des Confédérations syndicales hydrographiques en $1926^{2}$.

À l'échelle nationale, le régime a consolidé le pouvoir des grands propriétaires terriens (latifundistas) grâce à la mise en place d'une contre-réforme agraire fondée sur un remembrement concentrant massivement la propriété ${ }^{3}$. Face à cette tendance, le développement du Campo de Dalías affiche sa particularité : il est fondé sur une structure d'exploitation familiale impulsée par l'Institut national de colonisation (Instituto nacional de colonización) (INC qui deviendra l'Iryda ${ }^{4}$ en 1971).

Ce dernier a été créé en 1939 pour dissuader l'émigration ${ }^{5}$ et favoriser l'installation de populations venues de l'arrière-pays par la mise en valeur de terres hostiles et désertées (de los Llanos, 1990 ; Tout, 1990 ; Roux, 2010). Il vise ainsi à transformer des secanos déclarés « d'intérêt national » en terres irriguées (regadios) (lois du 26 décembre 1939 et du 21 avril 1949). L'objectif d'intérêt national justifie alors la forte implication de l'appareil étatique. Ses réalisations sont multiples, et aussi bien techniques qu'économiques et sociales (Guillaud, 1962). En outre, l'INC doit encourager l'initiative privée. Dans ce cas, il subventionne et supervise les réalisations, fixe les charges d'exploitation et en assure leur recouvrement, en appui aux propriétaires concernés qui peuvent se constituer en groupements chargés d'aider à l'exécution des travaux, d'administrer les ouvrages, de les entretenir et d'assurer leur exploitation 6 .

\section{L'émergence du modèle agro-exportateur almérien}

Sur les douze déclarations d'intérêt national entre 1940 et 1945, seulement trois plans généraux de colonisation sont acceptés, dont celui du Campo de Dalías

2. Organismes dotés d'une personnalité juridique propre dont le périmètre d'action est défini en termes géographiques, elles sont la première manifestation d'une planification régionale de l'aménagement du territoire.

3. Le nombre de parcelles agricoles est divisé par 7,5 entre 1954 et 1975 (Bosque Maurel, 1984).

4. Institut national de réforme et de développement agricole (Instituto de reforma y desarrollo agrario).

5. L'attractivité grandissante des régions du Nord (comme la Catalogne) accélère la chute du solde migratoire, négatif mais contenu jusque dans les années 1910 : il passe d'environ 2000 personnes au cours de la période 1901-1910, à près de 9000 dans les années 1930 (Sánchez Picón, 2005).

6. En fonction du statut des travaux « d'intérêt général », « d'intérêt commun » ou « d'intérêt agricole », les subventions de l'INC sont respectivement de $100 \%, 40 \%$ et $30 \%$ du montant total. 
(environ 33000 ha) (décret du 7 juillet 1941). L'INC découpe la zone en six soussecteurs, suivant les courbes de niveau, et réalise 120 puits de grande taille (qui s'ajoutent aux 79 en fonctionnement) permettant d'obtenir un débit total théorique de 4555 1/s. Entre 1953 et 1978, les périmètres I, II et III sont mis en eau, selon une procédure en trois étapes : (i) délimitation de la zone et définition des objectifs ; (ii) planification des aménagements et des infrastructures à réaliser ; (iii) partition des périmètres en parcelles (moyenne de $5000 \mathrm{~m}^{2}$ ). L'eau pompée est distribuée par gravité au moyen de canaux (seguias) jusqu'aux parcelles à irriguer. Comptabilisée en heures, la consommation devait être payée à l'INC-Iryda (CRA, 1997).

Les réalisations de l'INC, relais de l'initiative publique, modifient de manière durable le contexte hydro-géographique local (Pérez Picazo et Lemeunier, 2000). Néanmoins, le dynamisme de l'administration ne suffit pas à expliquer à lui seul la mise en place des structures agraires. En effet, selon les recensements agricoles successifs, seulement 600 colons et 110 familles ont été implantés sur le territoire par l'INC pour un total de 1600 ha (Jiménez Díaz, 2011), alors que 4000 exploitations agricoles sont apparues entre 1962 et 1982 dans les seules communes de Dalías, Félix, Roquetas et Vícar (de los Llanos, 1990). Via l'INC, l'État a joué le rôle de catalyseur de l'initiative privée : faire émerger le modèle et lui donner suffisamment d'attrait pour qu'il puisse s'auto-entretenir.

Chacun des trois piliers technologiques du modèle présente un caractère hybride entre innovation technologique plus ou moins radicale et savoir paysan, à la différence du modèle hollandais concurrent (von Elsner et al., 2000a, 2000b ; Berkers et Geels, 2011 ; Korthals Altes et van Rij, 2013).

Premièrement, à partir de la fin des années 1950, se diffuse la technique de l'enarenado (" ensablé »), qui vise à construire un sol arable grâce à la superposition de plusieurs couches à partir du sol nu : terre argileuse sédimentaire, fumier et terreau, puis sable. Cette pratique, qui existait depuis le XIX ${ }^{\mathrm{e}}$ siècle, était inconnue de l'INCIryda qui ne la redécouvre qu'en 1956 (observation fortuite d'une anomalie). L'expérience conduite sur 20 ha révèle qu'elle permet de répondre au problème de la salinité de l'eau et d'augmenter les rendements (Fernández Lavandera et Pizarro Checa, 1981). Aujourd'hui encore, même si la culture hors serres reste minoritaire dans la province, le sol est perçu comme un substrat auquel il est indispensable d'apporter tous les nutriments nécessaires.

Tableau 6.1. Évolution de la superficie des exploitations sous serre de la province d'Almeria (en ha)

\begin{tabular}{cccc}
\hline Année & Superficie & Année & Superficie \\
1963 & 0,05 & 1994 & 18261 \\
1971 & 1114 & 1995 & 18969 \\
1976 & 3440 & 2000 & 24764 \\
1980 & 7150 & 2003 & 26958 \\
1981 & 8250 & 2007 & 25983 \\
1985 & 10905 & 2012 & 28576 \\
\hline
\end{tabular}

Source : D’après La Voz de Almeria (2000), Sanjuan Estrada (2007) et Capma (2013). 
Deuxièmement, les premières serres en plastique font leur apparition en 1963 avec l'installation par l'INC d'une serre test de $500 \mathrm{~m}^{2}$ (Rivera Ménendez, 2000 ; entretiens). Les résultats en termes de rendements par rapport à l'air libre sont éloquents : ils sont environ deux fois supérieurs pour la tomate $(+113 \%)$, près de quatre fois supérieurs pour le concombre $(+284 \%)$ et près de cinq fois supérieurs pour le poivron $(+366 \%$ ) (ibid., $2000: 154)$. Aujourd'hui, les deux tiers des serres espagnoles se situent en Andalousie, et $80 \%$ sont concentrées dans la province d'Almeria pour une superficie totale de 28576 hectares en 2012, dont près de 20500 hectares rien que pour le Campo de Dalías (Capma, 2013). Le type parral (pergola) - dit type «Almeria »-, aux armatures initialement en bois et au toit plat, est aujourd'hui encore prédominant dans la zone. Même si elles restent relativement simples, ces structures et les matériaux plastiques utilisés ont progressivement acquis un plus haut niveau de technicité (armatures en métal, ventilation, etc.).

Troisièmement, l'irrigation localisée (goutte-à-goutte) s'impose rapidement et remplace l'irrigation gravitaire qui dominait jusqu'en 1976 (Losada et LópezGálvez, 1997 ; entretiens). L'irrigation localisée doit être associée à un système de mise en pression de l'eau et implique de transformer les infrastructures d'approvisionnement (remplacer les seguias par des conduites fermées). Enfin, dès les années 1990, la « fertigation » (association de fertilisants à l'eau d'irrigation) assistée par ordinateur commence à gagner les exploitations, pour être aujourd'hui la norme.

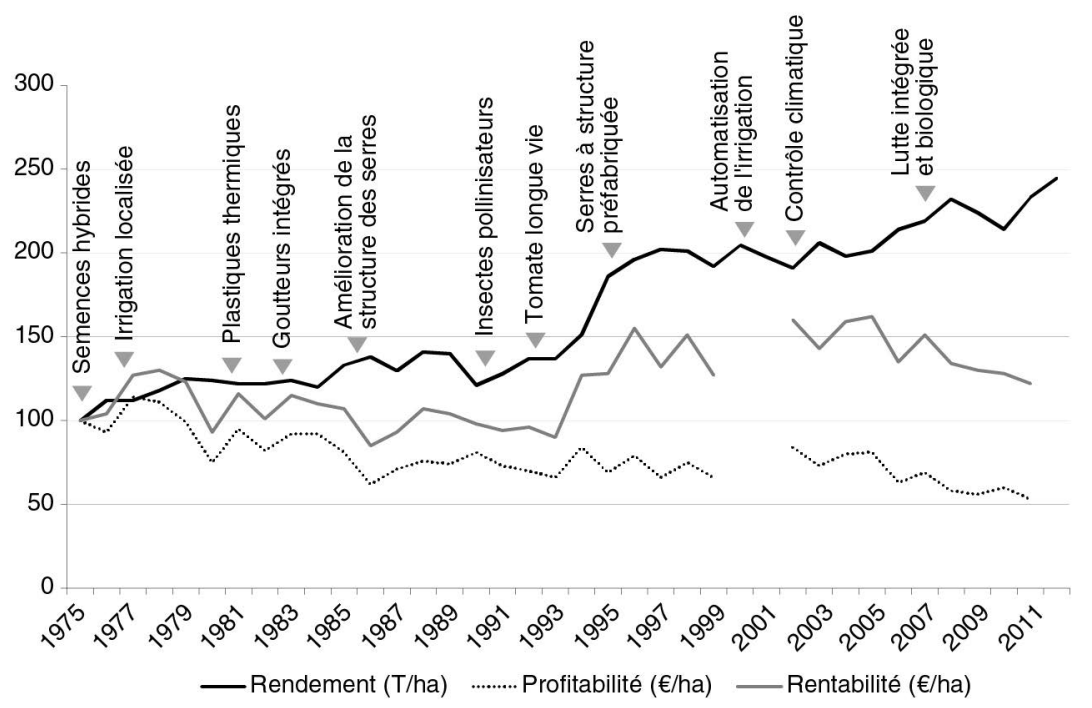

Figure 6.1. Rendements, profitabilité, rentabilité de la production agricole à Almeria et jalons technologiques (1975-2012)

Indice $1975=100$. Baisse des rendements après 1999 principalement liée à deux virus : celui véhiculé par la mouche blanche (TYLCV) et celui dit des « veines jaunes » (CVYV).

Sources : d'après La Voz de Almería (2000) et Fundación Cajamar (2011-2013).

Ces trois piliers technologiques, associés à d'autres innovations, ont permis d'élever considérablement le niveau des rendements agricoles et de contenir la tendance à la baisse de la rentabilité, liée à la fois à la concurrence accrue des producteurs étrangers 
(Maroc, Égypte, Israël, etc.), à la monopolisation de la rente par les intermédiaires, en particulier les grands distributeurs, et à l'augmentation des charges d'exploitation : coûts des intrants, notamment d'origine pétrolière, et de la main-d'œuvre.

La période qui débute aux alentours des années 1950 et s'étend jusque dans les années 1980 correspond à l'opérationnalisation du « rêve régénérationniste » (López-Gunn, 2009). Il s'agit de la phase de régime d'un mode d'usage de l'eau particulier que nous qualifions « d'hydrauliciste » (Buchs, 2010). Justifié par un " discours pénurique », ce mode d'usage vise - via l'ingénierie hydraulique - à réduire les déséquilibres hydrologiques et à soutenir une politique économique et territoriale volontariste favorisant notamment l'agriculture irriguée à vocation exportatrice (modèle californien). Les infrastructures hydrauliques se multiplient afin d'assurer l'augmentation de la production d'eau mobilisable pour la satisfaction d'usages finaux et de recomposer le territoire national (colonisation interne par l'INC-Iryda). Elles accompagnent l'évolution et la diffusion des nouvelles techniques agronomiques caractéristiques du modèle économique local en émergence. Les nouvelles normes sociales achèvent de centraliser la politique de l'eau, notamment par la révision en 1942 du rôle des Confédérations syndicales hydrographiques privées des représentants des usagers et par la création des commissariats des eaux ${ }^{7}$. Sous l'égide de la Direction générale des ouvrages hydrauliques, ces organismes concrétisent la mise en place d'un directoire d'ingénieurs d'État.

\section{Vers un nouveau mode d'usage de l'eau pour conjurer la crise du précédent?}

Dès les années 1980, l'ajustement de l'offre et des usages finaux de l'eau produite ne s'opère plus. Autrement dit, le volet économique du mode d'usage entre en crise. Pour le Campo de Dalías, l'Institut géologique et minier d'Espagne alerte sur un possible phénomène conjugué de surexploitation et d'intrusion marine (CRA, 1997) qui donne lieu à des restrictions légales à partir de 1984, alors même que la zone connaît son développement le plus intensif : si les volumes d'eau souterraine prélevée n'étaient que de $30 \mathrm{Mm}^{3} /$ an en 1964-1965 (Cuitó Sabaté et al., 2006) ils atteignent $156 \mathrm{Mm}^{3} /$ an en 2005 , dont $112,9 \mathrm{Mm}^{3}$ /an rien que pour l'irrigation (AAA, 2009). La baisse du niveau des nappes ne freine pas l'expansion agricole, et les superficies sous serres explosent (voir tableau 6.1).

Aujourd'hui, la surexploitation des ressources primaires dans le District hydrographique méditerranéen est estimée à $310 \mathrm{Mm}^{3} /$ an (AAA, 2009 : 34). Pour le seul système Campo de Dalías-Sierra de Gádor, les estimations font état d'une surexploitation comprise entre 40-60 Mm³/an et $74 \mathrm{Mm}^{3} /$ an (Pulido Bosch, 2005 : 5 ; AAA, 2009 : 182 ; entretiens). Cette surexploitation se traduit par une baisse généralisée du niveau piézométrique des aquifères conjuguée à une augmentation de leur salinité, obligeant au forage de puits de plus en plus profonds (jusqu'à $300 \mathrm{~m}$ ). Le paradoxe de Jevons est à l'œuvre : alors que le mode de production de l'agriculture forcée est un des plus efficients en termes hydriques à l'échelle de la parcelle, la rentabilité des

7. À partir de 1959, les commissariats des eaux, qui dépendent directement de l'autorité centrale, assurent un contrôle externe des confédérations et reprennent une partie de leurs prérogatives. Ils marquent ainsi une rupture du principe de l'unité de l'administration des eaux. 
exploitations conjuguée à un contrôle défaillant des autorités entraîne une augmentation des superficies irriguées et donc des prélèvements totaux.

À partir des années 1980, on observe également une crise institutionnelle : le cadre qui régit les usages de l'eau est presque entièrement réformé (loi sur l'eau de 1985 et décrets de surexploitation successifs) afin d'affirmer le statut public de l'eau. Néanmoins, il n'est que peu opérant : à partir des années 1970, les forages individuels, pour la plupart illégaux, se généralisent.

Le recours à l'eau dessalée tel que prévu par le programme Agua, qui se substitue au transfert de l'Ebre prévu par le Plan hydrologique national (PHN) de 2001 (loi 11/2005 de modification du PHN), témoignerait d'une rupture radicale selon les autorités. À travers la modification de la loi, le gouvernement affiche sa volonté de suivre la Directive cadre européenne sur l'eau, notamment dans ses dimensions environnementales, pour pouvoir bénéficier de financements européens, par exemple du Fonds européen agricole pour le développement rural (Feader).

Ce programme concerne initialement 103 projets répartis en trois ensembles : 29 projets visant à accroître l'offre d'eau (dont 16 nouvelles usines de dessalement et l'augmentation des capacités de 5 usines existantes); 52 projets visant à améliorer la gestion des ressources (construction et amélioration de réseaux, implantation et agrandissement de stations d'épuration et de recyclage de l'eau); 22 projets visant à améliorer la qualité de l'eau et à restaurer le milieu.

$\mathrm{Au}$ total, le plan vise à fournir un volume supplémentaire de $1063 \mathrm{Mm}^{3}$ pour un coût total estimé initialement à environ 3798 millions d'euros (contre plus de 4200 millions d'euros pour l'ancien plan) (données MMAMRM). Si bien qu'aux usines de dessalement s'ajoutent 102 nouveaux barrages. Pour le seul District hydrographique méditerranéen, 7 usines de dessalement et 7 projets complémentaires de réutilisation des eaux résiduelles sont envisagés pour un coût évalué à 1435,7 millions d'euros. À terme, le programme vise la fourniture de $364,5 \mathrm{Mm}^{3} / \mathrm{an}$, dont $109,5 \mathrm{Mm}^{3} /$ an rien que pour la province.

Ces différentes évolutions participent de l'émergence d'un nouveau mode d'usage de l'eau. Censé répondre aux limites du précédent, il ne témoigne pas pour autant d'une véritable rupture paradigmatique. Il s'apparente à un « régime de crise » (Buchs, 2014). Ainsi, le dessalement contribue à l'augmentation de l'offre aux dépens d'une maîtrise de la demande et, de manière plus insidieuse, il pourrait même accélérer la déplétion des aquifères en permettant de s'affranchir en partie de la dégradation qualitative de l'eau souterraine (augmentation de la salinité) par la possibilité de mélanger l'eau saumâtre à l'eau dessalée. Le risque de pénurie éloigné, le modèle peut donc perdurer.

\section{" La dimension sociale de la technique}

\section{L'apport de Commons et de l'économie des conventions}

Les normes, comme processus institués à la fois habilitants et contraignants, renvoient aux mécanismes de sanctions collectives présidant au renforcement des 
règles opérantes (working rules). Elles habilitent les activités en fixant des contraintes qui peuvent aller jusqu'à l'interdiction. Elles correspondent à des comportements admis dans un corps social précis, c'est-à-dire délimité en référence à une situation sociale et historique donnée. Elles sont le produit des interactions sociales et, plus précisément, de l'engagement des individus dans une action collective (Commons, 1931 ; Reynaud, 1989).

La distinction entre les normes techniques, qui renvoient à la régulation des rapports entre les hommes et les objets, et les normes sociales, qui président aux rapports des hommes entre eux, n'est pas étanche. Au contraire, ces deux types de normes font système (Billaudot, 2009 ; Buchs, 2014, 2016). Les normes techniques et sociales témoignent d'une rationalité qui a su s'imposer à un moment donné. Si bien qu'elles « instrumentalisent une vision du monde » (Baron et Isla, 2006 : 371).

Deux propositions de l'approche conventionnaliste permettent de comprendre cette articulation. Selon la première, toute coordination s'appuie sur des « conventions constitutives » $\left(\right.$ conventions $\left._{1}\right)$, référentiels cognitifs d'évaluation et de qualification des croyances, des personnes et des ressources mobilisées dans les activités et, partant, des modes de coordination préconisés (Dupuy et al., 1989 ; Eymard-Duvernay et al., 2006). Elles ont une fonction régulatrice : «bloquer l'indécidabilité, à travers un jugement global, qualifiant la relation entre l'agent et le collectif » (Favereau, 1999 : 167). Ainsi, les conventions de comportement et les règles (conventions ${ }_{2}$ ) ne s'imposent que parce qu'elles reposent sur des conventions constitutives (conventions ${ }_{1}$ ) qui président à leur existence et à leur institution. De fait, elles traduisent nécessairement une dimension réflexive et interprétative, même si elle n'est qu'implicite. La seconde proposition majeure est que, pour toute activité de coordination, il existe plusieurs solutions de coordination possibles. Autrement dit, il existe une pluralité des formes d'actions justifiées (Boltanski et Thévenot, 1991).

Le choix opéré entre les différentes conventions constitutives détermine le mode de coordination privilégié pour atteindre le bien supérieur visé par l'action collective. En effet, les normes « contraignent (par des procédures) et libèrent (en tant qu'interprétations du bien commun et propositions de valeurs raisonnables) » (Allaire, 2007 : 134). Parmi l'éventail des modes de coordination, nous nous restreignons aux trois types de transaction identifiés par Commons (1931 : $652 ; 2005$ [1934] : 58) : la «transaction de marchandage » (bargaining transaction) qui porte sur le transfert de la propriété d'un objet; la «transaction de direction » (managerial transaction) qui porte sur l'organisation de la production; et la «transaction de répartition » (rationing transaction) qui vise à répartir les charges et les avantages de la création de la richesse. Ensemble, elles épuisent toutes les activités relevant de la science économique (Commons, 2005 [1934] : 59). Ce faisant, le système théorique de Commons détrône le marché qui est relégué de catégorie de base de l'économie à une forme particulière de transaction (Théret, 2001).

En tant qu'activité finalisée, la transaction implique le règlement d'un conflit de prétentions entre des protagonistes aux intérêts contradictoires (Théret, 2005). À chacun des types de transaction est associé un principe fondamental. La transaction de marchandage est guidée par le principe de la rareté en tant que «pouvoir sur les autres » (Commons, 2005 [1934] : 387). La transaction de direction est motivée par le principe de l'efficacité en tant que « pouvoir sur la nature » (Commons, 2005 
[1934] : 387). Ce deuxième principe résulte du premier et vise à relativiser la rareté par la recherche d'efficacité. La transaction de répartition est, quant à elle, fondée sur les principes de commandement et d'obéissance (Commons, 1931 : 654). Dans une perspective conventionnaliste, chacune des trois modalités polaires de règlement d'une transaction identifiées par Commons est motivée par une grammaire de justification particulière. Par commodité, Billaudot (2009) associe la cité civique à la transaction de répartition, la cité marchande au marchandage et la cité industrielle à la direction.

\section{La technique au service d'une logique marchande}

Dès son émergence, le modèle almérien est caractéristique de l'influence d'un acteur prépondérant depuis le régime franquiste, l'ingénieur hydraulique, qui devient l'instrument du « chirurgien de fer » dépeint par Costa. La mise en place d'une administration d'ingénieurs (Pérez Picazo et Lemeunier, 2000) est à l'origine de la production d'une « techno-nature » (Swyngedouw, 2007). À l'objectif initial de recomposition territoriale, s'ajoute l'entretien du modèle agroexportateur caractéristique de l'économie de marché (planifiée) émergente.

Du point de vue des pratiques, le mode de règlement privilégié des transactions est la direction. Guidée par le principe d'efficacité, elle incarne l'action « rationnelle en finalité » (Weber, 1995 [1921]) afin de rompre avec une agriculture « traditionnelle ». Ainsi, les serres permettent de protéger la culture des intempéries et facilitent la maîtrise des paramètres essentiels à la production agricole en créant un microclimat. D'un point de vue agronomique, le recours à l'irrigation localisée a pour but de maîtriser les paramètres de croissance des plantes afin d'augmenter les rendements. C'est la principale motivation à son adoption, alors que l'argument écologique est fréquemment mis en avant. En raison du manque de ressources superficielles locales, l'accroissement constant des superficies irriguées n'aurait pu être possible sans l'exploitation massive des ressources souterraines.

Le retour de la démocratie en Espagne en 1975 et l'adoption d'une nouvelle Constitution en 1978 s'accompagnent d'une ouverture croissante, en particulier vers la Communauté européenne qu'elle intègre en 1986 à l'issue d'un processus initié en 1962. Depuis 1980, la part des exportations dans la production agricole locale totale n'a cessé d'augmenter, passant de $9 \%$ en 1980 à $68 \%$ en 2013.

Précisons que le secteur agricole ultra intensif ne bénéficie pas des aides directes à la production, ni des aides visant à garantir un revenu minimum aux agriculteurs (Feaga). Le marché des productions hortofruticoles est libéralisé et les revenus des agriculteurs dépendent des prix. Cependant, malgré ce que prétendent de nombreux agriculteurs rencontrés, ce secteur est loin d'être oublié par la Politique agricole commune. Il bénéficie d'aides à la construction et la rénovation d'infrastructures (notamment hydrauliques), au travers du Feader, et d'aides pour la constitution de coopératives. Ainsi, si pour l'Espagne en général, et même pour l'Andalousie, les aides de garantie (Feaga) représentent près de $90 \%$ du total des subventions européennes, pour la province d'Almeria, c'est la composante structurelle (Feader) qui prédomine (García Torrente, 2005). 
Pour le dire autrement, le modèle peut être caractérisé par la prépondérance de deux modalités de règlement des transactions, le marchandage et la direction, motivées par la poursuite de l'enrichissement par la concurrence sur un marché libéralisé (grammaire de justification qui renvoie à la cité marchande) et de l'efficacité technique instrumentale (référence à la cité industrielle). L'eau ne doit pas être un facteur limitant. C'est cette représentation de l'eau comme « ressource d'allocation » relative à la structure de domination de la nature par l'homme (Giddens, 1994) qui explique en grande partie la crise écologique majeure et irréversible. Elle illustre parfaitement la « révolution silencieuse » (Llamas Madurga et Martínez-Santos, 2005) à l'œuvre dans la plupart des pays arides et semi-arides au cours des cinquante dernières années. Elle a été rendue possible par deux dynamiques conjuguées. D’une part, elle exprime une logique de marché : l'augmentation spectaculaire de la mobilisation des eaux souterraines pour l'irrigation relève essentiellement de l'initiative privée de millions de paysans modestes en concurrence, individuellement ou en communautés d'usagers, et d'un calcul opposant coûts d'extraction insignifiants et profits attendus à court terme. D'autre part, son avènement est indissociable des progrès scientifiques et techniques pour l'exploration et l'exploitation (hydrogéologie, techniques de forage, généralisation de la pompe immergée, réseaux sous pression, etc.). Les évolutions techniques successives ont eu pour objectif de s'émanciper des contraintes naturelles et de valoriser les avantages comparatifs locaux par le marché (Roux, 2010).

La logique visant à augmenter l'offre d'eau produite à partir de ressources primaires de plus en plus rares pour satisfaire une demande considérée comme incompressible reste privilégiée. Du côté des usages, la prééminence de l'efficacité technique se traduit par des normes techniques (de procédé, d'immission et d'émission) de nature agronomique et agro-industrielle : généralisation de la micro-irrigation, fertigation automatisée et réseaux sous pression. Le rôle de médiation joué par les ingénieurs agronomes est révélateur de la persistance de la direction comme mode de règlement de nombre des composantes des transactions.

Dès l'origine, les lots alloués aux colons sont de petite taille, entre 2 et 3 ha, ensuite divisés en parcelles de 0,5 à 1 ha. Ces modestes exploitations visent à favoriser une agriculture où la famille nucléaire est à la base de la structure productive. En effet, plusieurs tentatives de concentration et de mise en place d'entreprises capitalistes de grande taille fondées sur un rapport salarial généralisé se sont soldées par des échecs. Le processus de production conviendrait mal à une exploitation salariée annualisée (imbrication constante des semis et des récoltes et manipulations spécifiques selon les plants). Ainsi, le phénomène du Campo de Dalías serait avant tout « un phénomène paysan » (de los Llanos, 1990 : 34).

Néanmoins, depuis les années 1990, le recours à de la main-d'œuvre intérimaire s'est accentué et son intensité est fortement corrélée à la taille de l'exploitation : en deçà de 2 ha, la composante familiale reste prédominante. Au-delà, les coûts liés à la main-d'œuvre représentent jusqu'à $40 \%$ des coûts d'exploitation totaux. Cette main-d'œuvre est essentiellement d'origine étrangère (Afrique du Nord, Afrique subsaharienne, pays de l'Est de l'Europe et d'Amérique latine), souvent clandestine. Elle est très bon marché (entre 2 euros et 4,50 euros de l'heure) et flexible, ce qui est pour beaucoup dans la compétitivité du modèle almérien (Delgado Cabeza et 
Aragón Mejías, 2006 ; Roux, 2010). Cependant, cette situation suscite des tensions locales $^{8}$ et de nombreuses critiques ${ }^{9}$.

Les modalités de commercialisation témoignent également de l'implication individuelle de l'agriculteur. Aujourd'hui encore, environ $40 \%$ des agriculteurs ne font pas partie de groupements ou de coopératives. L'essentiel de la production est vendu par lots individualisés dans les alhóndigas, anciennes structures qui fonctionnent selon une procédure d'enchère descendante (adjudication à la hollandaise). Ainsi, le principe de concurrence comme bien supérieur contribue à justifier un mode de règlement des transactions favorisant la logique marchande.

Localement, l'organisation du secteur est similaire à celle de toute autre activité industrielle globalisée. Un «cluster agro-industriel »s'est formé. Il est composé de tous les éléments de la chaîne de production-distribution (recherche agronomique, formation des agriculteurs et des conseillers, fabrication et distribution d'intrants, production agricole, manipulation, conditionnement, transport, services bancaires, etc.) suivant une stratégie d'intégration horizontale et verticale. En moins de quarante ans, Almeria est passée du rang d'avant-dernière région d'Espagne en termes de PIB par habitant à celui de vingt-quatrième région sur cinquante-deux. Cette croissance, qualifiée de «miracle économique » (Sánchez Picón, 2005), est essentiellement liée au développement agricole : en 2007, le secteur agricole participe à hauteur de 23,5\% du PIB provincial (contre 7,8 \% au niveau de l'Andalousie et $4 \%$ au niveau national). Ce dynamisme économique, reposant sur l'intensification des pressions sur les ressources territoriales et environnementales, a eu pour corollaire une crise écologique, sans pour autant conduire à la remise en cause du modèle : l'action rationnelle en finalité guidée par la recherche d'efficacité technique dans une perspective d'enrichissement par le marché ne s'est pas encombrée de considérations d'ordre écologique ou social.

\section{Régulation à trois niveaux et diminution de l'aquosité sociale}

Comme nous l'avons vu, l'activité agricole atomisée est pour une part planifiée par les autorités publiques, notamment par l'ingénieur d'État. Cette tension dialectique pourrait s'analyser en termes de structure de gouvernance hybride, entre marché et hiérarchie (Williamson, 1996), en l'absence d'un troisième niveau, intermédiaire, celui des communautés d'irrigants.

Le thème du lien entre autorité centrale et aménagements hydrauliques fait écho aux débats relatifs à l'« hypothèse hydraulique » de Wittfogel (1957). Cette hypothèse revient à postuler un lien étroit entre la pratique généralisée de l'irrigation au

8. Elle a donné lieu à des événements tragiques, dont les affrontements - qualifiés de racistes - à El Ejido en février 2000.

9. Voir par exemple le reportage diffusé par la RTS le mardi 15 avril 2008 intitulé « Poivrons : des pesticides et des esclaves dans votre assiette » : http://www.rts.ch/emissions/abe/1378073-poivrons-despesticides-et-des-esclaves-dans-votre-assiette.html (consulté le 24 octobre 2016) ; le site de The Guardian qui diffuse, depuis le 7 février 2011, une vidéo intitulée « Salad Slaves: Who Really Provides our Vegetables » : https://www.theguardian.com/environment/video/2011/feb/07/food-spain-migrants (consulté le 24 octobre 2016). Voir aussi Delgado Cabeza et Aragón Mejías (2006) ; Roux (2006), et le film de Rhalib Jawad, 2007. «El Ejido, la loi du profit ». 
sein d'une société et l'existence d'un pouvoir politique centralisé, voire despotique, seul à même de mobiliser les ressources financières et humaines requises par l'établissement de systèmes d'irrigation à grande échelle (Lorrain, 2008).

De nombreux auteurs se sont attachés à réfuter le modèle wittfogélien, tant sur le plan de la véracité historique que sur celui de la méthode mobilisée (Manning, 2002). Cependant, récemment, Molle et al. (2009) sont revenus sur cette hypothèse à partir d'études de cas, en particulier dans l'Espagne de Franco, emblématique d'une « hydrocratie » fondée sur un « hydro-populisme » (Pérez Picazo et Lemeunier, 2000). Les auteurs critiquent la linéarité du modèle de Wittfogel, mais montrent que la mobilisation des ressources primaires en eau par des organes bureaucratiques étatiques a joué un rôle important dans la formation de certains États et, en retour, a participé à légitimer la centralisation du pouvoir.

Le modèle almérien illustrerait le « nationalisme hydraulique » franquiste hérité du mouvement régénérationniste et de la solution hydrologique de Joaquín Costa. Le discours technique comme médiation permet à l'ingénieur de prendre place dans le processus social d'aménagement hydraulique, faisant de la gestion de l'eau une affaire d'État (Billaud, 1994). L'influence de l'ingénieur est véhiculée par deux relais principaux : la Direction générale des ouvrages hydrauliques et son réseau de confédérations hydrauliques, et l'Institut national de colonisation. C'est ce dernier qui dirige les infrastructures hydrauliques (forages et réseaux) dans le but de recomposer le territoire et de domestiquer la ressource. Il légitime la propagande aménagiste franquiste, et le Campo de Dalías compte parmi ses succès.

L'extension récente du DPH aux eaux souterraines (ainsi qu'à l'eau dessalée), la mise en place de la planification hydrologique coordonnée à l'échelle nationale et le mode de financement des infrastructures (qui restent, directement ou indirectement, dirigées et planifiées) témoignent de la prégnance de l'autorité publique. En effet, les infrastructures sont pour une grande part financées par des fonds publics et, pour certaines, réalisées par des entreprises publiques (c'est le cas, par exemple, des sociétés Acuamed et Seiasa dans le cadre du programme Agua lié au PHN de 2005). Néanmoins, le dynamisme du modèle ne peut s'expliquer seulement par l'interventionnisme étatique. La mise en valeur de la zone relève largement de l'initiative privée de milliers d'agriculteurs, si bien que l'hypothèse n'est que partiellement vérifiée, sinon invalidée.

Aux niveaux d'analyse déjà évoqués, s'ajoute l'échelle de la communauté, ce qui est une spécificité de cette zone produite « hors sol » à partir des années 1950. Si l'Espagne en général et l'Andalousie en particulier sont célèbres pour leurs communautés d'irrigants séculaires, les communautés de la zone du Campo de Dalías sont comparativement beaucoup plus récentes. Les deux communautés les plus importantes ont été créées par l'administration pour prendre le relais de l'INC-Iryda : la communauté d'irrigants Sol y arena en 1979 et la communauté d'irrigants Sol Poniente en 1986.

À l'échelle nationale, 7000 associations d'usagers gèrent environ $70 \%$ des terres irriguées, les $30 \%$ restants l'étant par des irrigants individuels. Cette proportion est similaire pour l'ensemble du bassin du Sud (Varela Ortega et Hernández-Mora, 2009). En revanche, à l'échelle du Campo de Dalías, près de $90 \%$ des terres irriguées sont gérées par des communautés d'usagers, principalement des usagers agricoles. 
Aujourd'hui encore, les communautés d'irrigants du Campo de Dalías et de Níjar dépendent étroitement de la puissance publique, notamment pour le financement, mais aussi pour la réalisation des infrastructures. Le projet de modernisation des infrastructures d'irrigation de la "Communauté des usagers de l'aquifère de la Sierra de Gádor » est exemplaire à cet égard. Son coût a été très majoritairement pris en charge par l'État au travers de la société étatique d'infrastructures agricoles Seiasa del Sur y Este en charge de réaliser les travaux en 2010. Les montages financiers des infrastructures hydrauliques sont variables, mais font généralement intervenir plusieurs sources de financement. Les usagers payent rarement plus de $25 \%$ ou $30 \%$ du montant total des investissements sous forme de participation directe (prêts à taux préférentiels). Ils doivent s'en acquitter pendant les vingtcinq premières années de fonctionnement. Le reste provient de subventions du gouvernement autonome, de prêts à taux préférentiels du gouvernement central (dont les échéances ne débutent qu'à la vingt-sixième année) et d'aides européennes (Feader).

L'agriculteur est donc un entrepreneur privé, investi dans une communauté d'irrigants, laquelle entretient une relation directe avec les autorités publiques. Les trois échelles se combinent pour donner lieu à un «compromis social vertical » qui résulte d'une tension entre échelle individuelle-privée, échelle communautaire et échelle nationale (Ruf, 2010) ${ }^{10}$. La structure productive décentralisée n'a pu émerger qu'avec le concours de l'autorité publique, laquelle a également favorisé l'émergence de communautés d'irrigants pour prendre son relais.

Aujourd'hui, le poids des structures communautaires pour la gestion de l'eau tend à diminuer du fait de l'individualisation de certains contrats de fourniture d'eau. Cette dernière est indissociable des progrès techniques, notamment le remplacement des anciennes conduites par des réseaux sous pression pour un approvisionnement à la demande. Dans ce système, l'usager agricole n'est plus contraint par des règles communautaires (les tours d'eau) qui le liaient aux autres usagers. La relation tend à se contractualiser entre l'usager-consommateur et la communauté d'irrigants restreinte à un organisme d'approvisionnement. Ce faisant, "l'aquosité sociale » (Cambon, 1996), relative à la socialisation liée à la maîtrise des infrastructures et à la répartition de l'eau, s'efface progressivement. Là encore, la dimension technique joue un rôle majeur dans cette reconfiguration. Cette évolution témoigne du renforcement des logiques de justification pour lesquelles les transactions de marchandage sont privilégiées. Apparaît alors, une fois encore, la dimension sociale de la technique, ou le lien entre normes techniques et normes sociales.

10. Barthélemy et al. (2003 : 134) mettent en lumière ce type de compromis instable entre plusieurs registres de justification et d'action pour l'agriculteur, en l'occurrence celui de l'économie marchande et celui du patrimoine : "Chaque agriculteur se trouve traversé par ce dilemme, en tant qu'il participe de chacun des ordres de relation. D'un côté, il est entrepreneur, inscrit dans l'économie de marché, ses relations d'échange et de concurrence ; de l'autre côté, il participe au groupe patrimonial, familial et/ou professionnel, avec ses normes d'allocation solidaire. Le compromis institutionnel, qui règle les rapports entre ces deux formes d'économie, s'exprime de fait dans le dualisme comportemental de l'acteur : dans certaines circonstances, parce qu'il envisage son insertion marchande, il tend à privilégier les prix de marché et donc une valeur de marché, alors qu'à d'autres moments, il se réfère plutôt aux prix patrimoniaux et donc à une valeur de patrimoine. » 


\section{Conclusion}

L'analyse historique a permis de mettre en évidence deux caractéristiques du modèle almérien. Tout d'abord, il relève d'une "production sociale de la nature » (Castree et Braun, 2001), où l'efficacité technique est érigée en dogme pour s'émanciper des contraintes du milieu. Ainsi, un quasi désert a été transformé en eldorado pour des milliers d'agriculteurs grâce à la généralisation d'infrastructures hydrauliques adaptées (forages au lieu des habituels barrages). Cette technique a permis une croissance économique «miraculeuse » faisant de la zone le principal lieu de production des produits horticoles consommés en Europe. À cette conjonction de la technique et du marché, s'ajoute un compromis social vertical : on observe la congruence d'une logique marchande décentralisée au niveau de l'agriculteur, d'une logique communautaire portée par les associations d'irrigants et d'une logique planificatricehiérarchique portée par les autorités publiques.

La normalisation actuelle reste ancrée dans une conception de l'eau comme ressource d'allocation abondante qu'il suffit de mobiliser, et ce d'autant plus que le marchandage prend de l'importance et que l'aquosité sociale autour de la gestion de l'eau s'efface. Nous reprenons et partageons ainsi les conclusions de Tordjman (2011) selon lesquelles « les phénomènes à l'œuvre dans ces différentes crises [économiques et écologiques] sont similaires, et relèvent de deux ordres : celui du marché et celui de la technique ». À Almeria, la dérive positiviste technicoscientiste (Habermas, 1973), illustrée par les « tomates de Noël », accroît la tendance à considérer l'eau comme une ressource dont l'abondance ne serait limitée que par les infrastructures hydrauliques. Malgré l'impact écologique désastreux du modèle, l'eau est encore loin d'être considérée comme un «milieu » écologique (Puech et Boisson, 1995 ; Ghiotti, 2007). 


\title{
Chapitre 7 \\ La race bovine Holstein, institution de la modernisation de l'agriculture entre bien marchand et bien commun
}

\author{
J. Labatut, G. Tesnière
}

La «Holstein » est le nom courant de la vache laitière noire et blanche, la plus commune, celle qui produit le lait que l'on retrouve dans la brique le matin. Race la plus présente dans les élevages et dans l'imaginaire collectif, elle est associée aux succès et aux crises auxquels l'élevage et l'industrie du lait sont confrontés. Elle est aussi l'une des populations animales les plus sélectionnées grâce au développement de l'industrie de la génétique $\mathrm{au} \mathrm{xx}^{\mathrm{e}}$ siècle et reste la pionnière en la matière. Le développement récent de la génomique dans la sélection des bovins laitiers en est la preuve puisqu'elle fut la première race concernée par ces avancées biotechnologiques permettant de « lire » l'ADN des animaux et de repérer instantanément les reproducteurs qui ont le potentiel pour de meilleures performances. Cette vache, « vache machine » par excellence (Ruet, 2004), est devenue l'un des symboles de l'industrialisation de l'agriculture et de la marchandisation du vivant. En effet, le marché du sperme de taureau, des embryons et des animaux Holstein pour la reproduction représente des flux financiers entre pays estimés à 335 millions d'euros au niveau international (source professionnelle en 2015). De nombreuses entreprises se sont spécialisées dans ce commerce et la Holstein est devenue planétaire. Elle est utilisée aussi bien dans les systèmes d'élevages français de taille modeste et basés sur le pâturage que dans les « usines à lait » californiennes ou d'ailleurs regroupant plusieurs milliers d'individus. Malgré des climats considérés comme peu favorables à cet animal de pointe, les pays émergents se tournent également vers la « holsteinisation », processus d'absorption de génétique Holstein conduisant à la diffusion de la race et à l'amélioration des performances laitières des races qui l'absorbent.

Toutefois, si la Holstein peut être l'un des emblèmes de la marchandisation du vivant, elle n'en garde pas moins le statut de " ressource commune », tant en ce qui concerne les éleveurs que les sélectionneurs, auxquels s'ajoutent aujourd'hui d'autres parties prenantes. En effet, en tant que race animale, aucun droit privé (exclusif) de propriété intellectuelle ne peut restreindre l'accès à ces animaux, ni pour l'instant aux produits génétiques qui en dérivent. Une race animale reste, aujourd'hui encore, en 2015, la propriété commune de l'ensemble des éleveurs qui l'utilisent. Ainsi, pour reprendre la distinction importante indiquée par Hess et 
Ostrom (2003 : 121) entre flux et ressources dans tout système de communs, si les unités de ressources produites (flux) par la ressource (race animale) sont des biens marchands (les animaux, les embryons, la semence), la ressource « race » est un commun, potentiellement menacé si sa gestion est entièrement laissée aux mécanismes de marché. Il s'agit par exemple du risque de consanguinité ou de la diffusion d'anomalies génétiques lorsque les meilleurs individus d'une population animale sont surutilisés pour la reproduction. Une étude a montré que le nombre d'ancêtres expliquant à eux seuls la moitié des gènes de la population (le cheptel de bovins Holstein) a été divisé par 3,5 en Holstein entre 1988 et 2003 (Mattalia et al., 2006). Dans le cas de races à plus petits effectifs, la menace peut venir de la non-utilisation d'une race (disparition) ou du désengagement des éleveurs des programmes de sélection (Labatut et al., 2012).

La race Holstein est un cas d'étude particulièrement pertinent pour analyser le paradoxe de la gestion d'une ressource commune confrontée à une marchandisation croissante des unités produites à partir de cette ressource. Cette question devient de plus en plus importante dans le contexte de l'évolution récente des marchés de la génétique animale : internationalisation croissante, libéralisation, désengagement de l'État du financement des dispositifs génétiques (en particulier dans le cas de la France où l'engagement était important), apparition de nouvelles technologies accroissant radicalement la vitesse de production de progrès génétique (génomique, sexage de la semence, etc.).

Nous proposons ici d'étudier l'évolution de la sélection de la race Holstein, entre ressource commune et bien marchand, comme un traceur de différentes formes d'industrialisation de l'agriculture. Dans un premier temps, nous rappellerons certaines étapes du processus à la fois génétique et marchand ayant conduit à la création biologique et institutionnelle de la race Holstein, et à la « holsteinisation » du cheptel français. Dans un deuxième temps, nous mobiliserons la notion de « régime de sélection » (Labatut et al., 2011, 2013) pour expliquer l'évolution de la sélection de la Holstein. Un « régime de sélection » est un régime institutionnel constitué des dispositifs politiques, scientifiques, techniques, informationnels et organisationnels qui conditionnent la dynamique d'une population animale et le progrès génétique. Nous montrerons en quoi la «holsteinisation » en France s'est inscrite dans un régime coopératif et public de sélection, basé sur une industrialisation de type fordiste, et quels ont été les dispositifs mis en ouvre pour gérer cette tension entre ressources communes et dynamiques marchandes. Enfin, nous dessinerons à grands traits l'émergence d'un nouveau régime de sélection, celui de la sélection génomique dont la Holstein est le fer de lance. Ce régime s'appuie davantage sur une industrialisation de type segmenté de la ressource génétique, en opposition à une industrialisation tournée vers une production de masse de biens homogènes.

\section{" De la Hollandaise à la Prim'Holstein, chronique de la construction d'une race}

Si, d'un côté, des travaux en zootechnie ont étudié l'évolution génétique de la Holstein et, d'un autre, des travaux en socio-économie ont analysé l'évolution des 
marchés du lait et l'industrialisation laitière, il n'existe pas de travaux mettant en parallèle l'histoire de cette race et celle de l'industrialisation laitière. Sans avoir la prétention de combler ce vide, nous tentons ici d'identifier des dynamiques parallèles entre ces trajectoires. Cette vache, dont le nom officiel aujourd'hui est « Prim'Holstein », est, contrairement à la grande majorité des races françaises, présente dans tous les bassins laitiers et n'a pas de véritable attache territoriale. Comme le souligne Pellegrini (1999), la race Holstein « ne renvoie plus à la vache de cette région d'Allemagne, mais à la race laitière la plus performante, sélectionnée en Amérique du Nord et répandue sur la planète via les sociétés de commercialisation des semences ». Elle est issue d'un long processus de sélection et de croisements avec différents rameaux de bovins pie noire ${ }^{1}$.

L'histoire de la « Prim'Holstein » ne peut être réduite à des faits nationaux. Cette race a été introduite en France à partir de bovins des Pays-Bas et a ensuite bénéficié de divers apports extérieurs de «sang nouveau » venus d'autres rameaux, néerlandais dans un premier temps, puis américain dans les années 1965-1970. L'évolution du nom de cette race en France témoigne des différentes influences qui sont à l'origine de sa construction : « Hollandaise », « Française Frisonne Pie noire », « Française Frisonne » et enfin « Prim'Holstein ». Mais reprenons cette histoire à ses débuts.

La population de bovins dits «Pie noire » présents sur le globe semble provenir d'une même région : le littoral de la mer du Nord, une zone comprise entre la région de la Frise aux Pays-Bas, la région du Jütland au Danemark en passant par le Holstein en Allemagne ${ }^{2}$. Le développement de cette population au Pays-Bas prend un tournant important à partir du $\mathrm{XIX}^{\mathrm{e}}$ siècle. Les éleveurs hollandais commencent à mettre en place une sélection rationnelle de la production laitière qui va faire la renommée de leur bétail pie noire. Au milieu du XIX ${ }^{\mathrm{e}}$ siècle, les exportations prennent de l'ampleur et les acheteurs du continent européen (Angleterre, Belgique, Prusse etc.) « attachaient une grande importance aux caractéristiques et à la « pureté » de la race, ce qui rendait nécessaire l'enregistrement des filiations »(Denis, 2010). Deux HerdBooks $^{3}$ sont alors créés, l'un (NRS) pour le bétail néerlandais en général, plutôt laitier, et l'autre (FRS) spécifiquement pour le bétail de la Frise, plutôt mixte ${ }^{4}$ Ce n'est qu'en 1905 que la race Pie noire hollando-frisonne est officiellement désignée ainsi au Pays-Bas. À l'étranger, elle sera réputée pour ses aptitudes laitières et qualifiée tantôt de «Hollandaise » tantôt de «Frisonne ». Les premières exportations en Amérique du Nord, Canada et États-Unis, datent de 1852, donnant naissance au rameau nord-américain qui se développe sous le nom d' «Holstein Friesian ». Depuis cette date, la sélection outre-Atlantique s'est faite pratiquement sans apport de «sang nouveau » (de l'étranger). En effet, cette phase d'ouverture des échanges et de circulation de la génétique entre pays sera suivie par une phase de fermeture

1. Se dit de la robe d'un animal composée de larges taches blanches et d'une autre couleur; se dit de l'animal lui-même. On désigne souvent une robe ou un animal en associant le «pie » à la couleur (par exemple pie noire, pie rouge) (source : Larousse, en ligne).

2. Source : Prim'Holstein France, http://primholstein.com/ (consulté le 24 octobre 2016).

3. Registres sur lesquels sont inscrits les reproducteurs des deux sexes d'une race ainsi que leur filiation.

Ce terme peut aussi désigner l'organisme chargé de la tenue d'un tel registre ou fichier.

4. Se dit des races de bovins bonnes productrices à la fois de viande et de lait. 
des frontières de l'Amérique du Nord en 1905, par précaution sanitaire. Cette race, y ayant son propre Herd-Book et une association dédiée créée en 1885 (HolsteinFriesian Association of America), a été dès le début sélectionnée exclusivement sur des aptitudes laitières (lait de consommation, pauvre en matière utile) et un format très longiligne.

En France, au milieu du XIX ${ }^{\mathrm{e}}$ siècle, les animaux issus du rameau laitier de la Pie noire hollandaise-frisonne des Pays Bas étaient peu répandus. Des introductions d'animaux ont été attestées au XVIII ${ }^{\mathrm{e}}$ siècle dans le pays d'Auge (Denis, 2010), mais les importations commencent significativement dans les années 1830-1840. Cette vache hollandaise était de grande taille, faiblement musclée, avec des hanches saillantes et, surtout, très laitière (Spindler, 2002). Elle va progressivement s'étendre en France, d'abord au nord sous le nom de «Hollandaise ». Son implantation se fait principalement chez les «nourrisseurs », exploitations laitières autour des grandes villes à cette époque, particulièrement Paris (Denis, 2010). Il existait quelques étables avec des vaches hollandaises dans les zones industrialisées fortement peuplées : Nord-Pas-de-Calais, Picardie, Île-de-France, Gironde. Cependant, les autres tentatives d'introduction dans les campagnes n'ont pas été très fructueuses, notamment en raison d'une mauvaise adaptation du bétail hollandais aux conditions d'élevage les plus répandues à l'époque. Selon Denis (2010), pendant la seconde moitié du XIX ${ }^{\mathrm{e}}$ siècle, la race commence à s'implanter le long des frontières du Nord jusqu'en Alsace et, au début du xx ${ }^{\mathrm{e}}$ siècle, elle progresse en Champagne-Ardenne et en Lorraine. Cette vaste zone va passer progressivement d'une polyculture céréalière vers une économie herbagère et laitière, qui se développera surtout après la dernière guerre.

Aux Pays-Bas, la mise en œuvre d'un contrôle des performances laitières et la création de stations de sélection des taureaux interviennent dès le début du $\mathrm{xx}^{\mathrm{e}}$ siècle. Pour Flamant (2011), « les Hollandais et les Danois ont joué un rôle pionnier dans ce domaine au début du $\mathrm{xx}^{\mathrm{e}}$ siècle, en organisant l'enregistrement systématique des productions individuelles des vaches, par la mise en ouvre du contrôle laitier dans les troupeaux, de manière à disposer d'une information fiable et diffusable pouvant être utilisée par tous les éleveurs, par exemple à des fins de comparaison dans les concours d'animaux ». La France ne suivra cet exemple qu'au lendemain de la Première Guerre mondiale (contrôle laitier beurrier, syndicats laitiers dans l'Est) (Vissac, 2002 ; Flamant 2011). Parallèlement, la fin du XIX ${ }^{\mathrm{e}}$ siècle et le début du $\mathrm{XX}^{\mathrm{e}}$ siècle voient se développer une véritable industrie du lait grâce à l'évolution des moyens de transport et des techniques de stockage. Ainsi, grâce au chemin de fer et à la généralisation de la pasteurisation, le réseau d'approvisionnement de Paris en lait s'accroît fortement jusqu'à près de 300 km (Vatin, 1996).

L'importance du cheptel hollandais et le désir d'améliorer la race conduisent des éleveurs du Nord de la France à créer, en 1922 à Lille, le Livre généalogique de la race Hollandaise créé sous le nom de «Herd-Book français de la race Hollandaise ». Le rôle du Herd-Book est alors d'enregistrer les animaux répondant à un « standard de race » garantissant leurs origines (enregistrement des naissances et édition d'annuaires). Pendant l'entre-deux-guerres, les effectifs de la race augmentent nettement, passant de 200000 têtes en 1918 à 600000 en 1938 (Denis, 2010). La race atteint 840000 têtes en 1943, ce qui ne représente encore que 5,2 \% du cheptel 
bovin français (source : Prim'Holstein France). Cependant, à l'issue de la Seconde Guerre mondiale, l'effectif français de la race ayant été dévasté, de nouvelles importations des Pays-Bas auront lieu pour reconstituer les cheptels. L'expansion de la race se réalise principalement dans le Nord, le Nord-Est, le bassin parisien et le Sud-Ouest. L'activité du Herd-Book, qui s'installe à Cambrai, croît rapidement. Le contrôle laitier devient obligatoire pour les membres du Herd-Book à partir de 1948, marquant le début de la relation entre objectivation des mesures de la performance et enregistrement des généalogies, les deux piliers de la sélection génétique.

Jusqu'à la fin de la Seconde Guerre mondiale, les animaux des deux principaux berceaux (américains et européens) présentent les mêmes caractéristiques de production et de morphologie. C'est alors que les éleveurs américains vont intensifier la sélection de la Holstein-Friesian sur la production laitière et les qualités de mamelles, tandis qu'en Europe le travail de sélection est porté sur l'amélioration du taux butyreux ${ }^{5}$ et de la conformation ${ }^{6}$. Au Pays-Bas, la race Pie noire hollandofrisonne, réputée à l'origine pour ses aptitudes laitières, est orientée à partir de 1945, « à l'instigation principalement du FRS, vers un modèle à aptitudes mixtes équilibrées, ce qui se traduisit notamment par une réduction du format et un développement de la musculature » (Denis, 2010). En France, la sélection s'oriente vers un type mixte et la race « Hollandaise » est alors rebaptisée « Française Frisonne Pie Noire » (FFPN) en 1952, selon le modèle de la frisonne du FRS, mais il s'agit toujours d'une vache appréciée comme laitière ; les effectifs atteignent alors 1500000 têtes. Cette tendance n'est toutefois pas suivie par tous les pays, le Royaume-Uni, l'Italie et la province de Noord-Holland aux Pays-Bas vont conserver un animal plus laitier.

Après la Seconde Guerre mondiale, la progression de la race FFPN s'est donc poursuivie en France, en partie encouragée par une plus grande consommation des produits laitiers et une spécialisation de la production. C'est en effet à cette époque que les entreprises laitières font d'importants investissements, et que des sociétés comme Danone et Chambourcy se lancent dans la production de yaourts (Vatin, 1996). Pour cet auteur, au début des années 1960, Paris était donc doté d'une « authentique industrie laitière ». Toutefois, pour analyser cette évolution, il faut revenir à la situation de l'agriculture française au sortir de la guerre.

Au moment de la reconstruction, l'agriculture française est critiquée pour sa faible efficacité en comparaison des agricultures étrangères comme la danoise, la hollandaise ou l'américaine, comme pointé par Pierre Fromont dans un article du journal Le Monde du 28 mai 1946. Pour cet auteur d'un traité d'économie rurale, « la révolution technique agricole est loin de résider dans le remplacement du cheval ou du bœuf par le tracteur : ce n'est qu'un aspect, le plus spectaculaire sans doute, mais non le plus important. L'instrument essentiel de la production agricole est l'être vivant, plante ou animal ; [ce] sont les véritables machines-outils de l'agriculture » (Le Monde du 28 mai 1946, article de Pierre Fromont «La révolution technique en agriculture et la politique », cité dans Cranney, 1996). Cet extrait illustre l'attrait des logiques industrielles pour l'amélioration de l'efficacité et du rendement

5. Teneur en matières grasses du lait, exprimée en grammes par kilo de lait (TB).

6. Apparence extérieure de l'animal d'élevage, appréciée par rapport aux objectifs de production (lait, viande ou mixte) 
des techniques et des outils du domaine agricole, où les êtres vivants sont dès lors assimilés à des machines. La Holstein américaine deviendra l'emblème de cette logique dont le développement est aujourd'hui dénoncé, car « le prix à payer » a été la fragilisation des animaux et donc l'évolution en conséquence du métier de l'éleveur, devant assurer de nombreuses interventions sanitaires (Ruet, 2004 : 66).

\section{Pour Pierre Fromont en 1946 :}

« de même [que] dans le domaine industriel on a étudié le vieillissement et prévu le renouvellement de notre équipement en machines-outils, de même en agriculture, il importe de considérer l'efficacité de notre outillage biologique. Or, il faut bien reconnaître que, dans l'ensemble, il n'a pas profité du même effort de perfectionnement que celui de nombreux pays étrangers. Il ne faut jamais se lasser de poser le problème de l'efficacité de la machineoutil vivante [...]. C'est ce travail de création qui a été accompli sur une plus petite échelle en France qu'au Danemark, en Grande-Bretagne ou aux États-Unis. [...] Ainsi, pour ne prendre qu'un seul exemple, le rendement moyen annuel d'une vache laitière est évalué à 1800 litres environ en France et dépasse 3000 litres au Danemark. »

Cependant, pour lui et là où l'avenir le contredira, la solution ne viendra pas de l'importation :

« c'est sans aucun délai qu'il faut nous mettre au travail. Outre que le perfectionnement de l'être vivant est une opération nécessairement lente, puisque l'homme doit attendre le déroulement d'un cycle qu'il ne peut hâter, il est presque impossible de recourir à la méthode qui est prévue pour le renouvellement de nos machines-outils industrielles : l'importation en provenance de l'étranger » (ibid.).

Ainsi, comme l'explique J.-C. Flamant (2011), les chercheurs de l'Inra, dans les années 1960, ajustent le schéma de sélection des vaches Frisonnes « à la situation concrète des élevages » :

« dans le contexte français de petites exploitations, le bilan économique repose certes sur la vente du lait qui constitue une garantie mensuelle de revenu, mais aussi sur la valorisation bouchère des animaux [...] [ils proposent] un parcours de sélection des taureaux dont l'horizon vise à conforter un type français de la race Frisonne d'origine hollandaise, la « Française Frisonne Pie Noire », avec un objectif d'augmentation de la production laitière des troupeaux pour être compétitif à l'échelle des pays de la Communauté européenne, tout en préservant les aptitudes bouchères » (Flamant, $2011: 2$ ).

Cependant, l'importation de génétique Holstein jouera un grand rôle dans le développement du cheptel français.

En parallèle, au cours des années 1960-1970, la « deuxième révolution laitière » (Vatin, 1996) est basée sur le développement d'élevages laitiers intensifs, « avec la création d'étables rationnelles, l'accroissement du rendement des vaches laitières, l'intensification des liens fermes-usines par la mise en place de la réfrigération à la ferme et du paiement du lait à la qualité » (ibid.). Le contexte économique favorable à la production laitière va inciter les éleveurs européens à importer massivement des taureaux Holstein des États-Unis et du Canada pour améliorer la productivité laitière de leurs animaux et ainsi intensifier leur production. Le processus d' « holsteinisation » débute, dans plusieurs pays européens et en France, sous l'influence des croisements réalisés avec la souche «Holstein » nord-américaine ; la FFPN mixte se spécialisera en production laitière, augmentera son gabarit et la qualité de sa mamelle. 
Denis (2010) rappelle « qu'au préalable, quelques tentatives de recours à des Frisonnes moins spécialisées [que la Holstein Friesian américaine] mais néanmoins meilleures laitières que le modèle mixte (British Friesian, Frisonne du Noord-Holland) avaient été tentées », sans succès face à ce qui allait devenir le « raz de marée Holstein ». Les premières introductions de bovins Holstein-Friesian (Amérique du Nord) ont lieu en 1965 et 1966 dans le département de l'Isère. Ce tournant ne provoque pas immédiatement un engouement particulier des éleveurs, notamment vis-à-vis d'un bétail qui est alors jugé inadapté aux conditions de l'élevage européen et avec une santé particulièrement fragile. Néanmoins, les éleveurs ont peu à peu appris à alimenter correctement ces vaches laitières à haut potentiel.

«Les conditions économiques s'avèrent de plus en plus favorables à l'augmentation de la production laitière par vache, les Américains développent une politique commerciale particulièrement efficace, la demande augmente du côté des éleveurs et les organismes officiels finissent par encourager le mouvement » (Denis, 2010).

En 1972, la race FFPN devient la première race française en termes d'effectif avec 6 millions de têtes, dépassant ainsi la Normande (5,7 millions, à son apogée). Au niveau européen, dans les années 1970, 8 populations nationales de Frisonnes Pie Noires constituent la grande majorité des 23 millions de vaches laitières de la CEE (Vissac, 2002 : 174) et vont constituer « la cible d'une absorption par la Holstein américaine » (ibid.). C'est en 1979 que la race devient la "Française Frisonne » (FF), qui englobe alors les animaux de l'ancien type hollandais, les animaux nés Holstein en France et les croisés Frison $\times$ Holstein.

Le processus d'« holsteinisation » est à la fois biologique et institutionnel. Il s'est déroulé selon des temporalités et des dynamiques différentes selon les pays européens. Par exemple, Vissac (2002) indique l'intérêt tardif des éleveurs du RoyaumeUni pour l'introduction de Holstein américaines, qu'il associe à un moindre intérêt pour l'amélioration des rendements laitiers individuels du fait de la grande taille des troupeaux (le Royaume-Uni avait fait le choix d'un type laitier dès le début avec les importations de hollandaises laitières). De même, les Pays-Bas auront une politique tardive d'infusion massive de Holstein américaine. Vissac (2002) fait l'hypothèse d'une position défensive des Pays-Bas, berceau racial de l'ancêtre de la Holstein. La part de la souche Holstein nord-américaine dans le cheptel français est passée de $40 \%$ vers 1970 à $78 \%$ au début des années 1990 (Boichard et al., 1993, 1996). Boichard et al. (1993) indiquent également que le pourcentage de gènes Holstein dans la population des taureaux d'insémination artificielle $\left(\mathrm{IA}^{7}\right)$ Pie Noire en France était faible avant 1970 et a ensuite fortement augmenté. À partir des années 1980, la part de sang Holstein est proche de $100 \%$ pour les taureaux utilisés pour l'insémination. Ainsi, le pourcentage de gènes Holstein chez les femelles est passé de $5 \%$ en 1970 à $83 \%$ en 1990, ce qui était nettement supérieur à la prévision, même la plus haute, qui avait été établie par les généticiens statisticiens de l'Inra (Colleau et Tanguy, 1984), et atteste de l'évolution brutale et inattendue de cette « holsteinisation ». À la veille de l'instauration des quotas laitiers, le processus d'absorption du rameau américain peut être considéré comme irréversible. Néanmoins, le gain de productivité s'est accompagné d'autres évolutions telles que l'augmentation du

7. Auparavant appelée insémination artificielle, aujourd'hui dénommée insémination animale. 
format, le changement de conformation, l'amélioration de la forme de la mamelle et une dégradation de la fertilité des femelles. De plus, l'arrivée de la Holstein en France ne s'est pas déroulée aussi sereinement que l'on pourrait le penser. Elle a opposé, parfois vivement, partisans et détracteurs dans les campagnes. Duroselle (1980) note que la Holstein était alors le « fin du fin de la sélection moderne en matière de lait pour les premiers » et « décrite comme une calamité par les autres ».

Plusieurs années après la loi sur l'élevage (1966), l’Union pour la sélection et la promotion de la race (Upra) de la Holstein (Française Frisonne à l'époque) est créée en 1975 (association Loi 1901). Dispositif collectif déterminant la visée assignée à la ressource commune qu'est la race (Allaire et al., 2016), elle vise à définir l'orientation de sa sélection, mais aussi à assurer des services aux éleveurs, gérer la tenue du livre généalogique des animaux qui en font partie et assurer la promotion de la race. Le siège de l'Upra est installé depuis 1989 à Saint-Sylvain-d'Anjou (Maine-etLoire) afin de se rapprocher des zones à forte densité d'élevages de l'Ouest de la France. En 1990, dans le but de « mieux faire connaître les efforts consentis au plan génétique et l'importance numérique de la race en France », l'Upra décide « d'abandonner à la fois les qualificatifs "Française" et "Frisonne" » et opte pour un nouveau nom : le choix se porte sur « Prim'Holstein».

La structure associative Upra a été créée comme une structure hybride, à la fois parlement de la race et organisme de conseil et de services aux adhérents (éleveurs). Ce mélange ambigu entre les fonctions régaliennes et les fonctions de services « posait quand même un certain nombre de soucis [...]» (D. Bieri, directeur PHF, entretien 2014). Suite à la réforme de la loi sur l'élevage en 2006 (Loi d'orientation agricole), Prim'Holstein France (PHF) devient, le $1^{\text {er }}$ juillet 2008, l'Association des éleveurs de la race bovine Prim'Holstein, avec pour objectif majeur de proposer « des services indépendants pour conseiller les éleveurs laitiers dans leurs choix génétiques et leur gestion de troupeau » (Prim'Holstein France). Les missions réglementaires (tenue du Livre généalogique, orientation de la race) sont confiées à une nouvelle organisation, l'Organisme de sélection «OS Prim'Holstein ». Cet OS est le « parlement de la race », où siège : Prim'Holstein France représentant les éleveurs adhérents ; les entreprises de sélection et les coopératives de mises en place (insémination artificielle) représentant les acteurs de la création et de la diffusion du progrès génétique ; et enfin les partenaires (contrôle laitier, EDE - Établissement départemental de l'élevage -, Cniel - Centre national interprofessionnel de l'économie laitière). En 2009, sur décision du ministère de l'Agriculture, un représentant de la race Pie Rouge (anciennement Pie Rouge des Plaines) est intégré comme quatrième membre à cet $\mathrm{OS}$ car la race possède une part importante de gènes Holstein (« red»), entre 90 et 95 \% (Directeur PHF, entretien 2014). Aux niveaux départemental et régional, des associations d'éleveurs ont été créées afin d'assurer une animation locale pour la race en organisant par exemple des concours d'animaux. Ces structures, bien qu'indépendantes de PHF, sont soutenues financièrement et techniquement dans l'organisation de ces activités. En 2014, PHF rassemble environ 6700 éleveurs adhérents et différents syndicats ou associations départementales de la race. Depuis quelques années, l'accent a été mis sur les critères fonctionnels, c'est-à-dire la reproduction et la santé, tout en cherchant à conserver un niveau de production élevé. Les différents composants de l'index de synthèse (Isu) global 
(permettant d'attribuer une valeur aux reproducteurs) révèlent la stratégie raciale choisie conjointement par les différents membres de l'OS. Ainsi, lors de sa dernière révision en 2012, les pondérations de l'Isu étaient les suivantes : les index de production laitière $(35 \%)$, de morphologie $(15 \%)$, fertilité $(22 \%)$, santé mamelle $(18 \%)$, longévité $(5 \%)$ et vitesse de traite $(5 \%)$.

En 2010, la race représente plus de $60 \%$ des vaches laitières françaises, ce qui témoigne du fort développement de cette race sur tout le territoire français et de son hégémonie par rapport aux autres races laitières. Au $1^{\mathrm{er}}$ janvier 2013, le cheptel français de race Prim'Holstein compte 2422000 vaches, soit $31 \%$ des vaches sur le territoire (laitières et allaitantes confondues) (données BDNI, traitement Idele). Chaque année, plus de 2500000 vaches sont inséminées en race pure Holstein (source : Prim'Holstein France). La production laitière moyenne des vaches de race Holstein en France est de $9329 \mathrm{~kg}$ de lait en 355 jours de production (données Contrôle laitier 2014, lactations brutes) avec en moyenne un taux butyreux de $39,1 \%$ et un taux protéique de $31,9 \%$.

Cette histoire, à la fois génétique et socioéconomique, de la « holsteinisation » du cheptel français s'est déroulée dans le cadre d'un régime fordiste de la sélection animale que nous détaillons ci-après.

\section{"Une holsteinisation qui s'inscrit dans un régime coopératif et public de sélection}

Avec la Loi sur l'élevage de 1966, l'État français met en place un dispositif national centralisé de sélection des races animales, notamment pour les espèces bovine, ovine et caprine, sur la base d'une alliance entre le monde des éleveurs, celui de la recherche (les généticiens de l'Inra) et l'administration. Pour Flamant (2011), la sélection d'une race animale, « dont le patrimoine génétique est considéré comme étant d'intérêt commun », justifie « les investissements publics qui lui sont affectés à tous les maillons de la chaîne » (Flamant, 2011). À partir des années 1960 et jusqu'au début des années 2000, se constitue ce que nous avons défini par ailleurs comme un « régime coopératif et public de sélection » (Labatut et al., 2013). La mutualisation des ressources et la gestion « en commun » de la race sont au cour de ce régime, dans lequel le dispositif génétique national est fortement financé par l'État, qui veille à la fois à contrôler la consanguinité et à assurer la diffusion nationale du progrès génétique. En effet, pour une économie nationale et la sécurité alimentaire, le progrès génétique peut être considéré comme un bien commun (Allaire et al., 2016). Pour atteindre cet objectif, la loi définit les rôles des différents acteurs de la sélection. La CNAG (Commission nationale d'amélioration génétique), réunissant agents du ministère de l'Agriculture, scientifiques et acteurs de la sélection génétique, encadre les activités de sélection (validation de l'agrément des Upra, objectifs de sélection, régulation des ventes de semences, etc.).

L'Inra, ainsi que l'Institut de l'élevage se voient confier par l'État une mission de gestion des systèmes nationaux d'information génétique. Il s'agit de bases de données nationales zootechniques, partagées par l'ensemble des acteurs de l'élevage 
constituant un socle d'informations publiques. L'évaluation des reproducteurs, la fonction régalienne de calcul des estimations de la valeur génétique des animaux (les index), est également confiée à l'Inra, en plus de ses missions de recherche, et à l'Institut de l'élevage. Contrairement au domaine de la sélection végétale où les objectifs et les critères de performances assignés aux variétés sont définis par les entreprises privées qui les produisent, dans le cas de ce régime de sélection animale coopératif et public, les objectifs de sélection assignés aux races et traduits dans des index génétiques, qui évaluent la valeur génétique de chaque animal selon ces objectifs, sont définis collectivement au sein des Upra. Dans ce régime, comme nous l'avons montré par ailleurs, " marché, coopération et domaine public ne sont pas opposés mais s'interpénètrent » (Labatut et al., 2013). La reconnaissance de l'enjeu public autour de ces ressources communes n'a ainsi été réellement établie qu'à la mise en place de dispositifs de marché qui assuraient la répartition des gains de progrès génétique et la durabilité de la ressource (Labatut et al., 2013). Ainsi, la Loi sur l'élevage a régulé le marché de la semence et de l'IA en limitant la concurrence, notamment en définissant un monopole de zone pour les coopératives d'insémination. Cette organisation du marché de la semence avait pour but d'assurer un accès au service d'insémination ainsi qu'au progrès génétique à un prix juste pour l'ensemble des éleveurs. Les coopératives d'insémination ont alors été investies d'une mission de service public de diffusion du progrès génétique.

Il est admis que ce régime de sélection a «permis [aux éleveurs] d'investir en toute sécurité dans des schémas de sélection à longue échéance. Aujourd'hui, il est reconnu que la stratégie mise en œuvre, dans un objectif de mutualisation, a porté ses fruits » (séminaire CSAGAD, 18 octobre 2006). Ce régime de sélection a accompagné le développement de la race Holstein en France dans un environnement structurel caractérisé par des troupeaux de petite taille dans une diversité de systèmes et de terroirs, comparativement aux pays historiquement exportateurs de génétique de cette race. Si la génétique Holstein française s'est relativement peu exportée durant ces années de la Loi sur l'élevage, elle a suffisamment progressé pour concurrencer la génétique nord-américaine sur le territoire. Ainsi, c'est sur la base de ce régime coopératif et public que s'est développée ce que l'on peut appeler une industrialisation fordiste de la génétique bovine. D’une part, celle-ci reposait sur une cohérence entre les entreprises et la «consommation de masse » de génétique (des objectifs collectifs de sélection et donc une offre non différenciée, une diffusion des semences par le service d'IA sur l'ensemble du territoire). D'autre part, se sont constitués des groupes socioéconomiques dotés de représentations collectives (les Upra). Comme dans la forme monopoliste-fordiste identifiée par la théorie de la régulation (Boyer, 2002), l'ouverture internationale des entreprises et du commerce de la génétique française restait faible et l'État contrôlait les échanges (au travers de la CNAG). Dans ce régime de sélection, les tâches de conception et d'exécution des schémas de sélection étaient clairement séparées entre les instituts publics, qui concevaient les schémas de sélection et les outils d'évaluation génétique, et les coopératives d'éleveurs, qui mettaient en œuvre ces schémas et commercialisaient les semences évaluées par l'Inra et l'Institut de l'élevage.

En France, cette forme d'industrialisation a participé au développement d'un marché de la génétique de la race Holstein, au même titre que dans d'autres pays, tout en 
participant malgré tout à une certaine forme de standardisation et à la réduction d'une partie de la biodiversité domestique (abandon des races les moins productives ; Audiot, 1995). En effet, la France possédait historiquement une grande diversité de races animales en fonction des terroirs et des produits régionaux traditionnels. L'un des enjeux identifiés était donc d'éviter que la Holstein remplace toutes les autres races laitières françaises dans les filières économiques. Vissac alertait dès le début des années 1970 sur la diminution du nombre de races : « le nombre de races bovines comprenant plus de 100000 femelles reproductrices est tombé de 21 en 1945 à 7 en 1971 »(Vissac, 2009 : 136). Comparativement à d'autres pays, ce régime de sélection a malgré tout été reconnu comme préservant une certaine diversité :

« le dispositif français est unanimement considéré comme performant car il a permis, alors même que ses instigateurs n'en mesuraient pas l'importance, de préserver notre diversité animale et raciale. C'est un point fort de l'élevage français, qui résulte de l'histoire et de la géographie. La France est sans doute le pays au monde qui possède l'élevage le plus diversifié en matière de races. Le système mutualisé de sélection a permis de travailler simultanément sur de nombreuses espèces et races » (Giroud, 2009).

Comme nous l'avons indiqué par ailleurs (Labatut et al., 2013), ceci est notamment lié au rôle de l'État et de la profession agricole dans la structuration des activités de sélection. Ainsi, si la Holstein est devenue majoritaire, d'autres races restent malgré tout fortement implantées dans des filières économiques importantes (Normande, Montbéliarde, Brune, Simmental, Tarentaise, Abondance, Vosgienne, etc.). Certaines d'entre elles sont même en développement dans des zones historiquement «Holstein », comme la Montbéliarde, en raison de ses caractéristiques plus rustiques (Courdier et al., 2012).

\section{" Le régime de la sélection génomique : vers une industrialisation segmentée?}

Depuis 2006, des changements politiques et technologiques profonds ont bouleversé les activités de sélection animale et ont conduit à l'émergence d'un nouveau régime de sélection (Labatut, 2013 ; Labatut et al., 2013 ; Allaire et al., 2016). En 2006, la Loi sur l'élevage de 1966 est révisée dans le cadre de la LOA (Loi d'orientation agricole), qui réorganise l'infrastructure de la sélection génétique et le rôle des acteurs.

Plusieurs années auparavant, le système de monopole territorial des coopératives de sélection avait été dénoncé par le Conseil de la concurrence français qui avait condamné la filière génétique à une amende pour entrave à la libre concurrence suite à des plaintes de vétérinaires et d'opérateurs privés ${ }^{8}$ étrangers voulant s'implanter sur le marché français. Les acteurs de la sélection et l'État se sont alors mobilisés pour réorganiser le secteur au travers de la LOA de 2006, qui supprime le monopole de zone des coopératives de mise en place, encourageant ainsi une libéralisation des marchés de la génétique, mais préservant l'accès au progrès génétique à tous au travers de la mise en place d'un Service universel d'insémination

8. Décision $n^{\circ}$ 04-D-49 du 28 octobre 2004 relative à des pratiques anticoncurrentielles dans le secteur de l'insémination artificielle bovine. 
artificielle (SUIA). Chaque éleveur est maintenant libre de choisir son entreprise de mise en place de la semence ou son opérateur de vente de doses de semence. Le SUIA intervient sous la forme d'appels d'offres pour assurer la couverture des zones à faible densité d'élevage et l'utilisation de semences de races à plus petits effectifs.

L'État diminue ses financements à la génétique animale, ayant atteint l'objectif historique de 1966 de rejoindre le niveau génétique des pays concurrents. Il délègue alors le pouvoir et la responsabilité de gérer le système national de sélection à une interprofession des acteurs de la sélection, FGE (France génétique élevage). Les missions de la CNAG ont été largement réduites : la gestion de la filière est devenue principalement professionnelle. Dans la LOA, les coopératives de sélection deviennent des ES (entreprises de sélection) et les Upra des OS (organismes de sélection), intégrant en théorie davantage les acteurs de l'aval des filières de production utilisant les races sélectionnées et gérées par les OS. Dans certains cas (comme celui de la Brune), les acteurs fusionnent pour créer des OES (organismes et entreprises de sélection), réunissant alors à la fois la gouvernance et la réalisation des schémas de sélection. Comme nous avons pu le rappeler (Labatut et al., 2013), un aspect central de cette nouvelle organisation est que l'État maintient malgré tout le monopole de production d'index « officiels » confié aux instituts publics de recherche et développement (Inra, Institut de l'élevage), et la gestion du système d'information génétique reste publique. Cependant, rapidement, d'autres changements liés à des nouvelles technologies (aussi profonds que lorsque l'IA a été développée) vont bouleverser ces principes. Notons déjà que la suppression du monopole de zone a contribué à accélérer le regroupement des opérateurs et les fusions entre coopératives. En 2015, il existe trois principales ES ayant un schéma de sélection pour la race Holstein au niveau français : Évolution, Gènes diffusion et Origenplus.

À partir de 2009, un changement de technologie radical entre en jeu dans les évolutions organisationnelles du secteur : la génomique. Cette innovation a été développée, dans un premier temps, pour les trois principales races laitières françaises (Holstein, Montbéliarde, Normande) grâce à une nouvelle forme de partenariat public-privé (mis en place dès le début des années 2000) par rapport aux modes précédents de coopération pour l'innovation : un consortium entre recherche publique et quelques entreprises de sélection partenaires. La génomique permet d'évaluer quasi instantanément le potentiel génétique d'un animal grâce à une puce à ADN, sans passer par les longues étapes du testage sur descendance (où on ne pouvait connaître la valeur d'un taureau que lorsque celui-ci avait suffisamment de filles contrôlées, c'est-à-dire au bout de quatre ou cinq ans). Nous détaillons le fonctionnement de la technologie d'évaluation génomique de façon plus précise dans de précédents écrits (Labatut et al., 2014). L'enjeu est ici d'identifier les différents changements qui permettent de mieux comprendre ce nouveau régime de sélection et l'évolution de la forme d'industrialisation de la génétique qui lui est concomitante.

Comme nous l'avons montré par ailleurs, le système complexe de ressources communes sur lequel reposent les activités de sélection en agriculture a deux composantes : 
- des ressources génétiques : le génome de la population qui constitue la race, pris dans sa globalité (et donc difficilement séparable et privatisable) ;

- des ressources informationnelles : le système d'information sur lequel repose un dispositif de sélection. «Ce système d'information concerne des attributs non directement observables par la morphologie des animaux (comme leur ascendance et descendance, ou leurs performances et celles de leurs ascendants ou descendants : quantité de lait produite par vache, quantité de viande, données de santé, etc.). Selon le régime de sélection, ce système d'information peut être plus ou moins codifié et transparent. Il peut être géré par un club d'éleveurs ou institué comme domaine public (comme c'est le cas en France depuis la Loi sur l'élevage de 1966), ou développé par des entreprises privées (cas les plus récents) » (Labatut et al., 2013).

Les changements dans ce nouveau régime s'opèrent dans ces deux composantes, en parallèle d'une transformation du régime de connaissance lié aux nouvelles technologies (génotypage mais aussi sexage, OPU-FIV ${ }^{9}$, etc.). La production, le traitement et la diffusion des données (phénotypes et génotypes) deviennent un enjeu stratégique majeur de différenciation pour les acteurs dans un contexte concurrentiel. La production de données génétiques, qui reposait sur le suivi dans les fermes d'un nombre important (mais limité) d'animaux afin de mesurer la valeur d'un reproducteur sur sa descendance, s'opère dans des conditions totalement différentes à partir du décryptage du génome qui peut s'effectuer au premier stade embryonnaire et mobilise des techniques pointues, généralement sous brevet. De fait, les opérateurs de la production de données se réorganisent. Ainsi, le laboratoire Labogena réalisait les génotypages pour la presque totalité des acteurs de la sélection grâce à l'investissement en 2008 dans une chaîne d'analyse Illumina - fabricant de puces à $\mathrm{ADN}$ - pour la recherche et la sélection génomique. Ce GIE (groupement d'intérêt économique), créé en 1994, regroupait jusqu'en 2013 l'Inra et des membres professionnels de la sélection (dont l'UNCEIA - Union nationale des coopératives agricoles d'élevage et d'insémination animale -, l'Apca - Assemblée permanente des chambres d'agriculture -, Races de France et l'Institut de l'élevage). En 2013, suite à différents problèmes financiers et à des désaccords dans la gouvernance du laboratoire, Labogena est mis en vente et racheté par Évolution, groupe issu de la fusion de plusieurs entreprises françaises de sélection, aujourd'hui l'un des principaux opérateurs de sélection bovine au niveau mondial.

Parallèlement, si l'Inra conserve jusqu'à présent le monopole réglementaire de la production d'index officiels selon la LOA 2006, une partie du service d'indexation devient marchand. Ainsi, des entreprises ou des structures régionales développent et proposent aux éleveurs leurs propres outils d'évaluation génomique. Gène diffusion, entreprise de sélection du Nord de la France, s'est ainsi associée à l'Institut Pasteur de Lille et à l'Université de Wageningen pour développer son propre système d'évaluation, GD Scan, sur des critères propres (la santé des pieds) pour la Holstein. Ingenomix, société de biotechnologie créée à l'initiative des professionnels français de la race Limousine, s'est spécialisée dans « les études d'association entre les phénotypes et les génotypes et dans l'ingénierie des tests $\mathrm{ADN}$ qui en découlent ${ }^{10}$,

9. Méthode de récolte des ovocytes et de fécondation in vitro en vue d'un transfert embryonnaire qui consiste à collecter ces ovocytes sur un animal vivant par ponction guidée par échographie.

10. http://www.ingenomix.fr/qui-sommes-nous.html (consulté le 7 mai 2015). 
et a développé Evalim, outil d'évaluation génétique privé. Ainsi, « les technologies génomiques substituent au lourd dispositif collectif et public de testage sur descendance un service privatisable, celui du génotypage des animaux grâce à des puces à $\mathrm{ADN}$ permettant la récupération à bas coût des informations sur le génome de chaque animal » (Labatut et al., 2013).

L'Inra et l'Institut de l'élevage ne sont plus les seuls partenaires de la R\&D pour les acteurs de la sélection, même si ces deux opérateurs continuent jusqu'à présent à réaliser les indexations sur les critères communs et historiques de sélection. Certains opérateurs privés s'orientent de plus en plus vers une logique d'intégration des différentes étapes de la production et du traitement des données, qu'il s'agisse du rachat de Labogena ou de projets en cours d'intégration d'organismes de contrôle de performance par les ES. Ainsi, le Snig (Système national d'information génétique), autrefois entièrement public, est aujourd'hui dans une phase de transition où, si les moyens de collecte de données restent mutualisés, certaines parties des bases régionales de données permettent une exploitation privative, pour la R\&D comme pour l'évaluation génétique. En effet, certains partenaires professionnels peuvent demander aux instituts publics de travailler avec eux sur certaines données ou certains critères de sélection sans que cela soit partagé et mis en commun avec tous les acteurs de la sélection. Cette logique d'intégration dépasse d'ailleurs largement les opérateurs historiques. Ainsi, depuis le développement de la génomique, la technologie du sexage de la semence a pris beaucoup d'ampleur, permettant d'optimiser et de rentabiliser encore plus l'utilisation de la génomique en favorisant la génération d'individus femelles dans le cas des accouplements entre animaux à haute valeur génétique. Une entreprise américaine, Sexing Technologies, a le monopole de cette technologie, dont elle a racheté l'ensemble des brevets, et outille maintenant les entreprises de sélection au niveau mondial. Grâce aux bénéfices apportés par ce succès technologique, cette entreprise investit maintenant dans la sélection génétique des reproducteurs. Propriétaire de taureaux, elle se positionne comme vendeur de semences et investit dans des fermes expérimentales de grandes tailles pour produire les données suffisantes nécessaires à la sélection sur des critères spécifiques de différenciation.

Si cette innovation technologique reconfigure, comme nous venons de l'illustrer, les droits de propriété liés à la production des informations génétiques, elle s'accompagne également d'évolutions importantes au niveau de la deuxième composante du système de ressources communes : celle des ressources génétiques et de l'offre de semence indexée. En effet, dans le régime précédent, l'offre génétique par race n'était pas différenciée (au-delà des variations individuelles d'un taureau à l'autre), les objectifs de sélection, traduits dans l'Isu (Index synthèse unique), étaient collectivement décidés au sein de l'OS et communs à toutes les ES. Dans le nouveau contexte concurrentiel de la LOA 2006 et du fait des possibilités offertes par la génomique (possibilité de créer de nouveaux critères de sélection «privés », indépendamment du lourd dispositif de testage sur descendance précédente), les ES cherchent à se différencier de la concurrence par une offre segmentée et diversifiée. Ces entreprises font appel à des consultants en marketing et investissent dans la création d'images de marque. Elles mobilisent des études identifiant des typologies d'éleveurs, dont elles font émerger des « segmentations comportementales » 
ou des profils d'utilisation de la génétique. Ainsi, l'un des dirigeants de ces entreprises, dans un discours introductif, mobilisait comme phrase d'accroche la citation de Christophe Lafougère dans La France agricole du 21 mai 2014 (directeur de Gira Food, cabinet de consultants spécialisé dans les études de marché) : «l'avenir est à la segmentation », ajoutant que « l'investissement dans la marque, dans l'image, c'est vraiment un investissement d'avenir ».

Ces entreprises construisent ainsi non pas une offre de taureaux Holstein, mais une offre segmentée de semence de leur «marque » de Holstein, dont elles développent l'image. Elles favorisent les accouplements génétiques « cumulatifs » et non « correctifs » pour produire des taureaux correspondant à ces segments : segment « production », segment « qualité », segment « santé », segment « autonomie, rusticité ». Certaines entreprises ont d'ailleurs mis en place la vente de packs de semences de taureaux correspondant à des segments. L'offre génétique n'est donc plus tant centrée sur la race ou le taureau individuel que sur une segmentation par profil (notamment du fait que, par la génomique, les taureaux sont renouvelés beaucoup plus vite dans les catalogues et sont plus nombreux, et donc moins connus par les éleveurs).

Ces éléments nous conduisent à identifier le passage d'un marché de masse, dans lequel une offre réduite de taureaux «stars » s'adressait à l'ensemble des éleveurs, à un marché par segment (dans lequel les taureaux « stars » gardent finalement leur place), le passage d'une industrialisation fordiste à une industrialisation flexible proposant la création d'une diversité de Holstein adaptées à différents enjeux. Ainsi, ce nouveau régime semble proposer non pas une réorientation de la sélection animale vers plus de durabilité, mais une segmentation dans laquelle certains de ces segments seront destinés, comme auparavant, à la création de vaches Holstein de plus en plus productives, tandis que d'autres seront tournées vers la création de vaches Holstein affichées comme « durables » ou « rustiques » (résistances aux maladies par exemple). Cette perspective, autour de laquelle s'est développé un consensus de plusieurs types d'acteurs, suppose une compatibilité des différents modèles de production correspondant.

Ces premières évolutions observées seront vraisemblablement renforcées par un nouveau changement politique profond : le Règlement zootechnique européen en cours de validation et prévu pour une mise en œuvre d'ici 2017. Ce texte, pour « simplifier et harmoniser les conditions d'échange de données, de matériel génétique entre les différents pays européens » (Dantin, discours SIA - Salon international de l'agriculture -2015), vise à se substituer à l'organisation historique des États en termes de gestion des livres généalogiques, de mise en œuvre des programmes de sélection, du contrôle de performance et de l'évaluation génétique, pour les espèces bovine, ovine, caprine, porcine et équine. Renforçant le mouvement de libéralisation des marchés de la génétique déjà entamé, ce règlement consiste « à passer d'un système encore assez fortement administré à un système basé essentiellement sur la contractualisation » (dossier de presse FGE - France génétique élevage - du 16 janvier 2015) et sous le " régime de la responsabilité propre » (Michel Dantin, discours SIA 2015). Le règlement est structuré autour de breeding societies (BSue), qui cumuleront à la fois les missions de tenue du Livre généalogique et de réalisation du programme de sélection, et auxquelles seront rattachées les activités de contrôle 
de performance et l'évaluation génétique (tandis que ces activités étaient jusqu'à présent, en France, prises en charges par des opérateurs différents travaillant en synergie dans un système mutualisé). Les BSue agréées pourront ainsi choisir leurs prestataires de services pour les contrôles de performance comme pour l'évaluation génétique, ces deux activités se retrouvant ainsi sur le marché par appel d'offres. Ce règlement rend également possible l'agrément de plusieurs BSue pour une même race (tandis qu'un seul OS par race était autorisé jusqu'à présent, définissant les objectifs de sélection pour l'ensemble de la race). Ainsi, nous pouvons faire l'hypothèse que chaque BSue, en intégrant l'ensemble des étapes de la sélection, et en choisissant ses propres objectifs de sélection et son propre système d'évaluation, participera à ce mouvement de différenciation déjà engagé, en France, depuis 2006 avec la LOA et la génomique, et encouragera le développement d'une gouvernance polycentrique des races et une segmentation accrue de l'offre génétique.

À l'heure où ce chapitre s'écrit, le règlement est débattu au sein des instances professionnelles et scientifiques françaises, avec des avis très divergents. Pour l'interprofession, ce règlement serait l'occasion de « placer l'éleveur au centre du dispositif et de créer les conditions d'une restructuration et d'une rationalisation des organismes et des entreprises qui gravitent dans la sphère génétique, pour accroître la compétitivité de l'élevage européen » (dossier de presse FGE du 16 janvier 2015). Un audit, réalisé en 2016 pour le compte de la Commission nationale de l'élevage, voit ce nouveau règlement comme une opportunité pour faire évoluer le système d'organisation précédent considéré par certains comme complexe et peu réactif. Cependant, l'audit propose un maintien d'une certaine logique mutualiste avec un fort pouvoir interprofessionnel. Pour certains politiques européens, ce règlement est l'occasion d'offrir « un espace de liberté, espace de liberté sous contrôle, [permettant aussi d'élargir] le champ de la créativité » (Michel Dantin, interview SIA, 2015). Pour les acteurs scientifiques et les instituts publics, jusqu'à présent en charge de la mission réglementaire de l'évaluation, les craintes sont un morcellement des activités de R\&D et une perte d'efficacité à long terme dans les innovations scientifiques à destination des acteurs de la sélection. Chaque groupe d'acteurs travaille aujourd'hui à l'élaboration de divers scénarios d'application. Les prochaines années seront donc cruciales pour observer l'évolution de ces débats et la mise en œuvre concrète de ces changements politiques et organisationnels profonds.

\section{" Conclusion}

Cette courte synthèse historique de la « holsteinisation » et des régimes de sélection qui l'ont accompagnée permet de soulever différents enjeux autour de la gestion des biens communs et des nouvelles formes d'industrialisation de l'agriculture. $\mathrm{Ce}$ qui est « commun » dans la Holstein en tant que race est un bien intangible (en ce sens que la production des ressources génétiques est le résultat de la façon dont le flux de ressources produit est lui-même utilisé) et, l'on pourrait dire, « ingouvernable ». Par sa dimension systémique, cette institution échappe en quelque sorte aux volontés de gouvernement, et ce d'autant plus lorsque l'on se trouve dans le régime de sélection actuel, celui de la génomique, qui semble favoriser une gouvernance 
polycentrique. Aurons-nous dans quelque temps plusieurs Holstein au sein d'un même pays ? Se dirige-t-on vers plusieurs « marques » et une dislocation de la notion de « race » ? Est-ce que l'enjeu de maintenir une diversité de races sur un territoire n'est pas encore plus menacé face à une Holstein qui ne sera plus « unique » mais «plurielle» (Holstein « durable », « rustique »...) et pourra peut-être davantage se positionner sur les mêmes marchés que les races rustiques à plus faibles effectifs ? On peut imaginer que la dimension culturelle des races plus territorialisées continuera à favoriser le maintien d'une certaine biodiversité. Si la génomique est souvent présentée comme une opportunité pour sélectionner les animaux sur des critères plus durables (Institut de l'élevage et Inra, 2011), les premières observations semblent plutôt montrer que la technologie est avant tout utilisée pour multiplier la vitesse du progrès génétique et accroître les parts de marché de la Holstein pour les entreprises qui souhaitent différencier leur offre (ainsi l'ajout d'un critère «santé » peut tout aussi bien s'accompagner de l'augmentation du poids donné au critère « quantité de lait» dans un index synthétique privé).

Alors que le régime coopératif et public précédent était largement critiqué par une partie des éleveurs « alternatifs » impliqués dans des dynamiques de type «semences paysannes » pour la sélection de leurs ressources végétales, le dispositif national français étant considéré comme trop complexe (Bessin, 2012), nous pouvons nous interroger sur la façon dont ces acteurs s'inscriront dans les dynamiques actuelles de libéralisation de la sélection et d'industrialisation flexible. Que restera-t-il de commun dans les formes de sélection animale à venir ? Observerons-nous l'émergence d'initiatives de réhabilitation des communs? 



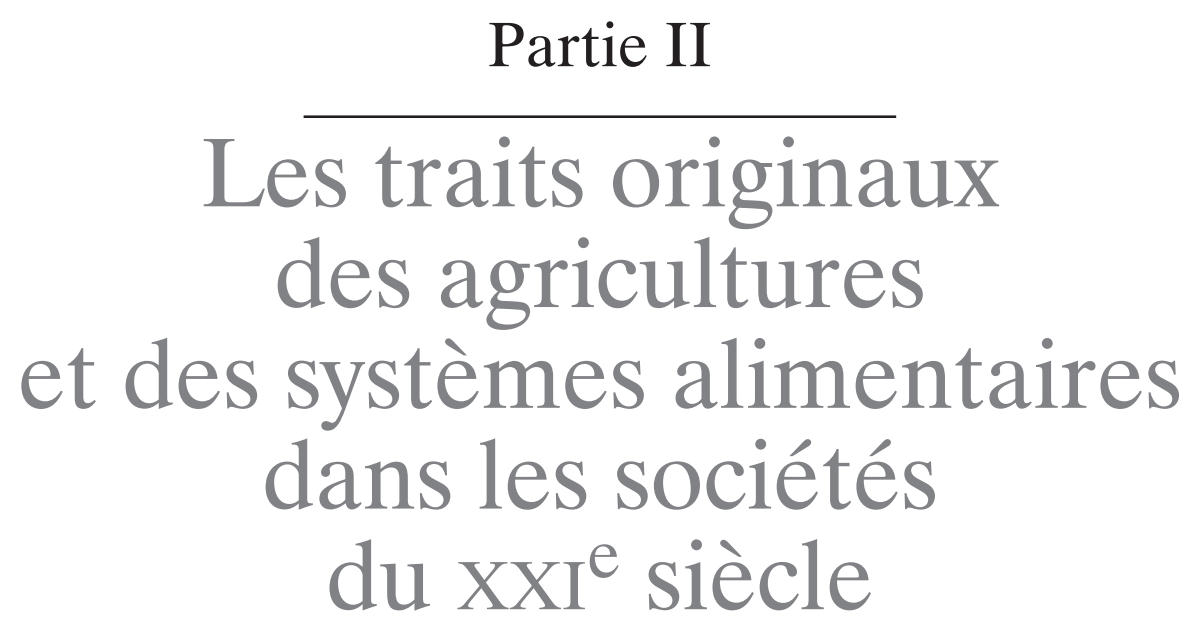





\section{Chapitre 8}

\section{La bioéconomie :}

\section{vers une nouvelle organisation des systèmes agricoles et industriels ? \\ P. Colonna, E. Valceschini}

La notion de bioéconomie, promue dès 2009 par l'OCDE (Organisation de coopération et de développement économiques), est posée par la Commission européenne (2012a) comme une clé à long terme de la croissance économique. La plupart des gouvernements occidentaux ont défini leur propre stratégie industrielle et scientifique sur cette base. Le développement de la bioéconomie est présenté comme une voie vers une économie décarbonnée et une grande transformation socioéconomique des systèmes de production, de transformation, et des pratiques de consommation. Toutefois, les moyens de la transition vers de tels systèmes sont encore l'objet de débats et d'expérimentations. Enfin, la confusion entre développement durable et croissance crée une ambiguité. D'un autre point de vue tout aussi volontariste mais à l'ambition plus réduite, le soutien à la bioéconomie est motivé par la perspective de faire émerger de nouveaux débouchés (voir par exemple Sgard et Harayama, 2013), projets et emplois. Dans les deux approches, les innovations technologiques et les changements économiques se structurent autour d'usages intégrés et complémentaires de la biomasse, nous invitant ainsi à repenser progressivement, mais durablement, notre rapport à cette ressource.

Au-delà de l'importance des innovations technologiques envisagées et de l'ampleur escomptée des changements économiques en termes d'emploi et de croissance, ne sont pratiquement pas analysées les éventuelles innovations et conséquences organisationnelles de ces transformations sur les structures économiques sectorielles ou territoriales. L'hypothèse que nous explorons est celle d'une possible reconfiguration, à terme, des systèmes agricoles et industriels jusqu'ici orientés vers la fonction alimentaire des activités agricoles ${ }^{1}$.

1. N'oublions pas toutefois que les productions actuelles de tabac, coton, hévéa, raisin de cuve, chanvre, sisal et lin représentent des usages importants des terres agricoles et répondent à des besoins d'hygiène, d'habitat et d'habillement. 


\section{La bioéconomie : stratégies économiques et trajectoire d'innovation}

Le terme de bioéconomie a pénétré récemment la sphère politique européenne, par la publication de documents à orientation stratégique pour l'industrie et d'agenda pour la recherche scientifique (voir par exemple SCAR, 2015), dans les organisations internationales (OCDE, 2009 ; Commission européenne, 2012a), ou par l'élaboration de stratégies nationales dans différents pays. Mais c'est aussi un terme qui renvoie à des projets industriels mis en œuvre depuis plusieurs années ou à des investissements en recherche avec des unités de démonstration faisant le pont entre recherche et industrie, et le développement ambitieux de bioraffineries ${ }^{2}$.

Si les définitions et les instruments proposés ne se recouvrent pas toujours, les biotechnologies occupent une place centrale dans l'argumentaire des institutions européennes, ainsi que la référence à l'impératif de compétitivité pour faire face à un diagnostic partagé de quatre grands enjeux :

- répondre aux besoins alimentaires d'une population mondiale d'environ 9,7 milliards d'individus en 2050 (7,3 milliards en 2015), dont certaines populations régionales en situation de fort développement économique, d'où un besoin d'accroissement de 50 à $70 \%$ de la biomasse, et, en corollaire, des besoins croissants en énergie $(45 \%)$ et en eau $(30 \%)$ (FAO, 2012);

- contrôler, limiter et réduire les émissions de gaz à effet de serre (GES) dans l'atmosphère pour conduire à un développement neutre au plan carbone ; avec l'engagement ${ }^{3}$ de réduire par quatre les émissions de GES à l'horizon 2050 par rapport à 1990 ;

- élaborer des produits de substitution aux synthons d'origine fossile, pour sécuriser les approvisionnements de l'industrie chimique et contrebalancer les déséquilibres d'approvisionnement créés par les gaz et les huiles de roche mère ;

- élargir la gamme des molécules disponibles pour répondre aux besoins de fonctionnalités et respecter les règles d'écotoxicologie.

Les États de l'Union européenne ont été incités à se positionner sur le sujet ${ }^{4}$, la bioéconomie est introduite dans les agendas politiques nationaux et oriente les agendas de recherche. Toutefois, à l'échelle européenne, ces enjeux sont à moduler par les objectifs de :

- transition nutritionnelle au profit des sources végétales ${ }^{5}$ et de souveraineté alimentaire en protéines (plus de la moitié des protéines pour les animaux est importée) ;

- réduction de la consommation d'énergie finale de $50 \%$ en 2050 ;

2. Voir le projet Star-Colibri : Joint European Bio Refinery Vision for 2030, Star-Colibri. http://www. forestplatform.org/files/Star_COLIBRI/Vision_document_FINAL.pdf

3. «Facteur 4 », fixé en France par la loi Programme d'orientation de la politique énergétique.

4. À ce jour, la France n'a pas arrêté une stratégie nationale sur la bioéconomie, mais de nombreuses activités peuvent être rattachées à la bioéconomie dans le cadre de diverses politiques publiques (agriculture, forêt, déchets, agroalimentaire, santé, énergie, chimie, matériaux, etc.), qui touchent autant la recherche et l'innovation que les industries.

5. Réduction de la part des produits animaux à $500 \mathrm{kcal} /$ jour contre $1200 \mathrm{kcal} /$ jour aujourd'hui, sur une ration de $3000 \mathrm{kcal} / \mathrm{jour}$. 


\section{- augmentation de la valeur ajoutée à la biomasse produite localement ${ }^{6}$;} - réindustrialisation des territoires.

Ces stratégies soulignent la nécessité et l'objectif de mieux valoriser les ressources propres (naturelles et territoriales, humaines, scientifiques) de chaque pays ou région. La bioéconomie repose sur une vision politique qui est par essence contextualisée en se fondant sur les ressources biologiques disponibles localement (d'où le poids de la forêt dans les pays scandinaves, des produits de la mer en Islande, des bouquets de biomasse plus équilibrés dans les autres pays) dans une logique de bioraffinerie territoriale couplant production et transformation. Le périmètre de la bioéconomie s'étend jusqu'à l'utilisation biologique du $\mathrm{CO}_{2}{ }^{7}$.

Les pays qui ont su associer des stratégies nationales et des plans d'action sont les États-Unis (2012), l'Allemagne ${ }^{8}$ (2011 et 2013), les Pays-Bas (2009) et l'ensemble Suède-Finlande-Norvège-Danemark (2012). De manière générale, les stratégies nationales en matière de bioéconomie mettent en avant, comme celle de la Commission européenne ${ }^{9}$, les objectifs de croissance, les nouvelles opportunités économiques et la création d'emploi. L'étude des différentes feuilles de route à l'échelle mondiale révèle de nombreux points communs entre les stratégies nationales : l'accent mis sur la recherche, la place fondamentale des biotechnologies, l'encouragement des partenariats publics-privés. Cependant, certaines feuilles de route inscrivent la bioéconomie au sein des questions de développement durable, alors que d'autres n'y font aucunement référence (par exemple la stratégie des États-Unis) (Staffas et al., 2013). Les États-Unis se distinguent en incluant dans la bioéconomie les biotechnologies rouges ${ }^{10}$ dédiées à la santé : ce choix reflète leur vision «technology-push » (par opposition à l'approche " society-driven » 11 en Europe) qui doit conduire à des impacts économiques et environnementaux. Ainsi, les définitions du terme bioéconomie peuvent différer selon le périmètre que chaque pays donne aux secteurs concernés en priorité par les stratégies industrielles et les stratégies de recherche.

6. Notamment pour les produits à base de bois (panneaux, pâte à papier, etc.).

7. Dans un système sans apport énergétique, le $\mathrm{CO}_{2}$ est le terme ultime de l'usage énergétique de la biomasse. Avec un apport d'énergie, le $\mathrm{CO}_{2}$ peut être recyclé dans la formation de nouvelles biomasses à l'instar de la biomasse produite par la photosynthèse à partir de l'énergie solaire. Ce mécanisme universel est connu pour être limité par la faible teneur de l'atmosphère en $\mathrm{CO}_{2}$. Si en revanche on considère, par exemple, des sources concentrées en $\mathrm{CO}_{2}$ en sortie de chaufferie, ou de cimenterie, la « recharge énergétique » de l'atome de carbone est envisageable dans des installations en atmosphère contrôlée, comme des cultures de micro-algues ou en électrochimie. La source énergétique est le point clé pour obtenir ce cycle. Un danger est de voir apparaître des technologies utilisant des sources énergétiques non renouvelables, renforçant les effets de serre et créant du « green washing ».

8. Soulignons le volontarisme de l'Allemagne qui a créé, en 2009, un conseil de la bioéconomie, indépendant des ministères et du gouvernement fédéral, et a élaboré une stratégie nationale et des feuilles de route régionales afin d'encourager le développement d'une bioéconomie allemande.

9. Pour une interprétation des stratégies européennes, on lira avec profit Levidow et al. (2012, 2013a). 10. Un code couleur a été adopté dans les années 2000 pour identifier les biotechnologies en fonction de leur domaine d'application, des procédés employés ou du type de biomasse utilisé : les biotechnologies vertes s'appliquent au domaine de l'agroalimentaire, à l'agriculture et à la sylviculture ; les biotechnologies rouges concernent le secteur de la santé ; les biotechnologies blanches sont liées à la production industrielle (chimie, matériaux, etc.) ; les biotechnologies bleues concernent la biodiversité marine.

11. C'est-à-dire centrée sur les demandes de la société. 
Potentiellement, la bioéconomie couvre un large éventail de secteurs de production. Les débouchés impliqués par l'utilisation de la biomasse sont multiples : il s'agit tant de l'alimentation, de l'énergie (biocarburants, bois-énergie, méthanisation, etc.) que de la chimie, ou encore des produits et matériaux chimiques pour l'hygiène, le textile et l'habillement, la construction et l'habitat, le transport (automobile...). Les secteurs de la santé (thérapeutique, pharmacogénétique, etc.) ou de l'activité biotechnologique (sélection animale ou végétale, organismes génétiquement modifiés, vaccins, etc.) sont aussi cités, mais de manière moins consensuelle. Le vaste champ couvert s'étend aussi à l'approvisionnement en matières premières renouvelables, à la biomasse jusqu'à la fin de vie du produit, en passant par les procédés issus ou non de cette matière organique (bioconversion ${ }^{12}$ ). En amont, sont donc concernés les secteurs de l'agriculture, de la foresterie, de la pêche et de l'aquaculture (et plus généralement du milieu marin) en tant que secteurs pourvoyeurs d'intrants. Le recyclage et la valorisation des déchets organiques issus des collectivités, des industries agroalimentaires ou des papeteries, etc. font eux aussi partie du domaine de la bioéconomie.

Les filières les plus actives sont celles de la chimie du végétal et des nouveaux matériaux biosourcés. Une part importante de la production dépend déjà en partie de matériaux biologiques. Plusieurs exercices de prospective conduisent à estimer la part des biotechnologies jusqu'à $35 \%$ de la production de produits chimiques et industriels, jusqu'à $80 \%$ des produits pharmaceutiques et des diagnostics en 2030.

La bioéconomie présente ainsi plusieurs particularités marquantes qui interrogent les économistes sur la question de l'organisation industrielle d'une part, et sur celle de la croissance d'autre part. La notion de " filière », en particulier, est mise en question par des activités forcément territorialisées qui s'organisent autour d'un axe production-transformation des biomasses auxquels s'ajoutent des axes de production d'outils biotechnologiques intrinsèquement génériques.

La bioéconomie s'inscrit en partie dans l'économie circulaire. Deux concepts nouveaux modifient le paysage des filières linéaires et parallèles : les usages successifs (en cascade) ; le bouclage des cycles C (carbone), N (azote), P (phosphore) et $\mathrm{K}$ (potassium). Ces concepts remettent en cause la valeur nulle, voire négative, des déchets dans les chaînes de valeur, et par voie de conséquence l'adéquation entre les cahiers des charges matière des produits sortant et entrant dans des opérations successives. Les déchets sont des ressources jusqu'au $\mathrm{CO}_{2}, \mathrm{~N}$, P et $\mathrm{K}$, avec des possibilités de substitution et des usages en cascade. À ce titre, la bioéconomie permettrait de découpler croissance et consommation d'intrants N, P et K.

C'est aussi la question de la nature de la croissance que renouvelle la bioéconomie. D'abord, la bioéconomie déplace les sources de carbone au profit d'une part plus grande d'origine biologique, pour répondre aux mêmes besoins des sociétés humaines. La création d'activités nouvelles, permises par les biotechnologies, respecte une logique schumpétérienne en déplaçant les activités fondées sur du carbone fossile ou relatives aux déchets, avec les usages en cascade et le bouclage des cycles. Ensuite, la bioéconomie peut s'inscrire aussi bien dans une logique de croissance (OCDE, 2009) que de décroissance. Cependant, à la différence de Georgescu-Roegen ${ }^{13}$ et de

12. Transformation de la biomasse par utilisation des biotechnologies.

13. Pour un point de vue synthétique et historique sur l'analyse de Georgescu-Roegen, voir Missemer (2013). 
Passet (1979), qui mettent l'accent sur les contraintes physico-chimiques de l'environnement dans lequel s'inscrivent les activités économiques pour poser la finitude des ressources, la perspective récente de la bioéconomie se place dans un système ouvert alimenté par le flux énergétique solaire, contrebalançant la croissance de l'entropie inhérente à toute activité consommant de l'énergie.

Au plan scientifique et technologique ${ }^{14}$, la bioéconomie se fonde sur la combinaison d'une connaissance accrue sur les génomes, facilitant l'obtention d'agents de transformation plus efficients et efficaces, d'un recours accentué aux procédés biotechnologiques et d'une plus grande utilisation de la biomasse dans les procédés industriels.

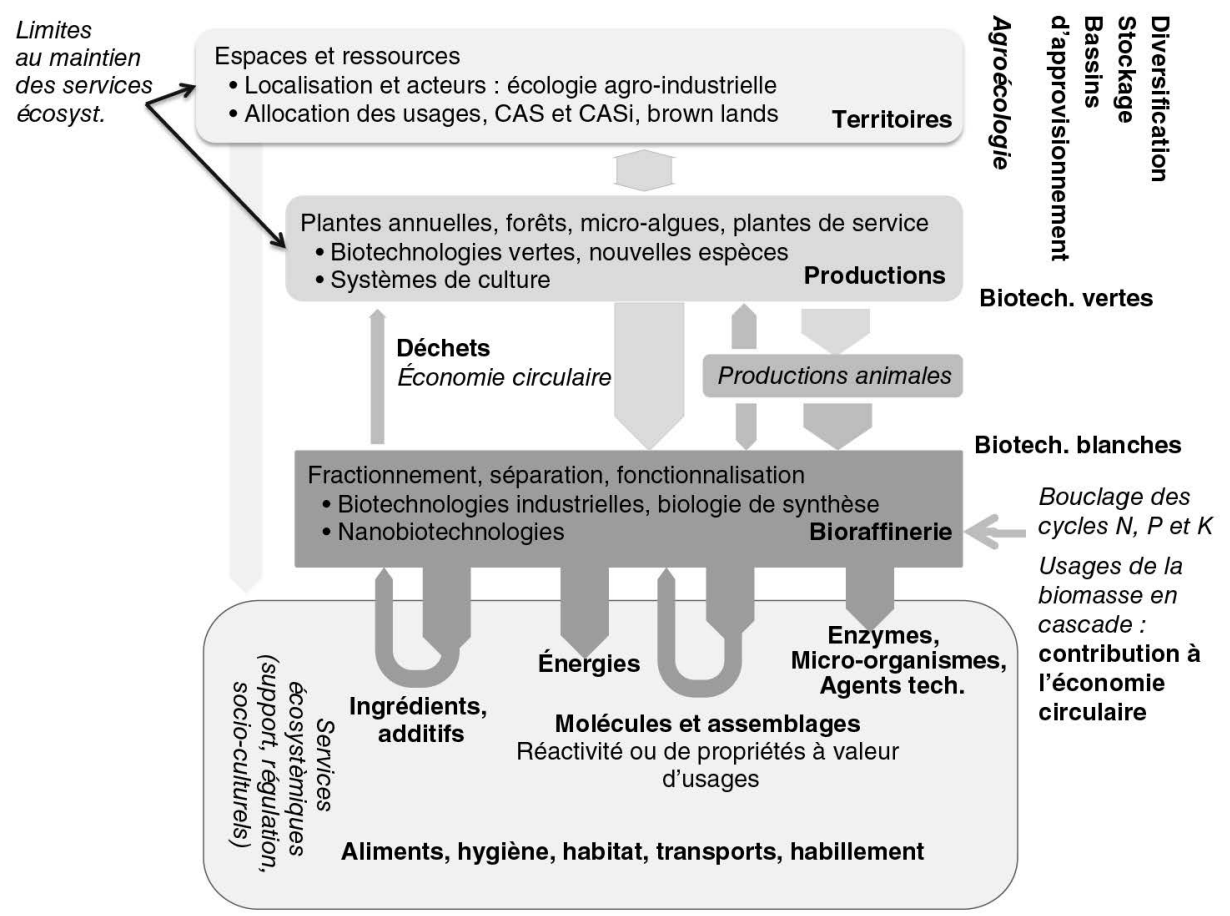

Figure 8.1. Les trois dimensions du système de la bio-économie.

Source : Colonna et al. (2014: 304).

Dans l'analyse comparative des stratégies et des politiques (Staffas et al., 2013), aucune définition canonique de la bioéconomie ne s'impose. Cependant, dans tous les schémas de pensée, on trouve deux points de convergence importants. Tous s'accordent d'abord sur le fort potentiel des biotechnologies vertes (plantes et micro-algues), blanches (enzymes et micro-organismes) et bleues (macro-algues), depuis la biodiversité - pour l'identification de nouvelles enzymes, d'espèces et de consortia microbiens, la biologie des systèmes - jusqu'à la biologie de synthèse. Ils mettent en avant trois capacités des biotechnologies : l'amélioration des

14. Voir en particulier le chapitre 4 «Biotechnologie et génie génétique au $\mathrm{XxI}^{\mathrm{e}}$ siècle » du rapport prospectif de l'OCDE (1998). 
performances par voie génétique, la sélectivité des mécanismes biologiques et la créativité, avec la biologie de synthèse. L'apport des savoirs et des connaissances de la biologie moderne (haut débit, post-génomique, etc.) serait un moteur du changement de paradigme technologique ${ }^{15}$ en bousculant les procédés de production classiques. La production de biomasses et des procédés de transformation adaptés aux usages des biotechnologies devraient limiter les impacts environnementaux. En effet, ces procédés génèrent moins de sous-produits et s'inscrivent dans des schémas industriels moins énergétiques.

Le second point de convergence est la prépondérance accordée à l'approche systémique (croisements de systèmes alimentaires, chimiques, énergétiques) aux dépens de la juxtaposition des filières (Colonna et al., 2014) ; chaque production végétale contribue à la satisfaction de différents besoins élémentaires. Les usages en cascade de la biomasse (le $\mathrm{CO}_{2}$ étant sa forme finale) conduisent à imaginer des combinaisons de technologies plus élaborées et diverses que celles fondées sur une logique « en silo » dans laquelle une matière première agricole ou forestière n'a qu'un usage, les autres étant des valorisations de sous-produits. L'idée que le co-produit d'une activité est la matière première d'une autre activité complexifie les chaînes de valeur et modifie les relations entre les acteurs économiques. Les productions oléagineuses en sont une illustration, avec la fraction azotée (tourteaux pour les alimentations humaine et animale) et la fraction lipidique (alimentation humaine, biocarburants, chimie). L'usage des huiles de friture usagées en biocarburants représente le stade ultime, la matière étant transformée en $\mathrm{CO}_{2}$.

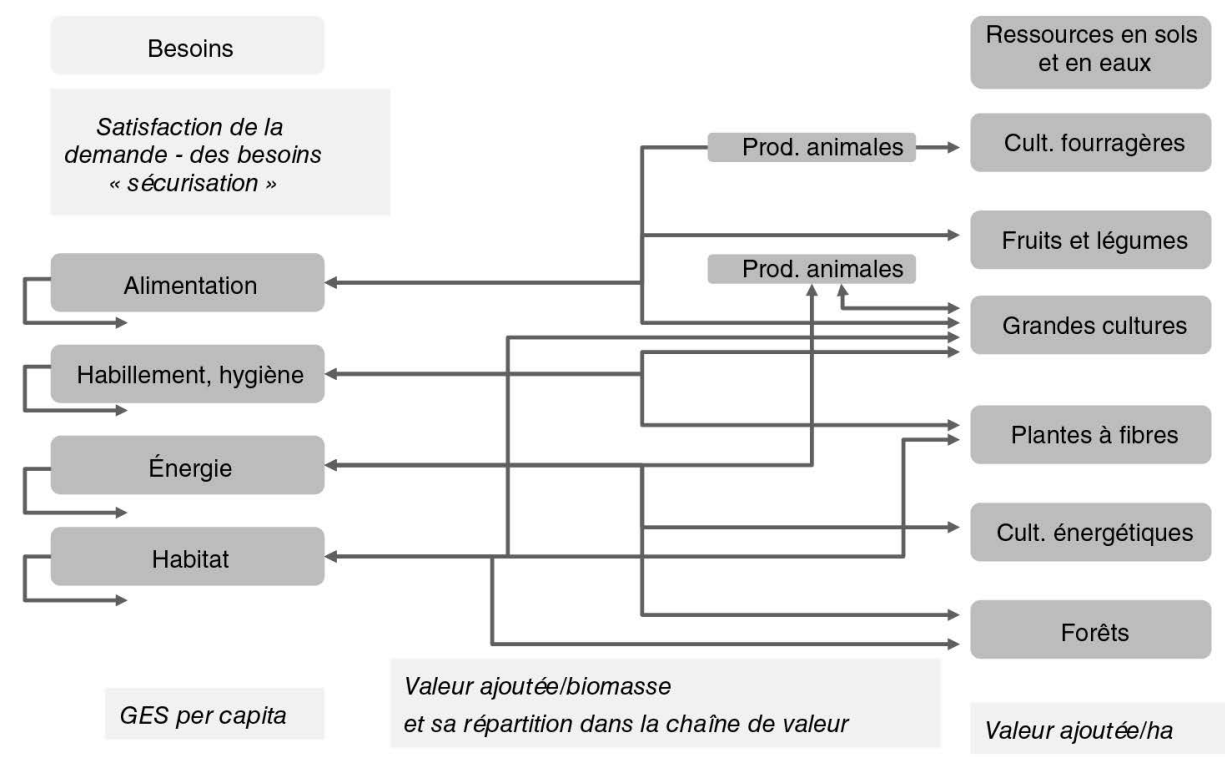

Figure 8.2. Besoins sociaux et ressources de la bioéconomie.

15. Soulignons qu'aucun changement de paradigme équivalent n'est visible pour la physique ou la chimie organique. 
Par rapport à la satisfaction des besoins de la planète, deux objectifs peuvent être définis comme prioritaires (voir Levidow et al., 2012), sans qu'ils soient aisément compatibles. Le premier est l'amélioration de l'efficience (la productivité) des ressources naturelles par « injection » intensive de progrès technologiques et de capital de connaissances scientifiques (les biotechnologies au sens large). Le second est une utilisation durable (plus sobre et mieux maîtrisée) de ces ressources biologiques par des innovations scientifiques, sociales et économiques dans la gestion des agroécosystèmes aux différentes échelles géographiques. Nous nous sommes interrogés ici sur la capacité de prélèvement sur les milieux naturels, sans affecter les autres services écosystémiques (support, régulation, socio-culturels) pour assurer une solidarité intergénérationnelle ${ }^{16}$. La bioéconomie revêt ainsi au gré des définitions deux visions complémentaires :

- BioBased Economy : une stratégie scientifique et économique pour créer les conditions d'un passage d'une économie fondée sur les ressources fossiles (et le nucléaire dans certains pays) à une économie fondée partiellement sur les matières premières biologiques (croissance économique efficace, en harmonie avec l'environnement et adoptée par la société) ; les biotechnologies sont alors des éléments de rupture technologique dans nos socio-écosystèmes. La bioéconomie devient le prolongement opérationnel du développement durable, en synergie avec les scénarios d'évolution fondés sur la sobriété pour les sociétés dites développées.

- BioEconomy : une croissance durable grâce à des progrès dans le domaine des biosciences visant à la «biologisation » des procédés et des produits industriels, avec le développement des écotechnologies et la réduction des déchets.

Dans les deux cas, la définition de la bioéconomie est étroitement liée au développement des biotechnologies considérées comme des « innovations de rupture » ${ }^{17}$ amenées à assurer une part substantielle de la production économique des pays de l'OCDE. À l'horizon 2030, la bioéconomie est ainsi envisagée comme l'ensemble des nouveaux modes de production, manières de consommer et styles de vie qu'entraîneront le développement et l'application des biotechnologies.

\section{W La biomasse : enjeux économiques et technologiques}

Le déploiement de la bioéconomie repose sur la biomasse. La bioéconomie remet donc au premier rang une ressource ancienne, la biomasse, source de matière organique, produite par des organismes vivants ou par leur décomposition. Cette biomasse est constituée de la matière organique carbonée produite par des organismes vivants et ses dérivés. Elle est formée essentiellement de carbone, d'hydrogène et d'oxygène, et à un moindre degré d'azote, provenant de divers types de ressources :

- les produits d'origine agricole, avec d'un côté les cultures traditionnelles de plantes annuelles (céréales, oléagineux) recherchées principalement pour leurs parties nobles (grains, graines et tubercules), et d'un autre côté les cultures dédiées à

16. Soulignons que les ressources minières (pétrole, charbon, gaz, minéraux) oublient, à ce titre, toute perspective de durabilité.

17. Dans les deux perspectives, la bioéconomie, avec les biotechnologies, pourrait supposer le renforcement des protections intellectuelles, agronomique (semences) et industrielle (enzymes, micro-organismes), qui doit précéder et accompagner la mise en place rapide d'une phase d'exploitation industrielle. 
la bioraffinerie (Miscanthus, taillis à courte rotation TCR, etc.), ainsi que les résidus de cultures (pailles, tiges, feuilles) et d'élevages ;

- les produits d'origine forestière : bûches, granulés, plaquettes et résidus de l'exploitation forestière ou de cultures sylvicoles spécifiques (taillis à courte ou à très courte rotation de peuplier et d'eucalyptus) ;

- les produits d'origine aquatique : micro-algues et macro-algues, résidus de la pêche et de la pisciculture ;

- les co-produits et les effluents des industries de transformation des matières biologiques : scieries, papeteries, industries agroalimentaires, élevages industriels ; - les autres déchets organiques : déchets urbains, boues issues des stations d'épuration, ordures ménagères, déchets verts provenant de parcs et de jardins.

Même si la biomasse disponible sur terre est limitée à chaque instant, la photosynthèse génère naturellement son renouvellement, induisant ainsi une circularité des flux biogéochimiques du carbone. Nous avons là trois éléments de différenciation de la bioéconomie par rapport à l'usage du carbone fossile :

- la diversité structurale des biomasses comparativement au carbone fossile présent sous les formes $-\mathrm{CH}=,-\mathrm{CH}_{2^{-}}, \mathrm{CH}_{4}$;

- la distribution géographique de la biomasse dans tous les espaces habités du globe donne des potentialités spécifiques à chaque territoire, sans obérer pour autant les échanges entre territoires ;

- la bioéconomie est dans une logique de flux, ce qui implique le respect des mécanismes de la biosphère pour ne pas altérer ses capacités productives.

L'alimentation est la première famille de produits issus de la biomasse. Les principaux domaines d'innovation actuels sont le mouvement "clean label », avec une simplification des formulations et une éviction des produits « chimiques » au profit d'ingrédients « naturels » issus par exemple de la bioraffinerie : les aliments fermentés, les protéines végétales et microbiennes.

Mais la biomasse a longtemps été l'objet d'usages non alimentaires. Par exemple, environ un million d'hectares étaient consacrés à ces usages alimentaires au XIX ${ }^{e}$ siècle en France. C'est la carbochimie fossile qui a entraîné la diminution de ce secteur. Toutefois, le haut niveau de performances atteint par ces produits pétro-sourcés ne permet pas d'appliquer des règles de substitution simples entre ces sources fossile et biologique, sans que des considérations sociales et environnementales ne soient sérieusement envisagées.

Les bioénergies et la chimie font l'objet de nombreuses études et prospectives (Colonna, 2013). À côté des scénarios strictement énergétiques comme ceux de l'Agence internationale de l'énergie, plusieurs publications traitent de projections ${ }^{18}$ en 2030-2050 pour décrire un projet de société, irriguée par les différents systèmes énergétiques, alimentaire, chimique à partir du carbone biosourcé, à l'échelle mondiale. Les scénarios sont conçus pour tenir compte du trilemme : garantir les services écosystémiques non productifs, assurer la sécurité énergétique et l'équité énergétique. Différentes options de régulation politique sont ainsi scénarisées mais aucune solution universelle

18. Ces exercices entrent dans une démarche de prospective, avec une définition et une représentation du système, une identification des forces de changement, entraînant des ruptures, à côté d'un scénario tendanciel business as usual. 
ne se dégage, notamment parce que les différences géographiques, y compris dans les cinétiques d'évolution, empêchent d'adopter des solutions transposables.

La biomasse disponible ne permet pas, en l'état actuel des connaissances, une substitution du carbone fossile et la garantie de la sécurité alimentaire. Les usages concurrents de la biomasse sont à raisonner sur plusieurs critères :

- la satisfaction des besoins (en soulignant que le système alimentaire mondial n'est déjà plus durable et pas équitable) ;

- la sécurisation des approvisionnements ;

- la réduction des émissions de GES per capita;

- la valeur ajoutée par biomasse récoltée et sa répartition entre les acteurs économiques ;

- la valeur ajoutée par ha.

Quelle que soit l'origine de la biomasse, elle ne peut pas être simplement considérée comme un puits de matières premières sans une prise en compte des conditions nécessaires à son renouvellement. La question des moyens pour garantir le respect de cette durabilité se pose, et la bioéconomie et son développement suscitent des controverses autour, notamment, des conflits d'usage et des arbitrages nécessaires. À cet égard, l'usage des terres est un point clé dans le décompte des biomasses disponibles. Une analyse, qui part des terres totales et distingue ensuite les biomasses techniquement récoltables, les biomasses rentables économiquement et les biomasses sans impact environnemental, conduira à identifier la biomasse durable, dont les usages alimentaire, énergétique et chimique sont révélés au niveau de la bioraffinerie.

Alors que le développement d'une bioéconomie repose sur la sollicitation de la biomasse, apparaît la contrainte de travailler avec le vivant. Ces intrants supposent une logistique complexe pour faire face aux contraintes d'un approvisionnement saisonnier et soumis aux aléas climatiques, qui peut ainsi différer temporairement de la demande de certains acteurs, alors qu'il est attendu de ces ressources qu'elles soient disponibles « en quantité suffisante, de façon pérenne et sous forme exploitable » (Appert et Alario, 2013). Au-delà des aspects d'innovation, via les biotechnologies ou la création de nouveaux produits, ainsi que des grands enjeux communs (par exemple le changement climatique), la mise en œuvre de la bioéconomie s'appuie sur le concept de bioraffinerie.

L'implantation des bioraffineries obéit à un calcul qui doit prendre en compte le fait que les ressources en biomasse sont non seulement limitées, mais également localisées. La logistique (réseau de transport, stockage de la matière première, etc.) et les coûts associés, ainsi que les prix des matières premières sont des critères essentiels pour la localisation des bioraffineries, et donc pour le développement de la bioéconomie. La grande importance des facteurs de coût liés à la localisation permet aussi de voir dans la bioéconomie une opportunité pour le développement territorial (voir par exemple Attali, 2013 ; Johnson et Altman, 2014).

L'augmentation des prélèvements en biomasse peut aussi conduire à des changements d'usage des sols, capables alors de provoquer des déstockages massifs de carbone organique des sols. Fortement décriée en raison de la faiblesse des données d'impacts environnementaux, la politique pour les biocarburants se trouve aujourd'hui confortée par des études solides (Valin et al., 2015). 


\section{Encadré 8.1. La bioraffinerie.}

Ce terme, construit par analogie au terme de raffinerie, désigne le fractionnement de ressources renouvelables, et non du pétrole, en molécules d'intérêt valorisées en produits alimentaires ou non. Aucun végétal ne donne une biomasse brute directement utilisable en chimie ou en fermentation sans un traitement préalable de purification et de fractionnement. Mais toutes ces molécules d'intérêt sont présentes dans des organes de réserve (les grains et les tubercules) ou de soutien (les tiges). La biomasse subit donc un prétraitement avant d'être traitée selon divers procédés (biotechnologiques, thermochimiques ou chimiques). La déconstruction des matières végétales constitue un verrou dans les usages de la biomasse. Elle a conduit à une activité particulière, la bioraffinerie, fondée sur une valorisation industrielle complète de chacune des fractions récoltées de la plante.

La bioraffinerie est en fait une technologie ancienne. Après la première génération (papeterie, meunerie, huilerie), elle a évolué, grâce à l'incorporation d'outils chimiques, vers la bioraffinerie de deuxième génération (acides gras, glycérol, polysaccharides, isolats de protéines). L'arrivée d'outils enzymatiques a permis l'approfondissement du fractionnement vers les oses et les peptides, en troisième génération. La gazéification, conduisant au gaz de synthèse (syngaz), est le stade ultime de la quatrième génération, avec un éclatement des molécules constitutives, en $\mathrm{CO}$ et $\mathrm{H}_{2}$.

Les bioraffineries sont aujourd'hui des infrastructures dites intégrées. Elles permettent de transformer sur un même site une diversité d'intrants pour différents marchés (matériaux, chimie, énergie ou encore alimentation). Plusieurs types de bioraffineries peuvent être distingués :

- les bioraffineries territoriales, qui traitent des matières premières agricoles ou forestières produites dans des bassins de production (grandes cultures et forêts) connexes ;

- les bioraffineries portuaires, qui traitent principalement des matières premières importées ;

- les bioraffineries environnementales, qui traitent des déchets en périphérie des mégapoles ou des écosystèmes industriels.

L'émergence de la bioéconomie est dépendante de conditions comme la connaissance de la biomasse disponible, les prix relatifs des molécules biosourcées et fossiles, la compétitivité via les disparités des coûts de production, etc. Autant de freins possibles dont un est peu cité, à savoir les conditions de soutenabilité de la mobilisation de la biomasse utilisée comme intrant. La bioéconomie, au travers de sa mobilisation des ressources issues du vivant, nécessite le respect des rythmes de renouvellement conditionnant une exploitation soutenable de la biomasse. De plus, la sollicitation de la biomasse pour des usages existants et nouveaux, ainsi que la croissance des volumes mobilisés, laisse transparaître des enjeux, qu'ils soient liés aux questions de conflits d'usages, d'acceptabilité sociale ou encore d'éthique.

\section{W L'invention d'un nouveau secteur économique?}

Les projets d'implantation de bioraffineries montrent bien que la bioéconomie réunit des acteurs aux approches très différentes autour d'un enjeu commun, mais qu'elle 
déstabilise aussi la vision « traditionnelle » des chaînes de valeur organisées par filières. La notion de bioéconomie incite à dépasser une vision additive des différents secteurs d'activité s'appuyant sur la biomasse et la biologie (hors santé), pour développer une vision systémique et opérationnelle des relations entre les sociétés humaines et les écosystèmes. La bioéconomie constitue potentiellement un secteur économique nouveau, organisé autour d'activités à la fois complémentaires mais aussi mises en concurrence, activités concernant l'accès, l'exploitation et le renouvellement de la biomasse, et plus largement des ressources naturelles et, au-delà, des sols. Ce secteur transcende et remet en cause les découpages traditionnels des secteurs économiques qui, en particulier, autonomisent jusque-là le système alimentaire et le système énergétique.

La transition énergétique conduit à développer une approche globale qui analyse l'utilisation de l'énergie et des ressources (eau). Au niveau industriel, l'intégration énergétique vise notamment à utiliser, voire à stocker, l'énergie thermique pour différents usages (notion de « cascade énergétique »).

Une originalité du concept de bioéconomie est de réfléchir en considérant un ensemble d'éléments pour lesquels les interactions entre les différentes opérations (production, transformation) sont aussi importantes que chacune d'entre elles pour appréhender l'efficience globale du système. L'idée de bioéconomie permet de reconsidérer le périmètre des activités agroalimentaires et remet même en cause le concept de système agroalimentaire organisé et hiérarchisé autour de la fonction alimentaire de l'agriculture et des ressources qu'elle consomme et produit.

La bioraffinerie déstabilise l'approche économique par filière linéaire au profit d'une approche systémique. Elle remet en cause l'enchaînement entre les différents stades d'un processus de transformation (ou « chaîne de production »). La plupart des biomasses sont interconvertibles, via la bioraffinerie, pour répondre aux besoins en produits finaux : par exemple, pratiquement toutes peuvent être utilisées pour produire de l'énergie. De plus, les co-produits et les produits de sortie (déchets) sont à considérer dans une logique de cascade dont les devenirs ultimes sont le $\mathrm{CO}_{2}$ et le retour des éléments carbone, azote, phosphore et potassium dans les systèmes de culture ou dans les sols. Parfois dénommée par simplification « économie circulaire », cette triple logique de fractionnement, d'interconversion et de cascade doit être envisagée comme un système global (« analyse systémique »). Étudier ces nouveaux axes de recherche suppose une approche pluridisciplinaire.

Ces concepts remettent en cause l'idée de valeur nulle, voire négative, des déchets dans les chaînes de valeur, et par voie de conséquence l'adéquation entre les cahiers des charges matière des produits sortant et entrant dans des opérations successives. À ce titre, la bioéconomie permet de découpler croissance et usage de matières premières.

Enfin, les relations entre les acteurs sont souvent déstabilisées car les options technologiques, du fait de l'innovation, conduisent à des réorganisations permanentes de l'arborescence des « filières ». Deux domaines d'innovation illustrent ces ruptures : - l'utilisation de protéines végétales issues de tourteaux sous des formes texturées, en remplacement de produits carnés, aux dépens des usages en alimentation animale ;

- les voies fermentaires d'obtention d'acides gras poly-insaturée ciblés aux dépens des sources animales (poissons en particulier). 
L'approche systémique (interactions entre systèmes alimentaires, chimiques, énergétiques) permet d'envisager d'optimiser les croisements de flux de matière, d'énergie et d'informations entre les mondes agro-industriels ou forestiers, et de la chimie classique. L'optimisation est forcément multicritères, pouvant conduire à des antagonismes entre les intérêts privés et publics. Elle renouvelle l'éco-conception dont l'approche classique par produit entraîne une incapacité à considérer l'ensemble des besoins de chaque société. Les exemples de Pomacle en France (Schieb et Philip, 2014) et de Kalundborg au Danemark (Wells et Zapata, 2012) illustrent ces approches globales «méso-économiques ».

Reste une question majeure. Sachant que les biomasses disponibles actuellement ne permettent pas une substitution complète du carbone fossile, la définition des usages prioritaires de la biomasse se fera-t-elle sur la base du statu quo, avec l'alimentaire en priorité, de la maximisation de la valeur ajoutée, de la durabilité, de l'efficience ou encore de la sécurité des approvisionnements ? Les complémentarités et les concurrences des usages des sols (Griffon, 2014) détermineront la place quantitative de la bioéconomie, avec l'élargissement de la réflexion aux terres marginales («brown lands ») au-delà des seules surfaces agricoles et forestières. Le choix des espèces végétales à implanter, des plantes pérennes aux micro-algues, est une variable majeure affectant la durabilité et les paysages. À la différence du carbone fossile dont l'exploitation est localisée ( « puits de pétrole »), la biomasse est uniformément répandue à la surface du globe, ce qui modifie les enjeux géopolitiques de souveraineté régionale ou nationale. En découlent des visions contrastées entre les bioraffineries territoriales dans des bassins de production (grandes cultures et forêts) et les bioraffineries portuaires.

Le territoire est l'élément structurant des réflexions car il associe le bassin de production(s), l'infrastructure de collecte et de stockage, les activités agro-industrielles et les infrastructures. Cette perspective, visant à utiliser tous les composants de la biomasse, constitue d'ailleurs l'un des vices de la bioéconomie, avec la tentation d'exporter toute la biomasse produite agronomiquement. Or une partie de la biomasse doit rester sur les parcelles agricoles ou forestières pour garantir un contenu organique au sol.

L'écologie industrielle est la manifestation physique que différents procédés et produits, en général d'agents économiques distincts, sont interconnectés par des flux de matières et d'énergie, ce qui permet de réduire collectivement les pertes, y compris thermiques, souvent dans un espace géographique défini (Asthon, 2009). L'économie circulaire en est l'étape la plus avancée (Mathews et Tan, 2011). La colocalisation des activités permet d'envisager la réduction des étapes séchagehydratation, nécessaires pour les transferts entre des unités très éloignées, pour des raisons microbiologiques essentiellement.

Enfin, les relations entre les acteurs sont souvent déstabilisées car les options technologiques, du fait de l'innovation, conduisent à des réorganisations permanentes de l'arborescence des «filières » en fonction des marchés : les oscillations d'usage du sucre, entre sa capacité sucrante et les bioénergies, illustrent la compétition entre la recherche de valeur ajoutée et le souci de robustesse des approvisionnements. L'approche systémique (interactions entre systèmes alimentaires, chimiques, énergétiques) permet d'envisager d'optimiser les croisements de flux de matière, 
d'énergie et d'informations entre les mondes agro-industriels ou forestiers, et celui de la chimie classique. Elle renouvelle l'éco-conception, dont l'approche classique par produit entraîne une incapacité à considérer l'ensemble des besoins de chaque société.

La bioéconomie pose la question des échelles pertinentes pour développer des approches holistiques dans des territoires, en lien avec les écosystèmes, avec les trois caractéristiques suivantes : variabilité des écosystèmes, trajectoire technologique pour les transitions chimiques, énergétiques, alimentaires, résiliencerobustesse des systèmes chimiques, énergétiques et alimentaires? La proposition de scénarios de spécialisations territoriales française, en suivant les étapes recherche, démonstration, déploiement, est à envisager en priorité. La bioéconomie est un moyen pour colocaliser les activités de production et de transformation dans un objectif de durabilité. Le choix de l'échelle de développement (territoire, nation, région, monde) mérite d'être pensé en fonction des contextes pédoclimatiques locaux et des porteurs d'enjeux mobilisables, au lieu de se projeter par la réplication de modèles importés d'autres parties du monde. L'enjeu est celui des changements d'échelle, pour passer du foisonnement des micro-projets à une vision à grande échelle. Cette perspective rejoint le concept de «smart specialization », qui reprend l'idée de politique industrielle à une échelle locale.

La prise en compte des considérations environnementales et des limites de la fourniture de biomasse d'un territoire conduit à dépasser les études « effet de... sur... » pour explorer les scénarios de gestion des agroécosystèmes en les maintenant dans des limites qui soient acceptables du point de vue de la durabilité des systèmes socio-écologiques. Au-delà de problèmes méthodologiques, la manière d'associer les parties prenantes est à revisiter : aucune d'entre elles ne peut prétendre prendre le pas sur les autres pour des biens communs.

\section{Conclusion : la durabilité}

L'histoire s'est montrée assez peu concernée par les questions bioéconomiques. L'évolution de nos rapports à l'énergie, à l'alimentation et à la chimie ne saurait se réduire à un récit linéaire des innovations techniques ayant permis d'exploiter telle ou telle ressource ou de mettre en ouvre de nouvelles technologies plus efficaces. Le système bioéconomique est toujours sous-tendu par des structures et des choix politiques, économiques et sociaux qu'il convient de mettre au jour pour en comprendre toutes les dimensions, et montrer comment, au-delà de la mobilisation de la biomasse existant dans la nature, sa conversion et ses usages ont des fondements et des effets très complexes. Les aspects sociaux, économiques, culturels, politiques et géopolitiques, avec les innovations organisationnelles attendues, sont tout aussi importants, si ce n'est plus, que les aspects proprement technologiques. Une transition sociotechnique est nécessaire pour réussir une certaine forme de durabilité, avec des changements en matière de production et de consommation. 



\title{
Chapitre 9
}

\section{Transition du régime agro-industriel européen vers la bioéconomie : life sciences versus agroécologie}

\author{
L. Levidow, N. Béfort, M. Nieddu, F.-D. Vivien
}

Le concept de food regime (forgé pour rendre compte des transformations historiques de la place de l'agriculture dans le capitalisme mondial) (McMichael, 2009a), discuté dans l'introduction et le chapitre 16, traduit par « régime agroalimentaire », mais que nous avons choisi pour notre part de rendre par la notion de « régime agro-industriel ", vise à étudier, tel que nous le mettons en œuvre $\mathrm{ici}^{1}$, comment des crises de natures multiples révèlent des lock-in (verrouillage) sur certaines trajectoires qui constituent ce régime, tout en ouvrant des opportunités aux acteurs pour des solutions alternatives. Il s'agit alors de documenter la confrontation entre un scénario où le régime agro-industriel se transforme en développant sa part non alimentaire, tout en conservant ses caractéristiques principales de régime dominant, et un scénario de trajectoires plurielles. En effet, certains acteurs cherchent à explorer la possibilité de faire émerger un régime porté par l'agroécologie. Pour explorer cette question, nous examinons les débats autour la transition vers une "bioéconomie ", portée par deux récits - l'un s'appuyant largement sur les life sciences, mais pas seulement, et l'autre étant celui de l'agroécologie. Pour ce faire, nous montrons que ces deux récits interrogent l'organisation de la production de connaissances d'une part, et le mode de définition de la qualité des produits d'autre part. Ces deux dimensions de la narration du changement forment ce que nous appelons des « régimes de production de connaissances et d'activités économiques » dont on cherche à montrer qu'ils conduisent à des conceptions différentes de la bioéconomie.

Dans la première partie, nous présentons les enjeux des concepts de régimes et d'innovation agroalimentaire. La deuxième partie traite de l'émergence du corps de doctrine de la Commission européenne autour d'une bioéconomie centrée sur la mobilisation des sciences chimiques et de la « révolution biotech », par opposition à un récit minoritaire centré sur l'agroécologie.

1. Ce chapitre synthétise deux communications au colloque de Montpellier (2014), celle de Levidow, et celle de Nieddu, Vivien, Béfort ; voir Levidow (2015) et Nieddu et Vivien (2016a). 


\section{"Quelles trajectoires d'innovations pour la transition entre régimes?}

Un régime agro-industriel, tel que nous le nommons, est défini par les auteurs du courant Food Regimes comme une « structure gouvernée par des règles [implicites ou explicites telles que celles du Gatt] au niveau mondial de la production et de la consommation alimentaire » (Friedmann, 1993 : 30-31). C'est en effet ce point du niveau mondial, qui suppose la reconnaissance d'un régime hégémonique, qui est important dans la définition et qui conduit à distinguer trois régimes internationaux (McMichael, 2009a) malgré l'existence de trajectoires nationales spécifiques significatives (chapitre 16). On décrira ces régimes pour discuter des alternatives actuelles, puis des paradigmes d'innovation susceptibles de porter ces alternatives.

Le régime agro-industriel contemporain, contesté depuis les années 1970, articulait un mode de consommation alimentaire carnée, des changements technologiques (substitution de l'énergie animale par l'énergie fossile, chimisation de l'agriculture) et une insertion sur les marchés des agriculteurs les plus compétitifs, repoussant les autres dans les zones urbaines, quand ce n'est pas dans les bidonvilles du tiersmonde. En diffusant les technologies de la révolution verte, il conduit l'agrobusiness à élaborer des liens transnationaux entre espaces nationaux qui se spécialisent au sein de chaînes de valeur globales (par exemple celle reliant le soja et les carbohydrates aux élevages intensifs). Dans ce régime dominant, « les entreprises agro-industrielles sont les principaux agents qui tentent de régler les conditions agroalimentaires, pour ce qui est d'organiser des conditions stables de production et de consommation qui leur permettent de planifier l'investissement, l'approvisionnement en matières premières agricoles et la commercialisation » (Friedmann, 1993 : 52).

Un tel régime pousse à adopter partout l'intensification, de même que les subventions à l'exportation, destinées à réguler l'insertion de l'agriculture sur les marchés, conduisent à générer des excédents venant miner les capacités de production et les méthodes moins intensives ailleurs, tandis que se développent les contestations écologiques, sociales, éthiques ou simplement culturelles et gustatives de celui-ci, jusqu'à former système dans des organisations aussi diverses que le Slow Food ou Via Campesina.

Le débat sur l'émergence d'un nouveau régime, à partir de la fin des années 1980, a trouvé ses racines dans l'usure des compromis nationaux et des règles implicites internationales issues des expériences pratiques de négociation entre États, corporations et lobbies nationaux en réponse à des problèmes immédiats de production, de consommation et de distribution (Friedmann, 1993). D'un point de vue académique, la réflexion a porté sur les limites du paradigme de l'agriculture industrielle et l'émergence de nouveaux paradigmes productifs (Allaire et Boyer, 1995), mais aussi, dans le cadre international de l'Uruguay Round, sur les politiques agricoles nationales. Il est important sur ce point, suivant en cela la démarche régulationniste qui insiste sur le fait que les évolutions de régime sont le produit endogène des actions collectives des acteurs, de considérer que la transition «peut être définie comme une période d'expérimentation et de contestation » (Friedmann, $2009: 335)$, et que « les périodes de transitions sont pleines de possibilités multiples » (ibid. : 336). 
Il en va aujourd'hui des stratégies de « verdissement » des chaînes d'approvisionnement, base potentielle d'un nouveau régime agro-industriel. Elles sont généralisées dans des fermes industrielles «vertes ». Celles-ci abandonneraient les intrants agrochimiques pour les produits de protection biologique, autorisant ainsi une certification biologique, comme cela est arrivé en Californie (Guthman, 2004). Elles pourraient aussi être le support de mouvements sociaux visant de nouveaux rapports sociaux de production et de consommation, et d'autonomie alimentaire. De même, le tournant vers les usages non alimentaires de la biomasse peut alimenter des stratégies d'autonomie énergétique locale et de réindustrialisation écologique, ou entrer dans des chaînes globales de valeur reliant l'huile de palme de Malaisie et la canne à sucre brésilienne aux bioraffineries portuaires européennes et américaines (Nieddu et al., 2013).

Le régime émergent pourrait être une forme d'intégration des tensions et des contradictions sociales ou environnementales dans un « capitalisme vert ». Il approfondirait dans deux directions le caractère transnational des chaînes de valeur. Dans la première direction, la trajectoire des filières céréales/protéines animales tend à incorporer l'alimentation dans un complexe industriel alimentation/agrocarburants, et de nouveaux pays dans sa division du travail (Brésil).

Les aliments de haute technologie composés d'ingrédients fractionnés, puis recombinés, y côtoient les productions non alimentaires, et partagent les mêmes bases de connaissances en matière de fractionnement et de recombinaison. Dans la seconde, l'incorporation de nouveaux pays dans les chaînes de valeur globales est portée par la politique de différenciation des grandes chaînes de supermarchés qui cherchent à capter la demande de produits frais - poissons, fruits et légumes - de clients privilégiés (Friedmann, 2005b : 258)2 .

Ce régime modèlerait l'accumulation du capital en transférant des méthodes agroindustrielles dans les moyens mobilisés pour réduire les effets néfastes sur l'environnement ou pour satisfaire la demande des consommateurs en produits « verts». Ce changement implique la construction de normes d'identités de produits, à la fois pour les produits « frais » et « reconstruits »; certaines de ces normes avaient été précédemment associées à des stratégies alternatives au régime dominant, elles sont recyclées en son $\operatorname{sein}^{3}$. La description, en tant qu'idéal-type du régime, retient donc la capacité de certaines entreprises, du fait de leur pouvoir sur les chaînes d'approvisionnement transnationales, à imposer des contrôles écologiques ou de qualité (notamment sur le plan sanitaire) et, par là même, à gagner le soutien du public.

Néanmoins, une telle perspective, qui ferait à une agriculture disposant de signaux de qualité une place en symbiose avec le régime dominant, minimise les tensions

2. À ce sujet, C. Laurent (2013) doute de l'association produits frais/faible mobilisation d'intrants chimiques, issue du marketing territorial faisant abusivement référence au mode de consommation méditerranéen. Deux conditions ont fait le « succès » de la production de masse des produits frais, l'une est l'utilisation massive des intrants chimiques et l'autre est le dumping social par des réseaux internationaux de fourniture de main-d'œuvre, qu'incarne le travailleur « détaché » venant concurrencer les traditionnels saisonniers du Maghreb.

3. On doit à Allaire et Daviron (2006) d'avoir théorisé des « marchés médiatiques » où ces identités articulent des normes privées et publiques afin de contenir les « crises d'opinion » liées à l'artificialisation des procédés. 
qui apparaissent de façon particulièrement vive en deux endroits : la résistance à l'approfondissement de la trajectoire agro-industrielle par les biocarburants et la question de l'ancrage local de l'alimentation.

Le refus de voir s'imposer avec les chaînes globales de valeur une " alimentation faite nulle part », et la volonté de préserver les « aliments en voie de disparition, la biodiversité et les connaissances traditionnelles locales » (Fonte, 2013) ont imposé aux négociateurs de l'Organisation mondiale du commerce l'agenda des considérations non commerciales et de la multifonctionnalité agricole, devenue un des éléments emblématiques de l'altermondialisme. L'opposition d'idéaux-types se situe alors entre un nouveau régime basé sur le pouvoir d'entreprises à même d'imposer des contrôles écologiques sur leurs chaînes d'approvisionnement transnationales et des systèmes localisés écologiquement résilients.

Si l'on retient l'existence de diverses stratégies de verdissement des systèmes agroindustriels, comment comprendre les conceptions de la qualité dont ils sont porteurs et les différences dans les bases de connaissances qui leur sont nécessaires ? Comment celles-ci viennent-elles compléter ou contester le régime agro-industriel alimentaire ? Une réponse prospective a besoin de mobiliser une typologie théorique des agro-innovations. Vanloqueren et Baret (2009 : 972) proposent une typologie générique des paradigmes technoscientifiques, qui divise les life sciences en opposant génie génétique et ingénierie agroécologique, et l'on verra que cette distinction finit par rejoindre celle proposée par Allaire et Wolf (2004) pour les innovations agroalimentaires entre une « logique cognitive de décomposition/recomposition » et une « logique cognitive d'identité ».

Le génie génétique vise à modifier des plantes pour améliorer la productivité, arguant de sa capacité à résoudre les conditions difficiles de certaines productions agricoles (pathogènes, sécheresse, milieux salins, sols peu fertiles, etc.) ou à concevoir de nouvelles plantes pour des objectifs précis, tels que des contenus nutritionnels modifiés ou des chaînes carbonées pour les usages non alimentaires. La révolution biotech, par le jeu de ses appellations (biotechnologies vertes, blanches, bleues), se propose donc comme candidate pour unifier les usages alimentaires et non alimentaires dans le même paradigme (Colonna et al., 2015).

L’ingénierie agroécologique vise à concevoir des systèmes agricoles réduisant drastiquement les usages des produits agrochimiques et des intrants énergétiques, comptant plutôt sur les interactions écologiques entre les composantes biologiques pour permettre aux systèmes agricoles de stimuler eux-mêmes leur protection, la fertilité des sols et la productivité (Vanloqueren et Baret 2009 : 972). Mais, surtout, le paradigme est un peu plus qu'un ensemble de sciences et de technologies. Van Dam et al. (2012) distinguent trois temps de l'agroécologie : «l'agroécologie des systèmes productifs au sens strict [qui applique les principes du courant de l'écologie systémique d'Odum à l'agroécosystème productif], l'agroécologie des systèmes alimentaires [alternatifs] et enfin l'agroécologie comme étude des rapports entre production alimentaire et société au sens plus large » (ibid. : 27). Ceci les amène à retenir la définition de Wezel et al. (2009) d'une agroécologie comme concept fédérateur entre des disciplines scientifiques, des mouvements sociaux et des pratiques (Van Dam et al., 2012:28).

L'idée d'une agroécologie dédiée au non-alimentaire est encore faiblement documentée, mais nos travaux récents sur la chimie doublement verte et dans le cadre 
du projet Bioca ${ }^{4}$ (Bioéconomie en Champagne-Ardenne, financé par la région et l'Inra) indiquent deux choses. D'une part, il existe des acteurs qui cherchent à ancrer les voies de transition vers le non-alimentaire dans des ressources locales, parfois en redécouvrant les potentiels de plantes écartées des assolements au moment de la chimisation des pratiques. D'autre part, il existe, en « chimie doublement verte », des stratégies d'adaptation aux structures complexes fournies par la nature qui, plutôt que d'en opérer un fractionnement approfondi, mime la raffinerie pétrolière et vise à reproduire terme à terme ses outputs (carburants et intermédiaires chimiques). Ces stratégies sont portées par des acteurs détenant des patrimoines productifs collectifs aussi anciens que ceux des voies thermochimiques pour le biodiesel (qui remontent aux années 1920) ou biochimiques (héritiers des vieux procédés de fermentation des sucres en alcools pour obtenir l'éthanol).

Les acteurs cherchent donc à innover pour rendre viable, des points de vue économique et environnemental, leur propre sentier de transition à partir de leurs propres patrimoines productifs collectifs qui guident leurs capacités d'adaptation au changement. Des innovations souvent présentées comme radicales (en catalyse, en biotechnologie, etc.) doivent en fait être reliées à ces patrimoines productifs collectifs (Nieddu et Vivien, 2016a).

On peut donc faire, dans le non-alimentaire, le même constat que celui fait par Vanloqueren et Baret (2009), pour l'agroécologie, d'une diversité de voies technologiques malgré les phénomènes de domination et de lock-in (verrouillage) liés au développement de l'agriculture industrielle (et de lock-out de voies minoritaires telles que l'agroécologie). Les innovations scientifiques et technologiques s'articulent alors, dans des régimes différents, avec des innovations organisationnelles et institutionnelles visant à doter le produit d'une identité fondée sur sa qualité sur les marchés (Allaire et Wolf, 2004) et instituer ces marchés (Allaire et Daviron, 2006). Il est alors possible d'opposer deux idéaux-types d'innovations dans ce domaine : celles qui sont destinées à porter les identités et les aspects médiatiques de produits semifinis aux différents stades de décomposabilité des chaînes de valeurs (par la traçabilité ou par l'ACV - analyse des cycles de vie - des produits chimiques biobasés) ; et celles qui portent la construction de l'identité intégrale d'un produit incluant son ancrage territorial et les relations sociales ou avec la nature qu'il engage (les labels Fair Trade en alimentation ou les produits biobasés prônant une économie circulaire en chimie, par exemple).

Dans un paradigme de décomposabilité, l'innovation identifie des traits simples à médiatiser pour des semi-produits (l'éthylène de la bouteille en bioplastique biosourcé par opposition à la bouteille en plastique d'origine fossile, qui ne s'en différencie que par l'âge du carbone utilisé). Mettant en exergue les données calculables, la connaissance technoscientifique va caractériser ces semi-produits (dans des ACV par exemple) pour les recombiner sélectivement dans les chaînes de valeur internationales. Bien que chaque entreprise puisse être tentée de développer des informations confidentielles, la construction de la qualité dépend ici d'une collecte plus large d'informations et de systèmes d'information standardisés concernant les

4. Bioca, 2015. Quelle variété possible en bioéconomie pour une ré-industrialisation écologique des territoires champardennais? 
caractéristiques de composition. La décomposabilité doit donc être soutenue par l'accès collectif à des données up-to-date (voir sur ce point Debref, 2014).

Par opposition idéal-typique, un paradigme de l'identité intégrale du produit cherche à produire les innovations sociales qui permettront d'en reconnaître la cohérence globale. Par exemple, la certification biologique ou le localisme ne satisferont pas, s'ils sont pris séparément, les acteurs qui considèrent que le produit doit aussi être accessible à des catégories sociales modestes ; l'agriculture bio doit aussi permettre la construction d'une souveraineté alimentaire, et des trajectoires soutenables localement (McEntree, 2010, ou Goodman et Goodman, 2009, qui prônent la nécessité d'un « localisme réflexif »). Dans celui-ci, le bio doit être le lieu de nouvelles alliances entre producteurs, distributeurs et mouvements sociaux engagés dans la préservation d'une agriculture paysanne et la fourniture de biens collectifs à l'ensemble des couches sociales (Allaire et Wolf, 2004 : 449). C'est dans ce sens d'innovations techniques et sociales en vue de la production d'une «identité intégrale » qu'il faut comprendre le manifeste de l'agroécologie : « les agroécologistes favorisent les systèmes alimentaires alternatifs opérant au niveau régional ou fondés sur des relations plus étroites entre agriculteurs et consommateurs, et où les réseaux de produits mobilisent les ressources localisées et des identités fortes » (Vanloqueren et Baret, 2009 : 981). De même, dans le non-alimentaire, les progrès en ACV ou dans le respect de quelques principes de chimie verte n'assurent pas d'une cohérence systémique, allant de l'ancrage territorial des productions dans des conditions acceptables pour les écosystèmes à la fin de vie des produits.

En conclusion de cette première partie, on retiendra la diversité de régimes qui sont autant des « régimes de production de connaissances » que « d'activités économiques » portés par des patrimoines productifs collectifs différents. Nous allons maintenant utiliser ces typologies pour analyser les grandes tendances ouvertes par ces deux agendas que sont celui de la bioéconomie et de l'agroécologie.

\section{\Bioéconomie : des agendas divergents ?}

Le terme bioéconomie, dont l'usage a explosé de façon exponentielle ces dernières années, recouvre trois acceptions très différentes les unes des autres. On présentera celles-ci, avant de décrire les dynamiques de la bioéconomie au sens de la révolution biotech, et de différencier celle-ci de la conception de la Commission européenne en la matière, afin de confronter cette dernière à l'agenda de l'agroécologie.

La première conception de la bioéconomie va contribuer à fonder le courant de l'économie écologique (Vivien, 1998) et, pour partie, de l'agroécologie ; elle trouve sa source dans les travaux de Georgescu-Roegen $(1971,1975)$ et de René Passet (1979). On connaît les travaux du premier sur l'économie paysanne et sa critique de la dissipation d'énergie insoutenable de l'agriculture industrielle (Vivien, 1999) : « la survie de l'humanité présente un problème totalement différent de celui de toute autre espèce car il n'est pas seulement biologique ni seulement économique. Il est bioéconomique » (Georgescu-Roegen, 1975 :130). Le célèbre schéma des trois sphères de l'introduction de L'économique et le vivant (Passet, 1979 :11) propose de 
reconsidérer le cœur du raisonnement économique en situant la sphère économique comme sous-système de la sphère sociale, elle-même sous-système de la biosphère.

La deuxième acception du terme est celle de la « révolution biotech ». La découverte de la triple hélice de l'ADN en 1953, l'élucidation de la régulation de la synthèse des protéines en 1961, de la capacité des enzymes à disséquer la molécule d'ADN dans un sentier entièrement prédictible en 1962 et l'isolement du gène en 1969 vont être très vite perçus - par Monsanto dès 1972 - comme le moteur non seulement d'une révolution paradigmatique dans les sciences du vivant, mais aussi d'une grande rupture schumpétérienne en pharmacie, en médecine, en agrosciences et en chimie. Dès lors, cette « révolution industrielle qu'il ne faut absolument pas manquer »va mobiliser de façon massive les politiques publiques (Aguilar et al., 2013) dans des programmes capables de briser les frontières disciplinaires et les « dépendances au sentier », dans des «technology-driven initiatives ».

Le régime de production de connaissances et d'activités économiques qui en découle est rendu visible par les controverses qu'il soulève. Il opère comme une économie des promesses technoscientifiques (Joly, 2010) qui repose sur l'instrumentalisation des life sciences au service d'une industrialisation de la vie ${ }^{5}$. Les espérances technologiques ont conduit les décideurs publics à promouvoir à la fois une modification des institutions gérant le droit de propriété intellectuelle, très contestée sur ses aspects éthiques et économiques (Faut-il breveter le vivant ? À qui appartiennent nos gènes ?), et un modèle linéaire d'innovation où les nouveaux produits ne sont guère que des applications de la recherche fondamentale. Le nouveau régime peut donc être caractérisé par ses aspects de développement d'une techno-science, par la médiatisation des avancées scientifiques et par l'économie des promesses qui en découle, laquelle s'inscrit dans la construction de dispositifs de légitimations variés (validation par le capital-risque ou par le soutien public aux programmes de recherche technologique).

Le récit dominant d'une bioéconomie fondée sur les biotechnologies va conduire à reconceptualiser les sentiers industriels tournés vers une biomasse décomposable et recomposable, dont il s'agit de favoriser la versatilité dans cette unité de production qu'est la bioraffinerie, à partir de la promesse de remplacer les combustibles fossiles au nom de la durabilité, tout en élargissant les possibilités de connaissances exclusives (Murphy et al., 2007 ; OCDE, 2006b).

Comme l'indique un rapport du Word Economic Forum (2010), les stratégies de bioraffinage anticipent la création d'un avantage concurrentiel pour les entreprises capables de réaliser l'intégration de plusieurs matières premières dans la chaîne de valeur de la bioraffinerie, pour les convertir de manière flexible en de multiples produits :

« La chaîne de valeur nouvellement créée créera une place pour des partenariats non traditionnels : transformateurs de céréales intégrant leur aval, entreprises chimiques intégrant leur amont, et entreprises technologiques maîtrisant des technologies clés, telles que les enzymes et les usines de cellules microbiennes qui les relient » (Word Economic Forum, $2010: 20)$.

5. Le rapport issu de l'exercice du National Research Council américain le plus récent du domaine s'intitule : «Industrialization of Biology: A Roadmap to Accelerate the Advanced Manufacturing of Chemicals » (2015). 
Dans le contexte européen, on peut considérer une troisième conception de la bioéconomie, plus ambiguë, fondée sur la préservation de l'agriculture européenne et qui relie les agro-innovations à différentes voies technologiques. Ces ambiguïtés sont sensibles lors des congrès réunissant les stakeholders sur la formation des feuilles de route technologiques. Les sciences de la vie (life sciences), dont les promesses tardent à se réaliser dans ce domaine - du fait, selon une très jolie expression, de la «biomass recalcitrance » à se laisser traiter par les biotech -, ne sont pas seules à servir de base de connaissances aux technologies de décomposabilité et de conversion : les voies thermochimiques restent fortement présentes. Certains définissent donc la bioéconomie comme la production de building-blocks issus de la biomasse pour substituer terme à terme les produits issus du pétrole dans ces usages non alimentaires que sont les matériaux, l'énergie, la chimie et les carburants, quelle que soit la voie technologique retenue, mais en oubliant parfois les débouchés alimentaires.

D'autres insistent sur une voie de substitution des fonctionnalités portées par les produits d'origine végétale, plutôt que la substitution stricte entre structures chimiques de carbone fossile par celles de carbone renouvelable identiques (Colonna et al., 2015). D'autres ne retiennent que la base de connaissance des sciences de la vie (au sens de genomics), fusse au nom d'une « approche holistique », dans la promesse d'une «knowledge-based bio-economy » ou KBBE (DG Research, 2005a) ; enfin, des visions minoritaires promeuvent la combinaison de l'agroécologie et d'une identité intégrale pour la qualité alimentaire (c'est-à-dire pas uniquement « bio » ou « local ») (Levidow et al., 2013b) ou des voies de « bioraffineries sans biocarburants » (Gallezot, 2010 ; Nieddu et al., 2013).

Cette diversité de définition va conduire à un compromis institutionnalisé dans une bioéconomie fondée sur la connaissance (= KBBE) comportant deux axes : la qualité de l'alimentation et le non-alimentaire. Il est donc nécessaire de comprendre pourquoi, dans cette KBBE, extension de l'agenda de Lisbonne visant à faire de l'Europe « l'économie basée sur la connaissance la plus compétitive du monde » (BioCouncil, 2000), l'alimentaire et le non-alimentaire n'ont pas été séparés, probablement à l'initiative des grandes fédérations de coopératives agricoles européennes. En effet, la KBBE a été définie de façon générique comme « la transformation durable, éco-efficace des ressources biologiques renouvelables dans la santé, l'alimentation, l'énergie et d'autres produits industriels »(DG Research, $2006: 3)^{6}$.

Dans cet agenda, l'agriculture est présentée comme le «puits de pétrole du $\mathrm{XXI}^{\mathrm{e}}$ siècle ». Cette métaphore de la biomasse comme «biocrude », et de la « bio » raffinerie comme unité de production, naturalise dans son discours le paradigme de la décomposabilité. En assimilant les composants de la plante à du pétrole brut, elle vise à mimer la capacité de fractionnement de la raffinerie pétrolière : «Les

6. La Commission européenne avait invité, en 2004, les industriels à établir des plateformes technologiques européennes (ETP), et à définir des programmes de recherche susceptibles d'attirer leurs investissements. Pour les secteurs agroalimentaire-sylviculture et biotech, les ETP ont été lancés principalement par les fédérations de coopératives agro-industrielles, des organisations de l'industrie dirigées par des multinationales, avec l'appui et les propositions d'organisations scientifiques (en particulier Epso et Epobio). Chaque ETP avait en charge la proposition d'une « vision pour le futur » à horizon 2025. 
huiles de graines de plantes sont structurellement similaires à des hydrocarbures à chaîne longue dérivés du pétrole brut » (Epobio, 2006 : 10). Le matériel végétal, devenu analogue à du pétrole brut, peut être « craqué » dans la bioraffinerie pour substituer terme à terme les produits de la pétrochimie de base par une dizaine de building-blocks issus de la biomasse, suivant ainsi la feuille de route technologique américaine autour du top ten (Bozell et Petersen, 2010) : "De nouveaux développements sont en cours pour transformer la biomasse en un "biobrut" liquide, qui peut être affiné, utilisé pour la production d'énergie ou envoyé à un gazogène » (Biofrac, $2006: 21)$.

Le régime de production de connaissances et d'activités économiques de cette troisième bioéconomie fonctionne donc de façon différente de celui de la "révolution biotech ». D'une part, il ne part pas de l'hypothèse d'une révolution biotech à laquelle il s'agit de s'adapter, mais de l'hypothèse d'une « grande transition » vers l'usage des ressources renouvelables pour l'énergie, la chimie et les matériaux, avec, au cour de cette transition, un objet technologique transitionnel jusque dans son étymologie : la bioraffinerie ; malgré la puissance du mythe rationnel de la révolution biotech au sein des life sciences, celle-ci n'unifie pas l'espace de ce régime car les acteurs de cette troisième bioéconomie cherchent à garder les options ouvertes, sur les deux voies thermochimique et biochimique.

Par ailleurs, la bioraffinerie a été interpellée, à propos des biocarburants, sur un ensemble de questions relevant de la première bioéconomie (Banse et al., 2011, Commission européenne, 2012b, 2012c ; Huang et al., 2012), d'où le développement d'une rhétorique des carburants de deuxième génération, issus de fractions non alimentaires des plantes, de cultures non alimentaires ou de déchets. La variable « développement durable » est donc bien devenue indissociable des contradictions à résoudre dans le développement de la troisième bioéconomie.

Enfin, le modèle de la start-up innovante destinée à devenir le Google de la bioéconomie, en s'appuyant sur l'extension des droits de propriété intellectuels, ne résiste pas à l'expérience réelle. Compte tenu des très importants engagements en capital fixe ${ }^{7}$ à consentir et de la complexité des savoirs à intégrer, le développement de nombre de bioraffineries se fait à partir d'extensions de sites de l'agroindustrie (le plus bel exemple européen étant le site de Pomacle-Bazancourt) ou de la papeterie pour le bois (dans les pays scandinaves notamment), nécessitant un ensemble de connaissances partagées dans des plateformes d'open innovation. Ces complexes industriels impliquent la complémentarité entre alimentaire et non-alimentaire, en particulier parce que l'alimentation animale, co-produit des agrocarburants, est un des débouchés qui contribue à l'équilibre économique des bioraffineries.

Le paradigme de l'innovation de décomposabilité permet également de comprendre les priorités de recherche de l'industrie alimentaire et leur incorporation dans le

7. À titre d'illustration, les engagements en financements accordés dans les projets européens fonctionnent par tranches de 25 millions d'euros, et le ticket pour le test d'un scale-up industriel est de 75 millions d'euros. Les start-up de cette bioéconomie sont donc condamnées au rôle de fournisseurs de connaissances, et au mieux à des joint-ventures avec des macro-acteurs, si elles n'obtiennent pas ces tickets d'entrée sous forme de subventions publiques. 
7 e PCRD (Programme cadre de recherche et développement 2007-2013). La fédération européenne de l'industrie alimentaire (CIAA) a développé une plateforme technologique européenne (ETP), « Food for Life », destinée à gérer les tensions sur l'évaluation par les consommateurs de la qualité de l'alimentation industrielle : « la demande des consommateurs doit conduire la R\&D et les besoins d'innovation » (Food for Life, 2005 : 13 ; 2007 : 6). Pour éviter les crises d'opinion liées à ces marchés médiatiques que sont les marchés alimentaires, il est « essentiel de construire des systèmes efficaces de traçabilité des produits et d'identifications des produits en qui les consommateurs peuvent avoir confiance » (Food for Life, $2007: 6)$.

Pour résoudre le problème de la résistance des consommateurs aux innovations de rupture alimentaire, l'industrie a combiné l'innovation technoscientifique à la demande pour des aliments « frais » ou « naturels » : « La plupart des nouvelles technologies de traitement des aliments portent la promesse d'offrir des aliments sains sans sacrifier le naturel et les bienfaits nutritionnels » (Food for Life, 2005 : 25). Ces revendications « de naturalité » étant difficiles à justifier, et encore plus à vérifier, le concept a disparu de documents ultérieurs de l'ETP, même si l'innovation technoscientifique reste au cour de sa stratégie : «Bon nombre des faiblesses identifiées pourraient être résolues sur le plan technologique » (Food for Life, 2008 : 7). L'industrie alimentaire va donc chercher à renforcer la production de connaissances dédiées à la légitimation des allégations de santé publique au sujet de nouveaux produits : «Ces produits, ainsi que les modifications recommandées dans les régimes et les modes de vie alimentaires, auront un impact positif sur la santé publique et la qualité de vie globale » (Food for Life, $2008: 3)$.

Un tel régime économique est donc indissociable d'un régime de production de connaissances : «Par conséquent, la connaissance accumulée dans les domaines prioritaires vise à reformuler un large éventail d'aliments, à concevoir de nouveaux aliments, et à les rendre admissibles aux allégations de santé » (ibid. : 18). L'industrie préconise alors le développement de la technologie d'ACV de la production alimentaire pour en démontrer les avantages d'éco-efficacité, comme base pour les choix éclairés des consommateurs (ibid. : 40). Pour clarifier les avantages des nouveaux aliments-santé, elle propose la constitution de grandes «bases de données nationales harmonisées sur la composition des aliments et des modes de consommation, y compris les aliments ethniques et traditionnels » (ibid. : 32).

Enfin, face à des demandes pour des aliments produits localement plutôt que pour les « alicaments », elle cherche à intégrer les traditions alimentaires dans l'innovation technoscientifique : "L'intégration des riches traditions de la cuisine européenne dans des marchés pilotés par l'innovation représente un défi important et constant », qui peut être résolu par «l'innovation et l'industrialisation de la gastronomie régionale » (Food for Life, 2005 : 9, 22). Ce programme tente donc bien de capter les désirs des consommateurs en matière d'identité globale du produit dans le paradigme de la décomposabilité.

En partie en réponse à l'agenda qui vient d'être présenté, les organisations de l'agriculture et de l'alimentation bio ont formé un réseau européen d'intervenants visant à préconiser une recherche agroécologique (Ifoam-Europe, 2006). Ils ont cherché à obtenir le soutien de parties prenantes, y compris d'acteurs de grandes organisations 
commerciales, ainsi que d'ONG environnementales. Ceci a abouti à la publication d'une Vision for an Organic Food and Farming Research Agenda to 2025 (Niggli et al., 2008), dans le but de mettre en place une plateforme technologique bio (TP Organics $\left.{ }^{8}\right)$. Son agenda stratégique de recherche reliait l'innovation à la production de biens publics et à la connaissance de l'agriculture paysanne, mettant ainsi l'accent sur la nécessité de développer « une intensification écofonctionnelle » :

Jusqu'à présent, la faiblesse de l'agriculture biologique demeure son insuffisante productivité et la stabilité de ses rendements. Cela pourrait être réglé au moyen d'une intensification " écofonctionnelle ", c'est-à-dire d'un usage plus efficace des ressources naturels, des techniques améliorées de recyclage des nutriments et des méthodes agro-écologiques pour accroître la biodiversité et la santé des sols, des plantes et du bétail (Niggli et al., 2008 : 34 ; Schmid et al., 2009 : 59).

L'intégration horizontale alimentaire/non-alimentaire (essentiellement énergie, mais aussi recyclage des déchets urbains comme intrants) y était présente :

Des usages diversifiés des sols peuvent offrir de nouvelles possibilités pour combiner la production alimentaire, la production de biomasse et la production, dans les exploitations, d'énergie renouvelable à partir du fumier, de petits biotopes, de plantes pérennes et d'aire non cultivées semi-naturelles. Les prairies semi-naturelles peuvent être conservées et intégrées dans les activités des fermes sans animaux en récoltant de la biomasse pour la production d'agro/bio-énergie et en recapturant les nutriments des effluents résiduels pour les utiliser comme fertilisants organiques supplémentaires sur les terres cultivées (Schmid et al., 2009 : 26).

Cette stratégie va alors participer au développement d'un débat sur la valeur du localisme et à forger la notion de reflexive localism évoqué plus haut autour d'alliances sociales plus larges que les seuls producteurs bio : "Les parties prenantes le long de toute la chaîne alimentaire sont en mesure de participer à ce développement et la société civile doit être étroitement impliquée dans le développement de la technologie et de l'innovation » (Schmid et al., 2009 : 16.). Cette vision a été traduite en plusieurs propositions de recherche pour raccourcir les chaînes agroalimentaires, en particulier grâce à l'engagement des consommateurs : « La production conjointe de modèle de connaissance transgresse la frontière entre les producteurs et les utilisateurs de connaissances, de sorte que tous les partenaires peuvent être impliqués dans les recherches » (Padel et al., $2010: 58)$.

Dotée de cette stratégie, TP Organics, en s'appuyant sur des réunions de consultation au niveau européen, a tenté d'influencer les programmes de la Commission européenne. Le programme FAFB a accueilli des études de prospective menées par des experts, dans des exercices qui ont été commandés par le Standing Committee on Agricultural Research (SCAR), avec le soutien de certaines agences nationales de promotion des connaissances des agriculteurs. Selon le premier rapport d'experts, les agriculteurs développent souvent des innovations modestes, mais celles-ci sont facilement rejetées ou ignorées (SCAR FEG, 2007 : 8). Par ailleurs, les programmes de recherche sont devenus plus éloignés des connaissances des producteurs, favorisant la connaissance décomposable de laboratoires spécialistes des intrants agricoles et des méthodes de traitement (SCAR FEG, 2007 : 11).

8. Voir sur le site http://www.tporganics.eu/ les partenariats avec ces plateformes nationales (consulté le 24 octobre 2016). 
Comme moyens de progresser, le groupe d'experts a préconisé des approches portant sur la diversité génétique in situ et les connaissances vernaculaires des agriculteurs. (SCAR FEG, 2007). Il a également préconisé de nouveaux types de systèmes de connaissances $(\mathrm{AKS})$ au-delà du système de recherche formelle : « Les AKS, qui ont été développés en dehors du courant dominant, pour soutenir le commerce équitable, et des systèmes agroécologiques, sont identifiés [...] comme méritant grandement l'augmentation de l'investissement public et privé » (SCAR FEG, 2007 : 42). Les préconisations des experts étaient également de donner la plus haute priorité aux approches qui promettaient des évolutions vers des systèmes à haut rendement, à faibles intrants, intégrant les principes de connaissance agroécologiques historiques, et dessinant une perspective d'autosuffisance, en opposition aux chaînes de valeur globales (SCAR FEG, 2007 : 8).

Les sujets de recherche retenus visent à faciliter la création de référentiels publics - sur l'agriculture soutenue par la communauté, les circuits courts et les marques territoriales - ; ils mettent l'accent sur « des solutions durables pour la gestion de l'eau et le recyclage des nutriments », et, comme une tâche spécifique pour les interactions institutionnelles, sur « la relation entre les pressions périurbaines et la participation des agriculteurs et d'autres intervenants dans les mesures de développement rural » (DG Recherche/FAFB, 2011 : 31). La plupart de ces thèmes ont donné lieu à des appels à propositions de TP Organics.

Cependant, il est clair que les hauts fonctionnaires de la Commission promeuvent encore quasi exclusivement la vision technoscientifique de la bioéconomie. Celleci domine les documents pour une consultation publique qui visait à informer sur les futures priorités de recherche pour une bioéconomie européenne, en particulier dans le successeur du $7^{\mathrm{e}} \mathrm{PCRD}$. Le processus politique pourrait donc à nouveau réduire la place marginale, mais réelle, qu'a pris l'agroécologie. TP Organics a changé de stratégie pour plaider, aujourd'hui au sein du concept de bioéconomie, pour l'existence de positions divergentes'.

En réponse à la consultation publique, TP Organics a critiqué la Commission qui favorise « de nouvelles technologies spécifiques (telles que la modification génétique) et les innovations capital-intensives au détriment de l'agriculture » (TP Organics, $2011: 7)$. Il y oppose les méthodes agroécologiques et la relocalisation de l'agroalimentaire pour une bioéconomie différente fondée sur les savoirs agricoles et la coproduction de l'agriculture et de biens publics (ibid. : 10). De même, en réponse à la Commission pour le programme-cadre, TP Organics (2011) a préconisé la mise en place d' « un réseau de centres d'innovation agroécologiques dans les communautés agricoles à travers l'Europe » pour des approches transdisciplinaires et participatives. Par tous ces moyens, il cherche un endroit institutionnel spécifique pour inscrire une vision agroécologique dans les documents politiques de l'UE, et des ressources sur le long terme pour les réseaux de production de connaissances des parties prenantes.

9. On notera que ses Organic Innovation Days de décembre 2015, en présence du DG Bioéconomie, mettent à leur agenda la question des bioplastiques et du non-alimentaire. 


\section{W Conclusion}

Le concept de régime agro[industriel] dominant a été mobilisé pour décrire les transitions potentielles par rapport au régime néolibéral agro-industriel dominant jusqu'à la fin des années 1970. Celui-ci a été ébranlé par des crises multiples et de nature différente qui ont créé des opportunités nouvelles en s'inscrivant dans un régime corporate-environmental (Friedmann, 1993). En particulier, en analysant l'agenda dominant pour une bioéconomie, nous avons pointé l'émergence d'un idéal-type de régime alimentaire et non alimentaire couplant dynamiques du capitalisme et dynamiques environnementales, grâce à des innovations « vertes ", qui étaient associées dans le passé à des alternatives au régime dominant. Cette incorporation nous amène à confronter des agendas (de l'agriculture paysanne) ne relevant pas simplement du greenwashing du régime dominant (fermes géantes « bio »).

Nous avons identifié deux trajectoires de la bioéconomie, celle de l'industrialisation du vivant à travers les life sciences et le projet agroécologique, pour analyser : Comment sont-ils promus en tant que bioéconomie alternatives ? Quels rôles jouent la production de connaissances et les qualités des produits ? En explorant les prospectives dessinées par les deux agendas, il est possible de pointer les points de tensions dans chacun des régimes de production de connaissances et d'activités économiques.

«Life sciences and chemistry» : l'agenda de la bioéconomie n'engage pas vers une société décarbonée, mais vers une substitution du carbone fossile par le carbone renouvelable. Dans cette substitution, la KBBE doit à la fois faire la preuve de sa soutenabilité économique et de la compatibilité de ses procès de fractionnement de la biomasse avec des coproduits qui n'ont pas que des débouchés non alimentaires ; certains reviennent dans les chaînes alimentaires, par le biais de l'alimentation animale ou d'additifs alimentaires. Par ailleurs, cette KBBE, en sollicitant les ressources du vivant pour de nouveaux débouchés, n'implique pas, bien au contraire, une baisse de pression sur les milieux.

La dernière décennie a vu la KBBE promue conjointement par les décideurs politiques de l'UE, l'industrie capital-intensive et sa base de recherche publique. Les sciences de la vie y ont été reliées à un paradigme de la décomposabilité, dans un agenda technologique qui recherche la flexibilité des chaînes de valeur, à travers une nouvelle intégration verticale entre agriculture, chimie et énergie, qui ferait de l'agriculture le producteur d'or noir du XxI ${ }^{\mathrm{e}}$ siècle. Ce paradigme de la décomposabilité est aussi étendu à la « qualité » de nouveaux aliments, qualifiés de «fonctionnels », et à l'industrialisation des spécialités alimentaires vernaculaires.

"Agroécologie »: le courant agroécologiste a retenu une stratégie cherchant aujourd'hui à perturber la formation de cette voie dominante par la construction de réseaux de parties prenantes et de recherche alternatifs, et en proposant une alternative au sein même des compromis d'institutionnalisation de la KBBE par la Commission européenne. Il propose de relier, dans une "intensification écofonctionnelle », l'agroécologie et la production d'une identité "intégrale » pour des produits fondés sur la souveraineté alimentaire. On notera néanmoins qu'il n'a que de façon très embryonnaire dessiné des convergences entre l'agroécologie et 
les paradigmes technico-économiques qui, dans le non-alimentaire, s'opposent au paradigme de la décomposabilité, et cherchent eux aussi à construire des « circuits courts » (Nieddu et al., 2013) ${ }^{10}$, ou à renouer avec des plantes vernaculaires et des connaissances paysannes.

On notera pour finir que le cas de la bioéconomie permet à la fois de valider et de souligner certaines limites des théories de la transition sociotechnique vers la soutenabilité (Smith et al., 2010). Les différents agendas s'organisent bien comme des récits autour de niches d'innovation que les acteurs cherchent à protéger par des dispositifs institutionnels et par des récits sur les promesses économiques et environnementales qu'ils sont censés porter (les « politiques et les récits de renforcements des pouvoirs » de Smith et Raven, 2012 : 1031-1033). Néanmoins, faute d'une conceptualisation des logiques d'innovation et d'une caractérisation de la diversité des régimes de production de connaissances et d'activités économiques, la dynamique des niches d'innovation y reste indéterminée, entre intégration (fit-andconform) dans le régime dominant ou contestation de celui-ci (stretch-and-transform); c'est précisément ce que l'on doit préciser (Levidow et al., 2014, 2015).

10. Un de ses archétypes étudié par nous (Nieddu et al., 2013) serait la voie, théorisée en Italie par la société Novamont, d'une bioraffinerie sans biocarburants, s'appuyant sur des plantes de sols pauvres (le chardon) pour produire localement la biomasse alimentant la bioraffinerie, pour des productions répondant à des principes stricts d'économie circulaire (Bastioli, 2008). 


\title{
Chapitre 10 \\ L'agriculture biologique en France, entre projet critique et conventionnalisation
}

\author{
T. Poméon, E. Fouilleux, S. Lemeilleur, A. Loconto
}

L'agriculture biologique est largement reconnue au sein des institutions et des marchés. Cette reconnaissance n'empêche pas des débats tenaces sur sa définition et son périmètre de légitimité. En effet, si elle fait l'objet d'une réglementation et d'un label publics (règlement européen (CE) $n^{\circ} 834 / 2007$ ), des divergences subsistent quant à sa nature, ses objectifs, et les représentations et valeurs associées. Entre les tenants d'une bio porteuse d'un projet alternatif de société, et ceux qui y voient un modèle technique et un marché complémentaires au modèle dominant, il existe un continuum de positionnements et de pratiques (Verhaegen, 2012). Ces divergences témoignent de rapports différents vis-à-vis du projet initial de l'agriculture biologique et de son évolution.

Les pratiques d'une agriculture dite biologique se sont affirmées comme telles à partir des années 1930. Elles ont été revendiquées par leurs pionniers comme un modèle alternatif à l'agriculture industrielle alors naissante, intégrant des dimensions à la fois agronomiques, économiques, sociales, politiques et philosophiques (Besson, 2011 ; Leroux, 2011). Mais l'institutionnalisation de l'agriculture biologique ne s'est vraiment faite qu'au début des années 1990. Elle est devenue une norme officielle et un standard de marché certifié avant de se retrouver enrôlée dans le champ du développement durable. La bio a dès lors connu une forte croissance (même si elle reste minoritaire, avec $4 \%$ des surfaces agricoles et 2,4\% du marché alimentaire en France selon l'Agence Bio en 2013), et une structuration et une intégration de ses filières et de ses réseaux professionnels. Ce processus d'institutionnalisation l'a dans un même temps éloignée de plusieurs de ses principes fondateurs. Des critiques se sont exprimées, notamment à travers la notion de conventionnalisation introduite par Buck et al. (1997) et largement reprise dans les milieux scientifiques, professionnels et militants (Darnhofer et al., 2010 ; Baqué, 2012). Ces critiques ont débouché sur l'émergence ou la réactivation de dispositifs cognitifs et organisationnels qui visent à affirmer la dimension de mouvement social de la bio, critique de la société capitaliste. Nous nous intéresserons particulièrement à une alternative à la certification par tierce partie, le système participatif de garantie, et à l'émergence et au renforcement de standards privés bio, qui posent de nouvelles exigences et mettent en avant une « bio + ». 
Le but de ce chapitre est d'analyser la trajectoire qu'a connue l'agriculture biologique, entre posture critique et politique, et constitution d'un segment de marché autour d'un label officiel, et les tensions que ces dynamiques ont suscité parmi les acteurs du champ de l'agriculture biologique. Il se base sur trois travaux portant sur la gouvernance, les systèmes de certification et les standards privés de l'agriculture biologique (Fouilleux et Loconto, 2014 ; Lemeilleur et Allaire, 2014 ; Poméon et al., 2014 ; présentés lors du même colloque en 2014), et qui se sont appuyés sur des entretiens auprès de producteurs, de représentants d'organisations professionnelles et d'organismes gestionnaires, sur diverses expériences d'observation participante et sur l'analyse de différents types de documents (sites Internet, cahiers des charges, etc.). Nous reviendrons dans un premier temps sur le projet initial de l'agriculture biologique et sa transcription dans un ensemble de pratiques et de dispositifs, et sur les tensions et les débats induits par son institutionnalisation progressive en France, puis nous verrons comment cette institutionnalisation réglementaire et marchande de l'agriculture biologique a modifié en profondeur les règles du jeu du champ, le type d'acteurs en présence et leurs pratiques. Cela nous conduira ensuite à nous intéresser au mouvement contemporain de réactivation de la dimension critique et alternative de la bio à travers la relance de la certification participative et la multiplication des standards privés visant à dépasser la norme publique.

\section{- De la critique multiforme du capitalisme à la conventionnalisation}

Alors que certains déplorent depuis quelques années une conventionnalisation de la bio, la question de la cohérence entre les pratiques, les principes et les valeurs associées à l'agriculture biologique se pose. Pour l'instruire, nous proposons de revenir en premier lieu sur l'évolution de ce champ, tant du point de vue des idées portées par les acteurs historiques de la bio que des dispositifs qu'ils ont développés. La dynamique des idées peut s'analyser par le prisme de sa relation avec la critique du capitalisme, l'agriculture biologique émergeant dans un milieu qui remet en cause l'intégration de l'agriculture dans les logiques capitalistes. Les concepts et la grammaire critique développés par Boltanski et Chiapello (1999) et Chiapello (2009) permettent de décrire et de caractériser les critiques du capitalisme, ses formestypes, ses effets et son appropriation par les acteurs capitalistes depuis le milieu du $\mathrm{XIX}^{\mathrm{e}}$ siècle. Ils sont en ce sens utiles pour décrire et analyser les formes de critique du capitalisme présentes dans le mouvement bio et leurs évolutions. L'agriculture biologique se construit en effet face à un modèle agricole conventionnel qu'elle dénonce, et c'est de là qu'elle tire à l'origine son identité. C'est en tant que mouvement social transversal, et pas seulement technique, qu'elle est porteuse d'une critique de la société capitaliste ; une critique située dans le temps et dans l'espace, qui évolue, est mise en avant ou au contraire en retrait. Pour caractériser les formes prises par la critique, deux questions adaptées du modèle analytique de Chiapello (2009) (voir tableau 10.1) doivent être analysées. Qu'est ce qui est dénoncé dans l'agriculture dite conventionnelle par les tenants de l'agriculture biologique ? Au nom de quelles valeurs? 
Tableau 10.1. Les quatre formes-types de la critique du capitalisme.

\begin{tabular}{|c|c|c|c|c|}
\hline & $\begin{array}{c}\text { Critique } \\
\text { conservatrice }\end{array}$ & $\begin{array}{l}\text { Critique } \\
\text { sociale }\end{array}$ & $\begin{array}{l}\text { Critique } \\
\text { artiste }\end{array}$ & $\begin{array}{l}\text { Critique } \\
\text { écologique }\end{array}$ \\
\hline $\begin{array}{l}\text { Causes } \\
\text { d'indignation }\end{array}$ & $\begin{array}{l}\text { Pauvreté/insécurité } \\
\text { Désordre moral } \\
\text { Destruction } \\
\text { des solidarités } \\
\text { Lutte des classes }\end{array}$ & $\begin{array}{l}\text { Pauvreté/inégalités } \\
\text { Relations salariales } \\
\text { Exploitation } \\
\text { Contrôle du capital } \\
\text { Domination de classe }\end{array}$ & $\begin{array}{l}\text { Médiocrité, } \\
\text { stupidité } \\
\text { Uniformisation, } \\
\text { massification, } \\
\text { commodification, } \\
\text { conditionnement. } \\
\text { Aliénation }\end{array}$ & $\begin{array}{l}\text { Destruction des } \\
\text { écosystèmes } \\
\text { et des espèces, } \\
\text { et des habitats } \\
\text { humains }\end{array}$ \\
\hline $\begin{array}{l}\text { Valeurs } \\
\text { sous-tendues }\end{array}$ & $\begin{array}{l}\text { Dignité partagée } \\
\text { commune à tous } \\
\text { les humains } \\
\text { Interdépendance } \\
\text { entre classes sociales } \\
\text { Devoir moral des } \\
\text { élites envers le reste } \\
\text { de la population }\end{array}$ & $\begin{array}{l}\text { Travail } \\
\text { Égalité (en termes } \\
\text { économiques et } \\
\text { dans les prises de } \\
\text { décisions) comme } \\
\text { condition nécessaire } \\
\text { pour une vraie liberté }\end{array}$ & $\begin{array}{l}\text { Autonomie } \\
\text { personnelle } \\
\text { (interne et externe) } \\
\text { Goût et existence } \\
\text { raffinée (art, } \\
\text { philosophie, vérité, } \\
\text { etc.) }\end{array}$ & $\begin{array}{l}\text { Dignité } \\
\text { partagée } \\
\text { commune à tous } \\
\text { les êtres vivants } \\
\text { Vie des } \\
\text { générations } \\
\text { futures }\end{array}$ \\
\hline
\end{tabular}

Traduit de Chiapello (2009).

Le début du $\mathrm{Xx}^{\mathrm{e}}$ siècle voit l'émergence de courants de pensée fondateurs de l'agriculture biologique, autour notamment des figures de R. Steiner et de A. Howard. D'autres figures pionnières vont participer à l'émergence d'une agriculture alternative, comme les époux Müller associés à $\mathrm{H}$. P. Rusch et $\mathrm{M}$. Fukuoka, ou encore B. Mollison et D. Holmgren à l'origine de la permaculture. Ces différents courants remettent en question le modèle agricole dominant, d'un point de vue technique mais aussi souvent plus globalement, et s'accordent sur la préservation de la fertilité des sols et les effets néfastes des produits chimiques de synthèse (Piriou, 2002 ; Besson, 2011 ; Vankeerberghen, 2012). En France, l'agriculture biologique est introduite en Alsace dans son versant biodynamique par une douzaine de personnes membres de l'Afran (Association française pour la recherche d'une alimentation normale), créée en 1952 par le docteur Bas, et qui regroupe des anthroposophes (qui s'inspirent de la pensée de Steiner) et des spécialistes de la nutrition (Piriou, 2002). En 1959, est créé le premier groupement d'agriculteurs biologiques en France, le Gabo (Groupement des agriculteurs biologiques de l'Ouest), qui s'inspire essentiellement des travaux de Howard qui ont été mis en œuvre par la Soil Association en Angleterre ${ }^{1}$.

Au-delà de la diversité des inspirations et des points de vue des différents acteurs, Piriou (2002) pointe une dénonciation partagée de l'agriculture productiviste basée sur trois types d'argumentaire : le lien entre modes de production, alimentation et santé ; la question de l'autonomie des agriculteurs vis-à-vis de l'achat d'intrants et de l'écoulement de la production; et enfin une préoccupation pour la préservation des ressources naturelles. Leroux (2011) montre pour sa part que la sociogenèse de l'agriculture biologique française est liée à une critique du capitalisme industriel et de sa déclinaison dans le secteur agricole et alimentaire. Elle est, à l'origine,

1. Pour plus d'informations sur l'histoire de l'agriculture biologique, voir les informations et les références indiquées dans les articles et les ouvrages cités dans ce paragraphe et le suivant. 
plus un mouvement social, avec une implication significative des non-agriculteurs (médecins, consommateurs, etc.), qu'une identité professionnelle caractérisant des agriculteurs (Viel, 1979 ; Piriou, 2002). S’y retrouve la dénonciation du primat de l'agriculture industrielle et productiviste et des marchés, sous différentes formes et intensités selon les cas. Un lien historique relie ainsi la critique du capitalisme et celle des transformations de l'agriculture et du système agroalimentaire, dans laquelle s'inscrivent les acteurs qui ont porté l'agriculture biologique. L'agriculture biologique émerge donc en France dans une critique plurielle des transformations de l'agriculture entamées à la fin du XIX ${ }^{\mathrm{e}}$ siècle (Viel, 1979 ; Piriou, 2002 ; Leroux, 2011) : artificialisation, industrialisation, poids des agro-industries (fournisseurs d'intrants et de semences) et des grands groupes de la transformation et de la distribution. Le Gabo se forme ainsi dans cet esprit, « c'est-à-dire en réaction à cette modernité [qualifiée de « progrès »] et qui remet en cause un ensemble de valeurs paysannes traditionnelles pour lesquelles et par lesquelles ils envisagent l'avenir » (Leroux, 2011 : 42-43). Ainsi, en France comme dans d'autres pays, les débuts de l'agriculture biologique sont surtout marqués par un rejet du capitalisme dans sa dimension technique et industrielle plus que par rapport aux inégalités des rapports sociaux qu'il engendre. C'est la déchéance physique et morale entraînée par l'industrialisation qui est pointée avant tout, avec comme solution le retour à une société paysanne idéalisée. À un conservatisme agrarien assez présent au départ, que Viel (1979) qualifie de « réactionnaire », vont s'adjoindre d'autres formes de critiques du capitalisme, qui vont donner formes aux valeurs propres de l'agriculture biologique.

En 1962, est fondée l'Afab (Association française de l'agriculture biologique) comme prolongement national du Gabo. Mais, rapidement, deux visions se détachent et donnent lieu à une scission. D'une part, la société Lemaire-Boucher allie une orientation commerciale et la défense de valeurs plutôt conservatrices (Viel, 1979 ; Leroux, 2011). D'autre part, en réaction avec cette posture jugée trop marchande, l'association Nature et progrès $(\mathrm{N} \& \mathrm{P})$ est créée, réunissant agriculteurs, transformateurs, fournisseurs, distributeurs et, surtout, consommateurs. Elle promeut à la fois un mode de production et un mode de vie, et se structure autour de groupes locaux relativement autonomes. Son projet évolue vers un caractère sociétal et transversal plus marqué, en opposition à la société capitaliste productiviste et consumériste. N\&P se rapproche progressivement des mouvements contestataires liés à Mai 68, anticapitalistes, anticentralisateurs et écologistes. L'association se détache ainsi progressivement de la matrice conservatrice originelle. Elle se centre sur des valeurs comme l'autonomie, la sobriété énergétique et technologique, et la proximité dans les échanges (Viel, 1979 ; Leroux, 2011). Ces éléments font écho aux différentes formes de critiques du capitalisme présentées dans le tableau 10.1, en particulier aux critiques dites artiste, sociale libertaire et écologique, qui caractérisent les mouvements contestataires des années 1960-1970. Ces mouvements vont ainsi jouer un rôle significatif dans la promotion de l'agriculture biologique et son essor dans les années 1980. Des valeurs se renforcent autour du rejet du consumérisme et de son organisation dans les circuits conventionnels de distribution, ou encore d'une posture collectiviste et communautaire présente initialement dans beaucoup de projets portés par des néo-ruraux. Au-delà des réseaux d'acteurs impliqués, la dimension critique de l'agriculture biologique se retrouve aussi dans le modèle prôné et pratiqué : des 
petites fermes diversifiées et autonomes, avec une préférence pour un système de vente directe de produits bruts ou peu transformés (Viel, 1979).

La perspective défendue par Nature et progrès va progressivement prendre le dessus sur celle de Lemaire-Boucher (Leroux, 2011), devenant à la fin des années 1970 la tête de pont du mouvement bio. C'est donc sa posture, ses critères et son cahier des charges qui vont servir de référence principale dans le processus d'institutionnalisation réglementaire, décrit par Piriou (2002), qui débute en 1980 avec la Loi d'orientation agricole. Ce processus, réclamé par le mouvement bio, Nature et progrès en tête, aboutira à la reconnaissance officielle et la régulation, en France puis en Europe, de l'agriculture biologique. De onze cahiers des charges privés reconnus pour l'attribution de la mention AB (Agriculture biologique) en 1989 en France, on passe à un standard et un label uniques, portés par l'Union européenne à partir de 1991. L'agriculture biologique va ainsi devenir progressivement une réalité unifiée, du point de vue institutionnel tout au moins.

Dans ce processus d'institutionnalisation réglementaire, la forme critique dite écologique, devenue centrale dans la forme actuelle de critique du capitalisme (Chiapello, 2009), va nettement s'affirmer. En même temps qu'elle devient un élément porteur et fédérateur (autour de la nécessité de réduire les charges en intrants et de la promotion de la multifonctionnalité de l'agriculture), permettant de mettre en avant les pratiques biologiques dans différentes arènes publiques et privées, elle marginalise les dimensions socioéconomiques du mouvement bio. L'intégration de la bio dans le marché est réaffirmée et constitue même la justification de l'État pour protéger le consommateur via un label officiel. Cette posture est dénoncée par un certain nombre d'acteurs, qui voient dans les dispositifs marchands un contexte, voire un facteur, propice aux dérives par rapport à la vocation transformatrice et sociétale du projet bio (Baqué, 2012). Dès ses origines, l'agriculture biologique a ainsi toujours été traversée par ces ambiguïtés par rapport à sa relation au marché. $\mathrm{Vu}$ parfois comme un facteur de dégradation de la situation de l'agriculture et de la qualité de ses produits, les agriculteurs biologiques ont été et sont en grande majorité inclus dans une économie de marché. S'ils privilégient souvent les circuits courts, des filières longues se sont assez rapidement constituées, avec leurs grossistes, leurs transformateurs et leurs distributeurs. Ces débats sur le positionnement de la bio par rapport au dispositif marchand restent aujourd'hui très présents en France, que ce soit en termes de relation à la grande distribution, de place prise par les transactions marchandes dans les dispositifs de certification ou du rôle attribué à la segmentation du marché (marché de niche versus transition globale de l'agriculture vers un nouveau modèle sociotechnique). Il témoigne à la fois de la posture critique de la bio en tant que mouvement social face au mode de régulation capitaliste libéral des échanges et des difficultés des acteurs pour se positionner, entre idées et pratiques.

Par ailleurs, l'agriculture biologique apparaissant progressivement comme une alternative crédible, un nombre croissant d'acteurs qui n'étaient pas présents initialement s'en saisit pour répondre aux critiques sur les impacts environnementaux de l'agriculture de la chimie et aux crises alimentaires successives qui inquiètent les consommateurs (vache folle, dioxine, etc.). Mais cette appropriation s'accompagne de compromis qui se traduisent par une sélection et une limitation de la critique et de sa portée transformatrice. Ce processus de désarmement de la critique est similaire 
à ce qu'ont montré Boltanski et Chiapello (1999) sur l'intégration de la critique artiste dans les pratiques de management suite au mouvement de Mai 68. Dans le cas de la bio, il conduit à en faire un standard de marché, soutenu par l'Europe en tant que pourvoyeur de biens publics environnementaux. C'est ainsi, dans des rapports de force renouvelés et des luttes d'influence, que se définit et évolue l'agriculture biologique (Piriou, 2002). Les acteurs liés à une critique plus radicale et holiste du système capitaliste et du complexe agro-industriel doivent composer avec de nouveaux acteurs, attirés notamment par les opportunités du marché bio, qui ne partagent pas les mêmes visions et objectifs. La domination de la critique écologique n'a pourtant pas évacué les autres formes. Elle peut même être associée à d'autres formes de critiques et participer ainsi à les relancer (Chiapello, 2009). L'enjeu est donc pour les différents acteurs de faire valoir leur projet, comme par exemple celui qui associe écologie et autonomie, contre une vision techniciste de l'écologie qui lui est souvent antagoniste ${ }^{2}$.

C'est dans ce contexte de succès de l'agriculture biologique, en tant que développement d'un marché spécifique (Allaire, 2016), et de débats autour de l'affaiblissement de sa portée critique qu'est apparu le concept de conventionnalisation (Coombes et Campbell, 1998 ; Darnhofer et al., 2010).

La notion de conventionnalisation apparaît pour la première fois dans une étude de Buck et al. (1997) sur la Californie. Selon les auteurs et les questions abordées, ce concept recouvre des processus de différentes natures. Une première définition est liée à l'évolution des motivations des pratiquants de l'agriculture biologique, parmi lesquelles l'opportunité économique jouerait un rôle croissant. Les structures et les modes de gestion tendraient à devenir similaires à ceux de l'agriculture conventionnelle, avec notamment une substitution de la terre et du travail par le capital (Guthman, 2004). La conventionnalisation peut également être entendue comme une normalisation des pratiques agronomiques qui en réduirait la portée écologique et éthique, attribuée à la réduction des principes qu'opère la certification ou à la dynamique propre des systèmes de connaissances (Stassart et Jamar, 2009). La logique de substitution des intrants (intrants bio à la place d'intrants de synthèse) prime alors sur une reconception des systèmes, basé notamment sur la connexion entre polyculture et élevage (Rosset et Altieri, 1997 ; Lamine et Bellon, 2009). Une autre définition se réfère au développement des circuits marchands pour les produits bio au sein des filières conventionnelles et globalisées, impliquant les multinationales agroalimentaires et la grande distribution (Jaffree et Howard, 2009), associée à une diversification des acheteurs et des pratiques d'achat des produits alimentaires bio.

De manière générale, la conventionnalisation renvoie simultanément aux changements opérés par les acteurs historiques de la bio et aux caractéristiques des nouveaux entrants, certains respectant les normes réglementaires de l'agriculture biologique, mais pas ses principes et ses valeurs historiques. La capacité des standards, et des dynamiques sociales et politiques qu'ils impliquent, à prendre en compte ces principes et ces valeurs et à les faire vivre (De Wit et Verhoog, 2007 ; Darnhofer et al., 2010) devient une question essentielle.

2. Pour illustrer cette vision, on peut citer l'argumentaire développé sur les OGM comme technologie au service de l'environnement car limitant l'usage des pesticides. 


\section{" Des effets d'une institutionnalisation centrée sur un standard de marché}

Le projet initial de l'agriculture biologique peut-il survivre à son institutionnalisation sous la forme d'un standard? Pour Piriou (2002: 409), « tant que l'agriculture biologique n'est reconnue que comme un ensemble de techniques ou un marché et non comme un système de production innovant, elle ne peut provoquer aucune remise en cause du modèle agricole dominant ». Au-delà de l'affaiblissement automatique de la critique portée par la réduction de l'agriculture biologique à un ensemble de normes techniques, les effets institutionnels connexes à la mise en standard doivent aussi être pris en compte dans l'analyse des processus de conventionnalisation à l'œuvre. C'est en particulier éclairant de s'intéresser au déploiement de marchés de services encadrant les activités de certification et d'accréditation.

En effet, l'instrument «standard (ou norme) volontaire » qui régule le champ de l'agriculture biologique a des effets institutionnels propres liés au fait qu'il repose sur des imbrications de marchés. Il s'appuie tout d'abord sur un cahier des charges (une liste de pratiques spécifiques à mettre en ouvre par le producteur ou le fabricant), auquel est associé un label que les producteurs bio veulent apposer sur leurs produits afin de les distinguer des autres produits d'aspect similaire. Le label signale au consommateur les conditions particulières de production (pas de produits chimiques, etc.) qui sont invisibles à l'œil nu sur le produit final. Pour l'obtenir, les opérateurs doivent se soumettre à un processus dit de « certification par tierce partie », garant de la crédibilité du système. Autrement dit, ils doivent accepter que leurs pratiques productives soient contrôlées par un opérateur indépendant, le certificateur, qui, s'il juge que celles-ci sont conformes au cahier des charges, leur délivre un certificat de conformité autorisant l'utilisation du label. Le producteur paie le certificateur pour ce service de contrôle. Dernier élément pour garantir la confiance et la crédibilité, le certificateur est lui-même contrôlé par un organisme dit «accréditeur », qu'il paie, qui est en charge d'attester de ses compétences pour certifier la conformité à un standard volontaire donné. L'instrument standard volontaire renvoie ainsi à un système de régulation complexe basé sur de multiples transactions marchandes, associant standards (avec ou sans label), certification et accréditation. Cette imbrication de marchés de produits et de services peut être qualifiée de "régime de standardisation tripartite », ou RST (Loconto et al., 2012; Fouilleux et Loconto, 2016 ; Busch, chapitre 12), système institutionnel internationalisé mêlant acteurs publics et privés. La mise en place d'un RST est justifiée par la volonté de légitimer un standard et de garantir l'effectivité des pratiques qu'il recouvre et s'appuie sur un ensemble de principes : harmonisation et lisibilité (simplicité) des règles et des critères, indépendance et impartialité du contrôle. L'effectivité de ces principes et les effets de la mise en œuvre d'un RST pour l'agriculture biologique éclairent les dynamiques passées et actuelles dans ce champ.

Dans l'Union européenne, ce sont les pouvoirs publics qui ont imposé la certification par tierce partie au moment de la mise en place du règlement sur l'agriculture biologique en 1991. Elle implique des procédures précisément standardisées, principalement basées sur le contrôle de documents écrits (comptabilité, factures, etc.), auxquelles viennent s'ajouter une visite du siège de l'exploitation et, parfois, 
une visite aux champs. Aucune interaction autre que celle liée au contrôle ne doit avoir lieu entre l'agriculteur et le certificateur, notamment en matière de conseil ou d'amélioration des pratiques. L'accréditation est aussi organisée au niveau européen et régie par le Règlement $(\mathrm{CE}) \mathrm{n}^{\circ} 765 / 2008$, qui implique d'une part qu'un organisme spécifiquement désigné par l'État contrôle et accrédite la capacité du certificateur à certifier en général (en conformité à la norme européenne ISO 17065/NE 45011), et d'autre part que le certificateur soit agréé pour certifier le standard européen de l'agriculture biologique. Dans l'ensemble de l'Union européenne, ces deux procédures sont déléguées aux États membres, qui eux-mêmes délèguent éventuellement à des acteurs privés ; en France, il s'agit respectivement du Comité français d'accréditation (Cofrac) et de l'Institut national de l'origine et de la qualité (Inao).

La mise en place du règlement européen a rapidement fait des émules, les standards publics pour l'agriculture biologique sur le modèle du RST se multipliant de par le monde. À partir de là, les discussions se sont principalement concentrées, tant au niveau européen qu'au niveau international, sur les moyens de faciliter et d'accroître les échanges commerciaux. Si les efforts d'harmonisation mis en œuvre ont permis d'étendre à la fois les marchés des produits issus de l'agriculture biologique et ceux des standards auditables pour l'agriculture biologique, ils ont aussi permis de transférer au Sud une vision particulière de l'agriculture biologique. Principalement développée par les organismes de coopération et les importateurs du Nord, l'agriculture biologique ne s'y est pas développée autour d'une critique multiforme portée par des mouvements sociaux ancrés territorialement, comme nous l'avons vu pour la France, mais quasi exclusivement autour de produits d'exportation, et selon les règles du RST, principalement incarné par des entreprises de services étatsuniennes et européennes (Willer et Lernoud, 2016). Il s'agissait de favoriser le développement de la bio en structurant un marché différencié et rémunérateur à même d'attirer de nouveaux acteurs. Au niveau de la détermination du standard bio, cela s'est traduit par une volonté d'harmoniser et de simplifier les règles, pour les rendre plus accessibles pour les producteurs et plus intelligibles pour les consommateurs. L'harmonisation des règles, au niveau national, européen (Gibbon, 2008) et international (via les projets d'organisations publiques comme la FAO ou la Cnuced par exemple, mais aussi de l'Ifoam, la Fédération internationale des mouvements d'agriculture biologique), a exclu de fait les dimensions idiosyncrasiques, les particularismes de chaque territoire. La nécessité de simplifier et de mettre en place des critères auditables a contraint au passage d'une bio fondée sur un ensemble de principes et d'objectifs globaux partagés et retraduits, selon le contexte, à un ensemble de critères techniques plus ou moins réducteurs. L'objectif principal du standard bio est ainsi devenu de garantir la bonne circulation des produits bio et de permettre l'extension de son marché.

Les fonctions et l'organisation de la certification ont elles aussi fortement évolué. Avant la mise en place d'une certification par tierce partie, le système de contrôle était fondé sur les échanges et l'accompagnement, impliquant les producteurs et d'autres acteurs de la bio (les consommateurs notamment). Avec la mise en place du RST, les certificateurs sont devenus des acteurs clés de l'agriculture biologique et de son institutionnalisation, alors même que leurs intérêts et leurs stratégies se sont de plus en plus émancipés des valeurs et des principes originels de la bio. Les associations et les groupes informels de certification sont devenus des entreprises 
autonomes à part entière. Des entreprises multinationales spécialisées dans la certification ont investi le champ de l'agriculture biologique, qui leur est apparu comme un marché attractif. La compétition s'est ainsi accrue entre certificateurs (Garcia Parpet, 2012). Ce mouvement a éloigné la pratique initiale de certification d'un engagement d'acteurs insérés et investis dans la bio. Le focus des certificateurs s'est recentré sur l'offre de prestations compétitives au niveau international, et sur le développement d'un large portefeuille d'activités incluant également la mise en place de nouveaux standards, au-delà du champ de l'agriculture biologique, voire en concurrence avec le label bio. La certification dans le cadre du RST est un service marchand (marché de la certification) qui a une valeur marchande (premium ou accès au marché) et qui est exclusif d'autres formes de certification. Elle peut exclure des acteurs légitimes, par exemple des producteurs qui n'ont pas les moyens de payer un certificateur. Pour certains, elle bloque également la créativité (Lemeilleur et al., 2015) et son caractère homogénéisant ignore la diversité des contextes sur laquelle se fondaient initialement les promoteurs de la bio.

Le système d'accréditation, sur lequel reposent la crédibilité et la cohérence de l'ensemble du RTS, a également connu un certain nombre de transformations. L'Union européenne définit l'accréditation comme une activité sans but lucratif confiée à des monopoles nationaux privés ou publics sous contrôle de l'État, afin de privilégier la mission plutôt que la compétitivité et le profit. Mais si la compétition est absente au niveau européen, les organismes d'accréditation se retrouvent en compétition au niveau international, une situation directement générée par la réglementation européenne. En effet, pour les pays hors UE ne bénéficiant pas du système d'équivalence $^{3}$, les certificateurs doivent contrôler l'application des règles européennes. Les organismes de certification approuvés au niveau européen sont ainsi transformés en organismes d'adaptation des standards publics de l'UE pour le marché privé du reste du monde, ce qui revient à un système d'accréditation parallèle contrôlé par la Commission européenne. Par ailleurs, les organismes d'accréditation se servent de l'autorité publique dont ils disposent au niveau européen pour devenir des « accréditeurs pour le monde » et élargir leurs marchés dans les pays du Sud. Par exemple, l'organisme national d'accréditation allemand (DakkS) accrédite Biolatina (Pérou), COAE et Ecoa (Égypte), CertiMex (Mexique), Argencert (Argentine) et Indocert (Inde). Enfin, les organismes de certification multinationaux accrédités, qui n'ont pas de bureaux dans tous les pays, ont tendance à confier la sous-traitance des services d'inspection à des organismes locaux non accrédités, induisant et alimentant ainsi un marché local parallèle de l'audit.

Plus globalement, cette situation fait converger les standards bio publics et privés des différents pays vers un modèle hégémonique, le standard bio européen, avec ses règles, ses acteurs dominants et sa logique de développement de marché ${ }^{4}$. Ce

3. Dans les pays tiers bénéficiant d'un accord d'équivalence avec l'UE, les produits certifiés en agriculture biologique par des certificateurs accrédités selon les procédures du pays sont exportés sur le marché européen sans que ces organismes de certification n'aient besoin d'une accréditation de l'UE.

4. L'hégémonie européenne dans le champ de l'agriculture biologique peut s'expliquer par plusieurs facteurs, en particulier par l'élaboration tardive d'un standard national aux États-Unis (2000), ainsi que par l'importance des mouvements européens (Nature et progrès, Soil Association, etc.) dans le mouvement international bio, sous la houlette de l'Ifoam. 
modèle ne laisse d'une part que peu de place aux dimensions politiques, éthiques et critiques ; et, d'autre part, son hégémonie remet en cause la dynamique initiale qui voulait que les principes généraux puissent être traduits et adaptés par les collectifs locaux (incluant les acteurs de la filière, mais aussi des consommateurs, des médecins, etc.), en fonction des spécificités du contexte et des projets portés par chaque collectif. Cela va dans le sens d'une désappropriation de l'agriculture biologique, qui pousse en réaction à une certaine remise en cause des différentes dimensions du RST bio que nous approfondirons dans la troisième partie.

L'autre conséquence du développement du RST bio est son inclusion dans le champ plus global de la durabilité. En effet, les années 2000 ont vu un fort développement de standards positionnés dans le champ de la durabilité (par exemple Rainforest Alliance, commerce équitable ou encore tous les produits dits " durables »), ou encore des mentions et des stratégies de communication mettant en avant le caractère durable des pratiques agricoles (agriculture raisonnée, production intégrée, etc.). L'agriculture biologique se retrouve en concurrence dans ce domaine avec d'autres labels et mentions, que ce soit en termes de parts de marché ou de légitimité politique et sociétale. Ce phénomène est cependant moins fort en France que ce qu'il peut être à l'international. Il pèse particulièrement pour les productions tropicales tournées vers l'export ; pour pouvoir s'en sortir, les producteurs doivent souvent être multicertifiés. Cette pression a par exemple conduit l'Ifoam à réfléchir à des modalités d'alignement du cahier des charges bio sur les critères imposés par certains standards devenus majeurs comme GlobalGap (UNCTAD, 2008).

L'insertion de fait du RST bio dans un RST « durable » plus vaste et moins exigeant en termes de pratiques agricoles a eu aussi des conséquences spécifiques au niveau des activités de certification et d'accréditation. Les certificateurs historiques bio ont progressivement étendu leurs activités vers d'autres domaines, s'alignant ainsi sur les certificateurs non issus du champ de la bio. Le cas d'Ecocert, principal organisme certificateur bio français, est à ce titre illustratif. À l'origine, Ecocert émane d'un groupe de conseillers engagés dans la bio et se constitue en certificateur indépendant suite au règlement européen de 1991. Aujourd'hui, Ecocert est une multinationale présente dans le monde entier qui, en plus de certifier les opérateurs bio, contrôle de nombreux standards dans le champ de la durabilité : IFS Food, GlobalGap, ISO, etc. Ecocert produit et propose aussi ses propres standards durables, pour les jardins, les restaurant, les spas ou encore les produits nettoyant. Ce positionnement est vu par certains acteurs comme un risque de renforcement d'une logique de profit parmi les certificateurs, au détriment d'un effort pour développer la bio comme alternative visant la réforme de l'ensemble du système agricole et alimentaire. Pour leur part, les certificateurs défendent une posture pragmatique qui vise à rationaliser l'offre de services et à réduire les coûts de certification dans un contexte où l'obligation de multicertification se diffuse. Un phénomène similaire se retrouve chez les organismes d'accréditation. L'IOAS, un organisme d'accréditation privé fondée par l'Ifoam et originellement centrée sur la bio, a également diversifié ses activités dans les standards de durabilité.

En somme, l'organisation de l'AB selon un régime de standardisation tripartite a été un des facteurs clés de la conventionnalisation. Il a renforcé le développement de la 
bio et participé à sa légitimation en mobilisant le marché comme levier de changement. Mais, en même temps, les dispositifs mis en place dans ce cadre ont institué l'agriculture biologique en tant que niche de marché et mode de production durable parmi d'autres, conduisant à une désappropriation des acteurs historiques de leur capacité de définir la bio. En effet, ce sont l'État et les organismes de certification et d'accréditation qui contrôlent dorénavant la définition du standard $\mathrm{AB}$, son application et son attribution. Cela a abouti à un appauvrissement du projet politique de la bio, via la transformation de valeurs en critères techniques et la marchandisation des activités/relations au sein du secteur (entre producteurs, certificateurs, accréditeurs). Les contraintes liées à l'internationalisation du standard bio (et des marchés liés) ont encore renforcé cette tendance. Face au constat de sa conventionnalisation progressive, et dans un souci de réappropriation et de réactivation des dimensions sociales et politiques de l'agriculture biologique, certains acteurs de la bio, en France et ailleurs, ont créé ou réactivé différents dispositifs en marge du RTS pour renouer avec le projet initial, entre autres, par la formulation de standards privés et la relance de la certification participative.

\section{- Multiplication des standards et retour de la certification participative}

Tout d'abord, si le règlement européen a remplacé les différents cahiers des charges nationaux préexistants à partir de 1991 (1999 pour les produits animaux), il n'a pas pour autant fait disparaître les standards privés. On recense actuellement en France une quinzaine de standards privés, qui sont juridiquement des marques privées contrôlées par des organismes gestionnaires. Si elles ne sont pas associées au label bio européen (autrement dit si le producteur n'est pas certifié selon le règlement européen), elles ne peuvent en aucun cas se revendiquer de l'agriculture biologique. Parmi les onze cahiers des charges homologués en 1991 en France, quatre existent encore en 2013 :

- Nature et progrès $(\mathrm{N} \& \mathrm{P})$, qui a eu un rôle significatif dans l'histoire de l'AB en France ;

- Demeter, le principal label pour la biodynamie et le premier label bio du monde, établi en Allemagne en 1928 ;

- Biobourgogne, une association et marque régionale, créée en 1981 et liée à N\&P ; - le syndicat des Simples (Syndicat intermassif pour la production et l'économie des simples), dédié au secteur de la production et de la cueillette de plantes, lié à N\&P.

Ensuite, de nouveaux standards privés sont apparus à partir de 2002 :

- Biobreizh, créé en 2002 par l'Association des producteurs de fruits et légumes bio de Bretagne, spécifique à une filière et à une région, et Bio Loire Océan (2005), son pendant dans les Pays de Loire ;

- Biodyvin (2002), destinée aux producteurs de vins en biodynamie, issue d'une scission avec Demeter ;

- Bio solidaire, créé en 2009 par l'association Bio partenaire, comme déclinaison pour les échanges « Nord-Nord» de la marque Bioéquitable, qui associe commerce équitable et bio ; 
- Bio cohérence, porté par la FNAB et créé en 2010 en réaction à l'assouplissement de la réglementation européenne de 2007 par rapport aux règles préalablement en vigueur en France 5 ;

- des marques régionales telles que Alsace Bio (2004), Paysan bio Lorrain (2005), Mon bio Pays de la Loire (2012), Saveurs bio Paris Île-de-France (2011), Bio di Corsica (2013), Bio Sud Ouest (2013) ou encore la charte Bio Rhône-Alpes (2010).

Ces standards privés représentent environ 2285 producteurs, soit $9 \%$ des producteurs bio, qui eux-mêmes représentent 4,9 \% des agriculteurs en 2013 (voir tableau 10.2) ${ }^{6}$. Certains standards privés associent également des transformateurs, des distributeurs, voire pour N\&P et Bio cohérence des consommateurs. Certains sont restreints à une région et/ou à certaines filières.

Tableau 10.2. Nombre des producteurs agricoles sous standard privé en $2013^{1}$.

\begin{tabular}{|c|c|c|c|c|c|c|c|c|c|c|}
\hline & \multicolumn{2}{|c|}{$\begin{array}{c}\text { Nature } \\
\text { \& Progrès }\end{array}$} & \multirow[t]{2}{*}{ Demeter } & \multirow[t]{2}{*}{ Biodyvin } & \multirow[t]{2}{*}{$\begin{array}{c}\text { Bio } \\
\text { Cohérence }\end{array}$} & \multirow[t]{2}{*}{$\begin{array}{c}\text { Bio } \\
\text { Solidaire }\end{array}$} & \multirow[t]{2}{*}{ Biobreizh } & \multirow{2}{*}{$\begin{array}{c}\text { Bio } \\
\text { Loire } \\
\text { Océan }\end{array}$} & \multirow[t]{2}{*}{ Autres $^{2}$} & \multirow[t]{2}{*}{ Total } \\
\hline & $\begin{array}{c}\text { Hors } \\
\text { label } \\
\text { AB }\end{array}$ & $\begin{array}{c}\text { Dans } \\
\text { label } \\
\text { AB }\end{array}$ & & & & & & & & \\
\hline $\begin{array}{l}\text { Nombre de } \\
\text { producteurs }\end{array}$ & 350 & 350 & 430 & 90 & 300 & 300 & 65 & 50 & 350 & 2285 \\
\hline
\end{tabular}

1. Les nombres de producteurs sont approximatifs et ont été obtenus lors des entretiens et/ou via les informations disponibles sur les supports de communication des organismes (plaquette, site internet).

2. Inclut BioBourgogne, Simples et les marques régionales citées plus haut.

En 1989, N\&P et Demeter, avec respectivement 1161 et 222 producteurs, représentaient $42 \%$ et $8 \%$ des 2768 producteurs bio (0,27\% des agriculteurs à l'époque) qui étaient alors tous liés à un standard privé (Robidel, 2014); les autres étaient rattachés à des standards aujourd'hui disparus. Les années 1990 ont ensuite été marquées par un recul relatif et absolu des standards privés, alors que la bio en France se structurait et croissait autour du standard public. N\&P a par exemple connu un départ massif de producteurs. Mais un processus de différenciation s'est réactivé au début des années 2000, avec un regain d'intérêt pour les standards privés bio.

Une explication de ce regain réside dans la recherche d'une différenciation pour une meilleure valorisation sur un marché bio de plus en plus concurrentiel. Mais les nouvelles adhésions ou la création de nouveaux standards sont également motivées par une insatisfaction par rapport au standard public et la volonté d'inscrire la bio dans une perspective plus exigeante et plus holiste, comme l'illustre l'exemple de

5. Ces assouplissements sont principalement l'autorisation des exploitations mixtes (mixité bio/non bio), une contrainte de lien au sol moins forte, une diminution de l'âge minimal d'abattage des poulets, le seuil de tolérance pour les OGM augmenté de 0,1 à $0,9 \%$.

6. On retrouve des standards privés bio dans l'ensemble des pays européens, standards qui généralement s'ajoutent au label bio européen. Dans certains cas, leur importance est beaucoup plus significative qu'en France. La Soil Association regroupe ainsi sous son label plus de $50 \%$ des producteurs bio du RoyaumeUni, et en Allemagne, plus de la moitié des producteurs bio sont aussi engagés dans un standard privé (comme Naturland, Bioland ou encore Demeter). 
Bio cohérence ${ }^{7}$. Le texte du cahier des charges de N\&P pour les productions végétales illustre également cette posture :

«Au regard du préambule de la réglementation CEE de l'agriculture biologique qui ne parle que de "marchés", Nature \& Progrès considère que la "BIO", dans sa dimension globale, n'est toujours pas reconnue, entraînant, de ce fait, des risques de dérives. Ce seul préambule de la "bio officielle" justifie pleinement le maintien de la mention Nature \& Progrès. »

De ce point de vue, l'existence et la création de standards plus exigeants que le label bio officiel peut se comprendre comme une composante du processus de négociation entre acteurs dans le champ de l'agriculture biologique. En effet, les mouvements qui portent ces standards participent également aux négociations sur la révision du cahier des charges européen.

Les standards privés diffèrent dans leur objectif, leur vision de l'agriculture, les modalités de fonctionnement (organisme gestionnaire, documents de référence, contrôle, financement, etc.) et dans leur lien avec le reste de la filière (Espagne, 2014). Ils s'inscrivent dans une démarche de dépassement du cahier des charges de la bio officielle, de manière plus ou moins marquée, sans pour autant s'y opposer frontalement. En effet, à part N\&P, l'ensemble des standards privés font de la certification $\mathrm{AB}$ un prérequis obligatoire ${ }^{8}$. Si ces standards privés sont quantitativement marginaux en termes de ventes, les collectifs qui les portent sont souvent actifs dans la diffusion d'idées et de pratiques alternatives. En fait, l'analyse des standards privés bio, dans leur histoire comme dans leur dynamique actuelle, fait ressortir trois grandes logiques à l'œuvre :

- segmenter et différencier l'offre pour répondre à la demande, gagner en compétitivité et créer une niche ;

- mieux coordonner et structurer l'offre, en particulier pour réaliser des économies d'échelle en termes de logistique et de commercialisation;

- pallier les insuffisances du standard public bio et proposer un standard alternatif s'inscrivant dans une vision de ce que doit être l'agriculture biologique.

Alors que les deux premières logiques se rattachent à l'organisation du secteur et du marché, la troisième se positionne dans un champ politique, au sens où elle questionne le devenir collectif de la bio à travers le projet de société qu'elle défend. La combinaison des trois logiques et la dominante qui en résulte varient d'un standard à l'autre.

La plupart des marques régionales imposent des règles sur la provenance des produits, accompagnées parfois d'une charte de principes, mais n'ont pas d'autres obligations. Portées par différents types d'acteurs (associations de producteurs, associations de transformateurs et/ou collectivités territoriales), elles visent principalement à promouvoir et à organiser l'offre bio locale. Elles sont souvent associées

7. La Fédération nationale d'agriculture biologique (FNAB), association à vocation syndicale à laquelle adhère la moitié des producteurs bio, pose ainsi la double question : « Le développement de la bio peut-il et doit-il échapper à la "conventionnalisation" ? » pour introduire le standard privé qu'elle porte depuis 2010, Bio cohérence, voir http://www.fnab.org/index.php?option=com_content\&view=article\&id=655:biocoherence\&catid =22: actualites-des-partenaires (consulté le 4 octobre 2016).

8. La moitié des producteurs labellisés N\&P sont néanmoins également certifiés AB. 
à une mise en commun de moyens, d'instruments marketing (logos, foires, promotion) ou de mise en marché (regroupement de l'offre en plateforme), et à des échanges de connaissances.

Les autres standards privés ont un positionnement agroécologique plus poussé que la réglementation officielle sur plusieurs critères (mixité, autonomie fourragère, liste des intrants autorisés, etc.), pour pallier à ce qui est considéré comme des manquements de celle-ci. Ils fixent aussi des règles plus strictes sur la composition des produits transformés. Ces pratiques introduisent des exigences supplémentaires sur le plan environnemental mais aussi sur les questions de l'autonomie, du local et de l'authenticité, ou de la naturalité des produits. Les produits labellisés par ces standards sont presque exclusivement vendus en magasins spécialisés bio ou en vente directe. La vente en grandes surfaces conventionnelles est même explicitement interdite pour les produits Bio solidaire et Bio cohérence. Seul le cahier des charges de Bio cohérence inclut explicitement un volet distribution, en proposant une certification pour les distributeurs. Biobreizh, inséré dans des circuits longs, n'exclut pas les grandes surfaces de ses débouchés.

Les exigences des cahiers des charges, sur les plans social, éthique et économique (taille des fermes, relations économiques, prix, marché, emploi, etc.), sont souvent complétées par des principes plus ou moins contraignants (jusqu'à éventuellement l'exclusion) édictés dans une charte associée. N\&P et Bio cohérence sont les standards les plus engagés, et Biobreizh travaille sur une évolution de ses pratiques pour plus de cohérence sur ces dimensions. Bio solidaire se distingue des autres standards par son caractère de démarche collective, avec au minimum une partie de la filière engagée (producteurs, acheteurs, transformateurs). Se réclamant d'un commerce équitable Nord-Nord, Bio solidaire impose une contractualisation des échanges, des prix minima garantis et des partenariats durables entre producteurs et acheteurs. Chez N\&P, les questions d'équité et de nature des échanges sont incluses dans une charte qui énumère les principes sociaux, économiques et environnementaux. Demeter renvoie aux principes de l'anthroposophie, qui constitue son référentiel de valeurs. Les aspects sociaux et économiques sont pensés et évalués par rapport à une agriculture «non industrielle » et «traditionnelle », sans qu'il y ait des règles spécifiques. Bio cohérence émet des recommandations explicites, voire des critères pour le cas des distributeurs certifiés (écarts de salaires, part d'emploi permanent), ou l'interdiction des contrats basés sur un droit du travail étranger.

En matière de certification, Demeter, Biobreizh, Bio cohérence et Bio solidaire délèguent le contrôle à des organismes certificateurs, qui en général certifient conjointement les standards privé et public pour réduire les coûts. Quant à N\&P, Biobourgogne et les Simples, ils appliquent et promeuvent depuis les années 1970 un système participatif de garantie $(\mathrm{SPG})^{9}$, qui s'appuie sur des groupes locaux de producteurs, de transformateurs et de consommateurs qui assument les fonctions d'inspection et de contrôle. S'ils restent marginaux en France, il faut noter que les systèmes participatifs de garantie sont fortement remis en avant depuis les années 2000 dans le champ international de la bio (Fouilleux et Loconto, 2016). Ils sont

9. Demeter est également en train de travailler sur la mise en place d'un système de contrôle participatif. 
aujourd'hui actifs ou en développement dans 72 pays du « Nord» et du « Sud » ${ }^{10}$. Ils sont même légalement reconnus au Brésil, en Bolivie et en Inde. L'Ifoam définit les SPG comme « des systèmes d'assurance qualité orientés localement. Ils certifient les producteurs sur la base d'une participation active des acteurs concernés et sont construits sur une base de confiance, de réseaux et d'échanges de connaissances ${ }^{11}$. Proches du système de certification de groupe ${ }^{12}$ (van der Akker, 2009) mis en place pour réduire les coûts de certification pour les petits producteurs du Sud, ils s'en différencient sur plusieurs points. Les producteurs restent indépendants les uns des autres, sans besoin d'une structure aval collective (coopérative, etc.) que l'on retrouve dans les systèmes de certification collective.

Le regain d'intérêt récent pour les SPG est notamment motivé par une critique de la logique et des effets du régime de standardisation tripartite et de son caractère hégémonique. Cette critique donne lieu à des débats au sein même de l'Ifoam et de diverses organisations (Ifoam, 2014). En effet, la certification par tierce partie repose sur la distance (absence de communication entre auditeur et producteur, pas de fonction de conseil) et l'indépendance pour garantir la conformité (Jahn et al., 2005 ; Hatanaka et Busch, 2008). Plutôt que d'être accompagné13, le producteur est l'objet d'un audit qui doit en quelque sorte prouver sa non-culpabilité (Ifoam, 2005). Par ailleurs, le coût de la certification par tierce partie est jugé trop élevé, surtout pour les petites unités et celles très diversifiées ${ }^{14}$. Ce système peut ainsi générer de l'exclusion et donc de l'iniquité dans le droit à utiliser la mention « Agriculture biologique » (Lemeilleur et Allaire, 2014). Enfin, il réduit la bio à un ensemble de points de contrôle et d'indicateurs prédéfinis. Il ne permet pas de prendre en compte les spécificités locales et propres des systèmes de production, ni la dimension de progrès dans le temps. La mesurabilité et la facilité de contrôle recherchées permettent d'assurer la traçabilité, mais pas vraiment un rendu des performances environnementales ou sociales effectives d'une exploitation certifiée (Lemeilleur et al., 2015). Ceci contredit les principes fondateurs de l'agriculture biologique, qui rejettent des solutions techniques toutes faites au profit d'une adaptation au milieu naturel, avec son potentiel et ses limites. La certification tierce partie accentue de ce fait le découplage entre un standard bio et une bio vue comme un ensemble de valeurs et de pratiques.

Les SPG sont quant à eux considérés comme des dispositifs de contrôle plus collectifs, flexibles et participatifs, confiés à des groupes locaux réunissant producteurs,

10. Ce qui est développé ici sur les systèmes de certification et leurs implications concerne également d'autres démarches de labellisation, comme par exemple le commerce équitable.

11. http://www.ifoam.bio/sites/default/files/pgs_definition_in_different_languages.pdf (consulté le 25 octobre 2016).

12. Ce mode de certification repose sur deux étapes : un contrôle interne réalisé par les producteurs ou la structure les fédérant, et un contrôle collectif par un organisme certificateur. Il existe déjà dans les pays en développement pour la bio et depuis 2008 dans les dispositifs de contrôle des indications géographiques en Europe.

13. C'était au départ un des objectifs de l'Acab (Association des conseillers indépendants en agriculture biologique), qui a été à l'origine du système de contrôle de la bio en France et donnera naissance à Ecocert.

14. Le coût est en général fonction de la taille de l'exploitation et du nombre de productions et d'activités (production, transformation, vente) à contrôler. 
consommateurs et d'autres acteurs (Nelson et al., 2010). Chaque participant, auditeur ou audité, est concerné au même niveau de responsabilité. Le SPG se veut avant tout un outil d'accompagnement visant une amélioration continue du producteur, en accord avec son projet et les spécificités du contexte environnemental et socioéconomique (Hochreiter, 2011). Les procédures d'élaboration de la norme, de vérification et de décision se basent sur les principes de participation et d'horizontalité pour élaborer un « compromis partagé ». Les groupes locaux sont en général insérés dans une organisation à plus grande échelle qui en assure la coordination, l'orientation et l'accompagnement (mise à disposition de documents de base, formation, etc.), et l'arbitrage, en cas de conflits. Les rapports et les décisions prises suite aux visites sont généralement publics (Nelson et al., 2010), engageant pleinement la responsabilité du groupe en charge du contrôle. L'expérience montre que le non-respect des règles est relativement faible et souvent lié à des problèmes d'enregistrement des pratiques (van Der Akker, 2009 ; Hochreiter, 2011). Dans les faits, les mécanismes de garantie, relevant de la responsabilité, de la parité et du contrôle social, pourraient donc apparaître largement aussi crédibles en termes d'efficacité que la certification par tierce partie (Lemeilleur et Allaire, 2014). Les systèmes participatifs proposent ainsi une alternative aux impasses liées au décalage entre des normes détaillées et élaborées à un niveau global et des conditions locales très diverses (Vogl et al., 2005). La cohérence entre les principes et les pratiques est priorisée par rapport à l'homogénéité visée par le standard public.

L'adaptabilité du référentiel et des règles de contrôle peut conduire à une certaine hétérogénéité qui, mal gérée, pourrait augmenter la confusion et l'asymétrie d'information, et réduire la confiance envers la production biologique. Toutefois, cette critique est aussi faite au système de certification par tierce partie, comme en témoigne l'ouvrage édité par Baqué (2012). Dans le cas des SPG, cette considération a poussé différentes organisations vers une réflexion collective (menée notamment au sein de l'Ifoam) sur la définition des SPG et leur reconnaissance institutionnelle. Une autre critique tient aux difficultés inhérentes aux dispositifs participatifs qui peuvent générer des tensions et freiner l'adhésion de certains producteurs. Enfin, la participation dépend des possibilités, des motivations et des capacités (matérielles ou non) des différents acteurs, et des asymétries de savoir et de pouvoir sont toujours effectives.

Globalement, les SPG sont vus par leurs promoteurs, N\&P en France, comme un dispositif plus en adéquation avec une vision holiste de la bio, comme un projet à mettre en œuvre plus qu'une recette à appliquer. Cependant, contrairement au RTS, ils ne revendiquent pas une légitimité exclusive : des systèmes hybrides sont d'ailleurs expérimentés, avec par exemple l'introduction d'un contrôle par un tiers dans des groupes SPG (SPG en Nouvelle-Zélande) ou encore la demande d'une reconnaissance d'équivalence à un système interne de contrôle (van Der Akker, 2009) pour obtenir une certification de groupe bio. Pour Teil (2013), la coexistence entre différents dispositifs et différentes logiques est même souhaitable car basée sur la complémentarité. Chacun contribue au développement de la bio et relève de différentes facettes (notamment entre logiques marchandes et politiques). Il faut en même temps faciliter la diffusion et la circulation des produits bio par des systèmes stables et lisibles, et faire vivre et évoluer le projet de l'agriculture biologique dans sa transversalité. 


\section{Conclusion}

L'histoire des formes de critique du capitalisme, et des alternatives proposées corollairement, s'inscrit dans des projets consistant soit à remplacer le système existant, soit à construire un système parallèle qui peut ensuite pousser au changement du système dans son ensemble. L'agriculture biologique s'inscrit initialement dans cette histoire. Son identité s'est construite d'abord en dehors, puis en interaction avec le modèle agricole et alimentaire dominant. Cette interaction a conduit à un compromis de coexistence, la bio devenant une niche de marché institutionnalisée et un standard durable parmi d'autres, coexistence entre bio et conventionnel, mais aussi entre différentes visions et mise en pratique de l'agriculture biologique. Radicaux et réformateurs s'opposent, pour reprendre une terminologie classique. Avec d'un côté ceux qui craignent que le compromis conduise à un affaiblissement du projet politique et systémique initial et de l'autre côté ceux qui craignent que l'incapacité à établir des compromis confine à une marginalité peut-être confortable, mais au final indolore pour le système dominant. L'agriculture biologique, en tant que bien public et voie politique pour l'écologisation des pratiques (Allaire, 2016), fait l'objet d'une renégociation et d'un renouvellement permanents, entre différents objectifs et visions portés par divers groupes sociaux.

L'agriculture biologique a été, successivement, dans une pluralité revendiquée, puis dans la recherche d'une homogénéité. Dans les deux cas, il est bien question de l'identité de la bio, de la définition et de la mise en ouvre de cette identité et de son contrôle, qui intègre régulation d'un marché et projet politique. Alors que le caractère critique et holiste, sous l'influence du régime de standardisation tripartite, a été marginalisé, des acteurs de la bio (producteurs, transformateurs, consommateurs et autres) mobilisent des dispositifs alternatifs, comme par exemple les SPG et les standards privés, pour se réapproprier la définition de la bio et renforcer son volet critique et pluriel. Cette pluralité est à la fois une force et une source de tension, et c'est dans cette tension que la bio cherche à jouer son rôle entre logiques de marché et standards durables, et alternative pour une remise en cause complète des systèmes agricoles et alimentaires. L'agriculture biologique est ainsi mise en tension entre la garantie de caractéristiques objectives prédéfinies et contrôlées, et la recherche et la mise en mouvement d'une philosophie intégratrice, mais singulière. Elle est en ce sens une qualité révélée par un jugement subjectif, qui se veut être un «cadre de jugement global de l'action qui subordonne les autres finalités, économiques, sociales...» (Teil, $2013: 217)$, entre produits de qualité et qualité de vie.

L'analyse du RTS bio, puis des standards privés et des SPG a illustré l'affaiblissement puis la réactivation de la dimension critique de la bio. Au-delà de l'organisation de l'offre ou de la segmentation de marché, les standards privés peuvent être porteurs, à différents degrés, d'une prise de parole pour défendre à la fois la pluralité de la bio, mais aussi son inscription dans un modèle critique de l'ensemble du système agricole et alimentaire. Avec les SPG, intégrés par une partie de ces standards, ils constituent un axe structurant d'un mouvement critique qui cherche à se réapproprier l'identité de la bio. Ils mettent en avant la cohérence avec les principes fondateurs, dans la diversité des contextes, plutôt qu'une homogénéité réductrice, liée notamment à la gouvernance et aux orientations prises par le standard bio 
officiel. Mais si la refonte des outils propres à la régulation du secteur bio lui-même est sans doute un élément fondamental des futurs développements de l'agriculture biologique, la réflexion ne peut néanmoins s'y cantonner. Les modalités de régulation et d'orientation de l'agriculture en général par les politiques publiques constituent un élément au moins aussi essentiel. Si la part des agriculteurs biologiques sur le total des agriculteurs français est passée de 0,27\% en 1989 à $4 \%$ en 2014, via le déploiement d'une réglementation précise, sans doute le succès et la pérennité de cette tendance ne pourront-ils se confirmer qu'à travers une réforme profonde des politiques agricoles européennes et nationales, et la mise en place d'un système d'incitations beaucoup plus marqué en faveur de pratiques agricoles et agroalimentaires plus respectueuses des équilibres à la fois écologiques et socioéconomiques. 


\title{
Chapitre 11 \\ La sécurité sanitaire des aliments : un nouveau modèle de régulation européen
}

\author{
L. SAUlais, E. VAlCESChINI
}

L'importance de la régulation de la sécurité sanitaire des aliments a été considérable ces vingt dernières années. Quand, au tout début des années 2000, apparaissent et se développent avec une rapidité fulgurante des « référentiels » de sécurité sanitaire des aliments d'initiative privée, pilotés par les grands distributeurs à l'échelle internationale (Codron et al., 2000 ; Busch et Bain, 2004 ; Fulponi, 2006 ; Lamanthe, 2007), certains observateurs y voient l'émergence d'une régulation dominée par le marché. Selon Loconto et Busch (2010), se construit à l'échelle internationale un système de gouvernance nouveau, un TSR (Tripartite Standard Regime), visant à produire de la sécurité via le marché et fondé sur une régulation volontariste à travers les standards privés. Cette analyse éclaire les stratégies au plan international. L'Europe n'en est pas absente (voir Valceschini et Saulais, 2005). En revanche, au sein de l'Union européenne, l'intervention publique a gardé un rôle central et structurant du système de régulation de la sécurité sanitaire des aliments. Au prix du renversement du modèle de régulation séculaire mis en place dans les pays industrialisés - y compris aux États-Unis - à partir du tout début du $\mathrm{xx}^{\mathrm{e}}$ siècle, a été construit en Europe un modèle de régulation de la sécurité sanitaire des aliments radicalement nouveau.

Malgré l'importance du phénomène, ni la dynamique historique des interactions entre les approches réglementaires et les stratégies privées, ni les conséquences de la complexité qui caractérise cette régulation de la sécurité sanitaire des aliments n'ont été analysées. Un rapport plutôt récent et très complet de l'OCDE (Smith, 2009) souligne que « la recherche sur les rapports et les interrelations entre normes publiques et normes privées dans les dispositifs nationaux de contrôle de la qualité des aliments et les échanges internationaux n'en est qu'à ses tout premiers balbutiements ». Ce chapitre analyse ces articulations à partir de l'étude de l'émergence du modèle européen de régulation de la sécurité sanitaire des aliments. Il approfondit d'abord la connaissance de la prolifération des systèmes de normalisation en montrant qu'ils ne sont substituables ni entre eux, ni avec la réglementation. Il propose ensuite une analyse de la combinaison des différents types de normes et de leur articulation autour de la réglementation, montrant un système assez éloigné d'une autorégulation et d'un gouvernement à distance de la sécurité sanitaire des aliments. 


\section{- La grande distribution internationale menacée}

Des années 1980 aux années 2000, en Europe particulièrement, la grande distribution est devenue un acteur majeur des filières agroalimentaires et le premier bénéficiaire de leur restructuration et de leur mondialisation. Elle s'est étendue internationalement, et a acquis une position dominante sur les marchés nationaux grâce à une très forte concentration et, aussi, à de puissantes stratégies de marque. Les grandes enseignes ne sont plus seulement des clients des industries agroalimentaires, elles sont des « donneurs d'ordre », parfois en position de piloter toutes les activités d'une filière (Busch et Bain, 2004). Elles créent de nouveaux systèmes de normalisation et, organisées à l'échelle internationale, elles imposent, à partir des années 2000, leurs propres normes de sécurité sanitaire des aliments. Busch et Bain (2004) relient le développement de ces standards privés à l'expansion du commerce international et au rôle prépondérant acquis par l'OMC (Organisation mondiale du commerce). En Europe pourtant, il est puissamment soutenu par les stratégies de réaction des distributeurs qui craignent pour leur réputation et leur responsabilité légale face à la très forte demande de réassurance de la part des consommateurs en prise à des crises sanitaires violentes et récurrentes.

L'évolution récente des systèmes agroalimentaires se caractérise par une intensification de la compétition entre les marques de fabricants industriels, les enseignes de la grande distribution et les certifications officielles de qualité (indications géographiques, labels, certification Agriculture biologique). Ce phénomène se caractérise, selon Allaire et Wolf (2004), par l'émergence de deux formes d'innovation : une innovation «produits » basée sur le développement des biotechnologies et des technologies de l'information, et une innovation davantage axée sur la logique d'identité, à travers les réseaux et les territoires. Au niveau des produits, les entreprises investissent dans les innovations technologiques, par exemple pour améliorer la qualité nutritionnelle ou la facilité de préparation ou de cuisson d'un produit (plat tout prêt, ouverture facile, longue conservation, etc.). Il peut aussi s'agir d'utiliser les différences de terroirs, de savoir-faire local, de recettes régionales. Au niveau de la commercialisation, on joue sur la perception des consommateurs par la signalisation des produits ou l'information sur les méthodes de production (via l'étiquetage, la publicité, le packaging, le merchandising ou un réseau de franchise...).

Avec la maîtrise des points de vente, les enseignes de la grande distribution disposent du meilleur poste d'observation pour capter les attentes des consommateurs. Elles ont renforcé leur position en développant leurs propres marques (MDD - marque de distributeur) et ont profité des crises de confiance alimentaire pour concevoir des marques de qualité qui se réfèrent à l'origine des produits ou aux méthodes de production. Les marques Terre et saveur de Casino, Filière agriculture raisonnée Auchan ou Engagement dès l'origine (EDO) de Cora, sont typiques de démarches qui mettent en avant les méthodes de production vis-à-vis des consommateurs. La maîtrise de la qualité totale a trouvé son prolongement dans les relations entre les distributeurs et leurs fournisseurs tout au long des filières. Les distributeurs s'impliquent dans le contrôle de leurs fournisseurs en développant des « cahiers des charges », des " contrats de filière », des « chartes de qualité ", etc. Il s'agit pour eux de sécuriser des produits qu'ils vendent mais ne produisent pas. Émergent 
progressivement des innovations organisationnelles permettant des coordinations plus efficaces tout au long de la chaîne alimentaire.

Les crises sanitaires successives, à partir du milieu des années 1990, ont marqué un premier tournant dans l'implication de la grande distribution dans la mise en œuvre de dispositifs de normalisation de la sécurité alimentaire. La problématique de l'hygiène, de la sécurité et de la fiabilité des produits et de leurs méthodes de production redevient centrale. Face aux objectifs de sécurité et d'information, une question est cruciale, celle de la crédibilité de l'information (sur l'étiquette, dans les documents accompagnant les produits...). Crédibilité de l'information et sécurité des produits obligent les distributeurs à revoir leurs systèmes d'approvisionnement et d'échange d'informations. Développant leurs marques propres (MDD), les distributeurs engagent leur nom, leur réputation et leur responsabilité pénale sur la question de la qualité et de la sécurité sanitaire des aliments. Ce sont eux les garants du niveau de qualité et de sécurité affiché. Lorsqu'un distributeur délègue à un sous-traitant la fabrication d'un produit vendu sous une marque propre, il est dépendant de la qualité du travail du fabricant. Le contrôle de cette qualité est alors stratégique pour : en matière commerciale, se prémunir d'une détérioration de sa propre réputation ; en matière juridique, se garantir contre une responsabilité pénale. S'assurer dès la phase précontractuelle que le nouveau fournisseur satisfera à des exigences minimales de respect des délais et des quantités à approvisionner se présente comme une étape critique.

Ce tournant s'accentue encore à partir du début des années 2000, avec comme facteur déterminant la réglementation de la sécurité sanitaire européenne. De plus en plus précise et stricte, notamment en matière de traçabilité, elle décuple leur responsabilité et leur impose la capacité de fournir des garanties et, éventuellement, des preuves. L'investissement de la grande distribution dans les systèmes de normalisation est alors motivé non seulement par l'augmentation de leur crédibilité, mais surtout par le renforcement des systèmes de contrôle à l'appui de la preuve. Ces référentiels (standardisation de type T2) ont en commun de définir des exigences de sécurité sanitaire allant au-delà des niveaux imposés par la réglementation, en réponse aux attentes des consommateurs. Le développement de ce système de standardisation privé avait été amorcé par les producteurs, et particulièrement les industriels dominants du marché, qui ont, dès le début des années 1990, développé leurs propres cahiers des charges ou normes internes de sécurité sanitaire (standardisation de type T1). Le rôle croissant des distributeurs dans la transformation va faire encore évoluer ce système et donner naissance à de nouvelles formes de standardisation privée, au cour desquelles se situent les distributeurs. Dans une première phase, chaque enseigne de distribution élabore ses propres cahiers des charges (en matière de sécurité sanitaire, de qualité organoleptique du produit, etc.) et réalise par lui-même l'audit de ses fournisseurs. Assez rapidement, les distributeurs recourent à des entreprises de services (de certification) pour renforcer ou remplacer leur propre contrôle. Dans une deuxième phase, les distributeurs s'associent pour harmoniser leurs cahiers des charges et leurs audits ; ils conçoivent des référentiels communs dont ils confient le contrôle à des organismes de certification (par exemple, Eurepgap, British Retailers - BRC - ou International Food Standard - IFS). L'objectif est ici de réduire l'ensemble des coûts de transaction associés à 


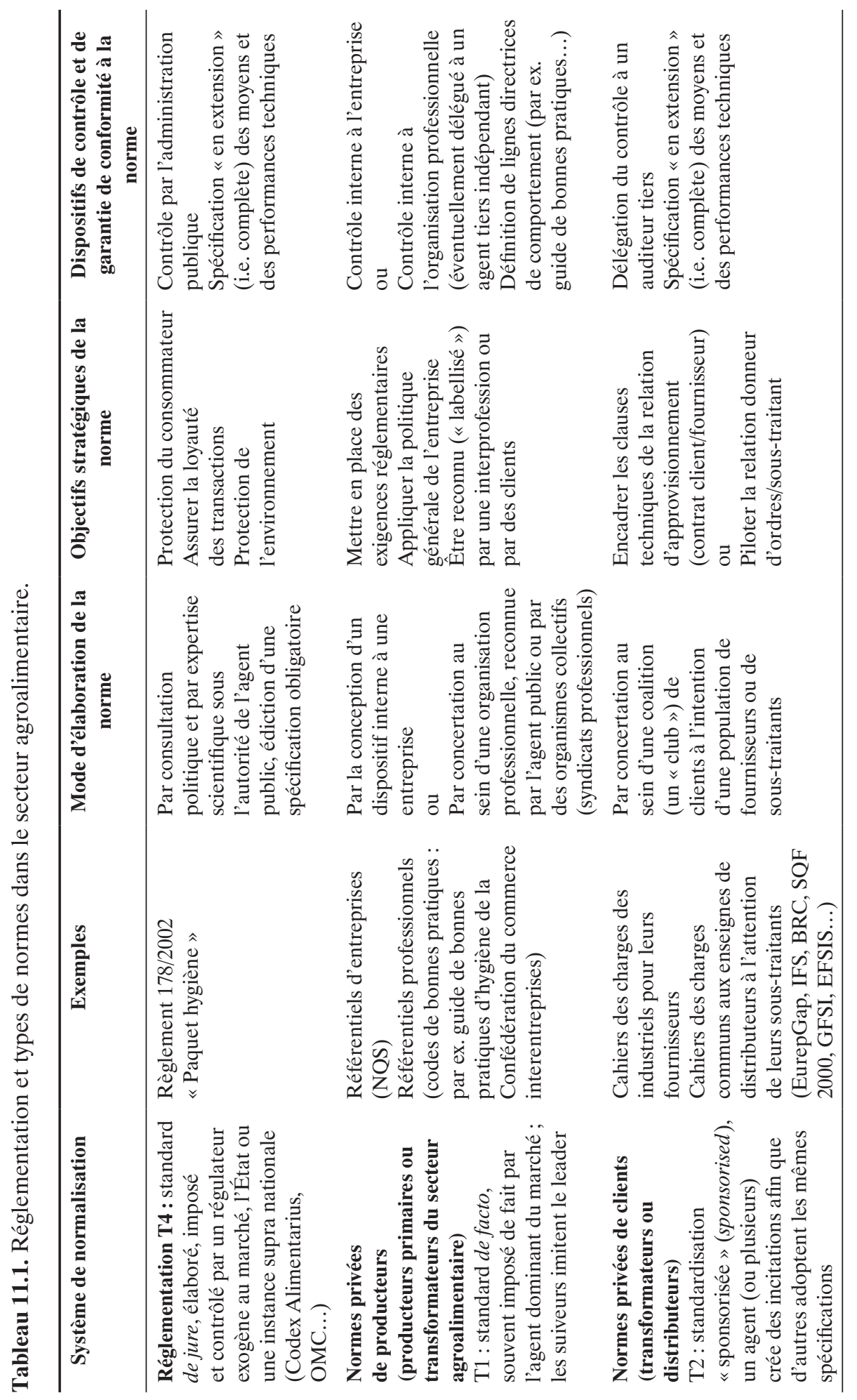




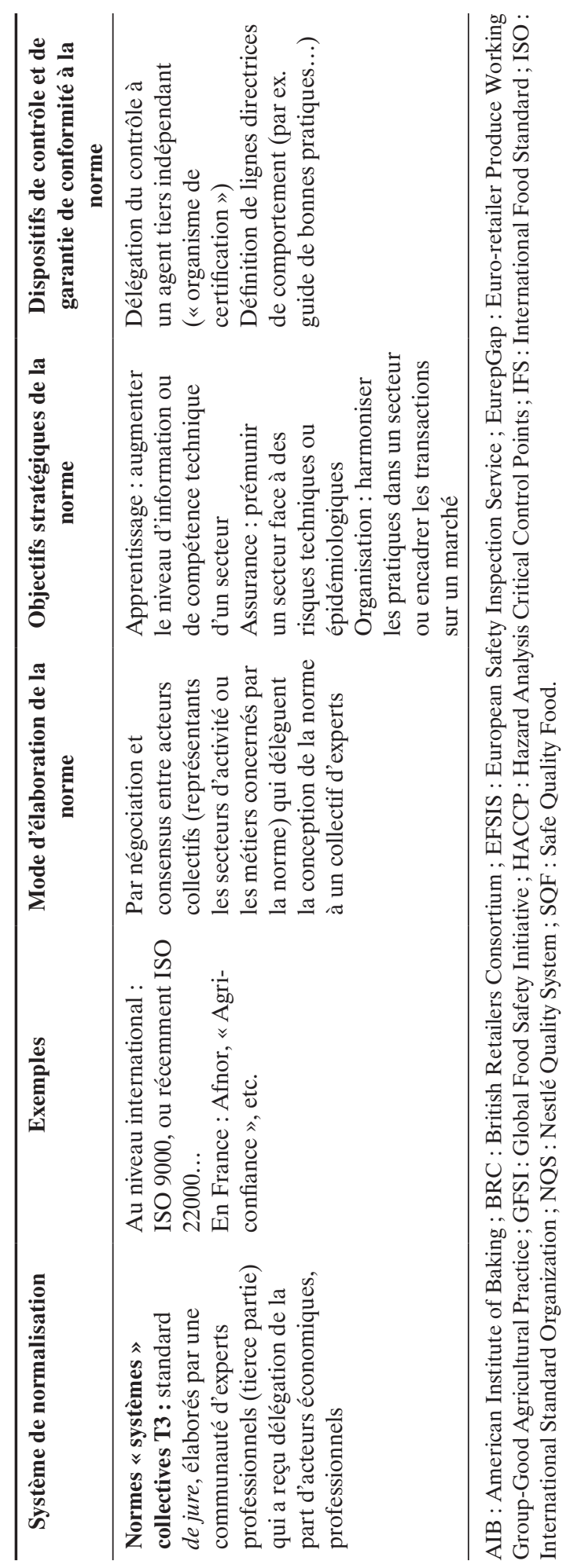


la normalisation : les coûts de négociation au niveau de la conception et de l'élaboration du standard, les coûts d'organisation au niveau de la mise en ouvre et de l'usage du standard et, enfin, les coûts de surveillance au niveau de l'expertise et du contrôle de la conformité au standard.

L'expansion de la normalisation se traduit par une diversification des systèmes de normalisation. Ainsi, au début $\mathrm{du}_{\mathrm{XxI}}{ }^{\mathrm{e}}$ siècle, aux côtés de la réglementation, trois grands types de normes encadrent l'activité des acteurs économiques des filières agroalimentaires. Ils ont une finalité commune, l'augmentation du niveau de confiance et l'amélioration de l'efficacité des systèmes de contrôle et de preuve. Pourtant, ils ne sont pas substituables les uns aux autres. Ils se distinguent d'abord par leur mode d'élaboration de la norme, leurs objectifs stratégiques et leurs dispositifs de contrôle. Ensuite, ils se différencient par leurs objectifs stratégiques.

Les types de norme se distinguent d'abord par leurs modes d'élaboration. Les normes proprement dites s'appuient sur la recherche d'un consensus entre l'ensemble des acteurs concernés (par exemple, ISO 22000 : norme internationale, 45 pays participants). De leur côté, les dispositifs élaborés par les professionnels pour leur propre usage s'inscrivent quant à eux dans une logique d'organisation d'un secteur. La démarche du réseau Reseda ${ }^{1}$ pour la filière « produits animaux » en fournit un bon exemple. Dans le cas des guides de bonnes pratiques, cette logique va encore plus loin ; ils sont validés officiellement par les autorités publiques sur la base d'une expertise scientifique (de l'Afssa - Agence française de sécurité sanitaire des aliments). Enfin, les référentiels élaborés par des acheteurs pour leurs fournisseurs ou par les donneurs d'ordre pour leurs sous-traitants s'inscrivent dans des relations contractuelles. Ils prennent traditionnellement la forme de cahiers des charges établis dans le cadre de transactions bilatérales entre deux opérateurs (par exemple entre MacDonald et ses fournisseurs). Au début des années 2000, certains référentiels, au contenu proche, ont été mis en commun par des collectifs d'acheteurs. C'est l'exemple de l'International Food Standard (IFS), issu de la mise en commun de cahiers des charges de différentes enseignes de distribution françaises. Enfin, le recours à la certification est utilisé différemment selon le type de norme. Les normes et les référentiels privés professionnels mobilisent la certification dans le cadre d'une démarche qui vise plutôt une « labellisation », un « plus commercial », une valorisation des produits sur le marché. De leur côté, les référentiels privés utilisés par les acheteurs s'inscrivent dans des relations de type « clients-fournisseurs », voire « donneurs d'ordre/sous-traitants » et recherchent, à travers le certificat, une garantie au sens de preuve.

Les divers systèmes normatifs se différencient également par leurs objectifs. Tous les systèmes de normalisation ont en commun de définir des exigences de sécurité sanitaire allant au-delà des objectifs de performance imposés par la réglementation. Cependant, une différence de structure initiale les distingue de manière fondamentale : on trouve, d'un côté, les référentiels privés d'acheteurs (IFS, BRC...) qui organisent un système de contrôle et de preuve « en extension », spécifiant des moyens ; et, d'un autre côté, les normes système (telle ISO 22000) qui fixent simplement des

1. Réseau pour la sécurité et la qualité des denrées animales, regroupant des organisations professionnelles et interprofessionnelles françaises dans le domaine des produits animaux. 
lignes directrices de comportement et de management des processus. Une autre différence tient également à leur champ d'application, qui est plus ou moins étendu : en plus de la sécurité sanitaire, certaines exigences concernent aussi le domaine de l'éthique, de l'environnement, du bien-être animal, des clauses sociales (travail des enfants...), etc. Par ailleurs, la mise en œuvre de tel ou tel type de standard correspond à des positionnements différents des entreprises dans la filière agroalimentaire et à des stades plus ou moins avancés d'intégration des systèmes de gestion de la qualité et de maîtrise des risques par les entreprises. À titre d'exemple, l'IFS ne concerne a priori que des entreprises de transformation qui fabriquent des MDD, pour la France (porté par la FCD, Fédération des entreprises du commerce ou de la distribution) ou l'Allemagne (par la HDE, Handelsverband Deutschland). L'ISO 22000 est en revanche internationale et conçue pour s'appliquer à tous les secteurs. De son côté, Eurepgap (aujourd'hui MondialGap) concerne uniquement la production primaire. De ce point de vue, l'émergence de nouveaux dispositifs normatifs semble moins génératrice de « désordre » qu'une réponse à des besoins de standardisation nouveaux et différenciés, qui résultent d'un changement de paradigme côté réglementaire, comme nous allons le voir dans ce qui suit.

\section{" La régulation européenne: risques sanitaires vs anticipation des crises}

En Europe, l'harmonisation européenne des années 1990 marque la mutation du rôle de l'État, de l'inspection vers l'évaluation et l'audition. Analysant l'évolution des pratiques d'inspection par les services vétérinaires en France au gré des changements de dispositifs réglementaires, Bonnaud et Coppalle (2008) mettent ainsi en évidence le passage d'un modèle basé sur la pédagogie et le relationnel (entre inspecteurs et inspectés) à un modèle basé sur la fabrication de preuves (la base des normes d'assurance qualité type ISO) et le recours aux normes et aux procédures ${ }^{2}$. Holt et al. (2007) montrent par ailleurs que cette mutation est d'envergure internationale. Busch et Bain (2004) décrivent le passage d'un système « public », basé sur la preuve scientifique, à un système de régulation privé, mené par le marché et la demande.

Loconto et Busch (2010) proposent le concept de «Tripartite Standard Regime » pour qualifier l'enchevêtrement des processus de standardisation, de certifications et d'accréditation. Ce système s'appuie non pas sur l'État, mais sur des processus d'échange et de négociation, contribuant à faire émerger une logique de «gouvernement à distance ». Il repose sur l'usage de mécanismes complexes de surveillance (les audits) qui assurent la crédibilité et l'intégrité des acteurs à tous les niveaux. Dans cette forme de gouvernance, l'usage de standards est une forme d'autorégulation ou de "gouvernementalité ». Cette analyse est cohérente avec l'accent mis par ces auteurs sur le rôle de l'évolution du commerce international dans l'émergence des nouveaux systèmes de standardisation, mais elle ignore ou sous-estime le rôle structurant joué conjointement par le changement d'approche du rôle de l'État

2. Pour une analyse plus générale, à l'échelle européenne, voir Fouilleux (2008) 
(son « désengagement » de la partie technique) qui, au moins en Europe, demeure le pivot autour duquel s'organise la régulation sanitaire des aliments.

Historiquement, les standards de qualité minima ${ }^{3}$ sont l'instrument d'action publique ${ }^{4}$ privilégié en matière de sécurité sanitaire des denrées alimentaires. L'autorité publique fixe des standards de qualité minima (notés $\mathrm{SM}_{0}$ dans ce qui suit), chargés de traduire directement, par la fixation d'obligations de moyens, le niveau d'exigences nécessaire pour que soit atteint un niveau d'efficience sociale, que traduit un régime de responsabilité pénale. En France par exemple, le système de standardisation, sur lequel repose la Loi de 1905 dite de protection générale contre les falsifications et les fraudes, relève clairement de cette logique.

Dans ce cadre, la régulation de la sécurité sanitaire des aliments relève quasi exclusivement du domaine réglementaire, et, jusqu'au début des années 1990, la réglementation est seule chargée de garantir la sécurité sanitaire et de définir le niveau de preuve/confiance exigé (noté $\mathrm{X}$ ). Le système de standardisation repose alors, de manière schématique, sur un seul type de dispositif (T4), la réglementation. La responsabilité des différents acteurs $\left(R_{0 F}\right.$ pour les fournisseurs, $R_{0 D}$ pour les distributeurs) se situe alors strictement au niveau de l'application de ces standards de qualité minima. Autrement dit, il y a ici une correspondance directe entre le seuil de qualité résultant de l'application du standard de qualité $\mathrm{SM}_{0}$ et le niveau exigé par la réglementation (lui-même associé à un niveau de responsabilité pour chaque acteur) ; cette correspondance est définie et affirmée par les pouvoirs publics, et l'ajustement entre $\mathrm{SM}_{0 \mathrm{D}}$ et $\mathrm{SM}_{0 \mathrm{~F}}$ ' inscrit dans le cadre d'une relation marchande simplement encadrée par un contrat commercial « classique ». La plupart du temps, le contrôle et la certification de l'application de $\mathrm{SM}_{0}$ reviennent également aux services de l'État.

La régulation par les standards minima est coûteuse pour les pouvoirs publics. Ils assurent en effet, dans ce schéma, l'intégralité des coûts de transaction liés à la standardisation. Au fil du développement des systèmes agroalimentaires, ces coûts tendent à augmenter de manière significative, pour deux raisons. D'abord, la standardisation suppose des connaissances techniques et scientifiques codifiées préalables, indispensables pour élaborer des prescriptions rigoureuses. Or, face à des processus biochimiques mal connus (c'est par exemple le cas des résidus de pesticides dans les conserves de fruits et légumes) ou à des phénomènes épidémiologiques en partie imprévisibles (par exemple l'encéphalite spongiforme bovine - ESB), l'édiction de références ou de seuils à respecter faisant consensus n'est pas toujours possible, ou alors ces prescriptions sont d'application et de vérification complexes. La capacité d'expertise, de coercition et de contrôle par la voie réglementaire rencontre des difficultés qui en accroissent le coût. Ensuite, l'activité réglementaire doit faire face à la croissance exponentielle du nombre de produits mis sur le marché. L'autorisation de

3. Pour une définition du concept de standard, voir David et Greenstein (1990). L'édiction de standards de qualité minima : ils ont pour fonction de garantir un niveau d'efficience sociale que le marché ne peut pas garantir ; c'est notamment le cas quand sont en jeu la sécurité des consommateurs ou la préservation de l'environnement.

4. «Nous entendons par "instrumentation de l'action publique" l'ensemble des problèmes posés par le choix et l'usage des outils (des techniques, des moyens, des dispositifs) qui permettent de matérialiser et d'opérationnaliser l'action gouvernementale » (Lascoumes et Le Galès, 2004 : 12). 
commercialisation suppose que leur conformité soit établie et homologuée. L'élaboration des référentiels techniques, la mise au point des procédures de vérification, les contrôles atteignent un nombre et un degré de complexité tels que les capacités de travail et les compétences de l'administration se trouvent dépassées.

Avec la mise en place d'un « marché unique » dans les années 1990, le cadre réglementaire européen vise à réduire ces coûts en restreignant le domaine d'intervention des services de l'État. Cela se traduit d'abord par un changement de la nature des standards de qualité minima fixés par la réglementation : alors que ceux-ci fixaient auparavant des obligations de moyens, ils édictent désormais des obligations de résultats. Ce changement s'accompagne d'un report sur le système normatif de la fixation des moyens à mettre en œuvre : la normalisation devient un outil complémentaire de la réglementation et permettant de la mettre en œuvre. Le travail de spécification technique est rejeté dans le champ de compétence des secteurs économiques et professionnels. Le renvoi au système normatif revient à remettre dans le champ d'action et de négociation des acteurs privés la résolution de problèmes jusque-là assumée strictement par les pouvoirs publics. L'idée est que leur potentiel technologique, leur proximité avec les consommateurs et leur capacité d'autoorganisation doivent permettre, bien mieux que l'intervention publique, de définir et de faire accepter certaines règles communes indispensables au fonctionnement efficace du marché. La normalisation devient un outil complémentaire de la réglementation dans la régulation de la sécurité sanitaire des produits.

Les années 1990 voient donc un déplacement du niveau de preuve et de confiance exigé en matière de sécurité de X vers $X^{\prime}$ du fait, en particulier, des crises sanitaires. Ce déplacement s'accompagne d'une modification du rôle de l'État dans l'élaboration et le contrôle des règles de sécurité sanitaire : la réglementation fixe essentiellement des obligations de résultats plutôt que des obligations de moyens; elle est doublée d'un dispositif normatif qui délègue les fonctions d'élaboration et de contrôle aux professionnels du secteur. La responsabilité de la mise en œuvre et du contrôle (en partie) des standards est transférée aux professionnels par le biais des normes (T3), dont l'articulation avec la réglementation (T4) est clairement définie. Le système de standardisation prend la configuration (T4+T3), dont nous allons examiner le fonctionnement de façon plus approfondie.

Les crises (1996 et 2000) de l'encéphalopathie spongiforme bovine (ESB ou crise de la «vache folle »), d'une part, qui ont instauré une profonde suspicion sur la viande de bœuf, et l'arrivée en Europe des grains de soja et de maïs génétiquement modifiés (indiscernables des grains classiques) en provenance des États-Unis, d'autre part, précipitent l'évolution de la réglementation européenne entre 1995 et 2005. Durant cette décennie, la médiatisation des crises sanitaires à répétition (fièvre aphteuse, dioxine, grippe aviaire, etc.) contribue à sensibiliser l'opinion publique au problème de la salubrité des aliments et des risques alimentaires, déplaçant ainsi, comme nous l'avons vu, le niveau de preuve et de confiance visé par le système de standardisation au niveau $X$ '.

À partir de l'objectif de maîtriser les sources de risques - et de contenir leurs éventuelles propagations en améliorant les dispositifs de contrôle -, les autorités européennes et les professionnels de l'agroalimentaire veulent désormais rassurer les consommateurs en leur fournissant une information pour éviter les incertitudes 
apparues (sur l'origine de la viande de bœuf, sur la composition des produits, etc.). Un profond remaniement est amorcé par la publication par la Commission européenne en 2000 du Livre blanc sur la sécurité alimentaire. L'architecture du nouveau dispositif réglementaire, certainement le plus ambitieux et le plus complexe au monde, repose sur un socle ${ }^{5}$ désigné sous le terme de "paquet hygiène ». Une nouveauté majeure est de systématiser le déclenchement des procédures de rappel de produits ou des mesures d'interdiction de mises sur le marché lorsqu'un effet indésirable est détecté. L'objectif est de contenir l'expansion des maladies et des épidémies. La réglementation de la traçabilité fractionnée ${ }^{6}$, mi-obligatoire, mi-volontaire, est au centre du dispositif. Elle correspond à un arbitrage entre un certain niveau de risque acceptable et des coûts de traçabilité limités. Elle permet des « retraits ciblés et précis » des produits repérés comme dangereux pour la santé (risque de toxi-infections) afin d'éviter un coût inutile de gestion du risque.

Par ce nouveau cadre réglementaire, la Commission européenne vise un objectif radicalement nouveau. Il s'agit d'anticiper les crises de sécurité sanitaire avec la volonté de limiter les possibles réactions de défiance, dévastatrices, de l'opinion publique et des consommateurs. La traçabilité est alors un outil d'anticipation des risques médiatiques, commercialement désastreux. Il s'agit de lutter par anticipation contre les comportements impétueux, voire la panique des consommateurs ${ }^{7}$. On assiste ainsi à une extension des procédures de traçabilité, mais aussi à l'émergence d'un nouveau sens de cette notion, qui tend à devenir un outil à grande échelle d'information et de contrôle. La traçabilité relève ici d'une " gestion anticipative de la contestabilité ». Dans un contexte de conscience du risque médiatique, les acteurs économiques et professionnels conçoivent les démarches de traçabilité comme susceptibles d'apporter la preuve, sinon technique (composition des ingrédients), du moins déontologique, de leurs efforts pour satisfaire les consommateurs, en excluant les OGM de leurs produits, en abattant les bêtes malades, etc. Le but est ici de montrer qu'on agit le « mieux possible » et, le cas échéant, d'en apporter la preuve formelle devant les tribunaux.

Cette évolution s'appuie sur le développement des « normes d'organisation » qui précisent les méthodes à suivre, les modes d'organisation auxquels il faut se conformer afin de garantir un niveau de performance donné en matière de qualité ou de maîtrise des risques. Ainsi, la standardisation peut concerner deux types d'objets très différents : les produits ou les organisations productives. D'un côté, les standards définissent des spécifications de produit auxquelles on associe généralement

5. Ce socle est constitué par le règlement (CE) 178/2002 (entré en vigueur au $1^{\text {er }}$ janvier 2005), autour duquel s'articule une série de six textes réglementaires (désignés sous le terme de " paquet hygiène »).

6. Pour restreindre les coûts d'organisation, la réglementation limite l'ampleur et le périmètre de la traçabilité imposée. La traçabilité obligatoire « se contente » seulement de suivre les utilisations et les transformations du produit pour tracer le chemin balisé par les points à risques sanitaires possibles. Ainsi, par exemple, les changements de composition des produits ne sont pas forcément enregistrés (ce qui rend possible une fraude sur la composition).

7. Des comportements de doute ou de défiance peuvent bouleverser de manière spectaculaire les marchés alimentaires, en faisant chuter brutalement et durablement les achats et les prix, et en provoquant, in fine, la faillite d'entreprises ou de filières entières. Par exemple, en 2000, en France, lors de la deuxième crise de l'encéphalite spongiforme bovine, la consommation de bœuf a chuté de $30 \%$ et les exportations de $40 \%$ en deux mois. 
des « obligations de résultats ». D’un autre côté, ils émettent des énoncés génériques («normes système ») portant sur l'organisation, auxquels on réfère des « obligations de moyens ».

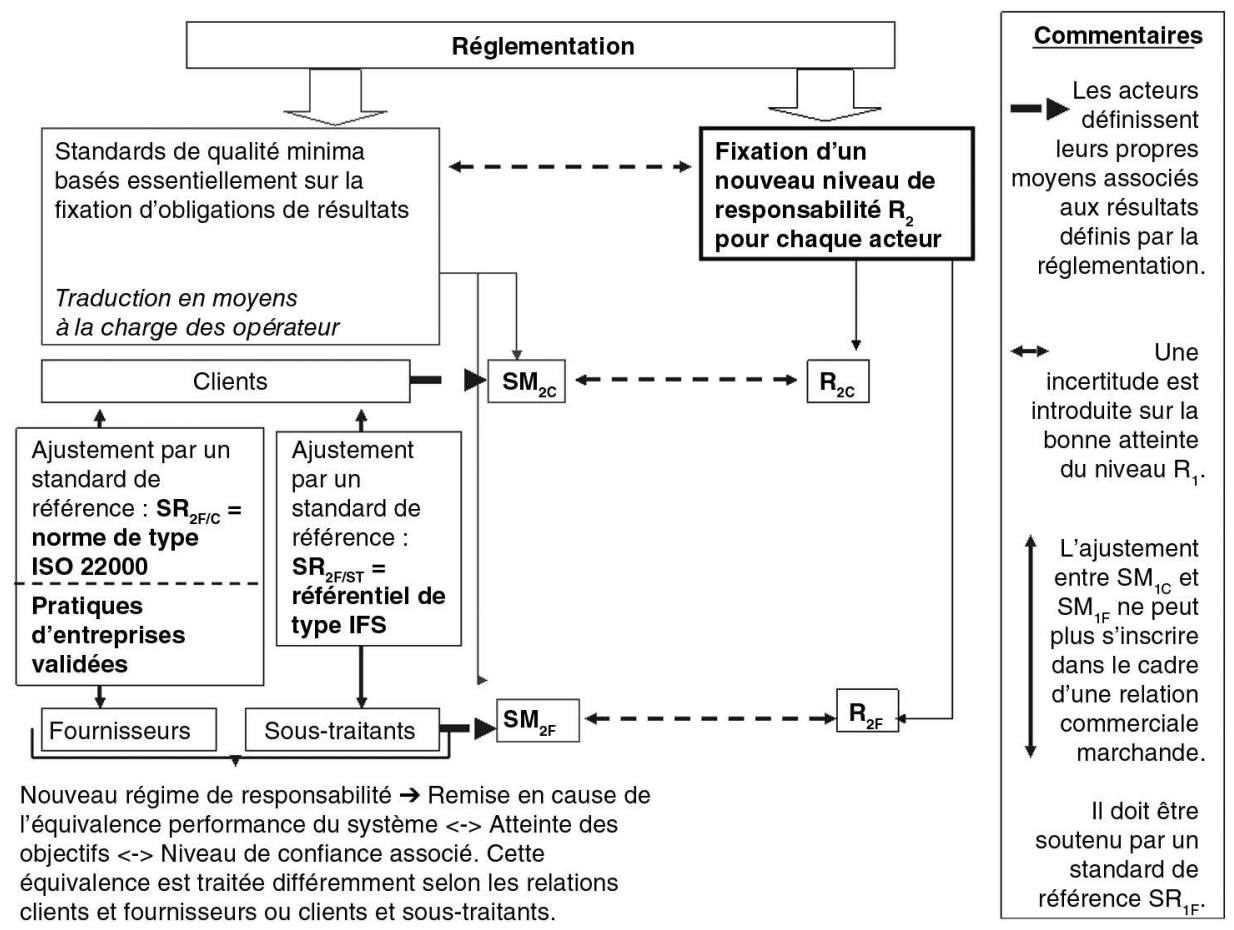

Figure 11.1. Le système européen de régulation de la sécurité sanitaire des aliments.

Le nouveau système de prévention des risques $(\mathrm{T} 3+\mathrm{T} 4)$ génère une forme d'incertitude nouvelle. Alors que, dans le modèle précédent, le lien entre l'application des moyens et le niveau de responsabilité des acteurs est explicitement défini par la réglementation, la nécessité de traduction des objectifs réglementaires en moyens par les acteurs économiques eux-mêmes rend ce lien plus indirect et crée une zone d'incertitude sur la bonne atteinte des objectifs. Pour réduire cette zone d'incertitude, l'ajustement entre les standards de qualité minima des clients et de leurs fournisseurs ne peut plus s'inscrire uniquement dans le cadre d'une relation commerciale marchande.

D'où vient cette incertitude ? Tout d'abord, comme nous l'avons vu, l'incertitude sur la bonne atteinte des objectifs de résultats (fixés par la réglementation, T4) rend nécessaire la mise en œuvre d'un standard de référence (T3) permettant cet ajustement et qui prend la forme, dans les années 1990, de normes «système » de type ISO 9000. Mais ce type de normes a comme caractéristique d'être basé sur un postulat problématique : il y aurait une équivalence entre la performance du système et l'atteinte des objectifs de résultats portant sur la sécurité des produits (autrement dit, « les produits sont sains parce que les systèmes sont efficaces »). 


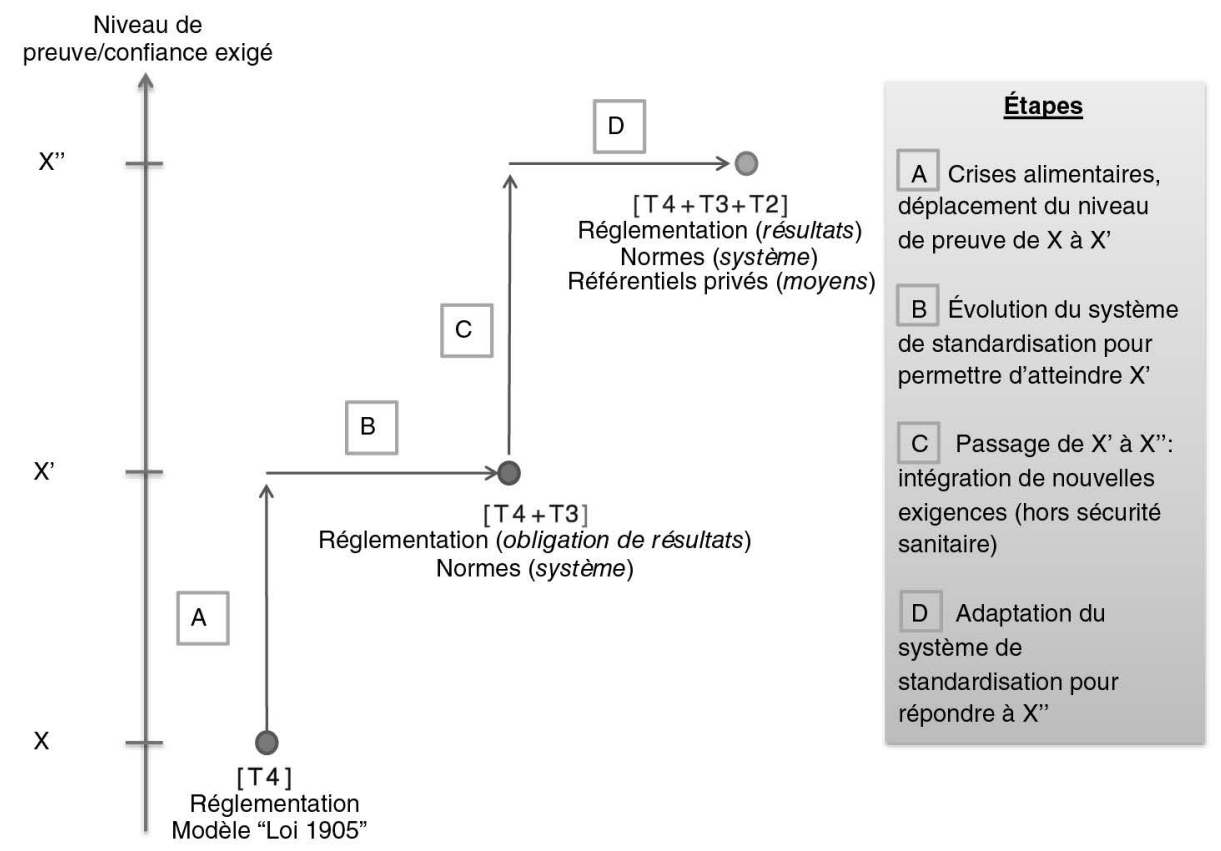

Figure 11.2. Les évolutions du niveau de preuve/confiance et du système de standardisation.

La confiance des différents opérateurs, et notamment celle des clients envers leurs fournisseurs, est supposée être assurée par cette équivalence. Mais cette équiva-

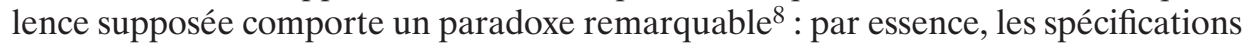
portant sur un produit particularisent ses caractéristiques alors que, au contraire, les normes systèmes constituent des énoncés génériques d'ordre méthodologiques. Il peut donc y avoir très grande distance entre les spécifications de produits et les normes systèmes.

On conçoit que, face au risque de détérioration de leur réputation, et, surtout, de mise en cause de leur responsabilité et de l'administration de la preuve, cette distance ne soit pas supportable par les entreprises de distribution alimentaire. L'émergence des référentiels privés des distributeurs (T2) correspond à l'objectif de dépasser ce paradoxe qui met en danger leur réputation d'enseigne et leur responsabilité de détaillant. Le développement rapide de référentiels privés de producteurs (standardisation de type T1) correspond à l'objectif de se soustraire à ces risques. Le développement, par la suite, de référentiels de distributeurs (de type T2) correspond à l'objectif de diminuer les coûts de transaction. Au début des années 2000, le niveau de preuve/confiance associé à la configuration précédente (X') ne correspond plus aux obligations de responsabilité et de garantie de réputation des distributeurs. La redistribution des responsabilités, accentuée par le développement des marques de distributeurs, induit un déplacement de X'vers X" correspondant à

8. Le sociologue Denis Segrestin (1997) avait déjà souligné ce paradoxe : « on imagine, écrit-il, la distance qu'il peut y avoir entre les spécifications de produits - par essence particularisantes - et les énoncés génériques, d'ordre "méthodologiques" ". 
une augmentation des exigences de preuve/confiance de la part des opérateurs dans le domaine de la sécurité sanitaire, mais également éventuellement, par extension, dans d'autres domaines (éthique, environnement, etc.) : c'est la montée des référentiels privés $(\mathrm{T} 2)$, et particulièrement des référentiels de clients. Le système de standardisation évolue vers la configuration $(\mathrm{T} 4+\mathrm{T} 3+\mathrm{T} 2)$ : il fixe des obligations de résultats et établit des recommandations en matière de système et de moyens.

\section{W Conclusion}

Au prix d'évolutions drastiques, la régulation de la sécurité sanitaire des aliments a contribué à transformer profondément et durablement l'économie des filières agroalimentaires à l'échelle internationale. Dans les pays industrialisés, la sécurité et l'hygiène alimentaires s'étaient véritablement affirmées comme un objet de régulation publique au début du xx ${ }^{\mathrm{e}}$ siècle. Aux États-Unis, en 1906, est promulguée la première loi générale réglementant les aliments et les produits pharmaceutiques, qui par la suite aboutit à la création de la Food and Drug Administration. En France, la loi de 1905 a rendu national le contrôle des aliments et donne au gouvernement le pouvoir de réglementer les produits. En Europe, l'harmonisation européenne au début des années 1990 d'abord, puis la réforme du cadre réglementaire communautaire au début des années 2000 avaient déjà provoqué des changements majeurs de ce type de régulation, essentiellement publique, de la sécurité sanitaire des aliments. Au début du $\mathrm{XxI}^{\mathrm{e}}$ siècle, l'approche réglementaire européenne s'appuie alors fortement sur les systèmes de normalisation privés (ou professionnels) des producteurs. Une nouvelle étape est franchie lorsque les normes privées de distributeurs se développent à leur tour, cette fois-ci à l'échelle mondiale. Le système européen de régulation de la sécurité sanitaire des aliments s'est intégré à ce mouvement de libéralisation. Pourtant, il a continué à faire jouer à l'intervention publique un rôle structurant, non seulement de manière interne au marché européen, mais aussi par l'influence qu'elle a eue sur l'adoption à l'échelle internationale de dispositifs de contrôle que le marché n'aurait pas de lui-même adoptés, en tout cas aussi rapidement que ce fut le cas. La diffusion des systèmes de traçabilité entre 2000 et 2010 est à cet égard exemplaire. 



\title{
Chapitre 12 \\ La nouvelle autocratie agroalimentaire
}

\author{
L. BuSCH
}

Il y a soixante ans, la mise en application de presque tous les standards agroalimentaires reposait sur certaines formes de régulation gouvernementale ; l'entrée sur un marché donné était soumise à des standards de jure. Dès la fin des années 1920, les industries de transformation adhéraient à des standards d'entreprise de facto, nécessaires à la production en masse de produits alimentaires (National Industrial Conference Board, 1929). Cependant, ces standards de facto étaient requis par des industries de transformation particulières cherchant à faciliter le fonctionnement interne de leurs entreprises. De plus, leur mise en application ne consistait qu'en une inspection visuelle au moment de l'achat des produits agricoles, et ces standards de facto jouaient un rôle commercial relativement mineur puisque différentes industries de transformation des produits alimentaires désiraient différentes qualités de producteurs.

Cependant, les aliments transformés et emballés ont permis le développement des supermarchés. Alors que les épiceries étaient conçues pour manipuler des produits en vrac - les employés y préparaient les commandes des clients : sélection, pesée et conditionnement des produits -, les supermarchés remplacèrent les produits en vrac par des produits emballés et déléguèrent le travail de sélection des produits aux clients eux-mêmes. Partant, les clients pouvaient parcourir le magasin et choisir les marchandises (déjà emballées) qu'ils désiraient. Cela permit de diminuer considérablement les coûts de main-d'œuvre et d'offrir des prix plus bas afin d'attirer plus de clients (Cochoy, 2011). Cela dit, tant que les supermarchés étaient des établissements individuels ou de simples regroupements de quelques magasins, les industries de transformation des produits alimentaires pouvaient fixer les prix et les formats.

En outre, dans les pays industrialisés autosuffisants en matière de production alimentaire, la majeure partie de la chaîne agroalimentaire était caractérisée par une production, une transformation et une vente au détail nationales. Les seules exceptions notables concernaient quelques denrées tropicales (principalement des stimulants comme le café, le sucre, le cacao et le thé, mais aussi les bananes) et certains produits de luxe comme le foie gras. De plus, la plupart des producteurs et des transformateurs produisaient «pour le marché », destinant leurs biens aux marchés de gros où la plupart des épiciers se livraient à des transactions de type cash and carry, achetant tout ce qui était disponible dans les marchés de gros pour le revendre aux consommateurs finaux.

En revanche, le secteur agroalimentaire a connu plusieurs transformations au cours des soixante dernières années. Premièrement, nous avons assisté au développement 
des grandes chaînes de supermarchés ayant d'importantes parts de marché national et pouvant ainsi imposer les prix et les qualités exigées auprès des transformateurs et des producteurs. Par exemple, en France en 2009, les cinq plus grandes entreprises se partageaient $65 \%$ du marché. Parmi les autres pays, le taux monte à $90 \%$ pour trois entreprises au Portugal (2011) et descend à $35 \%$ pour quatre entreprises aux États-Unis (2006) (Nicholson et Young, 2012). Cependant, les chiffres américains sont biaisés car les niveaux de concentration sont beaucoup plus élevés dans les aires métropolitaines (Cotterill, 1999).

Deuxièmement, au cours des dernières décennies, les grandes chaînes de supermarchés ont commencé à opérer à l'échelle internationale. L'effondrement du bloc de l'Est a ouvert la porte des nations relativement aisées d'Europe orientale (Dries et al., 2007). Mais ce développement a surtout eu lieu dans les pays pauvres, où les supermarchés peuvent mettre en œuvre leurs standards les plus exigeants et bénéficier d'un plus grand pouvoir d'achat ainsi que de systèmes d'achat sophistiqués pour attirer les consommateurs à revenu moyen. Par conséquent, le développement des supermarchés en Asie (Reardon et al., 2014), en Amérique latine (Reardon et $a l ., 2007)$ et en Afrique (Weatherspoon et Reardon, 2003) a été extraordinairement rapide. Et, dans la majorité des cas, il s'agissait de l'expansion d'enseignes dont le siège social se trouvait dans les pays occidentaux.

Enfin, nous vivons maintenant dans un monde caractérisé par « des chaînes d'approvisionnement » (supply chains). Deux versions assez différentes existent quant à l'origine de cette notion de chaîne d'approvisionnement. L'une la relie à l'émergence de la théorie des systèmes dans les années 1950 (New, 1997), tandis que l'autre considère qu'elle est apparue avec la réussite de l'industrie automobile japonaise dans les années 1970 (Cox, 1999)ํ․ Les deux phénomènes ont probablement joué un rôle dans le développement de ces chaînes d'approvisionnement et l'avènement de la gestion des chaînes d'approvisionnement est à la fois le fruit d'une nouvelle branche de la pensée économique et d'une nouvelle façon d'organiser les industries (Busch, 2007). Il s'agit de processus performatifs au sens où l'entendent Callon et ses collègues (1998; Callon et al., 2007) : tandis que les économistes ont défini les avantages de la gestion en chaînes d'approvisionnement, les opérateurs ont transformé leur fonctionnement pour le cadre des chaînes d'approvisionnement.

Un ingrédient clé de la gestion des chaînes d'approvisionnement est que chaque acteur de la chaîne doit se conformer à une large et croissante variété de standards de facto (de plus en plus internationaux). La conformité est assurée par des systèmes d'évaluation de la conduite, des chefs d'entreprise à celle des concierges, des entreprises de fournitures agricoles aux agriculteurs, des transformateurs aux détaillants. On peut distinguer quatre composantes de ce «meilleur des mondes » dans lequel nous vivons aujourd'hui. Premièrement, il y a le régime tripartite de standardisation (RTS ; Tripartite Standards Regime, TSR) mentionné dans d'autres chapitres de cet ouvrage. Deuxièmement, il y a l'extension à une grande partie de la chaîne agroalimentaire des technologies de chaîne de montage mises au point par Ford il $\mathrm{y}$ a un siècle. Troisièmement, il y a un nouveau taylorisme avec la généralisation à toutes les professions de quelque chose qui ressemble à l'organisation du travail

1. Note des coordinateurs : dans ce cas, « supply chain » est plutôt traduit par « chaîne logistique ». 
développée par Taylor. Quatrièmement, il y a la montée du big data, rendue possible par les progrès des technologies de l'information, qui permet à tout cela d'advenir. Dans ce chapitre, j'examine chacune de ces quatre transformations institutionnelles qui ont trait à l'alimentation et à l'agriculture en interrogeant la manière dont elles répondent aux crises auxquelles nous sommes confrontés aujourd'hui : entre autres, le changement climatique, la pollution de l'environnement, l'instabilité financière et l'obésité. En conclusion, je m'interroge sur les conséquences possibles pour le fonctionnement de la démocratie. Je commence par le nouveau régime, le RTS.

\section{" Le régime tripartite de standardisation (RTS)}

Bien que la création généralisée de standards ${ }^{2}$ formels, écrits, pour les produits remonte à au moins un siècle, c'est seulement au cours des dernières décennies que des institutions spécifiques ont été développées pour certifier que certains produits, certaines personnes ou certains procédés particuliers répondent à ces standards, et que les certificateurs sont eux-mêmes accrédités pour certifier les autres. Mon collègue, John Stone, a proposé d'appeler cette triple transformation, qui relie les standards (1), les certifications (2) et les accréditations (3), le régime tripartite de standardisation (Loconto et al., 2012). Ce que le RTS fait, c'est d'établir un système de gouvernance privée mondiale qui se prolonge bien au-delà des entreprises individuelles.

Les premiers standards agroalimentaires ont été établis par des entreprises individuelles engagées dans la production de masse de produits tels que les machines agricoles et les produits alimentaires emballés ${ }^{3}$. Pour les machines, chaque partie devait être normalisée de manière à simplifier leur assemblage tout autant que leur réparation. Pour les marchandises emballées, les standards devaient définir la qualité des produits aussi bien que la taille et la forme de l'emballage et les étiquettes. Ces standards d'entreprise remplacèrent la différenciation de la production artisanale. Mais les standards définis au niveau des entreprises individuelles ont conduit à une prolifération de produits et de procédés dont les composants ne sont pas interchangeables. Par exemple, les vis utilisées dans la fabrication des machines agricoles, les boîtes utilisées pour les aliments transformés, les caisses de fruits frais et d'autres produits intermédiaires variaient d'une société à une autre.

La Grande Guerre de 1914-1918 a montré au monde l'importance des standards. Non seulement les munitions, mais également les uniformes, les véhicules, les aéronefs et, bien sûr, les rations qui n'étaient pas standardisés ont généré des échecs lamentables. Les munitions qui ne correspondaient pas à toutes les armes du même type ne pouvaient être tirées sur l'ennemi. Les pièces de rechange d'un fabricant

2. Note des coordinateurs : la traduction française courante du terme anglais «standard» est «norme ». Toutefois, conformément à l'usage répandu dans la littérature économique, nous avons également adopté en français pour ce chapitre les termes standard et standardisation.

3. Comme Cochoy (2002) l'a suggéré, l'emballage des produits alimentaires rend simultanément possibles des choses telles que connaître les ingrédients utilisés et le poids net, cela empêche également au consommateur de voir ce qu'il y a à l'intérieur du paquet. Ainsi, certains produits peuvent être emballés avec succès tandis que d'autres restent non emballés. 
n'étaient pas adaptées à une autre machine. Les rations non standardisées ne permettaient pas une nutrition adéquate des soldats et prenaient plus de place dans les véhicules (Frontard, 1994).

Au début des années 1920, les leçons de la guerre étaient tirées. Il était devenu évident que l'absence de standards sectoriels générait un gaspillage de matériaux, de travail et de temps. Comme l'exprime Herbert Hoover (cité dans Cotton, 1922 : 144), devenu le secrétaire américain au Commerce : « Il y a une chose remarquable à propos de l'industrie américaine et qui apparaît quotidiennement au ministère, il s'agit de l'efficacité remarquable de l'industrie individuelle et de l'inefficacité considérable de l'industrie collective. » Ainsi, aux États-Unis et dans d'autres pays industrialisés, le processus extrêmement complexe de développement des standards sectoriels a commencé.

Ces standards répondaient à différents objectifs. Tout d'abord, ils facilitaient les contrats puisque les acheteurs pouvaient indiquer plus précisément ce qu'ils attendaient en se référant à un standard. Deuxièmement, ils réduisaient considérablement les coûts, dans la mesure où les fournisseurs d'emballage et d'étiquetage pouvaient réduire les variations inutiles. Troisièmement, comme les caractéristiques pertinentes étaient spécifiées par les standards, de nombreux produits pouvaient être achetés à l'aveugle 4 . Quatrièmement, à l'avantage des acheteurs, les fournisseurs d'un même pays pouvaient être mis en concurrence directe les uns avec les autres puisque chacun devait produire la «même » chose. Enfin, une fois ces standards largement utilisés, ils permettaient aux entreprises très capitalisées d'augmenter leur part de marché en utilisant des chaînes de montage ou des processus de fabrication en continu de manière à réduire les coûts tout en améliorant les bénéfices. De plus, puisque la plupart des échanges étaient limités par les frontières nationales, les contrats standards, les récépissés d'entrepôt et les documents connexes facilitaient la résolution des conflits entre les acheteurs et les vendeurs dans les tribunaux nationaux.

Alors que le commerce international des produits alimentaires et agricoles existe depuis des millénaires, l'avènement d'un régime alimentaire véritablement mondial a été rendu possible grâce à différentes réunions qui se sont déroulées dans le cadre de l'Accord général sur les tarifs douaniers et le commerce (Gatt) et qui ont abouti à la création de l'Organisation mondiale du commerce (OMC) et à d'autres accords internationaux. L'OMC (1994) a eu pour effet de mettre le Codex Alimentarius - qui était resté jusque-là une agence plutôt obscure, sous la responsabilité conjointe de l'Organisation pour l'alimentation et l'agriculture et de l'Organisation mondiale de la santé - au centre des débats. Référencées dans l'Accord sanitaire et phytosanitaire, ses décisions sont devenues essentielles au commerce international des produits alimentaires. Toutefois, le mandat du Codex étant assez limité, il s'est révélé insuffisant pour répondre aux besoins des entreprises capables et désireuses de participer au commerce international à grande échelle (par exemple Carrefour, Heinz, International Harvester), ainsi que pour les organisations non gouvernementales (ONG) souhaitant mettre la pression sur les grandes entreprises pour toute une

4. De Raymond (2013) note que les acheteurs en gros de fruits et légumes appellent ces produits «béton », faisant allusion à leur manque de maturité. 
série de raisons, notamment pour améliorer le bien-être des animaux, le commerce équitable et la durabilité environnementale. Alors que les institutions internationales officielles pouvaient théoriquement agir, il est devenu clair, à la fois pour les grandes entreprises et pour les ONG, que de telles actions prendraient des années, sinon des décennies. À la place, il y avait une pression croissante pour créer des standards de facto mondiaux pour certifier ces dernières qualités. Ainsi, des organisations telles que GlobalGap et le Consumer Goods Forum ont été créées par les plus grandes entreprises de manière à harmoniser les standards, tandis que l'Iseal et Fairtrade International ont été développés par les promoteurs internationaux du développement durable et du commerce équitable.

Néanmoins, cela créa en retour un nouveau problème : puisque les acheteurs et les vendeurs sur les marchés mondiaux opéraient souvent sous des régimes juridiques nationaux différents, les différends au sujet de la qualité des produits livrés - qu'il s'agisse de tomates fraîches ou de pièces de montage de tracteurs - faisaient l'objet d'affaires judiciaires complexes et coûteuses. En outre, les transformateurs et les détaillants craignaient que des produits dangereux ou de mauvaise qualité entraînent une perte de chiffre d'affaires. La solution devait être trouvée dans la création d'organismes de certification. Alors que quelques organisations de certification des aliments existaient depuis un siècle ou plus (par exemple l'American Institute of Baking), la plupart virent le jour au cours des dernières décennies. La Commission européenne a récemment identifié 441 programmes différents parmi ses États membres (European Commission, 2015). Au cours des dernières années, la certification alimentaire s'est avérée être une activité très lucrative, attirant l'attention des organismes de certification d'autres industries. Par exemple, Det Norske Veritas, un certificateur reconnu de l'inspection et de l'évaluation technique des navires, a élargi son spectre d'activité pour y inclure des produits alimentaires.

Cependant, puisque n'importe qui pouvait s'autoproclamer certificateur, il est devenu nécessaire de trouver des moyens pour accréditer les certificateurs. Et, puisque les grandes sociétés de certification s'étaient diversifiées dans pratiquement tous les secteurs, l'accréditation ne pouvait se limiter simplement à la certification des produits et des procédés alimentaires et agricoles. En fin de compte, l'International Accreditation Forum ${ }^{5}$ et l'International Laboratory Accreditation Cooperation ${ }^{6}$ ont été respectivement créés en 1993 et 1996 ${ }^{7}$. Le premier accrédite les programmes nationaux d'accréditation pour tous produits et procédés, tandis que le second vise à assurer des tests de laboratoire standard en accréditant les organismes nationaux chargés de la supervision des tests de laboratoire. Ce sont des organisations internationales, non gouvernementales ou quasi gouvernementales, qui accréditent désormais les accréditeurs nationaux qui accréditent les certificateurs qui certifient que certains standards particuliers sont respectés par les entreprises et les fermes dans tous les secteurs. Peu de temps après leur mise en place,

5. International Accreditation Forum, Inc., Cherrybrook (Australie) : http://www.iaf.nu/ (consulté le 7 mai 2015).

6. International Laboratory Accreditation Cooperation, «Welcome to ILAC », Stillwater (Australie) : http://ilac.org/ (consulté le 7 mai 2015).

7. Ces dates sont mentionnées à titre indicatif. En effet, dans les deux cas, de considérables efforts ont dû être déployés avant une reconnaissance internationale par les nations clés du commerce. 
des efforts considérables ont été faits par les États-Unis et l'Union européenne pour promouvoir la création d'organismes nationaux d'accréditation dans les pays qui n'en disposaient pas (Donaldson, 2005 ; Loconto et Busch, 2010).

Dans le même temps, les ONG désireuses de promouvoir, par exemple, le bien-être des animaux ou des standards de commerce équitable ont constaté que, avec l'augmentation du commerce international, cette tâche ne pouvait plus être poursuivie uniquement à l'intérieur des frontières nationales. Cependant, puisque les entreprises concernées étaient bien connues des consommateurs dans tous les pays où les produits étaient vendus, elles ont commencé à faire pression sur ces entreprises en soutenant leurs efforts. En outre, ces ONG ont formé des alliances à la fois avec les grands producteurs (par exemple Unilever et Rainforest Alliance), transformateurs (par exemple Coca-Cola et Nature Conservancy), ainsi qu'avec les détaillants (par exemple McDonald et l'Environmental Defense Fund). Elles ont également participé à des soi-disant initiatives multi parties prenantes (multi-stakeholder initiatives, MSI) dans de nombreux pays pauvres (par exemple la Table ronde pour l'huile de palme durable, Roundtable for Sustainable Palm Oil, RSPO). Les détaillants ont également formé des alliances pour parer aux actions des ONG (par exemple l'Ethical Trading Initiative).

En bref, le RTS a émergé afin de satisfaire les besoins des grandes sociétés agroalimentaires (et des autres) désireuses d'opérer sur les marchés mondiaux nouvellement ouverts d'une part, et des ONG cherchant à subordonner ces marchés à leurs objectifs d'autre part. Surtout, si de toute évidence les grandes sociétés ne sont pas gérées selon des principes démocratiques - elles ressemblent en fait aux aristocraties terriennes médiévales étant donné que c'est la propriété d'actions qui fournit des voix -, il en est de même pour les ONG. Alors que beaucoup pourraient trouver leurs actions juste et justifiable, elles font partie de ce qu'on a appelé le complexe ONG-industriel (Gereffi et al., 2001). Mais le développement du RTS est seulement une facette de la nouvelle autocratie. Intéressons-nous également aux chaînes de montage.

\section{" Les nouvelles chaînes de montage}

Les chaînes de montage ont été employées pour la première fois dans le cadre de la transformation des aliments. En Angleterre, les biscuits étaient fabriqués par des chaînes de montage dès 1833. À peu près au même moment aux États-Unis, les porcs étaient abattus et découpés à la manière d'une chaîne de démontage (Giedion, 1975 [1948]). Mais, comme on le sait, c'est Ford qui a popularisé la production par chaînes de montage au début $\mathrm{du} \mathrm{Xx}^{\mathrm{e}}$ siècle, ce qui lui a permis de rendre sa Ford $\mathrm{T}$ accessible à tous tout en payant des salaires nettement plus élevés que ses concurrents. Vers le milieu du $\mathrm{xx}^{\mathrm{e}}$ siècle, presque toutes les usines de transformation de produits alimentaires utilisaient certaines technologies de chaînes de montage, certaines partiellement automatisées, la plupart impliquant une division poussée du travail. Dans les années 1970, les chaînes de montage ont été étendues à la récolte des tomates (avec des machines sur lesquelles les travailleurs pouvaient retirer les tomates tachées d'un tapis roulant tout en se déplaçant à travers les champs) 
(Friedland et Barton, 1975) et aux fast-foods où les sandwichs pouvaient être préparés à la manière d'une chaîne de montage (Reiter, 1991). Cependant, avec le développement des chaînes de montage, les salaires élevés de Ford disparaissaient progressivement. Dans de nombreux autres pays, une forte résistance allait se manifester, notamment en France. Les nouvelles technologies qui réduisent le coût des petites unités de production, un regain d'intérêt dans les aliments locaux et les limites des processus biologiques révèlent que ces technologies peuvent rapidement atteindre leurs limites. Pourtant, ces technologies se sont lentement propagées de telle sorte qu'on les trouve aujourd'hui dans presque tous les pays de la planète.

Dans les usines contemporaines de transformation des produits alimentaires, ainsi que dans la restauration et les établissements de vente au détail, les chaînes de montage sont monnaie courante. Dans une usine de transformation, la préparation des produits bruts consiste généralement en la découpe des parties. Pour les ananas frais par exemple, le plumet, la peau et le cour seront enlevés successivement selon trois processus distincts. De même, aux États-Unis et dans de nombreux autres pays, l'abattage et la découpe des animaux se fait presque toujours dans des installations centrales où les travailleurs effectuent sans cesse les mêmes tâches, souvent à une vitesse pouvant entraîner le syndrome du canal carpien. Une étude récente a révélé que $8,7 \%$ des travailleurs de la transformation de la volaille avaient le syndrome du canal carpien, un taux plus de deux fois supérieur aux autres travailleurs manuels (Cartwright et al., 2012 ; voir également Lloyd et James, 2008).

Dans la restauration, des portions individuelles de salades sont assemblées de la même façon. Et il suffit d'aller chez McDonald pour voir l'assemblage des hamburgers, du poulet, du poisson et des autres sandwiches. Tout cela permet d'employer de la main-d'œuvre peu qualifiée, à temps partiel et parfois sans papiers, en passant outre les niveaux de salaire minimum. Mais les chaînes de montage fonctionnent avec une efficacité maximale uniquement lorsque les actions des travailleurs peuvent être bien contrôlées. Par conséquent, diverses formes de taylorisme se sont propagées.

\section{We nouveau taylorisme}

Il y a un siècle, l'ingénieur Frederick Winslow Taylor (1911) développait ce qu'il baptisa « le management scientifique ». Taylor pensait que le management devait dépasser les pratiques basées sur des règles tacites et en appeler à la science pour améliorer l'organisation du travail. Une telle approche, pensait-il, permettrait également de réduire les feintes et autres activités qui pouvaient ralentir la chaîne de production. De plus, Taylor était clair : le jugement des travailleurs devait être réduit et les décisions devaient être réservées aux managers. Grâce à l'utilisation de chronomètres et d'autres équipements, les actions répétitives de travailleurs manuels étaient mesurées afin de déterminer le moyen le « plus efficace » d'accomplir une tâche donnée. Son approche a eu un tel succès qu'elle est devenue l'un des piliers fondateurs de l'ergonomie. Cette approche n'a pas été utilisée que dans les pays occidentaux. Alexei Gastev de l'Institut central du travail soviétique l'a également mis en pratique dans les années 1920. Gastev pensait pouvoir promouvoir le taylorisme comme un moyen pour développer un « américanisme soviétique » (Bailes, 1977). 
Cependant, Taylor et ses partisans voyaient leur approche comme intrinsèquement limitée à une division poussée du travail et au travail répétitif des chaînes de montage, ou de certaines tâches exécutées dans les mines. Seul le travail manuel pouvait être sujet à ce genre de discipline industrielle. Les managers et les professionnels ne devaient pas être concernés.

Mais il a été démenti. Son approche a été finalement appliquée à la quasi-totalité des activités productives. Un nouveau taylorisme s'applique désormais à l'artisanat et au travail intellectuel dans pratiquement toutes les professions. Ceci est le fruit de ce que Michael Power (1997) a appelé « la société d'audit».

Le nouveau taylorisme a pris deux formes nouvelles : la certification et le suivi de la performance. Les certifications, partie intégrante du RTS comme nous l'avons indiqué plus haut, sont désormais requises pour tous les participants des chaînes d'approvisionnement agroalimentaires, des fournisseurs d'intrants aux agriculteurs, en passant par les transformateurs et même les détaillants. Comme je l'ai dit ailleurs (Busch, 2011), les certifications sont presque toujours basées sur les «meilleures pratiques », notamment dans le cas des normes ISO 9000 et 14000, mais également dans de nombreux autres systèmes de certification. Dans chaque cas, les « meilleures pratiques » sont définies par des experts techniques, généralement sans ou presque sans participation des praticiens. N'oublions pas que les certifications impliquent ce qu'on appelle dans le jargon des " évaluations de la conformité ». L'accent est mis autant, sinon plus, sur le respect des « meilleures pratiques » que sur le résultat final. Par exemple, les normes HACCP et les normes de l'agriculture biologiques sont toutes les deux focalisées sur ces « meilleures pratiques » et non sur le produit final. En effet, dans le pire des cas, les producteurs peuvent suivre les meilleures pratiques et produire un produit de qualité inférieure en raison de l'intervention d'autres acteurs humains et non humains. Ainsi, Hatanaka (2010) a montré comment les pêcheurs de crevettes indonésiens ont été tenus de se conformer aux meilleures pratiques, définies ailleurs, qui ne tenaient pas compte des conditions locales, notamment d'une importante pollution industrielle des estuaires.

Mais la certification ne constitue qu'une partie du nouveau taylorisme. Le suivi de la performance implique des audits de certaines personnes qui souvent ne sont pas parties prenantes des chaînes de montage. Tout le monde, des gardiens aux P.-D.G., peut être contrôlé au moyen d'une combinaison de méthodes. Premièrement, les employés engagés dans le travail de routine sont souvent soumis à des audits réguliers sur la base d'un ensemble de mesures prédéfinies. En outre, des incitations peuvent être données à ceux qui appliquent très bien les mesures, tandis que des sanctions sont prévues pour ceux qui les appliquent mal. Parmi les activités désormais fréquemment suivies, il y a la rapidité à laquelle les commandes de nourriture sont enregistrées dans une base de données, le temps requis par un chauffeur de camion pour livrer de la nourriture à un détaillant, ainsi que le respect d'un itinéraire prédéfini (contrôlé par GPS) ou la rapidité de traitement des commandes téléphoniques sur un marché de produits frais.

De plus, les managers sont souvent évalués sur la performance relative de leur magasin par rapport à d'autres magasins similaires. Par exemple, un manager de Walmart peut être évalué sur la base d'une comparaison des ventes dans son magasin par rapport à ceux des magasins de taille similaire situés dans des quartiers 
présentant des caractéristiques démographiques similaires. Un directeur d'une usine de transformation peut être évalué sur la base du débit journalier. Et les managers de fast-foods peuvent être évalués sur la base du nombre de repas vendus par rapport à d'autres magasins pour lesquels les données démographiques des clients sont similaires. Et, bien sûr, les P.-D.G. des grandes entreprises sont maintenant évalués en grande partie sur la base des profits trimestriels de leur entreprise.

En plus de ces audits « internes », il y a l'évaluation du rendement des employés par les clients. Beaucoup de restaurants distribuent des formulaires d'enquête aux clients pour qu'ils évaluent la qualité du service ; ces formulaires sont ensuite utilisés pour évaluer, récompenser ou punir les serveurs. De même, les grandes chaînes de supermarchés et les transformateurs d'aliments ont souvent un standard téléphonique où les consommateurs peuvent adresser leurs plaintes et acceptent des commentaires sur leurs sites Internet. Les fast-foods encouragent souvent les consommateurs à répondre à des questionnaires en ligne en offrant des réductions sur un achat futur ou la possibilité de gagner à un tirage au sort. Tout cela est conçu pour faciliter la vérification du comportement des employés et de la qualité des produits.

Mais, étant donné l'énorme quantité de données qui doivent être collectées pour mettre en œuvre ces suivis fréquents, ces certifications et d'autres mesures encore, les technologies de l'information sont devenues une partie essentielle de ces transformations. En effet, sans ces technologies, une grande partie du travail d'audit serait trop difficile ou trop coûteux. Je vais maintenant traiter de ces technologies.

\section{\# L'agroalimentaire à l'ère de l'information}

L'essor de ce qui est souvent désigné comme le big data a été crucial pour la diffusion des technologies de chaîne de montage dans les diverses chaînes d'approvisionnement et dans l'ensemble du système agroalimentaire, ainsi que pour la diffusion du taylorisme dans l'ensemble des professions. Autrement dit, la capacité à recueillir et à analyser de grands ensembles de données à grande échelle a permis (1) la création d'une division poussée du travail dans d'innombrables secteurs où, auparavant, l'artisanat ou la production professionnelle était la norme, et (2) l'application des principes du taylorisme à des formes plus complexes de travail. Quelques exemples devraient suffire :

- Les fast-foods utilisent maintenant couramment des logiciels pour planifier le travail des employés. Cela permet d'ajuster les heures de travail des employés au plus près des volumes d'affaires (Love et Hoey, 1990). Cela permet également la segmentation du volume d'affaires en ventes de produits alimentaires spécifiques permettant une meilleure gestion « juste-à-temps » des stocks du restaurant. En outre, cela favorise la substituabilité des travailleurs étant donné que la plupart des emplois exigent des compétences pouvant être acquises facilement. Ainsi, les fast-foods sont devenus suffisamment standardisés pour permettre l'utilisation de la simulation et de la recherche opérationnelle pour l'amélioration des bénéfices (Swart et Donno, 1981).

- Walmart précise que ses fournisseurs livrent à échéances fixes. Si ces échéances ne sont pas respectées, cela entraîne des pénalités pour le fournisseur (Bianco et 
Zellner, 2003) (ceci permet à Walmart de répartir le travail de déchargement sur des périodes de temps plus longues et de minimiser l'espace et le travail dédié à cette tâche). De plus, depuis 1983, il a maintenu un grand système d'information par satellite privé qui relie ses nombreux magasins par des dispositifs de communication audio et vidéo, ainsi que d'échange de données (White, 2004). Cela permet à Walmart d'avoir un contrôle sans précédent sur ses chaînes d'approvisionnement ainsi que sur ce qui se passe à l'intérieur de ses magasins.

- Il est maintenant devenu monnaie courante chez les fabricants de produits alimentaires et autres d'équiper les semi-remorques de systèmes de positionnement (GPS) afin que les chauffeurs puissent être suivis pendant tout leur voyage.

- Les codes à barres, utilisés initialement comme moyen de réduire les temps d'attente aux caisses des supermarchés, ont supprimé une large part du travail intellectuel aux caisses qui a été remplacé par le simple glissement des articles sur un scanner (Brown, 1997). Cela a également permis aux supermarchés de surveiller minutieusement les actions de caissiers et de supprimer presque toute forme de jugement dans le processus.

- Les points de vente sont désormais monnaie courante dans les supermarchés ainsi que dans certains magasins d'alimentaires plus petits. Ils permettent aux gestionnaires de surveiller plus attentivement le comportement des caissiers. Comme l'explique un fournisseur de logiciels :

Les caissiers qui utilisent notre logiciel de terminal de vente doivent s'enregistrer avec leur propre nom, ce qui conduit à une responsabilisation accrue des employés quant aux erreurs et à l'argent manquant. De plus, tout gestionnaire peut accéder à l'historique des transactions d'un registre et même imprimer un rapport. Cashier Live comprend également un dispositif de mesure du temps de travail qui facilite l'établissement de la paie à la fin d'une période de travail (Cashier Live, 2015).

- De plus, les logiciels de point de vente peuvent être utilisés par les grandes enseignes pour gérer leurs fournisseurs. Sachant combien d'unités de gestion de stock (UGS) particulières ont été vendues, ces détaillants peuvent exiger des livraisons juste-à-temps à leurs fournisseurs. En outre, les grandes enseignes peuvent utiliser des données multi-magasins pour discipliner les gestionnaires qui ne produisent pas à des niveaux attendus.

Mais les données ne sont jamais des représentations directes de la réalité. Les données doivent être créées et cela ne peut être fait que par standardisation, certification, accréditation, mesures et enregistrements. Cela ne pose généralement pas de problème lorsqu'elles sont principalement utilisées pour la surveillance des machines, comme dans le cas de l'analyse des risques et la maîtrise des points critiques. Tant que l'on identifie les bons risques et que l'on prend les bonnes mesures aux points de contrôle critiques, les big data peuvent alors être utilisées pour assurer, par exemple, la sécurité des aliments en conserve. Cependant, les big data peuvent également - et c'est de plus en plus le cas - être utilisées pour surveiller le comportement des travailleurs à tous les niveaux.

Néanmoins, les big data peuvent poser des problèmes importants lorsque les données peuvent/doivent être partagées à travers des frontières organisationnelles. Comme le décrivent Allaire et Wolf (2004), à propos de l'élevage des porcs, des logiciels développés par la Pig Improvement Company (PIC) permettent à leurs utilisateurs 
de partager des données provenant des élevages pour évaluer leurs propres lignées génétiques. Toutefois, certains producteurs préfèrent utiliser un autre logiciel de manière à éviter de fournir ces données à la PIC. De même, de nombreux producteurs américains de bovins ont résisté à l'utilisation du marquage auriculaire du bétail par nanotechnologie qui permettrait de recueillir des informations en temps réel sur les maladies, craignant que ces données puissent être utilisées par l'industrie du conditionnement de la viande afin de minimiser les prix (Whyte et al., 2014). Dans les deux cas, il est clair que les résistances qui se sont manifestées et qui continueront probablement de se manifester soulignent les limites de l'utilisation des big data.

Cela dit, à la limite, les big data peuvent être utilisées pour éliminer une grande partie du travail manuel et du travail intellectuel des systèmes d'approvisionnement agroalimentaire. Par exemple, la radio-identification (RFID) est déjà utilisée pour le contrôle des inventaires et pour passer de nouvelles commandes. Si les grandes enseignes surmontent les résistances, la RFID sera également utilisée pour enregistrer instantanément les commandes des clients et pour éliminer la plupart des emplois relatifs aux caisses de paiement et au contrôle des inventaires. De même, l'utilisation de capteurs pour la création de matériel agricole automatique sans conducteur servant pour les semis, la fertilisation et les traitements offre la possibilité d'une agriculture qui ne nécessite plus de main-d'œuvre dans le champ. De plus, des capteurs implantés sur les animaux de ferme peuvent être utilisés pour surveiller les maladies, ainsi que pour veiller à ce que la qualité des aliments soit liée aux besoins nutritionnels spécifiques des animaux. Dans les deux cas, les besoins en travail sont considérablement réduits (par exemple Zhang et Pierce, 2013). Déjà, les laiteries automatisées et l'agriculture de précision sont devenues monnaie courante dans une grande partie du monde industriel. De même, les emballages alimentaires Tetra Pak ${ }^{\circledR}$ sont presque entièrement automatisés et ne nécessitent que quelques mécaniciens qui attendent l'alarme occasionnelle quand une partie du processus automatisé tombe en panne. Reste à voir combien de temps cette tendance se poursuivra, mais les conséquences à long terme méritent d'être analysées.

\section{" Marchés et bureaucraties}

Il est également important de souligner une grande ironie dans tout cela. Les économistes néoclassiques ont insisté sur le fait que les marchés ont la grande vertu de permettre de se passer de la bureaucratie. De la même manière, les économistes néolibéraux, qui pensent que l'État doit être mobilisé pour promouvoir les marchés, insistent sur cette caractéristique souhaitable du marché ; c'est ce qui rend possible selon eux l'assimilation de la liberté et du marché. On nous dit en effet que le marché libre serait pratiquement l'antithèse des organisations et de leurs bureaucraties complexes.

Il y a quarante ans, Oliver Williamson (1975) nous expliquait comment les organisations choisissent entre le marché et les hiérarchies sur la base d'une réduction des coûts de transaction. Ce faisant, il a fourni un moyen pour comprendre les décisions relatives à la répartition de ce qu'il s'agit de garder à l'intérieur de l'entreprise et 
ce qu'il s'agit d'acheter à d'autres entreprises. Alors que Williamson a été critiqué à juste titre pour avoir oublié que la production supposait une hiérarchie (Dietrich, 1994), il a finalement proposé des modifications permettant d'intégrer cela. Mais ce que Williamson et ses partisans semblent avoir ignoré, c'est que les marchés modernes nécessitent des bureaucraties.

Il y a peu de doute que pratiquement aucune bureaucratie n'était nécessaire dans les petits marchés de village (largement mythiques) où, par exemple, les surplus alimentaires pouvaient être échangés pour de la poterie. Ici, les marchandises étaient simples et leur qualité pouvait être facilement examinée. De plus, toute tricherie pouvait compromettre les ventes futures. Cependant, même à l'époque médiévale, les marchés nécessitaient une bureaucratie considérable, souvent imposée par des corporations (Steel, 2008) ; la taille standard d'une miche de pain sculptée sur le mur de la cathédrale de Strasbourg servait de mesure, mais des inspecteurs devaient veiller à ce que les fournisseurs se conforment à cette mesure. En revanche, comme il est indiqué ci-dessus, les marchés modernes, et en particulier les marchés mondiaux construits au cours des dernières décennies, nécessitent la création de multiples et importantes bureaucraties. Ces bureaucraties fixent les règles, établissent les mesures, évaluent les participants au marché, règlent les différends, et, en d'autres termes, formatent chaque marché tout en créant des domaines de compétition et des quasi-marchés.

Tableau 12.1. Quelques-unes des bureaucraties nécessaires au fonctionnement des marchés agroalimentaires mondiaux.

\begin{tabular}{lll}
\hline \multicolumn{1}{c}{ (Inter)gouvernementales } & \multicolumn{1}{c}{ Privées } & \multicolumn{1}{c}{ Public/privé } \\
\hline Organisation mondiale du commerce & Consumer Goods Forum & $\begin{array}{l}\text { Organismes nationaux } \\
\text { de normalisation (Afnor } \\
\text { par exemple) } \\
\text { Fonds monétaire international } \\
\text { de certification }\end{array}$ \\
$\begin{array}{l}\text { Organisation mondiale de la } \\
\text { propriété intellectuelle }\end{array}$ & $\begin{array}{l}\text { International Accreditation } \\
\text { Forum }\end{array}$ & $\begin{array}{l}\text { International Laboratory } \\
\text { Accorditation Cooperation } \\
\text { par exemple, Accord de libre- }\end{array}$ \\
$\begin{array}{l}\text { échange nord-américain (Nafta), } \\
\text { Marché commun d'Amérique du Sud } \\
\text { (Mercosur), etc. }\end{array}$ & $\begin{array}{l}\text { International Organization } \\
\text { for Standardization (ISO) }\end{array}$ & \\
$\begin{array}{l}\text { Directive sur les mesures } \\
\text { phytosanitaires (IPPC) }\end{array}$ & \\
$\begin{array}{l}\text { Office international des épizooties } \\
\text { Comité international des poids et } \\
\text { mesures }\end{array}$ & & \\
Codex Alimentarius & & \\
$\begin{array}{l}\text { Convention sur la diversité } \\
\text { biologique }\end{array}$ & & \\
\hline
\end{tabular}


Ainsi, une énorme bureaucratie internationale composée d'organismes de normalisation, d'entreprises de certification, d'organismes d'accréditation, de développeurs de mesures, de collecteurs et d'analyseurs de données a été mise en place afin de créer des marchés mondiaux (voir Garcia-Parpet, 2007). Le tableau 12.1 présente une liste de quelques-unes des bureaucraties nécessaires pour le commerce mondial des produits alimentaires standardisés et des produits agricoles. Comme le lecteur pourra le constater, certaines sont spécifiques aux produits agroalimentaires, tandis que d'autres s'étendent à pratiquement tous les aspects de la société. Ensemble, ils forment un système invisible de gouvernance qui ne rend quasiment aucun compte à aucun gouvernement et qui est déconnecté de toutes élites nationales et internationales. Pour souligner la taille et la portée de cette bureaucratie, il suffit de voir que, selon son site internet, un seul certificateur (SGS) a 80000 employés et 1650 bureaux engagés dans la certification d'une vaste gamme de matériaux et de procédés ${ }^{8}$. Une conséquence inattendue de cela est la suppression de l'innovation. Après tout, comme de plus en plus de personnes sont soumises au nouveau taylorisme, aux «meilleures pratiques » et à d'incessantes vérifications, l'innovation est de plus en plus susceptible d'être condamnée. Même la gouvernance démocratique est en danger.

\section{W Conclusion : la démocratie peut-elle survivre ?}

Dans son ouvrage classique, Exit, Voice and Loyalty, Albert Hirschman (1970) a noté que seuls deux types de réponses sont possibles quand on est confronté à une situation qui ne nous plaît pas. On peut s'en aller ou s'opposer. Ces deux options relèvent de la loyauté. On peut s'opposer parce que l'on est fidèle à l'organisation, c'est-à-dire que l'on pense que notre prise de parole peut changer les choses. Inversement, on peut s'en aller parce que l'on pense que les changements liés à la prise de parole ont peu de chance d'advenir. De toute évidence, sans la démocratie, la prise de parole (voice) est impossible. Pourtant, les quatre transformations décrites ci-dessus sont en grande partie conçues pour transformer la société en limitant la prise de parole.

L’utopie néolibérale conçue par Friedman (2002 [1962]), Hayek (1973-1979, 2007 [1944]), Becker (1964), Buchanan (1968) et les autres consiste essentiellement à subordonner toutes les institutions aux marchés et à la compétition de façon à ce que, nous dit-on, la liberté soit optimisée. Mais, dans ce genre de société - dans laquelle tout est standardisé, certifié et accrédité, dans laquelle les lignes de montage prévalent, dans laquelle tout le monde est évalué sans cesse, tout est rendu possible par l'avènement des technologies de l'information à haut débit -, tous les choix sont binaires - soit on achète, soit on n'achète pas ; soit on reste, soit on part. Il y a peu d'espace pour la prise de parole. La liberté exige plus que de simples décisions binaires.

On pourrait refuser d'être constamment évalué, mais la société de marché que nous avons construite ne laisse pas beaucoup d'autres options possibles. En effet, comme

8. SGS, «SGS When You Need to Be Sure », Genève, SGS : http://www.sgs.com/ (consulté le 5 mai 2015). 
Power (1997) le suggère, il est presque impossible de s'opposer aux évaluations, que ce soit l'évaluation sur les bénéfices trimestriels d'un P.-D.G., ou l'évaluation du temps de parcours et de la consommation de carburant d'un chauffeur de camion. En outre, les audits eux-mêmes créent les véritables personnes dont leurs partisans souhaitent surveiller le comportement. Ils encouragent les gens à se considérer comme des individus isolés afin de maximiser leur capital humain et d'éviter tout travail inutile. Autrement dit, l'approche de l'individualisme méthodologique commune dans l'économie dominante devient réalité. De plus, cette transformation ne se limite en aucune façon au secteur agroalimentaire ; elle est devenue omniprésente dans la plus grande partie du monde. Pourtant, cette nouvelle autocratie sape la démocratie en minimisant ou en éliminant toute opportunité pour la prise de parole.

Traduit de l'anglais par Antoine Doré. 


\title{
Chapitre 13 \\ Libéralisation des marchés laitiers et différenciation régionale des régimes de concurrence
}

\author{
M. DeRVILlé
}

Le secteur laitier européen a été fortement régulé de 1968 à 2004 et de façon moindre jusqu'en 2015. La libéralisation progressive du secteur modifie depuis les conditions d'accès des producteurs au marché, fragilisant les exploitations laitières, avec des conséquences économiques et sociales importantes dans les zones où elles sont essentielles à la vie des territoires, notamment en montagne. La présente analyse vise à éclairer les leviers collectifs d'amélioration des conditions d'accès au marché des exploitations laitières dans les zones de montagne françaises avant et après la libéralisation.

Dans le cadre de la politique agricole commune (PAC), l'accès au marché était encadré par différents dispositifs : i) une qualité publique seuil pour le lait, la poudre de lait écrémé et le beurre, ii) des droits de douanes variables puis fixes protégeant le marché européen des fluctuations du marché mondial, iii) un prix indicatif et un mécanisme d'intervention ainsi que des aides à l'écoulement des produits visant à stabiliser les prix à un niveau satisfaisant pour les producteurs et les consommateurs, iv) des droits à produire ou des quotas à partir de 1984, permettant de continuer à stabiliser les prix tout en réduisant le coût de l'intervention. Parallèlement, les politiques structurelles soutenant les investissements dans le secteur sont restées du ressort des États membres.

Compte tenu de la diversité des structures de production et de la marge de manœuvre qui leur était donnée, les États membres ont mis en œuvre des stratégies contrastées au sein de ce cadre réglementaire européen, notamment dans la mise en œuvre des quotas. L'État français, en accord avec les syndicats majoritaires, a fait le choix de droits à produire non marchands, liés au foncier et administrés à l'échelle des départements en cogestion avec la profession agricole. Le développement d'exploitations familiales de taille moyenne réparties sur l'ensemble du territoire a été privilégié. En d'autres termes, les outils de la politique laitière ont été instrumentalisés en France pour soutenir les politiques structurelle et territoriale.

Par ailleurs, des dispositifs de gouvernance sectorielle ont été développés. Une interprofession laitière a été créée dans les années 1970 pour mettre en place un 
système de paiement du lait à la qualité, sa mission a ensuite été étendue de 1997 à 2008 à la négociation d'un accord national sur le prix du lait. De ce fait, les producteurs français, via leur syndicat et l'interprofession, ont exercé, dans le cadre de la réglementation européenne et nationale, un contrôle collectif sur toutes les composantes du revenu laitier (structure de production, qualité, volume, prix) et les conditions d'exercice de leur métier.

La baisse de l'intervention publique à partir de 2004 et la hausse progressive des quotas laitiers de 2008, et leur suppression en 2015, viennent modifier cela. Les prix diminuent à un niveau proche du cours mondial et deviennent volatils. Les crises qu'a connues le secteur en 2008-2009, 2013 et depuis 2015 en témoignent. Les aides directes mises en place à partir de 2004 pour compenser partiellement la baisse des prix ne sont pas parvenues à stabiliser les revenus. Ces crises laitières n'ont toutefois pas conduit l'Union européenne à proroger le système des quotas pour rétablir la stabilité des marchés. Une série de mesures a néanmoins été prise en 2012 pour favoriser l'émergence de nouvelles stratégies de stabilisation dans une économie contractuelle. Le règlement européen adopté en mars 2012, intitulé « Paquet lait », fournit en effet un cadre pour établir des contrats entre producteurs et transformateurs, encourage la formation d'organisation de producteurs (OP) sur une base territoriale large (jusqu'à $33 \%$ de la collecte nationale et 3,5\% de la collecte européenne) et reconnaît les organisations interprofessionnelles. Dans les filières de qualité spécifique, la maîtrise collective de la croissance de l'offre est tolérée.

Comme lors de la période précédente de marché administré, les États membres et les acteurs économiques s'emparent de façon contrastée de ce nouveau cadre réglementaire européen libéral. Les producteurs du Nord de l'Europe, organisés en coopératives puissantes, se sont saisis de la libéralisation pour restructurer, investir et développer la production de commodités (beurres, poudres, fromages industriels de type Gouda/Edam) pour l'exportation. En France, ainsi que dans d'autres États membres du Sud et de l'Est de l'Europe, les acteurs publics et les acteurs économiques, sont restés dans une logique de maîtrise de l'offre (Idele, 2015). Plusieurs facteurs peuvent expliquer ce choix. Tout d'abord, les laiteries privées y sont concentrées et puissantes (45\% de la collecte et $54 \%$ de la transformation, avec quatre entreprises dans le top 20 mondial), et ont affiché dès 2009 leur souhait d'une maîtrise stricte de la collecte au plus près de leur besoin dans une logique de flux tendu. Deuxièmement, dans un souci de sécurisation des débouchés, l'acteur public a rendu les contrats de vente de lait obligatoires dès 2010, avant même que la réglementation européenne ne donne la possibilité aux producteurs de s'organiser collectivement pour les négocier. Troisièmement, depuis la dénonciation de l'accord interprofessionnel sur les modalités de fixation du prix du lait par la Direction générale de la concurrence et de la consommation et de la répression des fraudes (DGCCRF) en 2008, l'interprofession laitière est en panne, les industriels refusant que les questions économiques y soient traitées. Enfin, le syndicalisme agricole et l'État n'ont pas proposé de vision claire pour le développement du secteur. Il en a résulté des contrats qui s'inscrivent dans la continuité du système passé avec une référence aux indicateurs interprofessionnels en matière de prix, à la grille de paiement du lait à la qualité et aux quotas en matière de volumes (avec toutefois des différences de dureté dans leur gestion). Les producteurs français se retrouvent 
ainsi dans une situation particulière : toujours fortement contraints en matière de volumes, ils bénéficient d'un certain lissage des prix (Perrot et al., 2015 ; Trouvé et al., 2016). Comme cela a déjà été montré par ailleurs, les relations contractuelles se sont accompagnées d'un transfert du risque vers le maillon le plus faible de la filière (Hueth et Marcoul, 2003 ; Henson et Reardon, 2005 ; Jongeneel et al., 2010).

Dans ce contexte, considérant l'impact des choix collectifs des acteurs économiques et politiques dans la mise en œuvre de la PAC, l'objectif est ici de penser la libéralisation des marchés de façon élargie, sans se limiter à la question de l'élimination des opérateurs non compétitifs, mais en intégrant, dans une perspective institutionnaliste, le rôle de l'action collective. En d'autres termes, il s'agit d'éclairer les leviers collectifs activables pour sécuriser un accès au marché aux exploitations laitières de montagne dans leur diversité. Le concept de régime de concurrence (Dervillé et Allaire, 2014b), défini comme l'arrangement institutionnel de dispositifs de coordination délimitant des domaines de coopération et de concurrence, est mobilisé. Ce concept, se référant à l'institutionnalisme de Commons, articule différentes échelles d'action et rend compte des conditions de stabilité des échanges marchands. Par rapport à nos précédents travaux, l'objectif est ici de mieux caractériser le rôle des collectifs sectoriels et territoriaux et des ressources communes sur lesquelles ils s'appuient pour négocier les conditions d'accès au marché. Au-delà des ressources communes matérielles, nous mettons l'accent sur les ressources immatérielles, et notamment intangibles ${ }^{1}$. Il s'agit de comprendre comment des collectifs d'acteurs se dotent de règles formelles et informelles pour structurer les forces productives, sécuriser leur insertion dans la société et rendre compatibles leurs comportements sur les marchés. Ces règles ont une portée territoriale régionale ou plus globale, et sont inscrites dans des compromis institutionnalisés qui ont une certaine résilience. Des liens établis avec les travaux de l'économie du patrimoine permettront d'expliciter le rôle des ressources communes et des droits de type communautaire dans la stabilisation des échanges marchands.

L'analyse empirique s'appuie sur l'analyse comparée sur le temps long de stratégies individuelles et collectives d'acteurs dans trois départements de montagne. Les marchés laitiers de montagne ont été choisis d'une part pour la spécificité de leur système productif (petites structures de production et rôle des stratégies de différenciation dans la création de valeur) et d'autre part pour leur exposition marquée à la suppression des quotas, ce dispositif leur ayant été favorable.

Le cadre d'analyse et les hypothèses sont développés dans la première partie. Dans la deuxième partie, la validation empirique du cadre est réalisée sur la base d'une approche comparative en trois temps : identification des ressources communes sous-tendant les projets productifs, caractérisation du régime de droits de propriété intangible sous régime quota, transformation du régime de propriété (ressources et structure de gouvernance). Dans la conclusion, les résultats relatifs à la diversité des régimes de concurrence et à la place des producteurs dans ces régimes, et les perspectives en matière d'action publique sont discutés.

1. Au sens de Commons (1934) de capacité à exercer un contrôle sur les prix futurs (voir la deuxième partie du chapitre). 


\section{$\rightarrow$ Cadre d'analyse}

\section{Stabilisation des échanges marchands et régimes de concurrence}

Les marchés sont des structures sociales caractérisées par de nombreuses interactions entre travailleurs, consommateurs, entreprises et autorités publiques (acteurs publics). Les institutions inscrivent les échanges marchands dans le temps, les stabilisent et sont donc nécessaires à l'existence des marchés. L'analyse institutionnelle des marchés va au-delà du cadre réglementaire organisant les échanges marchands, et intègre dans l'analyse les règles formelles et informelles dont se dotent les opérateurs des marchés pour réduire l'incertitude de l'échange (modèles productifs, normes de qualité, mécanismes de contrôle des volumes et des prix). En d'autres termes, la stabilisation des échanges marchands tient, d'une part, à l'action de l'acteur public, à différentes échelles et dans différents domaines, et, d'autre part, à la capacité des opérateurs de marché à s'organiser pour se coordonner et rendre leurs comportements compatibles. J.R. Commons met en avant trois formes de médiations qui soumettent l'individu au collectif : i) le droit garanti par l'État et adossé au monopole de la violence physique, ii) l'éthique, force de persuasion adossée à la menace de bannissement hors du groupe, iii) la méta-éthique conduisant à la sélection des «valeurs raisonnables $»^{2}$ formant l'intérêt commun (voir Théret, 2005). Ces deux dernières formes de médiation sont ici assimilées à une médiation " communautaire », encore qualifiée de patrimoniale par l'économie du patrimoine, selon laquelle elle se distingue de l'ordre marchand, tout en contribuant à en fixer les règles : « Il faut qu'existe un intérêt commun préalable au marché, à l'institution de celui-ci et cet intérêt commun s'organise, se manifeste dans un espace qui ne peut pas être celui du marché. L'institution du ou des marchés est une activité qui se réalise dans l'espace d'un groupe » (une communauté), qui est différent de l'espace marchand (Barthélemy, 2008). L'ordre communautaire ou patrimonial est cependant interdépendant avec l'ordre marchand. Les opérateurs de marchés, les réseaux qu'ils établissent, les organisations qu'ils élaborent à l'échelle d'un territoire ou d'un secteur, la nation constituent des communautés, au sens large, porteuses du double processus de patrimonialisation et de marchandisation. La coopération (ordre communautaire) dans l'élaboration de dispositifs d'évaluation et de qualification des biens, ainsi que dans la définition de droits de propriété et des statuts correspondant, sort les biens échangés de leur singularité et de la dépendance à un groupe particulier et permet leur appropriation individuelle sur une large échelle (ordre marchand). Les médiations portées par les communautés instaurent des droits et des devoirs communautaires ou collectifs, alors que les médiations portées par l'État instaurent des droits sociaux. Leur combinaison en arrangements institutionnels résulte de compromis sociaux.

Fligstein (1996) met en avant que les opérateurs économiques sur les marchés recherchent la stabilité autant que le profit immédiat. Les institutions, qui «permettent aux acteurs des marchés de s'organiser, d'entrer en concurrence et de coopérer et d'échanger » (Fligstein, 1996 : 658), séparent les domaines de coopération et de

2. Les valeurs raisonnables sont des compromis institutionnels : sélectionnées dans différents collectifs par l'expérience, elles permettent de hiérarchiser de façon légitime l'importance relative assignée aux objets de transaction (Commons, 1925a). 
concurrence, et déterminent ce que nous appelons un « régime de concurrence » (Dervillé, 2012 ; Dervillé et Allaire, 2014b). Pour un marché particulier, ces institutions sont particulières et dépendent du contexte institutionnel et légal défini à différentes échelles; échelles auxquelles on peut décliner les composants d'un régime de concurrence. Différentes évolutions du contexte, sur le plan des politiques publiques, des rapports de forces dans les chaînes de valeur, des conceptions de la qualité, etc., font que les régimes de concurrence changent selon les périodes. Nous nous intéressons ici aux changements liés à la libéralisation des marchés du lait, en nous focalisant sur les capacités collectives, qui s'expriment, selon les bassins laitiers, par différentes formes d'organisation des marchés du lait d'une part et d'appropriation des droits sociaux qui résultent de la politique agricole européenne d'autre part.

Fligstein (1996) distingue quatre institutions préexistant aux échanges marchands. Les « règles de l'échange » renvoient à des accords institutionnalisés dans un cadre légal et à des accords multilatéraux garantis par les États. Dans le cas du secteur laitier, il s'agit des accords internationaux à l'OMC, de la politique agricole et commerciale européenne, et des politiques structurelles nationales. Dans les années 1980 et 1990 respectivement, une politique de gestion de l'offre d'une part et l'émergence d'une économie de la qualité d'autre part se traduisent par une inflexion des règles d'échange. Les « conceptions de contrôle » (visions partagées des modèles d'entreprises et des chaînes de valeur) et les structures de gouvernance (règles encastrées dans des organisations) renvoient quant à elles aux formes « communautaires » de médiation. Il s'agit, pour le secteur laitier, des normes et des organisations professionnelles agricoles (syndicats, chambres d'agriculture, centres de recherche et interprofessions) qui orientent les modèles de production et d'entreprise. C'est plus particulièrement à ces deux institutions que nous allons nous intéresser ici. Nous les aborderons sous l'angle de la construction de ressources communes, tant professionnelles qu'interprofessionnelles.

L'industrialisation et la standardisation de l'agriculture durant la période du fordisme à la française (des années 1960 aux années 1990) se sont traduites par la diffusion d'innovations techniques et organisationnelles sectorielles et nationales, ainsi que par l'émergence de conceptions de contrôle industrielles et de structures de gouvernance professionnelles et interprofessionnelles au détriment d'institutions locales. Les choix français de patrimonialisation des quotas à l'échelle des départements ont néanmoins contribué à conférer une dimension territoriale à ces institutions sectorielles, permettant l'expression de différentes conceptions du métier d'éleveur laitier et contribuant au maintien de la production sur l'ensemble du territoire (Coulomb et Delorme, 1984 ; Mundler, 2006). La reconnaissance de qualités alimentaires liées aux modes de production a aussi permis aux producteurs et aux artisans de s'organiser collectivement pour valoriser des produits et des savoir-faire par une qualification spécifique (agriculture biologique, appellations fromagères ${ }^{3}$, labels). Ces évolutions, parallèles à celles des règles de l'échange, illustrent l'interdépendance entre institutions. Une quatrième institution distinguée par Fligstein, le

3. Une appellation d'origine protégée (AOP) désigne un produit dont toutes les étapes de fabrication sont réalisées selon un savoir-faire reconnu dans une même zone géographique, qui donne ses caractéristiques au produit. La politique française de valorisation des produits agricoles a inspiré l'élaboration d'une réglementation européenne, qui, dès 1992, établit des règles relatives à la protection des appellations d'origine et des indications géographiques (IG). 
système de droits de propriété, joue un rôle clé dans la restructuration des marchés, qu'il s'agisse, pour notre cas, d'une évolution des droits liés à la propriété physique du lait, à la propriété incorporelle dans le cas éventuel de création de marque ou à la propriété intangible, à l'instar des capacités collectives de négociation du prix du lait des producteurs organisés collectivement (en coopératives, interprofession ou organisations de producteurs) ou des droits sociaux. Résultant de la politique européenne de stabilisation des marchés et de la politique structurelle française, les droits sociaux accordés aux agriculteurs engagés dans le processus de modernisation (accès au crédit facilité et revenu stabilisé pour tout exploitant atteignant le standard professionnel) sont progressivement revus à la baisse (Barthélemy, 2000). Nous ne retenons pas ici la notion classique de droit de propriété au sens exclusif, nous considérons plutôt une diversité de droits d'action sur des ressources qui peuvent se superposer à l'instar de Commons ou d'Ostrom (Orsi, 2013). Avec cette perspective, nous aborderons les régimes de concurrence comme des régimes de droits de propriété intangible.

\section{Stabilisation des échanges marchands et système de ressources communes}

Coriat et Weinstein (2004) proposent une analyse des marchés autour de trois dimensions : i) structuration des systèmes productifs et leurs possibilités d'évolution future, ii) processus de qualification des produits et des services rendant possible les échanges marchands, et iii) régulation des interactions entre acteurs. De notre point de vue, le processus de marchandisation s'appuie sur un processus d'identification, à savoir sur l'émergence de communautés d'acteurs qui se structurent autour de ressources patrimoniales communes dans un cadre territorial et sectoriel.

La notion de patrimoine productif collectif, issue de l'économie patrimoniale à l'instar de celle d'ordre patrimonial précédemment introduite, permet d'expliciter la réorganisation des structures de production. « Les patrimoines productifs collectifs sont définis comme l'ensemble de ressources scientifiques, techniques, économiques et sociales existantes ou en formation autour desquelles se nouent des communautés d'acteurs économiques » (Nieddu et al., 2010). Ils peuvent aussi être recomposés et recombinés pour résoudre un problème productif, un nouveau champ d'activité s'ouvre alors. "La constitution de patrimoines productifs collectifs correspond donc à une nécessité : celle de reformer, au moins sur un sousensemble clairement délimité, l'unité et la cohérence du processus d'élaboration d'un projet productif. » (Nieddu et al., 2010). En d'autres termes, la constitution de patrimoines productifs collectifs conditionne l'ouverture de nouveaux champs d'activité et, en régulant les conditions d'accès aux ressources créées, contribue à la structuration des forces productives. Les patrimoines productifs collectifs soustendent les processus d'identification à l'origine de la stabilisation des marchés. Ce sont des ressources communes qui « doivent être produites ou identifiées comme telles et être préservées au cours du temps pour que des acteurs puissent se coordonner » (Nieddu et al., 2010). Toutefois, la contribution des patrimoines productifs collectifs à la structuration des échanges marchands n'est pas clairement 
explicitée. C'est ce à quoi nous nous intéressons ici, en étendant les résultats concernant la stabilisation des marchés sous indications géographiques (IG) à des marchés génériques.

Des travaux sur les appellations d'origine ont mis en évidence la dimension collective non seulement de la qualification d'un produit, mais aussi de la valeur qui lui est attachée. La réputation attachée au produit peut conférer une rente de marché aux producteurs (Torre, 2002 ; Allaire et Biénabe, 2013). Il ressort de ces travaux qu'au-delà des contrats et d'un socle de confiance mutuelle, les dispositifs de gouvernance jouent un rôle central dans la gestion durable d'un nom et de la valeur qui lui est associée. Dans la mesure où ils s'appuient sur un ensemble de règles et de normes, ces dispositifs de gouvernance (cahiers des charges, dispositifs de contrôle de la qualité, dispositifs de gestion de l'offre, règles de partage de la valeur) sont des ressources institutionnelles pour l'action. Ce sont des ressources immatérielles communes : l'identité du marché et la valeur associée ont un caractère diffus qui pose des problèmes de contrôle et d'exclusion; elles sont menacées par le non-respect des règles collectives de production (cahier des charges), par la surproduction (gestion de l'offre) ou par une remise en cause de la légitimité de la segmentation (système légal). Le cahier des charges sert de support à la stabilisation de ressources communes informationnelles (savoirs et compétences). Il soustend à la fois la structuration du système productif et la qualification des produits. Ces ressources sont portées par des communautés professionnelles qui produisent des conceptions légitimes de l'activité qu'elles séparent et stabilisent (Allaire, 2006). Elles conditionnent les possibilités d'innovation structurelle d'une part et les capacités d'élaboration de dispositifs d'évaluation et de qualification des biens (Favereau et al., 2002 ; Allaire, 2002) d'autre part. Les ressources matérielles (dispositifs techniques, infrastructures) et immatérielles (informationnelles, organisationnelles et institutionnelles) communes sous-tendant la mise en marché des produits sous IG ont un aspect systémique dans la mesure où c'est le régime de fonctionnement du système dans sa complexité qui est à l'origine du flux de ressources et de sa qualité (en l'occurrence la valeur de la rente qualité) (Allaire, 2013). La durabilité de ces systèmes de ressources communes dépend de la capacité d'une communauté plurielle d'acteurs, en cohérence avec la réglementation, à élaborer un ensemble de règles pour encadrer les comportements d'usage et de gestion de ces ressources, ce qui ne va pas sans possibilité de crises de gouvernance.

Dans les travaux sur les IG, les ressources concernées sont majoritairement spécifiques et territorialisées, dans le sens où leur valeur est liée au territoire d'activation et fonction des conditions d'usage. Toutefois, les mécanismes de qualification mis en évidence dans ces travaux peuvent être généralisés, dès lors que l'on considère que les marchés sont institués. Des phénomènes d'hybridation entre ressources génériques et spécifiques ont notamment été mis en évidence (Allaire et Sylvander, 1997 ; Perrier-Cornet et Sylvander, 2000). Les ressources génériques correspondent aux connaissances et aux techniques diffusées dans un cadre sectoriel et national, tandis que les ressources spécifiques se constituent dans des filières territorialisées.

La transformation des marchés laitiers apparaît ainsi comme la résultante d'une évolution concomitante des ressources communes qui sous-tendent l'économie 
marchande dans le secteur et des communautés qui les contrôlent : la phase de modernisation des années 1960-1990 a conduit à un affaiblissement de communautés villageoises contrôlant des ressources communes localisées (usage de terres, peu productives y compris, races ou espèces rustiques notamment) au profit de communautés professionnelles sectorielles contrôlant des ressources génétiques (races améliorées), techniques (ensilage et rationalisation de l'alimentation des animaux par exemple) ou intangibles (attribution du foncier et des droits à produire au sein des $\mathrm{CDOA}^{4}$, grille ${ }^{5}$ de paiement du lait à la qualité notamment).

La présente analyse s'intéresse à l'articulation entre ressources génériques et spécifiques au sein de systèmes de ressources communes gérés par des communautés laitières sectorielles et territoriales plus ou moins étendues et intégrées. Le système de ressources sous-tendant le régime de concurrence que nous appelons " générique » est plutôt sectoriel et s'étend dans différents territoires en concurrence. Il associe des ressources matérielles (outils, infrastructures) et immatérielles (connaissances, techniques, normes, règles), et n'est pas indépendant d'autres systèmes de ressources communes (système génétique, syndicats professionnels, dans le cas du marché du lait) et privées (du côté des acheteurs), avec lesquels existent des complémentarités et des incompatibilités. Dans Dervillé et Allaire (2014b), nous avons proposé une analyse des régimes de concurrence autour de deux systèmes de ressources communes, l'un lié à l'innovation, l'autre à la réputation. Compte tenu de la diversité et de l'imbrication des ressources sous-tendant ces deux systèmes, nous préférons ici considérer plus de catégories : i) structure de production, ii) technique, iii) capacité d'innovation, iv) qualité (type et contrôle), v) information, vi) gestion des volumes, vii) encadrement des prix (tableau 13.1). Ensemble de dispositifs de coordination, un régime de concurrence renvoie à la constitution et à la gestion par des communautés d'acteurs de différents types de ressources communes articulées en système. En étendant le cadre d'analyse développé par Ostrom aux ressources immatérielles et à la propriété intangible (Frischmann, 2013 ; Allaire, 2013 ; Dervillé et Allaire, 2014b), il est proposé dans la section suivante de détailler l'articulation entre systèmes de ressources, communautés et processus de stabilisation des marchés en éclairant le lien entre statut des producteurs et conditions d'accès au marché.

4. Les commissions départementales d'orientation agricole (CDOA) sont des commissions paritaires départementales. Elles ont un rôle consultatif auprès du préfet, dans le cadre du projet agricole départemental, visant à déterminer les priorités d'orientation des productions et d'aménagement des structures d'exploitation au niveau départemental. Elles furent le lieu de discussion des conditions d'attribution des droits à produire et du transfert foncier.

5. La loi Godefroy de 1969 instaure le paiement du lait à la qualité. Le texte stipule que le lait doit être sain et rémunéré selon sa composition (matière grasse, matière protéique) et sa qualité bactériologique et sanitaire. Les laboratoires interprofessionnels, reconnus par les pouvoirs publics, réunissent des représentants des producteurs et des laiteries coopératives et privées et se chargent d'analyser les échantillons de lait. Ils constituent un maillon fondamental de la filière laitière. Initialement organisés à l'échelle départementale, ils seront progressivement mutualisés à l'échelle régionale, voire suprarégionale (bassin de collecte). Une organisation interprofessionnelle nationale (Cniel) a aussi été créée en 1974 autour de missions de représentation des trois familles adhérentes (fédérations des producteurs de lait, des coopératives et des industries laitières), de promotion des produits laitiers et de médiations des démarches interprofessionnelles. C'est dans ce cadre qu'un accord interprofessionnel national sur le prix du lait a été négocié de 1997 à 2008. 


\section{Régime de concurrence : un régime de droits de propriété intangible}

L'analyse institutionnelle des marchés s'accompagne d'un déplacement de l'objet d'analyse du bien à la transaction. L'échange marchand apparaît comme un «transfert légal de propriété » (Commons, 1934 :50), un transfert de droit sur la propriété future de certains objets ou plus largement le droit de réaliser certaines actions. Complémentaire à la propriété corporelle et incorporelle, la propriété intangible renvoie au contrôle matériel futur (Commons, 1925a). Le « droit de fixer les prix » n'est pas l'apanage du capital. Il correspond à un droit accordé à une communauté, à la vue de ses compétences spécifiques, de restreindre l'abondance pour maintenir les prix. La notion de droit de propriété intangible correspond à une « version institutionnelle » des notions de pouvoir de marché et de rente. Dans le cas des échanges de lait par exemple, les droits de propriété intangible résultent de la répartition entre producteurs et transformateurs de la valeur générée par la vente de produits laitiers aux consommateurs. Ils résultent aussi des soutiens versés par les contribuables au secteur, dans le cadre de la politique laitière. Le double processus d'identification et de marchandisation apparaît alors comme un processus institutionnel d'élaboration et d'attribution de droits de propriété de nature différente (physique, incorporelle, intangible).

La notion de propriété intangible vient enrichir l'analyse des quatre institutions clés du marché proposées par N. Fligstein : i) les conceptions de contrôle participent à l'élaboration de droits de propriété intangible en légitimant les façons d'entreprendre ; ii) les structures de gouvernance apparaissent comme des dispositifs de coordination qui encadrent l'action collective de contrôle de la propriété intangible sur des marchés particuliers ; iii) les règles de l'échange confortent les structures de gouvernance et les conceptions de contrôle, et autorisent leur établissement. La notion de droits de propriété intangible permet d'expliciter et de synthétiser le rôle de l'action collective sur les marchés.

Les stratégies d'innovation, les modèles d'entreprises, les structures de gouvernance ou, plus largement, les institutions des marchés peuvent être analysés comme des communs, au sens d'Ostrom. Ostrom définit la notion de régime de droits de propriété pour rendre compte de l'articulation de règles qui définissent les actions que les individus peuvent entreprendre en relation avec d'autres individus dans un domaine (Schlager et Ostrom, 1992). En distinguant différents types de droits et différents statuts de membres d'une communauté, Ostrom met en évidence que le propriétaire au sens classique du terme (qui a le droit de transfert des droits de propriété) n'est pas le seul à avoir intérêt à investir dans le bien commun. Tous les membres qui participent à l'élaboration de règles, dans la mesure où ils ont une capacité de contrôle sur la préservation de la ressource et le niveau de prélèvement à court et à moyen termes, ont intérêt à investir dans le bien commun.

La notion de régime de droits de propriété est étendue ici à la propriété intangible. Nous nous concentrons sur la distinction de deux statuts : i) les usagers autorisés jouissant de droits opérationnels d'accès ou d'usage de la ressource (compétences ou solutions techniques ou organisationnelles pour résoudre un problème productif, droit d'accès à un marché et à la rente associée) ; ii) les membres autorisés à 
participer à la définition des règles opérationnelles d'usage ou des règles d'exclusion. Il est souvent impossible d'identifier un propriétaire au sens strict (ayant un droit d'aliénation du système de ressources et du droit d'exclusion) dans la mesure où la stabilité du régime repose sur un compromis social. Le régime de droit de propriété intangible peut toutefois entrer en crise suite à une rupture technique ou politique modifiant les rapports de force. Le statut des producteurs, associé à un ensemble de droits et de devoirs, résulte de leur place dans le système hiérarchisé de règles assurant la gouvernance du système de ressources communes.

Dans cette perspective, trois hypothèses sont formulées. Premièrement, les conditions d'accès au marché des exploitations laitières sont liées à la coopération dans la mise en commun ou l'activation de ressources communes, notamment intangibles. Deuxièmement, compte tenu du rôle des communautés sectorielles et territoriales dans les processus de stabilisation des marchés, les conditions d'accès au marché ont une dimension institutionnelle territorialisée et varient dans l'espace. Enfin, du fait de l'interdépendance entre les institutions de marché, la libéralisation et l'évolution des règles de l'échange déstabilisent les ressources communes intangibles, et les capacités de réponse (d'adaptation et de restructuration) sont spatialement différenciées.

\section{Différentiation des ressources communes et diversité des conditions d'accès au marché}

Trois cas d'étude ont été choisis, à partir d'un travail statistique et d'enquêtes réalisées à l'échelle nationale, pour leurs positionnements contrastés au regard du rôle joué par les filières de qualité spécifiques dans la structuration du secteur : pas d'appellation d'origine protégée (AOP) en Haute-Loire (cas type 1), valorisation de $60 \%$ et de $100 \%$ du lait en AOP dans le Cantal (cas type 2) et le Doubs (cas type 3) respectivement. Ils ont été instruits à partir d'un travail d'enquêtes (analyse des stratégies individuelles et collectives et du fonctionnement des organisations), d'une analyse de la structure de marché (mobilisation de bases de données permettant de caractériser tant le milieu que les structures amont et aval de la production) et d'une analyse de la littérature. Le département, échelle de mise en œuvre de la politique structurelle française (gestion du foncier, des installations et des quotas laitiers) au cour du processus d'institutionnalisation des marchés agricoles, a été choisi comme échelle d'analyse. Les trajectoires de développement et les ressources communes activées sont étudiées depuis les années 1960, et le régime de propriété intangible sous régime quota est caractérisé. Enfin, les pressions exercées par la libéralisation et les transformations du régime de concurrence sont explicitées.

\section{Ressources communes et conditions d'accès au marché sous quotas}

Les trois cas d'étude se distinguent par leur trajectoire de développement laitier plus ou moins façonnée par la modernisation agricole, c'est-à-dire les ressources génériques développées par le secteur. Alors que la montagne du Doubs et les 
zones d'altitude du Cantal se caractérisent par une tradition fromagère ancienne, ce n'est pas le cas de la Haute-Loire, et du sud et de l'est du Cantal. La modernisation agricole s'est traduite par une entrée en crise plus ou moins précoce et profonde des modèles traditionnels de polyculture-élevage. Le développement de la production laitière est apparu comme un levier permettant à de petites structures de perdurer par une intensification de la production. Il repose sur l'adoption partielle, dans la limite des contraintes naturelles et des apprentissages, de la technologie modernisatrice : race laitière spécialisée, culture et ensilage d'herbe et de maïs fourrage, modernisation des bâtiments. La collecte de lait standard et la transformation en produits laitiers ont été confiées à des industries de statut privé ou coopératif. Dans le Cantal, les professionnels ont fait le choix de développer une filière de lait standard et d'étendre le processus d'industrialisation aux filières AOP, le lait étant valorisé indifféremment dans une filière ou l'autre. La massification de la production autour de sites multiproduits et l'assouplissement des cahiers des charges AOP ont conduit à l'industrialisation partielle des processus de fabrication et d'affinage des fromages AOP (ensilage autorisé, pasteurisation autorisée, réduction des temps de maturation et création du Cantal jeune de moins de 60 jours d'affinage pour réduire les coûts et positionner le Cantal sur le marché des fromages ingrédients, à l'époque très porteur, mais concurrentiel). Ainsi, dans le Cantal et en Haute-Loire, le développement laitier s'appuie sur l'activation de ressources matérielles et immatérielles génériques au détriment, pour le Cantal, des ressources techniques et institutionnelles spécifiques liées à la fabrication fromagère à partir de lait à l'herbe.

Dans le Doubs au contraire, les communautés professionnelles s'appuient sur la spécialisation fromagère ancienne et favorisent le développement des ressources locales : la capacité d'innovation est distribuée et territorialisée, et la réputation des produits croît avec le temps et bénéficie à l'ensemble des opérateurs de la filière. Les exploitations du Doubs ont fait le choix de se moderniser en valorisant des ressources spécifiques locales : i) race locale Montbéliarde préférée à la Holstein, ii) refus de la pratique de l'ensilage, iii) travail du lait cru, iv) refus de la spécialisation à l'extrême en conservant le contrôle des fromageries. La fabrication et l'affinage des fromages sont le fait de petites structures de production (fruitières et maisons d'affinage) qui ont pu se moderniser grâce à un programme de recherche et d'innovation spécifique. Le Comité interprofessionnel du gruyère de Comté (CIGC) créé en 1963 a renforcé les compétences et le pouvoir de marché des acteurs locaux. Le cahier des charges a été régulièrement révisé pour maintenir la spécificité du système de production sous appellation et la réputation des fromages. Les acteurs de la filière se sont en outre dotés de dispositifs de coordination territoriaux légitimes et efficaces allant au-delà des règles techniques inscrites dans le cahier des charges. Des dispositifs de maîtrise des volumes (plan de campagne) et de suivi des marchés ont été élaborés. Ils participent à l'organisation de la production, à la création et à la répartition des droits de propriété intangible, et donc à la distribution de la valeur découlant de la valorisation du Comté. Enfin, les structures de gouvernance sectorielles (syndicat, CDOA) ont été mises au service des filières AOP : les installations sont raisonnées et les droits à produire distribués en fonction des besoins des fruitières et des filières ; les représentants syndicaux défendent le modèle fromager lors des échanges avec la profession et les acteurs publics. 


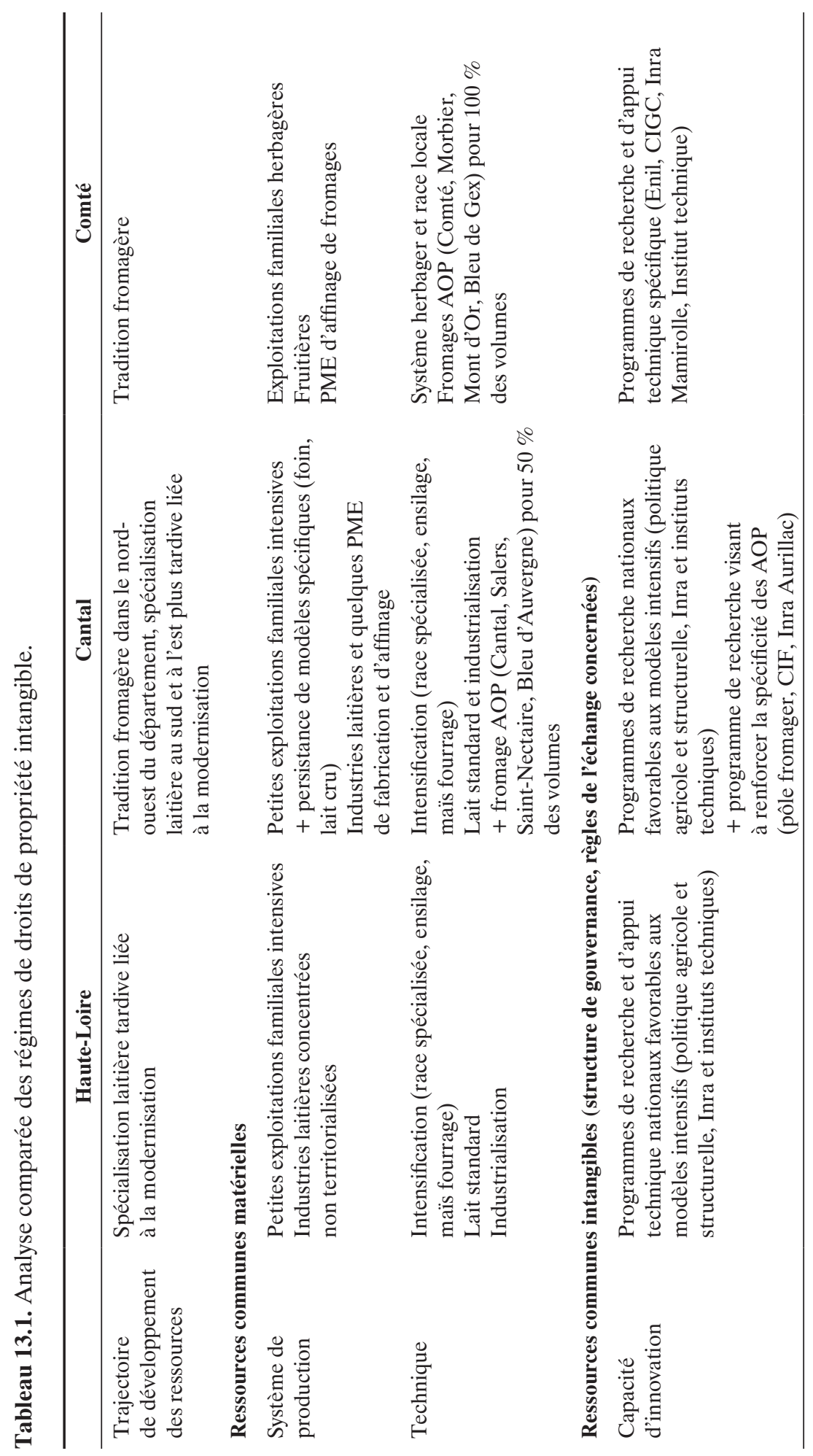




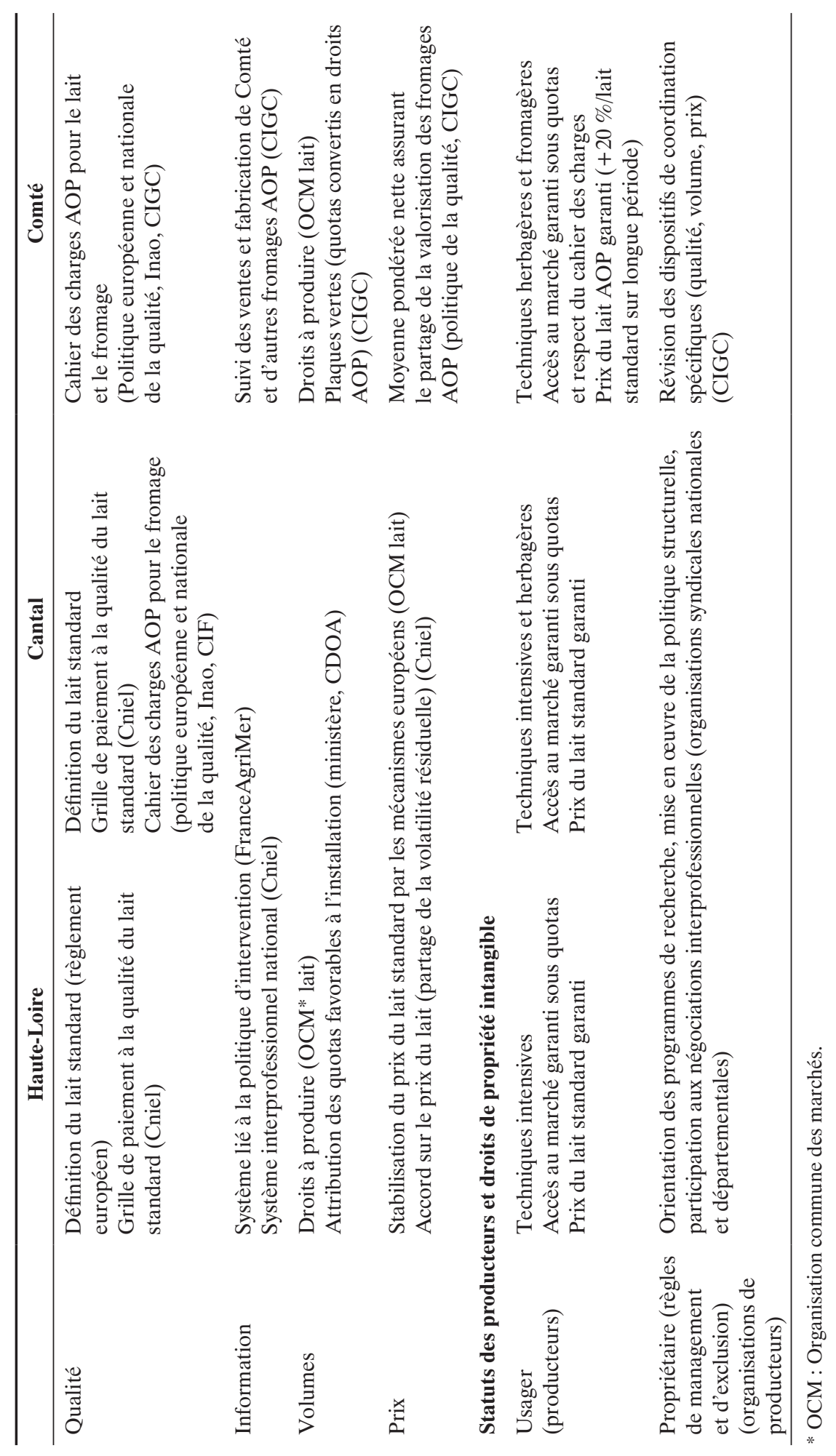


En Haute-Loire et dans le Cantal, la capacité d'innovation des acteurs départementaux repose sur une capacité d'adoption de savoirs agronomiques et industriels génériques. Ce sont les efforts publics et professionnels nationaux qui ont permis de développer cette capacité d'innovation sectorielle et une identité collective liée à une qualité standard du lait et des produits laitiers, à laquelle le rationnement de l'offre et les outils de protection aux frontières permettaient de garantir une valeur minimale. Les principales structures de gouvernance sont professionnelles (syndicat majoritaire, commissions paritaires et interprofession) et gèrent des ressources génériques (droits à produire, grille standard de paiement du lait à la qualité). L'ancrage territorial tient au choix public de lier les quotas au foncier. Compte tenu du rôle majeur joué par l'État à différentes échelles dans la gestion de ce système de ressources, les droits de propriété intangible associés peuvent être considérés comme des droits sociaux. La dimension communautaire tient au fait que le département soit une échelle d'action et de concertation avec la profession pour la politique structurelle agricole depuis les années 1960 et correspond à l'appropriation par les acteurs sectoriels départementaux de ces dispositifs publics. En Haute-Loire et dans le Cantal, la profession a fait le choix d'une répartition égalitaire des droits à produire : l'installation est privilégiée et les gros livreurs sont contraints. La HauteLoire est, avec le Cantal, un des départements de France où les plus petites structures de production sont les plus nombreuses, un certain nombre étant à la limite de la viabilité (Baud, 1999).

Dans le Cantal, des ressources spécifiques existent (savoir-faire herbager et fromager, cahier des charges de l'appellation), mais les conditions d'accès au marché des producteurs n'en dépendent pas. En l'absence de conditions portant sur la fabrication du lait dans les cahiers des charges AOP jusqu'en 2007, les producteurs n'avaient aucune idée du devenir de leur lait. Sans devoir envers l'appellation, ils ne bénéficiaient, à l'exception des producteurs fermiers, d'aucun droit sur les ressources communes de l'appellation. Réputation et rente de qualité éventuelle sont appropriées par l'aval. En effet, les opérateurs de la filière et l'interprofession du Cantal (CIF) ne sont pas parvenus à protéger la spécificité et l'identité de l'appellation. Le cahier des charges a été assoupli pour permettre une hybridation entre ressources territoriales spécifiques et ressources sectorielles génériques. La structure de gouvernance manque de cohérence du fait de la diversité des collectifs d'acteurs et des intérêts. Les dispositifs de coordination sectoriels (syndicat, chambre d'agriculture, CDOA, laboratoire interprofessionnel) coexistent avec et dominent les dispositifs de coordination territoriaux liés aux appellations (interprofession, syndicats de produit, pôle technologique fromager). Ainsi, si le système de ressources communes du département est hybride, les conditions d'accès des éleveurs aux marchés reposent, comme en Haute-Loire, sur des dispositifs de coordination sectoriels nationaux. Le régime de droits de propriété intangible est « laitier » (au sens générique et sectoriel).

Dans le Doubs par contre, l'intérêt commun autour de la production de Comté de qualité (identité commune) et la cohérence de la structure de gouvernance a permis la différenciation du régime de concurrence. La principale échelle d'élaboration des modalités de contrôle de la concurrence est régionale, elle est liée à l'aire d'appellation. La territorialisation de la production est assurée par la différenciation des ressources productives et des marchés. Ainsi, tous les opérateurs de la filière 
participent à la construction et à la gestion d'un système de ressources communes intangibles territorialisées. Les conditions d'accès au marché des éleveurs tiennent à leur capacité individuelle à se conformer au cahier des charges, ainsi qu'à leur capacité collective à participer au pilotage des filières AOP (évolution du cahier des charges, orientation des programmes de recherche) et à négocier une part de la valeur ajoutée créée. À la différence des producteurs des deux autres cas type, ils ont bénéficié sur une longue période d'un prix du lait supérieur de $20 \%$ à la moyenne nationale, suggérant une différenciation effective des marchés.

\section{Crise laitière, une crise du régime de concurrence}

Le régime de concurrence laitier expose les producteurs à la libéralisation des marchés. Sous régime quota, les producteurs exerçaient un contrôle collectif sur les conditions d'accès au marché, en s'appuyant sur les règles d'échange en vigueur, via leur syndicat majoritaire dans le cadre de la cogestion (volume) et de leur interprofession (qualité et prix). Ils doivent dorénavant négocier des contrats avec des entreprises aval très concentrées et internationalisées pour assurer la mise en marché du lait, et ce dans un marché générique de commodités de plus en plus étendu et instable. La situation est particulièrement problématique en montagne du fait de coûts de production et de collecte élevés.

En Haute-Loire, deux des principaux acteurs de la collecte du département (40\% de la collecte) n'ont pas résisté à la baisse du prix d'intervention et ont fait faillite en 2009. Le droit d'accès au marché de certains producteurs a ainsi été remis en question. Dans le Cantal, la situation a également été critique pour le premier opérateur de la transformation (80\% du volume sous appellation). Dans les deux départements, c'est aujourd'hui la première coopérative française (Sodiaal) qui assure un débouché à la majorité des producteurs restant. Toutefois, cette entreprise est fragilisée par des coûts de collecte élevés (collecteur en dernier recours) et par la dégradation des cours mondiaux, et offre un des prix du lait les plus bas de l'hexagone. Pour les producteurs livrant à des entreprises privées, la possibilité offerte par le règlement européen («Paquet lait» de 2012) de se regrouper en organisations de producteurs (OP) apparaît comme un levier pour activer de nouvelles ressources communes. Toutefois, le transfert des négociations économiques aux OP fragilise le pouvoir de la profession agricole et le levier d'action syndicale, alors même que leur morcellement et la faible représentativité des OP ne leur confèrent pas de pouvoir de marché (Trouvé et al., 2016). Le régime de concurrence laitier en montagne est en crise. Les organisations de producteurs n'ont pas de pouvoir de marché ; l'interprofession est en panne ; la concurrence sur les prix se renforce et la volatilité des prix internationaux se diffuse, mettant à mal les capacités d'investissement et interrogeant le devenir de la production. Le principe supérieur de la stabilité des marchés fait lui-même débat. Certains acteurs, la Commission européenne notamment, préfèrent déplacer la question de la stabilisation des marchés vers celle de la stabilisation des revenus, via des mécanismes d'aides publiques ou privés de type assurantiel.

Les producteurs de montagne ont progressivement pris la mesure de leur inadaptation à l'accroissement de la concurrence consécutive à la libéralisation des marchés 
et tentent d'initier et/ou de se réapproprier des stratégies de différenciation. Dans le Cantal, les opérateurs ont fait le choix de renforcer le cahier des charges des appellations et d'assurer la coexistence (et non plus l'hybridation) des filières génériques et spécifiques. De nouvelles ressources communes ont été constituées (système d'information notamment) et les institutions sectorielles (chambre d'agriculture, contrôle laitier, laboratoire interprofessionnel, etc.) travaillent de concert avec les institutions fromagères territorialisées (CIF, pôle fromager, Inra d'Aurillac) pour accompagner les exploitations laitières dans la mise en conformité de leur système de production, conduisant à l'émergence d'une capacité d'innovation régionale. Cependant, le succès de ce tournant qualitatif n'est pas garanti du fait d'une difficulté à transmettre les hausses de prix vers l'aval. Pour les laits de montagne non AOP du Cantal et de la Haute-Loire, la segmentation montagne dans le cadre de la dénomination Montagne a été relancée en 2009 avec la création d'une marque collective Lait de nos montagnes. Néanmoins, le choix de ne pas s'appuyer sur un véritable cahier des charges limite les perspectives de segmentation de marché et de création de valeur. La stratégie d'adaptation reste marquée par la logique sectorielle et corporatiste de la communauté d'acteurs à l'origine des ressources productives communes, traduisant une certaine dépendance au sentier.

\section{Responsabilité des producteurs et stabilisation des conditions d'accès au marché}

Dans le Doubs, les producteurs ne s'étaient pas désengagés de la mise en marché des produits. Participant activement à la gestion des ressources communes intangibles sous-tendant la stabilité de marchés spécifiques, ils ont contribué par leur adaptation à l'évolution des règles de l'échange pour préserver leurs conditions d'accès au marché. Les droits de produire du Comté ont notamment été dissociés des quotas et adossés à la surface agricole, et le plan de campagne a été reconnu comme programme AOP de gestion de l'offre par l'Union européenne pour la période 2015-2018. Le prix du lait, lié au niveau de valorisation du Comté, est resté stable et supérieur au prix du lait standard, sans subir les effondrements de prix de 20082009, 2013 et 2015. Ce constat suggère que la participation à l'élaboration des règles collectives de management et d'exclusion (liée à un droit intangible de propriétaire des ressources communes) favorise la préservation des conditions d'accès au marché des producteurs. Une organisation collective régionale efficace se substitue partiellement à l'intervention de l'État, favorise une différenciation effective des marchés et assure la stabilité du segment de marché ainsi créé. Toutefois, il faut noter que ce succès concerne un territoire et une communauté d'acteurs limités.

Les avancées en matière d'accès au marché obtenues par les producteurs AOP du Cantal plaident aussi en ce sens. Le renforcement des contraintes de production initié en 2007 (extensification et autonomie alimentaire), ainsi que l'obligation de certification ont en effet conduit de façon concomitante à un changement de statut et à une amélioration des conditions d'accès au marché des producteurs de lait. Ils participent maintenant activement à la gouvernance du système de ressources communes des appellations (élaboration des règles de management et d'exclusion). En outre, sous la double action de la restructuration aval (la coopérative Sodiaal 
assure $80 \%$ de la mise en marché de l'AOP Cantal depuis 2014) et de la pression de l'Inao (Institut national de l'origine et de la qualité) pour une différenciation des prix du lait AOP, le processus d'identification et de différenciation du marché AOP devrait se consolider. Une formule de prix visant à rémunérer les producteurs coopérateurs sur la base du niveau de valorisation des produits (fromage et lactosérum) était en cours d'élaboration en 2014.

\section{"Conclusion}

De la comparaison dans le temps et dans des contextes institutionnels territoriaux contrastés des régimes de concurrence, il ressort que les médiations communautaires (structures de gouvernance et conceptions de contrôle) sont complémentaires du système légal dans l'encadrement des échanges marchands et l'établissement d'un régime de droits de propriété intangible. Dans un premier régime, la protection aux frontières, l'intervention et le stockage privé et public, et les aides à l'écoulement des produits s'appuient sur la définition d'une qualité standard et permettent de maintenir un niveau de prix minimum et d'en limiter la volatilité. Cette stabilité des prix favorise les anticipations des acteurs. Mais les conventions de qualité et d'effort (conceptions de contrôle), en orientant le système productif, la qualification des produits et l'encadrement des relations marchandes, y contribuent également. Le fonctionnement du secteur laitier est illustratif d'un processus de stabilisation s'appuyant sur une combinaison cohérente de dispositifs publics et communautaires. Le système des quotas et les dispositifs interprofessionnels de paiement du lait à la qualité donnaient aux producteurs une capacité forte de négociation. Les organisations professionnelles agricoles exerçaient ainsi un contrôle collectif à plusieurs échelles. Les acteurs locaux disposaient de marges de manœuvre dans la mise en œuvre des droits sociaux issus de la PAC.

Dans le cadre de règles de l'échange sectorielles identiques, la diversité des conditions d'accès au marché des producteurs de lait rend compte de la capacité variable des acteurs locaux à coopérer dans la création de ressources spécifiques ou l'appropriation des ressources génériques. La place des ressources territoriales et des acteurs locaux (des producteurs de lait notamment) dans la gouvernance du système de ressources professionnelles et interprofessionnelles est constitutive de la différenciation spatiale des régimes de concurrence.

L'évolution des règles de l'échange et le désengagement de l'État de la régulation des marchés génèrent une crise des ressources communes intangibles génériques particulièrement marquée en montagne, les systèmes laitiers n'étant pas en mesure de mener la compétition en termes de coûts de production avec les exploitations du Nord de l'Europe se lançant à la conquête des marchés mondiaux.

La prise en compte des ressources communautaires permet de penser la libéralisation des marchés de façon élargie, sans se limiter à la question de l'élimination des producteurs non compétitifs sous un angle individuel. De fait, la libéralisation (et la modification des règles de l'échange) ne modifie pas uniquement les conditions individuelles d'accès au marché des producteurs. Elle exerce aussi une pression sur 
les ressources communes et les communautés sectorielles et territoriales qui en exercent le contrôle : modèles d'entreprises, normes de production et structures de gouvernance se recomposent ou entrent en crise. Les dispositifs choisis par l'acteur public à ce jour, privilégiant la stabilisation individuelle des revenus, via l'indemnité compensatrice des handicaps naturels, en montagne notamment, ne favorisent pas la coopération dans l'élaboration de solutions collectives. Ils sont peu adaptés au soutien d'initiatives de différenciation des marchés. Or, comme l'ont montré différents travaux (Chatellier et al., 2006 ; Ricard et Rieutort, 1995), le développement d'une stratégie globale de filière est nécessaire au maintien de la production laitière dans les régions de montagne. La politique agricole gagnerait à s'appuyer sur des dispositifs d'aides qui favoriseraient la responsabilisation collective et la recherche de solutions coopératives favorables au rétablissement d'un pouvoir de marché des producteurs. Dans le cas particulier des filières laitières de montagne, du fait d'une faible compétitivité coût, la coopération dans la différenciation des marchés, par la construction d'une offre spécifique de produits et de services adaptés aux marchés et aux injonctions des pouvoirs publics, apparaît comme un enjeu pour sortir de la concurrence frontale sur les coûts de production. L'analyse en termes de régimes de droits de propriété intangible apparaît comme un outil intéressant pour accompagner les acteurs publics et privés dans l'élaboration d'un nouveau cadre pour les échanges de lait, de produits laitiers et de services en montagne, en veillant à ce que les producteurs participent (règles de management et d'exclusion) à la gestion des filières (qualité et volume) et restent des participants effectifs des marchés après les quotas. 


\section{Chapitre 14 \\ Les organisations agricoles \\ dans la Russie de Vladimir Poutine : \\ une lecture commonsienne}

P. Grouiez

Le kolkhoze - comme le sovkhoze - n'est plus. Les pays post-soviétiques ont tourné la page du socialisme. Des formes capitalistes d'entreprise ont vu le jour dans l'agriculture et l'agro-industrie. Mais ces formes nouvelles de firme ont émergé à l'issue d'un processus transitionnel de vingt ans durant lequel deux questions majeures ont guidé l'action des acteurs publics et privés : la première porte sur la sécurisation de l'approvisionnement en intrants dans l'industrie agroalimentaire et en produits alimentaires pour la population; la seconde renvoie à la reconnaissance d'un droit des populations rurales sur une partie de la rente foncière. Les transformations dans l'agro-industrie russe découlent d'une articulation entre les intérêts :

- des entrepreneurs privés, pour qui l'objectif principal est de réaliser des gains de productivité dans une agriculture très largement sous-capitalisée ;

- des hommes politiques, pour qui la sécurité alimentaire et le développement des territoires sont des enjeux électoraux tant au niveau local que vis-à-vis du Kremlin ; - d'une population rurale qui a vu ses conditions de vie se dégrader depuis la fin du régime soviétique.

Pour rendre compte des conflits et des compromis qui sont nés de la confrontation de ces trois acteurs, nous mobilisons l'approche institutionnaliste de J.R. Commons (1934) sous l'angle des going concerns et de la façon dont les règles opérantes (working rules) qu'ils produisent sont encastrées dans un contexte institutionnel plus large nécessitant de hiérarchiser les rôles de chacune des parties dans la définition des règles qui structurent leurs actions. Pour rendre compte du contexte institutionnel, nous nous appuyons sur l'approche institutionnaliste en termes de path dependence et de path shaping qui combine les facteurs liés à l'héritage et ceux liés à l'introduction de la nouveauté, décrivant le cheminement contraint par les résultats existants des choix passés. Les forces sociales peuvent intervenir sur les circonstances actuelles et les réarticuler activement de manière à rendre possible des trajectoires nouvelles (Federowicz, 2000 ; Nielsen et al., 1995). Si l'incertitude qui découle de la recomposition d'un système économique peut favoriser la reproduction de comportements anciens par les individus et les organisations, elle est susceptible de déclencher - chez des agents « institués » et associés dans des groupements plus ou moins lâches - des actions délibérées mues par les anticipations de l'ordre émergent. 
De fait, cette approche est compatible avec la dialectique entre transactions routinières et transactions stratégiques qui a été mise en évidence dans les années 1930 par John R. Commons. Selon cet auteur, dans la résolution des problèmes courants, les individus adoptent un comportement habituel au sein de transactions routinières, régulées par les institutions existantes. Mais, dès lors que se pose un problème nouveau, les schémas de comportement ne sont plus donnés : les individus sont alors engagés dans des transactions stratégiques dans le sens où ils développent des comportements inédits qui peuvent déboucher sur la construction de nouvelles routines. Pour que les nouvelles pratiques trouvées au niveau individuel (local) deviennent des institutions régulant les organisations et la société, elles doivent être sélectionnées. Dans le capitalisme, cette sélection s'effectue à travers la négociation collective (au niveau de la société) et le choix par des décideurs (au niveau de l'organisation). Lorsqu'un compromis est trouvé, les transactions stratégiques deviennent routinières. Les nouvelles institutions sont le résultat d'une synthèse entre les nouvelles situations produisant de nouveaux comportements et les anciennes institutions (Commons, 1934). Notre approche est donc une « approche institutionnaliste de l'économie instituée » (Gislain, 2010) au sens où l'économie y apparaît comme un « fait social ». Les actions individuelles sont l'expression des institutions économiques et les individus sont placés à chaque instant dans des relations hiérarchisées avec le reste de la société en tant que groupement d'individus actifs (les going concerns). Ainsi, les institutions fournissent des règles de conduite mais ces règles sont en constante évolution du fait des actions individuelles et collectives. Par ailleurs, les institutions sont le résultat de conflits d'acteurs liés à la rareté des ressources et du fait que, pour agir, l'individu a besoin de conceptualiser les effets concrets futurs de ses actes présents (notion de «futurité »), ce qui suppose l'existence de règles. Sur cette base conceptuelle, Commons a construit une définition de « l'économie capitaliste instituée » autour de trois transactions qui assurent la reconnaissance des principes de propriété, d'efficacité productive et de légitimité du partage.

L'objet du chapitre est de faire la lumière sur les relations interindividuelles (les transactions principalement stratégiques) ayant eu lieu entre les trois principaux acteurs du changement institutionnel identifiés plus haut. Elles devraient nous permettre de décrire les règles opérantes (et les sanctions qui y sont associées) sur lesquelles les acteurs du changement dans l'agro-industrie sont parvenus à s'entendre. In fine, ce sont les formes organisationnelles innovantes dans l'agro-industrie que nous devrions être en mesure d'expliquer. Dans une première partie, nous rendrons compte de l'héritage institutionnel du secteur agro-industriel afin d'identifier les enjeux des négociations entre acteurs. Dans une deuxième partie, nous proposons une monographie d'une entreprise qualifiée d'agroholding, Eksima, en privilégiant l'identification des diverses transactions et des règles opérantes qui la caractérisent, et qui expliquent les raisons de l'émergence de l'agroholding en tant que forme d'organisation dans le secteur agro-industriel. Dans une troisième partie, nous proposerons une monographie de la multinationale Bonduelle-Russie, afin de comprendre comment certains entrepreneurs privés internationaux se sont adaptés au contexte russe. Enfin, nous discuterons de la portée de ces formes nouvelles d'organisation vis-à-vis de la grille d'analyse commonsienne, et notamment sur la pertinence - dans 
le cas russe - d'utiliser le concept de going concerns dont la soutenabilité repose sur un système juridique différent du système russe. L'interrogation portera sur la façon dont est garanti le respect de la règle en l'absence d'un système juridique sophistiqué en Russie, à l'opposé ce que pouvait être le système judiciaire américain sur lequel s'appuyait Commons.

\section{" L'héritage institutionnel russe}

La transformation des exploitations du début des années 2000 s'est appuyée sur un héritage institutionnel qui a affecté le rapport salarial ${ }^{1}$ émergeant au sein de l'agro-industrie. L'exploitation agricole collective reposait sur une forte division des tâches des employés affectés à des brigades de travail (groupes d'ouvriers et de cadres agricoles). Le modèle d'enseignement agricole soviétique était en conséquence fondé sur une forte spécialisation productive d'ouvriers et de cadres salariés d'exploitations (zootechniciens, agronomes, conducteurs d'engins agricoles, etc.). Ce système d'enseignement a perduré après la fin du système soviétique. Ainsi, les jeunes diplômés des instituts agraires ne sont aujourd'hui majoritairement pas formés à diriger une ferme. Il en résulte que l'exploitation organisée sur le modèle de la firme industrielle est en adéquation avec une population active agricole constituée d'ouvriers et de cadres à la recherche d'un emploi salarié2 2 Le deuxième héritage institutionnel porte sur l'implication des employés dans leur travail. Le désintéressement des kolkhoziens et des sovkhoziens pour le développement de l'exploitation tenait avant tout à ce qu'ils étaient très mal rémunérés. L'emploi était d'abord pensé comme un moyen de s'insérer dans une communauté et de bénéficier des avantages en nature offerts par l'organisation ${ }^{3}$. Ce désintéressement caractérise toujours le rapport au travail des employés agricoles russes.

Le dernier héritage est post-soviétique et porte sur la propriété de l'exploitation collective restructurée et des terres qu'elle exploite. De nombreux articles ont mis l'accent sur le fait que, au début de la période de transition (dans le milieu des années 1990), la propriété des exploitations agricoles a été transférée à un groupe restreint d'individus (ex-directeurs d'exploitations collectives, cadres supérieurs). Ces derniers se seraient appropriés dans le même temps les terres agricoles attachées aux exploitations. Or, le lien établi dans la littérature entre appropriation de

1. «On appellera forme du rapport salarial l'ensemble des conditions juridiques et institutionnelles qui régissent l'usage du travail salarié ainsi que la reproduction de l'existence des travailleurs [...]. De façon plus analytique, il est commode de décomposer le rapport salarial en cinq de ses composantes : l'organisation du procès de travail, la hiérarchie des qualifications, la mobilité des travailleurs (dans et hors de l'entreprise), le principe de formation du salaire, direct et indirect, l'utilisation du revenu salarial. » (Boyer, 1986).

2. Les emplois décrochés à l'issue d'une formation agricole sont fortement spécialisés, comme en témoignent les propositions d'emploi sur le site internet de l'université agraire d'Orel en 2014 : agronome, zootechnicien, vétérinaire, tractoriste, technicien de trayeuses, vachers, électro-soudeur, éleveur de veaux, électricien d'atelier, etc.

3. Ces avantages permettaient notamment d'approvisionner les lopins individuels en intrants agricoles, ce qui faisait vivre la population rurale (Maurel, 1980). 
l'exploitation et appropriation foncière est en partie erroné ${ }^{4}$. En effet, les réformes agraires du milieu des années 1990 ont surtout provoqué le transfert de la propriété foncière de l'État, d'une part vers les collectivités territoriales, d'autre part vers les collectifs de travailleurs des exploitations. Or, les titres de propriété accordés aux collectivités territoriales et aux anciens travailleurs des exploitations collectives n'ont pas été remis en cause au moment de l'appropriation des titres de propriété des exploitations agricoles par les ex-directeurs d'exploitations collectives. Dans certaines régions - dont celles d'Orel ${ }^{5}$-, les entrepreneurs privés ont en conséquence à composer avec des collectifs de propriétaires et les autorités locales pour accéder au foncier agricole, et non pas uniquement avec des ex-directeurs ou d'anciens cadres supérieurs d'exploitations collectives restructurées.

\section{H L'agroholding : une innovation organisationnelle complexe}

Au début des années 2000, les exploitations collectives restructurées et appropriées par d'ex-directeurs de kolkhozes et de sovkhozes se trouvaient dans des situations économiques délicates. Leur niveau d'endettement était important et leur lien avec le secteur agro-industriel était rompu puisque ce dernier avait privilégié l'importation comme source d'approvisionnement en produits agricoles. C'est dans ce contexte que l'agroholding va faire son apparition. L'agroholding est une innovation organisationnelle qui se caractérise par l'intégration d'exploitations agricoles dans une organisation comprenant des usines de transformation agroalimentaire, voire des infrastructures pour la commercialisation des produits (Visser et al., 2014 ; Voigt et Wolz, 2014). D'abord orientés dans des filières à retour sur investissement rapide (élevage de volaille notamment), les agroholdings occupent désormais un large spectre de la production agricole (Wandel, 2011). Ils sont présents dans les filières porcine, ovine, sucrière, céréalière et des légumineuses. Une des raisons principales de la constitution d'un agroholding est la volonté d'assurer la sécurisation de l'approvisionnement des usines de transformation agroalimentaire (Grouiez, 2010 ; Rylko et Jolly, 2005). Eksima-Agro est un agroholding dont le siège social est situé

\footnotetext{
4. La disparition des kolkhozes et des sovkhozes a donné lieu à un transfert des titres de propriété des entreprises ( $p a i i)$ et des titres de propriété foncière (dolya) aux anciens sovkhoziens et kolkhoziens. Une partie du foncier a également été transférée de l'État vers les collectivités territoriales. Alors que les titres de propriété des entreprises ont été frauduleusement appropriés par les directeurs des exploitations agricoles durant la phase de transition, les titres de propriété foncière sont restés entre les mains des travailleurs agricoles - que nous dénommerons dans ce chapitre des «propriétaires en collectif »-ou des collectivités territoriales. La confusion entre «paï » et «dolya » conduit à considérer que les employés ont perdu tout pouvoir sur l'exploitation. Pourtant, bien que la situation dépende du contexte politique et économique local, il existe de nombreux exemples de maintien de la propriété foncière en collectif des travailleurs des exploitations agricoles. Autrement dit, les travailleurs des exploitations ont perdu le pouvoir sur la société (SA, SARL, etc.) mais pas sur une partie du foncier agricole exploité par la société. 5. La région d'Orel, située à $450 \mathrm{~km}$ au sud-ouest de Moscou, est une région qui bénéficie pour partie de conditions géologiques favorables à l'agriculture (début des terres noires). Elle se caractérise également par l'engagement de son principal dirigeant durant toute la période de transition (E. Stroev) dans le secteur agricole. Nous y avons mené plus de 70 entretiens entre 2004 et 2009 auprès d'exploitants agricoles, de directeurs d'agroholdings, d'habitants et d'hommes politiques. Ces entretiens constituent la principale source de données sur laquelle nous nous appuyons ici.
} 
à Moscou et qui possède des usines de production de charcuterie, un abattoir ainsi qu'une usine de conditionnement de viande. Le groupe Eksima a fait l'acquisition entre 2006 et 2009 de quatre exploitations agricoles dans la région d'Orel (43000 ha et 203 salariés). Nous nous appuyons sur la monographie de cette firme pour rendre compte des caractéristiques de l'agroholding.

Ce modèle organisationnel constitue, en apparence, un retour vers une organisation de la production alimentaire de type soviétique. L'agriculture était alors placée sous le contrôle du secteur industriel, provoquant un effet ciseaux ${ }^{6}$ dont la conséquence était le déficit structurel des exploitations collectives (Ioffe et Nefedova, 2001). Or, ce déficit a conduit - lors de la transition vers l'économie de marché - une partie des collectivités territoriales ${ }^{7}$ à s'impliquer dans le processus de restructuration des exploitations. Certaines administrations régionales ont en effet décidé de soutenir les exploitations déficitaires, principalement en leur donnant un statut d'entreprises publiques (Davydova et Franks, 2006). Après la crise financière de 1998, les administrations qui s'étaient le plus engagées dans le sauvetage des grandes fermes ont vu dans l'agroholding une opportunité de transférer au secteur privé le coût de leur politique agricole.

Toutefois, les exigences économiques des entrepreneurs privés ne peuvent être compatibles avec une logique de soutien d'exploitations agricoles déficitaires sans modification réelle de leur organisation interne et externe. Compte tenu de l'héritage soviétique et des politiques agricoles régionales menées jusqu'à la fin des années 1990, les entrepreneurs privés se sont trouvés dans l'obligation de négocier les conditions d'une reprise des exploitations agricoles à la fois à l'intérieur de l'exploitation (avec les salariés) et à l'extérieur (avec les propriétaires fonciers et les autorités locales).

Le concept de «transactions $»^{8}$ proposé par Commons permet de caractériser d'un point de vue dynamique la nature et les objectifs des accords passés entre les

6. L'effet ciseaux est la différence entre le prix de vente des produits alimentaires et le coût d'achat des machines et des engrais nécessaires à la production agricole. Comme les prix étaient principalement administrés durant la période soviétique et la production agricole dictée par le Plan, l'écart entre ces deux prix générait un endettement inéluctable des exploitations agricoles qui nécessitait une intervention périodique des pouvoirs publics. Cette intervention prenait le plus souvent la forme d'un effacement des dettes des exploitations agricoles.

7. Il convient de distinguer deux types de politiques agricoles régionales en Russie. Une partie des administrations territoriales ont choisi de soutenir les exploitations agricoles dès le milieu des années 1990, tandis qu'une autre partie des administrations ont choisi de ne pas intervenir dans le processus de transformation du secteur. La région d'Orel est à classer dans la première catégorie, celle de Krasnodar - lieu d'implantation de Bonduelle - se trouve dans la deuxième catégorie, mais sa situation géographique (dans le sud de la Russie européenne, à proximité de la mer Noire et au niveau des terres noires) lui donne un avantage comparatif dans l'agriculture.

8. La transaction est considérée chez Commons comme le lieu d'expression des conflits qui surviennent entre acteurs, et des négociations sur les règles à mettre en place pour réaliser une activité future. Ces règles permettent l'existence d'une action collective, au sens où les individus sont interdépendants, ce qui nécessite de coopérer. Les interactions permettent à chaque individu inséré dans un going concern de stabiliser ses anticipations vis-à-vis du futur. Les transactions sont des interactions entre des individus disposant de pouvoirs différents (d'action et de contrôle) et ne se limitent donc pas à des échanges purement économiques, mais intègrent la définition de droits de propriété. Commons propose une typologie en trois catégories de transactions qui spécifie les modes de négociation des règles de l'action collective. La transaction de marchandage est une interaction liée à l'échange de la richesse produite. Le transfert de propriété qui en découle se fait entre acteurs disposant de pouvoirs comparables. La transaction de direction est liée à l'organisation et au contrôle de la production et se fait entre des acteurs aux pouvoirs 
acteurs publics et privés, et de rendre compte des règles opérantes sur lesquelles les compromis s'appuient. D'un point de vue statique, rendre compte des transactions permet de dessiner les contours des going concerns, puisque ces derniers sont le résultat des transferts de droit de propriété, de création et de redistribution des richesses que les relations interindividuelles permettent.

Plusieurs transactions de nature stratégique ont permis à l'innovation organisationnelle et institutionnelle qu'est l'agroholding de voir le jour. Dans le cas d'Eksima, une première transaction de marchandage a permis de céder les parts sociales des exploitations détenues soit par les ex-directeurs des exploitations collectives (pour deux des quatre exploitations), soit par la région d'Orel à un investisseur privé, Nikolai Demin. Une fois propriétaire des fermes, la direction d'Eksima-Agro a eu à négocier avec les salariés de ces structures. La directrice régionale des exploitations intégrées dans Eksima, que nous avons interrogée en avril 2009, a souligné que la culture du pillage et l'absentéisme - issu du manque d'intérêt des salariés pour leur entreprise - sont autant de comportements qu'elle a eus à endiguer. La transaction de direction a porté sur la question de l'implication au travail. Une des conclusions de l'entretien est que la direction d'Eksima a conditionné la rémunération de la rente foncière, en partie détenue par ses salariés propriétaires du foncier agricole, à la productivité de leur travail au sein de l'agroholding. D'autres entretiens avec des directeurs d'exploitations agricoles ont confirmé cette politique salariale (Davydova et Franks, 2006 ; Grouiez, 2014). Ainsi, les dirigeants des agroholdings se sont appuyés sur l'héritage institutionnel - c'est-à-dire le transfert d'une partie de la propriété foncière aux travailleurs des anciennes exploitations collectives - pour influencer le rapport des salariés à leur travail. C'est ce qui explique le souhait de ces mêmes dirigeants de ne pas reconnaître la propriété foncière des retraités et des personnes qui ne sont pas des salariés de leur firme (Davydova et Franks, 2006).

Cette transaction de direction est elle-même liée à une transaction de répartition qui a permis, au niveau local, la reconnaissance des titres de propriété sur le foncier. Les groupes de propriétaires en collectif des terres agricoles, ainsi que les responsables politiques au niveau local (le gouverneur d'Orel notamment) ont plaidé auprès d'Eksima et d'autres investisseurs pour que ces derniers s'engagent à signer des contrats de location de terres auprès des collectifs de propriétaires et des administrations locales. Cette négociation obligea les directeurs d'agroholdings à admettre que les collectifs et les autorités locales étaient les véritables propriétaires des terres (Grouiez, 2013). Une transaction de direction s'est également jouée à un niveau supérieur. Elle a porté sur le transfert des outputs des exploitations agricoles vers les entreprises de transformation de l'agroholding. Lors d'un entretien avec la directrice régionale d'Eksima-Agro, celle-ci a reconnu que les prix des produits agricoles qu'elle vendait pour la totalité aux usines de transformation d'Eksima-Agro étaient fixés par la direction de l'agroholding.

Le gain qui découle de l'innovation organisationnelle pour les usines de transformation intégrées dans l'agroholding n'est pas pour autant obtenu sans contrepartie.

différents (dans le cadre d'un commandement). La transaction de répartition désigne des interactions entre des acteurs d'une organisation et une communauté aux pouvoirs juridiques supérieurs. Elle porte sur la distribution de la richesse créée. 
Dans le cas d'Eksima-Agro, le pouvoir économique sur lequel la direction s'est adossée pour conclure les transactions de marchandage, de direction et de répartition que nous venons de présenter provient en partie de crédits contractés dans des conditions favorables auprès des autorités moscovites. La transaction de répartition entre l'agroholding et les autorités de la ville de Moscou a porté sur le transfert d'une partie de la production de l'agroholding dans un circuit de distribution organisé par la capitale (hôpitaux, écoles publiques, etc.) à des prix administrés (Departament Prodovol'stvennyh resursov goroda Moscra, 2008). Cette politique de la ville de Moscou s'inscrit dans le cadre d'un plan visant à assurer sa sécurité alimentaire. L'autre contrepartie repose sur une transaction de répartition liée à la prise en charge d'une politique sociale par l'agroholding Eksima-Agro et destinée à la population rurale du raïon d'Orel. Plus de 2,1 millions d'euros ont ainsi été dépensés entre 2006 et 2009 par Eksima pour subventionner les écoles locales, moderniser les réseaux routiers et le réseau de distribution de $\mathrm{gaz}^{9}$.

\section{- L'adaptation des firmes multinationales au marché russe : le cas de Bonduelle}

L'insertion sur le marché agroalimentaire russe des firmes multinationales peut passer par des partenariats stratégiques avec des industriels. Par exemple, Danone a signé des accords avec la firme Unimilk qui lui ont permis de pénétrer le marché laitier et de faire l'acquisition de laiteries. La firme française Bonduelle a tenté une stratégie similaire en 1998. Spécialisée dans la mise en conserve de légumes, principalement du maïs doux et des petits pois, Bonduelle souhaitait augmenter ses marges sur les ventes en Russie en limitant les coûts liés à l'importation de conserves venues de ses propres usines de production en Slovaquie. Bonduelle a signé des contrats d'approvisionnement avec des exploitations agricoles de la région de Krasnodar. Mais ces accords se sont rapidement révélés inopérants, les entreprises ne suivant pas les recommandations de la firme française. Les terres sous contrats avec Bonduelle ne faisaient pas l'objet des mêmes soins que celles directement exploitées par les fermes. Ceci a conduit à des difficultés d'approvisionnement et à des produits dont la qualité ne correspondait pas au cahier des charges fixé par Bonduelle. Le directeur de Bonduelle-Russie, rencontré en mars 2009, voyait dans l'héritage soviétique les raisons de cet échec : des salariés peu consciencieux, une méfiance de la direction des fermes vis-à-vis de l'industriel et des salariés insuffisamment polyvalents. Bonduelle a pour ces raisons modifié sa stratégie en intégrant des exploitations agricoles et en louant des terres, ce qui contraste avec ses pratiques habituelles Au même moment, la firme a fait l'acquisition d'une conserverie.

\footnotetext{
9. Au niveau macroéconomique, nous avons pu constater que les agroholdings ont engagé une transaction de répartition avec le ministère de l'Agriculture pour fixer un niveau de taxes à l'importation particulièrement dissuasif pour la viande de volaille, de porc et de bœuf. L'engagement porte sur un investissement dans le secteur agricole de la part d'hommes d'affaires russes des secteurs des matières premières (pétrole, gaz, aluminium, etc.) en contrepartie de la mise en place de dispositifs sectoriels visant la protection du marché alimentaire russe face aux produits importés (Grouiez, 2010).
} 
Tableau 14.1. Résumé des transactions ayant permis l'émergence de deux nouveaux going concerns.

\begin{tabular}{|c|c|c|c|}
\hline $\begin{array}{c}\text { Transactions } \\
\text { (au niveau des } \\
\text { entreprises) }\end{array}$ & de marchandage & de direction & de répartition \\
\hline \multirow[t]{2}{*}{$\begin{array}{l}\text { Direction du } \\
\text { groupe Eksima } \\
\text { (agroholding) }\end{array}$} & $\begin{array}{l}\text { Avec les exploitations } \\
\text { restructurées, en } \\
\text { bénéficiant d'un } \\
\text { pouvoir économique } \\
\text { (liée à la transaction } \\
\text { de répartition } \mathrm{n}^{\circ} 2 \text { ) }\end{array}$ & $\begin{array}{l}\text { Avec les salariés } \\
\text { des exploitations : } \\
\text { obtention d'une } \\
\text { meilleure productivité } \\
\text { du travail. La création } \\
\text { de richesse passe par } \\
\text { un investissement en } \\
\text { services sociaux et une } \\
\text { rémunération de la } \\
\text { rente foncière issue } \\
\text { des transactions de } \\
\text { répartition } n^{\circ} 1 \text { et } n^{\circ} 2 \text {. }\end{array}$ & $\begin{array}{l}\text { Avec les propriétaires } \\
\text { en collectif des terres : } \\
\text { distribution d'une partie } \\
\text { de la richesse créée } \\
\text { par l'entreprise au } \\
\text { profit des habitants des } \\
\text { villages propriétaires du } \\
\text { foncier (transaction de } \\
\text { répartition } \mathrm{n}^{\circ} 1 \text { ). }\end{array}$ \\
\hline & & $\begin{array}{l}\text { Avec les quatre } \\
\text { exploitations intégrées : } \\
\text { fixation d'un prix } \\
\text { administré sur la } \\
\text { vente des produits } \\
\text { agricoles (output) } \\
\text { en contrepartie d'un } \\
\text { financement de services } \\
\text { sociaux ( } 2,1 \text { millions } \\
\text { d'euros dépensés } \\
\text { entre } 2006 \text { et } 2009 \text { ), } \\
\text { lié à la transaction de } \\
\text { répartition } n^{\circ} 1 \text {. }\end{array}$ & $\begin{array}{l}\text { Avec la ville de Moscou : } \\
\text { négociation pour le } \\
\text { transfert d'une partie de } \\
\text { la production dans un } \\
\text { réseau de distribution } \\
\text { géré par la ville à } \\
\text { des prix administrés. } \\
\text { La contrepartie est } \\
\text { l'obtention de crédits } \\
\text { pour financer des } \\
\text { investissements dans le } \\
\text { domaine économique } \\
\text { et social qui entrent } \\
\text { dans les pourparlers } \\
\text { des transactions de } \\
\text { marchandage et de } \\
\text { direction }(\operatorname{transaction~de~} \\
\text { répartition } n^{\circ} 2 \text { ). }\end{array}$ \\
\hline $\begin{array}{l}\text { Bonduelle } \\
\text { (firme } \\
\text { multinationale) }\end{array}$ & $\begin{array}{l}\text { Avec l'exploitation } \\
\text { collective } \\
\text { restructurée pour } \\
\text { l'emploi d'ouvriers } \\
\text { agricoles (une } \\
\text { brigade) et la location } \\
\text { de terre : transfert } \\
\text { de droit de propriété } \\
\text { sur du foncier et de } \\
\text { l'immobilier. }\end{array}$ & $\begin{array}{l}\text { Avec les salariés de la } \\
\text { nouvelle structure pour } \\
\text { l'amélioration de la } \\
\text { productivité du travail : } \\
\text { création de richesse } \\
\text { en contrepartie d'une } \\
\text { meilleure rémunération. }\end{array}$ & $\begin{array}{l}\text { Avec les autorités } \\
\text { régionales de Krasnodar } \\
\text { portant sur la protection } \\
\text { contre les logiques } \\
\text { de corruption de } \\
\text { différents organismes : } \\
\text { la transaction reflète } \\
\text { une négociation sur le } \\
\text { non-paiement de «taxes } \\
\text { informelles » et un choix } \\
\text { régional en matière } \\
\text { de redistribution de la } \\
\text { richesse créée. }\end{array}$ \\
\hline
\end{tabular}


Pour ce faire, Bonduelle a réalisé une première transaction de marchandage avec une exploitation agricole dans la région de Krasnodar. Elle a porté sur un contrat de location de terre de quinze ans, signé en 2004, pour 1500 ha. L'exploitation russe avait elle-même au préalable signé des baux avec chacun des propriétaires en collectif. Bonduelle s'est assurée de l'existence et de la conformité juridique des contrats individuels entre les propriétaires et la ferme ${ }^{10}$. L'enjeu était de garantir que la location du foncier se faisait avec l'accord des réels propriétaires - c'est-àdire le collectif des ex-kolkhoziens - et dans des conditions qui garantissent une rémunération convenable du foncier. En 2014, Bonduelle louait 10000 ha et réalisait $8 \%$ de son chiffre d'affaires en Russie (Les Échos, 5 septembre 2013 et 8 août 2014). Le groupe français a ensuite embauché certains des ouvriers de la ferme, qu'il a formés (en faisant intervenir des agronomes français). Une transaction de direction a eu lieu afin de garantir un meilleur engagement dans le travail. Les salaires chez Bonduelle sont d'environ 350 euros/mois (14 000 roubles) pour un simple ouvrier et jusqu'à trois fois plus pour un cadre. La rémunération proposée limite les risques de désengagement dans le travail. Enfin, des investissements pour un montant d'environ 23 millions d'euros sur dix ans ont permis la modernisation du site d'exploitation ${ }^{11}$. Une dernière transaction, de répartition a eu lieu et se réitère régulièrement entre la firme, un certain nombre d'intermédiaires et les autorités régionales. Par exemple, au moment de l'ouverture du site d'exploitation agricole en 2004, Bonduelle a dû plaider sa cause auprès de l'autorité régionale de Krasnodar dans un différend avec les pompiers locaux. Ces derniers exigeaient de l'entreprise française un nouveau camion en l'échange de l'autorisation d'ouverture et de la validation du respect des normes incendie. Une négociation a eu lieu pour éviter à Bonduelle de devoir entrer dans une logique de corruption - endémique dans les institutions russes mais non étudiée ici - qui est passée par le fait que l'autorité régionale a reconnu l'implication de Bonduelle dans le développement économique de son territoire, la protégeant ainsi de la nécessité de payer des pots-de-vin.

De la même manière que pour Eksima-Agro, l'émergence de Bonduelle-Russie, une structure atypique vis-à-vis des pratiques habituelles du groupe agro-industriel français, traduit la volonté de sécuriser l'approvisionnement des conserveries russes. Elle s'accompagne d'une reconnaissance du rôle de l'entreprise dans le développement économique du territoire de Krasnodar.

\section{$\rightarrow$ Communauté et territoire aux origines de la « futurité » des acteurs russes}

Le contexte institutionnel à partir duquel Commons définit la manière dont est régulé le système capitaliste est celui des États-Unis. Les mécanismes d'exécution effective des règles de fonctionnement des going concerns reposent sur le rôle prépondérant

10. Une autre transaction de marchandage a eu lieu entre Bonduelle et l'administration locale pour un bail foncier de quarante-neuf ans portant sur 100 ha de terre.

11. Auxquels il faut ajouter 46 millions d'euros d'investissement sur dix ans pour la recapitalisation des conserveries. 
de la cour suprême (Commons, 1924). Il convient de confirmer ou d'infirmer la pertinence de l'emploi des concepts développés par J.R. Commons puisque ce modèle de régulation n'existe pas en Russie. Autrement dit, il faut identifier - en l'absence d'un système judiciaire autonome vis-à-vis du pouvoir économique - les autorités de contrôle du respect des règles collectives dans le capitalisme russe.

Dans la pensée de Commons, la société est composée d'individus autonomes et de going concerns. Contrairement à la vision proposée par Rousseau, l'affranchissement de l'ordre naturel des règles ne passe pas chez Commons par le contrat social. Sa conception de l'ordre est davantage empruntée à celle de Hobbes. Le droit y apparaît comme à l'origine d'un ordre permettant la régulation des interactions sociales, ce qui permet à l'individu d'entreprendre une action tout en ayant relativement confiance dans ses anticipations (notion de futurity). Les transactions sont de fait encadrées par un tiers : l'État, à travers la jurisprudence de la cour suprême américaine. Les transactions « autorisées », de nature économique, sont régulées par des transactions « autorisantes » de nature politique qui garantissent l'impartialité des règles. Les transactions de nature économique sont prédominantes et permettent l'innovation institutionnelle, mais le pouvoir économique sur lequel elles s'appuient est limité par un pouvoir souverain.

Dans le cas russe, nous avons constaté que des transactions de répartitions basées sur des interactions dont la nature économique est difficilement dissociable de la nature politique (enjeu de sécurité alimentaire dans le cas d'Eksima et de développement territorial dans le cas de Bonduelle) étaient à l'origine d'un pouvoir économique spécifique des entrepreneurs privés dans le cadre des transactions de marchandage. Dès lors, il est pertinent d'interroger les éléments sur lesquels les acteurs au pouvoir économique réduit se reposent pour agir. Leur «futurité » s'appuie sur des territoires et des communautés dont il convient de souligner le rôle régulateur. Il faut pour cela envisager que les transactions « autorisantes » se jouent à un autre niveau que celui de l'État. C'est ce que propose Barthélemy (2007) avec le concept de « relation patrimoniale ». Dans ce type de relation, l'individu n'est pas dans une position égalitaire face à son interlocuteur. Il se trouve inséré dans une communauté solidaire et territorialement située qui le contraint dans ses interactions de nature économique (de marchandage, de direction ou de répartition). L'individu hobbesien est remplacé par un être dual enclin à défendre ses intérêts tout autant que ceux de la communauté dont il partage les objectifs de solidarité.

En l'absence d'un État dont le pouvoir serait limité par la séparation entre, d'un côté, les représentants de l'État à qui sont conférés des devoirs envers les citoyens et, de l'autre, le citoyen - soumis aux mêmes règles que tous les autres -, la communauté territorialisée devient un rempart contre tout pouvoir économique excessif. La communauté apparaît comme l'institution sur laquelle les acteurs fondent la légitimité de leurs interactions. Cela se traduit concrètement par l'importance, pour Eksima comme pour Bonduelle, d'investir dans l'intérêt communautaire du territoire sur lequel ils s'implantent. Pour Eksima, c'est le financement des services sociaux aux habitants des villages qui a joué ce rôle. Pour Bonduelle, c'est le fait d'avoir obtenu, de la communauté des propriétaires en collectif des terres agricoles et de l'exploitation, la possibilité de vérifier la validité des contrats passés entre l'exploitation agricole et chacun des propriétaires en ayant recours à des juristes 
expérimentés alors même que le bail foncier n'était signé qu'entre Bonduelle et l'exploitation agricole en tant que personne morale (entretien du 27 mars 2009). Cette confiance acquise par les entrepreneurs privés leur est primordiale pour garantir la durabilité des transactions de marchandage, de direction et de répartition qui fondent les innovations organisationnelles que sont l'agroholding et l'agrofirme multinationale.

\section{- Conclusion}

À partir d'une lecture commonsienne, nous avons cherché à rendre compte de l'existence de formes nouvelles d'organisation agricoles en Russie : l'agroholding et l'agrofirme multinationale. Sur la base de deux études de cas, celle de l'agrohodling Eksima-Agro et celle de l'entreprise Bonduelle-Russie, nous avons établi l'existence de transactions de marchandage, de direction et de répartition qui définissent les règles opérantes sur lesquelles se dessinent les contours des nouvelles organisations. Cette analyse révèle que l'agroholding intègre des enjeux qui vont au-delà de la simple optimisation de la rentabilité économique de l'exploitation agricole. Les frontières de l'agroholding sont un moyen de garantir la sécurisation de l'approvisionnement des usines de transformation agroalimentaire, voire - dans le cas d'Eksima - de porter une politique de sécurité alimentaire pour la ville de Moscou. L'entreprise Bonduelle a dû quant à elle modifier les contours de son métier - exploitant de conserveries - en devenant pleinement agriculteur dans le but d'assurer la sécurité de son approvisionnement en maïs et en petits pois, ainsi que leur qualité. Pour y parvenir - et en raison de l'héritage institutionnel soviétique -, les entrepreneurs institutionnels ont engagé des réformes tant au niveau du rapport salarial, que sur la question de la symbiose entre l'exploitation agricole et la communauté villageoise (Maurel, 1980). La relative exécution des règles au sein de ces structures s'explique n'ont pas par le rôle prépondérant du système judiciaire russe, contrairement au cas américain sur lequel s'appuie Commons, mais par le caractère territorialisé et communautarisé des firmes nationales et multinationales. 



\title{
Investissements fonciers à grande échelle et financiarisation de l'agriculture : une analyse par les filières agrofinancières
}

\author{
A. Ducastel, W. Anseeuw
}

Du $1^{\text {er }}$ au 3 décembre 2014, la conférence « Global AgInvesting Europe 2014 » a réuni des organisations aussi diverses que le fonds de pension américain TIAA-CREF ${ }^{1}$, la Fondation Bill et Melinda Gates, Rabobank ${ }^{2}$ ou encore la Société financière internationale ${ }^{3}$ pour discuter des perspectives d'investissement dans l'agriculture. Pour des entrées à partir de 2895 dollars, les participants ont pu assister à une trentaine de panels sur des thèmes tel que « l'agriculture de précision et l'évolution des big data », " les opportunités agricoles en Australie et en Nouvelle-Zélande » ou encore « qu'est-ce qu'un investissement agricole responsable ? ${ }^{4}$. Ce type de conférence est organisé plusieurs fois par an par différents promoteurs ${ }^{5}$ et sur tous les continents.

Longtemps désertée par les investisseurs et les capitaux externes (Lipton, 1977 ; Bezemer et Headey, 2006), l'agriculture, depuis peu qualifiée « d'or vert ${ }^{6}$, fait un retour fracassant sur le devant de la scène. Au niveau macro-économique, ces investissements reposent sur une grille de lecture malthusienne (Ducastel et Anseeuw, 2011) selon laquelle la production agricole ne pourrait suivre une demande augmentant à un rythme continu (pour répondre à l'augmentation de la population mondiale, à l'émergence d'une classe moyenne dans les pays émergents ou encore au développement de l'industrie des biocarburants). Mais, à côté de ces facteurs macroéconomiques, des motivations purement financières sont aussi mises en avant pour appuyer ce retournement. Ainsi, à la suite de la crise financière de 2008, l'industrie

1. TIAA-CREF (Teachers Insurance and Annuity Association - College Retirement Equities Fund) assure et gère les plans de retraite de plus de 3 millions de personnes et de 15000 institutions dans le domaine de l'éducation, de la recherche et de la santé aux États-Unis.

2. Banque néerlandaise issue de la fusion des réseaux de banques coopératives.

3. Filiale de la Banque mondiale dédiée à l'appui au secteur privé.

4. Voir le site de Global AgInvesting, http://www.globalaginvesting.com/Conferences/Agenda?eventId=25 (consulté le 10 octobre 2016).

5. Outre Global AgInvesting, on peut par exemple citer Ag Innovation Showcase et Terrapinn Agriculture Investment Summit.

6. CCFD, 2006. « Le soja contre la vie », http://ccfd-terresolidaire.org/infos/souverainete/agriculture/ campagne_613 (consulté le 10 octobre 2016). 
financière se serait engagée dans la quête « d'actifs alternatifs » qui ne soient pas corrélés avec les marchés boursiers et qui puissent constituer une protection contre l'inflation (HighQuest Partners, 2010). Plusieurs travaux ont alors souligné les bonnes performances financières historiques et le caractère contra cyclique des actifs agricoles, et ainsi justifié leur place dans un portefeuille financier, en complément notamment des actions et des obligations (Chen et al., 2013).

Ces investissements agricoles recouvrent un ensemble composite de produits financiers. Dans un effort de clarification, Golberg et al. (2012) proposent une typologie de ces actifs liés à l'agriculture et distinguent :

- les produits dérivés et les fonds indiciels sur les marchés à terme de produits agricoles ;

- les actions et les parts sociales des entreprises agricoles et agroalimentaires ;

- et, enfin, les fonds d'investissement spécialisés dans le foncier agricole.

Tous ces produits financiers ont connu un essor rapide au cours de la dernière décennie. Premièrement, les marchés à terme ont connu un véritable boom marqué par l'afflux de spéculateurs, notamment à la suite d'innovations financières telle que les fonds indexés sur les cours de certains produits (Kerckhoffs et al., 2010 ; Clapp, 2014) ${ }^{7}$. Deuxièmement, les prises de participation au capital d'entreprise, soit par des opérations boursières, soit par des opérations de capital-investissement pour les entreprises non cotées (Burch et Lawrence, 2013), ont modifié profondément la structure du capital des entreprises agroalimentaires, et en particulier des multinationales, au bénéfice de puissants conglomérats d'actionnaires professionnels ${ }^{8}$. Troisièmement, l'investissement dans le foncier, directement ou plus souvent via un fonds d'investissement spécialisé, s'inscrit dans une dynamique plus large de «land grabbing » qui voit des investisseurs, publics ou privés, nationaux ou étrangers, acquérir des terres à vocation agricole 9 .

Le «land grabbing » financier a été l'objet de nombreux travaux scientifiques au cours des dernières années qui ont tenté de définir et de caractériser ce phénomène social (Cotula et Blackmore, 2014) ; néanmoins, ces efforts se sont souvent heurtés à un manque d'empirie. À partir de deux études de cas de fonds d'investissement dédiés au foncier en Afrique du Sud, ce chapitre présente une étude du phénomène du land grabbing financier «par le bas » (Bayart et al., 1992), en mobilisant une analyse en termes de filières agrofinancières. Dans un premier temps, nous ferons une revue critique de la littérature sur le sujet, ce qui nous conduira à exposer la pertinence d'une approche par les filières agrofinancières ; puis, nous étudierons empiriquement une de ces filières particulières en suivant le sens de circulation des capitaux, des investisseurs aux exploitations agricoles ; enfin, nous nous interrogerons sur les transformations induites sur l'agriculture par le développement de ces filières.

7. Cette participation accrue de fonds spéculatifs est pour beaucoup dans la crise alimentaire de 20072008 (Clapp, 2014) puisque l'accroissement et l'accélération des transactions sur ces marchés tendent à augmenter la volatilité des prix des produits agricoles.

8. Ainsi, Palpacuer et al. (2006), pour le cas des multinationales de l'agroalimentaire européen, et Beaud et Durand (2011), pour celui de la grande distribution, montrent la place croissante de ces actionnaires et leur influence prépondérante dans la gouvernance de ces entreprises.

9. Voir Cotula et al. (2009), World Bank (2010), ILC (à paraître). 


\section{- La financiarisation de l'agriculture et du foncier agricole}

Le rôle des acteurs financiers dans le processus de land grabbing a fait l'objet d'une attention particulière. Une première série de travaux s'est attachée à identifier les fonds et les sociétés d'investissement engagés dans ce processus d'acquisition foncière (Grain, 2010; Daniel, 2012 ; Buxton et al., 2012). Puis un pan de la littérature a proposé une analyse plus structurelle en situant les acquisitions foncières dans le cadre d'un processus général de financiarisation de l'agriculture et du foncier agricole.

La notion de financiarisation s'est diffusée au cours des années 2000 pour désigner une grande diversité de phénomènes sociaux (expansion et prolifération des actifs financiers, évolution de l'actionnariat des entreprises, endettement des ménages), diversité qui génère un grand flou conceptuel (Fine, 2012). Pour caractériser ces différents travaux, French et al. (2011) distinguent trois « écoles de la financiarisation » : la première s'inscrit dans la tradition de l'école de la régulation et considère la financiarisation comme un régime d'accumulation spécifique qui se décline à l'échelle nationale (Boyer, 2000) ; une approche "d'économie politique culturelle » qui analyse l'influence croissante des marchés financiers sur les entreprises - à travers la valeur actionnariale - et les ménages (Froud et al., 2002); enfin, une approche socio-culturelle qui se focalise sur la diffusion des mécanismes et des logiques financières dans la vie quotidienne (Langley, 2008 ; James, 2014).

Les analyses portant spécifiquement sur la financiarisation de l'agriculture s'inscrivent souvent dans une tradition d'économie politique que l'on retrouve condensée dans une citation d'Epstein (2005) :

« La financiarisation signifie le rôle croissant des motivations financières, des marchés financiers, des acteurs financiers et des institutions financières dans le fonctionnement des économies locales et internationales. »

Autrement dit, la financiarisation s'entend d'abord comme l'influence croissante du « capital financier » sur les différentes facettes de l'économie.

Cette approche revêt plusieurs avantages. Premièrement, elle permet de faire le lien entre une pluralité de pratiques financières spatialement dispersées en les rattachant aux transformations globales du capitalisme contemporain. De ce point de vue, la prolifération de fonds indiciels sur le marché à terme de Chicago et l'acquisition de plus de 3000 hectares de terres arables par un fonds d'investissement britannique en Zambie (Chu, 2013) s'inscrivent tous les deux dans le même processus global de financiarisation de l'agriculture. Deuxièmement, cette approche ouvre une réflexion sur les bouleversements suscités par la «pénétration » de la finance dans l'agriculture, et notamment sur les relations et les rapports de force entre le «capital financier » d'un côté, et les acteurs, les groupes sociaux et les coalitions d'intérêts qui sont partie prenante de l'économie politique sectorielle de l'autre, que ce soit la grande distribution organisée (Burch et Lawrence, 2013) ou les travailleurs et les exploitants agricoles (Isakson, 2014). Troisièmement, le développement actuel de fonds et de sociétés d'investissement dédiés au foncier agricole est l'occasion de s'interroger sur la temporalité de la financiarisation et la dynamique du capitalisme contemporain ; pourquoi le capital financier investit-il aujourd'hui dans le foncier agricole ? Pour Fairbain (2014), cette financiarisation du foncier agricole illustre les 
mutations récentes du capital financier marqué par « un désir de retourner à l'économie réelle ». À ce titre, la financiarisation de l'agriculture serait la dernière frontière, ou «spatial fix » (Harvey, 2006), d'un processus global d'expansion du capital financier vers de nouvelles activités et de nouveaux secteurs afin de renouveler sans cesse les conditions de son accumulation. Ce processus se décline alors dans l'agriculture selon des modalités et des mécanismes comparables aux financiarisations sectorielles antérieures. Dans ce cadre, la financiarisation de l'agriculture est associée à l'émergence d'un nouveau « régime agroalimentaire » (Burch et Lawrence, 2009) qui se traduit par le renouvellement des formes d'accumulation au sein du secteur puisque les acteurs non financiers voient la part de leurs revenus financiers augmenter.

Cependant, cette grille de lecture comprend aussi de sérieuses limites et mérite d'être enrichie par d'autres courants d'étude du processus de financiarisation (Ouma, 2014). Tout d'abord, cette approche donne à la financiarisation un caractère homogène, ne permettant pas d'appréhender ni les multiples déclinaisons locales et nationales, ni les formes de résistance qu'elle rencontre, ni les échecs qu'elle subit. Elle tend à faire abstraction de la diversité des acteurs engagés dans le processus et utilise des catégories floues et homogénéisantes, à commencer par celle de « capital financier », laquelle fait abstraction des rapports de force et des conflits qui structurent et organisent l'espace de la finance (Williams, 2014). D'une manière générale, cette approche masque toute la chaîne d'intermédiaires - investisseurs, gestionnaires d'actif, consultants, administrations nationales et locales, agriculteurs - engagés en interaction dans le cadrage et la mise en ouvre de cette financiarisation du foncier. Enfin, la finance d'un côté et l'agriculture de l'autre sont réifiées comme des espaces clos, cantonnées à des échelles spatiales distinctes, le global et le local, qui s'auto-excluent mutuellement. Cette opposition entre global et local a été critiquée par Bayart (2004) à travers son analyse d'une globalisation par le bas qui inclut des mécanismes de réappropriations, de subjectivation et d'extraversion. De la même manière, plutôt qu'un processus imposé par le haut, la financiarisation est bien davantage un processus négocié à tous les niveaux comme l'ont montré plusieurs travaux, que ce soit dans le cadre des entreprises par l'intermédiaire des contrôleurs de gestion (Pezet et Morales, 2010), ou dans le secteur de l'automobile allemande (Kadtler et Sperling, 2002).

Plusieurs travaux ont tenté de dépasser ces critiques, tout d'abord, en s'engageant dans des études empiriques plus fines afin de caractériser les déclinaisons de la financiarisation, en l'inscrivant notamment dans le cadre de trajectoires historiques et de dynamiques foncières nationales et locales de long terme. Ces travaux font ressortir une carte originale du phénomène en se focalisant sur les pays «émergents »-Égypte (Dixon, 2013), Russie (Visser et al., 2012) -, et plus récemment sur les États-Unis (Gunnoe, 2014). Ensuite, en mobilisant d'autres écoles et d'autres cadres d'analyse du processus de financiarisation (sociologie économique, études sociales de la finance, théorie de l'acteur-réseau), une réflexion s'est développée à propos des interactions entre les acteurs et les dispositifs (techniques et cognitifs) qui rendent possible et incarnent la financiarisation du foncier agricole. Ainsi, des auteurs se sont interrogés sur les conditions d'émergence du processus de conversion du foncier agricole en actifs financiers à travers par exemple les modes innovants de 
titrisation (Fairbain, 2014) ou encore l'introduction de nouvelles méthodes d'évaluation (Williams, 2014).

D'autres travaux étudient davantage le travail quotidien qui permet la financiarisation du foncier agricole. Il s'agit alors de mieux comprendre les pratiques qui guident l'allocation des capitaux dans l'agriculture (Ortiz, 2014), comme par exemple les pratiques d'intermédiation (Ducastel et Anseeuw, 2015) ou les ressources cognitives et discursives qui rendent ces investissements possibles et légitimes (Chu, 2013), toujours en insistant sur les tâtonnements et les expérimentations qui jalonnent ces processus (Ouma, 2014). Enfin, une dernière série de travaux se focalise plus sur les enjeux de pouvoir et les alliances entre acteurs qui sous-tendent la financiarisation $\mathrm{du}$ foncier, en inscrivant par exemple le processus dans le cadre de la reproduction des élites nationales (Dixon, 2013). Cet ensemble disparate de travaux se donne comme objectif « d'ouvrir la boîte noire de la finance »(Ouma, 2014) en étudiant les interfaces concrètes entre la finance et l'agriculture qui font progressivement du foncier agricole un actif financier. L'approche par les filières agrofinancières que nous proposons dans ce chapitre se donne un objectif similaire.

Comme le rappellent Raikes et al. (2000), la notion de filière est apparue dans le contexte de la recherche agronomique française afin de caractériser les chaînes de production et de commercialisation des produits phares de l'agriculture coloniale (café, cacao). La notion originelle de filière accorde une importance particulière aux interdépendances entre acteurs le long de ces chaînes et trace des continuités entre la métropole et les colonies. L'école de la régulation s'est par la suite intéressée à cette notion en tant qu'espace de régulation. Allaire (1995a) les définit ainsi comme « un espace technologique et un champ de coordination d'acteurs » dont le développement s'inscrit dans le cadre d'un processus de désectorisation et de prolifération de règles et de conventions locales. Les filières permettent donc de penser l'émergence et l'institutionnalisation de cadres de régulation transnationaux et « transsectoriels » (Gras et Hernández, 2014) constitués autour d’un produit spécifique.

On peut compléter cette approche régulationniste en analysant les filières en termes de réseaux sociotechniques, comme le font Callon et al. (2000) dans le cadre d'une économie des qualités. Dans cette perspective, l'attachement entre acteurs se fait à travers les étapes successives de qualification et de requalification qui jalonnent la construction du produit. Dans ce cadre, la filière et le produit sont construits simultanément. Cette approche insiste sur le rôle des objets, ou des instruments (Lascoumes et Le Galès, 2005), dans la mise en relation et la coordination entre ces acteurs.

Le succès, ou l'échec, d'une filière donnée et sa stabilisation reposent sur la mobilisation d'acteurs qui sont chacun engagés dans des rapports sociaux et des structures de pouvoir dans leurs champs respectifs (Bourdieu, 2000). Les ressorts et les formes de l'enrôlement des acteurs dans les filières renvoient largement à leurs positions sociales dans leurs champs respectifs et donc à la structure de leurs capitaux; en retour, l'engagement des acteurs dans les filières tend à modifier la structure de leur champ d'origine.

La notion de filière agrofinancière est proposée ici pour caractériser l'enchâssement d'échanges stabilisés et d'interdépendances entre une pluralité d'acteurs issus 
d'espaces sociaux divers (investisseurs institutionnels, gestionnaires d'actifs professionnels, agriculteurs, etc.) dans le cadre de la construction d'un produit financier spécifique. Plutôt que d'opposer finance et agriculture et d'analyser comment le premier tend à coloniser le second, une approche en termes de filière agrofinancière permet de penser l'autonomisation progressive d'un espace social particulier « à cheval » sur ces deux secteurs. Ainsi, la notion de filière agrofinancière se rapproche de celle d' «AG space » proposée par Williams (2014:423), c'est-à-dire un espace hybride au croisement de l'agriculture et de la finance ${ }^{10}$. Cependant, notre approche se situe à une autre échelle puisqu'elle s'articule autour d'un seul produit financier.

Il ne s'agit pas de réifier ces filières qui ne sont pas directement perçues et organisées en tant que telles par les différents acteurs qui en sont partie prenante. Il s'agit plutôt, d'une part, de mobiliser cette notion pour tenter de rendre compte de la complexité du processus de production d'un produit financier original, en intégrant la dimension non financière de ce travail productif, d'autre part, de mieux comprendre les répercussions que peut avoir l'enrôlement d'acteurs issus du secteur agricole (en l'occurrence sud-africain), à commencer par les agriculteurs, sur l'organisation du travail agricole. Il nous reste désormais à illustrer empiriquement cette approche.

\section{" Construire des titres financiers à partir d'exploitations agricoles sud-africaines}

Dans la suite de ce chapitre, on s'attachera à analyser deux filières agrofinancières particulières dédiées à la production d'actifs financiers à partir d'exploitations agricoles sud-africaines. Les acteurs de ces filières sont engagés dans la construction de produits financiers originaux, les fonds d'investissement Alpha et Bêta ${ }^{11}$. À travers les divergences et les convergences entre ces deux produits, on analysera à la fois la stabilisation de dispositifs propres à " une industrie agrofinancière » naissante, et les stratégies de différenciation et d'expérimentation mises en œuvre d'une filière à l'autre.

$\mathrm{Au}$ fondement de ces deux produits financiers, deux groupes d'acteurs jouent un rôle moteur : les investisseurs institutionnels et les gestionnaires professionnels. La coordination entre ces acteurs repose sur un « véhicule de titrisation » ${ }^{12}$, c'est-à-dire un dispositif financier temporaire qui permet d'une part de convertir des biens ou des activités économiques en titre financiers ${ }^{13}$, et d'autre part de formaliser une

10. «Un espace social et institutionnel distinct, un champ particulier d'engagement, l'idée, opérante, qu'il existe quelque part entre la finance et l'agriculture des traits communs qui dans chaque cas sont irréductibles à des traits propres » (Williams, 2014).

11. Cette étude de cas repose largement sur des observations participantes réalisées par l'un des auteurs au sein de deux entreprises de gestion d'actifs sud-africaines ; l'une des conditions ayant permis ce travail de terrain est la préservation de l'anonymat des sociétés concernées et de leurs investisseurs.

12. Que l'on retrouve aussi qualifié selon les juridictions de fonds commun de titrisation ou de «special purpose vehicule».

13. Voir Jorion (2007) sur la titrisation de l'immobilier américain ou Deffontaines (2013) sur la titrisation des financements de la commande publique. 
délégation de la gestion des capitaux des investisseurs au gestionnaire. Une fois le fonds d'investissement formalisé, les gestionnaires s'engagent dans l'acquisition d'exploitations agricoles en Afrique du Sud pour le compte de ce fonds, puis ils mettent en place des stratégies de gestion et de valorisation de ces exploitations en mobilisant une pluralité d'acteurs et de dispositifs. À la fin de la durée de vie du fonds, le gestionnaire revend les exploitations agricoles afin de rémunérer les investisseurs détenteurs de parts du fonds.

Aglietta et Rigot (2009) définissent les investisseurs institutionnels comme « des institutions financières spécialisées gérant collectivement des plans d'épargnes contractuelles pour le compte de tiers avec des objectifs spécifiques de risque, de rendement et de maturité ${ }^{14}$. Leur politique d'investissement est largement déterminée par la structure de leurs bilans ${ }^{15}$, ils investissent dans des «portefeuilles » diversifiés de titres financiers à base d'actions, d'obligations, mais aussi potentiellement d'actifs financiers liés à l'agriculture.

Les gestionnaires d'actifs professionnels gèrent un portefeuille de titres pour le compte de tiers ${ }^{16}$. Dans le cas de la gestion d'actifs liés à l'agriculture, ces sociétés de gestion jouent le rôle d'entrepreneurs financiers en opérant un «processus de traduction incertain » (Bessy et Chauvin, 2013) entre les demandes des investisseurs en produit financier et les acteurs et les institutions du secteur agricole. Ces intermédiaires ne sont pas engagés dans « une traduction mot à mot », mais ils jouent un rôle actif dans l'appareillage de l'offre et de la demande, d'autant plus grand qu'ils mettent en relation des objets et des acteurs éloignés physiquement et culturellement.

Le premier fonds d'investissement, le fonds Alpha, lancé en 2008, est exclusivement financé par un grand fonds de dotation ${ }^{17}$ d'une université américaine ${ }^{18}$. Dans le cadre de ses investissements labellisés « ressource naturelle », ce fonds de dotation a d'abord massivement investi dans les plantations forestières à travers le monde à partir de la fin des années 1990 ; plus récemment, il s'est aussi tourné vers les exploitations agricoles, d'abord aux États-Unis, puis dans différents pays dont l'Afrique du Sud. La gestion de ses capitaux a été déléguée à une société sud-africaine initialement dédiée aux activités de couverture et de spéculation sur le marché à terme agricole, la South African Futures Exchanges. Progressivement, cette société a diversifié ses activités, notamment vers la gestion d'actifs physiques agricoles (exploitations) et agro-industriels (usine de concassage) pour le compte de tiers.

14. Comme des fonds de pension, des compagnies d'assurances, des fonds de dotation, etc.

15. C'est-à-dire les caractéristiques de leurs dépôts (durée des engagements, contreparties financières, etc.).

16. À la différence des investisseurs institutionnels, ils sont souvent spécialisés dans une seule catégorie d'actifs.

17. Le fonds de dotation, ou «endowment fund », est un fonds d'investissement détenu par une seule organisation, souvent une organisation à but non lucratif, qui y investit des donations et dont le bénéfice doit financer les activités de ladite organisation.

18. Ce fonds de dotation disposait en 2013 d'un portefeuille de plus de 30 milliards de dollars réparti entre plusieurs classes d'actifs : actions (49\%), hegde fund (15\%), obligations et titres à revenus fixes $(11 \%)$, actifs physiques $(25 \%)$. Cette dernière catégorie comprend des investissements immobiliers, des contrats à terme sur des matières premières et enfin une fraction « ressource naturelle ». 
Le deuxième fonds, le fonds Bêta, a été quant à lui lancé en 2010. Plus de $85 \%$ de ses parts sont détenues par un fonds de pension de la fonction publique sudafricaine ${ }^{19}$ et par l'une des plus anciennes compagnies d'assurances du pays ${ }^{20}$. Tous deux inscrivent leurs premiers investissements dans le foncier agricole local dans le cadre de la promotion d'une politique «impact investment ». Développé par un réseau d'investisseurs et d'institutions financières, ce cadre établit une corrélation entre les capitaux investis et la «production » environnementale et sociale de l'entreprise qu'il faut alors mesurer grâce à une méthodologie standard ; l'allocation des capitaux repose alors à la fois sur la rentabilité financière et sur la « rentabilité sociale » de l'entreprise (Chiapello, 2015). Enfin, une société d'investissement à capital variable (Sicav), créée au Luxembourg et qui regroupe plusieurs investisseurs institutionnels et individuels européens, détient le reste des parts du fonds Bêta. La gestion de ce fonds a été déléguée à une joint-venture associant la compagnie d'assurances et des entrepreneurs spécialisés dans l'exportation des fruits sudafricains. Spécialement créée pour l'occasion, cette société de gestion a depuis lancé un deuxième fonds pour l'acquisition d'exploitations agricoles en Afrique du Sud et un fonds similaire au Swaziland.

À travers ces rapides portraits, il émerge plusieurs traits caractéristiques des filières agrofinancières. Tout d'abord, les investisseurs sont chacun dans leur domaine respectif (fonds de dotation, fonds de pension et compagnie d'assurances) parmi les leaders à l'échelle mondiale. Ainsi, l'innovation financière, ou plutôt la financiarisation comme «extension du domaine de la finance » (Desffontaines, 2013), est portée par quelques acteurs globaux qui concentrent les capacités financières, mais aussi techniques et humaines pour produire de nouvelles classes d'actifs. Ces investisseurs de long terme (Aglietta et Rigot, 2009) s'engagent dans l'agriculture dans une optique de diversification de leur portefeuille afin de préserver la valeur réelle à long terme de leurs capitaux. À ce titre, il est intéressant de souligner que les produits financiers analysés dans ce chapitre ont été lancés alors que la crise financière battait son plein. Ainsi, l'intérêt pour les exploitations agricoles doit se comprendre dans son interdépendance avec les autres catégories d'actifs ; autrement dit, ces actifs liés à l'agriculture n'ont une valeur pour ces investisseurs institutionnels que par rapport aux actions et aux obligations de leur portefeuille. Mais l'engagement dans l'agriculture s'inscrit aussi dans une rhétorique et un ensemble de discours autour de la responsabilité sociale de la finance, que l'on retrouve en particulier chez les investisseurs sud-africains, et dont l'appartenance au réseau global de l'«impact investment » constitue le dernier avatar.

Les sociétés de gestion sont quant à elles toutes deux enracinées en Afrique du Sud, même si l'une d'entre elle emploie principalement des étrangers. Ces sociétés de gestion se posent en intermédiaire entre les investisseurs à l'échelle globale et le marché foncier agricole national. Cet ancrage local illustre le poids déterminant des réseaux et des carrières locales pour assurer le passage d'une échelle à l'autre et construire un produit financier. Par ailleurs, ces sociétés illustrent la porosité

19. En 2013, ce fonds de pension détenait plus de 100 milliards de dollars d'actif en gestion en Afrique du Sud et sur le reste du continent ; $5 \%$ de ces capitaux sont alloués aux « investissements pour le développement », parmi lesquels sa participation au sein du fonds Bêta.

20. En 2013, cette société détenait l'équivalent de 385 milliards de dollars d'actifs. 
entre les différentes filières agrofinancières puisqu'elles passent de la gestion d'un produit financier à l'autre - des contrats à terme aux exploitations - et d'un pays à l'autre - de l'Afrique du Sud au Swaziland. Ces entreprises de gestion emploient des équipes restreintes, entre cinq et dix personnes, dont on peut dresser une typologie grossière : un pôle en charge des relations avec les investisseurs et les autres acteurs du secteur agricole ; un groupe d'analystes financiers (en charge de l'identification, de l'évaluation et de la négociation des transactions); un back-office en charge du suivi comptable et administratif des exploitations ; enfin des consultants techniques viennent compléter ces effectifs. Les fonctions comptables et financières prédominent donc largement; les évaluations financières occupent en effet une place prépondérante, à la fois comme support privilégié de la prise de décision et comme vecteur de communication entre gestionnaires et investisseurs.

Le véhicule de titrisation constitue le troisième maillon de ces filières agrofinancières. Ce dispositif financier spécifique est à la fois le support d'une relation de délégation et d'un processus de titrisation. En effet, la rencontre entre investisseurs et gestionnaires donne naissance à une entité juridique ayant une existence propre et indépendante des deux premières, mais aussi formatée au gré de cette relation particulière. Cette entité est donc une structure ad hoc qui n'existe que pour permettre les investissements du binôme investisseurs-gestionnaire et qui disparaît lorsque cesse cette collaboration. Dans nos deux cas d'études, ces entités ont des durées de vie limitée dans le temps, soit entre dix et douze ans ${ }^{21}$, période au cours de laquelle les capitaux des investisseurs sont bloqués. Les parts de ces véhicules sont réparties entre les investisseurs en proportion de leurs apports de capitaux; la gestion de ces capitaux est alors confiée au gestionnaire. Ce type de structures peut prendre différents statuts selon les juridictions ; cependant, dans notre cas, toutes s'inscrivent dans le principe juridique du partenariat en vertu duquel le gestionnaire a une responsabilité de moyens à l'égard des investisseurs et non une obligation de résultat, ce que Montagne (2006) a qualifié de « responsabilité procédurale ».

Ainsi, le fonctionnement et la gouvernance de ces fonds, telles que les modalités de décaissement des capitaux, sont strictement encadrés par un ensemble de procédures contractuelles que sont tenus de respecter les gestionnaires ${ }^{22}$. Une « thèse d'investissement » est intégrée à cette documentation juridique, laquelle définit les entreprises cibles potentielles en termes de montant minimum et/ou maximum des investissements, de localisation, etc. Enfin, un comité d'investissement, composé de membres indépendants et de représentants des investisseurs et du gestionnaire, valide les investissements en dernier ressort. Dans les cas présents, ces deux véhicules financiers ont été enregistrés à l'île Maurice, et non pas en Afrique du Sud. L'île Maurice a en effet développé au cours des années 2000 des politiques fiscales très avantageuses pour l'implantation de compagnies étrangères, notamment financières, les exonérant par exemple de taxes sur les dividendes et les revenus du capital. Dans le même temps, elle a su intégrer dans sa juridiction nationale les dispositifs internationaux en matière de lutte anti-blanchiment ou de

21. Ce qui correspond à la norme des fonds d'investissement, et notamment des fonds de capitalinvestissement.

22. En vertu de cette documentation juridique, le fonds Bêta ne peut investir moins de 50 millions de rand par exploitation, soit 3,8 millions d'euros. 
réglementation financière ${ }^{23}$ qui lui permettent de se positionner idéalement pour capter les flux financiers en direction de l'Afrique. Il se dessine alors une géographie des filières agrofinancières entre les bureaux des plus gros investisseurs institutionnels concentrés dans les hubs financiers mondiaux (États-Unis, Europe, Afrique du Sud), l'île Maurice qui concentre de plus en plus de véhicules financiers dédiés au continent africain, et les exploitations agricoles sud-africaines.

La structuration des filières agrofinancières doit alors se comprendre par rapport à une relation investisseur(s)-gestionnaire donnée, mais aussi par rapport à la mobilisation par ce binôme d'un ensemble de dispositifs juridiques et financiers stabilisés : le trust, la juridiction mauricienne, la thèse d'investissement, etc. En effet, les filières agrofinancières sont très largement calquées sur l'architecture institutionnelle d'autres filières financières, en particulier celles du capital-investissement et des actifs immobiliers, dont les «sous-jacents » (des entreprises et de l'immobilier urbain et péri-urbain) sont jugés proches. Ces dispositifs institutionnels permettent aux acteurs de se mouvoir dans des espaces qu'ils connaissent, ou reconnaissent. Bien qu'ils investissent dans une activité économique originale, à savoir la production agricole, ses promoteurs mobilisent un ensemble de repères (Karpik, 2007) pour rendre ce produit innovant, cet actif, légitime au sein des marchés de produits financiers. Par exemple, les promoteurs de ces fonds affichent des objectifs de rendement financier qui leur permettent d'être comparés au rendement des actions ou des placements immobiliers sur des durées identiques ; le fonds Bêta affiche ainsi un objectif de rendement fixé à $10 \%$ plus l'inflation.

Une fois les fonds d'investissement formalisés, leurs gestionnaires se sont attelés à mettre en pratique leurs thèses d'investissement respectives, en l'occurrence acquérir des exploitations agricoles en Afrique du Sud afin de les valoriser. Les politiques d'investissement des fonds se sont alors avérées sensiblement différentes dans la sélection des exploitations et dans leurs stratégies de valorisation.

Le fonds Alpha détenait en 2013 cinq exploitations agricoles, qui étaient toutes le résultat du regroupement de plusieurs exploitations, soit 22000 hectares répartis dans quatre provinces différentes ${ }^{24}$. Ces exploitations produisaient essentiellement des « cash crops », c'est-à-dire du maïs, du blé et du soja sur des parcelles irriguées et non irriguées. En 2014, le fonds Bêta détenait quant à lui quatre regroupements d'exploitations, soit 5500 hectares répartis dans les quatre mêmes provinces. Ces exploitations étaient toutes dédiées à la culture de fruits sur des parcelles irriguées, principalement des citrons et du raisin de table, mais aussi des poires, des pommes et des pêches.

Plusieurs traits communs rapprochent cependant les pratiques d'investissement des deux fonds. Tout d'abord, ils n'investissent que dans des exploitations agricoles situées en Afrique du Sud. Ce choix de se concentrer sur le seul marché foncier sud-africain découle de l'ancrage local des gestionnaires, mais aussi des avantages comparatifs du pays sur le marché mondial ${ }^{25}$ des actifs liés à l'agriculture. À ce titre,

23. Ainsi, l'île Maurice est l'un des seuls pays africains membre du Forum mondial sur la transparence fiscale.

24. Limpopo, KwaZulu Natal, Western Cape et Northern Cape.

25. «La terre en Amérique du Sud est sept fois plus cher qu'en Afrique du Sud alors qu'elle est utilisée 
les infrastructures financières existantes dans le pays, telles que le marché à terme de produits agricoles de Johannesburg ou l'encadrement juridique strict de la propriété foncière privée, constituent un atout par rapport aux autres pays de la région. Ensuite, leurs exploitations sont réparties entre plusieurs provinces situées parfois à des milliers de kilomètres les unes des autres. Cette stratégie de diversification provinciale cherche à atténuer les risques naturels propres à l'activité agricole, en particulier en acquérant des exploitations dans des zones ayant des caractéristiques écologiques différentes ${ }^{26}$. Les exploitations agricoles détenues par les fonds sont dans les deux cas le résultat d'un processus de concentration de plusieurs exploitations familiales et témoignent d'une volonté de générer des économies d'échelles. Par ailleurs, dans la plupart des cas, les exploitations étaient avant leur reprise en difficultés financières ${ }^{27}$.

Enfin, les deux entités misent sur leurs capacités à valoriser les exploitations agricoles, c'est-à-dire à créer de la valeur à partir des capitaux initialement investis, laquelle valeur permettra ensuite de rémunérer les investisseurs et le gestionnaire. Ces stratégies de création de valeur peuvent jouer sur deux leviers : la valeur marchande de l'exploitation et le flux de revenus productifs. Comme nous le verrons, ces stratégies s'appuient beaucoup sur une rationalisation financière poussée, la mise en œuvre d'économies d'échelles, l'intégration des activités d'amont ou d'aval, et l'augmentation des capacités productives des exploitations ${ }^{28}$. Néanmoins, les techniques de valorisation du foncier agricole sont loin d'être standardisées et les gestionnaires des fonds sont engagés dans un processus d'expérimentation à la recherche d'une « formule » de valorisation optimale. Les différences entre les deux fonds, en ce qui concerne le mode de gestion des exploitations par exemple, s'inscrivent dans cette quête de valorisation.

Le gestionnaire du fonds Alpha gère directement la production agricole sur ses exploitations. C'est donc lui qui engage les travailleurs et les sous-traitants, supervise les opérations, achète les intrants, « couvre »sa production sur le marché à terme, puis vend sa production. Ses revenus reposent donc à la fois sur les revenus opérationnels et sur l'appréciation du prix de l'exploitation au cours de la période de détention. Le fonds Bêta en revanche a dès le départ loué ses exploitations à des opérateurs pour des périodes de dix ans en échange d'un loyer annuel correspondant à $8 \%$ de la valeur de l'exploitation, séparant ainsi la propriété de la terre et les activités de production. Ce deuxième fonds est alors structuré sur le modèle des fonds d'investissement immobilier, les real estate investment trust, ou de ses équivalents

pour les mêmes activités agricoles avec les mêmes sols, climats et rendements. Il y a donc là une très bonne opportunité pour tirer profit de cet arbitrage et, simultanément, pour générer des retours supérieurs à la moyenne », Fonds Alpha, brochure de présentation.

26. Cette diversification des actifs et l'utilisation de modèles probabilistes pour l'allocation des capitaux s'inspirent de « la théorie moderne du portefeuille » (Markowitz, 1952) qui tend à dissoudre le risque spécifique associé à un actif dans le cadre d'un portefeuille diversifié et complémentaire en vertu de la force de la moyenne.

27. L'une d'entre elles a ainsi été achetée lors de sa mise aux enchères à la suite de sa liquidation judiciaire.

28. Le fonds Bêta a ainsi directement financé le développement de nouvelles parcelles, l'introduction de nouvelles variétés d'agrumes plus productives ou encore l'installation de filets de protection, contre la grêle notamment. 
dans le secteur forestier (Gunnoe, 2014). Il tire ainsi ses revenus du loyer perçu et de l'appréciation du prix de l'exploitation à la revente finale.

La construction des deux fonds d'investissement étudiés repose sur la mobilisation d'acteurs et de dispositifs inscrits dans des espaces sociaux multiples. C'est ce multipositionnement sur lequel repose le succès, ou l'échec, de ces filières agrofinancières. Il est alors intéressant de se pencher sur leurs formes d'ancrage au sein d'un espace social en particulier, le secteur agricole sud-africain. Il s'agit de saisir les ressorts sociaux de cette expansion du domaine de la finance d'une part, et les bouleversements induits par cette expansion sur la structure économique et sociale d'autre part.

\section{Vers une transformation des structures agraires et agricoles sud-africaines sous l'effet de la financiarisation?}

En acquérant des exploitations sud-africaines, et en mobilisant tout un personnel et un répertoire de compétences et de savoir-faire dans le secteur agricole local, les fonds se confrontent aux institutions sectorielles et aux acteurs du secteur agricole sud-africain ; dans le même temps, ils contribuent à introduire et à diffuser des nouvelles manières de faire et de penser l'agriculture et le foncier agricole en Afrique du Sud.

Autour des exploitations sud-africaines acquises, les deux fonds mobilisent un personnel spécifique dans le cadre de leurs stratégies de valorisation. Leur capacité à recruter et à conserver ce personnel dépend, comme on va le voir, des dynamiques en cours de recomposition du secteur. Progressivement, l'intégration de ces exploitations agricoles aux filières agrofinancières va de pair avec une forme originale d'organisation de la production mais aussi du travail productif et non productif sur et autour des exploitations.

Sur les exploitations, les deux fonds engagent des managers de terrain qui sont embauchés soit directement par le gestionnaire du fonds, soit par l'opérateur. Ces managers sont des agriculteurs blancs afrikaners qui sont souvent d'anciens propriétaires, ou des fils de propriétaires d'exploitations agricoles familiales. Ils ont souvent vécu le passage d'un statut d'agriculteur indépendant à celui de manager salarié, parfois en restant sur la même exploitation. En s'engageant dans cette carrière de manager de terrain, ils saisissent l'opportunité de se maintenir en activité sur une exploitation rurale, mais aussi parfois de s'émanciper de la tutelle familiale. Il est intéressant de noter que cet enrôlement ne concerne pas seulement l'homme, mais plutôt le ménage puisque les sociétés de gestion engagent souvent aussi l'épouse de l'agriculteur-manager, qui est en charge des tâches administratives. Ainsi, les produits financiers se construisent en mobilisant un groupe social et racial spécifique, en l'occurrence les ménages ruraux afrikaners menacés de déclassement, en leur offrant une possibilité de maintenir leur position sociale.

Les managers de terrain sont principalement en charge de la médiation entre la réalité économique et sociale de l'exploitation et la réalité financière du 
gestionnaire. En effet, les gestionnaires des fonds centralisent le pilotage des activités de valorisation, et parfois de gestion, entre leurs différentes exploitations dispersées. Ce mode de contrôle à distance s'appuie sur un ensemble de techniques et de compétences spécifiques. Les fonds ont ainsi développé des procédures poussées de suivi et d'évaluation auxquelles doivent se conformer les managers de terrain : report quotidien des activités, validation des frais de fonctionnement et d'investissement par le siège, suivi des stocks d'intrants. Ainsi, tout au long des filières agrofinancières, des investisseurs aux managers de terrain, se développe une chaîne du « reporting » qui doit favoriser le contrôle à distance et la coordination entre les acteurs dispersés physiquement. Par ailleurs, les gestionnaires du fonds mobilisent des technologies de pointe telle que Google Earth Pro qui permet un suivi des exploitations précis, parcelle par parcelle, et un archivage des performances. Au niveau de la gestion des travailleurs agricoles, les fonds recourent de plus en plus à la sous-traitance et/ou introduisent des modes de gestion par intéressement à la performance.

Les procédures de contrôle des managers de terrain encadrent et contraignent leur champ du possible, et transforment leur fonction en imposant que toujours plus de temps soit consacré aux tâches bureaucratiques (Hibou, 2012). Il ne s'agit donc pas seulement d'un changement de statut, mais aussi d'un changement de métier pour ces agriculteurs-managers, qui implique d'autres rythmes de travail et d'autres formes de responsabilité. Ainsi, la relation paternaliste héritée de l'apartheid, qui voulait que les travailleurs habitent en famille sur l'exploitation, est progressivement remplacée par une relation de marché via le recours à la sous-traitance. Dans une logique entrepreneuriale, la responsabilité des managers exploitants se borne à l'atteinte des objectifs de performance et des budgets définis par le siège.

La reconversion des exploitants-managers au salariat ne se fait cependant pas sans heurts puisque le strict encadrement procédural des pratiques agricoles est parfois vécu comme une perte de temps sur le terrain au détriment des activités réellement productives. Des conflits récurrents se manifestent entre le siège d'un côté, les managers de terrain de l'autre autour de l'utilisation des capitaux et de la hiérarchisation des tâches sur l'exploitation. Dans les deux cas étudiés, le fort turn-over des effectifs témoigne des difficultés à importer une logique managériale dans un secteur historiquement structuré autour d'exploitations indépendantes.

À côté des managers de terrain, les ingénieurs agronome occupent une fonction à part dans le pilotage des filières agrofinancières et la valorisation des exploitations. En effet, les fonds Alpha et Bêta emploient tous deux un agronome en tant que consultant ou directement au sein de l'organisation. Celui-ci est en charge de l'évaluation des paramètres écologiques, pédologiques et climatiques précédant l'acquisition d'une exploitation agricole par le fonds; il contribue ensuite activement à définir un plan de valorisation en termes agronomiques de ces exploitations (plan d'amélioration de sols, sélection de meilleures variétés, introduction des cultures sans labour, etc.) ; enfin, il opère un suivi physique en se déplaçant régulièrement sur les sites pour le compte du siège. Ainsi, de par sa formation et son expérience, cette figure de l'agronome sait jongler avec les références et les normes propres au secteur agricole d'une part, au milieu des affaires d'autre part. Il est donc un acteur majeur de la traduction dans les filières agrofinancières. 
Les promoteurs des filières agrofinancières véhiculent des pratiques et des formes organisationnelles spécifiques pour atteindre leur objectif de rentabilité financière. Elles sont des « armes organisationnelles » (Foureault, 2014) transformant les formes de l'organisation productive au bénéfice des investisseurs institutionnels.

En effet, en acquérant des exploitations agricoles, les fonds importent leurs propres logiques qui diffèrent radicalement des logiques qui ont structuré le secteur agricole sud-africain autour de la figure de l'agriculteur commercial indépendant. Premièrement, ils s'engagent pour des périodes de temps définis, entre dix et douze ans, et par conséquent ils s'inscrivent dans une temporalité qui leur est propre et qui diffère de l'engagement « à vie » qui prévaut parmi les exploitants agricoles.

Deuxièmement, dans leur finalité même, les fonds se distinguent des agriculteurs commerciaux. En effet, tandis que pour les agriculteurs la détention d'une exploitation renvoie à des logiques économiques, comme outil de production, culturel, comme lieu de vie, et patrimoniale, comme source d'épargne, la détention par les fonds d'investissement s'inscrit dans une logique purement financière de valorisation. L'objectif est d'augmenter la valeur de l'exploitation en actionnant une pluralité de leviers, et dont le revenu de l'activité agricole n'est qu'une composante parmi d'autres. Parce que la détention du foncier agricole s'inscrit dans cette logique financière de valorisation, les formes d'organisation qui s'articulent autour du foncier diffèrent de la forme historique de l'exploitation agricole. On peut alors parler d'exploitation « agrofinancière » avec ses propres métiers.

On a déjà évoqué un certain nombre de leviers propres aux stratégies de valorisation mises en ouvre par les fonds, et notamment la conversion d'exploitants familiaux à une logique entrepreneuriale incluant la création d'économies d'échelles. Mais ces stratégies se répercutent aussi sur le choix des cultures et des variétés. En effet, chaque produit agricole est associé à un couple risque/rendement plus ou moins stable et plus ou moins important. Ainsi, le maïs et le blé bénéficient de contrats à terme sur le marché de Johannesburg qui permettent de garantir une régularité de revenu au fonds Alpha ; à l'inverse, les marges induites par la production de citron sont plus importantes mais il n'existe pas d'instrument sophistiqué de gestion du risque, ce qui peut expliquer l'externalisation de la production à un tiers par le fonds Bêta. Par conséquent, le choix de la culture est essentiel pour maximiser la valeur du revenu agricole et de l'exploitation, et ce choix est solidaire d'un modèle d'investissement spécifique. Les deux gestionnaires ont par ailleurs entrepris des plans de conversion des cultures ou d'introduction de variétés plus productives.

Les fonds ont aussi massivement recours aux services d'un large panel de consultants pour créer de la valeur autour des exploitations. Au niveau juridique en premier lieu, ils mobilisent toute une expertise relative aux droits des sociétés et au droit fiscal afin d'optimiser leurs montages de holdings et de filiales ${ }^{29}$. Ils mobilisent en outre de manière croissante une expertise autour de l'évaluation environnementale et sociale, et des «impact investments ». En effet, ce type d'investissement nécessite toute une métrologie, c'est-à-dire un ensemble de pratiques d'évaluation spécifiques, dont l'objectif est de mettre en lumière et de quantifier leurs retombées

29. Dans le cas du fonds Alpha, chaque groupement d'exploitations est constitué comme une filiale de la société mère basée à l'île Maurice. 
positives (Chiapello, 2015). Ainsi, le fonds Bêta adresse chaque année aux investisseurs un rapport spécifique qui mesure les performances du fonds par rapport aux indicateurs de performance sociaux et environnementaux développés par la Société financière internationale $(\mathrm{SFI})^{30}$. Une consultante spécialisée est engagée à mi-temps pour la rédaction de ce rapport, mais aussi afin de formaliser un ensemble de normes et de procédures sociales et environnementales auxquelles doivent se conformer les exploitations agricoles du fonds. Ce cadre de référence est «bricolé » au niveau de chaque fonds à partir d'un ensemble composite de codes de bonne gouvernance (indicateurs SFI, "Principes pour des investissements responsables dans les terres agricoles ») et de certifications externes (GlobalGap). Cette dimension environnementale et sociale est donc de plus en plus reconnue comme un levier de valorisation à part.

Une dernière dimension du processus de valorisation réside dans la méthode d'évaluation utilisée par ces fonds. En effet, évaluation et valorisation constituent les deux faces d'un même processus (Vatin, 2013). Les deux fonds ont élaboré des matrices d'évaluation largement inspirées par la méthode de l'actualisation des flux de trésorerie (NBP). Ces matrices calculent un taux de rémunération des capitaux dans le futur - le taux de rentabilité interne - à partir d'une série de projections et d'anticipations. Si cette méthode est largement diffusée dans l'industrie financière (Middelberg, 2014), le marché du foncier agricole sud-africain utilise historiquement la méthode des "ventes comparables ». Tandis que cette dernière se focalise sur l'évolution des transactions foncières, donc sur la dynamique du marché, la méthode par actualisation des flux de trésorerie se focalise sur la valeur productive de l'exploitation. Pour les fonds, elle permet donc de mesurer dans le temps la capacité des gestionnaires à les valoriser d'une part ; d'autre part, en évaluant les flux de trésorerie disponibles, elle mesure le niveau de rémunération des investisseurs (Redon, 2014). Ce changement de méthode d'évaluation n'est pas seulement un changement de perspective, mais a des conséquences sur le travail sur et autour des exploitations agricoles, orienté désormais vers une maximisation de la valeur future de l'exploitation, mais aussi sur les formes mêmes des exploitations, comme des instruments de valorisation du capital.

Le produit financier, l'actif, n'est donc ni le foncier agricole, ni la production extraite des exploitations agricoles, mais bien les actions des fonds d'investissement qui détiennent les exploitations. Si la valeur de ces actions et leur rémunération sont bien corrélées à la valeur du foncier et des produits agricoles, elles ne s'y réduisent pas. Il faut alors considérer une pluralité d'autres facteurs (architecture entrepreneuriale et fiscale, impacts environnementaux et sociaux, pratiques d'évaluation) pour comprendre le codage sous-jacent propre à ce produit financier. Les filières agrofinancières ne participent donc pas à un approfondissement de la marchandisation du foncier, mais s'engagent plutôt dans une «métamorphose » financière de ce foncier.

La détention de foncier agricole et l'organisation de la production par des fonds d'investissement, bien que marginales en nombre en Afrique du Sud, n'en produisent

30. Il s'agit de huit « Normes de performance en matière de durabilité environnementale et sociale » qui constituent la référence en la matière. 
pas moins des effets sur l'architecture sectorielle de l'agriculture. En effet, on peut penser que la production de ces actifs financiers va de pair avec un processus de « désectorialisation » (Muller, 2010b) de l'agriculture sud-africaine qui se traduit par une disparition, ou tout du moins une hybridation, des institutions sectorielles, et induit une nouvelle configuration sociale et de nouveaux rapports de force.

Tout d'abord, grâce à leurs apports conséquents en capitaux ${ }^{31}$, les fonds sélectionnent et légitiment certains acteurs et certaines pratiques agricoles au détriment d'autres (Ortiz, 2008). Le gestionnaire du fonds Bêta, par exemple, ne loue ses exploitations qu'à d'importantes compagnies dédiées à l'exportation et à la commercialisation de fruit qui cherchent à garantir leur approvisionnement. Il s'agit pour lui de se prémunir contre le risque d'un défaut de paiement du loyer de la part du locataire, d'où le recours privilégié à des entreprises multinationales et fortement intégrées. Ainsi, dans ce cas précis, le développement des filières agrofinancières va de pair avec le renforcement des acteurs agro-industriels dominants, et en particulier le renforcement en Afrique du Sud d'une « agriculture de firme » (Hervieu et Purseigle, 2009).

Par ailleurs, ces transformations favorisent certains groupes sociaux et raciaux par rapport à d'autres. Ainsi, les ménages ruraux blancs afrikaners sont affectés à double titre ; d'abord, de nombreux agriculteurs cèdent leurs exploitations à des fonds provoquant des reconversions et des départs en ville ou à l'étranger ; ensuite, une minorité d'entre eux trouve la possibilité de s'engager dans une carrière de manager-agriculteur. Ainsi, l'émergence des filières agrofinancières participe à la remise en cause du modèle de l'agriculteur commercial indépendant, pivot de l'architecture sectorielle, et contribue à affaiblir la position de cette élite sectorielle. En outre, elles offrent des possibilités de reconversions professionnelles à un pan de cette élite. À l'inverse, les populations rurales discriminées sous les gouvernements de l'apartheid, les noirs ou les coloured, restent cantonnées au rôle de travailleurs agricoles. Le développement de filières agrofinancières semble donc accélérer le processus de transformation des structures sectorielles héritées de l'apartheid, mais pas toujours là où on attendait des changements (Anseeuw, 2013).

Enfin, les fonds et leurs gestionnaires ne s'engagent pas dans les institutions sectorielles, à commencer par le syndicat des agriculteurs commerciaux sud-africains AgriSA. Autrement dit, ils ne se mobilisent pas sur les enjeux politiques, économiques et sociaux de la profession agricole. Pourtant, dans le même temps, ils s'engagent dans des initiatives collectives à l'échelle globale, telle que les forums internationaux « Global AgInvesting » ou le réseau d'investissement d'impact Global Impact Investing Network, au sein desquels se côtoient des investisseurs, des gestionnaires de fonds, des agriculteurs et des régulateurs. Ces espaces contribuent à la diffusion et à la légitimation de pratiques et de cadre cognitifs ${ }^{32}$, et s'apparentent donc à des arènes de régulation émergentes. Les exploitations agricoles sont alors des enclaves territoriales qui semblent de moins en moins insérées dans le secteur agricole sudafricain au bénéfice de ces espaces agrofinanciers globaux.

31. Le fonds Bêta dispose de 462 millions de rand, soit environ 35 millions d'euros.

32. Lorsqu'ils débattent par exemple de la question «qu'est-ce qu'un investissement agricole responsable ? » comme mentionné en introduction. 
Cependant, plusieurs éléments tendent à relativiser cette « désectorisation », à commencer par les capacités de résistance et d'adaptation des anciennes élites sectorielles. À ce titre, l'exemple des anciennes coopératives de producteurs est intéressant (Ducastel et Anseeuw, 2014). Ces coopératives étaient pendant l'apartheid aux mains des agriculteurs et jouaient un rôle central dans la politique du canal unique de commercialisation. Malgré leur conversion en entreprises de droits privés, les politiques de dérégulation du secteur dans les années $1990^{33}$ et, plus récemment, les offensives menées sur leur capital par des fonds d'investissement, elles sont restées aux mains des agriculteurs, ou plutôt aux mains des plus importants d'entre eux. Mieux, ces anciennes coopératives ont adopté ces dernières années des stratégies de valorisation financière de leurs actifs ${ }^{34}$ et témoignent d'une véritable « financiarisation à l'envers » (Burch et Lawrence, 2009) menée par les élites sectorielles agricoles.

Il est donc légitime de s'interroger sur la capacité de ces élites sectorielles à se réapproprier ces dispositifs de la financiarisation pour maintenir leur position entre le global et le secteur. Cette interrogation est d'autant plus légitime que les véhicules financiers ont des durées de vie limitées comprises entre dix et douze ans, et, à échéance, les gestionnaires du fonds doivent revendre les exploitations agricoles ; qui seront alors les prochains acquéreurs de ces exploitations?

\section{" Conclusion}

Nous avons tenté d'analyser les dynamiques sociales qui conduisent une pluralité d'acteurs, financiers et non financiers, à s'engager dans la production d'un produit financier, en l'occurrence un fonds d'investissement dédié au foncier agricole sudafricain. Ce processus de production mobilise des dispositifs cognitifs et techniques spécifiques, à la fois pour coordonner les investisseurs, les gestionnaires, les consultants et les sous-traitants entre eux, et pour valoriser l'actif sous-jacent. La mise en relation de ces acteurs et l'autonomisation progressive de ces filières transforment progressivement les formes d'organisation de ces acteurs, leurs ancrages territoriaux et sectoriels.

À travers cette approche en termes de filière agrofinancière, apparaissent donc les modalités concrètes de circulation du capital. Cette circulation s'organise autour de la construction d'un produit financier, c'est-à-dire la transformation d'une activité économique, la production agricole, et/ou d'un bien, le foncier agricole, en titre financier. Un autre visage au processus de financiarisation de l'agriculture est alors donné, qui dépasse l'opposition entre agriculture et finance et souligne les ramifications qui se développent. Par ailleurs, la financiarisation n'est pas le processus englobant et homogénéisant parfois décrit, mais plutôt le produit de configurations sociales spatialement et temporellement situées. Par exemple, la capacité des gestionnaires de fonds à enrôler et à conserver des agriculteurs locaux détermine largement le succès de leurs opérations de valorisation du foncier agricole.

33. Marketing of Agricultural Products Act (1996).

34. À travers par exemple la création de sociétés d'investissement spécialisées (Ducastel et Anseeuw, 2014). 
Le cas du secteur agricole sud-africain est particulièrement intéressant pour enrichir les études sur la financiarisation. En effet, les fondations sociales et politiques du secteur ont été consolidées et stabilisées tout au long de l'apartheid. Le développement des filières agrofinancières repose sur la capacité des gestionnaires à contourner ou à mobiliser ces structures sectorielles. Les élites agricoles sudafricaines sont aujourd'hui partagées entre contestation et coopération à l'égard de ces fonds d'investissement et de leurs filières. Ces lignes de fracture au sein du secteur agricole détermineront alors largement la recomposition de l'agriculture à la fois comme espace social et comme activité économique. 


\section{Partie III}

Diversité, hybridation et renouvellement des approches institutionnalistes 



\title{
Chapitre 16 \\ Les analyses en termes \\ de « food regime» : une relecture
}

\author{
J. WiLKInSON, D. GOODMAN
}

Depuis quelque trente années, les travaux menés sous l'appellation de « food regime analysis » - théorie des régimes agroalimentaires ${ }^{1}$ - ont fourni au monde anglo-saxon un cadre d'analyse macrohistorique pour les études du secteur agroalimentaire, servant de guide tant pour la compréhension des changements systémiques que pour la construction des programmes de recherche. Critiquée pour ses grands récits et son historiographie, directement remise en cause dans les années 1990 par les tenants du «tournant de la qualité », cette approche a depuis connu une résurrection (Le Heron et Lewis, 2009 : 346) et est devenue la perspective conceptuelle retenue par beaucoup de chercheurs pour analyser les vastes transformations en cours dans le système agroalimentaire mondial. Diverses interprétations des moteurs de ces changements et l'identification des projets alternatifs ont elles-mêmes prétendu partir du récit historique proposé par la théorie des régimes agroalimentaires.

Le contenu de la théorie des régimes agroalimentaires - qui depuis le départ est un mélange de différentes traditions intellectuelles, incluant la théorie des systèmes Monde, la théorie des régimes internationaux et l'approche de l'école française de la régulation - a de son côté évolué sous l'effet des différents débats contemporains. Le récit initial continue cependant de servir de cadre de référence standard pour resituer les transformations du niveau macroéconomique.

Dans ce chapitre, nous affirmons que l'analyse que propose la théorie des régimes agroalimentaires des transformations historiques des systèmes agroalimentaires est imparfaite et nous discutons comment son cadre analytique empêche de pleinement comprendre les transformations que connaît l'économie politique agricole internationale en ce début du $\mathrm{XXI}^{\mathrm{e}}$ siècle. Plutôt que d'entreprendre une exégèse critique des textes, nous nous sommes concentrés sur la «version stylisée » de la théorie

1. Note des éditeurs. Nous avons traduit l'expression «food regime » par « régime agroalimentaire ». En effet, en français, l'expression « régime alimentaire » est couramment utilisée pour qualifier le modèle de consommation alimentaire d'une population donnée, donc dans un sens bien plus restrictif. En outre, la plupart des travaux discutés dans ce chapitre accordent une large place à l'analyse de la production agricole, bien plus large d'ailleurs qu'à celle de la consommation. Néanmoins, le terme agroalimentaire a le défaut de ne pas rendre compte de la dimension agro-industrielle autre qu'alimentaire qu'il convient d'inclure dans cette perspective (voir chapitre 9). 
des régimes agroalimentaires qui prédomine dans la littérature sur les systèmes agroalimentaires. Nous pensons que la principale limite de cette version réside dans l'importance exagérée qu'elle donne aux ruptures systémiques et à la succession des hégémonies. Ce biais a conduit les analyses à négliger les situations de multipolarité dans le système capitaliste mondial, ainsi que les continuités historiques des stratégies d'accumulation dans le secteur agroalimentaire adoptées par les autres puissances ascendantes. Pour cette raison, nous pensons qu'il est plus exact historiquement et plus éclairant analytiquement de considérer une pluralité d'ordres alimentaires régionaux qui partagent, de manière croissante, des frontières scientifique et technologique similaires et des arrangements institutionnels communs plutôt que de conserver les concepts d'hégémonie et de "régime agroalimentaire international ».

Dans le texte qui suit, nous défendons la nécessité d'une réévaluation fondamentale des concepts centraux, relations de causalités, périodisations et dispositifs analytiques de la théorie des régimes agroalimentaires. Nous basons notre argumentation sur un examen de la trajectoire agraire de l'Europe de l'Ouest depuis 1870, la caractérisation des économies paysannes du Sud, l'impact de l'aide alimentaire américaine, la Révolution verte, les relations de pouvoir Nord/Sud et les principaux moteurs de changement dans le système agroalimentaire mondial contemporain.

Les récentes contributions de l'histoire mondiale, discipline en pleine ébullition, qui n'était pas disponible pour les initiateurs de la théorie des régimes agroalimentaires, ont mis à jour les sérieuses faiblesses de leur récit historique fondateur. Le cadre homogénéisant des « régimes » et des «stratégies hégémoniques » échoue à reconnaître la diversité des trajectoires agraires et la variété du paysage institutionnel existant depuis la deuxième moitié du XIX ${ }^{\mathrm{e}}$ siècle. Il a aussi bien du mal à expliquer l'émergence d'une « agriculture sociale » et des « systèmes alimentaires localisés » depuis les années 1980 dans le Nord, et surtout dans l'Union européenne (Goodman et al., 2011 ; Buller, 2004).

Ce désintérêt pour les différences régionales et nationales et pour les multipolarités qu'elles produisent est à l'origine de prédictions radicales, mais erronées sur les futurs politiques et économiques du Sud. Il est aussi la cause d'un soutien déplacé à une stratégie exclusive de souveraineté alimentaire centrée sur la paysannerie. En bref, soumettre le récit de la théorie des régimes agroalimentaires à une analyse critique approfondie est maintenant devenu une précondition pour une caractérisation adéquate du système agroalimentaire mondial et de ses trajectoires futures.

Bien que notre récit alternatif ne soit encore qu'un squelette, nous espérons qu'il offre un aperçu convaincant des idées (connaissances) que pourrait générer une approche multipolaire et pluraliste de l'émergence d'un système agroalimentaire mondial qui dégage les continuités historico-spatiales et leur pertinence pour comprendre les évolutions actuelles.

La première section du chapitre critique la présentation du premier « régime agroalimentaire » en termes d'hégémonie britannique. Nous prétendons que cette vision oblitère les politiques alternatives mises en œuvre par les économies montantes d'Europe continentale et de quelles façons leurs trajectoires agraires ont structuré l'agriculture et le système alimentaire de l'après-guerre jusqu'à la période actuelle. 
La théorie des régimes agroalimentaires ne saisit pas ces différences régionales et, de ce fait, ne peut reconnaitre leur importance pour comprendre les formes des changements en cours. De même, en donnant une importance disproportionnée à l'hégémonie britannique et aux rôles des nouveaux pays (États-Unis, Canada, Australie, Nouvelle-Zélande), le récit de la théorie des régimes agroalimentaires présente un traitement tronqué et partiel du colonialisme qui sous-estime son impact dévastateur sur les économies et les sociétés rurales, et sur leur capacité à mener un développement autonome basé sur la paysannerie. Enfin, il ignore la politique de colonialisme préventif basé sur les ressources menée par le Japon qui a tant transformé le paysage asiatique et qui explique le rôle clef que joue le Japon dans la structuration du système alimentaire mondial jusqu'à aujourd'hui.

La deuxième section met l'accent sur les différents modèles d'accumulation sur lesquels ont reposé le premier et le second « régime agroalimentaire », et questionne les analyses existantes de l'aide alimentaire américaine, de la Révolution verte et de l'internationalisation de l'agro-industrie américaine. Nous critiquons la théorie des régimes agroalimentaires pour son utilisation de généralisations erronées et pour son désintérêt pour les continuités historiques et les différences géographiques. Selon nous, l'aide du Plan Marshall, qui dans la théorie des régimes agroalimentaires est d'abord considérée comme une manifestation de l'internationalisation du complexe agroalimentaire américain, remet sur les rails les trajectoires respectives des systèmes agroalimentaires européens et japonais établies durant la deuxième moitié du XIX ${ }^{\mathrm{e}}$ siècle. Bien que l'aide alimentaire américaine ait pu avoir un impact dévastateur sur les petits pays dotés d'un État faible, sa logique était avant tout géopolitique et dirigée vers des grands pays stratégiques qui avaient généralement la capacité de définir leur propre politique. En outre, beaucoup de ces pays étaient des producteurs et des consommateurs de blé de telle façon que l'aide alimentaire a eu peu d'impact sur les modèles alimentaires. Les technologies de la Révolution verte ne doivent pas non plus être vues exclusivement sous l'angle de l'hégémonie américaine. Beaucoup d'avancées génétiques dans la création variétale ont été le produit du réseau de recherche publique internationale qui a mené ses travaux sur le blé et, surtout, sur le riz dans une perspective tiers-mondiste. La Révolution verte chinoise des années 1960 est ici un cas exemplaire (Naughton, 2007). De la même façon, l'accent mis sur le régime agroalimentaire américain minimise l'énorme influence de l'Union soviétique et de la Chine dans les restructurations agraires menées dans beaucoup de pays africains et asiatiques, restructurations qui ont affaibli l'agriculture paysanne bien plus radicalement que l'aide alimentaire.

La troisième section examine les débats récents concernant les forces de changement actuellement en œuvre dans les systèmes agroalimentaires. Nous remettons en cause le postulat d'une hégémonie du Nord, et nous défendons l'idée que la montée des Brics et des autres pays émergents crée un ordre mondial polycentrique. Nous questionnons aussi la pertinence analytique et politique des perspectives Nord/Sud adoptées par les récits de la théorie des régimes agroalimentaires. Tout en reconnaissant la façon dont l'agriculture et la terre ont été incorporées de manière croissante dans la dynamique de financiarisation, nous affirmons que les nouvelles demandes des pays émergents pour les produits alimentaires, les aliments de bétail et les ressources naturelles en sont les principaux moteurs. Les politiques de soutien aux agrocarburants, promues 
durant la première décennie du millénaire par le Brésil, les États-Unis et l'Union européenne, ont aussi été importantes, et ont certainement été un facteur clef dans la volatilité et les flambées des prix de la période. Finalement, la notion de « régime agroalimentaire » ne permet pas de mettre à jour ce qui, dans la dynamique historique du développement capitaliste, est lié à la stratégie d'accès aux ressources naturelles, stratégie au sein de laquelle la nourriture occupe une place particulière. La réduction progressive de l'agriculture à l'alimentation durant le $\mathrm{Xx}^{\mathrm{e}}$ siècle peut ainsi être mieux comprise comme le résultat d'une stratégie visant à remplacer des ressources naturelles par des ressources synthétiques, un processus aujourd'hui partiellement inversé, ce qui renforce l'importance du contrôle sur la terre et les ressources qu'elle porte, en particulier face à la demande croissante des pays émergents.

\section{" Le premier régime agroalimentaire}

Comme nous l'avons mentionné dans l'introduction, l'idée qu'un régime agroalimentaire mondial s'organise autour de l'intérêt de l'hégémon interdit de voir les développements alternatifs que connaissent les économies montantes concurrentes en réponse aux ambitions hégémoniques. Les conséquences de cet « oubli » sont clairement révélées par la caractérisation et la périodisation problématique du premier régime agroalimentaire, couvrant la période allant du début des années 1870 à 1914.

Cette période est classiquement caractérisée par une expansion rapide du commerce international qui, dans le cadre de l'hégémonie anglaise, repose sur les exportations, par les colonies et les nouveaux pays, de produits alimentaires de base destinés aux prolétariats industriels en croissance, en échange de biens manufacturés. Cependant, l'Allemagne et les États-Unis défient le leadership industriel britannique et recourent au protectionnisme pour contrer son pouvoir hégémonique. Le Japon, de son côté, après avoir accru la production agricole au nord, dans l'île de Hokkaido, avance à Formose, en Corée et, plus tard, en Mandchourie (Cwiertka, 2006). Les stratégies d'approvisionnement en ressources, qu'elles prennent la forme du protectionnisme ou du colonialisme, ne se limitent pas à l'alimentation et comprennent aussi l'accès à des matières premières, en particulier le coton, le bois ou le charbon.

La théorie des régimes agroalimentaires échoue à reconnaître le caractère unilatéral de l'adoption du libre-échange par la Grande-Bretagne et sa volonté de «sacrifier son agriculture », selon l'expression de Polanyi (1957). La voie britannique, entérinée par l'abolition des Corn Laws en 1846 (Schonhardt-Bailey, 2006) et l'abrogation des Navigation Acts en 1849, n'a été suivie que brièvement par les autres puissances européennes dans les années 1850 et après le Traité franco-britannique de 1860. Cet interlude s'est avéré être de courte durée alors que la chute du prix du transport maritime après 1851 renforçait, lentement mais sûrement, la compétitivité du blé des États-Unis et menaçait les agricultures européennes (North, 1958).

Loin de reproduire le modèle britannique, l'Europe continentale a pris une trajectoire radicalement différente. En réponse à l'émergence d'un marché mondial du blé ${ }^{2}$ et aux chutes de prix constatées sur les marchés internationaux, les grandes

2. La théorie des régimes agroalimentaires, à la différence de la théorie de la régulation, met l'accent sur le commerce plutôt que sur les relations intersectorielles intranationales. La décennie $1870 \mathrm{a} v \mathrm{vu}$ 
puissances européennes continentales ont réinstitué des politiques de protection de l'agriculture, tout en accordant des avantages tarifaires sélectifs pour les matières premières industrielles essentielles au fur et à mesure du développement de la base productive de leurs colonies (Gerschenkron, 1989 [1943]).

À la fin des années 1870, le protectionnisme est en place en Europe continentale. Il renforce les classes agraires traditionnelles et soutient la petite agriculture familiale et les territoires ruraux (Tracy, 1982). Ces politiques agricoles et alimentaires protectionnistes sont confirmées avant 1914, renforcées dans la période d'entre-deux-guerres et poursuivies après la Deuxième Guerre mondiale dans le cadre de la Politique agricole commune. Plus récemment, elles sont revenues en vogue dans l'Union européenne sous la forme des programmes qui visent des objectifs de développement rural et de systèmes alimentaires territorialisés. Ces développements, depuis les années 1980, ne peuvent être compris que si nous nous intéressons aux systèmes agricoles («farming systems ») et agroalimentaires qu'a connus l'Europe continentale, plutôt que la Grande-Bretagne, et aux institutions qui leur correspondent, ou " ordres », « ordres » dont l'origine peut être trouvée dans les politiques adoptées dans le dernier quart du XIX ${ }^{\mathrm{e}}$ siècle, politiques bien éloignées du modèle libre-échangiste britannique.

En résumé, une histoire mondiale proposant une interprétation en termes de modèle hégémonique britannique est mal équipée pour rendre compte des différentes trajectoires de l'agriculture et du développement rural en Europe, et de leurs conséquences pour les systèmes agroalimentaires actuels. Elle est tout autant incapable de saisir le rôle de l'agriculture et de l'alimentation dans le développement du capitalisme américain au XIX ${ }^{\mathrm{e}}$ siècle ou les stratégies différentes mises en œuvre par le Japon. Le modèle de l'exploitation agricole familiale spécialisée du Midwest, identifié par Friedmann (1978), qui a permis la formation du marché mondial des grains a dépendu en amont du prodigieux développement du secteur du machinisme agricole américain, et en aval de l'émergence d'une industrie nationale de transformation et de conserve qui s'internationalise très rapidement à la même période (Aglietta, 1979 ; Brenner et Glick, 1991). Bien que le Japon ait vu l'ouverture de ses ports imposée par l'Américain Perry en 1854, pour le plus grand profit des Britanniques, le pays a pu créer sa propre base régionale d'approvisionnement, base régionale qui, dans les années 1930, fournissait $20 \%$ de ses besoins en riz (Smil et Kobayashi, 2012).

Une seconde, et sans doute plus problématique, limite du récit relatif au premier régime agroalimentaire est que sa base empirique porte entièrement sur les relations commerciales entre la Grande-Bretagne et les économies pionnières des ÉtatsUnis d'après la guerre de Sécession et d'Océanie (Australie et Nouvelle-Zélande), « économies clairement distinctes des trois continents où la « question paysanne » s'est posée le plus brutalement, dans le contexte colonial et après » (Bernstein, 2014 : 1037). Cet auteur ajoute : « les paysanneries sont globalement absentes du premier siècle [...] qui est analysé par la théorie des régimes agroalimentaires, si ce n'est qu'en étant affectées par les courants d'échanges que le régime [britannique] à contribuer à créer » puisque ces nouveaux pays (avec lesquels commerce la Grande-Bretagne) « en effet [...] manquent précisément de paysanneries » (ibid., 1037-1038).

l'émergence d'un marché de niveau mondial du blé, mais, d'un point de vue institutionnel, le régime britannique a été mis en place dans les années 1840-1850. 
Le colonialisme est présent dans le récit relatif au premier régime agroalimentaire sous la forme réduite du développement des nouveaux pays d'Amérique du Nord et d'Océanie, et de leur intégration comme greniers et fronts pionniers soumis à l'hégémonie britannique. Ce récit extrêmement sélectif laisse de côté sans plus de discussion l'impact de l'expansion impériale en Inde, dans l'Extrême-Orient et dans les territoires saisis lors de la ruée vers l'Afrique. Cette vision partielle sous-tend en revanche une proposition centrale de la théorie des régimes agroalimentaires, celle selon laquelle la désarticulation des économies paysannes du Sud est un phénomène propre au deuxième régime agroalimentaire causée par l'aide alimentaire américaine, la Révolution verte et l'internationalisation du système agroalimentaire américain.

Les nouveaux pays pionniers, et en particulier les États-Unis, le Canada, l'Australie et la Nouvelle-Zélande, occupent une place centrale dans le récit relatif au premier régime agroalimentaire et sont principalement analysés du point de vue de leur contribution à la création d'un marché mondial des céréales et à la baisse des prix. En fait, seuls les États-Unis jouent un rôle important durant la période 1870-1900 avec l'avancée de sa frontière agricole. La Russie est le seul concurrent significatif dans ce commerce en croissance, tandis que la contribution de l'Inde dépasse de loin celle de l'Australie à cette période (Tracy, 1982). Ce marché des céréales en pleine expansion conduit à un déclin drastique de la production céréalière en Grande-Bretagne et à la disparition du modèle du gentleman farmer adepte du « high farming ». En Europe continentale, comme nous l'avons vu, la protection limite l'impact de la concurrence mondiale, permet de maintenir la production céréalière, y compris en combinaison avec des importations, et facilite la transition des agriculteurs vers des exploitations laitières mixtes (Tracy, 1982).

Il faut souligner que, dans les nouveaux pays, l'agriculture et la production alimentaire sont subordonnées aux stratégies domestiques d'industrialisation. Bien qu'intégré aux marchés mondiaux, le système agroalimentaire de ces pays contribue au développement national. Cette situation apparaît clairement dans le Tariff Act américain de 1828 qui protège l'industrie textile des États du Nord contre les importations britanniques au détriment des États du Sud, principal fournisseur de coton de la Grande-Bretagne. L'Australie et la Nouvelle-Zélande favorisent de la même manière le développement industriel à l'abri de mesures protectionnistes pour créer des sources alternatives d'emploi, et ainsi prévenir l'avancée continue de la frontière agricole et les revenus décroissants qu'impliquerait la spécialisation dans le seul secteur primaire (Reinert, 2007).

Bien que le récit relatif au premier régime agroalimentaire reconnaisse l'importance de l'esclavage et des économies de plantation dans les relations britanniques et européennes avec le nouveau monde, il est tacitement supposé qu'en général le colonialisme a laissé les systèmes alimentaires et le monde rural foncièrement inchangé. Ce récit donne une représentation fausse de la logique du colonialisme, du capitalisme marchand et de leur impact dévastateur sur le tissu économique et social des sociétés rurales, incluant la destruction des proto-industries rurales et l'adoption de mesures visant à restreindre le développement d'une production industrielle (Parthasarathi, 2011 ; voir aussi Pomeranz, 2000 ; Beckert, 2014). À l'inverse, la désindustrialisation (Bagchi, 2010) ou la « re-primarisation » (Reinert, 2007) a augmenté la pression sur les terres puisque les autres activités et sources de subsistance ont été supprimées. Bagchi (2010) rend compte du processus en Inde, mais identifie les mêmes 
processus à l'œuvre en Chine, en Birmanie, aux Philippines, en Thaïlande, en Égypte et dans l'Empire ottoman. La combinaison du colonialisme et du « capitalisme libreéchangiste de la canonnière » a détruit l'économie rurale diversifiée et l'a réduite à une production paysanne de subsistance.

La période couverte par le premier régime agroalimentaire (1870-1914) est un mauvais choix puisqu'elle correspond au retour généralisé vers le protectionnisme dans l'Europe continentale et à l'extension de la domination coloniale. De fait, la période antérieure, de 1840 au début des années 1870, correspond véritablement à l'apogée de l'institutionnalisation du régime agroalimentaire britannique. Les pays pionniers, de leur côté, ont mené des politiques subordonnant l'agriculture et l'alimentation à l'objectif de développement industriel. Plutôt qu'un seul régime agroalimentaire mondial, nous pouvons identifier la consolidation d'une variété de différents régimes agroalimentaires « nationaux-coloniaux » en lien avec des marchés mondiaux émergents.

\section{" Le deuxième régime agroalimentaire}

Selon la théorie des régimes agroalimentaires, le passage du premier au second régime est caractérisé simultanément par une rupture et un changement d'hégémonie - de la Grande-Bretagne aux États-Unis - et par la continuité dont témoigne l'usage, pour caractériser les deux périodes, de la notion de régime agroalimentaire mondial. Dans la pratique cependant, il s'agit de deux processus qualitativement très différents. Durant la période 1870-1914, classiquement considérée comme celle du premier régime, la Grande-Bretagne promouvait une organisation internationale de la production du commerce de produits alimentaires et de matières premières agricoles qui représentait une composante intégrale de son modèle d'accumulation. Dans ce cas spécifique, et contrairement aux puissances montantes de l'Europe continentale, l'agriculture était délibérément subordonnée aux besoins de l'industrie, et le modèle alimentaire britannique, ainsi que la relation entre salaire et alimentation étaient structurés par le commerce international ${ }^{3}$.

Dans le cadre du second régime, produit de l'hégémonie américaine, la relation entre commerce international et biens de consommation pour les salariés n'est plus centrale dans le modèle d'accumulation. Dans sa présentation de l'approche de la régulation, Aglietta (1979) identifie une relation intersectorielle classique entre agriculture et industrie, dans le cadre de l'économie nationale américaine, comme une dimension caractéristique du modèle d'accumulation « fordiste », avec la combinaison de nourriture bon marché et de grandes quantités de protéines animales, et la consommation de masse de biens manufacturés. Les produits coloniaux ou quasi coloniaux sont limités, pour l'essentiel, au sucre et aux fruits.

De ce fait, dans ce récit, les dimensions internationales ou globales du second régime émergeraient de la géopolitique de la Guerre froide. Elles se manifesteraient

3. Alors que la théorie des régimes agroalimentaires donne une très grande place aux grains et plus tard au bœuf, le modèle alimentaire britannique était aussi largement dépendant du sucre, du thé, du beurre, du lard, des pommes de terre, du poisson et de la bière (Oddy, 2003). 
initialement dans le cadre du Plan Marshall avec l'envoi d'excédents de blé américain à l'Europe de l'Ouest ravagée par la guerre, et plus tard dans la stratégie d'aide alimentaire, institutionnalisée en 1954 par la loi PL 480, qui allait devenir une composante majeure de la relation salariale dans quelques pays en cours d'urbanisation et ayant une politique d'industrialisation par substitution aux importations. La dimension globale du régime agroalimentaire serait en outre renforcée, selon les arguments avancés, par l'internationalisation du complexe agro-industriel américain, plus connu sous le nom de « Révolution verte ». La dynamique du second régime agroalimentaire serait donc significativement différente de celle du premier régime.

Dans le cadre général de ce second régime, nous allons examiner un peu plus en détail le Plan Marshall, l'aide alimentaire et la Révolution verte. Immédiatement après la Seconde Guerre mondiale, les alliés mettent en œuvre le Plan Morgenthau dont le but est la désindustrialisation de l'Allemagne et sa transformation en pays agricole. Deux ans plus tard, le déclin accéléré de la productivité agricole et l'apparition d'une situation de surpopulation dans les campagnes conduisaient à l'adoption du Plan Marshall. Désormais, les exportations agricoles et la production alimentaire ne devenaient qu'une des composantes d'une stratégie plus large visant à la réindustrialisation non seulement de l'Allemagne, mais aussi des autres pays jouant le rôle de zone tampon avec l'URSS : la Norvège, la Corée du Sud et le Japon. Plutôt qu'une diffusion internationale du modèle américain, chacun de ces pays s'est redéveloppé sur la base de ses caractéristiques historiques, le protectionnisme étant une composante intrinsèque du Plan. Parallèlement à sa réindustrialisation, chaque pays a reconstruit son agriculture et son système alimentaire sur la base des ressources et des capacités domestiques (Reinert, 2007). Ainsi, il n’y eut pas une généralisation du modèle agroalimentaire américain.

Comme stratégie géopolitique, l'aide alimentaire a été une opération hautement sélective. La plus grande part des livraisons a été à des grands pays en développement, où la consommation de blé était traditionnelle. Bien que la production d'aliments locaux dans des petits pays comme la Colombie (Friedmann, 1982 ; Gaviria, 2011) ait pu indiscutablement souffrir des importations de céréales subventionnées, la plupart des grands pays en développement ayant reçu de l'aide alimentaire sont demeurés des grands producteurs et exportateurs de céréales. Plus généralement, la théorie des régimes agroalimentaires voit l'aide alimentaire et les technologies de la Révolution verte comme des forces combinées qui auraient affaibli les agricultures du tiers-monde, rangées de manière normative dans la catégorie indifférenciée de « paysannerie ». Mais cette représentation ne permet pas de comprendre comment un ensemble de pays asiatiques ont été capables de combiner réception d'aide alimentaire et investissement dans des stratégies de développement fructueuses ${ }^{4}$.

De la même façon, les programmes nationaux de développement agricole et les institutions politiques mises en place par différents pays latino-américains en cours d'industrialisation, adoptées alors même que l'aide alimentaire américaine était à son sommet, ont permis au cône Sud d'émerger comme un concurrent des États-

4. La Corée du Sud était le septième récipiendaire de l'aide alimentaire dans les années 1960, avant de monter à la troisième et quatrième place dans les années 1970 et 1980. Aujourd'hui, elle n'apparaît plus dans la liste des quinze premiers récipiendaires. 
Unis après la crise alimentaire des années 1970. Le Brésil, par exemple, qui était un bénéficiaire important d'aide en blé dans les années 1950, a vu sa production nationale de blé promue par une politique de substitution aux importations et de modernisation, incluant des crédits subventionnés, des droits de douane protecteurs, des importations de tracteurs et l'appui aux coopératives. C'est ce secteur, soutenu par l'État, d'exploitations familiales hautement capitalisées et organisées dans de puissantes coopératives qui a permis au Brésil de répondre rapidement aux opportunités créées sur le marché international du soja par la mise en place de l'embargo américain en 1973. Sans ces politiques nationales, le Brésil n'aurait pas pu défier les ÉtatsUnis pour le titre de premier pays exportateur de produits agricoles du XXI ${ }^{\mathrm{e}}$ siècle.

L'analyse de l'aide alimentaire par la théorie des régimes agroalimentaires est basée sur une caractérisation très générale des pays alors dits du «tiers-monde » qui la rend aveugle à la capacité institutionnelle des pays en développement les plus grands à poursuivre leurs propres priorités stratégiques dans le domaine agroalimentaire. Ce manque de différenciation des situations interdit de comprendre la montée des Brics (Brésil, Russie, Inde, Chine, Afrique du Sud) et le défi que cela pose aujourd'hui aux États-Unis et à l'Europe.

L'analyse selon laquelle le renouveau de l'Europe après la Seconde Guerre mondiale serait essentiellement l'expression de l'internationalisation du système agroalimentaire américain est, comme nous l'avons vu, également biaisée. La relation entre la reconstruction industrielle de l'Europe dans l'après-guerre et l'émergence de la Politique agricole commune (PAC) dans les années 1960 est oubliée dans ce récit. Loin de représenter une simple adoption du modèle régulateur américain des années 1930, la PAC présente de fortes continuités avec les politiques protectionnistes adoptées depuis 1870 et renforcées par les deux terribles guerres mondiales et leurs suites. C'est seulement en donnant toute son importance à ces voies alternatives de développement agricole que peut être appréciée la signification des politiques et des trajectoires européennes spécifiques - territorialité, multifonctionnalité, indications géographiques -, et que peut être reconnue leur contribution particulière aux débats actuels sur la configuration et la dynamique du système alimentaire mondial.

L'accent exagérément mis sur l'internationalisation du modèle agroalimentaire américain ignore aussi le cas du Japon, qui a non seulement défendu son système alimentaire traditionnel basé sur le riz en contrôlant l'accès à son marché intérieur, mais a aussi développé de puissants négociants internationaux de matières premières agricoles et activement exploité les « nouvelles frontières agricoles » à l'étranger (Ciccantell, 2009) pour faire face à ses propres besoins alimentaires. Cela inclut les cerrados du Brésil qui ont servi à consolider la position de ce pays dans les marchés mondiaux de céréales et oléagineux après 1970. Brautigam (2009) et Ciccantell (2009) suggèrent tous deux que la stratégie d'accès aux ressources suivie par le Japon lors de son ascension a pu servir de modèle à la Chine pour ses investissements actuels dans le pétrole, les minerais et l'agriculture. Le Japon est de nouveau en train d'émerger comme un acteur clef du développement agroalimentaire via l'expansion agressive de ses négociants et la promotion de nouvelles frontières agricoles, notamment dans le corridor de Nacala au Mozambique (Hall, 2015).

Parallèlement à l'aide alimentaire, la théorie des régimes agroalimentaires considère que la Révolution verte est la deuxième dimension de l'internationalisation du 
modèle agro-industriel américain, avec des effets également déstabilisateurs pour les paysanneries du tiers-monde. Il faut cependant rappeler que les principales plantes concernées - le blé et le riz - ont été l'objet de recherches menées par un réseau international public de centres de recherche agricole (CGIAR). En outre, la Chine, pourtant coupée du commerce et des investissements internationaux dans les années 1960, a mené sa propre Révolution verte sur les mêmes bases : création de variétés à haut rendement capables de répondre aux engrais et destinées à l'irrigation (Naugthon, 2007). Ainsi, ces innovations doivent d'abord être vues comme le résultat généralisé d'un paradigme technologique dominant et disponible mondialement.

Comme nous l'avons noté plus haut, les nombreuses paysanneries du Sud avaient déjà été réduites à l'état d'économie de subsistance alimentaire et de producteur de matières premières lors de la colonisation aux $\mathrm{XIX}^{\mathrm{e}}$ et $\mathrm{XX}^{\mathrm{e}}$ siècles. L'accent actuellement mis sur la promotion d'un système alimentaire alternatif basé sur la paysannerie ignore le fait que le colonialisme et les ravages exercés par les luttes des indépendances et les stratégies post-indépendance, y compris les expériences collectivistes, ont ruiné les bases nécessaires à des économies rurales viables en désarticulant les systèmes agricoles traditionnels et en détruisant les industries rurales. De ce point de vue, l'influence du bloc soviétique et de la Chine sur le développement rural des pays non alignés est totalement absente du récit des «food regime analysis ». Dans de nombreux pays, particulièrement en Afrique, les politiques de collectivisation ont, dans les campagnes, détruit les pratiques et les droits traditionnels bien plus que l'aide alimentaire.

\section{" La théorie des régimes agroalimentaires et les transformations en cours de l'agroalimentaire mondial}

Les crises multiples des années 1970, interprétées par la théorie des régimes agroalimentaires comme la disparition du second régime agroalimentaire dominé par les États-Unis, ont provoqué de riches débats sur les contours d'un nouveau régime mondial, proposant des caractérisations diverses, mais souvent complémentaires : gouvernance privée (ou privée/publique) via les standards et la certification, reconstruction des chaînes d'approvisionnement sous la tutelle des multinationales de la distribution libérées de leur ancrage national, nouveau paradigme biotechnologique réorganisant l'agriculture mondiale, nouvelle dynamique Nord/Sud basée sur les exportations de produits alimentaires non traditionnels et, dans le sillage de la crise financière mondiale de 2007-2008, subordination croissante des systèmes agroalimentaires aux rythmes du capital financier.

Néanmoins, ces débats sur les forces motrices d'un éventuel troisième régime agroalimentaire, souvent qualifié de « régime néolibéral d'entreprise », ont en commun une focalisation exclusive sur les acteurs du Nord et sont tous basés sur une géopolitique mondiale dépassée. La référence demeure celle d'un ordre mondial fondé sur l'hégémonie Nord-Atlantique, de manière prépondérante sur les États-Unis et les transnationales de l'agroalimentaire, qui repose sur une relation asymétrique Nord/Sud et propose une lecture centre-périphérie des relations inter-étatiques. Le Japon, les nouveaux pays industriels asiatiques, des pays comme la Thaïlande, qui sont historiquement passés 
entre les mailles de la colonisation, le développement du complexe agroalimentaire du cône Sud et, surtout, la montée de la Chine remettent pourtant en cause la caractérisation générale d'un Sud simple instrument des intérêts du Nord.

Ce cadre homogénéisant va dans le même sens que le récit qui met en lien la désarticulation des économies paysannes après 1950 avec l'aide alimentaire américaine et l'internationalisation des technologies de la Révolution verte. Dans ce récit, ces déterminants ont été renforcés par les réformes néolibérales imposées par le FMI (Fonds monétaire international) et la Banque mondiale dans le cadre du Consensus du Washington après la crise mondiale de la dette du début des années 1980, réformes qui ont conduit à une réduction des programmes de développement rural, des subventions et des pouvoirs réglementaires des agences publiques.

La difficulté avec cette perspective provient, à nouveau, de sa vision « centre/périphérie » qui ne fournit que de faibles fondations pour la généralisation et conduit à l'impossibilité de reconnaître la persistance d'États porteurs d'un projet de développement national, la diversité des relations État/économie dans le Sud et l'affaiblissement de l'hégémonie néolibérale (Arrighi, 2007 ; voir aussi Storz et al., 2013 ; Cooper et Flemes, 2013). Cette diversité a été clairement mise à jour récemment par les analyses des Brics qui « défendent un rôle pour l'État dans le développement bien au-delà des limites que fixe le Consensus de Washington » (Ban et Blyth, 2013 : 242). En outre, « la vision d'un commerce mondial qui reposerait principalement sur des échanges Nord/Nord et Nord/Sud a été définitivement contestée par le boum des investissements extérieurs des Brics dans les pays développés comme dans les pays en développement » (ibid., 243).

Cette dernière analyse souligne la survivance de la diversité dans l'économie mondiale. Chaque pays des Brics s'est adapté de manière particulière au Consensus de Washington tout en conservant un rôle central pour l'État, que cela soit sous la forme d'investissements publics ou de politiques de crédit, pour soutenir les « industries nationales championnes », comme dans le cas de la Chine, ou dans le cas du Brésil sous la forme hybride d'une « néo-développementalisme libéral » (Ban, 2013) qui se traduit par des participations de l'État dans les secteurs stratégiques pour garantir leur compétitivité. Comme Wilkinson (2014) le souligne, les Brics «ont tous des États développeurs forts, avec des firmes publiques et des banques nationales de développement qui jouent le rôle d'acteurs stratégiques. Ils n'agissent jamais comme ou ne ressemblent pas au modèle d'un régime néolibéral. »

De nombreux travaux de géopolitiques et d'économie politique internationale montrent l'existence d'une rivalité inter-étatique et la montée d'un ordre mondial multipolaire : « nouveau dynamisme régional » (Schott, 2009), architecture changeante de la gouvernance mondiale (Golub, 2013 ; Mielniczuk, 2013), et montée en puissance économique de l'Asie du Sud-Est et de la Chine (Arrighi, 2007 ; Breslin, 2005, 2011 ; Strange, 2011). Ces travaux renforcent l'idée d'une redéfinition de la hiérarchie du système capitaliste mondial sous l'effet des économies émergentes du Sud agissant en son sein. Selon la formule de Golub (2013 : 1000) :

« Le système mondial vertical de la modernité tardive centré sur l'Ouest laisse la place à une structure internationale polycentrique dans laquelle se renforcent les liens régionaux et transnationaux Sud-Sud. » 
Ces arguments ont récemment été renforcés par une étude des principaux négociants internationaux de grains, le groupe de compagnies dites ABCD pour Archer Daniels Midland (ADM), Bunge, Cargill et Louis Dreyfus, qui considère que « le monde de l'agriculture et de l'alimentation est dans un nouveau moment » (Murphy et al., 2012 : 56). Soulignant le rôle essentiel que le Brésil, la Chine et l'Inde jouent désormais dans la négociation commerciale multilatérale, ces auteurs notent qu' « un changement profond est en cours, modifiant l'équilibre des pouvoirs irrévocablement : les pays en développement représentent aujourd'hui $47 \%$ de toutes les importations et plus de la moitié des exportations totales. Les compagnies du groupe $\mathrm{ABCD}$ se repositionnent déjà face à ce changement et sont devenues des acteurs importants au Brésil, en Chine, en Inde et dans les autres économies émergentes. Mais le changement apporte de nouveaux concurrents et de nouvelles tensions politiques » (ibid., 56). Les recherches menées sur le complexe mondial de la viande mettent à jour la nature de ce nouveau défi concurrentiel, soulignant « l'émergence d'une agro-industrie aux caractéristiques chinoises »(Schneider et Sharma, 2014 : 10, italique dans l'original), qui a été particulièrement illustrée par l'acquisition en 2013 du plus grand producteur de porc nord-américain, Smithfield Foods Inc., par la firme chinoise Shuanghui. Ces études renforcent l'idée selon laquelle l'axe Nord/ Sud au cœur de la théorie des régimes agroalimentaires ne reflète plus les modalités et les conflits d'une économie alimentaire mondiale multipolaire en gestation.

À cet égard, l'émergence de la Chine, depuis le début du XxI ${ }^{\mathrm{e}}$ siècle, comme centre de la restructuration de l'agroalimentaire mondial montre clairement la fragilité de ce paradigme. À elle seule, la Chine a aujourd'hui la capacité de redéfinir les règles du jeu sur les marchés mondiaux des matières premières. Après le désastre du Grand Bond en avant et la famine massive qui l'a suivi, la Chine a modernisé son agriculture grâce à une combinaison hybride d'usines d'engrais industriels importées et des capacités locales en amélioration variétale. Une augmentation rapide de la productivité agricole, stimulée par un accès direct aux marchés domestiques en pleine croissance, a permis la première phase de la modernisation industrielle. La deuxième phase, basée sur une intégration à grande échelle des industries des zones côtières d'exportation dans des chaînes mondiales de valeur, a coïncidé avec l'adhésion à l'OMC et un recours planifié aux marchés mondiaux. Au début, ce recours a été limité aux importations de matières premières non alimentaires - produits forestiers, coton et tabac -, la Chine conservant son objectif géopolitique ancien d'autosuffisance en aliments de base. Une stratégie d'importations d'aliments pour animaux et d'huiles végétales (soja) a ensuite été adoptée dans le cadre d'une politique donnant la priorité aux cultures alimentaires de base, notamment au maïs. Cependant, avec la hausse des revenus, l'urbanisation rapide et la transition vers des modes de consommation alimentaires « occidentaux », marqués notamment par l'importance des protéines animales, cette politique a été redéfinie, et la Chine a assoupli ses quotas d'importation sur le maïs, le blé et d'autres céréales pour stimuler la production animale sous la forme croissante de complexes industriels (Naughton, 2007 ; Aglietta et Bai, 2013).

L'ampleur de la demande chinoise en produits alimentaires et en ressources naturelles, et sa dépendance attendue vis-à-vis de l'approvisionnement extérieur ont des implications énormes pour le système alimentaire mondial. Le concept de sécurité alimentaire, qui était auparavant associé aux Objectifs du millénaire pour le 
développement, est maintenant lié à la stratégie nationale d'un pays dont la demande, même avec des volumes d'importation modestes au regard de la consommation (5 à $10 \%$ ), générera des tensions énormes dans le commerce mondial. Observant que « les besoins de la Chine ont dépassé sa capacité productive » (Farooki et Kaplinsky, 2012 : 103) et que le pays a connu un «basculement important de la consommation d'aliments à base de céréales vers celle de produits carnés, en particulier de porc » (ibid., 71), Farooki et Kaplinsky affirment que la pression sur l'offre mondiale en alimentation humaine et animale ne peut que s'intensifier. Schneider et Sharma (2014 : 15) donnent une idée de l'ordre de grandeur du phénomène en citant l'USDA (United States Department of Agriculture) qui estime que les importations représentent environ $1 \%$ de la consommation chinoise de porc, mais « près de $12 \%$ des exportations mondiales ». Dans le cas du soja, la Chine n'est devenue un pays importateur net qu'en 1996, mais importait en 2005 la moitié du soja échangé dans le monde. Au fur et à mesure de l'ouverture de ces frontières, l'impact de la Chine sur ses partenaires commerciaux et sur la géographie du commerce mondial sera profond. Par exemple, « en 2011-2012, $82 \%$ des exportations de soja brésilien sont allées en Chine » (Sharma, $2014: 24)$, et la Chine est également devenue un marché clé pour le bouf brésilien, le premier pays exportateur de viande bovine. Le marché laitier mondial commence également à ressentir les répercussions de la demande croissante de la Chine (Sharma et Rou, 2014).

Ces faits stylisés montrent comment le commerce agricole mondial et les investissements sont en train d'être reconfigurés alors que la Chine n'en est encore qu'aux premiers stades de la transition vers un statut de grand pays importateur de produits alimentaires. La recherche de la sécurité alimentaire par la Chine provoque un remaniement fondamental de l'économie alimentaire mondiale du fait de l'incorporation, par ses stratégies commerciales et d'investissement, de fronts pionniers anciens et nouveaux. Cette dynamique sera déterminante dans la réorganisation du système alimentaire mondial et plus importante que les différents « moteurs » mis en avant dans les débats sur la forme et le contenu d'un putatif troisième «food regime » (Burch et Lawrence, 2005, 2009). L'influence de la Chine et de ses partenaires commerciaux dans le repositionnement géopolitique du commerce agricole mondial et des flux d'investissement doit être au centre des cadres d'analyses qui visent à élucider les relations entre le développement capitaliste et la structuration des systèmes alimentaires mondiaux.

\section{$\leadsto$ Conclusion}

Au cours de ces dernières années, en particulier dans les travaux anglophones, la théorie des régimes agroalimentaires a fourni, pour beaucoup, une référence commune permettant de penser les grandes questions du système agroalimentaire mondial moderne. Elle a été fortement contestée quand de nouveaux marchés de produits de qualités spécifiques et de produits « alternatifs » sont devenus le centre de l'attention (Whatmore et Thorne, 1997 ; Murdoch, 1998), mais elle a fait un retour en force dans les années 2000 lorsque de nouvelles préoccupations et défis mondiaux (sécurité alimentaire, environnement, énergie) se sont imposés, et ont été renforcés par la crise financière mondiale et l'explosion des prix des produits 
agricoles. Dans l'analyse qui précède, nous avons soutenu que la théorie des régimes agroalimentaires s'est révélée incapable de prendre en compte les forces nouvelles qui façonnent le système agroalimentaire mondial. Nous affirmons également que cet échec a ses racines dans la notion même de régimes hégémoniques qui a rendu aveugle la théorie des régimes agroalimentaires à la multipolarité du système agroalimentaire mondial, présent dès le début, mais aussi aux caractéristiques communes et aux continuités qui ont caractérisé le développement de ce système au cours des cent cinquante dernières années.

Le projet alternatif, qui se définit autour des notions de local, de circuits courts et de réseaux agroalimentaires, acquiert une plus grande intelligibilité si l'on considère l'expérience de l'Europe continentale, tant comme réponse initiale à l'émergence des marchés mondiaux de matières premières agricoles que dans le contexte de la reconstruction d'après-guerre du modèle européen. De même, la montée des Brics et d'autres pays «émergents » comme grands acteurs de l'agroalimentaire se comprend mieux une fois qu'une plus grande attention est donnée à l'histoire des politiques agroalimentaires nationales de ces pays dans les périodes où des composantes importantes de la frontière technologique sont restées dans le domaine public. Le Japon, qui est pratiquement ignoré dans les récits de la théorie des régimes agroalimentaires, a joué un rôle stratégique, à la fois dans la diffusion des pratiques agroalimentaires et dans l'ouverture de fronts pionniers agricoles alternatifs, de façon particulièrement évidente dans le cas du Brésil.

La théorie des régimes agroalimentaires est sous-tendue par une polarisation simplifiée, opposant d'un côté le « Nord » et le «Sud », de l'autre les systèmes alimentaires agro-industriels et les systèmes alimentaires paysans. En présentant l'agro-industrie comme une force exogène, largement identifiée avec le « modèle américain » et ses sociétés transnationales, la théorie des régimes agroalimentaires minimise la façon dont les technologies agricoles et agroalimentaires ont été progressivement diffusées et ont servi de base pour des politiques nationales de développement, même dans des pays comme la Chine qui étaient fermés aux investissements occidentaux. La représentation de la paysannerie comme alternative globale s'appuie, dans la théorie des régimes agroalimentaires, précisément sur ses aspects qui sont les plus discutables. La caractérisation du premier régime agroalimentaire néglige l'ampleur de l'affaiblissement qu'a subi l'économie paysanne lors de la domination coloniale, qui combine l'esclavage, le déracinement massif des communautés paysannes au profit des économies de plantation, et la destruction de l'artisanat et de l'industrie rurale qui jouaient un rôle décisif dans la durabilité de l'économie paysanne. Dans le cadre du second régime agroalimentaire, le rôle attribué à l'aide alimentaire dans l'affaiblissement de l'économie paysanne, à la fois, surestime l'impact global de cette aide, tant sur la production et que sur les modèles de consommation, et sous-estime les dégâts provoqués dans les économies paysannes par le colonialisme et les politiques de collectivisation.

Enfin, la résurgence des activités agricoles non alimentaires (énergie, biocarburants, biomatériaux) met à jour ce qui est peut-être la plus importante faiblesse de la théorie des régimes agroalimentaires, la focalisation exclusive sur l'alimentation alors que les stratégies coloniales, l'économie paysanne et les projets alternatifs ne sont intelligibles que dans un cadre considérant l'ensemble des ressources naturelles.

Traduit de l'anglais par Benoit Daviron. 


\title{
Chapitre 17 \\ Théorie de la régulation et transformations de l'agriculture : nouveaux enjeux, nouvelles perspectives de recherche?
}

\author{
J.-M. TOUZARD, P. LABARTHE
}

Les travaux se référant à la théorie de la régulation (TR) ont très tôt retenu l'échelle sectorielle comme échelle pertinente pour illustrer, mieux comprendre ou questionner les transformations et la diversité des formes du capitalisme (Boyer et Saillard, 1995). L'agriculture et l'agroalimentaire ont constitué un domaine privilégié pour développer ces approches sectorielles (Boyer, 1990), contribuant notamment à l'établissement du concept de régime de fonctionnement économique appliqué à l'échelle sectorielle (Bartoli et Boulet 1990). L'ouvrage coordonné par Gilles Allaire et Robert Boyer (1995) témoigne de la vivacité et des perspectives de ces travaux au milieu des années 1990. Des recherches sur l'agriculture et l'agroalimentaire ont continué à se référer à la TR et se sont enrichies de nouvelles questions, par exemple au regard des enjeux liés à l'environnement, au développement territorial ou à l'évolution des politiques agricoles (Laurent et du Tertre, 2008). Ces travaux soulignent l'émergence de nouveaux régimes de fonctionnement des secteurs agricoles et agroalimentaires, dans un monde capitaliste plus libéral, mais la synthèse de ces évolutions reste en chantier. La question posée dans ce chapitre est celle du rôle que pourrait jouer la TR dans une telle synthèse et, au-delà, dans l'analyse comparée des régimes agricoles et agroalimentaires. Le renouvellement de débats politiques questionnant la place de l'agriculture et des aliments dans la société, tout comme l'éclatement récent de « crises alimentaires » justifient de notre point de vue un réinvestissement de la TR sur ce secteur. Nous revenons tout d'abord sur les apports de la TR à l'analyse des régimes sectoriels (section 1), puis nous montrons comment l'évolution récente du contexte international offre précisément une opportunité pour les relancer. En nous appuyant sur nos travaux personnels ainsi que sur une revue de la littérature, nous ouvrons deux perspectives pour cette relance. Nous proposons de mieux intégrer les apports de la TR, d'une part, dans l'analyse des transitions environnementales de l'agriculture ( transition studies»; section 2) et, d'autre part, dans celle de la diversité des modèles alimentaires et des régimes agroalimentaires internationaux (section 3 ). 


\section{- L'analyse du régime agricole de la période fordiste et de sa crise}

Dès le début des années 1980 (Perraud, 1985), des travaux se référant à la TR ont mis en évidence l'institutionnalisation d'un mode de développement fordiste de l'agriculture dans les pays industrialisés, en analysant l'évolution de variables macroéconomiques et en repérant les institutions clés et les compromis politiques qui les sous-tendent (Nefussi, 1987 ; Allaire, 1988a ; Debailleul, 1990 ; Laurent, 1992). Ces premiers travaux ont aussi interrogé les expressions que pouvaient prendre les formes institutionnelles canoniques de la TR dans l'agriculture : l'évolution et la spécificité des « rapports de travail » (Allaire, 1988b ; Lacroix et Mollard, 1990), le rôle de l'état et des compromis institutionnalisés débouchant sur une cogestion agricole (Coulomb et al., 1990), l'évolution des institutions de marché en lien avec l'émergence de la PAC (politique agricole commune) (Bartoli, 1985), la différenciation des produits selon la qualité (Bartoli et Boulet, 1989), ou les relations entre agriculteurs et firmes de l'agro-industrie (Chevassus-Lozza et al., 1999).

Le développement de telles recherches a rapidement questionné la possibilité de transposer des concepts de la TR, construits à l'échelle macro-économique, vers l'échelle d'un secteur (Boyer, 1990), contribuant aux réflexions théoriques sur la régulation sectorielle, notamment à partir de l'exemple du vin (Bartoli et Boulet, 1990). À partir d'une même démarche de recherche autour de la caractérisation sur de longues périodes des dynamiques économiques et des institutions, les travaux ont alors traité deux niveaux sectoriels : i) le secteur agricole dans son ensemble, considéré dans la période fordiste (régime d'accumulation intensif centré sur la consommation de masse) ; ii) des secteurs plus restreints construits autour de produits comme le vin. Les notions génériques, souvent reprises, et notamment celle de « régime économique de fonctionnement », ont ainsi été construites dans le cadre de travaux sur des produits agricoles pour désigner des institutions sectorielles qui se déploient sur de longues périodes et conduisent à des trajectoires relativement autonomes. L'articulation, à différentes échelles, entre dynamiques sectorielles d'une part et modèles de développement nationaux du capitalisme d'autre part, a ainsi pu être mieux envisagée (Boyer, 1990).

L'ouvrage La grande transformation de l'agriculture (Allaire et Boyer, 1995) a alors constitué un effort de synthèse important pour analyser la croissance et la crise de l'agriculture dans les économies industrielles, tout en pointant la montée de nouveaux enjeux : la construction de nouvelles qualités des produits alimentaires, l'évolution des systèmes d'activité des ménages agricoles, la complexification des politiques agricoles, les rapports de l'agriculture au développement territorial et à l'environnement, etc. En insistant sur la coexistence d'une pluralité de formes d'agriculture se positionnant différemment sur ces enjeux, et sur les collaborations à renforcer au sein des approches institutionnalistes, l'ouvrage proposait d'ouvrir un agenda pour de nouvelles recherches, des perspectives qui apparaissaient prometteuses.

Au moment où cet ouvrage (Allaire et Boyer, 1995) est paru et jusque dans les années 2000, les travaux se référant à la TR se sont effectivement déployés dans 
plusieurs directions pour approfondir les différentes dimensions des transformations agricoles et agroalimentaires :

- les recherches sur les « rapports sociaux d'activité » ont précisé les changements en cours dans l'évolution du métier d'agriculteur (Laurent, 1995) en élargissant l'analyse aux « systèmes d'activités » des ménages agricoles (Laurent et al., 1998), vus comme une composante de la régulation du secteur;

- l'analyse des formes de concurrence et d'organisation des marchés s'est focalisée sur la question de la qualité, et sur son rôle central dans la définition de différents « régimes économiques » et la différenciation des marchés agroalimentaires (Bartoli et Boulet, 1989 ; Sylvander et al., 2000 ; Allaire, 2002), ou dans l'existence de « crises sectorielles de qualité » (Allaire et Sylvander, 1997);

- les politiques agricoles européennes, nationales ou régionales ont été étudiées à partir d'une analyse des soutiens publics à l'agriculture, montrant l'importance de l'articulation des différentes échelles d'action (Berriet-Solliec, 1999 ; Delord et al., 2000 ; Delorme, 2002) et des compromis politiques régionaux (Genieys et Smith, 2001 ; Berriet-Solliec et al., 2006);

- l'insertion de l'agriculture dans les dynamiques territoriales a constitué un champ d'étude nouveau, permettant de mieux comprendre des mécanismes de coordination intra et intersectoriel, mais aussi les conditions d'émergence de formes alternatives au modèle agro-industriel (Touzard, 1995 ; Laurent, 1995 ; Nieddu et Gaignette, 2000);

- les rapports entre l'agriculture et les enjeux liés à l'environnement ont été également un nouvel axe de recherche, montrant l'importance des nouveaux compromis sociaux autour de la nature, et soulignant que l'agriculture prenait une place importante dans l'émergence d'une écologie politique (Lipietz, 1995 ; Lacroix et al., 1995 ; Becker et Raza, 2000 ; Barthélemy et Nieddu, 2003);

- de manière transversale aux travaux précédents, la question de l'innovation et de la construction des connaissances dans le secteur agricole et agroalimentaire a été étudiée en référence à la TR pour saisir les processus de transformation du secteur ou pour porter un regard critique sur les changements technologiques (Byé, 1997 ; Touzard, 2000 ; Allaire, 1996);

- il faut enfin noter l'ouverture sur les transformations de l'agriculture dans d'autres pays, à travers notamment différents travaux de thèse, en particulier en Amérique latine, en Europe ou en Amérique du Nord (Lopez, 2006 ; Goodwin et al., 1995 ; Quemia, 2001 ; Trouvé, 2007 ; Labarthe, 2006), avec plusieurs tentatives sur les économies africaines (Hugon, 1993 ; Chastel, 1995 ; Griffon, 1994 ; Losch, 2000 ; Marzin, 2006 ; Anseeuw, 2004).

Ces travaux ont été discutés et développés au sein de la communauté scientifique régulationniste durant une dizaine d'années, notamment à l'Inra et au Cirad, ou à travers le groupe "Régulation sectorielle et territoriale » (Laurent et du Tertre, 2008), ainsi que dans différents colloques, séminaires et forums organisés par l'Association recherche et régulation, ou encore dans la Revue de la régulation. Une particularité du développement de la TR est que son développement s'est aussi opéré à travers des échanges avec d'autres programmes de recherche en économie institutionnelle, mais aussi avec d'autres sciences sociales. Le développement des travaux inscrits dans la TR et appliqués à l'agriculture en est l'illustration : 
- l'analyse des transformations du travail agricole s'est opérée avec des approches inscrites dans la sociologie rurale et l'agronomie (systèmes d'exploitation, systèmes d'élevage). Ces collaborations se sont prolongées (Mundler et Laurent, 2004 ; Malderieux et al., 2010), contribuant à stabiliser la notion générique de « rapport social d'activité » (Laurent et Mouriaux, 2008);

- les travaux sur les régimes des produits de «qualité spécifique » ont été associés à la dynamique d'autres approches, en particulier l'économie des conventions ou la sociologie économique (Boulet et Touzard, 1995 ; Allaire et Sylvander 1997 ; Chiffoleau et al., 2008 ; Karpik, 2007 ; Allaire et Daviron, 2006 ; Allaire, 2013). À l'échelle internationale, ils rejoignent des travaux davantage positionnés en sciences politiques (Bonanno et Busch, 2015), en particuliers sur les «food regimes » (Friedman, 2005b) ;

- les recherches sur les politiques agricoles, le développement rural et la politique européenne (Berriet-Solliec et al., 2006, 2008 ; Labarthe, 2009 ; Trouvé, 2009) ont tissé des collaborations avec des approches en sciences politiques (Smith et al., 2007) ;

- l'évolution de l'agriculture dans les dynamiques territoriales a fait l'objet de nouvelles recherches en lien avec l'économie de la proximité (Pecqueur, 2001 ; Pecqueur et Zimmerman, 2004 ; Gilly et Wallet, 2005) ou avec les travaux sur les systèmes agroalimentaires localisés (Muchnik et al., 2007 ; Albaladejo, 2012) ;

- les travaux de la TR sur des thématiques plus récentes, liant l'agriculture à l'environnement, l'éthique ou l'innovation, ont connu le même processus de collaboration avec d'autres programmes : développement durable et économie de l'environnement (Zuindeau, 2007), théorie évolutionniste et approches des transitions (Nieddu et al., 2010 ; Labarthe, 2010 ; Touzard et al., 2014) ou même histoire et droit (Tordjman, 2008).

Le croisement des approches issues de la TR avec d'autres approches institutionnalistes ou d'autres disciplines a eu une valeur heuristique indéniable pour mieux comprendre les transformations de l'agriculture. Réciproquement, le secteur agricole a constitué un vivier de recherches empiriques qui ont contribué à développer ou à préciser de nouvelles notions pour la TR (régulation sectorielle, régime de qualité, système social d'activité, gouvernance territoriale, etc.). Toutefois, ces travaux n'ont pas conduit à l'élaboration d'une nouvelle synthèse, qui permettrait de caractériser et de cartographier les nouveaux régimes de fonctionnement du secteur agricole, dans une perspective historique et comparative plus globale. Dans les deux sections suivantes, nous présentons deux axes de recherche qui appellent de notre point de vue à une contribution de la TR à des exercices comparatifs et des synthèses sur les régimes agricoles : un axe portant sur les transitions écologiques, et l'autre sur les régimes agroalimentaires. Nous pensons que la participation de la TR à ces synthèses permettrait d'enrichir les analyses menées dans ces communautés pluridisciplinaires. En retour, la TR pourrait bénéficier des débats au sein de ces communautés, notamment pour poursuivre la caractérisation des formes institutionnelles permettant de faire ressortir des mécanismes importants de régulation sectorielle (sur la régulation de l'accès aux connaissances, sur celle des standards de qualité, etc.).

La première perspective que nous développons concerne la contribution possible de la TR à l'analyse des transitions des régimes sectoriels agricoles vers une meilleure prise en compte de l'environnement. 


\section{W Renforcer les recherches sur les transitions environnementales}

Comme nous l'avons évoqué dans la section précédente, une partie des travaux inscrits dans la TR et appliqués à l'agriculture a mis en avant la dimension environnementale des crises qu'ont traversées les régimes de fonctionnement économique des agricultures des pays industrialisés depuis la fin des années 1980. L'analyse des transitions des régimes agricoles et agroalimentaires vers une meilleure prise en compte de l'environnement constitue donc un axe de recherche important pour la TR, et plus largement pour les approches institutionnalistes, comme le montre le développement de la communauté Ecological Economics (Plumecocq, 2014).

Or il existe depuis le début des années 2000 un très fort développement de recherches sur cette question des transitions environnementales. Ce mouvement n'est pas issu des sciences économiques ; il est plutôt porté par les sciences politiques ou des sciences des techniques et des sociétés. Certains auteurs ont ainsi proposé un schéma intégrant différentes échelles d'analyse («multi level perspective »), notamment celle de la « niche », où apparaît une innovation environnementale, et celle du « système sociotechnique », où s'institutionnalise un régime de fonctionnement du secteur intégrant ou non ces innovations (Geels, 2002). Le point de départ de ces approches réside en partie dans une critique du manque d'intégration de la demande dans les approches en termes de systèmes sectoriels d'innovation des travaux d'économie institutionnelle (Geels, 2004), notamment évolutionniste (Malerba, 2002). Ce faisant, ces travaux permettent d'intégrer les nouvelles modalités de construction sociale de la qualité des produits alimentaires et de l'innovation (Geels, 2010), mais aussi de mettre en évidence des verrouillages techniques et institutionnels (Vanloqueren et Baret, 2009).

Pour autant, de telles approches en termes de transitions ont aussi fait l'objet de critiques, notamment dans la façon dont y est conceptualisé le niveau analytique du régime sociotechnique où s'institutionnalise le soutien aux innovations (Berkhout et al., 2004 ; Genus et Cole, 2008 ; Markard et Truffer, 2008, Holtz et al., 2008). Les critiques portent aussi sur le manque d'analyse du rôle de certains acteurs (entreprises, organisations intermédiaires, etc.) dans les transitions et des conflits potentiels entre ces acteurs (Smith et al., 2005 ; Shove et Walker, 2007 ; Genus et Cole, 2008). Ces travaux laissent donc dans un angle mort une partie des mécanismes régulant l'accès aux ressources nécessaires aux transitions. Des travaux inspirés de la TR peuvent jouer un rôle important dans la conceptualisation de ces formes institutionnelles, par exemple celle permettant d'analyser l'accès d'une diversité d'acteurs à des connaissances pertinentes et fiables pouvant soutenir le changement technique (chapitre 18).

Autrement dit, les travaux issus de la TR pourraient davantage contribuer aux débats associés aux transitions, en analysant comment les compromis qui s'institutionnalisent entre différents groupes d'acteurs pour réguler l'accès à certaines ressources, et notamment l'accès aux connaissances, peuvent favoriser ou, au contraire, contraindre des transitions (Labarthe, 2009) : « la performance économique d'un système technique dépend très notablement de facteurs sociétaux $[\ldots]$ : 
ce sont des compromis institutionnalisés qui définissent des trajectoires sociotechniques marquées par des phénomènes de réversibilité et d'irréversibilité » (Boyer, 1989). L'analyse des mécanismes de dépendances du chemin et des phénomènes d'irréversibilité est en effet au cœur de la TR (Boyer et al., 1991), et des dialogues avec d'autres approches hétérodoxes, notamment évolutionnistes (Dosi et Coriat, 1995).

En retour, cette participation de la TR aux débats sur les transitions pourrait contribuer à l'effort collectif nécessaire pour adapter la conceptualisation des formes institutionnelles de la TR aux transformations contemporaines des régulations de secteurs économiques tels que l'agriculture. Les formes institutionnelles canoniques de la TR, ou les notions directement dérivées, conservent une forte valeur heuristique pour comprendre les transformations actuelles de l'agriculture. Elles constituent un des socles méthodologiques de la TR que nous devons collectivement faire évoluer pour analyser des nouvelles composantes des capitalismes contemporains et des régimes de régulation sectoriels (Petit, 1998).

Il apparaît ainsi nécessaire de poursuivre l'analyse des rapports sociaux construits autour du travail dans le secteur agricole, compte tenu des profondes transformations que l'on observe : diminution radicale du nombre d'exploitations agricoles, augmentation de la part du salariat dans l'emploi agricole, avec une part croissante de populations migrantes (Laurent, 2015), nouvelles formes d'organisation collective du travail ou d'intégration de services dans l'agriculture (Nguyen et Purseigle, 2012), évolution des compétences et des qualifications en lien avec les nouvelles technologies ou les exigences des industries d'aval (par exemple pour gérer la traçabilité), etc.

De même, le rapport à l'État s'est profondément transformé, avec des formes d'interventions consistant moins en des investissements directs dans le secteur, et plus en des politiques de normes (sur l'environnement, la santé, etc.), ou de renforcement des capacités et des coordinations à des échelles locales/régionales (par exemple promotion de partenariats et plateformes pour l'innovation ou la commercialisation). Ces politiques s'inscrivent dans des nouvelles formes de compromis institutionnalisés entre agriculteurs, propriétaires fonciers, associations environnementales, collectivités et État, qui diffèrent selon les pays et se confrontent dans la construction des politiques européennes (Trouvé et Berriet-Solliec, 2010 ; Lataste et al., 2012).

L'analyse des formes de concurrence est elle aussi au cœur des transformations des agricultures, d'une part, du fait de la montée en puissance de nouveaux critères de qualité, notamment sur les aspects sanitaires (Saulais, 2015), d'autre part, compte tenu de la transformation des régimes internationaux, avec la montée en puissance de nouveaux acteurs dans la demande (Chine..., Chaumet et Pouch, 2012), l'offre (Brésil..., Fèvre et Pouch, 2013), le stockage (chapitre 4), ou dans l'accaparement des terres agricoles (Anseeuw et al., 2012), en particulier par de grandes firmes multinationales.

Une participation plus forte aux débats portant sur les transitions permettrait d'enrichir les débats théoriques au sein de la TR sur l'articulation des échelles d'analyse des formes institutionnelles, entre échelles micro, méso et macro économiques 
(Lamarche et al., 2015), articulation qui est au cœur de la perspective proposée par les travaux sur les transitions (Geels, 2002). Cette articulation nous semble être indispensable pour traiter de trois dimensions centrales des nouveaux régimes régulant le fonctionnement de l'agriculture (Touzard, 2008 ; Colonna et al., 2013) : i) la légitimité et l'usage des technologies et des connaissances, en particulier la place des biotechnologies et des connaissances scientifiques versus des techniques agroécologiques et des connaissances empiriques ; ii) la construction de la qualité des produits alimentaires, au-delà d'une spécification des formes de concurrence déjà retenues dans la TR, en précisant et en revisitant les dimensions qui fondent cette qualité (Allaire, 2010) ; iii) le rapport au territoire (territorialité), faisant l'objet de compromis politiques majeurs pouvant influencer l'ensemble des acteurs d'une chaîne agroalimentaire (place des produits sous indication géographique (IG), représentation géographique ou relationnelle de la proximité, etc.). Ces dimensions peuvent contribuer à conceptualiser de nouvelles formes institutionnelles pour décrire les modes de régulation des régimes sectoriels.

Les travaux sur les transitions offrent également un cadre institutionnel intéressant (avec des forums, des séminaires, des groupes de travail, des projets de recherche, etc.) pour mener des travaux avec des approches historiques et des comparaisons internationales, approches qui sont au cœur de la TR. Des travaux appliqués à l'agriculture ont déjà exploré le potentiel de cette démarche, par exemple dans le cas du développement de la chimie verte (Nieddu et Vivien, 2015, 2016b). Un atelier, organisé en 2015 lors du Forum de la régulation et intitulé " Problématiques de "transition" : quels outils pour l'analyse régulationniste ? $»^{5}$, a également montré la richesse des débats entre TR et analyse des transitions. Ces débats constituent une opportunité, pour les travaux issus de la TR, de poursuivre l'analyse i) de la crise du modèle agro-industriel intensif, ii) des nouvelles frontières pour le déploiement d'une nouvelle alliance entre la science et le capitalisme (nouvelles doctrines autour des partenariats publics-privés pour l'innovation, etc.), par exemple sur la bioéconomie (chapitre 8), ou iii) du développement de systèmes alternatifs de production, voire de modes de vie.

Une autre voie possible, complémentaire, pour accentuer et enrichir la contribution de la TR à l'analyse des régimes agricoles, est d'enrichir le dialogue avec les approches en termes de régimes agroalimentaires internationaux.

\section{" Renforcer l'analyse de la transformation des modèles à l'échelle internationale}

Les travaux de la TR - ou proches de celle-ci - sur la transformation de l'agriculture montrent donc à la fois i) un emboîtement des espaces de régulation et de transition, avec un maintien malgré tout du poids de l'échelle nationale, ii) la coévolu-

5. Cet atelier a été organisé par Martino Nieddu, Franck-Dominique Vivien, Cédric Durand, Ozgur Gün, Pierre Labarthe et Philippe Légé. Les présentations de cet atelier peuvent être trouvées sur le site de l'association Recherche et régulation : https://theorie-regulation.org/colloques/colloque-rr-2015/ programme-rr2015/\#22 (consulté le 13 octobre 2016) 
tion d'une diversité de modèles agricoles et agroalimentaires et iii) l'importance des dépendances internationales, en partie nouvelles et révélées notamment par la crise alimentaire de 2007-2008. Celle-ci invite à analyser l'évolution des échanges agroalimentaires internationaux, en interrogeant la manière dont des agencements d'institutions, d'acteurs et d'actions publiques et privées, constitués aux échelles nationale et internationale, interviennent aux différents stades de circulation des biens alimentaires, depuis la production jusqu'à la consommation. Deux mouvements antagonistes jouent un rôle majeur dans les transformations actuelles :

- un mouvement de « libéralisation des marchés » et de désengagement de l'État conduisant à banaliser l'agriculture et les aliments ("désectorialisation »);

- un mouvement de réinvestissement politique dans les chaînes de valeurs et dans les espaces de confrontation/négociation internationale, pouvant déboucher sur la réaffirmation de spécificités de l'agriculture et de l'alimentation à l'échelle mondiale, du fait notamment de ses liens avec la production de biens publics et la sécurité alimentaire (Touzard, 2016).

Penser et analyser conjointement ces évolutions dans le cadre de la TR appelle alors à explorer plus avant ses complémentarités avec : i) d'une part, la notion de régime agroalimentaire international inspirée des travaux sur les «food regimes » (Friedmann et McMichael, 1989 ; Friedmann, 2005b ; McMichael, 2009b) ou les « régimes de marché » (Allaire et Daviron, 2006) ; ii) la notion de système ou de modèle alimentaire d'autre part, issue des travaux de Malassis (1979).

Nous proposons la notion de régime agroalimentaire international pour caractériser les configurations institutionnelles et les compromis qui rendent compatibles à l'échelle internationale les activités de production, d'échange et de consommation alimentaire.

Le régime agroalimentaire international de la période fordiste peut être associé au second «food regime » de Friedmann et McMichael («mercantile-industrial » ou « state regulated ») marqué par l'hégémonie américaine ou au régime de standardisation industrielle suggéré par Allaire et Daviron (2006). Il est caractérisable ex post par des marchés internationaux où les États jouaient encore un rôle très fort (Gatt, usage de l'arme alimentaire, régulations sectorielles nationales ou régionales de type PAC, etc.), couplés au modèle de développement intensif de l'agriculture (la Révolution verte promue au plan international par les États-Unis) et au développement de la consommation alimentaire de masse (industrialisation, urbanisation, standardisation, concentration, etc.). Ce régime a renforcé la spécialisation régionale agricole tout en maintenant globalement la modernisation d'une agriculture familiale insérée dans une diversité de modèles agroalimentaires (dominée par le modèle agro-industriel). Les spécificités sectorielles, orientées par les politiques nationales de modernisation agricole, étaient globalement affirmées (Marsden et Murdoch, 2006).

L'évolution de ce régime vers un régime agroalimentaire international « néolibéral et médiatique » (à partir de la fin des années 1970) peut être associée au «corporate (and environmental ?) food regime » discuté par Friedmann (2005b, 2016) et au « régime médiatique » avancé par Allaire et Daviron (2006). Il se caractérise par un désengagement des États (OMC), une financiarisation des marchés agroalimentaires, un renforcement du rôle des firmes multinationales développant une 
« économie politique des normes », l'importance prise par les NTIC et la promotion de nouvelles biotechnologies... Ce régime se développe dans des espaces médiatiques complexes et prend en compte la question de la qualité et de la différenciation des produits, avec d'un côté les échanges de produits agroalimentaires de base (commodities), objets d'une régulation minimale (sanitaire), de l'autre une multiplicité de «value chains » (Goodman et Watts, 1997), organisées autour de standards de qualité, américains et européens, IG ou marques, bio, équitable, etc. Il intègre des enjeux environnementaux, poussés par les mouvements sociaux et repris partiellement par les firmes (Friedmann, 2005b)

La crise de 2007-2008 a montré les limites de ce régime et a ouvert des perspectives dans trois directions possibles :

- l'aménagement, le renouvellement et la poursuite in fine du « régime agroalimentaire néolibéral médiatique » avec le renforcement d'une gestion privée (corporate) des commodities (partiellement encadrée par des garde-fous publics construits à l'échelle mondiale) coexistant avec des «global value chains » ciblées sur différents standards de qualité... Les États eux-mêmes sont invités, dans ce cadre, à avoir recours à des « outils financiers » pour se couvrir et à maintenir un rôle de superviseur ou d'orientation des normes (World Bank, 2009). Le développement d'un nouveau capitalisme agraire, autour du contrôle des ressources productives (foncier, biotechnologies, logistique, financement, informations, etc.), entre parfaitement dans ce cadre, où le marché permet l'affirmation des revendications des consommateurs et le maintien (dans des niches) d'une diversité de modèles agroalimentaires ; - l'affirmation d'un « régime agroalimentaire international civique » autour de confrontations et de négociations internationales entre puissances publiques, firmes et mouvements sociaux, reconnaissant la diversité des modèles agroalimentaires et les contributions possibles de l'agriculture et des agriculteurs (familiaux) aux biens publics, la légitimité d'une souveraineté alimentaire nationale ou régionale, l'importance de l'agroécologie et des savoir-faire locaux. L'émergence de ce régime, soutenue par des scientifiques et la société civile, peut être repérée par des changements dans les instances internationales concernant la sécurité alimentaire (Bricas, 2008) ou le changement climatique (Soussana, 2013), mais elle apparaît fragile. Ce scénario correspond à une forme de « resectorialisation » de l'agriculture construite dans le cadre d'une gouvernance mondiale.

- le « retour» vers une régulation internationale plus fragmentée, redonnant une place plus importante aux États (accords bilatéraux entre États, avec les firmes multinationales...), avec une diversité de trajectoires et de combinaisons de modèles d'agriculture selon les politiques nationales... Ce scénario composite, déjà pointé pour l'agriculture (McIntyre, 2009), peut être soutenu par des compromis politiques de natures très différentes, notamment défensifs (protectionnisme), mais donne aussi la possibilité d'une resectorialisation de l'agriculture, variable selon les pays ou les espaces régionaux.

L'analyse de ces régimes agroalimentaires internationaux renvoie aussi à la « coexistence » de différents « systèmes alimentaires » (Malassis, 1979), vus ici comme des modèles de développement (Touzard et Fournier, 2014). Qu'ils résultent de la persistance d'une diversité inhérente à l'agriculture ou de l'éclatement du modèle agricole productiviste antérieur, ces modèles peuvent se distinguer par des 
combinaisons spécifiques entre un dispositif institutionnel (organisation du travail, forme de concurrence, rapport à l'État) et une dynamique économique particulière, mais aussi, précisément, par l'institutionnalisation de rapports spécifiques aux technologies, à la qualité de l'aliment et au territoire, et par des formes particulières d'innovation.

Le modèle agro-industriel repose sur une logique fondamentale de maximisation du profit des firmes agro-industrielles et des distributeurs, grâce au développement d'économies d'échelle technologiques ou commerciales, produisant des aliments à prix réduit avec une qualité standardisée et régulière pour des marchés de masse, et en s'appuyant sur des processus de spécialisation des zones de production. Il repose sur des principes de décomposition/recomposition des produits agroalimentaires et crée une distanciation géographique, économique et cognitive entre le producteur et le consommateur. Deux variantes peuvent être distinguées : un modèle intégrant l'agriculture familiale aux firmes agro-industrielles (amont et aval, privées et coopératives), issu de la période fordiste et qui s'est prolongé dans le cadre du maintien d'un soutien public et de l'influence d'organisations corporatistes au moins formellement contrôlées par les agriculteurs ; un modèle salarial et financier néoproductiviste qui s'est réaffirmé, notamment en Amérique du Nord et du Sud autour du soja (OGM), du maïs, du blé, de la canne à sucre et de la poursuite de l'industrialisation alimentaire, mais qui semble aussi se relancer en Europe dans l'élevage intensif (voir la «ferme des mille vaches ») et en Afrique autour de l'accaparement de terres ou de complexes agro-industriels.

En interaction avec ce modèle agro-industriel, plusieurs modèles apparaissent comme des héritages renouvelés de formes antérieures.

Le modèle « domestique » est construit autour d'une consommation alimentaire à l'échelle de l'unité de production et de transformation, généralement familiale. Les excédents peuvent être échangés localement et les réseaux familiaux y jouent un rôle majeur. Ce modèle assure toujours la subsistance d'une grande partie des populations des pays du Sud, mais il connaît aussi un renouvellement important au Nord et au Sud, y compris en milieu urbain (jardins familiaux ou communautaires, agriculture urbaine, etc.).

Le modèle « de proximité » est caractérisé par un faible nombre d'intermédiaires entre les producteurs et les consommateurs (circuits courts, vente directe, etc.). La garantie de la qualité repose sur la connaissance directe du producteur par les consommateurs, ou par des informations fournies à ces derniers par une tierce partie (vendeur, sites internet). On peut ainsi distinguer des systèmes de proximité locaux ou à distance, favorisés par les nouvelles technologies de l'information de la communication (NTIC). Le renforcement récent de ce modèle dans les pays du Nord ne doit pas occulter sa présence historique sur toute la planète.

Le modèle artisanal de « commodités » (ou « circuits traditionnels vivriers ») permet l'échange de produits vivriers sur de moyennes distances grâce à des filières fortement intermédiées (producteurs, collecteurs, grossistes, transformateurs artisanaux ou semi-industriels, détaillants...). Les relations restent peu contractualisées (importance des relations et de la confiance interpersonnelles). Ce modèle a été important historiquement dans les pays du Nord et reste très présent dans les pays du Sud. 
Les travaux de l'économie de la qualité (notamment conventionnalistes) ont mis l'accent sur l'affirmation de modèles « de qualité différenciée » reposant sur une logique de différenciation des produits, justifiant un coût unitaire plus élevé, au sein de filières intermédiées. Des labels et des signes de qualité sont généralement nécessaires pour garantir les attributs du produit, qui participent souvent à des conditions spécifiques de consommation (différenciation sociale, conditions festives ou culturelles...) et peuvent contribuer à la construction ou à la valorisation de biens publics (Belletti et al., 2015). Plusieurs variantes existent :

- modèle de qualité selon l'origine : la différenciation se fait par l'origine des produits, la valorisation du patrimoine d'un lieu (de production). Ce modèle regroupe les produits sous indications géographiques, et plus largement l'ensemble des produits d'origine ;

- modèle de qualité naturaliste : la différenciation des produits se fait sur la base de pratiques (agricoles, post-récolte) respectueuses de l'environnement, un « rapport aux technologies et à la nature » particulier. Les filières des produits bio ou se revendiquant de l'agroécologie illustrent pleinement ce modèle ;

- modèle de qualité éthique : ce modèle regroupe les produits différenciés par le respect d'une éthique, que celle-ci soit sociale, religieuse ou communautaire. Le mode de production garantit le respect de valeurs morales ou religieuses, le soutien à une catégorie de personnes (petits producteurs ou handicapés par exemple);

- modèle « de qualité supérieure » ou «dédiée » : la qualité est dans ce cas liée à des variétés ou à des races, à des technologies ou à des savoir-faire spécifiques, ou à la prise en compte de besoin spécifique (sportif, diététique...). Des signes de qualités spécifiques sont également nécessaires (Labels rouges, marques à forte notoriété, etc.), mais la logique fondamentale reste souvent proche du modèle agroindustriel, conduisant certains auteurs à en faire une simple extension (Rastoin et Ghersi, 2010).

La caractérisation plus précise de ces modèles peut largement s'appuyer sur la méthode de la TR (Colonna et al., 2013 ; Touzard et Fournier, 2014). Leur coexistence dans la plupart des pays interroge en retour les approches sectorielles de la régulation, en posant notamment la question de leur articulation aux échelles nationale et internationale. De fait, c'est la généralisation de cette coexistence qui semble être un trait actuel de la mondialisation.

L'analyse des modèles agroalimentaires et de leur insertion dans différents régimes agroalimentaires internationaux invite également à revenir sur la question des spécificités de la sphère agroalimentaire, au regard des évolutions globales du capitalisme et des autres dynamiques sectorielles (Friedmann, 2016). Il faut distinguer les évolutions qui expriment une convergence globale et celles qui semblent renouveler les bases de spécificités sectorielles. Les transformations générales du « rapport de travail » ou « d'activité » dans l'agriculture, la médiatisation et la responsabilisation (accountability) des filières agroalimentaires, l'effacement de politiques agricoles nationales, la financiarisation des activités sur les principales «commodities » et l'affirmation " compensatrice » de gouvernances territoriales, etc. sont des traits généralement partagés avec les autres secteurs. En même temps, les caractéristiques fondamentales de l'activité agricole et agroalimentaire (dépendance aux ressources et risques bioclimatiques, périssabilité des produits, externalités paysagères et 
territoriales, structures productives familiales héritées, importance des savoirs locaux, dimension culturelle ou symbolique des aliments, etc.) créent une série de problèmes et d'enjeux spécifiques (Touzard et al., 2014), et incitent à la pérennisation ou à l'émergence d'arrangements institutionnels particuliers, par exemple dans la construction des « modèles agroalimentaires alternatifs » (Goodman et al., 2011) ou des négociations sur les « services environnementaux » de l'agriculture (Aznar et al., 2007 ; Zuindeau, 2007). C'est dans la combinaison de ces caractéristiques structurelles (jamais totalement exclusives au secteur) que peut se renouveler une spécificité agroalimentaire, plus ou moins affirmée selon les modèles considérés.

\section{" Conclusion}

Les travaux inscrits dans la TR ont apporté une contribution importante à la stabilisation de la notion de régime de fonctionnement économique appliquée à l'échelle sectorielle. Une période de travaux fructueux mobilisant la TR sur l'agriculture à partir du début des années 1980 a abouti à un effort de synthèse au milieu des années 1990 (Allaire et Boyer, 1995) permettant de caractériser le régime de fonctionnement de l'agriculture des pays industrialisés dans la période fordiste, puis les différentes dimensions de l'entrée en crise de ce régime. Les travaux portant sur l'agriculture se sont ensuite développés dans ces différentes dimensions durant les années 2000. Ils ont été caractérisés par un foisonnement d'échanges avec d'autres courants de pensée en économie institutionnaliste (théorie des conventions, théorie évolutionniste, etc.), mais aussi avec d'autres sciences sociales (sociologie, sciences politiques, etc.), dans une diversité de trajectoires de recherches. Cependant, cette période ne s'est pas accompagnée d'un nouvel effort de synthèse, qui aurait pu permettre de caractériser les nouveaux régimes de fonctionnement de l'agriculture dans la diversité des situations nationales, et dans un contexte de globalisation et de libéralisation des échanges. Dans ce chapitre, nous défendons l'idée que le contexte actuel de l'agriculture offre précisément des opportunités pour relancer cet effort de synthèse collectif, articulant des travaux à plusieurs échelles et prenant en compte une diversité de modèles agricoles et agroalimentaires, et questionnant enfin les mécanismes de leurs transitions vers une intégration des enjeux environnementaux.Lerenouvellementdesdébatspolitiquesautourdel'agricultureetdel'agroalimentaire, la diversité de ces modèles et de ces trajectoires, les interrogations sur l'évolution des spécificités de ces secteurs et sur leurs crises offrent en effet un contexte propice à un réinvestissement de la TR.

Dans ce chapitre, nous avons proposé, sans prétention d'exhaustivité, deux voies possibles et complémentaires permettant d'intégrer la TR dans des efforts de synthèse déployés au plan international sur la diversité des régimes de fonctionnement du secteur agricole. La première voie consiste en une meilleure inscription de la TR dans les débats pluridisciplinaires sur les transitions de l'agriculture. Ces débats offrent une possibilité intéressante d'intégration multi-niveaux de l'analyse des formes institutionnelles soutenant les régimes économiques. La deuxième voie consiste en un dialogue entre les travaux inscrits dans la TR et ceux caractérisant la diversité des régimes alimentaires à l'échelle mondiale. Dans les deux 
cas, les fondements conceptuels de la TR conservent une valeur heuristique forte pour contribuer à une meilleure compréhension des régimes agricoles et de leurs transformations, en mettant l'accent sur certaines formes institutionnelles et sur la dynamique des compromis institutionnalisés entre différents groupes d'acteurs. En retour, les communautés de recherche sur les «transitions studies» ou sur les «food regimes » sont deux exemples de communautés ouvrant des perspectives à la TR pour être mieux insérée dans des réseaux et des projets de recherche donnant une place important aux analyses comparatives et historiques. Elles pourraient fournir un matériau empirique important, qui pourrait être combiné et discuté avec des données macro-économiques décrites dans d'autres axes de recherches, par exemple sur les transformations structurelles de l'agriculture (Losch et al., 2012), et contribuer ainsi à une synthèse sur les transformations des régimes agricoles et agroalimentaires. 



\title{
Chapitre 18 Régime de connaissances et régulation sectorielle en agriculture
}

\author{
C. Laurent, P. LANDel
}

La question centrale des approches régulationnistes porte sur les conditions de reproduction des systèmes économiques contemporains : pourquoi cette reproduction en dépit des contradictions profondes dont est porteur le capitalisme? Par quels mécanismes, par quelles procédures de régulation, ces contradictions sont-elles dépassées pour que des dispositifs institutionnels se stabilisent pour une période autour de nouveaux compromis politiques?

Dans ces processus, la production et l'utilisation de connaissances issues de l'expérience ou d'investigations systématiques (statistiques, recherche...) jouent des rôles importants car elles sont à la fois instruments de l'exercice du pouvoir, éléments constitutifs de nouvelles normes, ressources pour la production pour différents types d'acteurs, etc. L'objectif de ce chapitre est de montrer que la façon dont les connaissances scientifiques et techniques sont produites, évaluées et rendues accessibles est une dimension essentielle des compromis qui se sont institutionnalisés ces dernières décennies.

De nombreuses analyses décrivent à un niveau global l'importance des connaissances dans les différents ordres sociaux, politiques et productifs. Certaines analyses s'attachent à décrire la façon dont les modalités de production des connaissances évoluent à l'échelle des rapports entre sciences et société, en montrant les rôles nouveaux donnés à la puissance publique, aux acteurs économiques privés, aux universités, et aux « profanes » et citoyens (Callon et al., 2001 ; Nowotny et al., 2001). D'autres abordent les sciences et les techniques comme des institutions historiquement liées aux pouvoirs politiques et économiques et montrent comment les modalités de production des connaissances peuvent s'articuler à la mise en œuvre de formes libérales de gouvernement (Pestre, 2003, 2013). Dans le domaine agricole, des études montrent l'implication grandissante des firmes privées, parallèlement au retrait de l'État, dans la fourniture de connaissances pour l'élaboration des politiques agricoles et alimentaires et la construction de normes techniques internationales (Fouilleux, 2010). Au niveau national, plusieurs travaux ont aussi décrit les récentes évolutions des organisations de recherche et de développement agricole, montrant que, depuis les années 1990-2000, les firmes de l'agrofourniture sont toujours plus impliquées dans la production de connaissances, et de références techniques pour les agriculteurs et pour le débat public (Bonneuil et Thomas, 2009; Ekboir, 2003 ; Goulet, 2008). 
Mais comment ces transformations, objet d'observations fragmentées, s'articulentelles dans les configurations institutionnelles concrètes des États, des secteurs productifs, là où s'élaborent les politiques économiques ? Pour mieux comprendre ces processus, nous proposons de nous appuyer sur la notion de régime de connaissances.

Chaque formation sociale et chaque secteur peuvent en effet être caractérisés par la configuration d'un "régime de connaissances », qui peut être défini comme l'ensemble des règles, des dispositifs et des acquis disponibles (ressources cognitives, compétences...), qui déterminent la façon dont les connaissances sont produites pour différents types d'objectifs, dont la qualité est évaluée, sont rendues accessibles aux services de l'État et à divers types d'acteurs (Laurent et al., 2009).

Ce régime de connaissances est le produit institutionnel de la médiation de conflits propres liés au pouvoir, mais aussi le produit institutionnel de compromis entre des dynamiques économiques et sociétales qui échappent à l'État. Il se déploie sur la base de dispositifs cognitifs et matériels hérités. Sa configuration révèle la capacité de l'État et de divers types d'acteurs à concevoir des formes d'intervention adéquates à leurs objectifs et à les défendre. Pour les services de l'État, certaines fonctions du régime de connaissances peuvent avoir des finalités principalement politiques qui visent au renforcement de l'État lui-même (par exemple connaissances statistiques, recensements, etc.), comme l'ont montré par exemple Fourquet (1980) et Desrosières (2008), d'autres concernent les relations dont l'État est partie prenante avec d'autres agents (par exemple garantir la qualité des connaissances mobilisées dans certains domaines relevant de l'intervention publique).

Dans cet ouvrage, nous focaliserons notre analyse sur l'évolution du régime de connaissances dans le secteur agricole en France. Les travaux sur les régulations sectorielles conduits pour divers secteurs d'activité (automobile, bâtiment, agriculture, éducation, etc.) ont en effet montré l'intérêt de l'analyse de niveaux spécifiques de régulation, qui permet à la fois de mieux analyser la dynamique institutionnelle particulière de chaque secteur et de saisir les mécanismes concrets qui sous-tendent les modes de régulation nationaux (Laurent et du Tertre, 2008).

L'agriculture occupe une place particulière dans l'analyse économique. D'une part, les exploitations agricoles restent des entreprises dont les collectifs de travail sont de taille modeste. Ainsi, le recensement de 2010 dénombrait en France 514694 exploitations, dans lesquelles étaient actives 778377 personnes appartenant à la main-d'œuvre familiale (chef d'exploitation, conjoints, autres parents), aux côtés de 181023 salariés permanents et de salariés non permanents (93 795 équivalents temps plein). Cette structure productive engendre des spécificités institutionnelles marquées en matière de recherche-développement, aucune de ces exploitations n'ayant les moyens de développer son propre service de R\&D. C'est pourquoi la profession s'est dotée de moyens collectifs importants (instituts techniques, conseil, etc.). D'autre part, l'agriculture est un secteur économique qui joue un rôle important dans l'exercice des fonctions régaliennes de l'État (sécurité alimentaire, occupation/aménagement du territoire), mais dont l'activité peut aussi avoir des retombées négatives significatives sur l'environnement, la santé, la qualité sanitaire des aliments... C'est pourquoi il s'agit d'un secteur très administré, où l'intervention publique est souvent prescriptive, avec un contenu technique précis. 
Cependant, en dépit de ces spécificités, à quelques exceptions près (par exemple Allaire, 2002), les analyses de la régulation sectorielle en agriculture ont accordé peu de place à la façon dont les connaissances scientifiques et techniques sont produites et rendues accessibles dans ce domaine, reprenant implicitement l'hypothèse que, pour ce qui concerne la recherche agronomique et l'environnement, les connaissances circulent de façon ouverte, sans enjeux institutionnels importants (Dascupta et David, 1994). Nous allons montrer qu'il n'en est rien.

Après avoir précisé le matériel mobilisé pour cette analyse, nous présenterons les caractéristiques du régime de connaissances agricole du compromis de la modernisation qui se met en place dans les années 1960 (section 1) jusqu'aux années 1980, qui sont marquées par une remise en cause profonde du projet du secteur et de son insertion dans le régime de concurrence international (section 2). Un nouveau régime de connaissances émerge dans un contexte marqué par la libéralisation des politiques publiques, la place grandissante de l'agrobusiness et la mise en avant de l'idée de participation comme principe régulateur nouveau pour l'accès aux connaissances dans le débat public et l'innovation technologique en agriculture (section 3). Les conséquences de ce changement, et de la régulation par l'opacité qui en résulte, seront analysées en nous appuyant notamment sur le cas concret de l'agriculture de conservation (AC).

La démarche s'appuie :

- d'une part, sur des données recueillies pour faire une analyse d'ensemble de l'évolution du régime de connaissances sectoriel en agriculture (évolution des institutions qui contribuent à définir le rôle des connaissances dans le régime de fonctionnement du secteur - règles de financement, règles régissant les organisations et leurs collaborations);

- d'autre part, sur des données recueillies pour analyser la façon dont les connaissances de diverses origines (recherche, statistiques, savoirs d'expérience...) ont été mobilisées pour éclairer les décisions, et la façon dont elles sont produites, évaluées, capitalisées et rendues disponibles dans des dispositifs matériels (bases de données, dispositifs expérimentaux...).

Plusieurs types de sources ont été mobilisés :

- la littérature scientifique, comme source de données primaires sur les évolutions des institutions du secteur depuis les années 1960, en particulier (i) le corpus des études sur la modernisation agricole (évolution des services de l'État et la mise en place des services de recherche publique et de conseil technique), (ii) les analyses régulationnistes de l'évolution de la régulation sectorielle (notamment, Perraud, 1985, 1995 ; Bartoli et Boulet, 1989 ; Allaire et Boyer, 1995 ; Laurent, 1992 ; Touzard, 1994 ; Nieddu, 1998 ; Laurent et du Tertre, 2008 ; Trouvé, 2007...), (iii) des analyses sur l'évolution des modèles techniques, et notamment l'usage de pesticides en agriculture ;

- les réglementations européennes et françaises visant à encadrer l'usage des connaissances dans la décision publique et le conseil concernant l'agriculture ;

- les débats parlementaires sur les lois d'orientation agricoles successives ;

- les rapports politico-administratifs analysant et/ou formalisant les procédures qui accompagnent l'usage des connaissances scientifiques dans la décision publique, notamment les rapports de la Cour des comptes et les documents retraçant l'évolution du budget du ministère de l'Agriculture et de ses effectifs. 
Par ailleurs, l'analyse s'appuie sur les informations recueillies lors de deux vagues d'entretiens semi-directifs destinés à recueillir des informations sur l'usage des connaissances dans la décision publique et le conseil dans l'agriculture française : en 2007-2008, 78 entretiens conduits par les chercheurs du programme EBP-Biosoc (ANR, ADD) auprès des services de l'État $(n=36)$ et des représentants de trois groupes d'intérêt (syndicats agricoles, collectivités territoriales, associations environnementalistes) $(\mathrm{n}=42)$; et, en 2012-2013, 31 entretiens, réalisés par P. Landel auprès d'acteurs institutionnels impliqués dans des politiques publiques agroenvironnementales et dans les débats concernant le développement de l'agriculture de conservation. Dans les deux cas, il s'agissait d'un échantillonnage raisonné. Les personnes rencontrées étaient informées préalablement par écrit des objectifs de la recherche, et la vague d'entretiens a été interrompue après que plusieurs entretiens n'aient plus apporté d'information supplémentaire. Les questions structurant les entretiens, ainsi que les grilles de dépouillement du contenu des entretiens et les analyses détaillées sont disponibles dans Laurent et al. (2008), Labarthe et al. (2009) et Landel (2015).

\section{" Le régime de connaissances du compromis de modernisation de l'agriculture : 1960-1980}

De nombreuses études (Gervais et al., 1977 ; Jobert et Muller, 1987 ; Hervieu et Purseigle, 2013) ont montré comment les années 1960 voient se mettre en place un nouveau compromis entre l'État et la profession, formalisé dans plusieurs lois d'orientation visant à favoriser la modernisation de l'agriculture française. Ce compromis est fondé sur une alliance entre l'État et un groupe de jeunes agriculteurs issus de la jeunesse agricole catholique. Il débouche sur une nouvelle façon dominante de penser la production et le sens du progrès technique en agriculture : le modèle de l'exploitation agricole à deux personnes, la parité de revenus avec les autres secteurs, des modèles techniques permettant d'augmenter la productivité de la terre et du travail grâce aux progrès de la génétique, de la mécanisation, au recours accru aux intrants chimiques (engrais, produits phytopharmaceutiques, etc.) et à la mise en œuvre de nouvelles pratiques (Aubert et al., 1985 ; Muller, 2000). Ce compromis est également fondé sur une vision partagée entre l'État et la profession de la dynamique sociale qui peut accompagner ce mouvement. L'idée qu'une sélection des exploitations est nécessaire pour atteindre les objectifs de production et de parité des revenus s'impose et débouche sur la mise en place de mesures favorisant le départ d'une partie des exploitants (indemnité viagère de départ...). Mais, en accord avec la philosophie du personnalisme (fondée par Emmanuel Mounier) qui les inspire, l'idéal d'une partie du mouvement des jeunes agriculteurs est que toutes les personnes qui veulent jouer le jeu de la modernisation puissent le faire. Ainsi, sont mis en place un ensemble de dispositifs visant à compenser les inégalités initiales en capital (crédits à taux bonifiés...), en terre (Safer...) et en connaissances (informations économiques et techniques, formation, conseil).

Ces transformations s'élaborent dans une dynamique à la fois nationale et européenne. Mais alors que, dès 1962, les choix du compromis de modernisation 
structurent la contribution française à la construction de la politique agricole commune (PAC), la question du conseil agricole est renvoyée au principe de subsidiarité et à la responsabilité des États membres. Ceci contribuera à marginaliser l'analyse des dispositifs de connaissance dans le champ académique, à l'écart des grandes analyses sur la PAC et des études comparatives européennes.

Pourtant, l'État et les représentants de la profession impliqués dans la cogestion du secteur vont progressivement construire un dispositif institutionnel et matériel significatif pour produire et rendre accessible des connaissances permettant de soutenir le projet de modernisation. Cet objectif est explicite : les réformes des années 1960 ne sont pas seulement celles des structures et des marchés.

Ces dispositifs concernent d'abord les services du ministère en charge de l'Agriculture qui sont profondément réorganisés. Dès sa prise de fonction en 1961, E. Pisani précise que, pour donner un contenu aux textes réglementaires et préparer les négociations européennes, le ministère doit devenir aussi « un outil d'études ». [...] «Il faut totalement repenser l'organisation du ministère. Disons d'abord qu'il est surprenant pour celui qui s'y installe de constater qu'il n'y existe pas de bureau d'études et de synthèse. Vous vous étonnez sans doute qu'il n'y ait pas de politique agricole. Mais comment y en aurait-il une puisqu'il n'y a pas d'outil pour l'étudier? (Journal officiel, 14 septembre 1961)

Les réorganisations qui suivent, détaillées par Tavernier (1967), se traduisent notamment par la création de directions générales dotées de services techniques dans les services centraux et la création d'une direction générale « des études et des affaires générales », qui dispose donc d'un «bureau d'étude et de synthèse » chargé notamment de la prospective. Des fonctionnaires ayant des compétences diversifiées sont recrutés, notamment en économie (Tavernier identifie un seul économiste au ministère avant la réforme). Les services sont également réorganisés pour que les compétences agronomiques et économiques puissent être combinées.

E. Pisani rappelle aux parlementaires que « les moyens dont nous disposons pour connaître de façon suffisamment rigoureuse les phénomènes agricoles sont encore dérisoires », et en conclut que « le développement d'un bureau d'études et le développement des moyens d'études statistiques sont la condition même de la maîtrise par le Gouvernement des phénomènes auxquels il est affronté » (Journal officiel, 11 janvier 1963 : 663). La division centrale des enquêtes et études statistiques, créée en 1961, sera donc renforcée et deviendra le service central des enquêtes et études statistiques (Scees) en 1964. Ce service comportera des agents mieux formés, plus nombreux : en 1960, les services statistiques de l'agriculture employaient quelques dizaines de personnes, sans services départementaux organisés ; en 1975, ils emploient 750 personnes et 145 statisticiens agricoles départementaux ont été formés entre 1963 et 1968. Il utilisera des méthodes révisées pour fournir des connaissances plus fondées sur des investigations conduites de façon systématique et moins sur l'expertise (Desrosières et al., 1976 ; Galas, 1997 ; Tavernier, 1967).

En effet, l'enjeu est double. Il s'agit non seulement de rendre disponibles des connaissances pertinentes et robustes pour éclairer l'action publique, mais aussi de se dégager des représentations du monde paysan portées par les notables ruraux, de leur expertise et de celle des ingénieurs issus de leurs rangs. 
Parallèlement, l'Inra reçoit des moyens nouveaux. La pluralité de ses missions est réaffirmée (éclairer les politiques publiques, fournir des connaissances appliquées, etc.). Il a pour mission explicite de concevoir des systèmes techniques innovants, d'en évaluer les impacts (en termes de rendement, de rentabilité pour les exploitations, etc.) pour accompagner la modernisation de l'agriculture et son insertion dans les marchés, en France comme à l'export. Comme l'annonce E. Pisani dès son arrivée au ministère de l'Agriculture, « si demain le lait doit être rouge pour être vendu et les pommes carrées, il faudra que l'Institut national de la recherche agronomique se consacre à cette tâche pour que nous puissions obtenir des produits qui se vendent » (Journal officiel, 14 mai 1961 : 2269).

La réforme modifie aussi la façon dont les connaissances ainsi produites pour les services de l'État sont mises à disposition des autres acteurs. Il est attendu de la production et de la circulation de connaissances statistiques, scientifiques et techniques qu'elles favorisent la réappropriation du projet de modernisation par un ensemble le plus large possible. Le Scees met en place un ensemble conséquent de publications. Le ministère lui-même produit une série de publications à contenu technique et économique et destinés à l'ensemble des acteurs de l'agriculture, dont E. Pisani souligne l'importance et le rôle stratégique (Journal officiel, 11 janvier 1963).

La conviction que le progrès des connaissances est source de progrès économique et social est aussi un moteur puissant de la réorganisation de l'enseignement et du conseil agricole. En même temps que les services de l'État se dotent d'instruments nouveaux, s'affirme une politique publique qui vise à améliorer les compétences dans le monde agricole.

L'amélioration de la formation initiale et continue des paysans est un des piliers de la réforme. L'enseignement agricole est renforcé, avec notamment la création d'établissements supérieurs destinés à mieux former les enseignants (Dijon, Rennes).

Le conseil est réorganisé via une série de décrets émis par la puissance publique et négocié avec la profession $(1959,1966)$. Ils définissent les missions, le financement et les modalités de cogestion du dispositif de développement et de conseil technique. Un dispositif complexe se construit peu à peu (Cerf et Lenoir, 1987), dont nous ne pouvons mentionner que les principaux intervenants. L'Association nationale pour le développement agricole (Anda), composée pour moitié de représentants de l'État et pour moitié de représentants de la profession, a un rôle de coordination, elle conseille les pouvoirs publics et gère les fonds alloués au développement issus de taxes parafiscales.

Les instituts techniques agricoles (ITA), organisés par filières et pilotés par des représentants d'agriculteurs et des acteurs de la filière, sont chargés de missions d'appui technique et d'expertise, mais aussi de mener des expérimentations, de fournir des référentiels pour éclairer les choix techniques, et d'assurer la formation et l'information des conseillers et des agriculteurs. Ils sont financés, via l'Anda, par des taxes parafiscales sur les produits agricoles, ainsi que par les cotisations des agriculteurs spécialisés par filière. Ils collaborent aussi avec les services de recherche publique pour l'échange et la production de connaissances.

Les chambres départementales d'agriculture acquièrent quant à elle une mission de service public. Elles accueillent notamment les services d'utilité agricole de 
développement (Suad) qui sont chargés de fournir gratuitement du conseil technique à l'ensemble des agriculteurs, du moins en principe.

Divers dispositifs coordonnent les actions de ces organisations et celles d'autres intervenants (contrôles laitiers, centres de gestion, établissements de l'élevage, etc.) pour mutualiser les connaissances disponibles et garantir l'accès à du conseil technique fondé sur des connaissances robustes (éprouvées par des essais expérimentaux, consignées dans des référentiels techniques, etc.).

$\mathrm{Si}$, comme nous le verrons plus loin, des critiques se font entendre sur le contenu du conseil et l'accaparement de l'appareil d'encadrement, elles ne remettent pas en cause l'idée même qu'il est nécessaire et important d'avoir des connaissances adéquates pour éclairer les politiques et étayer le conseil et la décision des agriculteurs. Plus encore, l'existence d'un dispositif soutenu par l'État et indépendant des intérêts commerciaux de l'amont (agrofourniture) et de l'aval (organismes de collecte), même s'il doit être amélioré, est considérée comme un acquis de la profession qu'il faut défendre. C'est ce qui apparaîtra en 1976 lorsque le rapport d'un groupe d'experts dénommé « Horizon 80 » proposera de déléguer les tâches de conseil liées aux produits aux entreprises d'amont et d'aval (Cerf et Lenoir, 1987). Devant la levée de boucliers que suscitera cette idée, l'État décidera de ne pas donner suite.

Sur la base du compromis de modernisation, a donc été mis en place un ensemble de dispositifs institutionnels et matériels permettant i) d'informer précisément les services de l'État sur l'évolution des structures et des marchés, sur les avancées technologiques, ii) de fournir des éléments permettant de soutenir le projet technique de la modernisation et la négociation politique entre acteurs français et à l'international (construction de la PAC), iii) de se dégager des représentations de la paysannerie française portées par les notables ruraux et iv) d'améliorer les compétences des professionnels de l'agriculture (agriculteurs, mais aussi services para-agricoles, fonctionnaires, statisticiens...) pour mener à bien le projet de modernisation. Ces dispositifs se sont développés et ajustés progressivement, mais, au final, les grands instruments pérennes qui ont été mis en place (services statistiques, enseignement professionnel supérieur, services techniques pluridisciplinaires des ministères, procédures de circulation de l'information, instituts techniques, dispositif départemental de conseil technique, etc.) ont fourni un cadre général stabilisé dans le temps de dispositifs matériels et de règles partagées pour produire et échanger des connaissances dans le secteur (suffisamment stabilisé pour qu'on puisse parler de régime de connaissances).

\section{* Crises des années 1980, recherche d'un nouveau compromis et tournant libéral}

À partir des années 1980, la régulation du secteur entre dans une crise profonde bien que l'on n'observe pas l'abandon annoncé de l'agriculture familiale au profit d'une agriculture capitaliste (Gervais et al., 1965 ; Lambert, 1970).

L'organisation du conseil est mise à l'index pour la façon dont elle tend à privilégier une frange d'agriculteurs modernistes qui ont investi les organes d'orientation et de 
direction des diverses instances cogérées par la profession (caisses de crédits, agricoles, Safer, chambre d'agriculture, instituts techniques, FNSEA, etc.) au détriment de la masse des autres agriculteurs (Gerbaux et Muller, 1984).

Les instruments de régulation des marchés et des prix mis en place dans la Communauté européenne et en France montrent leurs limites (surproduction, coûts du stockage et du soutien aux exportations...) (Hairy et Perraud, 1985 ; Perraud, 1985 ; Bartoli et Boulet, 1989) ; la standardisation des produits et l'organisation des circuits de distribution sont mises en question (Allaire, 1995b ; Touzard, 1998).

Une partie des agriculteurs qui ont joué le jeu de la modernisation ont fait faillite ou sont en grande difficulté (Rémy, 1982 ; Laurent, 1992), alors que subsiste une large fraction d'exploitations dont la disparition à court terme avait pourtant été annoncée parce qu'elles s'écartaient du modèle dominant (pluriactifs, agriculteurs n'ayant pas suivi les modèles d'investissements prescrits, etc.). Le contenu des connaissances produites et mises en circulation par le développement est critiqué pour son caractère trop exclusivement centré sur des choix techniques gros consommateurs d'intrants et de matériel, et entraînant des investissements (et un taux d'endettement) lourds pour les agriculteurs (Pernet, 1982 ; Lacombe, 1987 ; Brun, 1986 ; Laurent, 1992 ; Jas, 2005).

Les impacts négatifs de la modernisation sur l'aménagement du territoire et l'environnement sont dénoncés en France et au niveau européen (Livre vert de la Commission européenne, 1985).

Les divergences au sein de la profession agricole, et entre l'État et les syndicats agricoles se renforcent. La prétention de la FNSEA à représenter l'ensemble de la profession est remise en cause par la création de deux nouveaux syndicats. La Confédération nationale des syndicats de travailleurs paysans (CNSTP) créée en 1981 a fusionné avec la Fédération nationale des syndicats paysans pour constituer la Confédération paysanne en 1987. La Coordination rurale est créée en 1992.

Tous les piliers du compromis de la modernisation sont ainsi ébranlés - instruments de régulation des prix et des marchés, limites du modèle technique dominant, cogestion... - sans qu'émerge encore une proposition précise et concrète en termes de modèle de développement alternatif (Fouilleux, 2003).

À ces difficultés, s'ajoutent de nouveaux enjeux : les principes du développement durable sont entérinés au Sommet de Rio (1992) et la nécessité d'une politique rurale intégrée pour l'Europe est énoncée à la Conférence de Cork (1996). Par ailleurs, des groupes sociaux non sollicités (associations environnementales, mouvements ruraux, collectivités territoriales) s'invitent dans les débats sur l'agriculture, attestant du déclin de l'hégémonie de l'agriculture professionnelle sur le territoire (Laurent, 1995). Ce contexte va susciter la recherche de solutions originales. De nouvelles compétences se constituent, pour la recherche publique, les services techniques des ministères, le conseil (Colson, 2006) et les services statistiques (Boucher et al., 2012), afin de relier les dimensions économiques, sociales et environnementales de la production agricole dans l'analyse comme dans la conception de formes d'intervention publiques.

Cette recomposition s'opère alors que les politiques mises en place au sortir de la seconde Guerre Mondiale sont progressivement amoindries sous la pression de 
nouvelles doctrines. Pour l'agriculture, le régime de concurrence international est profondément transformé avec la fin de l'exception agricole entérinée en 1994 dans les Accords de Marrakech.

La réflexion sur l'avenir du secteur est pour un temps écartelée entre deux perspectives radicalement différentes : d'une part, la doctrine libérale qui postule l'efficacité de la régulation marchande avec ses conséquences (lutte contre toute action considérée comme une " distorsion de concurrence », réduction des soutiens publics) : d'autre part, une vision qui prend acte des nombreuses défaillances de marché rapportées par l'histoire économique (environnement, égalité des territoires, crises sanitaires), et réaffirme la nécessité d'une intervention de l'État et de la permanence de dispositifs institutionnels permettant la coordination et la coopération entre acteurs.

Dans la seconde moitié des années 1990, les réflexions sur la nécessité de refonder les politiques agricoles aboutissent à un ensemble de propositions d'abord portées par le ministère de l'Agriculture français, autour de la reconnaissance de « la multifonctionnalité de l'agriculture » (MFA) (Hervieu, 2002).

Ainsi, lors d'une Conférence organisée par la FAO sur la multifonctionnalité en septembre 1999 à Maastricht, la contribution française énonce que :

«Le concept de multifonctionnalité permet de rendre compte des contributions de l'agriculture au patrimoine et aux objectifs de la nation. Ceux-ci définissent sa place et ses rôles dans la société, au côté de sa fonction originelle de production de biens alimentaires, garante de son existence. [...] Les fonctions pour lesquelles l'agriculture est déterminante (fonction de production, sécurité alimentaire, fonction sociale et d'occupation du territoire, fonction environnementale) répondent aux préoccupations des populations et relèvent des politiques générales des gouvernements. [...] Elles relèvent souvent de logiques régaliennes (objectifs politiques), globales (échelle du pays ou de la région), non purement économiques dans leur objet (absence ou imperfection des marchés). La défaillance des marchés à satisfaire à l'heure actuelle ces objectifs légitimes, les choix sociétaux opérés entre fiscalité directe ou indirecte (collectivisation des coûts) rendent nécessaire l'intervention correctrice de la puissance publique. » (Ministère de l'Agriculture, 1999).

Comme dans les années 1960, cette position s'appuie sur une vaste consultation des parties prenantes en France et elle propose une vision globale de l'évolution du secteur susceptible de refonder un nouveau compromis. Des instruments d'intervention publique, plus intégrés, sont conçus avec l'appui d'une partie de la profession et des services de conseil (notamment les contrats territoriaux d'exploitation). Mais la situation est fort différente. Deux éléments, au moins, vont concourir à l'échec du projet.

D'une part, les nouvelles formes d'insertion de l'agriculture dans le régime de concurrence internationale mettent en partie la régulation sectorielle sous tutelle de la Commission européenne et de l'OMC. L'idée de la MFA, et des formes d'intervention publique qu'elle suppose, sera combattue avec une très grande violence sur la scène internationale par les adeptes d'un libéralisme économique radical qui occupent alors des positions dominantes dans la plupart des organisations internationales (OMC, OCDE, Commission européenne, Mercosur, etc.). Dans les années 2000, il sera même interdit d'utiliser l'expression « multifonctionnalité de l'agriculture » à la FAO'

1. Les études sur le thème parlent alors «des rôles » de l'agriculture faute d'accord entre les États membres (de Haen, 2001). 
D'autre part, la complexité du projet technologique associé à la MFA est sans commune mesure avec celle du compromis de modernisation. Aux objectifs de performance relativement simples des années 1960, se substituent des objectifs complexes associant performances productives, environnementales, sociales et sanitaires. L'éclairage de politiques soutenant la reconnaissance de la MFA suppose une révision profonde des façons d'analyser l'activité agricole et ses impacts, et le développement de moyens adéquats. Mais, contrairement à ce qui s'est passé dans les années 1960, cette question de l'évolution du système de connaissances agricole fait l'objet de peu d'attention. Plus encore, dans la même période, deux phénomènes contribuent à transformer les conditions dans lesquelles les services des ministères ont accès aux connaissances.

Tout d'abord, les injonctions gouvernementales prescrivent à l'Inra de s'orienter vers une recherche plus académique. Cela se traduira par une réduction de la production de documents directement utilisables par les services des ministères pour étayer leur décision. Ainsi, les rapports de recherche associant synthèse et présentation de données de base sont progressivement remplacés par des articles fragmentés dispersés dans des revues peu accessibles ; les recueils de données utiles pour documenter précisément dans la durée les évolutions en cours, mais qui ne visent pas à déboucher sur des fronts de recherches originaux, perdent de leur légitimité et sont réduits.

Parallèlement, un nouveau mode de gestion des moyens de l'État est promu. Au niveau européen (Majone, 1996), comme pour les gouvernements nationaux (OCDE, 2002), s'installe une doctrine selon laquelle il est souhaitable de déléguer une partie de la production de connaissances pour éclairer la décision publique à des autorités autonomes de ces ministères - en créant notamment des agences -, et de réduire les services techniques des ministères en conséquence. Ces principes, qui trouvent une de leurs expressions dans les théories du New Public Management, sont mis en œuvre de façon très hétérogène selon les pays (Verhoest et al., 2012). Mais en France, au ministère en charge de l'Agriculture, va s'imposer progressivement l'idée que les services techniques du ministère doivent être réduits, sans qu'une analyse précise du rôle qu'ils jouent et des besoins du ministère en matière d'appui technique pour éclairer ses décisions ne soit conduite et mise en débat.

À la fin des années 1990, certes des comités d'experts ad hoc sont mis en place pour produire des analyses sur la situation française, mais, in fine, les instruments mis à disposition du gouvernement pour étayer ses décisions sur la MFA dans les négociations internationales, et dans la temporalité imposée (et acceptée) de ces négociations, sont limités. Cette situation laisse le champ libre à des instruments fondés sur des principes d'analyse et d'action d'autant plus simples et faciles à mettre en œuvre qu'ils préconisent d'en faire le moins possible, postulant l'efficacité d'une régulation par le marché dans pratiquement tous les domaines (Laurent, 2002). A posteriori, l'impossibilité dans laquelle s'est trouvé le gouvernement de réformer les services techniques du ministère pour servir les objectifs politiques du ministre de l'Agriculture ressort comme une des causes de l'échec de cette tentative de refondation du compromis.

Suite à l'échec de faire de la MFA un projet pour l'ensemble de l'Europe, la doctrine de l'efficacité de la régulation marchande devient dominante dans les débats de 
politiques publiques et contribue fortement à orienter les réformes des politiques communautaires relatives à l'agriculture (Trouvé, 2007). Cette perspective va aussi s'imposer en France. Certes, avec la mise en ouvre de l'Agenda 2000 au niveau communautaire, les préoccupations relatives à l'environnement et au développement rural sont plus explicitement affichées dans la PAC, mais les soutiens économiques pour ces objectifs restent proportionnellement modestes.

\section{" Libéralisation et régulation par l'opacité}

À partir de 2002, les orientations de la période de la MFA sont progressivement abandonnées. En 2006, une nouvelle loi d'orientation agricole est votée. Ainsi que l'a exposé D. Bussereau, ministre de l'Agriculture (Journal officiel, 6 octobre 2005), elle vise avant tout à mettre en place « des entreprises agricoles puissantes, fondées sur la valorisation de la démarche d'entreprise » (ibid., 4758), à faire évoluer le statut des exploitants familiaux dans ce sens et à renforcer les liens économiques entre les différents acteurs des filières. Cette orientation contribue à donner un poids croissant aux points de vue des entreprises de l'agrobusiness (entreprises impliquées dans l'amont et l'aval de l'agriculture) dans la conception de la gestion du secteur. Cette alliance entre le gouvernement, l'agrobusiness et une fraction de la profession ayant les plus grandes exploitations sera notamment favorisée par un relâchement du contrôle des structures pour moins freiner l'agrandissement des plus grands, par des mesures visant « à attirer les jeunes vers le salariat agricole » (ibid., 4767) et des encouragements à développer les productions à finalité non alimentaires (biocarburants, chimie verte, etc.). Cette orientation, n'est pas remise en cause sur le fond par les ministres de l'Agriculture des gouvernements suivants, quelles que soient leurs appartenances politiques. Elle se déploie sur un fond de tensions fortes entre ministres de l'Environnement et ministres de l'Agriculture, mais ces derniers restent les principaux décisionnaires des choix de politique agricole. Dans ce contexte, l'alliance avec l'agrobusiness sera confortée à partir de 2010 par l'arrivée à la tête de la FNSEA de l'homme d'affaires X. Beulin, dirigeant d'une exploitation agricole engagée dans la démarche d'entreprise et dirigeant du groupe financier et industriel multinational Sofiprotéol (actuel groupe Avril). Si les petites exploitations familiales apparaissent parfois dans les argumentaires, c'est principalement pour renvoyer à la régulation territoriale et ses institutions (collectivités territoriales...) la charge de trouver des solutions spécifiques (agrotourisme...) à leurs problèmes.

Au fil des années, les impacts négatifs de l'activité agricole s'aggravent (érosion de la biodiversité, impact des pesticides sur la santé humaine et les écosystèmes, etc.). Cependant, l'analyse de cas précis permet de constater qu'au-delà des déclarations de principe sur la transition écologique ces questions sont en partie éludées par le ministère de l'Agriculture. De ce point de vue, le cas de l'agriculture de conservation (AC) est éloquent. Ces techniques (encadré 18.1) qui reposent sur une réduction importante du labour se sont développées en France à grande échelle, en particulier dans les exploitations de grande dimension. En 2011, selon l'enquête « Pratiques culturales », elles concernaient plusieurs millions d'hectares (31\% des surfaces en grande culture). Elles permettent de faire des économies de main-d'œuvre 
significatives et auraient un impact positif sur les sols et l'émission de $\mathrm{CO}_{2}$. Mais, globalement, elles sont associées à une consommation accrue de pesticides (notamment herbicides), ce qui n'a pas empêché que ces techniques soient encouragées sans restriction par les gouvernements successifs.

\section{Encadré 18.1. L'AC, modèle candidat pour la « transition écologique ».}

L'AC regroupe un ensemble de technologies basées sur la diminution, voire l'arrêt, du travail du sol (labour). Même si certains auteurs soulignent qu'il existe des solutions permettant de maîtriser la consommation de pesticides dans l'AC (Aubertot et al., 2005 ; Agreste, 2010 ; Labreuche et al., 2007), les données d'enquêtes sur les pratiques culturales montrent qu'en l'état actuel la diffusion de l'AC s'accompagne d'une utilisation accrue d'herbicides (SPP-Enquêtes pratiques culturales, Aubertot et al., 2005 ; Labreuche et al., 2007 ; Landel, 2015).

Les données statistiques permettant de réaliser que ces techniques sont une des causes de l'augmentation de l'usage des pesticides ces dernières années existent, mais elles sont difficilement accessibles aux différents types d'acteurs concernés, y compris aux agences et aux services de l'État (expertise Anses, Laurent et al., 2016).

Ces contradictions entre production et protection sont d'autant moins présentes dans les débats que les données qui les documentent restent dans l'ombre. Ainsi, lors du débat parlementaire sur la loi d'avenir de l'agriculture en 2013, le ministre de l'Agriculture fournira des chiffres donnant à penser que la consommation de pesticides en France a régressé et que le problème est réglé (CAE, 2013) - alors que ce n'est pas le cas (MAAF, 2013, 2014) - sans susciter de réaction dans l'assemblée.

De façon progressive, pour ce domaine comme pour d'autres questions (Laurent, 2013), les dispositifs visant à informer la décision publique et les différents types d'acteurs avec des connaissances issues d'investigations systématiques (statistiques, recherche, etc.) ont été réduits. Les débats s'appuient moins qu'avant sur une connaissance fiable et partagée des faits. Déjà en 2005, plusieurs commentateurs du projet de loi d'orientation relevaient que le projet était relativement muet sur le conseil, la recherche, la formation agricole et continue, la réorganisation des services techniques de l'administration. Ces questions sont en effet passées au second plan. Progressivement, s'est mis en place un régime de connaissances qui, sans que cela soit toujours intentionnel, conduit à masquer les contradictions inhérentes au fonctionnement du secteur plutôt qu'à les documenter, contribuant ainsi à une forme de régulation par l'opacité.

La question de l'évolution du régime de connaissances est peu abordée dans les débats politiques et professionnels du monde agricole. Pourtant, comme nous avons commencé à le voir, des recompositions importantes sont à l'œuvre.

Sans entrer dans les grandes controverses comme celles sur les OGM où la science est accusée d'être source de problèmes plutôt que de solutions, les enquêtes réalisées sur l'utilisation des connaissances issues de la recherche montrent que le fossé se creuse entre la recherche française et la décision publique. Les performances de la recherche publique et de ses agents, y compris à l'Inra, sont désormais mesurées 
à l'aune de standards académiques internationaux incitant à la publication fragmentée, en anglais, de résultats ayant une portée internationale. Ces publications sont accessibles via des bases documentaires payantes (type Web of Science, Scopus, Social Science Index, etc.) auxquelles ni les ministères de l'Agriculture et de l'Environnement (Laurent et al., 2008, 2009), ni la plupart des acteurs hors mode académique (Labarthe et al., 2009) n'ont d'accès organisé (abonnement, service documentaire...). Il n'a pas été développé dans l'administration française de procédures permettant de traiter et de valoriser de façon raisonnée et systématique la masse d'informations scientifiques et de techniques disponibles, et de les mettre à disposition de leurs services et du public comme cela a pu se faire dans d'autres pays comme le Royaume-Uni ou l'Allemagne.

En outre, les services du ministère ont été restructurés. Les enquêtes réalisées sur la question de l'AC (encadré 18.2) font ressortir les conséquences de la diminution des moyens humains et matériels résultants de la Réforme générale des politiques publiques (RGPP) lancée en 2007 par le gouvernement Fillon : mutation et nonremplacement de chargés de mission travaillant à plein temps sur l'évaluation de dossiers techniques précis ; diminution des moyens, voire dissolution, des groupes de travail comme le Corpen (Comité d'orientation pour des pratiques respectueuses de l'environnement) créé en 1984, etc.

Ces observations ne sont que l'indice d'un mouvement plus général. Les rapports de la cour des comptes et l'analyse du budget du ministère de l'Agriculture montrent que, depuis quinze ans, la restructuration des services et l'évolution des moyens se traduisent par une perte de compétences techniques et un recul des dispositifs visant à produire des connaissances pour éclairer la décision technique au profit de tâches administratives et de gestion de dossiers. Si les budgets et les effectifs sont à la baisse comme dans tous les services de l'État, les budgets de fonctionnement des services techniques et des études ${ }^{2}$, et les effectifs de personnels « techniques » subissent des réductions plus que proportionnelles à la réduction globale. De plus, les nouvelles règles, qui subordonnent la progression de carrière des agents à une mobilité rapide, empêchent les personnes concernées de consolider leurs compétences techniques sur les dossiers dont elles ont la charge.

Les services statistiques ont été totalement restructurés et leurs moyens réduits (Boucher et al., 2012). Les services statistiques départementaux construits dans les années 1960 ont été démantelés en 2005. Ces évolutions conduisent des statisticiens du Scees à estimer que « la pression budgétaire sur les programmes [...] aboutit à des suppressions d'enquêtes et des allégements d'échantillons incompatibles avec le maintien de la qualité de nos sources » (Caron et Troye, 2012 : 122).

La diffusion à l'ensemble des acteurs (y compris les agences et les organisations professionnelles) d'informations statistiques, scientifiques et techniques n'est plus une priorité pour les services de l'administration et le bulletin d'information du ministère de l'Agriculture est lui-même devenu depuis 2014 une plaquette de communication revendiquant une " nouvelle formule du magazine du ministère fai(san)t la part belle à la photo et aux témoignages terrain ».

2. Ainsi, entre 2006 et 2015 , le budget de fonctionnement de l'action « Évaluation des politiques publiques et information économique » a diminué de $31 \%$ (action 2, ligne programme 215). 
Encadré 18.2. L'évolution de la prise en charge du dossier de l'Agriculture de conservation par les services de l'État.

Au début des années 2000, l'AC est un sujet de préoccupation au sein des services du ministère. La commande d'études et d'évaluations par ses services a permis de nourrir le débat technique et de mettre à jour les controverses (expertise collective Inra ; organisation de séminaires et présentation de travaux scientifiques auprès du Corpen en 2004 ; commande d'une évaluation des impacts environnementaux des techniques à l'Ademe, réalisée en collaboration avec l'Inra et les ITA). Un chargé de mission était dévolu au suivi du dossier, avec comme objectif de rédiger le contenu d'une mesure agroenvironnementale soutenant le développement de ces techniques tout en proposant des moyens de maîtriser le risque. Cependant, le dossier a progressivement disparu des services à la fin de la décennie (Landel, 2015). Le chargé de mission a été muté sans que son remplaçant ne soit désigné. La diminution drastique des moyens du Corpen, suite à la mise en œuvre de la RGPP, a empêché la mise à jour des données et conduit à un abandon des études visant à nourrir le contenu de mesures techniques. L'absence de suivi de la consommation de pesticides en AC en témoigne alors même que les données de base (Enquêtes pratiques culturales 2011) ont été recueillies. Le dossier « pesticides » est sorti des prérogatives du service agriculture de l'Ademe (Agence de l'environnement et de la maîtrise de l'énergie) suite à l'évolution de ses missions, sans pour autant que l'évaluation des systèmes techniques soit confiée à un autre acteur. L'inspection générale de l'agriculture juge que les compétences techniques du ministère de l'Agriculture sur l'usage des pesticides sont insuffisantes pour faire face aux enjeux actuels (Blanchet et Dreyfus, 2013)

Parallèlement à ce désengagement, plusieurs auteurs observent l'institutionnalisation de l'idée de participation comme principe régulateur de l'accès aux connaissances dans les débats technologiques et environnementaux (Barbier et Larrue, 2011 ; Ferretti, 2007 ; Joss, 1999 ; Levidow et Marris, 2001 ; Landel, 2015). La contribution de nouvelles parties prenantes à l'élaboration des politiques publiques doit permettre d'améliorer l'accès aux connaissances pour le débat public, la décision technique et l'innovation technologique ${ }^{3}$. La mise en œuvre de ces procédures participatives se traduit par exemple par l'organisation d'un Grenelle de l'environnement en 2007, ouvrant le débat sur l'agriculture et l'environnement aux organisations environnementales, aux syndicats minoritaires, aux associations de consommateurs, aux élus locaux, mais aussi aux entreprises de l'agrobusiness. Cette consultation déclinée aux niveaux national et régional aboutira à la rédaction du plan Écophyto 2018, qui se donne comme objectif de réduire l'utilisation des produits phytopharmaceutiques d'ici 2018, « si possible ». Dans ce dispositif, les entreprises de l'agrofourniture seront d'autant plus présentes que, contrairement à d'autres organisations (associations de consommateurs, représentants de salariés...), elles disposent de moyens humains

3. Plusieurs directives européennes rendent ainsi obligatoire pour les États membres, dont la France, l'organisation de cette participation élargie du public et des parties prenantes non sectorielles dans la mise en œuvre des politiques agroenvironnementales et de R\&D (directive-cadre sur l'eau ; directive participation 2003/35/CE ; partenariats européens pour l'innovation). 
et de dispositifs d'appui techniques conséquents pour participer aux nombreuses réunions et faire valoir leur point de vue (Landel, 2015)

Les nouvelles injonctions participatives, combinées à la diminution des ressources humaines dans les services, accompagnent donc le désengagement du ministère de l'Agriculture d'une partie des débats de fond sur les orientations technologiques du secteur et les priorités du financement du système de $\mathrm{R} \& \mathrm{D}$, au bénéfice de ce type de dispositif multipartenarial où les entreprises de l'agrobusiness jouent un rôle clé, bien loin du schéma antérieur de la cogestion État/profession.

Ce renforcement du rôle des entreprises de l'agrobusiness s'observe aussi dans la recherche, la formation et le conseil.

Pour la recherche, l'encouragement, voire l'obligation de créer des consortiums incluant des partenaires privés, notamment pour les programmes financés au niveau européen, donne à ces partenaires une importance grandissante dans le choix des domaines de connaissances qui sont explorés, alors même qu'ils bénéficient aussi de soutiens financiers spécifiques du public pour développer leurs propres activités de recherche.

Pour l'enseignement agricole, comme dans d'autres secteurs professionnels, les établissements et la formation professionnelle voient eux aussi l'entrée des entreprises privées d'amont et d'aval dans leurs dispositifs, dans leurs conseils d'administration, mais aussi via les « chaires d'entreprises » qui se multiplient. Les entreprises finançant ces chaires (Veolia, Bayer, Basf, Total, Nestlé-Purina, etc.) interviennent directement dans l'élaboration des programmes de formation et de recherche, utilisent la réputation des établissements pour leur propre notoriété et peuvent sous certaines conditions bénéficier d'une réduction d'impôts au titre du mécénat. La réflexion sur les conditions de mise en œuvre de ces partenariats, sur le contrôle de leur dimension éthique, politique et pédagogique, qui fait l'objet d'analyses et de réglementations dans d'autres pays, reste en grande partie à construire en France (voir par exemple Quetglás et Grau, 2002, pour les États-Unis). Il en est de même pour la formation professionnelle où, par exemple, la formation à l'usage des pesticides « Certiphyto », financée par l'État, a été confiée à divers types de partenaires, parfois aux vendeurs de produits phytopharmaceutiques eux-mêmes, avec un faible contrôle de l'État sur le contenu des formations (Ansaloni et Smith, 2014) et aucune évaluation rigoureuse ex post de son efficacité. Le dispositif de conseil a lui aussi été pris dans cette vague de réforme.

Les soutiens financiers de l'État sont restés relativement importants, comparativement à d'autres pays européens (Labarthe, 2014) mais ils sont gérés de façon nouvelle. L'Anda, association qui était un des lieux de la cogestion et de la coordination des actions et qui gérait les fonds du développement, a été dissoute sous les effets convergents d'une remise en cause de son fonctionnement par la Cour des comptes, par une partie de la profession et par la Commission européenne. Finalement, c'est un nouvel organisme, le Casdar (Compte d'affectation spéciale pour le développement agricole et rural) qui dépend exclusivement du ministère de l'Agriculture, qui répartit les fonds sur la base de réponses à des appels d'offres. Ces principes de gestion favorisant des projets non pérennes peuvent être justifiés pour mieux prendre en compte les questions émergentes. Mais, appliqués à l'ensemble du dispositif, ils rendent difficile la coordination et la cohérence à moyen terme des actions de développement. 
Par ailleurs, par différents mécanismes budgétaires et réglementaires, les acteurs du monde agricole ont été invités à délivrer des prestations de services sur des bases commerciales (conseil, essais dans les ITA), y compris dans les organisations soutenues par l'État (chambres d'agriculture, instituts techniques), et à favoriser l'émergence d'entreprises de conseil privées. Comme le confirme le cas de l'AC (encadré 18.3), ceci a eu des conséquences directes sur la délimitation du contenu et de la population des bénéficiaires du conseil. Cela s'est traduit à la fois par une offre plus diversifiée de conseil pour les exploitations les plus solvables (apparition de consultants spécialisés, de cabinets de conseil, développement du conseil des organismes économiques - entreprises de collecte, de fournitures d'intrants -, etc.) (Lémery, 2006 ; Compagnone et al., 2015), l'augmentation de la part relative de conseils sur les productions délivrés par des conseillers non indépendants (entreprises d'amont et d'aval) (Compagnone et al., 2009 ; Labarthe, 2006), et par des difficultés plus grandes pour les petites exploitations à bénéficier de conseil adéquat pour leurs systèmes de production (Labarthe et Laurent, 2013).

La disparition de plusieurs instances de coordination entre différentes fractions de la profession - entre l'État et la profession, entre la recherche et le développement et l'importance croissante d'opérateurs privés qui ont leurs propres références techniques se traduisent aussi par une fragmentation de la base de connaissances utilisable pour le conseil et la formation des conseillers. D'une part, les connaissances, qui pour les Lumières et le personnalisme mouniériste étaient vectrices d'émancipation collective, sont désormais considérées par une fraction des acteurs comme des ressources qui ne doivent plus être partagées. D'autre part, il n'y a pas de réflexion organisée sur les instruments matériels qui pourraient soutenir un dispositif d'appui mutualisé au niveau français ou européen (via des sites Internet et des bases de connaissance partagées, des dispositifs de formation continue, etc.) indépendant, c'est-à-dire conçu et mis en œuvre par des organisations qui n'ont pas d'activités commerciales liées à la vente d'intrants agricoles ou de produits de l'agriculture.

\section{Encadré 18.3. Orientations des recherches appliquées et du conseil sur l'AC.}

Une fraction de la profession agricole a incité les ITA à conduire des travaux sur l'AC. Ils concernent surtout les technologies adaptées aux grandes exploitations très mécanisées de grandes cultures ; les alternatives existantes pour les petites exploitations et/ou l'agriculture biologique sont peu testées (Landel, 2015). De leur côté, les firmes de l'agrofourniture s'impliquent dans la production de connaissances adéquates à la diffusion des technologies qu'elles commercialisent, qui sont le plus souvent rentables dans des exploitations de grandes dimensions. Elles nourrissent une partie du débat technique sur l'AC en fournissant des références techniques lors de conférences où elles convient acteurs professionnels, décideurs publics et hommes politiques.

Au niveau du conseil, on observe que l'implication des firmes dans les dynamiques d'innovation, leur soutien logistique sur le terrain auprès des agriculteurs et leur offre de conseil technique, adaptée à la diffusion de techniques fondées sur l'utilisation de pesticides, expliquent en partie les mécanismes de verrouillage sur des technologies à forte consommation d'intrants (Goulet, 2008 ; Landel, 2015). 
Les évolutions observées ces dernières années confirment bien la nature structurelle du changement observé dans le régime de connaissances du secteur agricole en France. Elles accompagnent l'installation d'une régulation sectorielle dominée par l'alliance entre ministres de l'Agriculture et agrobusiness/grandes exploitations. L'analyse des réformes administratives et de celles concernant les acteurs du système de connaissances agricoles (recherche, conseil, dispositifs d'information, etc.) fait ressortir le renoncement progressif de l'État à formuler un projet technologique pour l'agriculture. Comme le montre le cas de l'AC, ce rôle est largement délégué aux intérêts dominants de la profession et aux entreprises de l'agrobusiness. Non seulement l'État ne fournit plus aux autres groupes d'intérêt les connaissances permettant de contester ce projet ou de construire des alternatives, mais il a aussi amoindri ses propres dispositifs d'appui technique, de contrôle et d'évaluation.

À court terme, ce système a des vertus régulatrices car il permet de nier et de plonger dans l'opacité des contradictions majeures qui peuvent être associées aux choix technologiques promus par l'industrie. Un exemple de ces contradictions a été fourni ici avec le cas de l'AC et l'usage des pesticides, mais elles concernent aussi bien d'autres questions : préservation de la biodiversité, santé et sécurité au travail, statut des travailleurs détachés, etc. À moyen terme, les bénéfices de cette régulation par l'opacité sont cependant plus douteux car elle prive l'État et les autres acteurs de la possibilité d'ajustements successifs permettant d'éviter des crises majeures.

Cette situation a une configuration nationale spécifique. La logique de libéralisation économique est devenue dominante en Europe, mais elle s'est accompagnée dans plusieurs pays de la mise en place de dispositifs destinés à favoriser une régulation par l'information (Majone, 1996), en construisant des outils nationaux (grandes bases de connaissances informatisées accessibles à tous les acteurs gérées par des autorités indépendantes) ou en investissant les dispositifs où s'élaborent les prescriptions réglementaires, permettant ainsi à l'État de garder un rôle d'orientation (Le Galès et Scott, 2008, pour le Royaume-Uni).

En France, le choix a été de se détourner de ces grands outils et des réflexions internationales sur l'usage des connaissances dans la décision publique, qu'il s'agisse d'analyses des effets de capture des services techniques des États par divers groupes d'intérêts ou de réflexions méthodologiques telles que celles sur les approches en termes d'evidence-based policy (politiques fondées sur des données factuelles) (Laurent et al., 2012). D'autres façons de faire entrer les connaissances dans la décision publique sont privilégiées. Ainsi, sont mises en avant des formes d'expertise dont la qualité doit être garantie par la qualité individuelle des experts ${ }^{4}$, mais qui ne peuvent que rarement reposer sur des méthodologies demandant des moyens conséquents (notamment revues systématiques des connaissances disponibles, évaluations ex post rigoureuses de l'efficacité des politiques publiques mises en œuvre). Par ailleurs, l'idée de participation est convoquée comme principe réformateur pour améliorer l'accès aux connaissances pour le débat public et l'innovation, mais ces dispositifs eux-mêmes peuvent faire l'objet d'effets de capture par les groupes d'intérêts les mieux dotés financièrement. De plus, sans appui adéquat pour accéder

4. Répondant à la norme Afnor NF X 50-110 qui ne comporte pas de cahier des charges méthodologique précis. 
Tableau 18.1. Configuration des régimes de connaissance agricoles en France.

\begin{tabular}{|c|c|c|}
\hline & $\begin{array}{c}\text { Régime de connaissances } 1 \\
1960-1985\end{array}$ & $\begin{array}{c}\text { Régime de connaissances } 2 \\
2002-2015\end{array}$ \\
\hline $\begin{array}{l}\text { Caractéristiques } \\
\text { de la régulation } \\
\text { sectorielle }\end{array}$ & $\begin{array}{l}\text { Régulations sectorielles : compromis } \\
\text { État-profession autour d'une façon } \\
\text { dominante de penser la production. } \\
\text { Mécanismes de compensation des } \\
\text { inégalités pour ceux qui veulent } \\
\text { jouer le jeu de la modernisation } \\
\text { Cogestion avec la profession du } \\
\text { secteur }\end{array}$ & $\begin{array}{l}\text { Régulation sectorielle : dominée } \\
\text { par une alliance entre État, } \\
\text { agrobusiness, exploitations de } \\
\text { grande dimension. Réduction } \\
\text { du périmètre de la cogestion } \\
\text { (notamment n'inclut plus le conseil). } \\
\text { Petites exploitations familiales } \\
\text { renvoyées à la régulation territoriale. } \\
\text { Absence d'accord sur un modèle } \\
\text { technique pour répondre aux } \\
\text { préoccupations environnementales, } \\
\text { économiques et sociales. }\end{array}$ \\
\hline $\begin{array}{l}\text { Rapports avec } \\
\text { l'UE }\end{array}$ & $\begin{array}{l}\text { Construction de la PAC. } \\
\text { Principe de subsidiarité des } \\
\text { dispositifs de conseil. } \\
\text { Financements nationaux des } \\
\text { programmes de recherches. } \\
\text { Dispositifs de conseil agricole } \\
\text { renvoyés à la subsidiarité nationale. }\end{array}$ & $\begin{array}{l}\text { PAC cohérente avec OMC, } \\
\text { renationalisation partielle. } \\
\text { Préconisation d'un recours accru } \\
\text { à la participation (directive). } \\
\text { Subsidiarité pour les dispositifs } \\
\text { d'accompagnement technique } \\
\text { remise en cause à partir de } 2003 \text {. } \\
\text { Développement de financements } \\
\text { européens de la recherche. }\end{array}$ \\
\hline $\begin{array}{l}\text { Accès aux } \\
\text { connaissances } \\
\text { pour les services } \\
\text { de l'État }\end{array}$ & $\begin{array}{l}\text { Développement des compétences } \\
\text { techniques dans les services du } \\
\text { ministère de l'Agriculture (sciences } \\
\text { biotechniques et sciences sociales). } \\
\text { Développement de services } \\
\text { statistiques. } \\
\text { Développer et faciliter la diffusion } \\
\text { de connaissances économiques et } \\
\text { techniques dans le monde agricole. }\end{array}$ & $\begin{array}{l}\text { Réduction des compétences } \\
\text { techniques dans les services du } \\
\text { ministère en charge de l'Agriculture } \\
\text { et des moyens accordés aux études } \\
\text { et services statistiques. } \\
\text { Délégation de services et montée } \\
\text { des partenariats public-privé avec } \\
\text { peu d'évaluations ex post. } \\
\text { Réduction des instruments de } \\
\text { diffusion des connaissances dans le } \\
\text { monde agricole. }\end{array}$ \\
\hline $\begin{array}{l}\text { Accès pour les } \\
\text { autres acteurs }\end{array}$ & $\begin{array}{l}\text { État engagé dans des dispositifs } \\
\text { de développement (recherche } \\
\text { appliquée) produisant des } \\
\text { connaissances adéquates pour } \\
\text { accompagner la modernisation et les } \\
\text { rendre accessibles aux agriculteurs } \\
\text { (conseil individuel et de groupe, } \\
\text { formation dans les chambres, Ceta, } \\
\text { etc.). } \\
\text { État soutient l'existence d'instances } \\
\text { de coordination. }\end{array}$ & $\begin{array}{l}\text { Réorganisation de la recherche } \\
\text { (Inra) vers des priorités } \\
\text { académiques. Production de } \\
\text { connaissances appliquées focalisée } \\
\text { sur les exploitations les plus } \\
\text { solvables (y compris par les instituts } \\
\text { techniques). } \\
\text { Développement d'une pluralité } \\
\text { d'offre de conseil dominée par } \\
\text { les organismes économiques } \\
\text { (coopératives d'approvisionnement, } \\
\text { firmes d'amont). } \\
\text { Pas de dispositif de back-office } \\
\text { mutualisé indépendant. }\end{array}$ \\
\hline
\end{tabular}


aux connaissances disponibles, les évaluer, valider les propositions techniques issues de l'expérience, etc., sans connaissances validées pour évaluer l'efficience de propositions alternatives, les participants aux dispositifs participatifs ayant des ressources financières limitées ne peuvent à eux seuls compenser le renoncement de la puissance publique à produire des connaissances pour éclairer ses décisions. Ces dispositifs apparaissent plutôt comme des cache-misère visant tout à la fois à masquer et à légitimer le délitement du dispositif mutualisé d'accès à des connaissances robustes.

\section{W Conclusion}

Le regroupement d'informations fragmentées fait donc ressortir que, selon la période, le régime de connaissances sectoriel peut prendre des configurations extrêmement différentes. Le tableau 18.1 en résume les grandes caractéristiques pour l'agriculture française de ces cinquante dernières années.

A posteriori, concernant le régime de connaissances de la modernisation, un constat est frappant : quelles qu'aient pu être les critiques du contenu des connaissances alors privilégiées et des institutions organisant leur diffusion, le régime de connaissances qui s'est ainsi constitué a acquis un caractère d'évidence, au point que l'on en vient parfois à oublier que les institutions qui le constituaient n'ont dû leur naissance et leur maintien qu'à la conjonction d'une volonté politique partagée et d'efforts constants. Encore aujourd'hui, ce qui apparaît à certains comme «normal », comme relevant « du bon sens commun », par exemple un dispositif statistique efficient fournissant des données à tous pour éclairer le débat public, relève d'une norme passée qui, dans les faits, n'organise plus le secteur où s'est imposée une forme de régulation par l'opacité.

Dans cette situation, la notion de régime de connaissances telle que nous l'avons définie permet de moins se laisser piéger par le poids des normes antérieures et de conduire une analyse méthodique qui donne sens à des observations éparses, en articulant projet politique, données structurelles sur les services de l'État et les dispositifs de $\mathrm{R} \& \mathrm{D}$, règles d'évaluation de la qualité des connaissances et de mise à disposition.

Bien entendu, ces résultats ne concernent qu'un secteur, dans un pays. Une analyse complète de l'évolution des régimes de connaissances devra articuler la mise à jour de ces mécanismes à un niveau global (national et supranational) avec des analyses sectorielles. Mais d'ores et déjà, deux choses peuvent être affirmées. L'agriculture n'a pas le monopole de la régulation par l'opacité. Ces phénomènes s'observent dans d'autres secteurs, en France comme à l'international, comme le montrent les débats de plus en plus nombreux sur l'opacité des justifications techniques des évolutions réglementaires qui encadrent l'économie et les multiples domaines où s'observent des défaillances de marché (risques sanitaires, environnement, etc.). Cependant, les transformations en cours prennent des formes très différentes selon les pays. C'est un programme collectif de recherche qui est ainsi ouvert. 



\title{
Chapitre 19 \\ Le paquet de cigarettes neutre : des dangers de l'intelligence en sciences sociales
}

\author{
F. COCHOY
}

\begin{abstract}
« Sganarelle, tenant une tabatière.
Quoi que puisse dire Aristote et toute la philosophie, il n'est rien d'égal au tabac : c'est la passion des honnêtes gens, et qui vit sans tabac n'est pas digne de vivre. Non seulement il réjouit et purge les cerveaux humains, mais encore il instruit les âmes à la vertu, et l'on apprend avec lui à devenir honnête homme. Ne voyez-vous pas bien, dès qu'on en prend, de quelle manière obligeante on en use avec tout le monde, et comme on est ravi d'en donner à droit et à gauche, partout où l'on se trouve ? On n'attend pas même qu'on en demande, et l'on court au-devant du souhait des gens : tant il est vrai que le tabac inspire des sentiments d'honneur et de vertu à tous ceux qui en prennent. Mais c'est assez de cette matière. Reprenons un peu notre discours. » (Molière, Dom Juan, Acte I, Scène 1).
\end{abstract}

Cet incroyable éloge du tabac livré par Sganarelle, le valet de Dom Juan, ouvre la célèbre pièce de Molière, sans aucun lien apparent avec la grande tragédie qui suit (voir la transition : " Mais c'est assez de cette matière. Reprenons un peu notre discours. »). Le tabac est-il présenté sans emballage ? Non, au contraire, et plutôt trois fois qu'une. Nous avons ici non pas un, mais trois paquets : l'emballage matériel de la tabatière, qui est un vrai paquet neutre, sans le moindre message (au moins dans le texte); l'emballage symbolique des paroles de Sganarelle, qui va du non-sens complet (comme nous le savons tous, Aristote a écrit bien avant que le tabac ne soit introduit en Europe depuis l'Amérique du Sud) à l'éloge vibrant («il n'est rien d'égal au tabac», etc.). Enfin et surtout, l'éloge du tabac est emballé entre la couverture du livret et la partie restante du texte, à savoir une tragédie mythique et métaphysique sur la liberté, la séduction et la mort. La leçon est claire : le tabac est toujours emballé, quel que soit l'emballage. Les marchandises ne sont jamais seulement des biens ; elles peuvent être ou des biens, ou des maux (Latour, 2014), selon les médiations qui les introduisent et qui les qualifient. D'où la question consistant à déterminer quelle est la forme d'emballage la plus appropriée pour présenter le tabac.

Depuis Molière, tout est resté semblable et a changé en même temps. Les choses sont toujours les mêmes, dans la mesure où le plaisir individuel et charnel associé au tabac est toujours là, ainsi que sa dimension collective/culturelle (pour une délicieuse défense des cigarettes, voir par exemple le film envoûtant de Paul Auster, 
Smoke). De même, la transgression des normes sociales est toujours présente. Si le discours pro-tabac de Sganarelle imite maladroitement les provocations de Dom Juan en direction de la morale et de la religion, les fabricants de tabac modernes soutiennent encore la promotion d'un vice dangereux avec des arguments très similaires. Mais les choses ont aussi radicalement changé : les emballages et les mots ne sont plus les mêmes. Le paquet neutre est l'une des dernières manifestations singulières de cette histoire. Il essaie de revenir du vice à la vertu en changeant le slogan « à la Marlboro » de Sganarelle, «l'homme qui vit sans tabac n'est pas digne de vivre », en son exact contraire : «L'homme qui vit avec du tabac est presque certainement sûr de mourir... » pour la bonne raison que "fumer tue » - grâce à l'emballage moderne, aucun d'entre nous désormais n'ignore cette leçon. Comme on le sait, les dispositifs de différenciation par la qualité et les institutions connexes sont parmi les principaux apports de la grande transformation de l'agriculture, et avec elle de notre économie moderne tout entière (Allaire et Boyer, 1995).

Mais que sont au juste ces paquets neutres que l'on envisage d'introduire bientôt pour lutter plus avant contre le tabagisme ? Comment fonctionnent-ils ? Et cela fonctionne-il vraiment? Dans cet article, je voudrais questionner la nature, le fonctionnement et les implications de ce dispositif grâce à un examen attentif de ce qu'est un emballage, de ce qu'il promet et de ce qu'il est censé faire. Je présenterai donc d'abord le paquet de cigarette comme un " dispositif de captation » visuel (Cochoy, 2004), c'est-à-dire comme une machine destinée à jouer sur la cognition des consommateurs par le truchement d'impressions visuelles. En conséquence, je proposerai de conduire l'étude des paquets de cigarettes à partir de la mobilisation et de l'examen d'une série d'éléments picturaux. Avec l'aide de ce type de données, j'en montrerai et j'en discuterai les effets. Un premier effet du paquet neutre consiste à modifier mais aussi à mettre en danger la démocratie marchande, en remplaçant la lutte entre les intérêts privés et le plaisir, entre le bien public et la santé, par un règne totalitaire de la politique publique. Un deuxième effet découle du premier, sous la forme d'une préférence pour des étuis opaques ${ }^{1}$, des cigarettes de contrebande, des médicaments de substitution, des cigarettes électroniques, etc. Au final toutefois, j'examinerai de façon critique le chemin accompli, en suggérant de se méfier des critiques qui sont adressées au paquet neutre : j'expliquerai pourquoi nous, spécialistes des sciences sociales, et quel que puisse être le bien-fondé de nos arguments, devrions prendre soin de ne pas devenir stupides en tentant d'être trop intelligents.

\section{" De la démocratie d'emballage au totalitarisme sanitaire?}

L'emballage moderne a été inventé par des entreprises privées pour lutter contre la substitution des produits, la concurrence déloyale des biens de qualité inférieure

1. Voir sur le site smoking.fr : http://www.smoking.fr/articles-fumeurs-etuis-cigarettes-c-1_46.html ; http://www.smoking-paradize.com/etui-cigarette/291-etui-cigarette-cache-paquet-noir.html. 
vendus en vrac, et pour promouvoir les noms de marque et la qualité des produits à travers leur affichage direct sur les marchandises. Cela dit, ce serait une grave erreur de concevoir l'emballage comme un dispositif entièrement privé. Depuis ses origines, l'emballage est devenu le site d'une économie mixte où les messages des entreprises libres sont combinés avec des mentions légales obligatoires. L'emballage fut dès l'origine un outil et un remède pour/contre la fraude. C'est un outil de fraude, dans la mesure où les boîtes, en empêchant l'appréciation directe de produits avant leur paiement et leur consommation, ont favorisé les pratiques trompeuses. Mais c'est aussi un remède contre ces mêmes pratiques, dans la mesure où l'inscription de la marque et de la description détaillée du contenu sur le produit a fonctionné comme un contrat écrit entre le fournisseur et le consommateur. Au début du $\mathrm{Xx}^{\mathrm{e}}$ siècle, peu de temps après la diffusion des technologies d'emballage et des produits emballés (Twede, 2012) - voir la loi de 1905 sur la répression des fraudes en France et le Pure Food and Drug Act de 1906 aux États-Unis -, les autorités juridiques ont profité de cette dimension contractuelle implicite pour imposer la mention du nom et de l'adresse du producteur et la description précise de la nature, du poids et/ou du volume du contenu de chaque emballage. En d'autres termes, les informations qui pouvaient être présentes sur la boîte selon le bon vouloir de l'entreprise sont devenues obligatoires et ont donc revêtu un caractère public. La réglementation a fait de l'emballage le premier dispositif de traçabilité et de qualité susceptible d'engager la responsabilité du fabricant et donc de protéger les consommateurs contre d'éventuels abus.

À partir de là, l'emballage est devenu une véritable arène politique, où les intérêts privés et les valeurs publiques entrent en concurrence pour emporter l'attention des consommateurs, tout comme les partis politiques opposés luttent pour gagner le vote de la population et occuper chacun leur part des sièges au parlement (Cochoy et Grandclément, 2005).

Retenir cette vision des choses pour rendre compte de l'histoire de l'emballage des cigarettes a deux avantages. D'abord, cela permet de décrire les paquets de cigarettes comme un « dispositif de captation ». Comme je l'ai expliqué ailleurs (Cochoy, 2004), la captation, qu'il ne faut pas confondre avec la capture, vise à faire en sorte qu'une cible vienne vers soi sans pouvoir la forcer à agir de la sorte. C'est la seule stratégie d' « attachement » réalisable et acceptable en contexte politique et marchand, où les votes ou les ventes forcées sont prohibés. Légalement, les électeurs et les consommateurs sont libres de choisir et doivent donc être convaincus de faire leurs choix par d'autres moyens que la violence et la coercition. La captation repose souvent sur l'utilisation de dispositifs spéciaux qui jouent sur les dispositions des personnes. L'emballage est l'un de ces dispositifs : il s'agit d'une entité matérielle qui parie sur les dispositions sociales et cognitives de ses lecteurs. Mais l'emballage de cigarettes est particulier, en cela qu'il se prête à des activités de captation et de contre-captation. À la surface du parlement du paquet en effet, chaque parti joue le jeu de la captation différemment. Le parti privé/conservateur des fabricants de cigarettes, qui a pendant longtemps dominé la scène, joue surtout sur les émotions et la séduction, comme le montrent par exemple les marques françaises Gauloises et Gitanes, avec leurs noms féminins séduisants, ou l'imagerie virile de Marlboro, avec son cow-boy et son cheval. De l'autre côté, le parti progressiste/public des autorités publiques, qui est progressivement entré dans le jeu, a essayé de jouer sur le calcul 
rationnel, en fournissant des faits froids sur le contenu du produit et plus tard sur ses dangers ( «Fumer tue ») comme autant de stratégies de « dé-captation » destinées à couper les attachements entre les fumeurs et leurs cigarettes.

Évaluer l'évolution du rapport de force entre les partis privés et publics est très simple : il suffit de suivre le parlement-emballage sur longue période et d'examiner comment la répartition des sièges a varié. Cela peut être fait en mesurant leur équivalent graphique, c'est-à-dire le nombre de millimètres carrés occupés par chaque parti (marque et logo d'une part, messages sanitaires de l'autre). Un tel examen met au jour un net renversement qui s'est produit dans la période récente, en particulier après le $1^{\text {er }}$ septembre 2003 , lorsque la nouvelle réglementation européenne imposant des messages sanitaires en noir et blanc de grande taille a été introduite sur les paquets de cigarettes et a remporté la majorité (Cochoy et Grandclément, 2005).

Le cas des cigarettes montre toutefois que, dans un tel parlement, les identités des acteurs peuvent être floues, ou même usurpées. Il serait faux de considérer que la régulation et la lutte pour la santé résident du côté public seulement, tandis que la promotion des images et du plaisir associés aux cigarettes résiderait uniquement du côté privé. Parfois, le discours le plus vertueux n'est pas tenu par ceux que l'on croit. Paradoxalement, les fabricants de cigarettes peuvent changer de rôle et jouer le jeu des messages sanitaires public. Philip Morris a agi volontairement de la sorte en accompagnant les messages obligatoires des autorités publiques par ses propres programmes de prévention. Tout d'abord, l'entreprise a publié un code de marketing dans lequel elle met en avant sa « responsabilité sociale de l'entreprise » en s'interdisant de s'adresser à d'autres publics que les seuls adultes :

« Philip Morris International est totalement engagé dans la promotion de sa responsabilité en matière de cigarettes. À cet égard, Philip Morris ne commercialise pas ses cigarettes auprès des mineurs. L'entreprise est fermement convaincue que les cigarettes doivent être consommées par les fumeurs adultes. Par conséquent, toutes les publicités et actions promotionnelles doivent être orientées vers les fumeurs adultes seulement, et non vers les mineurs » (Cigarette Marketing Code de Philip Morris souligné dans le texte original).

Ensuite, cet engagement, loin d'être limité à des intentions vertueuses mais dépourvues d'effets, est mis en œuvre comme une véritable politique, systématique et vérifiable, par exemple sous la forme d'un message imprimé universellement sur chaque paquet de cigarettes à l'échelle mondiale : « Les mineurs ne doivent pas fumer ». Ce message est une déclaration volontaire de l'entreprise, absente de la liste des mentions proposées par les autorités sanitaires, mais très proche d'eux tant en matière de terminologie que de style, d'intention que de contenu (voir par exemple l'avertissement public : «Fumer pendant la grossesse nuit à la santé de votre enfant »). D'où l'étonnement : pourquoi une entreprise motivée par le profit agirait-elle contre son propre intérêt en refusant de cibler l'un des segments de marché possibles, et plus encore un segment de marché qui n'est pas n'importe lequel, mais sans doute le plus stratégique ? En effet, le segment de l'adolescence est le marché sur lequel l'habitude de fumer se développe le plus efficacement et peut donc assurer les bénéfices futurs de Philip Morris. Les adolescents sont-ils en mesure d'identifier que c'est la marque qui leur parle et sont-ils sensibles à ses messages, et de quelle manière ? 
Afin de répondre à ces intrigantes questions, j'avais, avec l'aide de deux de mes anciens étudiants, effectué une enquête auprès des élèves d'un lycée professionnel toulousain (Cochoy et al., 2006). Nous avons obtenu 282 réponses de personnes en majorité de sexe masculin (94\%) âgées de 14 à 23 ans. L'âge moyen de la population était de 17 ans, avec une proportion de mineurs de $59 \%$. Les résultats sont étonnamment contre-intuitifs. Confrontés au message « Les mineurs ne doivent pas fumer », nos jeunes répondants l'ont principalement associé à la loi, dans une proportion supérieure même aux véritables avertissements légaux, tels que « Fumer peut diminuer l'afflux sanguin et provoque l'impuissance » $(67,8 \%$ contre 46,7 \%). Encore plus surprenant, 67,8 \% des fumeurs ont été les victimes de cette confusion, tandis que 52,9\% des non-fumeurs se sont montrés incapables de distinguer le message de Philip Morris d'un avertissement légal. Nos répondants ont été évidemment abusés ; ils ont pris le discours de la marque pour un message public. Et l'abus pourrait aller encore plus loin : en disant à des adolescents qui rêvent de devenir des adultes que « les mineurs ne doivent pas fumer », le message ne fonctionne-t-il pas comme un moyen pervers de provoquer la transgression et donc de les inciter à fumer ? La morale de cette histoire est claire : tout fonctionne comme si Marlboro jouait au même jeu que le loup avec les sept petits chevreaux ; il trempe sa patte dans la farine vertueuse de la responsabilité sociale des entreprises et des avertissements sanitaires pour gagner en respectabilité et provoquer la transgression en même temps. En agissant de la sorte, il trouve les moyens de développer son marché, tout en faisant semblant de le refuser ; malgré cet avertissement sanitaire adressé exclusivement aux mineurs, Philip Morris est une marque de premier plan parmi les adolescents ${ }^{2}$.

De toute évidence, le paquet neutre prend le contrôle du parlement au point que l'idée même de débat démocratique contradictoire disparaît. En remportant $98 \%$ des sièges, le discours public tue son homologue privé : tout se passe comme si l'on passait de la démocratie marchande au totalitarisme sanitaire ! L'emballage neutre va-t-il trop loin ? Ne devrions-nous pas nous méfier des arènes politiques dans lesquels un seul parti possède (et même confisque) le droit de parler?

\section{" Le paquet neutre \\ comme agencement marchand risqué}

Pour répondre à ces questions très délicates et politiques, je propose tout d'abord d'explorer la logique du paquet neutre à un niveau plus générique, indépendant du cas particulier du tabac. Pour cela, je vais me référer à une expérience scientifique et artistique que Catherine Grandclément et moi-même avions eu la chance de conduire avec l'aide de l'artiste Alexis Bertrand dans le cadre de l'exposition de Bruno Latour et Pieter Weibel, " Making things public », présentée en $2005 \mathrm{au}$ ZKM à Karlsruhe, en Allemagne (Latour et Weibel, 2005). L'objectif général de l'événement était d'exposer un « parlement de parlements ». L'idée était de montrer

2. Voir sur le site yesmoke.eu : http://yesmoke.eu/blog/young-adult-smokers-words-big-tobacco/ (consulté le 14 octobre 2016). 
que la politique, au sens d'effort destiné à assembler le public, est loin de se limiter aux institutions classiques de la démocratie représentative, mais fonctionne plutôt comme une activité omniprésente et dispersée, dont la présence peut être tracée en une multitude de lieux, tels les écrans des marchés financiers, le code informatique d'une machine à voter, etc. Notre propre installation était axée sur les chariots de supermarché et sur les emballages comme autant de parlements distribués, banals et négligés (Cochoy et Grandclément, 2005). Dans le dernier cas, nous avons soumis un ensemble de paquets de corn-flakes Kellogg's, avec son célèbre coq vert et rouge, à une série d'opérations destructrices mais aussi créatives. Deux de ces expériences essayaient de prendre au sérieux l'invitation de Naomi Klein (2000) à instaurer une économie «sans logo », afin d'en éprouver les effets (à la fois physiques et cognitifs). En d'autres termes, nous avons pratiqué deux types distincts de «logotomies ».
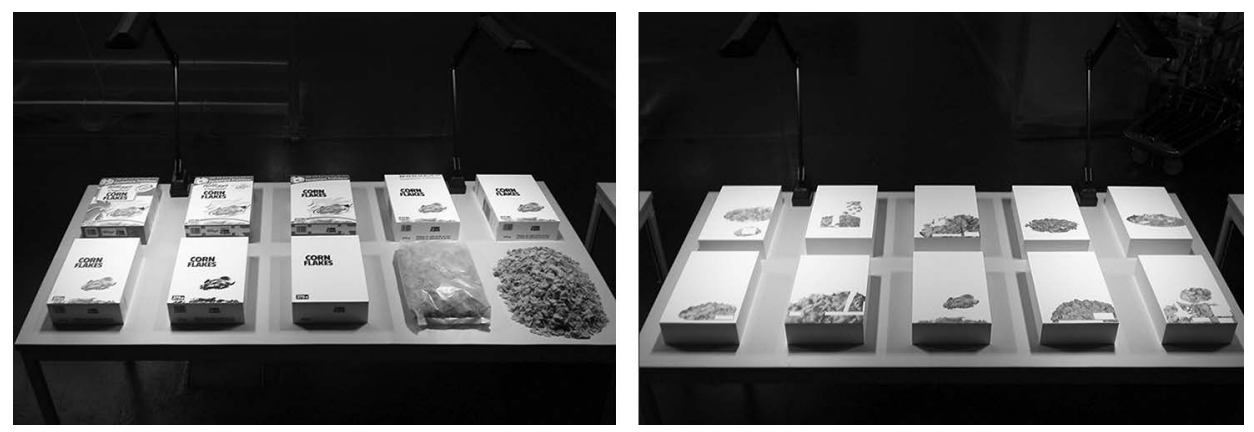

Figure 19.1. Rendre les choses publiques : logotomies (C) F. Cochoy.

L'expérience visible sur l'image de gauche tente de rejouer la commercialisation de l'histoire à rebours, en supprimant toutes les couches de qualification du marketing, une par une, de l'emballage contemporain, avec tous ses logos, ses images et ses messages colorés, jusqu'à la désignation de son simple contenu générique avec des mots et des images en couleur puis en noir et blanc, puis seulement des mots (nom du produit et quantité), puis le paquet en plastique brut, et enfin le produit nu. L'expérience photographiée sur l'image de droite fonctionne à partir d'un ensemble de dix paquets de corn-flakes de différentes marques, dont nous avons supprimé tout ce qui avait rapport aux marques, aux messages écrits et à la qualification externe. Nous avons juste conservé les images du produit lui-même et l'indication la plus simple du contenu, afin de se rapprocher le plus possible de la présentation en vrac, mais sans abandonner l'économie d'emballage pour autant.

Ces deux expériences aident à comprendre ce qu'un paquet neutre signifie. Elles le font en vertu d'une stratégie compréhensive wébérienne duale, sauf que, dans ce cas, la stratégie suit des lignes visuelles plutôt que mentales, et se concentre sur la compréhension des objets plutôt que des personnes, ou plutôt sur la façon dont les gens comprennent les objets. Avec la première table, nous réalisons mieux, en retraçant le chemin qui mène du produit en vrac à l'économie d'emballage contemporaine, ce qu'il en coûte d'abandonner tout ce que nous avons appris, ce que cela signifie d'être privé de toutes les entités matérielles que nous avons désormais l'habitude de mobiliser pour évaluer les produits, ce que cela fait de perdre toutes 
les dimensions «qualculatives » internes et externes grâce auxquelles nous choisissons les produits (Cochoy, 2011). Dans ce processus, nous revenons du testing au tasting : sans mentions packagées, la qualité ne peut plus s'apprécier qu'au travers d'une expérience sensorielle directe mais très partielle et imprécise (tasting), loin du jugement délégué, systématique et standardisé effectué sur la base de mesures et de qualifications de laboratoire qui soutient le packaging contemporain (testing). Sur la deuxième table, avec la suppression des identifications de marque et des mentions écrites des paquets concurrents, nous comprenons ce que cela signifierait de se comporter de nouveau comme des ânes de Buridan, c'est-à-dire comme des consommateurs obligés de choisir entre le même et le même (Cochoy, 2002). Sans qualification externe, l'économie d'emballage, qui n'est qu'une affaire de différenciation des produits, devient sans objet : soit les produits sont emballés et l'on a besoin de quelques mentions pour les distinguer, soit ils sont privés de qualifications et l'on doit supprimer les emballages et les vendre nus et mélangés, exposés en vrac comme un bien générique et placés dans un récipient unique et neutre.

Mais le détour par les paquets de corn-flakes contribue également à pointer la plus grande différence entre les soi-disant «paquets neutres » de cigarettes et ce qu'un paquet neutre est vraiment. Avec les expériences sur les corn-flakes, nous obtenons des paquets neutres sous la forme de boîtes blanches privées de toute information, sauf le nom du produit et le volume dans le premier cas (image de droite) ou l'aspect visuel d'un produit générique vendu en vrac dans le second (image de gauche). Les paquets de cigarettes neutres d'aujourd'hui sont en contradiction avec ces deux variantes : s'ils montrent le nom du produit, ou plutôt sa marque, ils n'abandonnent pas les images externes et les autres qualifications du régime de testing. Ils les exagèrent même, avec l'affichage d'images choc de maladies possibles, en multipliant et en mettant l'accent sur l'information sanitaire externe et sur les avertissements caractéristiques du testing. La seule différence réside dans la suppression de

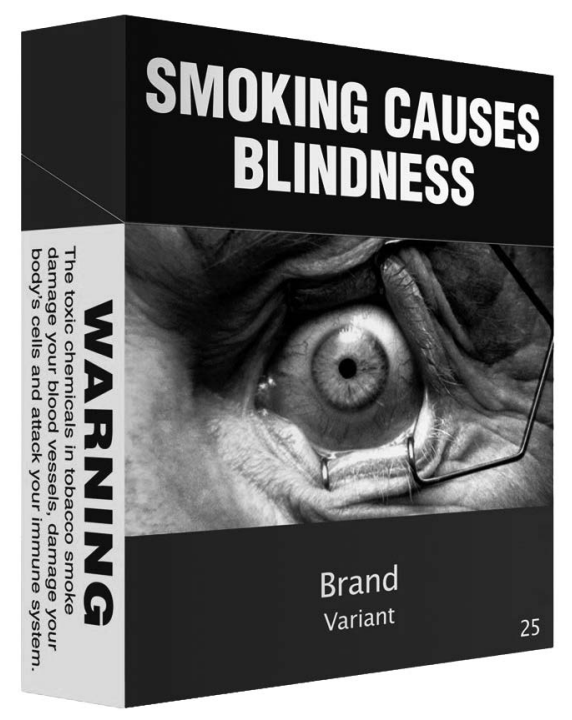

Figure 19.2. Paquet de cigarettes « neutre». 
tous les aspects positifs des paquets précédents qui ont été remplacés par des effets négatifs et par eux seuls.

Les soi-disant paquets de cigarettes neutres n'ont donc rien à voir avec l'idée de neutralité ; il serait plus pertinent de parler d'emballages de cigarettes « négatifs ». En ce sens, ils ne sont qu'un résultat parmi d'autres d'un processus qui a commencé tôt sur d'autres marchés. C'est le cas avec la « nutrition négative » de la fin des années 1980 (Levenstein, 1993) qui a conduit par exemple les autorités britanniques à mettre en évidence les pires nutriments, comme le sucre, le gras ou le sel, grâce à l'emploi de feux tricolores vert, orange et rouge (Séguy, 2014) ; c'est aussi le cas de la pratique du «screening négatif » en vigueur dans le secteur de la finance éthique, qui consiste à bannir les produits financiers qui sont associés à des entreprises immorales comme l'armement, l'alcool ou les industries du tabac (Waring et Lewer, 2004). Quels sont les effets possibles d'une telle soustraction, d'une telle présentation biaisée et incomplète ? Je propose d'en évoquer trois.

À première vue, et comme nous venons de le voir, le but du paquet neutre n'est pas de nous ramener au tabac en vrac. Les cigarettes restent emballées, mais d'une manière négative visant à provoquer leur rejet. Mais quel rejet ? L'objectif officiel est bien sûr de faire en sorte que les fumeurs fuient les cigarettes, mais les fumeurs peuvent fuir le paquet neutre plutôt que les cigarettes et/ou les pratiques nocives. Deux comportements adaptatifs peuvent intervenir ici.

Les fumeurs peuvent d'abord contrer la dissonance cognitive entre le plaisir de la cigarette et le dégoût de l'emballage négatif en jouant le jeu de l'autruche. Bien sûr, l'idée n'est pas d'enfoncer leur tête dans le sable, mais de mettre le paquet effrayant dans un étui à cigarettes rassurant qui transforme ironiquement le soidisant paquet neutre en un paquet neutre véritable. Par ailleurs, nous réalisons que si la suppression des symboles des cigarettes met au premier plan le dégoût pour les maladies liées au tabac, elle isole également le goût des cigarettes comme l'un des rares éléments restants. Le paquet neutre transmet donc le plaisir sensuel, charnel de la consommation du tabac, tout en rejetant l'image de marque qui est pourtant beaucoup plus fragile et a besoin d'efforts permanents pour être soutenue. C'est un effet ironique du paquet neutre : en interdisant les mots et les images, mais pas le produit lui-même, ce dispositif reconnaît implicitement que le produit n'est pas l'aspect principal, que les gens consomment aussi les mots, les symboles et la socialité qui lui sont attachés, et que ces éléments sont peut-être plus importants que la dépendance sous-jacente.

Ensuite, les fumeurs peuvent fuir aussi l'emballage négatif en revenant à des présentations en vrac du produit comme le tabac à rouler, les cigarettes de contrebande, ou même des alternatives plus dangereuses comme le cannabis qui, en dehors de ses versions pharmaceutiques, est vendu sans aucune forme d'emballage juridique et d'avertissements sanitaire. Ce faisant, l'emballage négatif des cigarettes, au lieu d'avoir des effets positifs sur ses cibles, pourrait paradoxalement, au mieux, n'avoir aucun impact réel, au pire, induire des comportements plus dangereux. Ici, nous rencontrons la tragédie des «marchés contestés », tels qu'ils ont été présentés dans un livre récent dirigé par Philippe Steiner (2014). D’une part, comme le montrent les auteurs, certains marchés sont contestés selon l'argument que certains biens ne devraient pas être commercialisés, en raison de leur nocivité pour tout ou partie du 
public (le tabac, l'alcool ou la pornographie qui ne conviennent pas pour les enfants) ou en raison des graves questions environnementales ou éthiques qu'ils soulèvent (les OGM, les mères porteuses, etc.). Mais, d'autre part, il a souvent été objecté qu'interdire un objet sur le marché officiel est la meilleure façon de voir ce même objet proliférer sur le marché noir, c'est-à-dire une forme de marché très néfaste, très libérale, sans règlement, sans taxes, sans État, bref hors de contrôle. En ce sens, le paquet neutre est face à un dilemme : à être trop négatif, il peut se montrer contre-productif.

\section{" Discussion : par pitié, essayons de ne pas devenir stupides en nous montrant trop intelligents !}

J'ai montré plus haut que l'évolution des paquets de cigarettes conçus comme parlements a glissé de la démocratie marchande au totalitarisme sanitaire. Mais nous ne devons pas oublier que, même si le régulateur prend le contrôle total de l'emballage, l'emballage et les cigarettes qu'il contient sont toujours là. L'emballage neutre est massivement totalitaire en termes de politique de l'offre, mais reste entièrement libéral en termes de choix du consommateur. En d'autres termes, ce dispositif est très ambigu : il s'agit de bannir le tabac sans le bannir. Est-ce judicieux ? Pourquoi supprimer les mots et les images et conserver les cigarettes, si ce sont ces dernières plutôt que les premiers qui font du tort aux fumeurs ? Si un produit est mauvais, si le tabac tue, si le tabagisme consiste à consommer de la mort, pourquoi continuer à vendre des cigarettes? En fait, ce qui ressemble à un non-sens en surface est beaucoup plus compréhensible lorsque l'on divulgue la philosophie sous-jacente. Le paquet neutre peut être considéré comme une variante de l'économie des «nudges » (coups de pouce), qui propose d'opérer une articulation subtile entre le dogme libertarien du libre-choix et les préoccupations du public pour la santé des personnes, d'après l'hypothèse que les consommateurs ne sont pas pleinement conscients des conséquences possibles de leur action, mais doivent néanmoins conserver leur liberté de choisir (Thaler et Sunstein, 2008). Afin de préserver le principe démocratique de la liberté de choix, mais aussi d'aider les personnes à ne pas prendre des décisions qui pourraient contrevenir à leur meilleur intérêt, les auteurs proposent de leur donner des « coups de pouce » en concevant des dispositifs spéciaux, par exemple en plaçant le brocoli avant les frites dans les restaurants scolaires en libre-service. Le paquet neutre fonctionne selon la même logique : il suppose que fumer ou non doit rester une décision individuelle, mais il change l'apparence des paquets de cigarettes de façon à ce que les décisions puissent être prises selon une autre logique qui mettrait au premier plan les problèmes de santé (les avertissements viennent d'abord sur l'emballage) au détriment du plaisir de la consommation (les cigarettes ne viennent qu'ensuite, une fois que le paquet a été ouvert).

Disons-le autrement. Interdire les cigarettes consisterait à s'inscrire dans la perspective du marché contesté, qui remet en question la «valeur marchande » de certains biens, au risque de favoriser le développement de la contrebande et même pire, comme nous l'avons vu. L'approche du paquet neutre propose plutôt de passer des «marchés contestés » aux « marchés concernés ». Cette dernière notion a récemment 
été proposée par Susi Geiger et al. (2015). Les auteurs suggèrent que postuler une opposition radicale entre l'économie de marché et la "société sociale » pourrait être erroné, pour la bonne raison que toute situation marchande combine des ressources prélevées dans les deux sphères. Selon ce point de vue, la question n'est pas de contester les marchés et de chercher des solutions de rechange que l'on ne peut atteindre, qui s'avèrent limitées, ou qui peuvent être contrées par la prolifération d'avatars illégaux des marchés que l'on prétend éradiquer, mais d'être " concernés » par la possibilité de concevoir de meilleurs agencements marchands (Cochoy, 2015). Le paquet neutre s'oriente exactement dans cette direction : à première vue, il revêt l'apparence d'un marché alternatif entièrement public et presque totalitaire, mais lorsque l'on examine plus attentivement la façon dont il fonctionne, on réalise qu'il joue encore le jeu du marché, en acceptant le caractère commercialisable du tabac, mais aussi en poussant les fumeurs du mieux qu'il peut afin de les conduire à changer leurs pratiques dans la «bonne » direction.

Le problème est bien sûr d'évaluer la façon dont ce type d'action est mis en œuvre. Or, la façon dont les paquets neutres ont été promus me semble très discutable. Quand on soutient des causes aussi incontestables que la nocivité du tabac, il est vraiment dommage de le faire à reculons, honteusement, en utilisant des termes trompeurs. En effet, toute l'ironie du paquet neutre est d'utiliser un argument pour dire la vérité sur le tabac qui est lui-même un gros mensonge. Le paquet neutre n'a rien de «neutre » : un paquet neutre n'est pas une boîte vide sans aucun message, mais plutôt une boîte totalement négative qui travaille dur pour inverser l'éloge de Sganarelle sur le tabac en supprimant tous ses aspects positifs et en les remplaçant par tous les maux, et seulement par ces maux. En d'autres termes, le paquet neutre est aussi trompeur que le tabac : il n'est pas neutre, mais absolument partial. Cela rappelle les Mythologies de Barthes, où l'auteur expliquait comment les autorités françaises, au cours de la période de la décolonisation en Algérie, avaient jugé opportun d'inverser le sens des mots en nommant ce qui était à l'évidence une guerre sanglante avec le mot doux et inoffensif de «pacification ». L'avertissement de Barthes concernant l'usage de ce genre de procédé est clair :

«La rhétorique officielle a beau entasser les couvertures de la réalité, il y a un moment où les mots lui résistent et l'obligent à révéler sous le mythe l'alternative du mensonge ou de la vérité : l'indépendance est ou n'est pas » (Barthes, 1957 : 143-144).

Cet avertissement pourrait bien s'appliquer au paquet neutre. Si ce dispositif veut se montrer efficace, il doit être juste : on ne peut pas dire la vérité en s'appuyant sur un mensonge ; le paquet soi-disant neutre devrait assumer son statut d'emballage entièrement négatif. Il devrait accepter aussi ce qu'il essaie de cacher : les gens sont probablement d'autant plus prêts à reconnaître que le tabagisme tue si l'on admet qu'il leur apporte aussi plaisir et sociabilité.

Cela dit, ce point est un simple détail périphérique dans la mesure où il ne concerne que la façon appropriée de nommer le dispositif, et non ce dispositif lui-même et comment l'encadrer. Pour ce qui concerne ce deuxième aspect, ma suggestion serait plutôt de tenter l'expérience et d'attendre assez longtemps avant de risquer tout jugement sur la pertinence et la performance du paquet neutre. Tout comme les paquets mettent en garde les fumeurs contre les dangers de la cigarette, je voudrais mettre en garde mes collègues, les sociologues, contre le risque qu'il y a à se montrer trop intelligent. 
L'un des problèmes majeurs du paquet neutre est de se concentrer sur le tête-à-tête entre le fumeur et son paquet. Les sociologues sont beaucoup moins bornés et beaucoup plus intelligents : ils sauront faire remarquer que fumer est aussi une affaire de culture, de sociabilité et de comportements collectifs, comme le montre le bel éloge de Sganarelle, bien avant l'invention de la sociologie :

«Non seulement [le tabac] réjouit et purge les cerveaux humains, mais encore il instruit les âmes à la vertu [comme les aliments], et l'on apprend avec lui à devenir honnête homme. Ne voyez-vous pas bien, dès qu'on en prend, de quelle manière obligeante on en use avec tout le monde, et comme on est ravi d'en donner à droit et à gauche, partout où l'on se trouve ? On n'attend pas même qu'on en demande, et l'on court au-devant du souhait des gens. »

Fumer est à la fois une affaire de qualcul, c'est-à-dire d'évaluation des qualités du produit en fonction de nos préférences individuelles, et de calqul, du verbe « calquer », c'est-à-dire d'ajustement de nos comportements de consommation à nos partenaires (Cochoy, 2011). Au total, s'intéresser au seul emballage et au têteà-tête entre le fumeur et sa cigarette n'est pas suffisant et pourrait être trompeur.

La question la plus importante est bien sûr celle du pouvoir performatif du paquet neutre. Les gens lisent-ils les paquets ? Les paquets performent-ils un seul de leurs avertissements ? Les gens contrôlent-ils leur action ? Ces questions sont délicates. Entre 2013 et 2012, un an après l'introduction du paquet neutre en Australie, les ventes de cigarettes ont diminué de seulement 0,1\% (Vanlerberghe, 2014). La conclusion semble s'imposer : l'étiquetage ne produit aucun effet d'aucune sorte; ce dispositif ne marche pas, ou tout au moins marche très mal. Tout se passe comme si le paquet neutre partageait le sort de la faible performativité des messages publicitaires (Cochoy, 2015). Cette faible performativité n'est pas une surprise pour des publicités diffusées de loin, mais semble plus décourageante pour des messages imprimés sur les produits eux-mêmes, juste avant leur consommation.

Mais alors, un mystère reste à éclaircir : pourquoi certains se battent-ils aussi dur contre quelque chose qui est censé marcher aussi mal ? Parce que de nombreux acteurs sont probablement conscients que ce qui semble inefficace sur le court terme est beaucoup plus puissant sur le long terme. Au cours de l'histoire, l'emballage s'est montré capable de transformer profondément la consommation et les marchés. À travers quel processus et dans quelle mesure ? Une première réponse est théorique et s'appuie sur le modèle du «faire faire » identifié par Bruno Latour. L'auteur cite une scène de la célèbre bande dessinée espagnole Mafalda. Mafalda demande à son père, qui fume sur le canapé : «Que fais-tu ? » Et le père répond : «Comme tu peux le voir, je fume. » Et Mafalda de répliquer : «Oh, je croyais que ta cigarette te fumait. » À cette réponse, le père, pris de panique, prend des ciseaux et coupe toutes ses cigarettes en morceaux.

Bruno Latour prend cette scène humoristique comme une occasion de réfléchir sérieusement à l'« agentivité » des personnes et des choses. Il observe que ni la forme active («je fume ») ni la forme passive («je suis fumé ») ne peuvent rendre compte de ce qui est en jeu, et du tabagisme : si nous étions en total contrôle de l'action, il serait facile d'arrêter de fumer ; or comme nous le savons tous, ce n'est pas le cas. Mais évidemment, à l'inverse, les cigarettes ne peuvent pas nous fumer seules, car elles ont besoin de notre aide pour que nous les achetions, que nous les allumions et que nous les fumions. D'où la conclusion et la proposition de Bruno 
Latour : nous ne fumons pas plus nos cigarettes qu'elles ne nous fument, mais les cigarettes nous «font fumer ». Au-delà des formes active et passive, Bruno Latour pointe l'existence d'une troisième forme, le « faire faire », qui permet de rendre compte du caractère distribué de l'agentivité (Latour, 2000). Je soutiens que ce qui est valide pour les cigarettes ne peut que l'être aussi pour leurs conteneurs : si les cigarettes « nous font fumer », les paquets nous les font choisir (Cochoy, 2004).

Ce schéma théorique permet de comprendre pourquoi le paquet neutre est faiblement performatif : les conteneurs matériels comme les sacs en plastique ou les boîtes en carton ne peuvent pas être accusés (ou loués) de tout (pour tout), car ils ne travaillent jamais seuls, mais prennent simplement une part, souvent modeste, à l'action. Lorsque l'action n'est pas entièrement sous le contrôle des entités impliquées, elle peut être sujette à des fuites et à des débordements d'extension variée. Mais, quelle que soit l'étendue de ces débordements, quelque chose se produit, comme l'histoire de long terme de l'emballage le montre clairement. Grâce aux emballages, les consommateurs ont appris à aimer des substances invisibles, inodores et insipides, comme les vitamines, les OGM ou la nicotine. Sans emballage, pas de nicotine, pas de goudron, pas de dioxyde de carbone, pas de cancer, pas de mort : juste le plaisir de l'odorat, du goût, de la fumée et de la vie sociale. Le tabac en vrac de Sganarelle est l'exact opposé du paquet neutre moderne, et inversement. Selon ce que l'on regarde, la perception du produit est renversée. La transformation à long terme mise en place par l'emballage moderne est donc colossale. Il n'est pas un consommateur qui n'a pas entendu parler des bienfaits des vitamines et des maux du sucre, du gras ou du sel ; il n'est pas un fumeur qui n'a pas entendu parler des dangers de la nicotine, du goudron et du dioxyde de carbone. Si l'étiquetage n'a pas d'impact direct, il produit des effets latéraux à long terme. Les gens savent ce qu'ils ingèrent.

\section{"Conclusion}

En fin de compte, qui devrions-nous écouter lorsque le paquet neutre est soumis à la critique ? Et que devrions-nous dire ? J'ai moi-même soulevé plusieurs questions sur les aspects et les effets potentiellement indésirables du paquet neutre, comme son caractère trompeur, son aspect totalitaire, et sa tendance possible à favoriser des pratiques alternatives et peut-être plus dangereuses. En outre, j'ai même reconnu que le plaisir et la sociabilité immédiats et sensoriels du tabagisme pourraient être plus forts que les avertissements abstraits portant sur des conséquences à long terme. Mais, pour se faire une opinion, il est très important d'être conscient que presque tous les arguments que j'ai développés de façon libre rejoignent les arguments promus par l'industrie du tabac. Il suffit pour s'en convaincre de se référer aux mémorandums étonnants rédigés par Philip Morris (2014) pour informer le public et les autorités quant à ses propres positions ${ }^{3}$. Dans son rapport écrit pour le gouvernement britannique, le cigarettier cite plusieurs études niant toute réduction de la

3. Phillip Morris Limited, 2014. Response to the Consultation on "Standardised Packaging", consultable en ligne : http://www.pmi.com/eng/tobacco_regulation/submissions/Documents/UK\%20-\%20\%20Standardised\%20Packaging\%20Submission\%20PML.pdf (consultés le 14 octobre 2016). 
prévalence du tabagisme en Australie depuis l'adoption du paquet neutre (ibid. : 17.) ; en revanche, il cite d'autres études montrant que le commerce illicite du tabac a augmenté dans le même pays (ibid. : 22). Enfin et surtout, Philip Morris dénonce l'aspect totalitaire du paquet neutre en soulignant son caractère illégal supposé, et le fait qu'il viole les principes de libre-échange et du droit de propriété (ibid. : 4). Nous pouvons avoir l'un et l'autre raison, mais aussi être en total désaccord.

Pendant longtemps, nous avons vécu au gré d'une division du travail entre les profanes et les sciences sociales. Les premiers étaient censés être immergés dans l'action tandis que les secondes étaient supposées avoir le temps de faire preuve de réflexivité, d'engager des études appropriées et donc d'aider les premiers à voir plus clairement les situations qu'ils vivent. Ce régime n'est plus valide. Lorsque l'on parcourt Internet sur un sujet comme le paquet neutre, on réalise rapidement que la scène est remplie d'intellectuels, dans tous les coins, dans tous les lieux, dans toutes les disciplines. Nous rencontrons des gens intelligents de tous les bords mais, sur cette base, nous devrions admettre qu'aucune intelligence supplémentaire n'est nécessaire. Il se pourrait même que ce soit le contraire qui soit souhaitable ! Comme Luc Boltanski et Laurent Thévenot (1991) l'ont fait valoir de façon convaincante, une telle situation devrait nous conduire à réinventer notre mission. Il y a tellement d'études sur le paquet neutre qu'il devient vain de prétendre apporter une contribution marginale supplémentaire. J'irais même jusqu'à proposer d'engager une inversion entre le savant et le politique, pour parler dans les termes de Max Weber. Nous serions mieux inspirés d'abandonner la science aux profanes et aux experts, et de faire en sorte que le chercheur en sciences sociales devienne un politique. Ou plutôt, nous devrions inventer une science nouvelle, qui ferait de la politique son meilleur guide pour savoir quoi écrire, quoi faire ou quelle action soutenir. Nous devrions changer de niveau en essayant de trouver une autre façon d'être intelligents. Au lieu de trouver des faits durs et de développer des arguments éclairés, nous devrions quitter la science des « faits » pour celle des «préoccupations » (Latour, 2014). Pour le dire en d'autres termes, nous devrions revenir à Aristote, malgré Sganarelle : ce qui est nécessaire pour des questions telles que les paquets de cigarettes neutres, ce sont des essais philosophiques plus que des constats empiriques. Lorsque des questions sont controversées, la science conventionnelle n'est d'aucune aide immédiate. Par conséquent, nous devrions être en mesure de prendre des décisions sans attendre d'avoir des certitudes (Callon, Lascoumes et Barthe, 1991).

Être concerné consiste à juger la science non pas sur son exactitude, mais sur l'identité de ceux qui parlent, et sur la nature des valeurs qu'ils défendent. Fumer tue ? Oui. Qui se bat contre le paquet neutre ? Les fabricants de cigarettes. Ces simples réponses sont suffisantes pour savoir quels sont les arguments que l'on doit soutenir et ce qu'il convient de faire. Nous n'avons pas à examiner ces questions sur le plan intellectuel. Nous devrions tenter l'expérience du paquet neutre et voir ce qu'il en résulte. Au moins, nous sommes certains que des mots et des images nuiront moins que le tabac, et c'est assez pour prendre les bonnes décisions. En outre, nous devons examiner qui apprécie les arguments que nous promouvons et décider si ces arguments doivent être conservés sur cette base, plutôt que sur leur pertinence scientifique supposée. Il vaut beaucoup mieux ne pas dire ce que vos ennemis aiment entendre. Il vaut mieux les laisser se battre pour eux-mêmes, sans prendre le risque 
de conforter et de légitimer leurs objectifs discutables en leur fournissant des arguments convergents supplémentaires. À cet égard, et malgré l'amour que nous avons pour notre discipline, le meilleur sociologue est celui qui réalise que parfois le silence est préférable à la science.

Ici, nous rejoignons la grande leçon d'Albert Hirschman : pour aller de l'avant, il est paradoxalement préférable de se masquer les yeux avec une « main cachante » capable de nous distraire des effets négatifs possibles de notre action (Hirschman, 1967). Ne pas trop penser est la meilleure façon d'avancer, alors qu'imaginer de possibles conséquences néfastes de nos entreprises a toujours été l'une des meilleures façons de refuser tout changement (Hirschman, 1991). Penser trop, argumenter de façon trop pointue, imaginer les possibles inconvénients et les effets pervers d'une politique donnée - tel le développement des cigarettes de contrebande que le paquet neutre pourrait encourager - ont toujours été le meilleur moyen de ne rien faire. Une fois de plus, faisons juste un essai, et tenons bon. Souhaitons que Sganarelle, après deux siècles de connaissances, déchargé de son bon tabac à l'abri dans sa vieille tabatière, et équipé d'un tout nouveau packaging entièrement négatif, ne sera pas aussi stupide que nous aurions pu le penser :

«Quoi que puissent dire les sociologues avec toute leur science sociale, il n'y a rien d'égal à l'emballage négatif : c'est la passion des honnêtes gens, et qui vit sans emballage négatif n'est pas digne d'écrire. Non seulement il réjouit et purge les cerveaux humains, mais encore il instruit les âmes à la vertu, et l'on apprend avec lui comment rester un homme sain. Mais c'est assez de cette matière. Arrêtons-nous au point où nous sommes parvenus. » 
Chapitre 20

\title{
L'économie des conventions
} dans les études agroalimentaires anglophones : filiations avec l'école française, circulation et nouvelles perspectives

\author{
E. Cheyns, S. Ponte
}

Au cours des deux dernières décennies ${ }^{1}$, l'économie des conventions a influencé différents courants de recherche dans le domaine agroalimentaire. Cette influence se repère dans le champ des sciences sociales anglophones (Wilkinson, 1997; Raikes et al., 2000 ; Biggart et Beamish, 2003 ; Stark, 2009 ; du Gay et Morgan, 2013 ; Barnett, 2014 ; Diaz-Bone, 2012), en particulier depuis la traduction en anglais, au milieu des années 2000, de deux références majeures : De la justification (Boltanski et Thévenot, 1991 [2006]) et Le nouvel esprit du capitalisme (Boltanski et Chiapello, 1999 [2005]).

C'est en 1997 qu'apparaît le premier article dans la littérature anglophone se référant à l'école française de l'économie des conventions - sous la traduction de convention theory -, appliquée aux questions agroalimentaires (Wilkinson, 1997). Par la suite, de nombreuses publications s'y sont référées, apportant un éclairage analytique majeur pour étudier le « tournant qualité » (quality turn) opéré dans les années 1990, l'émergence de réseaux alimentaires alternatifs, ainsi que les formes de coordination et de gouvernance dans les chaînes de valeur. La convention theory dans les études agroalimentaires anglophones a attiré des chercheurs de nombreuses disciplines, la sociologie, la géographie, mais aussi les études régionales et la géographie économique, dans la filiation des travaux de Salais et Storper (1992; Storper et Salais, 1997), et l'économie politique internationale.

Comment la convention theory, appliquée aux questions agroalimentaires, a-t-elle été introduite dans la littérature anglophone, à quelles conclusions analytiques a-telle conduit, quelles originalités ou proximités sont apparues avec l'école française de l'économie des conventions? Nous proposons ici une revue de la littérature

1. Nous remercions Laurent Thévenot et Olivier Favereau pour leur relecture attentive de ce texte. 
anglophone appliquée aux études agroalimentaires à partir du recueil de 51 publications entre 1997 et 2014. Nous entendons par « littérature anglophone » les travaux publiés en anglais par des chercheurs dont l'institution de rattachement n'est pas en France et qui n'ont pas été formés en France. Ce recueil résulte d'une recherche bibliographique sur des bases de données (Google Scholar et Scopus) avec les motsclés : " conventions », " convention theory » et "pragmatic sociology », croisés avec des entrées sur l'agroalimentaire au sens large ${ }^{2}$. Cette recherche dans les bases de données a été complétée par un repérage d'autres références dans les listes bibliographiques des textes listés. Parmi les 51 références recensées, 38 ont une entrée «études agroalimentaires »; 13 autres publications ont été retenues car elles constituent des revues importantes sur les débats théoriques et analytiques.

Ce chapitre est organisé autour de trois grandes questions :

- première partie : quelles sont les filiations de la convention theory chez les chercheurs anglophones avec l'école française de l'économie des conventions?

- deuxième partie : à quelles questions ces études se sont-elles attachées ? Quelles ont été les contributions analytiques de ces recherches ?

- troisième partie : quelles proximités et divergences y lit-on avec les développements théoriques se poursuivant en France ? La circulation de la théorie dans le champ anglophone a-t-elle ouvert de nouveaux questionnements ? Quelles sont les perspectives d'évolution de la théorie dans le champ anglophone?

\section{" « Convention theory» : origines et filiations}

La convention theory dans la littérature anglophone se développe au milieu des années 1990 en référence à l'école française de l'économie des conventions. Des liens scientifiques entre chercheurs anglophones (certains lisant le français) et francophones contribuent à cette circulation, dans un premier temps, avant que les travaux de l'école française ne soient en partie traduits en anglais et plus largement accessibles. Dans les recherches appliquées aux questions agricoles et alimentaires, l'ouvrage La grande transformation (Allaire et Boyer, 1995) participe de ce développement. Nous rappelons très brièvement quelques caractéristiques de l'école française de l'économie des conventions ${ }^{3}$, avant de présenter les références et les orientations retenues par les premières publications anglophones.

\section{Émergence de l'école française de l'économie des conventions}

L'école française de l'économie des conventions, qui émerge au milieu des années 1980, réunit des préoccupations d'économistes institutionnalistes, de sociologues

2. «Agroalimentaire» pris au sens de production, transformation, commerce, consommation, usage et recyclage des produits de l'agriculture, de la pêche et des forêts, pour l'alimentation ou les usages industriels et leurs interactions avec l'environnement.

3. Pour une lecture de contributions et une revue détaillée sur le programme, voir Dupuy et al. (1989) et les articles publiés dans ce numéro spécial de la Revue économique ; ainsi que Orléan (1994), Batifoulier (2001), Eymard-Duvernay (2006a, 2006b), Bessis (2008), et, dans le champ anglophone, Diaz-Bone (2011), Diaz-Bone et Salais (2011). 
et d'historiens. Elle se formalise alors comme courant de pensée de l'économie hétérodoxe avec, en particulier, un numéro manifeste dans la Revue économique, dont l'introduction est portée conjointement par J.P. Dupuy, F. Eymard-Duvernay, O. Favereau, A. Orléan, R. Salais et L. Thévenot (1989). Cette école s’intéresse à la résolution des problèmes de coordination en situation d'incertitude (sur la détermination de la qualité des biens et du travail en particulier). Elle remet en cause le postulat, en économie classique, de rationalité substantive des agents et de complétude des contrats et des règles, en y opposant les concepts de rationalité procédurale et d'incomplétude de l'information (ou incertitude radicale ${ }^{4}$ ). Dans ce programme cognitiviste, le courant de l'économie des conventions constitue un paradigme alternatif en économie et se positionne dans le champ de l'économie dite "non standard », en vue de dépasser les limites de la théorie économique «standard » (théorie néoclassique) et de la «théorie standard étendue » (théorie des contrats et de l'information) (Favereau, 1989).

La forme de coordination entre individus postulée dans le modèle standard d'économie classique est de nature purement marchande : la coordination s'effectue par le marché, avec la seule présence « d'une main invisible », c'està-dire affranchie de toute référence extérieure. Les recherches menées en économie des conventions développent l'hypothèse inverse "en considérant que l'accord entre les individus, même lorsqu'il se limite au contrat d'un échange marchand, n'est pas possible sans un cadre commun, sans une convention constitutive » (Dupuy et al., 1989 ; voir aussi Orléan, 1994). Dans ce cadre, les règles acquièrent un autre statut que celui de contrainte ou de contrat : elles sont des dispositifs cognitifs collectifs. Dépassant l'opposition entre « holisme » et «individualisme $»^{5}$, la convention est définie comme « une régularité qui a sa source dans les interactions sociales mais qui se présente aux acteurs sous une forme objectivée » (Dupuy et al., 1989 : 145).

Plutôt que de considérer une juxtaposition marché-organisation (ou marchérègles) ou un système d'enchâssement du social dans l'économique (Polanyi, 1983 ; Granovetter, 1985), l'école des conventions considère une diversité de formes de coordination, dont le marché ne constitue qu'une des formes possibles. La possibilité de modéliser, de décrire ou de caractériser cette diversité des formes de coordination est offerte par le travail majeur de Boltanski et Thévenot, formalisé dans leur ouvrage De la justification : les économies de la grandeur (1991). Les auteurs y proposent un modèle général d'analyse portant sur les mobiles et les modalités de l'action justifiable. L. Boltanski et L. Thévenot offrent ainsi un cadre d'analyse des formes de légitimité sur lesquelles peuvent s'appuyer les individus pour justifier leurs accords en pratique. Ces formes de légitimité étant diverses (ils en relèvent six), les justifications et les cadres cognitifs peuvent être de différentes natures.

4. Voir Orléan (1989). Incertitude non probabilisable (à la différence du risque), qui ne peut être intégrée dans un calcul d'utilité et qui résulte de l'impossibilité de prévoir la liste complète des états futurs. Voir aussi «incertitude critique » (Thévenot, 1989a).

5. Le « holisme » conduit à considérer que la société affecte les choix individuels, à l'inverse de «l'individualisme » qui considère que l'individu modifie la structure sociale (voir Defalvard, 1993). 


\section{La Convention Theory : l'influence de l'école française dans la littérature anglophone}

Le premier article s'appuyant sur l'école française de l'économie des conventions dans le champ des études rurales et agroalimentaires anglophones paraît en 1997 dans la revue Economy and Society. Il est écrit par John Wilkinson (1997), sociologue à l'université rurale fédérale de Rio de Janeiro. L'auteur y présente deux nouveaux courants français d'économie hétérodoxe, l'économie des conventions (convention theory) et la théorie de la régulation (regulation theory), porteurs d'une promesse : la constitution de «paradigmes alternatifs à celui néolibéral pour l'analyse économique ». Il présente les principaux concepts de l'école de l'économie des conventions en se référant d'abord aux travaux de Salais et Thévenot (1986), soulignant ainsi le cadrage initial de l'école française sur la qualification du travail, puis décrit les apports croisés des travaux de Boltanski et Thévenot (1991), Favereau (1994), Eymard-Duvernay (1994) et Salais et Storper (1992).

Dans cet article, John Wilkinson souligne trois apports fondamentaux du travail de Boltanski et Thévenot (1991) :

- une attention centrale à la situation dans laquelle s'inscrit l'action, dans une relation spécifique des personnes et des choses, qui remet en cause la notion intrinsèque de classe sociale ;

- un regard sur l'action collective, constituée de processus de justifications et d'épreuves ; la saisie d'engagements des personnes dans l'action justifiable, plutôt que guidées par des intérêts, écarte la notion d'intérêts comme attributs permanents et univoques des groupes;

- une pluralité dessens du juste (à travers le modèle des «cités» et des «mondes» marchand, domestique, industriel, civique, de l'opinion et de l'inspiration), sans que soit établie une hiérarchie externe ou déterminée entre les différents mondes ; cette pluralité (de conventions) contient une possibilité puissante de critique de «l'impérialisme du marché ».

L'auteur souligne, dans le travail de Favereau (1994), l'apport fondamental du concept d'apprentissage collectif (collective learning dans le texte), élément constitutif des règles et des organisations. Les règles sont une réponse à des problèmes de coordination et dépendent d'une forme préalable de constitution du commun. Ce savoir commun est interprété, en situation, à travers un processus de qualification des objets et des personnes impliqués dans une série de justifications et d'épreuves (Wilkinson, 1997). L'auteur souligne ainsi les liens étroits entre le travail de Boltanski et Thévenot sur «l'action justifiable », celui fondateur de l'école des conventions sur « l'interprétation de la règle » et ceux, plus appliqués, sur la qualification des produits et du travail. Pour Wilkinson, la valeur heuristique du travail de Boltanski et Thévenot apparaît dans les travaux sur les firmes de Eymard-Duvernay (1994) et sur les «mondes de production » de Salais et Storper (1992). Ces travaux sont présentés comme fondateurs dans les recherches de l'école des conventions, en orientant l'objet des recherches sur les cohérences ou les tensions entre organisation de l'offre (dispositifs de production) et qualité des biens, ou entre « conventions du travail » (modèles de firmes) et « conventions de qualité ». Le pluralisme des conventions permet de saisir une analyse «plus réaliste de la diversité de la relation salariale et des profils des firmes » (Wilkinson, 1997). 
La deuxième moitié de cette publication est consacrée aux récentes applications de la convention theory dans le domaine agroalimentaire, telles que menées par l'Inra et publiées dans le livre La grande transformation (Allaire et Boyer, 1995). Wilkinson y présente trois apports majeurs :

Un cadre méthodologique et analytique à l'étude du «tournant qualité », attentif aux processus de qualification ou de stabilisation du jugement, par les dispositifs, les objets qualifiés et les conventions.

Des résultats empiriques sur la coexistence de multiples formes de coordination, celle du marché étant rarement suffisante.

La mise en évidence de nouvelles configurations institutionnalisées. Alors que le compromis productif d'après-guerre est centré sur une justification marchande et industrielle (Thévenot, 1995), ces travaux montrent le caractère composite de nombreuses formes de coordinations et en particulier l'importance que revêt la convention domestique, investie dans l'émergence de cette "économie de la qualité ». Ces travaux ouvrent sur des perspectives de reconnaissance et de développement de formes institutionnelles plus composites que les seules marchandes et industrielles (Wilkinson, 1997).

Les premières publications dans le champ agroalimentaire qui ont suivi, entre 1997 et 2003, se réfèrent toutes à ces mêmes travaux fondateurs français (en y ajoutant ceux de Nicolas et Valceschini, 1995 ; Sylvander, 1995 ; Storper et Salais, 1997) et au premier article dans la littérature anglophone publié en 1997 par Wilkinson (à l'exception d'une publication). Ils sont écrits par des chercheurs de l'université de Cardiff (Grande-Bretagne) (Murdoch et Miele, 1999; Murdoch et al., 2000 ; Mardsen et al., 2000 ; Parott et al., 2002), de quatre universités américaines (Busch, $2000^{6}$; Raynolds, 2002 ; Barham, 2002 ; Freidberg, 2003) et de centres de recherche danois (Raikes et al., 2000). La plupart de ces premiers auteurs avaient des connexions ou des collaborations étroites avec la recherche en France ${ }^{7}$ (années sabbatiques à Paris, coorganisation de séminaires à l'Association internationale de sociologie rurale, invitations à des ateliers, etc.). Par la suite, les travaux anglophones se sont surtout appuyés sur des travaux français publiés ou traduits en anglais, laissant de côté des contributions françaises importantes (notamment Sylvander, 1995 ; Eymard-Duvernay, 1989, 2006a, 2006b). Des travaux relatifs à la convention theory se développent alors

6. Deux articles de L. Busch (1992; Busch et Tanaka, 1996), en sociologie, sont publiés avant l'article de Wilkinson (1997). Ces articles ne se positionnent pas explicitement en référence à « l'école des conventions » ou à la convention theory, mais citent déjà les travaux de Boltanski et Thévenot (1991).

7. Lawrence Busch découvre le travail de Boltanski et Thévenot (d'abord paru en 1987) au cours d'une année sabbatique à l'IRD (Institut de recherche pour le développement, ex-Orstom) en 1987 et d'une rencontre avec Bruno Latour. John Wilkinson, un an après la sortie du livre La grande transformation, passe une année sabbatique à Paris en 1996 et découvre l'école des conventions. Elizabeth Barham, qui fait en France une enquête sur les mouvements sociaux, assiste à Toulouse à une présentation du livre $L a$ grande transformation. Gilles Allaire et Michael Watts organisent un séminaire à Berkeley en 1998 auquel participaient notamment John Wilkinson, Terry Marsden, Lawrence Busch, Michael Storper, Raymond Jussaume, et d'autres chercheurs du RC40 (Comité de recherche sur la sociologie de l'agriculture et de l'alimentation) de l'Association internationale de sociologie rurale, ainsi que plusieurs auteurs de $L a$ grande transformation, dont Laurent Thévenot. Benoit Daviron est invité à Copenhague en 1999 pour présenter l'approche française de l'analyse des filières et les travaux de l'école des conventions dans le domaine rural et agroalimentaire. 
progressivement autour des travaux de Storper et Salais (traduits en 1997) et de Boltanski et Thévenot (traduit en 2006), ainsi que sur les désormais nombreuses publications de chercheurs anglophones qui s'inscrivent dans ce courant.

\section{Wa théorie des conventions dans la littérature anglophone des études agroalimentaires}

\section{Observations générales}

La majorité des publications recensées concernent des études de cas spécifiques ou comparatives situées en Europe, en Amérique du Nord et en Océanie (24). Les autres publications concernent des études en Afrique (5) et en Amérique latine (3), ou ne sont pas liées à une région spécifique. Une diversité de produits alimentaires et agricoles est concernée, des marchés de niche, locaux ou régionaux, au commerce de longue distance, mais c'est l'industrie du vin qui a été la plus étudiée (10), suivie par le café (4) et les fleurs, les fruits et les légumes frais (4). Les certifications durables, bio ou équitables (8) et les indications géographiques (6) ont aussi fait l'objet d'attention (tableau 20.1).

D'un point de vue thématique, le premier objet saisi, et qui reste le plus investi, concerne l'analyse du « tournant qualité ». Il s'est récemment étendu à l'analyse des réseaux agroalimentaires alternatifs : 23 entrées. Viennent ensuite : la coordination et la gouvernance des chaînes de valeur (10) et le changement institutionnel et l'innovation (7). Dans ces catégories, les contributions en lien avec la théorie des conventions semblent s'être arrêtées au début des années 2010, à l'exception de travaux de Raynolds (2012a, 2012b), Diaz-Bone (2013) et Ponte et Sturgeon (2014). De nouvelles thématiques apparaissent ces dernières années autour de la gestion environnementale et du foncier (3), de la consommation alimentaire des ménages (3) et du travail agricole (2).

Cette littérature apparaît essentiellement dans des articles de revues (45 entrées) plutôt multidisciplinaires, les deux principales étant Journal of Rural Studies (9) et Sociologia Ruralis (6). Viennent ensuite Economy and Society (4), Agriculture and Human Values (2), Geoforum (2), Journal of Agrarian Change (2) et Regional Studies (2). Les auteurs sont issus essentiellement de trois zones géographiques : les ÉtatsUnis (17 entrées), les pays nordiques - Danemark et Norvège - (14) et le RoyaumeUni (14), avec d'autres contributions d'Espagne (4), Italie (1), Nouvelle-Zélande (3), Portugal (1), Allemagne (1), Brésil (1) et Mexique (1). Les disciplines des auteurs sont variées : géographie, planification et études environnementales (20), approche multidisciplinaire (15) et sociologie (14).

D'un point de vue analytique, cette littérature s'inscrit dans deux mouvements relativement distincts : une partie des travaux s'engage dans l'adaptation au domaine agroalimentaire des « mondes de production » (Salais et Storper, 1992 ; Storper et Salais, 1997), une seconde partie s'inscrit dans la lignée des travaux de Boltanski et Thévenot (1991) et des contributions liées en termes de « conventions de qualité » (Eymard-Duvernay, 1989 ; Sylvander, 1995 ; Thévenot, 1995). Ces deux approches organisent les deux sous-parties suivantes. 


\section{Les études en lien avec les « mondes de production »}

Les «mondes de production » ont été adaptés pour saisir des objets liés aux études agroalimentaires, opérant ainsi une modification sémantique vers le concept de «worlds of food » (Morgan et al., 2006 ; voir aussi Murdoch et Miele, 1999; Murdoch et al., 2000). Ces «mondes de l'alimentation » sont caractérisés par différentes logiques culturelles locales et régionales, mais aussi écologiques, politiques et institutionnelles : 1) un monde de la production alimentaire " industrielle de masse ", dans lequel des technologies standardisées permettent de produire de larges volumes de produits génériques ; 2) un monde de production alimentaire « de niche »: des technologies standardisées permettent de produire des produits différenciés à forte valeur ajoutée ; 3) un monde de la «production locale » : des procédés artisanaux/traditionnels sont utilisés pour des produits spécialisés/dédiés et vendus à des clients à travers des relations de proximité ; et 4) un monde de la production «de haute technologie »: des procédés spécialisés sont utilisés pour des produits nouveaux, spéciaux ou fonctionnels sur des marchés de masse (SánchezHernández et al., 2010 : 470).

L'approche «worlds of food » a permis d'accorder une attention spécifique à des mondes de production alimentaires ne répondant pas aux critères de la production standardisée et générique, et généralement ignorés par d'autres approches, alors qu'ils n'en sont pas moins dynamiques (Murdoch et al., 2000). Elle a aussi été utilisée pour comprendre le positionnement stratégique des entreprises et leurs trajectoires d'un monde vers l'autre (Murdoch et Miele, 1999, 2004), voire leurs positionnements au croisement de plusieurs mondes (Trabalzi, 2007). Nombre de travaux ont porté sur l'analyse d'approches collectives qui inscrivent des groupes, des localités ou des régions au cœur de trajectoires d'apprentissage, d'innovation et de changement institutionnel (Cidell et Alberts, 2006 ; Guthey, 2008 ; Lindkvist et Sánchez, 2008 ; Sánchez-Hernández et al., 2010 ; Sánchez-Hernández, 2011). Ils ont aussi porté sur les systèmes d'innovation et les régulations qui permettent à une entreprise de se déplacer entre plusieurs mondes (Stræte, 2004 ; Barbera et Audifredi, 2012).

Par exemple, Cidell et Alberts (2006) mettent l'accent sur les négociations de la qualité liées aux lieux de transformation du chocolat plutôt qu'aux lieux de production du cacao. Ils inscrivent la qualité alimentaire dans des " géographies de la fabrication ». Pour Guthey (2008), dans une analyse de l'industrie du vin en Californie du Nord, les changements dans les pratiques de production et la qualité des produits émergent de processus locaux et collectifs porteurs de conventions spécifiques. De même, Sánchez-Hernández et ses collègues, à travers leurs travaux sur l'innovation dans le secteur du vin en Espagne, montrent que l'innovation peut émerger d'une volonté des acteurs d'une filière " d'adapter leurs conventions et d'attacher de nouvelles qualités à leur produit de base » (Sánchez-Hernández, $2011: 105$; voir aussi Stræte, 2004). Ils montrent cependant que cela ne peut se produire que si l'ensemble de la filière entreprend des réarrangements de conventions. Mettant en question une vision duale des conventions dominantes entre Europe du Sud et du Nord (voir, par exemple, Morgan et al., 2006 et Parrot et al., 2002), Lindkvist et Sánchez (2008) montrent que les producteurs de vin en Espagne adaptent leurs systèmes de production à de nouveaux marchés, alors que les producteurs de poissons en Norvège maintiennent des conventions ancrées dans des procédés 
traditionnels et peu innovants. Dans une étude de cas sur le vin dans le Piémont en Italie, Barbera et Audifredi (2012) indiquent que le scandale autour du méthanol au milieu des années 1980 a conduit à des changements de conventions de qualité, entraînant des modifications majeures dans la configuration institutionnelle de la production du vin. Ensemble, ces auteurs montrent que l'innovation, pour assurer le passage d'un monde de production à l'autre, s'appuie sur un changement de conventions de qualité.

\section{Les études s'appuyant sur les « grandeurs » et la « justification »}

\section{Le tournant qualité et les réseaux agroalimentaires alternatifs}

Une application fréquente de l'économie des conventions dans la littérature anglophone a été de révéler ou de spécifier les conventions qui garantissent la qualité des produits et facilitent ainsi la coordination. De nombreuses discussions se sont focalisées sur l'émergence des conventions civiques et domestiques, et sur leur capacité à être combinées dans des compromis avec des conventions marchandes et industrielles, permettant ainsi à des traits de qualité « alternatifs » de devenir largement étendus sur un marché, voire standardisés (Andersen, 2011 ; Barham, 2002, 2003 ; Freidberg, 2003, 2004 ; Kirwan, 2006 ; Murdoch et al., 2000 ; Raynolds, 2002, 2004, 2012a, 2012b ; Raynolds et al., 2007 ; Renard, 2003).

Le « tournant qualité » dans la littérature anglophone s'est appuyé presque exclusivement sur des études de cas dans des pays industrialisés (en particulier en Europe). Il repose sur le constat que des consommateurs de ces marchés se détournent de produits agroalimentaires industriels pour rechercher des produits « de haute qualité ». Cette qualité est caractérisée par des pratiques bio ou utilisant peu d'intrants, des produits issus de régions ou de lieux spécifiques et/ou distribués sur des marchés paysans, des circuits courts et d'agrotourisme, ou dans des formes valorisant la multifonctionnalité de l'agriculture. Ce tournant vers la qualité est expliqué par une forte réflexivité des consommateurs, mais aussi en réaction aux peurs alimentaires apparues dans les années 1990 (BSE, E. coli, Salmonella). Ces évolutions ont donné un poids croissant au besoin et à la production de confiance sur la qualité des produits dans les réseaux alimentaires, qu'elle soit produite par des dispositifs d'assurance sur la qualité, de traçabilité, d'indication d'origine géographique, des labels ou encore par des circuits de vente directe (Goodman, 2004).

Murdoch et al. (2000 ; voir aussi Murdoch et Miele, 1999, 2004) parlent d'une tendance générale, dans les réseaux alimentaires, à la valorisation des conventions domestiques, basées sur la confiance, la tradition et le lieu, plutôt que celles industrielles (et comportant une logique de production de masse). Murdoch et al. (2000) montrent que la qualité, de plus en plus fréquemment définie par une origine plus «locale » et plus « naturelle », réinscrit les systèmes de production alimentaires dans des milieux locaux. S'ils admettent que les « conventions alternatives » ne sont pas suffisantes pour transformer un système alimentaire mondial, ils suggèrent que les « critères domestiques et écologiques soient utilisés par les producteurs locaux pour sécuriser leurs propres positions au sein des réseaux dans des termes qui leur sont favorables » (ibid. : 119). 
D'autres travaux ont cependant été plus critiques sur le potentiel que représenteraient des conventions domestiques et civiques pour transformer les systèmes agroalimentaires. Freidberg $(2003,2004)$ se montre critique sur les capacités qu'auraient les réseaux agroalimentaires alternatifs et des échanges fondés sur la confiance interpersonnelle pour promouvoir de substantiels changements socioéconomiques dans les pays en développement. À partir d'une étude historique et comparative des conventions dans le commerce horticole anglophone (Royaume-Uni et Zambie) et francophone (France et Burkina Faso), l'auteure précise que « les relations basées sur la confiance $[. .$.$] ne relèvent souvent que de situations où une ou toutes les parties n'a$ pas d'autre choix que d'espérer bénéficier de chance ou de pitié [...]. Les économies de la qualité [...] ne relèvent pas forcément moins de l'exploitation que d'autres » (2003 : 98). Elle note aussi que, dans les « situations d'échange » du commerce Nord-Sud, les acteurs ne partagent pas forcément les mêmes " normes éthiques ou de comportement ». Les producteurs se conforment à la demande des détaillants parce qu'ils n'ont pas le choix (voir aussi Busch et Tanaka, 1996), alors que leurs conditions écologiques et socio-culturelles de production sont différentes de celles qui prédominent dans les pays consommateurs.

Raynolds (2002, 2004, 2012a, 2012b ; Raynolds et al., 2007), dans ses travaux sur la certification bio, équitable ou durable, a recours à la théorie des conventions pour comprendre comment les contestations sur la qualité émergent et la façon dont elles sont intégrées dans des réseaux insérés sur les marchés internationaux. Elle défriche la question des formes de contrôle à distance dans ces réseaux par l'enrôlement dans des conventions ou au contraire par la contestation de qualifications divergentes (Raynolds, 2002). Elle souligne d'abord la tentative du commerce équitable de renouveler des formes d'investissement dans la confiance (convention domestique) au moyen de ressources matérielles et discursives ancrées dans un « ordre de la connectivité $»^{8}$ (partenariat, alliances, etc.). Le commerce équitable prend aussi appui sur une qualification civique, ancrée dans la « responsabilité collective » et l'évaluation des bénéfices sociaux, étendant ainsi la convention domestique à des personnes et à des espaces socialement et physiquement éloignés. Le commerce équitable s'ancre aussi de façon substantielle dans une convention marchande, dans un lien étroit avec des distributeurs et des détaillants du marché dominant, et dans une convention industrielle par la formalisation qu'imposent les standards, les audits et les certifications (voir aussi Renard, 2003). Dans la comparaison qu'elle fait des différents marchés de standards, elle conclut que les certifications liées au commerce équitable et aux produits bio sont plus à même de conduire à un changement social progressif que les initiatives volontaires basées sur des certifications et des conventions de nature industrielle. Enfin, elle montre le poids que peuvent jouer des certificateurs, dont les pratiques et les connaissances s'alignent avec celles des entreprises orientées vers la recherche de profit, et par là donner une ampleur considérable aux standards industriels et à la compétition par les prix. Dans cette évolution, les principes du commerce équitable se voient convertis en attributs

8. «Les ordres sont à la fois discursifs (des façons d'expliquer le monde) et matériels (mises en œuvre et inscrits de façon concrète, non verbale, dans un réseau). » Dans l'ordre de la connectivité, « les discours portent sur le partenariat, l'alliance, la responsabilité et la loyauté » (Whatmore et Thorne, 1997 : 294, 295). 
« auditables » et en pratiques de certification, elles-mêmes au cour de nouvelles formes de contrôle à distance (Raynolds, 2012b : 286).

\section{La théorie des conventions et la gouvernance des chaînes de valeur}

D'autres travaux se sont appuyés sur la théorie des conventions pour expliquer la prédominance de certaines formes de coordination et d'organisation et des dynamiques spécifiques de gouvernance dans les chaînes de valeur mondiales (Ponte et Gibbon, 2005 ; Tallontire, 2007 ; Ponte, 2009 ; Coq-Huelva et al., 2012 ; SánchezHernández, 2011 ; Ponte et Sturgeon, 2014). Ils examinent les différentes grandeurs et principes d'organisation qui leur sont liés, la façon dont elles sont questionnées au cours d'épreuves et de mesures de la qualité du produit, et enfin leurs différentes capacités de transmission (de déplacement ou de transport) le long des chaînes de valeur (Gibbon et Ponte, 2005 ; Daviron et Ponte, 2005 ; Ponte, 2009 ; Ponte et Daviron, 2011). Ils contribuent à une approche plus imbriquée, et à un dialogue entre des analyses macro et structurelles et des analyses plus micro et méso des formes d'exercice du pouvoir. Ils mettent en exergue des combinaisons spécifiques de conventions qui dominent à certains endroits (« nœuds ») et moments particuliers dans la chaîne de valeur. Ils examinent par ailleurs comment ces conventions dominantes « voyagent » le long d'une chaîne, quels facteurs y contribuent et quels acteurs ont un pouvoir normatif d'imposer une convention plutôt qu'une autre au-delà d'un seul « nœud » dans la chaîne.

Ponte et Sturgeon (2014) développent une typologie des liens facilités par différentes conventions de qualité (liens « marchand », « modulaire », « relationnel », « captif », « hiérarchique »; voir aussi Gereffi et al., 2005). Le lien marchand apparaît facilité par les conventions marchandes où la qualité est associée au prix, alors que le lien modulaire apparaît dans la prévalence de conventions industrielles qui soutiennent les standards, et le lien relationnel dans la prévalence de conventions domestiques. Toutefois, les auteurs mettent en garde contre une vision déterministe et rigide de ces associations : différentes conventions peuvent coexister à un même nœud de la chaîne de valeur, les entreprises peuvent mobiliser différentes conventions selon leurs fournisseurs, et différentes conventions de qualité peuvent être mobilisées en même temps avec le même fournisseur selon un portefeuille de produits et de contrats.

Par ailleurs, Ponte et Sturgeon (2014) lient les conventions de qualité à différents degrés de «facilité de transmission » le long des chaînes de valeur (tableau 20.2). Une application empirique de cette approche est fournie par Ponte (2009) à propos de la chaîne de valeur du vin entre l'Afrique du Sud et le Royaume-Uni. L'auteur montre comment certains instruments de vérification de la qualité, qui mettent à l'épreuve des conventions de qualité spécifiques, supportent un certain type de relations avec les fournisseurs et de division du travail, qui influent sur la gouvernance de la chaîne de valeur. Ces instruments de vérification rendent visible et traduisent des négociations complexes qui ont soutenu l'émergence de la convention, à un moment et à un endroit particulier de la chaîne. Le moment de l'épreuve de vérification est un moment privilégié au cours duquel les justifications sont rendues explicites ; les dispositifs sociotechniques, les différentes formes d'expertise et de savoir sont engagés. 
Tableau 20.2. Conventions de qualité et facilités de transmission.

\begin{tabular}{|c|c|c|c|c|c|c|}
\hline & \multicolumn{6}{|c|}{ Grandeurs et conventions de qualité } \\
\hline & Marchand & Industriel & Domestique & Civique & Inspiré & Opinion \\
\hline $\begin{array}{l}\text { Principe } \\
\text { organisationnel }\end{array}$ & $\begin{array}{l}\text { Compé- } \\
\text { titivité }\end{array}$ & Productivité & Loyauté & Représentation & Créativité & Réputation \\
\hline Justification & $\begin{array}{l}\text { Unités de } \\
\text { produits }\end{array}$ & $\begin{array}{l}\text { Plans, } \\
\text { systèmes, } \\
\text { contrôles, } \\
\text { prévisions }\end{array}$ & $\begin{array}{l}\text { Capitaux } \\
\text { spécifiques }\end{array}$ & $\begin{array}{l}\text { Négociation, } \\
\text { consultation, } \\
\text { distribution }\end{array}$ & $\begin{array}{l}\text { Innovation, } \\
\text { créativité }\end{array}$ & $\begin{array}{l}\text { Relations } \\
\text { publiques, } \\
\text { couverture } \\
\text { médiatique, } \\
\text { réputation } \\
\text { de marque }\end{array}$ \\
\hline Questions clés & $\begin{array}{l}\text { Est-ce éco- } \\
\text { nomique? }\end{array}$ & $\begin{array}{l}\text { Est-ce } \\
\text { techni- } \\
\text { quement } \\
\text { efficace, } \\
\text { fonctionnel? }\end{array}$ & $\begin{array}{l}\text { Suit-il/ } \\
\text { elle la } \\
\text { tradition? }\end{array}$ & $\begin{array}{l}\text { Quel impact } \\
\text { sur la société ? } \\
\text { Est-ce sain, bon } \\
\text { pour l'environ- } \\
\text { nement, la } \\
\text { santé? }\end{array}$ & $\begin{array}{l}\text { Est-ce } \\
\text { nouveau? } \\
\text { Une } \\
\text { découverte? }\end{array}$ & $\begin{array}{l}\text { Est-ce } \\
\text { accepté par } \\
\text { le public? }\end{array}$ \\
\hline $\begin{array}{l}\text { Évaluation } \\
\text { de la qualité } \\
\text { du produit }\end{array}$ & Prix & $\begin{array}{l}\text { Mesure } \\
\text { technique }\end{array}$ & $\begin{array}{l}\text { Confiance, } \\
\text { répétition, } \\
\text { histoire }\end{array}$ & $\begin{array}{l}\text { Social, travail, } \\
\text { environnement, } \\
\text { impact collectif }\end{array}$ & $\begin{array}{l}\text { Esprit, } \\
\text { personnalité }\end{array}$ & $\begin{array}{l}\text { Opinion, } \\
\text { média, } \\
\text { jugement } \\
\text { d'experts }\end{array}$ \\
\hline $\begin{array}{l}\text { Facilité de } \\
\text { transmission } \\
\text { le long de } \\
\text { la chaîne }\end{array}$ & Haute & Haute & Faible & Moyenne & Faible & Moyenne \\
\hline
\end{tabular}

Sources : traduit de Ponte et Sturgeon $(2014: 208)$.

Cette intention de combiner la théorie des conventions et l'économie politique s'est aussi manifestée, plus récemment, autour de l'analyse des systèmes de gestion du travail dans les grandes fermes en Afrique (Gibbon et Riisgaard, 2014 ; Riisgaard et Gibbon, 2014). Alors que la littérature classique faisait état, dans ce champ (dans une perspective analytique différente), d'une transition linéaire d'un système « domestique » à un système « marchand » dans les années 1980 et au début années 1990, Gibbon et Riisgaard (2014) montrent que les configurations actuelles peuvent être vues comme des combinaisons de conventions civiques et industrielles, avec des conventions marchandes et domestiques toujours présentes mais résiduelles. Ils questionnent ainsi une perspective largement établie sur l'organisation du travail agricole intensif, à travers une étude de cas dans l'industrie horticole au Kenya, et étendent leur argument aux cultures « à haute valeur » en Afrique plus généralement. Dans un dialogue constructif avec l'économie politique, Gibbon et Riisgaard (2014 : 100) mobilisent la théorie des conventions « comme un outil pour mieux discriminer les contraintes et les opportunités implicites (pour le travail) contenues dans différents systèmes de gestion de la main-d'œuvre ».

Dans un travail proche, Riisgaard et Gibbon (2014) appellent à aller au-delà d'une description de la façon dont les conventions se manifestent pour analyser pourquoi certaines conventions dominent, dans un contexte spécifique. Ils examinent les 
conditions dans lesquelles certaines conventions et combinaisons spécifiques peuvent émerger et devenir dominantes dans le travail agricole à partir du cas du secteur horticole au Kenya. Alors que des compromis avec les conventions marchandes et industrielles s'avèrent nécessaires pour entreprendre un «business », les compromis avec les conventions civiques n'émergent que comme résultante d'impératifs politiques, provoqués par des luttes populaires. Dans leur étude de cas, les auteurs suggèrent que la stabilisation d'une convention industrielle peut être une condition nécessaire pour que des éléments de la convention civique émergent, et qu'une pression politique continuelle et adéquate doit accompagner ce processus.

\section{Originalité, proximités et divergences avec les développements de la théorie en France}

Dans cette partie, nous proposons de repérer les proximités et les divergences entre le développement de la convention theory et l'école française. La circulation de la théorie dans le champ anglophone a ouvert de nouveaux questionnements, mais elle a aussi laissé des éléments de la théorie de côté. Elle a aussi apporté des contributions nouvelles, originales. Enfin, nous nous intéresserons aux perspectives qu'offrent ce courant et ses nouveaux chantiers.

\section{Connexions de la littérature anglophone aux approches françaises}

Ces travaux marquent de fait un lien fort avec l'approche française. Ils rendent visibles une diversité des formes de coordination dans un « univers complexe » (Thévenot, 1989a) et rejoignent ainsi les premiers travaux dans le champ français, attentifs à la « pluralité des conventions » (Eymard-Duvernay, 1989), à « l'équilibrage de règles » (Favereau et Thévenot, 1991) ou encore à différents « assemblages composites » (Thévenot, 1989b). Ils marquent ainsi une forte proximité avec l'école française dans leur capacité à formaliser un pluralisme, contre une vision réductrice des coordinations économiques. Cela dit, d'autres développements ont été moins investis par cette littérature anglophone.

La littérature anglophone a accordé une grande attention à des moments historiques de passage d'une convention dominante à une autre, mais aussi d'un agencement de conventions à un autre. Des travaux plus récents commencent à explorer l'importance de conventions de qualité plurielles sur lesquelles les firmes peuvent s'appuyer en fonction de leur marché ou de situations différenciées. D'une manière générale, nombre de ces travaux introduisent la formulation d'un pluralisme des grandeurs (ou des conventions), qui permet de rendre compte d'une plus grande complexité des situations empiriques, y compris dans les pays industriels, venant enrichir de nombreuses analyses préalables. Ainsi, la caractérisation duale d'une division Nord-Sud de l'Europe, basée sur une prévalence de conventions spécifiques à chacune de ces deux grandes régions, est replacée dans une approche plus nuancée (Lindkvist et Sánchez, 2008 ; Barbera et Audifredi, 2012). De même, les 
trajectoires de changement unidimensionnelles entre «mondes de production » ou «mondes de l'alimentation» sont enrichies par des dynamiques composites. Rosin et Campbell (2009) s'appuient en particulier sur cette complexité pour remettre en cause la vision linéaire et duale, portée dans d'autres approches sur l'agriculture biologique en Nouvelle-Zélande en des termes de « conventionalisation » et de «bifurcation ».

Ensuite, certains travaux introduisent une temporalité, orientée vers l'analyse dynamique de ces équilibres de conventions, permettant de poser un regard particulier sur l'innovation. Sánchez-Hernández et al. (2010) expliquent par exemple des faits d'innovation dans la production régionale de vin en Espagne au cours de changements de conventions, et notamment dans le passage d'un monde interpersonnel à un monde industriel. D'autres travaux ont introduit une temporalité au cœur des changements de conventions et de compromis imposés par l'évolution des marchés et l'adaptation des entreprises à ces marchés.

L'insatisfaction à caractériser des faits empiriques par l'une ou l'autre des conventions a enfin conduit des auteurs à examiner comment plusieurs justifications peuvent être mobilisées par les mêmes acteurs de façon simultanée plutôt que de se référer à un engagement sélectif dans un seul monde (Busch, 2000 ; Rosin, 2008 ; Truninger, 2011). Le rapport à l'action située, central dans l'école française, est progressivement introduit dans une partie des travaux, sans forcément s'y référer. L'engagement dans des conventions particulières est associé à des pluralités de marchés, d'audiences ou de clients. Murdoch et Miele (2004) comparent les justifications apportées par une entreprise fast-food et le mouvement Slow Food pour montrer comment chacun utilise différentes justifications pour s'ajuster à différents publics. Ponte (2009) montre comment les mêmes opérateurs mobilisent différentes conventions de qualité en fonction du marché, activant un portefeuille de conventions plutôt qu'un compromis stabilisé (voir aussi Trabalzi, 2007). De même, Andersen (2011) et Truninger (2011) analysent les conventions associées à des situations différentes d'achat ou d'approvisionnement.

D'autres concepts fondateurs de l'école française ont été moins investis mais sont cela dit repérables dans certains travaux plus récents.

La prise en compte des formes d'exercice du pouvoir dans la théorie des conventions a fait l'objet de nombreux débats dans le champ français. Les critiques ont fait état d'une quasi-disparition de la notion de pouvoir dans les dispositifs de coordination étudiés en termes de conventions (Bourdieu, 1997). La question du pouvoir est pourtant au cour de l'économie des conventions (Thévenot, 2012, 2015a, 2015b, 2016). Cependant, elle s'est déplacée vers l'étude d'oppressions liées à l'imposition de certaines formes de normalités (associées aux grandeurs) et ainsi de « conventions légitimées » (Orléan, 2004). Chaque forme de grandeur spécifie une façon par laquelle les personnes et les choses sont qualifiées pour une certaine caractérisation du bien commun. Les formes conventionnelles, qui équipent la vie en commun et les capacités qui s'y rattachent, génèrent inévitablement des asymétries de pouvoir (Thévenot, 2012).

Murdoch et al. (2000) et Raynolds (2002) soulignent dès le début des années 2000 le potentiel que constitue la théorie des grandeurs pour analyser ce nouveau type d'exercice du pouvoir. Cela dit, cette approche du pouvoir dans la littérature anglophone des études agroalimentaires a en réalité été peu mobilisée, si ce n'est dans des travaux récents. C'est le cas des travaux de Gibbon et Riisgaard (voir aussi Cheyns et Riisgaard, 2014) 
qui, dans un dialogue avec l'économie politique, se sont attachés à étudier le pouvoir normatif des conventions. Ils remettent en cause la vision d'un pouvoir qui ne serait lié qu'à des capacités et une rationalité stratégiques, et déplacent l'analyse des autorités, depuis celles issues de l'État et du pouvoir économique des firmes, vers une plus grande variété d'autorités légitimes, au cour de la théorie (Orléan, 2004 ; Thévenot, 2015a). D'autres travaux récents se sont par ailleurs attachés à spécifier les différents formats de connaissance, de savoir et d'expertise qualifiés dans certains dispositifs (Ponte et Sturgeon, 2014 ; Ponte et Cheyns, 2013), et ce qu'ils imposent en termes de pouvoir.

Le recours aux objets qualifiés, qui permettent de stabiliser le jugement, est relativement peu présent dans cette littérature anglophone. Une des caractéristiques de l'école française a été de considérer les objets au-delà de leur matérialité de bien de production ou de consommation, c'est-à-dire aussi en tant que repères ou guides pour l'action, qui équipent des coordinations (Norman, 1993). Ces « repères conventionnels » (Boltanski et Thévenot, 1991) servent d'éléments tiers sur lesquels la règle s'appuie et qui déterminent la situation dans laquelle elle s'applique (Livet et Thévenot, 1994 ; Favereau, 1989). La notion majeure d'épreuve, au cœur de la théorie, est de même peu reprise dans cette littérature. Le repérage de l'épreuve, définie comme un dispositif permettant d'attribuer les états de grandeur (Boltanski et Thévenot, 1991), permet de saisir les tensions critiques et les jugements en situation. Il doit aussi permettre de ne pas ramener toutes les actions humaines à des opérations de justification au sens où l'entend la théorie. L'analyse en termes de conventions s'est cela dit parfois éloignée de ces éléments majeurs, et certains travaux (y compris en France) ont eu tendance à réifier les grandeurs dans des dispositifs organisationnels. Pour autant, certains travaux dans la littérature anglophone ont renoué avec une analyse des dispositifs attentive aux épreuves et aux objets conventionnels. Le recours aux épreuves, comme catégorie analytique, est par exemple à l'œuvre dans les travaux de Ponte et Sturgeon (2014) et Ponte (2009), attentifs aux critiques que suscite l'usage de différents instruments de vérification de qualité. Ces moments sont précieux pour saisir la façon dont les personnes justifient leur action en pratique et explicitent ce qui convient dans la situation en se référant à différentes grandeurs de bien commun (voir aussi les travaux de Nyberg et Wright, 2013). Ekbia et Evans (2009) ont, quant à eux, accordé une attention particulière à la qualification des objets liés à la transmission d'information (voir plus loin).

La plupart des travaux qui se réfèrent aux économies de la grandeur se sont intéressés aux conventions de qualité. Les études sur les conventions du travail sont plus rares. En la matière, on relève essentiellement les travaux de Gibbon et Riisgaard (2014 ; Riisgaard et Gibbon, 2014) portant sur les diverses qualifications du travail dans les grandes fermes agricoles en Afrique. De même, l'interdépendance entre les « modèles d'entreprise » et les « conventions de qualité » (Eymard-Duvernay, 1989, 1994) a finalement été peu étudiée dans la littérature anglophone. Une étude récente s'en rapproche, celle de Rosin (2008) qui révèle les effets de l'audit sur la reconstruction des identités de producteurs de lait et de kiwi en Nouvelle-Zélande. L'auteur montre que l'audit, parce qu'il « altère l'esprit du métier d'agriculteur » (the spirit of farming), modifie les conventions d'échange entre producteurs et industries. D’une qualité construite par le métier de producteur, la qualité devient produite par une capacité individuelle « à se conformer à l'audit ». 


\section{De nouveaux développements dans la littérature anglophone}

La littérature anglophone a aussi proposé de nouveaux développements analytiques et théoriques. Sans les reprendre tous, nous mettrons l'accent sur trois contributions qui nous semblent originales.

La plupart des travaux considèrent les compromis sous l'angle d'accords relativement stabilisés. Une étude est ici intéressante en ce qu'elle explore la prévalence de « compromis instables et temporaires » avec la grandeur marchande (Nyberg et Wright, 2013). Les auteurs montrent comment des entreprises s'engagent vers des compromis avec la grandeur marchande pour résoudre des disputes liées à des perceptions de l'environnement différentes, et combien ceux-ci, instables, sont contestés mais aussi constamment renouvelés. Les entreprises engagées dans la gestion de l'environnement répondent à la critique par la « création de biens compatibles avec plusieurs mondes, qui satisfont en même temps les épreuves des mondes marchand et écologique », tels que des voitures « vertes » ou des compensations carbones (ibid. : 409). Dans de nombreux cas, ces biens sont à nouveau contestés ; les entreprises, soumises à la critique, s'ajustent et font alors évoluer ces biens vers de nouveaux compromis plus «environmental friendly » (par exemple, les « biocarburants de seconde génération » comme adaptation à la critique de ceux de «première génération »). Dans les dispositifs d'élaboration de compromis cités par l'auteur, les acteurs n'ont pas cherché à clarifier leur accord en se référant à l'une ou l'autre grandeur, évitant ainsi un travail coûteux et risqué de dévoilement de la critique. Le format de l'action, orienté vers une recherche de « consensus » et un rejet des positions antagonistes, conduit à une dépolitisation. Cette dépolitisation (qui écarte une critique) facilite une plus grande « domination du marché » en validant, de fait, les mécanismes de marché (ibid. : 420).

À travers les préceptes de la modernisation écologique et les partenariats qu'il noue avec des ONG de conservation de l'environnement et des autorités gouvernementales, le «monde des entreprises » prend ainsi peu à peu le rôle de gardien naturel de l'environnement. Pour les auteurs, cette production de compromis temporaires, écartant la critique, contribue à la dégradation de l'environnement, en faveur du marché. Les auteurs rejoignent ainsi les travaux de Boltanski (2011), Boltanski et Chiapello (199) et Thévenot (2009) pour rendre compte d'une hégémonie et d'une subjugation du monde marchand sur les autres mondes. Cette approche a été relativement peu développée dans le champ français et apporte ici de nouvelles pistes de recherche.

Ekbia et Evans (2009) se sont quant à eux intéressés aux formats d'information qui guident les producteurs dans le Midwest des États-Unis dans leurs décisions d'usage de leurs terres. Au même titre que les objets acquièrent une valeur différente dans chaque monde et sont des guides pour l'action, les informations diffusées, reçues de différentes sources, acquièrent une valeur différente. Les auteurs introduisent la notion de « régime d'information » pour examiner les « pratiques situées de la vie quotidienne impliquées dans la création et la diffusion de l'information », chacun accordant de la valeur à un format d'information spécifique et rattaché à des mondes différents. Ils montrent ensuite le lien entre les décisions d'usage des terres des propriétaires et les régimes d'informations. Ce travail rejoint un des premiers mouvements à l'origine de la différenciation des mondes, qui a porté sur les différents types d'« investissement de formes », de connaissances et de «formes du probable » (Thévenot, 2009) rattachées à différentes grandeurs. 
Kirwan (2006) a de son côté conduit un travail sur la façon dont les producteurs et les consommateurs coordonnent leurs attentes réciproques sur la qualité de produits, dans l'échange direct et donc en «face à face », sur des marchés paysans. Ce travail le conduit à formuler la proposition analytique d'une nouvelle convention, rendant compte de l'attention à autrui, de la considération réciproque que se portent les partenaires de l'échange (regard convention). Cette convention de la considération permet de saisir des attributs de qualité qui ne sont pas contenus dans le produit (et ne déterminent pas sa qualité), mais qui, comme les conventions domestiques, sont construits par des interactions personnelles. L'auteur s'appuie sur les travaux de A. Offer (the economy of regard, 1997) qui formalise l'attention à autrui dans le don de cadeaux, mais aussi plus généralement dans des interactions de face-à-face, prenant des formes aussi bien verbales que non verbales. Cette considération est garante de l'authenticité de la relation : «A gift without regards would be a bribe » (Un don sans respect s'assimile à un pot-de-vin) (Offer, 1997 : 454). Kirwan note qu'elle n'établit pas la valeur du produit (ne porte pas sur la résolution de l'incertitude sur la qualité), mais apporte un bénéfice non marchand dans l'évaluation d'ensemble de l'expérience d'échange. Les consommateurs en parlent comme des échanges plus « intimes, profonds et agréables » et relèvent le changement de temporalité ( "have time to talk») opposé à la relation fonctionnelle («mechanical ») de l'échange marchand. L'échange d'attentions et de considération est inévitable dans des interactions de face-à-face entre producteurs et consommateurs et produit une satisfaction mutuelle. La proximité, la confiance, la réciprocité et la connexion sociale jouent un rôle important dans cette convention, sorte de combinaison de traits habituellement rattachés à un agencement de conventions domestiques (confiance gagnée dans les interactions personnalisées, ancrage dans un lieu et liens personnels) et civiques (bien-être collectif, social) (Kirwan, $2006: 310$ ), mais qui ne saurait être vue comme un compromis entre ces deux conventions.

\section{L'extension aux « régimes d'engagement » dans les études sur l'environnement et l'usage de la terre}

Si les utilisations de la théorie dans la littérature anglophone ont été riches et porteuses de nouveaux développements, elles montrent aussi que certains auteurs se sont heurtés aux limites de la théorie des conventions et de la justification pour expliquer toutes leurs observations empiriques. Les modalités de l'action ne cadrent pas toutes avec «l'action justifiable » et une mise en ordre général, et ce n'est d'ailleurs pas ce que prétend la théorie. C'est le cas des relations de considération dans l'étude de Kirwan (2006), qui se rapprochent d'une économie du care (l'attention à autrui) et d'un engagement en «familiarité » (Thévenot, 2006) inscrit dans le proche, au lieu d'une mise en ordre générale faisant appel à des conventions visant une légitimité publique. C'est aussi le cas, dans l'étude de Nyberg et Wright (2013), des «stakeholders » qui s'affranchissent d'une visée de constitution de bien commun ouverte aux capacités critiques des acteurs pour se concentrer sur la négociation stratégique d'intérêts reliés à des préférences individuelles. Les modalités de l'action convergent plus vers une grammaire « d'individus dans un public libéral » (Thévenot, 2015c) que vers la « qualification de biens communs ». Les travaux de Raynolds sur 
les nouvelles conventions du commerce équitable indiquent cette même exigence, apportée par le terrain, de considérer de façon particulière des modalités d'actions orientées vers la négociation d'intérêts, même si les interactions s'inscrivent dans une forme personnalisée d'interconnaissances. On voit ainsi apparaître, avec ces études, la nécessité d'une ouverture à une théorie plus générale de l'action.

Cette ouverture est apparue dans l'école française de l'économie des conventions au début des années 2000, à partir d'une publication collective au colloque « Conventions et institutions » en 2003 (Eymard-Duvernay et al., 2006a, 2006b) qui inscrit, dans le programme de recherche à venir, un second «pluralisme des coordinations ». Celui-ci vise notamment à aborder, au côté des modes généraux de coordinations (programme majeur de l'économie des conventions jusque-là), des coordinations qui reposent sur des engagements de proximité, en deçà des exigences de justification publique. Cette extension "sous les conventions » (Breviglieri et Stavo-Debauge, 2006) s'appuie sur les travaux de Laurent Thévenot et la sociologie qu'il développe autour des « régimes d'engagement» (Thévenot, 2006). À côté de « l'action justifiable », Laurent Thévenot développe un programme de recherche visant d'autres modalités de l'action, notamment celles de «l'action en plan » et de «l'engagement familier » (ibid.).

Cette extension à différents régimes d'engagements et modalités de coordination, des plus publics aux plus proches (Thévenot, 2007), a circulé dans la littérature anglophone sociologique, par une autre entrée disciplinaire : la « French pragmatic sociology » (voir notamment Blok, 2013, 2015 ; Friedland et al., 2014 ; Hansen, 2016 ; Jagd, 2011 ; Luhtakallio, 2012 ; Luhtakallio et Eliasoph, 2014 ; Scott et Pasqualoni, 2014 ; Silber, 2003). Elle a par contre peu circulé dans les études appliquées aux questions agroalimentaires.

Le « tournant qualité » et les « réseaux alimentaires alternatifs » ont laissé peu à peu la place à de nouveaux chantiers de recherche, l'un, engagé au début des années 2000, sur les dispositifs de gouvernement par les standards et la certification, l'autre, émergent, autour de la question de la terre et des attachements à l'environnement. Sur ces objets plus récents, quelques contributions étendues aux régimes d'engagement apparaissent dans la littérature anglophone. Comment cette extension aux régimes d'engagement a-t-elle permis d'étendre les analyses ? Dans cette partie, nous nous appuierons aussi sur des travaux de chercheurs positionnés dans la littérature anglophone (publiés en anglais) dont l'institution de rattachement peut être basée en France ${ }^{9}$.

\section{Le gouvernement par les stakeholders : dépolitisation et mise à mal des attachements}

Des travaux qui se sont intéressés aux modes de gouvernement par les «stakeholders » (parties prenantes) dans des dispositifs de management participatif des ressources conduisent à questionner les prétentions à l'horizontalité dans ces

9. Sur ces objets, les travaux publiés en anglais par des chercheurs non rattachés à une institution de recherche française sont encore peu nombreux. Cette ouverture permettra de mieux saisir les possibilités que propose cette extension aux régimes d'engagement. 
interactions contemporaines. Ces dispositifs prétendent en effet gérer l'accès et l'usage des ressources, ou les normaliser (avec des standards de durabilité par exemple), par des dispositifs multi-parties prenantes dont la forme serait participative et inclusive de toutes les voix. Les auteurs mettent à jour deux formes d'oppression (et d'exclusion) dans ces dispositifs.

Dans le premier cas, les travaux examinent des processus de dépolitisation ou de technicisation du débat, qui traduisent l'oppression qu'exerce un gouvernement par les stakeholders sur une qualification du bien commun, ouverte à l'expression des sens du juste et de l'injuste en pratique (Nyberg et Wright, 2013 ; Cheyns, 2011). Dans le gouvernement par les stakeholders, l'action est orientée vers le « plan » (Thévenot, 2006), les participants sont détachés, et les interactions canalisées dans des échanges techniques. Ces travaux examinent les alliances que constituent des firmes et des ONG transnationales professionnalisées (Blok, 2013 ; Nyberg et Wright, 2013 ; Cheyns, 2011 ; Blok et Meilvang, 2015), qui partagent des formats d'action communs, transforment les problématiques écologiques en opportunités de construction de "marchés verts ", ou encore partagent un langage commun autour de la technique et de la mesure (Blok et Meilvang, 2015 ; Cheyns, 2011). Les tensions et les conflits imposés par cette échelle de pouvoir restent confinés en deçà du débat public. En repolitisant les dispositifs de gouvernement contemporain, ces travaux ont ce pouvoir critique de rendre ces dispositifs contestables (Hansen, 2016).

Dans le deuxième cas, les travaux montrent en quoi l'engagement des stakeholders met à mal les attachements de certains participants. Blok et Meilvang (2015) montrent ainsi comment certains activistes, dans le processus de développement durable d'une aire urbaine de Copenhague, ont dû avoir recours aux images pour exprimer, partager et rendre publics différents attachements familiers à la ville et à son écologie. Dans le dispositif mis en place, la durabilité émerge au cour d'une gouvernance stratégique des stakeholders, où industries et ONG valorisent une expertise technique et détachée, inscrite dans le plan. Dans ce régime, les opposants sont contraints de mobiliser des références aux standards techniques (par exemple autour de la pollution de l'air). L'analyse des visuels apportés par les activistes révèle des écologies alternatives sous-estimées par le pouvoir du plan. Ces images traduisent des sensibilités spécifiques au site, des attachements difficiles à verbaliser et qui requièrent d'autres moyens d'expression. Elles rappellent aux participants l'existence d'une valuation politique alternative, plus accueillante des attachements familiers (Ibid.). De la même manière, dans le cas de la gestion de l'eau, RichardFerroudji et Barreteau (2012) mettent en exergue la charge qui pèse sur les participants pour opérer des basculements d'un régime d'engagement à l'autre.

\section{L'exercice du pouvoir par la légitimité de formes de connaissance attachées à des régimes d'engagement}

L'exercice du pouvoir peut être lié à la légitimité de certaines formes du probable, selon ce qui est considéré comme probant ou preuve (Thévenot, 2009). La forme statistique du probable sert ainsi souvent à discréditer des informations monographiques, car celles-ci sont supposées ne concerner qu'un cas singulier, opposé à la généralisation d'un fait statistique (Ibid.). Silva-Castañeda (2012), Cheyns (2011) 
et Ponte et Cheyns (2013) ont montré comment la domination des variables macro et statistiques a conduit à disqualifier les voix des « communautés locales » dans les dispositifs multi-parties prenantes de standardisation des «bonnes pratiques » de production de l'huile de palme. Par ailleurs, ces formes du probable valorisées, de nature industrielle, tendent à favoriser l'expression d'une grandeur industrielle dans la spécification du bien «durable »-sans que celle-ci ne soit vraiment éprouvée.

Au-delà d'un conflit de grandeurs pour asseoir une légitimité, ce sont des formes de connaissance liées à des « engagements familiers » (Thévenot, 2006) qui sont disqualifiées. Ainsi, les récits qui font état d'expériences monographiques, qui s'appuient sur des témoignages vécus ou sur des empreintes personnelles ou anciennes sur la nature (des arbres anciens plantés par des ancêtres, des rivières) faisant « évidence » pour ceux qui habitent et partagent un même lien avec l'environnement, sont écartés (Silva-Castañeda, 2012 ; Cheyns, 2011). De même, les «communautés locales » affectées par l'expansion du palmier à huile se trouvent exclues du débat quand elles tentent de faire état des atteintes à leur vie quotidienne et font le récit de pertes de terres coutumières, d'arbres sacrés ou de destruction de leur environnement, avec une émotion vive et en utilisant des repères peu partageables avec des étrangers aux lieux. Elles communiquent un fort attachement qui embarrasse et est étranger aux autres participants, là où le format attendu est l'expression d'intérêts (Thévenot, 2015a ; Cheyns, 2014 ; Silva-Castañeda, 2015).

\section{L'incommensurabilité des dommages faits à la nature et aux personnes}

L'attention au régime d'engagement familier et aux attachements à l'environnement a aussi conduit à traiter l'environnement comme espace habité (Centemeri, 2015 ; Centemeri et Renou, 2015). Centemeri (2015) invite dès lors à dépasser la question des problèmes de commensuration liées aux grandeurs (la commensuration est difficile car plusieurs commensurations générales peuvent être mobilisées) pour introduire une autre forme d'incommensurabilité, « radicale ». Dans ce cas, l'incommensurabilité est liée à des langages et à des pratiques de valuation qui relèvent d'attachements personnels et intimes à l'environnement construits à travers une familiarisation. Ces valuations peuvent être comprises et partagées mais ne sont pas des arguments légitimes dans un débat public (voir aussi Blok et Meilvang, 2015), ou, pour l'être, doivent être traduites en intérêts ou rendus compatibles avec la médiation en grandeurs. Dans l'engagement familier, l'environnement est un environnement habité, un lieu auquel la personne donne de la valeur car il y vit, s'y déplace et s'y sent à l'aise, et parce que sa mémoire y est déposée. La personne est distribuée dans l'environnement habité, qui devient une partie constitutive de sa personne, si bien que, si l'environnement est affecté, cela le touche directement (Centemeri, 2015). Les possibilités de réparation du dommage font appel à d'autres formes que la critique dans l'espace publique ou la transformation en droit (Ibid.). Cette approche a aussi conduit à remettre en cause l'évaluation environnementale qui met un prix sur l'environnement (voir aussi Nyberg et Wright, 2013).

Elle est centrale pour comprendre les tensions et les souffrances que crée la transformation d'une plainte autour de la perte (de terres) en métriques d'intérêts 
communs, transformation que proposent les modèles win-win ou les mécanismes de compensations monétaires. Les dispositifs contemporains de gestion des ressources « multi stakeholders » composent avec une pluralité d'intérêts et par la négociation. Dans ce gouvernement, les personnes recherchent des solutions win-win, partant de l'hypothèse qu'elles peuvent atteindre un intérêt partagé (Richard-Ferroudji et Barreteau, 2012; Silva-Castañeda, 2015). Silva-Castañeda (2015) décrit par exemple les options proposées aux communautés locales indonésiennes quant à la perte de leurs terres occupées par des sociétés de plantations. Dans le premier cas, dit de « compensation monétaire », la terre est transformée en valeur monétaire, qui doit compenser sa perte. Dans le deuxième cas, les parties s'engagent dans un partenariat productif (dit win-win) : au lieu de restituer les terres, la compagnie s'engage à installer une nouvelle parcelle de palmiers à huile, dont la communauté touchera une partie du revenu (et la compagnie l'autre partie) et dans laquelle les membres de la communauté seront, dans certains cas, employés. Cette parcelle est généralement située dans un autre lieu que celui réclamé par les communautés. La terre devient ainsi une ressource productive, quand elle était aussi, et avant tout, un espace habité (Silva-Castañeda, 2015, 2016). Les schémas productifs et les compensations monétaires sont ainsi le plus souvent refusés par les communautés locales, ou, avec la pression du temps, acceptés, mais n'en deviennent pas moins alors, pour ces communautés, des choix tragiques (Centemeri, 2015). Les communautés locales y opposent d'autres traitements : la reconnaissance des souffrances occasionnées par la perte et une forme de compassion, l'établissement d'une faute, et la réparation coutumière et/ou en droit (Silva-Castañeda, 2015). Les processus de négociation retenus pour gérer les conflits fonciers supposent une traduction des droits et des attachements en « options (intérêts) mutuellement bénéfiques » aux compagnies et aux communautés locales. Les intérêts partagés relèvent cependant du domaine des intérêts économiques. Les résultats de la négociation ne répondent dès lors pas aux attentes des communautés et aux promesses de protection des droits fonciers (Ibid.).

Cette extension aux régimes d'engagement, si elle a encore peu circulé dans la littérature anglophone appliquée aux études agroalimentaires, a permis d'étendre, dans ce nouveau grand chantier de l'environnement, l'analyse à une pluralité de valuations des relations humaines et de leurs dépendances à l'environnement, ainsi qu'aux pratiques qui mettent à mal cette base existentielle des vies humaines. 


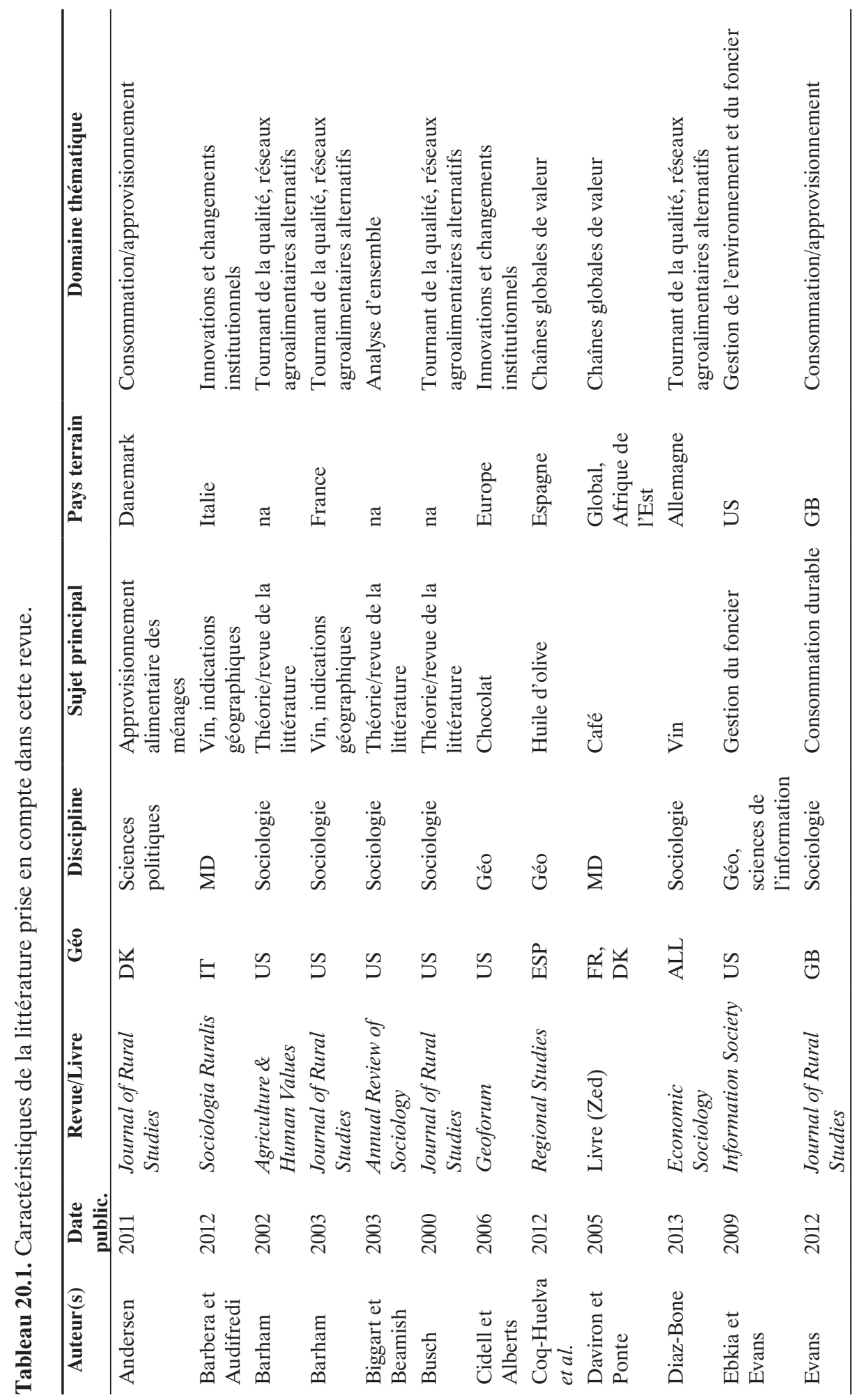




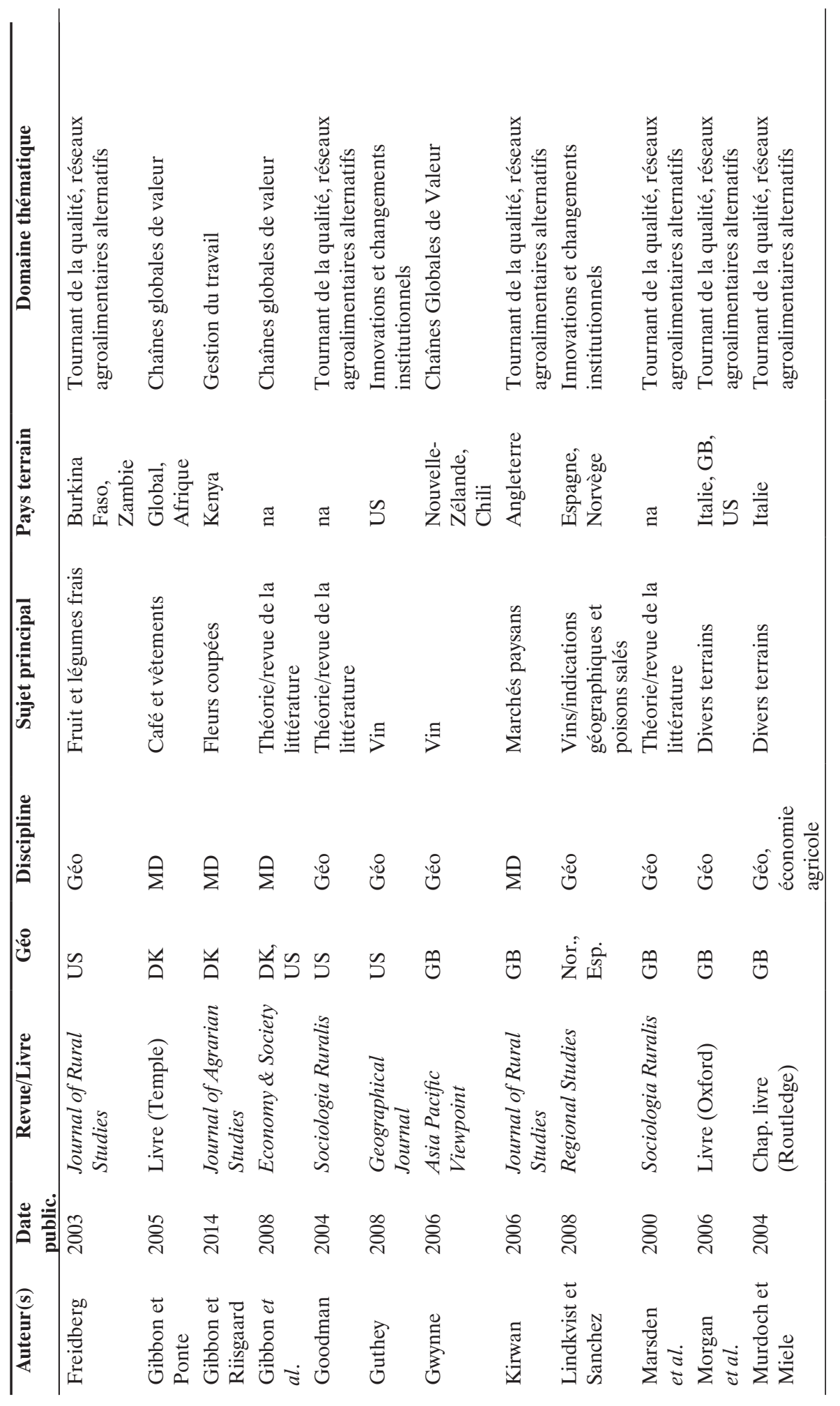




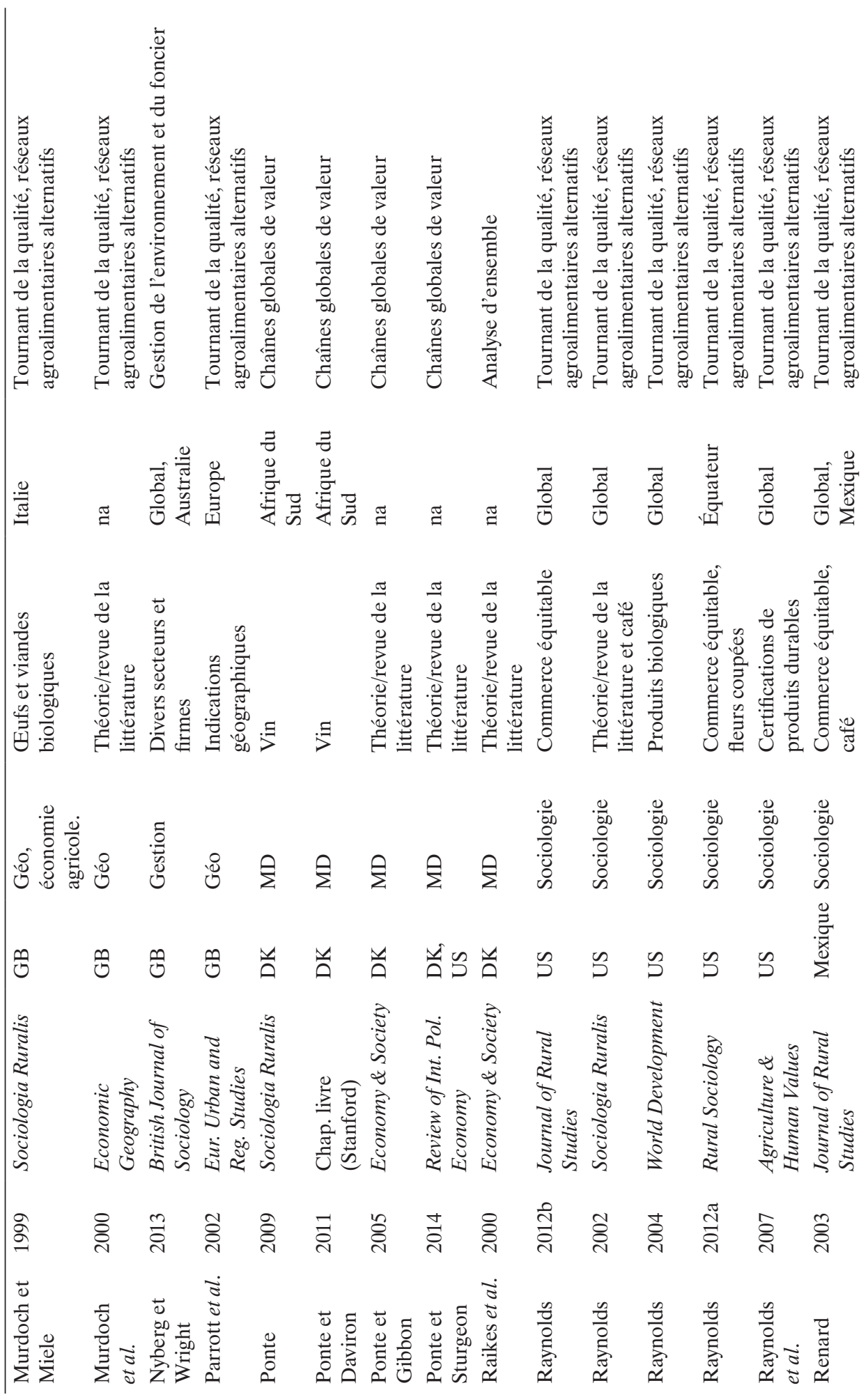




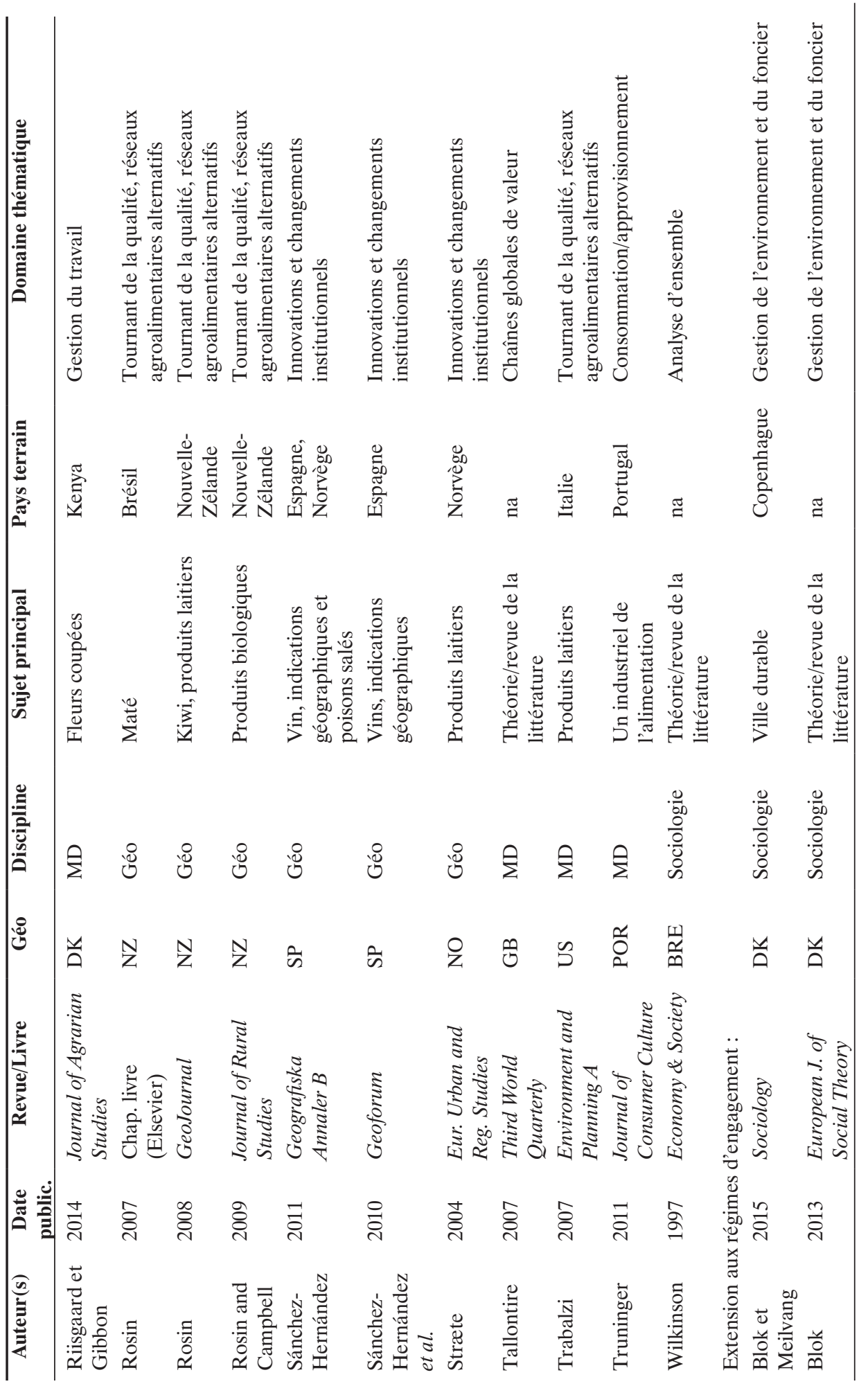




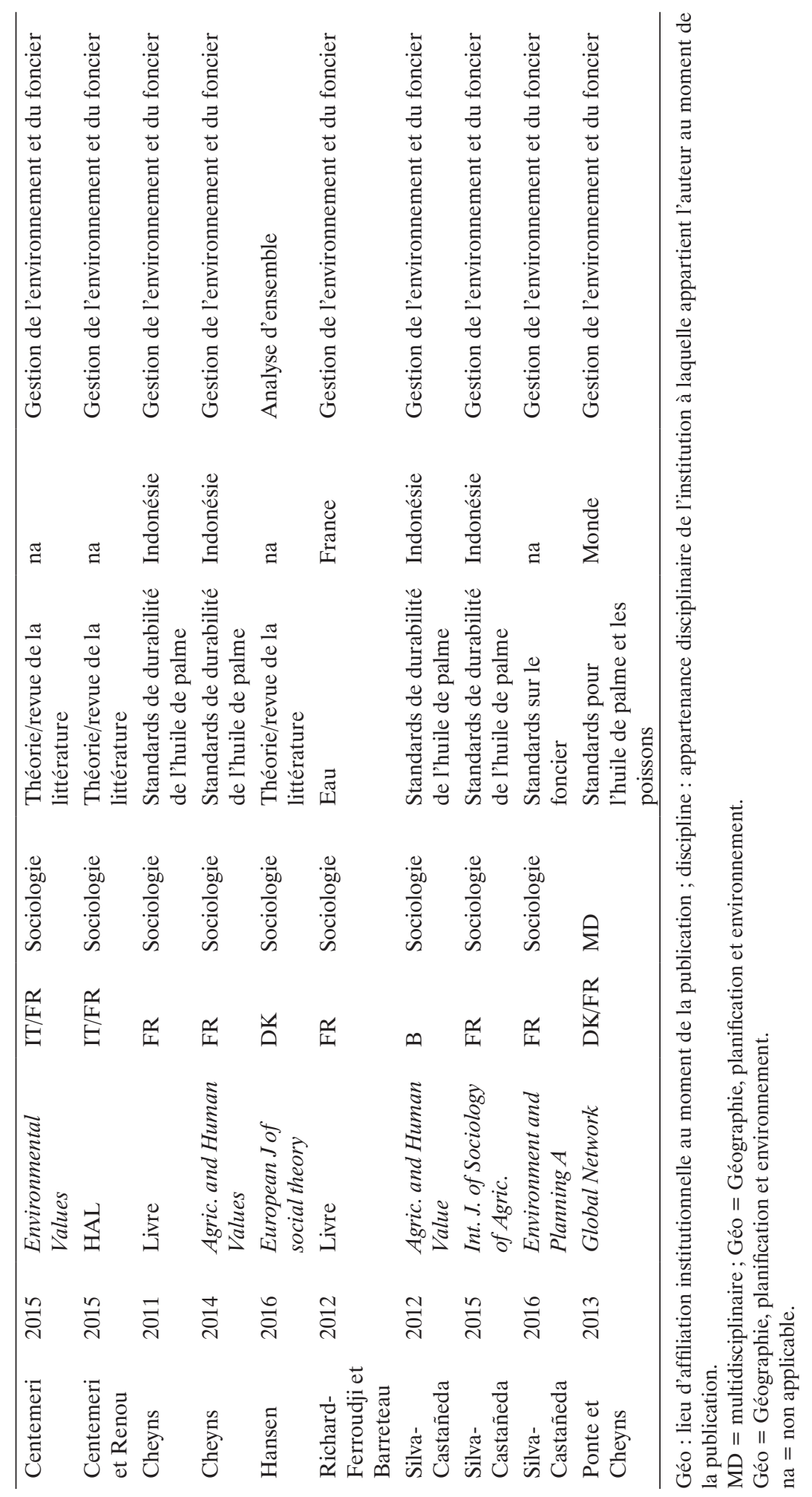





\title{
Chapitre 21 \\ L'ambivalence de la socialisation de l'agriculture
}

\author{
G. Allaire
}

Ce chapitre s'intéresse à l'encadrement de l'agriculture par les marchés et par les politiques publiques, que l'on peut voir comme une sectorisation et une socialisation de l'agriculture. Le choix, inhabituel, de l'expression socialisation de l'agriculture fait écho à la «propriété sociale »(Castel, 2008) qui se développe au cours $\mathrm{du} \mathrm{Xx}^{\mathrm{e}}$ siècle sous la forme de la protection sociale et des dispositifs du droit du travail et qui inclut les services publics et les politiques économiques. Les notions d'État social (Ramaux, 2012), d'État providence et de Welfare State ont, à quelques nuances près, la même portée. La littérature faisant référence à ces notions est très vaste, mais traite peu les aspects sectoriels de la question, la sécurité sociale des agriculteurs, les services publics spécifiques à l'agriculture (soutien à l'organisation professionnelle, vulgarisation, formation et recherche et développement) et les politiques agricoles. Ce chapitre ne vise pas à y suppléer. Telle qu'elle est développée ici, l'idée de socialisation ne recouvre pas uniquement l'émergence et le développement de politiques sociales et économiques (avec leur spécificité sectorielle), mais aussi la façon dont les marchés sont organisés et régis selon des conceptions socialement formulées dans un contexte donné des questions sociales, agraires, alimentaires et, aujourd'hui, environnementales. À l'instar des politiques publiques, les forces qui manipulent les marchés, du moins les moins obscures, justifient leur contrôle au regard de finalités sociales : la sécurité alimentaire, la biodiversité, la protection des cultures et des patrimoines alimentaires, entre autres.

Par socialisation de l'agriculture, j'entends des transformations, sur longue période, concernant le travail agricole, l'accès aux ressources et les façons de produire, les conceptions de la qualité et des circuits alimentaires, etc., qui ont généralement été décrites comme le passage de formes dites « traditionnelles » à des formes dites « modernes », qui, contrairement aux premières qui relèvent de rapports sociaux locaux, relèvent elles du marché ou des politiques publiques. Cette socialisation prend des contenus différents selon les périodes et les pays, avec des rôles différents du marché ou de l'État.

Tout en défendant l'idée de socialisation, je ne parlerai pas d'agriculture « sociale » car l'expression a l'inconvénient majeur de recouvrir plusieurs sens du terme social : - la paysannerie relevant de l'assistance sociale (exploitations de semi-subsistance bénéficiant de revenus sociaux en Europe ou d'un accès à un marché institutionnel réservé comme au Brésil); 
- la population rurale qui, après le démantèlement de l'URSS et des kolkhozes, dispose d'un droit foncier qui est du type de la «propriété sociale » définie par Castel, c'est-à-dire qui ne correspond pas à la possession d'un actif tangible, mais à un droit d'accès à des services sociaux, que sont encore tenus de fournir les nouveaux agroholdings, directement ou via les autorités locales (chapitre 14) ;

- cette nouvelle agriculture voulue par la politique agricole commune (PAC) européenne des années 2000 , une agriculture tenue de «fournir des biens publics » en justification du budget agricole (de fait, essentiellement des biens environnementaux).

On peut voir en effet cet impératif de fourniture de «biens publics », qui plus largement que par la PAC est mis en avant, dans les programmes internationaux, comme un devoir de l'agriculture de contribuer au maintien d'un patrimoine commun, dont les contours sont d'ailleurs flous (les territoires ruraux, les systèmes alimentaires régionaux, l'environnement ?), voire mythiques (les terroirs). Ce chapitre vise à éclairer les différentes formes de socialisation auxquelles correspondent ces exemples, le premier relevant à la fois de la protection sociale et des politiques économiques à finalité sociale, le second de la propriété sociale dans le cadre d'une autonomie territoriale, le troisième d'une redéfinition des contours et des justifications de la propriété sociale, avec l'inclusion de l'environnement.

La socialisation de l'agriculture est une transformation plus que séculaire (comme l'État providence) qui n'est pas un processus rectiligne, mais varie selon les contextes sociohistoriques et selon les périodes. Ce qui a été décrit comme la crise de l'État providence, à partir des années 1980, est également une rupture dans les formes de la socialisation de l'agriculture, qui débouche, dans les termes de l'ouvrage de 1995 (Allaire et Boyer, 1995), sur une crise structurelle de «l'agriculture du fordisme ». Ce chapitre vise à replacer ce changement dans une histoire plus longue. Mais il cherchera aussi à en rendre compte en s'appuyant sur les chapitres du présent ouvrage. Il s'agit d'une évolution ambivalente. Car, si la réforme des politiques agricoles vise à laisser plus de place au rôle « d'orientation du marché » (selon l'expression consacrée), les marchés, eux, sont orientés d'une façon nouvelle car la construction des normes techniques ou nutritionnelles est sortie du cadre sectoriel. La réflexion a alors porté sur la façon dont sont distinguées, hiérarchisées et valorisées les « qualités », celles de l'aliment comme celles du producteur, et sur la distinction entre régimes de qualité selon le type d'acteurs sociaux participant à l'établissement de hiérarchies entre qualités. Ces régimes appartiennent aux « formes de concurrence » de la théorie de la régulation. Mais cette notion est restée, de mon point de vue, sous développée.

Orléan (2011 : 87-97) et Boyer (2015 : 24), s'intéressant à la « construction des marchés » ou à ce qu'Orléan appelle « l'objectivation marchande », considèrent comme un «préalable » la « définition de la qualité ». Ils s'appuient sur Akerlof (1970), la référence classique à ce sujet ${ }^{1}$, qui montre que le modèle d'économie pure walrassien est en échec devant le problème de la connaissance de la qualité des marchandises. La thèse que je défends ici est que la définition de la qualité et la

1. La première partie de cet article est une démonstration logique de l'impossibilité du marché lorsque la connaissance de la qualité est « asymétrique ». De là, la théorie néoclassique a construit une économie du signalement de la qualité. La seconde partie donne différents exemples du rôle des institutions, mais ne bâtit pas une théorie institutionnaliste des marchés. 
valorisation des marchandises sont un même processus (en y incluant les salaires). Selon Orléan (2011), l'insignifiance de la monnaie dans l'économie walrassienne a pour «fondement conceptuel : le primat absolu des relations aux objets de telle sorte que l'économie se trouve réduite aux seules productions et consommations ». Ce primat rend tout aussi insignifiante la notion de qualité et donc de marchandises. La production ou la consommation sont bien des relations aux objets (corporelles et symboliques), mais ce qui est en jeu dans la possibilité de l'échange marchand, ce n'est pas l'accord sur un niveau de qualité mais la hiérarchie des qualités, c'est-à-dire des échelles de valeur.

Les « conventions de qualités » (Eymard-Duvernay, 1989) rendraient possible, selon les auteurs cités, l'accord entre échangistes. Or, celles-ci ne sont pas des définitions de la qualité, mais des justifications de hiérarchies de qualités. Si des « accords » sont préalables à l'échange (c'est-à-dire que l'on sort du cadre de la pure concurrence), ils portent sur des valeurs. La question est celle de la nature de ces valeurs. La thèse défendue ici est qu'il s'agit de «valeurs raisonnables », au sens défini par Commons (1934), c'est-à-dire correspondant à un jugement de raison. Lorsque l'action collective et des négociations sociales, arbitrées par l'État en dernière instance, sont impliquées dans la production de valeurs raisonnables, la richesse, plutôt que la propriété de choses matérielles ou de créances, devient le pouvoir de fixer les valeurs ou, dans les termes de Commons, de «manipuler les marchés ». Cette forme moderne de la propriété est la «propriété intangible ». Ces deux concepts, qui sont fondamentaux dans l'institutionnalisme commonsien, me paraissent le mieux à même de rendre compte du processus de formation des valeurs dans le monde capitaliste du $\mathrm{xx}^{\mathrm{e}}$ siècle. Mais, il est vrai, ce sont des notions peu connues. Non seulement parce que Commons est peu lu, mais aussi parce que les économistes s'intéressent aux droits de propriétés, définis de façon intemporelle, mais peu à la propriété.

Le développement de la propriété intangible recouvre une série de changements institutionnels qui vont du développement de la propriété intellectuelle à la propriété sociale (telle que définie ci-dessus). Ce développement ne résulte pas uniquement d'un changement de philosophie de l'État légitimant son intervention dans l'économie, après le développement libéral (politique du « laisser-faire ») d'un capitalisme concurrentiel au XIX ${ }^{\mathrm{e}}$ siècle, mais aussi de la négociation entre les forces du capital et du travail organisées en mouvements sociaux autour de la répartition de la richesse produite, non la richesse actuelle mais la richesse future résultant de leur collaboration. Commons (1925b) voit, dans la transformation qui s'opère à partir de la fin du siècle, la voie d'un sauvetage (recovery) du capitalisme, qui était condamné par Marx et Engels dans le Manifeste du parti communiste de 1848. Je voudrais ici étayer l'idée que le concept de régime de propriété développé par l'ancien institutionnalisme américain permet de rendre compte de la socialisation de l'agriculture, à condition de décortiquer les formes historiques des institutions qui supportent la propriété intangible, de la fin du XIX ${ }^{\mathrm{e}}$ siècle à aujourd'hui.

La conception de la valorisation que je défends amène à modifier la définition des formes de «concurrence » que l'on trouve dans le récent manuel de Boyer (2015 : 27) : «On appellera forme de concurrence le processus de formation des prix qui correspond à une configuration type des relations entre les participants au marché. » Il s'agit plutôt du processus de formation des valeurs, qui se traduit dans 
l'établissement de droits de propriété sur des valeurs qui ont différentes modalités, selon qu'il s'agisse de droits privés incorporels (propriété intellectuelle), de droits d'accès à des ressources (propriété commune) ou de droits sociaux (propriété sociale). La distribution du pouvoir de valorisation, avec l'accès aux ressources, est l'enjeu des conflits sociaux, et cette distribution se transforme historiquement.

Le terme socialisation, tel que je l'entends ici, ne préjuge pas du sens de l'histoire ${ }^{2}$. Le piège de concepts comme économie de la qualité ou propriété sociale est leur assimilation automatique au progrès social ou à la démocratie. L'émergence de la propriété intellectuelle au XIX ${ }^{\mathrm{e}}$ siècle, celle de la propriété sociale (État providence) au $\mathrm{XX}^{\mathrm{e}}$ siècle, comme la possibilité d'une gestion commune efficace de certaines ressources (comme le défend Elinor Ostrom) ont été combattues politiquement et intellectuellement. Hirschman (1991) montre que les arguments des " réactionnaires ", qu'il s'agisse des droits civils au XVIII ${ }^{\mathrm{e}}$ siècle, du suffrage universel au $\mathrm{XIX}^{\mathrm{e}}$ siècle ou de l'État providence au Xx $\mathrm{x}^{\mathrm{e}}$ siècle (et j'ajouterai de la propriété commune), relèvent de la même rhétorique : effet pervers, inanité (futility) et mise en péril (jeopardy). Il ajoute que la « rhétorique du progrès » use d'arguments similaires mais inversés (par exemple l'argument du péril imminent pour la société). Pour que le débat politique puisse avoir lieu, il faut reconnaître « la nature profondément ambivalente du mouvement historique » (Ibid.).

Dans la section suivante, je soulignerai les limites de la notion d'économie de la qualité dont le succès a été lié aux réflexions sur la sortie de la crise structurelle de l'agriculture du fordisme. Dans la section 3, j'introduirai la propriété intangible, en en montrant deux versants moraux opposés, selon que l'on suit Veblen ou Commons. Dans les sections suivantes, j'aborderai les différentes facettes de la propriété intangible : la propriété intellectuelle (section 4), la propriété commune (section 5), la propriété sociale et les politiques agricoles (section 6).

\section{" De l'économie de la qualité aux crises de qualité}

\section{L'économie de la qualité en ses limites}

Les références à l'ouvrage 1995 le créditent souvent de l'introduction de la notion « d'économie de la qualité » ${ }^{3}$. Par la suite, j’ai cherché à donner un contenu « régulationniste » à cette notion (Allaire, 2002). En m'inspirant de la théorie des systèmes productifs (Boyer et Durand, 1993), j’ai opposé (à partir du cas français), au

\footnotetext{
2. Mon propos est inspiré par et concerne essentiellement l'histoire des sociétés « occidentales ». Il pourrait cependant être étendu, car l'idée de socialisation de l'agriculture concerne évidemment les anciens pays « socialistes », qui ont connu différentes trajectoires historiques, et elle est liée à la notion de « développement » portée par les organisations internationales (FAO, Banque mondiale, etc.).

3. En fait, c'est Karpik (1989) qui le premier désigne par cette expression l'extension de marchés régis par des dispositifs de jugement de qualité. Allaire et Boyer (1995, Introduction) y voient une transformation des formes de concurrence. Les contributions à cet ouvrage collectif couvraient différentes questions qui ne sauraient se résumer dans cette expression et les contributeurs ont par la suite exploré différentes voies (chapitre 17). Un autre ouvrage collectif concernant l'agroalimentaire, de la même année (Nicolas et Valceschini, 1995), se situe plus directement sous cette bannière.
} 
« modèle des années 1960 », celui de « l'agriculture du fordisme » (Allaire, 1988b), régi par un principe de rationalisation des facteurs de production dans un contexte de débouchés non limités et d'inflation rendant le crédit facile, un " modèle des années 1990 » correspondant, dans un contexte macroéconomique différent et de réforme libérale des politiques agricoles, à une transformation des marchés des produits et des services alimentaires centrée sur la différenciation des qualités. Dans ce texte, j'identifiai deux forces de transformation : la première, la réponse des acteurs des marchés à de nouvelles demandes liées à une évolution des styles de vie ; et la seconde, l'extension de cette demande à une dimension immatérielle en associant qualité et responsabilité sociale. C'est le cas par exemple des produits biologiques (chapitre 10) ou des normes de sécurité sanitaire des aliments (chapitre 11). La diffusion de ce modèle était vue comme se développant à travers des crises sectorielles et répondant à plusieurs lignes de perception des demandes des consommateurs. Associant l'économie de la qualité à un régime d'accumulation centré sur les valeurs immatérielles (du Tertre, 2002), j'ai présenté les crises propres à cette économie comme des «crises d'opinion » qui peuvent devenir des crises de valeurs ou des crises de qualité (Allaire, 2002, 2010). Ce chapitre revient sur cette analyse, dans une perspective nouvelle.

Dès le départ, je me suis démarqué d'une vision qui donne à la qualité une connotation «alternative » ou positive. Car, si l'économie de la qualité recouvre un changement qui a à voir avec le mode de régulation sectoriel de l'agriculture, il concerne le système alimentaire tant dans sa globalité que dans sa diversité (chapitre 17). La notion d'économie de la qualité, en mettant l'accent sur le marché plus que sur la production, soulève la question de la capacité des organisations sectorielles à se saisir de questions globales. Elle nous conduit à la question de la construction et du contrôle des marchés.

\section{Les marchés comme «projets de contrôle »}

Pour Fligstein (1996), « les États modernes créent les conditions institutionnelles pour que les marchés soient stables, dont les banques centrales, les syndicats, les lois, la sécurité sociale et des programmes sociaux, etc. ». Il distingue quatre préconditions institutionnelles pour l'existence d'un marché : les droits de propriété (pour ce point voir les sections suivantes), les structures de gouvernance, les conceptions du « contrôle » et les règles de l'échange. Les structures de gouvernance, relevant de la loi et des pratiques instituées, sont les règles générales qui régissent les relations entre concurrence et coopération. Les règles de l'échange définissent les contours d'un marché et les statuts des participants. Les conceptions du « contrôle » sont les conceptions qui structurent la compréhension du fonctionnement et du positionnement d'un marché qu'en ont les participants.

Le terme « contrôle » est emprunté à White (1992), pour qui il n'est pas d'«identité » sans recherche permanente de contrôle, tentative de maîtriser un environnement incertain par la recherche d' « appuis » apportant une stabilité. Les conceptions du contrôle sous-tendent des « agréments spécifiques à un marché entre les acteurs au sein des firmes sur les principes d'organisation interne (c'est-à-dire les formes de hiérarchies), les tactiques de concurrence ou de coopération et l'ordre hiérarchique 
des statuts des firmes dans un marché donné » (Fligstein, 1996 : 658). Ces conceptions ne prédéterminent pas l'organisation des firmes ou leurs stratégies, mais les orientent, car elles reflètent une représentation partagée de la distribution, spécifique à un marché, du pouvoir de valorisation.

Les deux menaces qui pèsent sur l'existence d'un marché sont la tendance des firmes à se faire la guerre des prix et le problème de leur maintien comme identités cohérentes ("the problem of keeping the firm together as a political coalition », Fligstein, 1996 : 659). Les conceptions du contrôle recouvrent les articulations entre différentes échelles de valeurs : un ordre des firmes (ou plus généralement des producteurs) selon leur statut dans un marché donné ; une hiérarchie des marchés, selon le statut des produits (qui sont aussi des identités au sens de White) ; et des hiérarchies d'activités, selon le statut des professions et des métiers. La «négociation de la qualité » (Eymard-Duvernay, 1995) n'est pas indépendante de la construction d'un marché. Selon le type de marché et de période, il y a différents types de protagonistes dans les luttes entre projets de contrôle, et des scènes ou des arènes variées où sont mises en critique les conceptions du contrôle. Une fois installées, les conceptions du contrôle sont des schémas culturels résilients. Elles sont encastrées dans les cultures d'entreprise, industrielles, professionnelles, de métier, alimentaires, civiques, religieuses, etc.

La valorisation des qualités se réfère à des « biens en soi » (Dodier, 2005). L'idée de biens en soi ressort d'enquêtes sociologiques qui ont montré « la place cruciale qu'occupe dans l'argumentation publique, le fait d'en référer à des biens qui présentent deux caractéristiques : les personnes considèrent que ces biens valent en tant que tels, et elles estiment que le collectif se doit de leur réserver une certaine place » (ibid. : 22). Il faut inverser le schéma implicite qui voit la formulation de l'idéal comme précédant la conception du bien. Au contraire, l'idéal, le bien en soi, procède d'évaluations successives et de « l'autonomisation réussie de certaines finalités » comme résultat « d'opérations critiques » (Ibid.). Un régime de qualité correspond à « une architecture légitime des pouvoirs [de valorisation], au carrefour de plusieurs biens en soi » (Ibid.). Si, par exemple, on examine les justifications des politiques de protection des indications géographiques depuis leur création à la fin du XIX ${ }^{\mathrm{e}}$ siècle (Sylvander et al., 2006), on observe différents biens en soi, alternativement dominants selon les acteurs impliqués et les périodes : l'information du consommateur et la répression des fraudes, le contrôle de l'offre en vue de stabiliser des marchés sectoriels, la fourniture de services écologiques.

Les analyses qui s'intéressent à l'évolution des institutions sous-tendant l'existence des marchés mettent l'accent soit sur la diversité et la relative indépendance des instances productrices de normes (Brunsson et Jacobsson, 2000), soit sur la centralisation et le gouvernement autocratique des systèmes de normalisation, comme le fait Lawrence Busch (chapitre 12). Elles convergent cependant sur le fait que s'est développée toute une économie pour contrôler les processus de valorisation. De ce point de vue, le «modèle des années 1990 »doit être resitué dans une histoire plus longue, qui, dans le mouvement de socialisation de l'agriculture, peut embrasser tant « l'agriculture du fordisme », dont l'établissement tient fortement aux politiques agricoles, que le tournant des années 1990, poussé par les acteurs des marchés et correspondant à une certaine désectorisation. 


\section{" Les deux versants de la propriété intangible : les « valeurs raisonnables » sont-elles raisonnables?}

Il y a plus d'un siècle, les auteurs institutionnalistes américains décrivaient une transformation de la propriété et de la richesse, et l'apparition d'une nouvelle forme de propriété, la propriété intangible. Thorstein Veblen (1857-1929) et John R. Commons (1862-1945) qui, à la suite de Richard T. Ely (1854-1943), ont mis en avant et analysé cette forme nouvelle divergeaient sur la signification de cette transformation pour l'avenir des sociétés capitalistes, le second étant plus optimiste et réformiste que le premier.

\section{Les régimes de propriété selon l'ancien institutionnalisme américain (Ely, Veblen et Commons)}

Une conception historique de la propriété, qui implique le droit et l'éthique, est au fondement de l'ancienne économie institutionnelle américaine. Ely, dans un ouvrage de 1914, propose une analyse de l'évolution de la propriété privée, juridiquement comprise comme « un faisceau de droits » qui se modifient dans l'histoire. Pour Ely (1914), selon la présentation de cet ouvrage par Guéry (2010 : 22-23), la propriété privée s'étend avec le progrès des sociétés dans l'histoire, car «la propriété privée n'évolue pas au gré des seuls intérêts particuliers, mais autant de l'intérêt de la société toute entière ». Par la loi, la propriété privée est peu à peu "socialisée ». Cette socialisation de la propriété n'est pas une collectivisation mais la limitation des droits du propriétaire par des règles de responsabilité qui ont une sanction légale ${ }^{4}$. Mais, au moment où il écrit, pour Ely, l'histoire de la propriété est surtout marquée par une « extension de son emprise d'un droit sur les choses à un droit sur les droits ». Cette conception de la propriété est développée par Commons, pour qui la propriété d'un droit sur les droits est devenue celle d'un droit sur des valeurs futures. Ely et ses successeurs considèrent également que la jurisprudence a autant d'importance pour la vie économique et sociale que les codes et les lois.

Comme on le sait depuis Marx, la réalisation des valeurs au «moment » de l'échange sur un marché est périlleuse (soumise à la loi de l'offre et de la demande). Pour Commons (qui ne reprend pas la notion de valeur-travail), la raison en est que l'échange ne se réduit pas à un pur moment, mais s'inscrit dans une durée. Ce temps peut être de l'ordre de l'attente, lorsque l'on attend le remboursement d'une dette. Mais ce n'est pas le cas du temps qui s'écoule entre l'échange financier, qui marque l'échange des droits de propriété, et la disposition ou possession réelle qui est la conséquence de l'échange. Commons souligne qu'il ne s'agit pas là d'une simple question matérielle (de non-conformité des produits livrés ou des services délivrés) mais d'une question de valeur, car la possession débouche sur des actions dans le futur (qu'il s'agisse d'un usage de consommation ou de production) qui dépend de

4. Des travaux récents, faisant référence à l'ancien institutionnalisme, ont déplacé la notion de patrimoine vers le fondement de ce type de règles. Le patrimoine, non considéré de façon comptable, n'est pas un ensemble tangible de biens, mais une institution qui vise l'existence dans le futur d'une ressource considérée comme vitale pour une communauté et pour l'humanité (Barrère et al., 2005 ; Allaire, 2007). 
conjonctures futures et des choix (arbitrages) qui seront faits. C'est en ce sens que la propriété, «dans sa forme moderne de propriété intangible », devient des «droits sur des valeurs futures ». Pour Commons :

" deux théories de la propriété moderne intangible ont été développées depuis les années 1890. L'une est la «théorie de l'exploitation » de Veblen, l'autre la théorie de la valeur raisonnable des tribunaux. Les deux correspondent à la nouvelle conception de la propriété comme valeur présente de transactions profitables futures » $(1934: 640)^{5}$.

La «propriété intangible » émerge comme une théorie juridique, à partir des décisions des tribunaux, lorsque la cour suprême, par un arrêt de 1890, réévalue (très fortement) la valeur des actions d'une compagnie de chemin de fer et, à cette occasion, se réserve les solutions à apporter à ce type de problème. La valeur raisonnable des tribunaux consiste à tenir compte, au-delà de la valeur de la propriété du capital corporel (machines, locaux, etc.), d'une propriété non corporelle, intangible, qui correspond à la valeur que l'on peut raisonnablement attendre aujourd'hui de transactions profitables futures. Veblen (1908), s'appuyant sur l'opinion des managers, a également fait la découverte de cette propriété intangible reposant sur un flux de profit futur. Il en voyait l'origine dans l'exploitation du travail qui, par son habilité et son engagement, produira les valeurs futures. Le développement de la propriété intangible va avec celui de la finance, dont le rôle ambivalent est de sécuriser les valeurs futures en en tirant des profits spéculatifs ${ }^{6}$.

Commons, se démarquant de la théorie de l'exploitation de Veblen, construit sa propre théorie de la propriété intangible sur la notion de «valeur raisonnable ». La fixation de «valeurs raisonnables » ne concerne pas, évidemment, que la valeur des actions, mais autant celle des brevets, de la réputation (goodwill) ou des salaires et des revenus sociaux ${ }^{7}$. La valeur raisonnable n'est pas une valeur « moyenne », mais correspond à un jugement de raison qui conduit à choisir ce qui est le plus bénéfique à la communauté dans son ensemble. Il reconnaît cette façon de raisonner dans les décisions des cours de justice.

Pour Ely ou Commons, le salarié dispose d'une créance sur une valeur qui est en rapport avec celle que l'on attend du produit quand il sera prêt à être vendu, il s'agit là aussi d'une propriété de nature intangible. C'est par la négociation et la résolution de conflits sur le niveau des salaires qu'en ce domaine également sont déterminées des «valeurs raisonnables ». Dans les références des valeurs raisonnables, Commons donne une place importante à la « coutume », dans un sens qui renvoie à ce que nous avons appelé dans la section précédente des « conceptions du contrôle ». Les «valeurs raisonnables » sont fixées dans différents espaces sociaux ${ }^{8}$ par des «transactions de répartition », qui, dans le cas américain, sont in fine arbitrées par la Cour suprême, et ailleurs dans des cadres constitutionnels différents. Pour être raisonnable, il faut ajouter que les valeurs raisonnables sont contestables.

5. Le terme de transaction doit être entendu dans le sens commonsien. Il s'agit en particulier ici des « transactions managériales » qui permettent la mise en valeur du capital dans un procès de production.

6. Cet aspect ne sera pas développé dans le chapitre.

7. Sur la naissance de l'État providence aux États-Unis et le rôle de John Commons, voir da Costa (2010).

8. Dans le vocabulaire intraduisible de Commons, il s'agit de « going concerns ». Pour une application de cette notion, voir le chapitre 14 . 
C'est en lien avec sa conception de la valeur raisonnable que Commons voit le régime de propriété intangible s'instaurer lorsque les acteurs sociaux (employeurs et salariés essentiellement, mais on peut ajouter les paysans) sont organisés dans de vastes mouvements (syndicats). La négociation collective se traduit dans des droits sociaux qui sont des créances sur la richesse future.

Les normes de facto ou de jure, qui, comme le soulignent Brunsson et Jacobsson (2000), chacune à leur façon, poursuivent le projet de rendre le monde meilleur, ont également à voir avec les valeurs raisonnables telles que les conçoit Commons. J'entends ici par normes les règles qui participent des « structures de gouvernance » des marchés (section précédente), dont les règles professionnelles et celles des affaires qui concernent les activités de production et commerciales. Pour une part, ces règles relèvent de la propriété intellectuelle. Les signes de qualité, tels que le label Agriculture biologique, ont généralement comme propriétaire juridique une autorité publique et font appel à la certification tierce-partie, ce qui les distingue des droits de propriété intellectuelle au sens strict. Mais le certificat délivré correspond bien à une propriété sur une valeur future. Pour une autre part (ou sous un autre angle), ces règles relèvent de savoirs partagés ou de compétences collectives, qui sont une richesse immatérielle. Les connaissances sont réputées du domaine public (en libre accès), mais les choses ne sont pas si simples. Car il n'y a ni d'accès immédiat au savoir, ni de valorisation immédiate du savoir, ce qui donne aux connaissances une valeur qui relève de la propriété commune.

Commons distingue la propriété, qui est la revendication contradictoire de droits (claims), et les droits de propriétés : «la propriété n'est pas seulement un droit mais aussi un conflit de droits [claims] sur tout ce qui est rare, mais les droits de propriété sont l'action concertée qui régule [regulates] ce conflit» (1934:303). Dans le même passage, Commons introduit une distinction entre « analyse » et «justification »; l'analyse concerne les relations entre rareté, propriété et droits de propriété, tandis que la justification des droits de propriété est les raisons avancées pour les conserver ou les changer. La justification d'actions en faveur du changement s'appuie sur la critique des valeurs raisonnables établies. Ainsi, du mouvement critique, tel que l'analyse Dodier, émerge des « biens en soi » qui déplacent les valeurs raisonnables. Dans le cas d'étude de Dodier (2005) (le Sida), ce déplacement des valeurs raisonnables aboutit à la création de nouveaux droits pour les malades. Il reste à s'assurer qu'une distinction est possible entre des justifications raisonnables et la rhétorique, réactionnaire ou progressiste, mise à jour par Hirschman (1991).

Il ne faut pas confondre la propriété intangible (en tant que forme de la richesse) avec les droits de propriété qui l'inscrivent dans la propriété privée. Selon les différentes dimensions de la première, la nature des seconds diffère. Dans le cas de la propriété commune et de la propriété sociale, il s'agit de droits d'accès à des ressources. Il faut aussi distinguer la justification de la propriété sociale des politiques publiques qui en assurent la gestion. Dans le cas des droits de propriété intellectuelle, ils sont privatifs et sont valorisables comme actifs incorporels, mais ils sont justifiés, institués et contestables au nom du bien commun ou de l'intérêt social. 


\section{Les formes historiques de la propriété intangible}

Qu'en est-il au $\mathrm{XxI}^{\mathrm{e}}$ siècle du régime de propriété intangible ? L'État providence s'est déployé au $x^{\mathrm{e}}$ siècle, puis par certains aspects a régressé, mais les droits sociaux réels ou proclamés (comme le droit à la sécurité alimentaire) ont néanmoins continué de progresser au niveau mondial. De leur côté, les normes ont proliféré avec le développement d'un droit réglementaire. Ce développement est sans commune mesure avec ce qui était imaginable dans les années 1920, lorsque débute le processus de normalisation des industries, une fois tirées les leçons de la Grande Guerre (chapitre 12). Ce processus était censé générer des économies sur les « coûts de transaction », mais il a en fait généré un marché des normes en expansion et en restructuration permanente. Le régime de la propriété intangible est bien celui sous lequel se poursuit et s'étend le capitalisme, mais, à différentes époques, dans différents pays et sous l'influence des luttes politiques, il a pris des formes variées et on ne peut pas lui associer un seul régime économique.

L'utilisation du cadre commonsien pour une analyse historique des formes de la propriété intangible pose deux problèmes : éviter l'anachronisme et généraliser hors du cadre politico-légal des États-Unis. Le second problème peut se résoudre en considérant la distribution de l'autorité souveraine dans des cadres constitutionnels variables. Du local au global, il y a de très nombreuses sources de production de «valeurs raisonnables ». Ces valeurs peuvent perdurer dans un contexte de changement de système légal (chapitre 14).

Pour éviter l'anachronisme, il faut revenir sur le contexte historique dans lequel a été développée la théorie de la propriété intangible. Veblen et Commons ont vécu à une période où l'énergie devenait abondante, où la grande industrie rationalisait les activités de production et le travail, et dans laquelle les connaissances techniques pouvaient se diffuser assez facilement, du fait de l'extension significative de l'éducation et du caractère générique des savoirs techniques. Ils sont en admiration devant la «technique » et les prouesses de l'« industrie ». Commons voyait l'industrie atteindre son « point culminant avec la circulation rapide à grande échelle des marchandises et avec la transmission instantanée du savoir et des négociations, à l'échelle du monde » (1934 : 774). Certes, il y a aujourd'hui un usage considérable des techniques de recueil d'information au sein même des processus de production ou du vivant, et une multiplication des capacités de traitement de cette information. Mais, l'idée d'une transmission instantanée du savoir et de l'expérience est illusoire ! À la même époque, Keynes faisait une claire distinction entre la rareté des ressources matérielles et la rareté du crédit allant avec l'appât du gain. Il ne s'inquiétait pas particulièrement d'un épuisement des ressources naturelles et pensait que, grâce à la révolution technologique, la « rareté économique » pouvait être éliminée, ce qu'il promettait à ses petits-enfants, pour les années $1970^{9}$. Si, jusqu'aux années 1920, la question d'une conception raisonnable de l'abondance n'était pas posée,

\footnotetext{
9. Voir «Perspectives économiques pour nos petits enfants » (1928, reproduit in Keynes, 2002) et les commentaires de Dostaler et Maris (2009). La prévision de Keynes, pour se réaliser, aurait supposé non seulement des politiques appropriées, mais surtout une conception raisonnable de l'abondance et «l'euthanasie des rentiers »!
} 
les critiques de la «société de consommation » et les avertissements concernant la «crise écologique » se sont développés depuis.

La vision de Commons des liens entre la science et les valeurs raisonnables pose aujourd'hui question. Il faisait jouer à la science un rôle essentiel dans l'évolution générale des valeurs raisonnables, une sorte de rôle d'évaluateur supérieur, tant à la «science physique », qui supprime une grande partie des incertitudes techniques pour rationaliser la production, qu'à la « science sociale » réflexive, qui s'attache à rendre les valeurs raisonnables. On reconnaît là un idéal de la science. Mais la science n'est pas au-dessus de la société. Des mouvements d'opinion de grande ampleur ont plusieurs fois mis en garde contre l'application de découvertes scientifiques, par exemple au moment de la bombe atomique ou des OGM. L'investissement public dans la recherche scientifique au cours du $\mathrm{xx}^{\mathrm{e}}$ siècle a été légitimé par la finalité du progrès certes, mais aussi motivé par la recherche de puissance militaire.

Plutôt que de trancher de façon péremptoire le débat entre Veblen et Commons, tout en laissant sa part au changement profond de contexte à un siècle d'écart, je propose de retenir simultanément leurs deux visions de la propriété intangible, car les deux questions de l'exploitation et de la formation des accords sociaux (question de la régulation) restent au cœur de la compréhension du capitalisme. Ces deux visions caractérisent deux faces de la propriété intangible.

\section{La rareté et les « monopoles radicaux »}

La propriété intangible est associée, pour Commons, au stade historique de « l'abondance ». D'un côté, c'est la socialisation de la propriété qui peut générer une économie d'abondance au sens de la réduction des inégalités, mais d'un autre côté la propriété intangible permet de réduire l'abondance de certaines choses (par exemple celle du Champagne AOC ou des produits d'une marque donnée) pour en manipuler le prix. Il faut alors comprendre que la rareté n'est pas le signal d'un manque, mais plutôt la justification de la distribution d'opportunités limitées. Pour Commons, « la rareté engendre, comme dit Hume, à la fois l'intérêt personnel et le sacrifice personnel, et une économie fondée sur la rareté de Hume permet une union de l'économie, de l'éthique et de la jurisprudence » (1934 : 143), bref, un capitalisme raisonnable.

Sur ce point, Veblen se distingue en suggérant que la rareté peut être maintenue en entretenant un besoin infini de consommation. L'économie de l'abondance s'est développée en générant infiniment des demandes, en reposant donc sur des institutions qui créent de la rareté (Hoeschele, 2016). Le premier, Ivan Illich, s'intéressant au système des transports, à la santé et à l'éducation, a dénoncé ces institutions comme des « monopoles radicaux ${ }^{10}$. Il ne s'agit pas du pouvoir monopoliste classique de restriction de l'offre, mais d'une obligation à consommer du fait d'un monopole technique ou organisationnel, qui certes peut être justifié par des finalités sociales, mais aussi dénoncé au nom d'une conception de ce qu'est la bonne vie. Pour Illich, ces monopoles sont plus puissants que tous les monopoles

10. «Quand une industrie s'arroge le droit de satisfaire, seule, un besoin élémentaire, jusque-là l'objet d'une réponse individuelle, elle produit un tel monopole. » (Illich, 1975a). 
professionnels ou que les gouvernements. Les institutions qui mettent en œuvre les principes de la sécurité sociale contrôlée par le pouvoir médical sont un exemple de monopole radical (Illich, 1975b). Mais il ne faut pas confondre, dans cette dénonciation, la forme qu'a prise le système de santé, ni avec le droit fondamental aux soins, ni avec les droits sociaux inscrits dans les législations sociales (médecine du travail, assurance invalidité, etc.).

Des monopoles radicaux peuvent être décrits à propos de l'industrialisation de l'agriculture, créant des besoins en inputs résultant des conceptions dominantes de l'efficacité agricole. Là où on peut voir une synergie d'innovations qui permettent la croissance de l'agriculture fordiste qui, par ailleurs, est justifiée par l'objectif de sécurité alimentaire, on peut également voir, en considérant d'autres questions sociétales, une série de monopoles radicaux qui associent les industries d'aval, la recherche et les services de l'État pour faire consommer plus d'engrais et de pesticides. Il ne faut pas confondre le droit fondamental à la sécurité alimentaire avec les formes qu'a prise la socialisation de l'agriculture.

La critique des monopoles radicaux n'est pas qu'une dénonciation d'une logique financière, mais aussi de la technique et de la technoscience. Elle appelle généralement des formes de propriété collective comme solution pour l'autonomie et échapper à la logique infernale du développement. Reste à faire la part de l'utopie.

\section{" La propriété intellectuelle}

Les droits de propriété intellectuelle, qui regroupent les brevets, les marques, les droits d'auteur, les indications géographiques ${ }^{11}$, sont justifiés par l'économie néoclassique comme permettant l'investissement privé dans la production de connaissances et l'innovation. Ils confèrent à leurs détenteurs un monopole légal et réglementé sur l'utilisation d'une invention. La propriété intellectuelle est la propriété de droits sur des valeurs futures résultant de ce monopole. Elle assure à la fois la protection d'un droit reconnu à la propriété individuelle des œuvres de l'esprit (qu'il s'agisse d'une personne ou d'une communauté) et la diffusion des connaissances, par la publicité (l'enregistrement) des droits de propriété reconnus.

On peut trouver des origines lointaines de la propriété intellectuelle, entre autres, dans les monopoles que les autorités conféraient à l'époque médiévale aux guildes, groupements d'artisans et de commerçants qui opéraient un contrôle étroit des techniques et de la diffusion des savoirs de métier. L'autorité conférée à ces groupements en faisait les arbitres de «valeurs raisonnables », mais c'est au nom de la restriction de la liberté d'entreprendre que ces monopoles ont été contestés et généralement supprimés par les révolutions bourgeoises au XVIII ${ }^{\mathrm{e}}$ siècle. Se développe alors un débat philosophique sur la propriété intellectuelle en tant que composante ou non des droits humains. Comme le souligne Marie-Angèle Hermitte : « Les droits intellectuels ont été créés tardivement, entre la fin du XVII ${ }^{\mathrm{e}}$ siècle et le XIX ${ }^{\mathrm{e}}$ siècle où ils s’internationalisent. » (Hermitte, $2016: 17$ ). Ce qui est en jeu, c'est la nature sociale

11. Ces droits sont actuellement reconnus par l'Organisation mondiale du commerce, dans le cadre de l'accord ADPIC (Aspects des droits de propriété intellectuelle qui touchent au commerce). 
de l'innovation et le rôle de l'État dans le contrôle de l'innovation, « laissez faire » vs régulation. Comme elle le dit :

« Les droits intellectuels modernes naquirent lorsque l'administration abandonna l'idée d'utilité et de recherche du bien commun contenu dans l'invention pour se fonder exclusivement sur la nouveauté et le caractère industriel. Il fut admis que le bien commun découlerait automatiquement du libre jeu du marché [...]. Cet abandon d'un idéal de poursuite du bien commun dans l'attribution des brevets fut la condition de la création d'une économie de l'innovation au XVIII ${ }^{\mathrm{e}}$ siècle. Or, aujourd'hui que l'on a créé un mécanisme neutre, on cherche à y introduire du bien commun » (Hermitte, 2016 : 19-20).

On distinguera les droits de propriété que sont, par exemple, les brevets ou les indications géographiques de leur institution, qui a pour but de contrôler les modalités de l'innovation. De la même manière, on se gardera de confondre les valeurs sollicitées par les doctrines qui définissent des qualités avec les standards de qualité au sens des cahiers des charges, qui sont des obligations au regard d'un droit de propriété (incorporelle), dont le respect est légalement contrôlable (liability), tandis que les doctrines qui les justifient sont soumises à la critique publique (accountability).

Les débats en justification ou en contestation des droits de propriété intellectuelle portent fondamentalement sur leur extension - quelles sont les valeurs qui entrent dans ce domaine et celles qui doivent en être exclues, question qui renvoie à celle du domaine du marché (Zelizer, 1988) - et sur leurs conséquences économiques, non seulement en termes de croissance mais aussi du point de vue des finalités sociales. Les arguments contestataires ont toujours la forme d'une dénonciation de monopoles indus. À titre d'exemple, on peut mentionner, dans le cadre des débats toujours en cours concernant la révision de l'accord ADPIC, la contestation, par les juristes (Josling, 2006) et le gouvernement des États-Unis, de la revendication par l'Europe d'une protection universelle de ses indications géographiques les plus fameuses (telles que Champagne ou Parmigiano Reggiano), qu'elle considère comme appartenant au patrimoine mondial.

Dans son principe, le système des brevets, en ouvrant un marché des connaissances, est censé favoriser la dynamique d'innovation. Mais lorsque la détention de brevets entre dans les stratégies concurrentielles, cette justification ne tient plus, car elle fait courir le risque d'une " tragédie des anti-communs », qui se produit lorsque des ressources rares sont sous-utilisées parce que trop de détenteurs de droits d'exclusion se bloquent les uns les autres. Ce blocage peut être dénoncé au nom de «biens en soi ». Ce phénomène a été mis en évidence dans le cas de la recherche biomédicale aux États-Unis (Heller et Eisenberg, 1998) et dénoncé au regard du bien attendu de l'innovation en ce domaine. Cette dénonciation a conduit à des réactions comme la mutualisation de pools de brevets, ce qui limite leur effet d'exclusion et réduit leur valeur concurrentielle tout en libérant leur valeur sociale. L'apparition des brevets dans le domaine de la sélection végétale a également été critiquée pour son rôle d'anti-commun au regard de la conservation de la biodiversité (Thomas, 2015). Ce qu'il faut retenir est l'ambivalence du système de brevet (une analyse parallèle pourrait être faite pour les autres types de droits de propriété intellectuelle).

La propriété intellectuelle ne saurait assurer seule la diffusion des connaissances, à moins d'envisager un monde parfaitement normé ! Madison et al. (2010 : 691-692) distinguent trois types de « communs » (voir section suivante) qui émergent en 
rapport avec le régime de propriété intellectuelle : i) comme instances de coopération, pour créer des environnements particuliers de partage de ressources intellectuelles pour des projets spécifiques, cas des licences libres ou des normes volontaires ; ii) construits en résistance contre la privatisation de ressources ; iii) permettant de compléter les connaissances qui circulent sous la forme de droits de propriété ou de normes, cas des communautés d'utilisateurs épistémiques et scientifiques.

\section{W La propriété commune}

Les ressources immatérielles mobilisées par l'activité économique, au-delà de la propriété intellectuelle, relèvent de régimes de propriété commune, en définissant celle-ci comme l'accès partagé à des ressources, réservé à une communauté d'utilisateurs plus ou moins vaste. Elle se traduit dans des droits exclusifs qui portent sur les valeurs résultantes de la mobilisation de ces ressources. Les systèmes à l'origine de ces ressources sont appelés des « communs », plus précisément « common pool ressources » par Elinor Ostrom. Cette notion a d'abord concerné des ressources " naturelles », comme un lac ou une forêt, dont le caractère indivisible fait que l'utilisation privée peut en menacer l'existence si font défaut des règles raisonnables de gestion. Dans le sillage d'Ostrom (2010 ; Chanteau et al., 2013), la notion a été étendue pour désigner des communs « immatériels », «culturels » ou « intellectuels » liés aux domaines de l'information et des connaissances, ainsi que pour caractériser les systèmes complexes de ressources immatérielles qui encadrent les activités économiques et politiques, privées et publiques (Allaire, 2013). Je ne vise pas à traiter ici de la survivance ou du renouveau de pratiques communautaires de gestion de ressources locales, mais de la constitution de vastes patrimoines productifs collectifs, comme par exemple la vache Holstein configurée par la sélection génétique (chapitre 7).

Ostrom a régulièrement dénoncé trois confusions sémantiques qui obscurcissent la nature des communs : i) entre la propriété commune et le libre accès (common property and open-access regimes) ; ii) entre ressources gérées en commun (commonpool resources) et régimes de propriété commune (common property regimes) ; et iii) entre le système qui fournit les ressources (a resource system) et le flux d'unités de ressources qui peuvent être appropriées (the flow of resource units). Elle souligne que, tandis que le système producteur de ressources relève de la propriété commune, les unités de ressources délivrées sont généralement appropriées pour un usage privé (productif ou non). Il s'agit d'un flux de services qui seront délivrés lors de mobilisations futures de cette ressource.

Il faut distinguer la propriété commune des droits de propriété sur un commun. Schlager et Ostrom (1992) citent différents types de droits (d'accès, de prélèvement, de gestion et d'exclusion). Ils déterminent le statut ou la position de ceux qui en sont détenteurs. L'accès ou la capacité de gestion qu'ils confèrent sur un système de ressources permettent d'en tirer un bénéfice qui dépend non seulement de la distribution de ces droits entre divers types d'acteurs, mais aussi et surtout des stratégies futures des autres détenteurs de ce type de droits. Il y a rarement un propriétaire au sens plein formellement identifié du système de ressources lui-même 
(si c'est le cas il s'agit d'une autorité publique). La propriété commune repose sur un droit d'exclusion, mais pas sur un droit d'aliénation (abusus). Les détenteurs de droits (accès, gestion, exclusion) sont tous les acteurs bénéficiaires directs et autres parties prenantes, qui contrôlent de façon plus ou moins consensuelle la propriété commune. L'enjeu de ce contrôle est la visée qui oriente les règles de gestion et sa justification. À ce propos, des controverses se développent toujours, qui peuvent conduire à des crises existentielles (à l'instar des crises de qualité) et faire émerger des questions politiques et éthiques.

Un système de ressources gérées en commun ne peut être vu de façon isolée, car tout système de ressources, fussent-elles immatérielles, est intégré d'une façon ou d'une autre dans des infrastructures techniques et institutionnelles, écologiques et sociales. Un commun particulier doit être analysé à différents niveaux, interreliés, tant écologiques que socioéconomiques (Ostrom 2005). Pour regrouper des systèmes de ressources se rapportant à différentes formes de connaissance et de création, Madison et al. (2010) utilisent l'expression « communs de l'environnement culturel », en considérant « des environnements pour développer et distribuer le savoir scientifique et culturel via des institutions qui gèrent l'intégration (pooling) et le partage de ce savoir ». Ils citent les pools de brevets, les systèmes open source, les agences d'information ou les universités modernes. Ils précisent que l'utilisation du terme environnement, de façon métaphorique, renvoie au caractère intégré (nesting process) identifié par Ostrom comme un élément saillant des communs. Hess et Ostrom (2004) utilisent une autre métaphore pour décrire le «système d'information académique » comme « un écosystème complexe » se déployant à plusieurs niveaux. Dans un autre texte, elles soulignent que l'information a en général « de complexes attributs tangibles et intangibles : frontières floues, une communauté diverse d'utilisateurs de niveau local, régional, national et international, et de multiples couches d'institutions établissant des règles » (Hess et Ostrom, 2003 : 132). Sur ce modèle de l'écosystème, on peut analyser un marché spécifique en tant qu'il est régi par des conceptions du contrôle, en analysant cet environnement comme un système ou un réseau complexe de ressources immatérielles ${ }^{12}$. On peut rapprocher les « communs de l'environnement culturel » de la notion de «patrimoines productifs collectifs » (Nieddu et al., 2010 ; chapitre 9) ou des « conceptions du contrôle » précédemment introduites.

Je relie propriété commune et propriété intangible car la transformation historique de cette propriété est à rapprocher de celle des autres formes de la propriété intangible. L'évolution des technologies et des modes de vie est responsable d'un double phénomène d'extinction et de globalisation des communs. L'existence future de ces systèmes de ressources étendus dépend de règles de différents niveaux, tandis que la valorisation des unités de ressources est liée à des opportunités dépendantes de marchés et de technologies dont le contrôle échappe de plus en plus aux groupes locaux d'utilisateurs. Ce point de vue a été développé tant pour les communs intellectuels que pour les communs du vivant avec l'industrialisation des ressources génétiques (Bonneuil et Thomas, 2009 ; chapitre 7). L'industrialisation de l'agriculture

12. Les marchés comme systèmes d'information sont fragmentés. Les systèmes de connaissance spécifiques à un marché ne sont maintenus qu'au travers de séries d'investissements privés et collectifs, dont les interdépendances dynamiques créent de complexes systèmes de ressources communes. 
a conduit, partout dans le monde, à la marginalisation de communs autrefois indispensables à l'activité agricole, et, simultanément, a reposé sur la construction de vastes systèmes sociotechniques et le développement d'un environnement culturel des activités agricoles complètement nouveau. Cet environnement connaît dans la décennie actuelle un nouveau bouleversement avec le numérique, les capteurs, le GPS et la génomique. La globalisation qui en résulte reconfigure la propriété commune et fait réapparaître la question politique de la visée de l'action collective.

Pour certains critiques, les vastes ensembles sociotechniques qui configurent les ressources biologiques et les connaissances, tout en relevant de la propriété commune, ne sont pas loin de constituer des monopoles radicaux. Le gouvernement de ces systèmes de ressources communes repose sur un pouvoir d'orientation des systèmes techniques qui peut bloquer le développement d'alternatives (chapitre 9).

\section{"Propriété sociale et politiques agricoles}

Commons fonde le lien social sur la distinction entre deux catégories de dettes : les « dettes d'autorité », une relation de l'individu à la communauté, et au-delà à un ordre souverain, dont on ne peut se défaire ; et les «dettes autorisées » interindividuelles ou « volontaires », négociables et dont le lien qu'elles instituent peut être coupé par un paiement monétaire. Dans les États modernes, les dettes d'autorité sont liées à la citoyenneté ; on s'en acquitte par l'impôt, et les citoyens, en retour, avec le développement de la propriété sociale, acquièrent des droits sociaux.

\section{Propriété sociale et droits sociaux}

C'est à la fin du XIX ${ }^{\mathrm{e}}$ siècle, lorsque se développe le capital financier et qu'apparaît la propriété intangible, que commence également à se construire la forme « d'État social », c'est-à-dire un État qui se veut « fondamentalement réducteur d'insécurité »(Castel, 2008). La transformation de la propriété patrimoniale (familiale, communautaire) avec le développement du marché et du salariat va avec le développement de l'assurance et l'institutionnalisation de droits sociaux. Dès le XIX ${ }^{\mathrm{e}}$ siècle, il s'est constitué une nouvelle rationalité juridique et politique, qui a débouché, en Europe et en Amérique, sur une réglementation des compagnies d'assurances et une diversité de mesures sociales, dont l'obligation d'assurance, formant des systèmes complexes de protection sociale, caractérisant l'État social ou l'« État providence » (Ewald, 1986).

Castel (2008) voit cette nouvelle rationalité comme une réponse à la question de la sécurité économique des individus, condition de l'égalité, qu'était censée apporter la constitutionnalisation de la propriété privée :

« À la fin du XIX ${ }^{\mathrm{e}}$ siècle une solution nouvelle devient pensable et va commencer à se mettre en place, qui respecte la propriété privée tout en promouvant un certain mode d'égalité entre les hommes, en construisant un type tout à fait nouveau de propriété, une propriété pour la sécurité que l'on peut nommer la propriété sociale» (Ibid. : 171-172). 
La propriété sociale "résulte de l'inscription dans un système juridique d'obligations qui, en retour produit des droits et des ressources » (Ibid.). Ce sont des droits d'accès à des biens et des services collectifs qui ont une "finalité sociale », c'est-àdire à la fois assurer la sécurité des membres d'une société et « renforcer leur interdépendance de telle sorte qu'ils continuent "à faire société" " (Ibid.). À cet égard, l'État providence a initialement été justifié pour maintenir l'ordre économique en place. Selon Théret (2013), dans les sociétés démocratiques, l'État reconnaît l'existence d'une dette sociale dont il est débiteur en dernier ressort. Les citoyens, ayants droit des systèmes nationaux de protection sociale, sont par là créanciers d'une dette mutuelle devenue publique. Cette dette recouvre un ensemble de droits sociaux qui concerne les citoyens dans leur ensemble.

La révolution libérale, si elle ne peut supprimer la dette sociale, vise à la mettre sous le contrôle de la finance. Orléan, à partir de l'opposition entre les formules de retraite par répartition et par capitalisation, oppose au régime dans lequel la dette sociale est garantie par l'État, un nouveau régime qui introduit « la logique de la dette privée, du contrat et de la responsabilité individuelle». L'individu « voit ses droits [sociaux] affirmés sous la forme de titres négociables. L'exercice de ces droits ne dépend plus ni de sa citoyenneté, ni de son appartenance à telle ou telle entreprise, mais de la liquidité boursière » (Orléan, 2000 : 19). Les orientations libérales déstabilisent l'État social. Ce changement s'opère progressivement à travers une série de réformes qui se heurtent à la résilience des conventions qui fondent la propriété sociale. La finance tend à dévorer la propriété sociale quand la valeur des dettes des États, du blé, de la terre et des points de retraite dépend des marchés financiers, tandis qu'avec la régulation stabilisatrice du fordisme ces valeurs dépendaient de valeurs raisonnables fixées dans des négociations sous l'égide des autorités publiques. Les mouvements qui s'opposent à la révolution libérale sont à la recherche de nouvelles valeurs raisonnables de répartition. Comme nous allons le voir dans le cas de l'agriculture, il s'agit de refonder la dette sociale.

\section{L'avenir des politiques agricoles}

Les politiques agricoles sont l'une des composantes du régime de propriété sociale. Elles sont créatrices de droits qui vont avec la création de statuts sociaux pour les producteurs et les entreprises agricoles. Cette gamme de droits, à l'instar des droits sociaux des salariés, varie grandement selon les contextes nationaux et historiques. Ce régime est légitimé par la fonction de l'agriculture quant à l'indépendance nationale et par la finalité sociale des États modernes d'assurer la sécurité économique (ici alimentaire). Après la crise de 1929, il repose sur des instruments de contrôle et de protection des marchés intérieurs, et de stabilisation des revenus des familles paysannes. Se définissent dans le même temps des statuts sociaux et les règles de l'échange (statut des biens fonciers, régimes de succession, standards minimaux de qualité, etc.). Dans l'Union européenne, le Traité de Rome (1957) reprend les principes de stabilisation des politiques agricoles nationales et les met en ouvre dans le cadre du «marché commun » (Barthélemy et Nieddu, 2002). Le cadre d'analyse de Théret (2013) vaut également pour la partie de la dette sociale qui est liée à la stabilisation des marchés agroalimentaires. 
On peut distinguer deux types de droits sociaux. Les politiques de stabilisation, s'il s'agit d'intervention directe sur les marchés répondant à une finalité sociale, ne créent pas des détenteurs légaux particuliers ; il s'agit d'un droit ayant un caractère public. Par exemple, tout producteur de blé bénéficie d'un prix garanti, et tout consommateur d'une stabilisation du marché du blé ou d'un prix subventionné du pain. Il n'est pas facile de modifier ces droits du fait des accords sociaux sur lesquels veillent les syndicats ou parce que les conséquences sociales sont immédiates («émeutes de la faim »). Les politiques économiques de stabilisation peuvent également créer des droits d'accès à la dette sociale pour des ayants droit particuliers, comme lors de la création des quotas laitiers en 1984, puis lors de la réforme de la PAC à partir de 1992. Les instruments de marché (stockage, taxation des importations, etc.) ont été désactivés ou la portée en a été réduite, et ils ont été remplacés par des aides directes. Ceci a nécessité d'en désigner les bénéficiaires, détenteurs d'un « droit à prime », ce qui a d'abord été fait sur une base dite historique, ce droit étant réservé à ceux qui étaient producteurs une année de référence et au prorata de la surface cultivée, puis ces droits ont été regroupés pour être attribués à des « agriculteurs actifs », dont la définition a demandé de longs débats et est encore instable. Cette individualisation de l'accès ne supprime pas le caractère social de cette politique, mais en modifie le sens. La PAC initiale avait un double objectif : la parité sociale de revenu pour les agriculteurs et des prix raisonnables pour les produits alimentaires. Le deuxième objectif reste affirmé mais désolidarisé de la dette sociale agricole.

La protection sociale des salariés et le droit du travail n'ont pas été intégrés à la construction de l'Europe. La dette sociale est restée au niveau des États, alors que le marché a changé d'échelle, ce qui exacerbe la concurrence interne et, selon les mots de Théret (2013), fait de l'euro une monnaie « unique » et non une monnaie commune. Au contraire, la création de la politique agricole «commune » a reposé sur un transfert des dettes sociales agricoles nationales à l'Europe. Cela s'est traduit, en termes de principes, d'une part par la «préférence communautaire » pour l'approvisionnement, et d'autre part par l'affirmation que l'agriculture familiale, qui certes devait être modernisée, était la base sociale de l'indépendance alimentaire. Le démantèlement libéral de cette politique, avec les réformes entamées en 1992, n'a pas pour autant supprimer la dette sociale agricole, mais a créé un décalage entre les marchés globalisés et financiarisés de l'agroalimentaire, et le niveau d'expression de cette dette. Les organisations corporatistes tendent à en perdre le contrôle économique, mais ont gardé un poids politique suffisant pour en assurer une certaine pérennité. Le renouvellement d'un compromis politique pour limiter la baisse relative des dépenses agricoles dans le budget européen au fil des cadres financiers pluriannuels confirme la résilience de cette dette.

La PAC a néanmoins changé de base. La déréglementation ne s'est pas arrêtée à la suppression des organisations communautaires des marchés agricoles. L'exception agricole en matière de politique de la concurrence a été battue en brèche, en particulier par l'interdiction d'accords interprofessionnels fixant les prix. Les stratégies individuelles et collectives tendent à s'adapter dans un double sens, d'une part par une plus grande attention aux signaux du marché (ce qui était attendu), mais aussi, d'autre part, par l'évitement de la concurrence sur les marchés de masse où règne désormais l'insécurité économique, par des initiatives locales de valorisation 
et l'établissement de relations contractuelles (chapitre 13). La crise financière et alimentaire de 2007-2008 et, depuis, la forte instabilité des prix à la production qui s'étend aux marchés nationaux ont fait changer certains points de vue. La nouvelle PAC adoptée en 2014 a pris acte d'un déséquilibre des pouvoirs de marché entre les agriculteurs, et les industries ou les centrales d'achat; l'organisation des producteurs est de nouveau encouragée ; le contrôle local des volumes mis en marché est même possible dans le cas des AOC. Mais l'idéologie néolibérale, qui vise à substituer aux droits sociaux des solutions marchandes (notamment des services d'assurances), reste fortement prégnante.

Si l'héritage politique de la PAC, c'est-à-dire sa participation à la souveraineté communautaire, ne peut être liquidé d'un trait de plume, comment formuler aujourd'hui des objectifs communs ? Ces objectifs doivent s'inscrire tant dans une responsabilité vis-à-vis du monde global que dans des projets collectifs locaux, et à ces deux niveaux, local et global, s'inscrire dans la perspective d'une transition énergétique et écologique. La mutation énergique concerne de façon importante l'agriculture et les territoires ruraux. Mais une voie qui pourrait redonner à la PAC une ambition doit dépasser l'agriculture et concerner, de nouveau, le destin de la société dans son ensemble.

\section{Conclusion}

L'ambition de ce chapitre, qui clôt l'ouvrage, n'était pas d'en fournir une conclusion. Les premiers chapitres ont proposé une compréhension socioécologique du phénomène d'industrialisation et, plus particulièrement, de l'industrialisation de l'agriculture, en s'appuyant sur les concepts de métabolisme et de colonisation de la nature, et ont mis en perspective les métabolismes correspondant aux systèmes Monde successifs depuis un quart de millénaire. Les régimes économiques et les types d'État dans lesquels s'est développée cette industrialisation ont varié. Progressivement, l'industrialisation de l'agriculture a reposé sur un double encadrement, celui assuré par des normes qui s'imposent comme conditions d'accès aux marchés et celui assuré par l'État, dans le cadre des politiques agricoles.

Ce chapitre propose le concept de socialisation de l'agriculture pour penser ce double encadrement qui a ses racines dans le $\mathrm{XIX}^{\mathrm{e}}$ siècle aux États-Unis, notamment, et se développe considérablement au $\mathrm{xx}^{\mathrm{e}}$ siècle dans l'ensemble des pays industrialisés, depuis la Grande Guerre et la crise des années 1920. Cette socialisation de l'agriculture est mise en relation avec l'apparition d'une nouvelle forme de régulation économique et politique. Le parti a été pris ici de se référer aux travaux fondateurs de l'institutionnalisme aux États-Unis, et tout particulièrement à Commons, qui permettent d'analyser cette nouvelle forme de régulation à partir d'un concept central, celui de formes et de régimes de propriété. Ces travaux mettent en évidence la tendance à la « socialisation de la propriété privée » et le développement d'une nouvelle forme de richesse, appelée «propriété intangible ». Pour développer ce régime, plusieurs aspects ont été ici distingués (la propriété intellectuelle, la propriété commune et la propriété sociale), et, dans chaque cas, une analyse de la transformation des justifications et des contestations des droits qui en découlent a 
été esquissée, en s'appuyant notamment sur les différents travaux rassemblés dans cet ouvrage. Le régime de la propriété intangible est celui sous lequel se poursuit et s'étend le capitalisme, mais, à différentes époques, dans différents pays et sous l'influence des luttes politiques, ce régime a pris des formes variées et on ne peut pas lui associer un seul régime économique ou un seul modèle d'agriculture.

Pour analyser les régimes économiques du $\mathrm{Xx}^{\mathrm{e}}$ siècle, une analyse conjointe du développement historique des différentes formes de la propriété intangible serait nécessaire. L'ambition de ce chapitre ne va jusque-là, mais il voudrait faire partager cette perspective théorique, en soulignant l'ambivalence du développement historique de la socialisation de l'agriculture.

Cette perspective implique un développement des fondements institutionnalistes de la théorie de la régulation. La thèse défendue est que les fondements des valeurs sont des points de vue normatifs sur la hiérarchie des qualités qui, dans un contexte donné, résultent d'arbitrages sociaux justifiés par des représentations de l'avenir (Gislain, 2010). En ce sens, il s'agit de valeurs « raisonnables » (au sens finalement ambigu de Commons), donc contestables. Si l'on donne un fondement scientifique ou moral à ces valeurs raisonnables, qui ne serait pas contestable et révisable, on est dans le domaine de l'utopie ou de la folie. L'histoire est au contraire ambivalente et la recherche du bien ne va pas sans conflits, qui, comme on le sait, ne se limitent pas aux idées. Souligner cette ambivalence n'est pas un refus de prendre parti, mais un moyen d'attirer l'attention sur la nécessité de justification. Aujourd'hui, l'argument du péril imminent est utilisé pour justifier le financement de recherches agronomiques et continuer de soutenir l'intensification agricole, dont une version « écologiquement intensive ». À l'opposé, se développe une réflexion sur la capacité de l'agroécologie à relever le défi de « nourrir le monde » et, en même temps, sur le contenu du droit à l'alimentation (de Schutter, 2010). Pour poser correctement la question d'une abondance soutenable et équitable, il faut le faire sans utiliser l'argument du péril imminent. L'évaluation des formes de socialisation de l'agriculture peut nous y aider. 


\section{Références bibliographiques}

AAA (Agencia ANdAluza del Agua), 2009. Demarcación hidrográfica de las cuencas mediterráneas andaluzas: estudio general de la demarcación. Malaga, AAA, mars.

Adams R.N., 1975. Energy and Structure: A Theory of Social Power. Austin, University of Texas Press.

Agarwal A., Narain S., 1991. Global Warming in an Unequal World: A Case of Environmental Colonialism. Delhi, Centre for Science and Environment.

Aglietta M., 1979. A Theory of Capitalist Regulation. Londres, New Left Books.

Aglietta M., 1997. Régulation et crises du capitalisme. Paris, Odile Jacob.

Aglietta M., Bai G., 2013. China's Development: Capitalism and Empire. Londres, Routledge.

Aglietta M., Rigot S., 2009. Crise et rénovation de la finance. Paris, Odile Jacob.

Aguilar A, Magnien E., Thomas D, 2013. Thirty Years of European Biotechnology Programmes: From Biomolecular Engineering to the Bioeconomy. New Biotechnology 30 (5), 410-425.

Akerlof G., 1970. The Market for Lemons: Qualitative Uncertainty and Market Mechanism. Quarterly Journal of Economics, 89 (3), 488-500.

Albaladejo C., 2012. Les transformations de l'espace rural pampéen face à la mondialisation. Annales de géographie, 4, 387-409. mimeo.

Alic (Agriculture and Livestock Industries Corporation), 2012. Dairy Industry in Japan,

Allaire G., 1988a. Itinéraires et identités professionnelles des travailleurs de l'agriculture. Actes et communications de l'Inra. 3, 175-211.

Allaire G., 1988b. Le modèle de développement agricole des années 1960. Économie rurale, 184, 171-181.

Allaire G., 1995a. De la productivité à la qualité, transformation des conventions et régulation dans l'agriculture et l'agro-alimentaire. In : La grande transformation de l'agriculture : lectures conventionnalistes et régulationnistes (Allaire G., Boyer R., dir.). Versailles/Paris, Inra éditions/ Economica, 381-410.

Allaire G., 1995b. Croissance et crise en agriculture. In : Théorie de la régulation : l'état des savoirs (Boyer R., Saillard Y.). Paris, La Découverte, 341-349.

Allaire G., 1996. Émergence d'un nouveau système productif en agriculture. Canadian Journal of Agricultural Economics/Revue canadienne d'agroéconomie, 44 (4), 461-479.

Allaire G., 2002. L'économie de la qualité, en ses secteurs, ses territoires et ses mythes. Géographie économie société, 4 (2), 155-180.

Allaire G., 2006. Conventions professionnelles et régimes de responsabilité. In : L'économie des conventions, méthodes et résultats (Eymard-Duvernay F., dir.). Paris, La Découverte, 279-293.

Allaire G., 2007. Les figures patrimoniales du marché. Économie appliquée, 60 (3), 121-156.

Allaire G., 2010. Applying Economic Sociology to Understand the Meaning of "Quality" in Food Markets. Agricultural Economics, 41 (1), 167-180.

Allaire G., 2013. Les communs comme infrastructure institutionnelle de l'économie marchande. Revue de la régulation, 14 (2), revue en ligne : https://regulation.revues.org/10546 (consulté le 8 octobre 2016).

Allaire G., 2016. Que signifie le « développement » de l'Agriculture Biologique ? Innovations agronomiques, 51, 1-17, revue en ligne : http://www6.inra.fr/ciag/Revue/Volumes-publies-en-2016/ Volume-51-Mai-2016 (consulté le 16 novembre 2016).

Allaire G., Biénabe E., 2013. Quality Regimes and Property Regimes: A Framework for Assessing Geographical Indications' Sustainability Implications. In : 10th International Conference of the European Society for Ecological Economics, 18-21 juin, Lille, ESEE. 
Allaire G., Boyer R. (dir.), 1995. La grande transformation de l'agriculture : lectures conventionnalistes et régulationnistes. Versailles/Paris, Éditions Inra/Economica, Collection Synthèses.

Allaire G., Daviron B., 2006. Régimes d'institutionnalisation et d'intégration des marchés : le cas des produits agricoles et alimentaires. In : Les nouvelles figures des marchés agro-alimentaires, présenté au GDR Économie et sociologie « Les marchés agro-alimentaires », 23-24 mars, Montpellier, Paris, Inra, 113-125.

Allaire G., Labatut J., Tesnière G., 2016. Systèmes complexes de communs et régimes de propriété : le cas des ressources génétiques animales (à paraître).

Allaire G., Sylvander B., 1997. Qualité spécifique et innovation territoriale. Cahiers d'économie et sociologie rurales, 44, 29-59.

Allaire G., Sylvander B., 2011. Globalization and Geographical Indications. In : Labels of Origin for Food: Local Development, Global Recognition (Barham E., Sylvander B., dir.). Cambridge (Mass.), Cabi International, 106-121.

Allaire G., Wolf S., 2004. Cognitive Representations and Institutional Hybridity in Agrofood Innovation. Science, Technology \& Human Values, 29 (4), 431-458.

Alphandery P., Djama M., Fortier A., Foullleux E. (dir.), 2012. Normaliser au nom du développement durable. Versailles, Éditions Quæ.

Andersen A.H., 2011. Organic Food and the Plural Moralities of Food Provisioning. Journal of Rural Studies, 27 (4), 440-450.

Ansaloni M., Smith A., 2014. Whither the State When It Acts Through Markets? Economic Sociology European Electronic Newsletter, 15 (2), 34-40.

ANSEEUw W., 2004. Reconversion professionnelle vers l'agriculture marchande et politique publique en Afrique du Sud. thèse de doctorat, Grenoble, Université de Grenoble II.

Anseeuw W., 2013. Between Subsistence and Corporate Agriculture: The Reinforcement of South Africa's Agricultural and Territorial Dualisms. In : Conference Land Divided: Land and South African Society in 2013, in Comparative Perspective, 24-27 mars, Le Cap, 12 p.

Anseeuw W., Ducastel A., Boche M., 2012. Nouveaux modèles de production et d'investissement en Afrique du Sud. Études rurales, 190, 147-160.

Appert O., Alario F., 2013. Vers une chimie biosourcée. Réalités industrielles, 1, février, dossier La bioéconomie, élément clé des transitions énergétiques et écologiques, 44-53.

Arrighi G., 1994. The Long Twentieth Century: Money, Power and the Origins of our Times. Londres, Verso.

Arrighi G., 2005. Global Governance and Hegemony in the Modern World System. Contending Perspective on Global Governance: Coherence, Contestation and World Order (Ba A.D., Hoffmann M.J., dir.). Londres, Routledge, 57-71.

Arrighi G., 2007. Adam Smith in Beijing: Lineages of the Twenty-First Century. Cambridge, Verso.

Arrighi G., 2010. The Long Twentieth Century. Money, Power, and the Origins of Our Time. $2^{\mathrm{e}}$ édition, Londres, Verso.

AsAKAwA Y., 2012. TPP de Nihon wa sekaiichi no nogyo taikoku ni naru (With the TPP Japan Can Become the Worlds Biggest Agricultural Country). Tokyo, KK Bestsellers.

Ashton W. S., 2009. The Structure, Function, and Evolution of a Regional Industrial Ecosystem. Journal of Industrial Ecology, 13 (2), 228-246.

Aso T., 2013. What is Abenomics: Current and Future Steps of Japanese Economic Revival. mimeo.

Atтali C., 2013. Les usages non alimentaires de la biomasse. Réalités industrielles, 1, février, dossier La bioéconomie, élément clé des transitions énergétiques et écologiques, 78-79.

Aubert C., 2008. Food Security and Consumption Patterns in China: The Grain Problem. China Perpectives, 2, 5-23.

Aubert D., Lifran R., Mathal P., Perraud D., Viallon J.B., 1985. Systèmes de production et transformation de l'agriculture, 2 tomes. Paris, Inra éditions.

Aubertot J.-N., Barbier J-M., Carpentier A., Gril J.-J., Guichard P., Lucas P., Savary S., SAVini I., Voltz M., 2005. Pesticides, agriculture et environnement : réduire l'utilisation des pesticides et limiter leurs impacts environnementaux. Expertise scientifique collective, Paris/Antony, Inra/Cemagref.

Audiot A., 1995. Races d'hier pour l'élevage de demain. Versailles, Inra éditions, Collection Espaces ruraux.

Ayres R.U., Warr B., 2009. The Economic Growth Engine: How Energy and Work Drive Material Prosperity. Cheltenham/Northhampton, Edward Elgar. 
Aznar O., Guérin M., Perrier-Cornet P., 2007. Agriculture de services, services environnementaux et politiques publiques : éléments d'analyse économique. Revue d'économie régionale et urbaine, 4 , 573-587.

Baccini P., Brunner P.H., 1991. The Metabolism of the Anthroposphere. Berlin, Springer.

BAGCHI A.K., 2010. Colonialism and the Indian Economy. Oxford, Oxford University Press.

BaILEs K.E., 1977. Alexei Gastev and the Soviet Controversy over Taylorism. Soviet Studies, 29 (3), 373-394.

Bairoch P., 1985. The Main Trends in National Economic Disparities since the Industrial Revolution. In : Disparities in Economic Development since the Industrial Revolution (Bairoch P., LevyLeboyer M., dir.). Londres, Macmillan, 7-14.

Bairoch P., 1999. Mythes et paradoxes de l'histoire économique. Paris, La Découverte.

BAN C., 2013. Brazil's Liberal Neo-developmentalism: New Paradigm or Edited Orthodoxy? Review of International Political Economy, 20 (2), 298-331.

Ban C., Blyth M., 2013. The BRICS and the Washington Consensus: An Introduction. Review of International Political Economy, 20 (2), 241-255.

Banse M., Van Meisl H., Tabeau A., Woltjer G., Hellmann F., Verburg P.H., 2011. Impact of EU Biofuel Policies on World Agricultural Production and Land Use. Biomass and Bioenergy, 35 (6), 2385-2390.

BAQUÉ P. (dir.), 2012. La bio entre business et projet de société. Paris, Agone.

Barbera F., Audifredi S., 2012. In Pursuit of Quality: The Institutional Change of Wine Production Market in Piedmont. Sociologia Ruralis, 52 (3), 311-331.

Barbier E., 2011. Scarcity and Frontiers: How Economies Have Developed Through Natural Resource Exploitation. Cambridge/New York, Cambridge University Press.

Barbier R., Larrue C., 2011. Démocratie environnementale et territoires : un bilan d'étape. Participations, 1 (1), 67-103.

Barham E., 2002. Towards a Theory of Values-Based Labeling. Agriculture and Human Values, 19 (4), 349-360.

BARHAM E., 2003. Translating Terroir: The Global Challenge of French AOC Labeling. Journal of Rural Studies, 19 (1), 127-138.

BarnetT C., 2014. Geography and Ethics III from Moral Geographies to Geographies of Worth. Progress in Human Geography, 38 (1), 151-160.

BARON C., Isla A., 2006. Marchandisation de l'eau et conventions d'accessibilité à la ressource : le cas des métropoles d'Afrique sub-saharienne. In : L'économie des conventions : méthodes et résultats. Tome 2. Développements (Eymard-Duvernay F., dir.). La Découverte, Paris, 369-383.

Barrère C., Barthélemy D., Nieddu M., Vivien F.D., 2005. Réinventer le patrimoine : de la culture à l'économie, une nouvelle pensée du patrimoine ? Paris, L'Harmattan.

Barthélemy D., 2000. Être et avoir. Patrimoine versus capital : le cas de l'agriculture. Économie rurale, 260, 27-40.

Barthélemy D., 2007. Économie identitaire versus économie marchande. Économie appliquée, 60 (3), 57-84.

BARTHÉLEMy D., 2008. Présentation : positionnement. In : La multifonctionnalité de l'agriculture : une dialectique entre marché et identité (Groupe Polanyi). Versailles, Éditions Quæ, 1-10.

Barthélemy D., Boinon J.-P., Nieddu M., 2003. Le dualisme comportemental des agriculteurs : une interprétation institutionnaliste dialectique. Économie et institutions, 3, 118-150.

Barthélemy D., Nieddu M., 2002. PAC et multifonctionnalité de l'agriculture. Oléagineux, corps gras, lipides, 9 (6), 383-389.

Barthélemy D., Nieddu M., 2003. Multifonctionnalité agricole : biens non marchands ou biens identitaires ? Économie rurale, 273, 103-119.

Barthes R., 1957. Mythologies. Paris, Seuil.

BAtifoulier P. (dir.), 2001. Théorie des conventions. Paris, Economica.

BARToli P., 1985. La politique viticole, un exemple de régulation. In : Colloque franco-hongrois d'économie rurale, Versailles/Budapest, Inra/ESR.

Bartoli P., Boulet D., 1989. Dynamique et régulation de la sphère alimentaire, l'exemple viticole. thèse d'État en sciences économiques, Montpellier/Paris, Université Montpellier I/Inra ESR.

Bartoli P., Boulet D., 1990. Conditions d'une approche en termes de régulation sectorielle : le cas de la sphère viticole. Cahiers d'économie et de sociologie rurales, 17, 7-38. 
Bastioli C., 2008. Renewable Raw Materials and the Transition from a Product-based Economy to a System-based Economy. In : Conferral of her Honorary Degree in Industrial Chemistry by University of Genoa, 4 juillet, Gênes, Italie.

Bataille G., 1967. La part maudite, précédé de La notion de dépense. Paris, Éditions de Minuit.

BAUD G., 1999. Dynamique de la redistribution du foncier entre agriculteurs à l'échelle de petites régions. Ingénieries-EAT, 17, 47-p. 60.

Baud C., Durand C., 2011. Financialization, Globalization and the Making of Profits by Leading Retailers. Socio-Economic Review, 10 (2), 241-266.

BAYART J.-F., 2004. Le gouvernement du monde : une critique politique de la globalisation. Paris, Fayard.

Bayart J.-F., Mbembe A., Toulabor C., 1992. Le politique par le bas en Afrique noire : contribution à une problématique de la démocratie. Paris, Karthala, Collection Les Afriques.

Bayliss-Smith T., 1982. The Ecology of Agricultural Systems. Cambridge, Cambridge University Press.

Becker G., 1964. Human Capital: A Theoretical and Empirical Analysis. Chicago, University of Chicago Press.

BeCKert S., 2014. Empire of Cotton. Londres, Penguin/Allen Lane.

BECKer J., RAZA W., 2000. La théorie de la régulation et l'écologie politique : une séparation inévitable ? Économies et sociétés, 34 (1), 55-70.

Beinart W., Hughes L., 2007. Environment and Empire. Oxford, Oxford University Press.

Belesky P., 2014. Regional Governance, Food Security and Rice Reserves in East Asia. Global Food Security, 3 (3-4), 167-173.

Belletti G., Marescotti A., Touzard J.-M., 2015. Geographical Indications, Public Goods, and Sustainable Development: The Roles of Actors' Strategies and Public Policies. World Development, http://doi.org/10.1016/j.worlddev.2015.05.004 (consulté le 13 octobre 2016).

Berger S., 2003. Notre première mondialisation. Paris, Le Seuil.

Berkers E., Geels F.W., 2011. System Innovation through Stepwise Reconfiguration: the Case of Technological Transitions in Dutch Greenhouse Horticulture (1930-1980). Technology Analysis \& Strategic Management, 23 (3), 227-247.

Berkhout F., Smith A., Stirling A., 2004. Socio-technological Regimes and Transition Contexts. In : System Innovation and the Transition to Sustainability: Theory, Evidence and Policy (Elzen B., Geels F.W., Green K., dir.). Cheltenham, Edward Elgar, 48-75.

Bernstein H., 2014. Food Sovereignty via the "Peasant Way": A Skeptical View. The Journal of Peasant Studies, 41 (6), 1031-1063.

Bernstern H., 2016. Agrarian Political Economy and Modern World Capitalism: The Contributions of Food Regime Analysis. The Journal of Peasant Studies, 43 (3), 611-647.

BERRIET-SOLlieC M., 1999. Les interventions décentralisées en agriculture : essai sur la composante territoriale de la politique agricole. Paris, L'Harmattan.

Berriet-Solliec M., Déprés C., Trouvé A., 2008. La territorialisation de la politique agricole en France. Vers un renouvellement de l'intervention publique en agriculture ? In : Secteurs et territoires dans les régulations émergentes (Laurent C., du Tertre C., dir.). Paris, L'Harmattan, 121-136.

Berriet-Solliec M., Mouriaux M.-F., Delorme H., Mundler P., Laurent C., Perraud D., 2006. Régulation de l'agriculture : les régions comme nouveau lieu de mise en cohérence territoriale des politiques agricoles? La région Rhône-Alpes dans le contexte européen. Canadian Journal of Regional Science, 29 (1), 55-73.

Berthelot J., Galtier F., 2014. La conférence de Bali a-t-elle rendu licites les politiques de stockage aux yeux de l'OMC ? Économie rurale, 343, 103-110.

Bertrand H., 1980. Le régime central d'accumulation d'après-guerre en France et sa crise. Économie rurale, 138, 16-21.

Bertrand J.-P., Delorme H., 2007. Les régulations blé-soja sous le coup de la concurrence mondiale. In : La régulation des marchés agricoles internationaux, un enjeu décisif pour le développement (Boussard J.-M., Delorme H., dir.). Paris, L'Harmattan, 163-182.

Bertrand J.P., Laurent C., Leclerce V., 1985. Le monde du soja. Paris, La Découverte.

Bessin J., 2012. Maintien de la biodiversité animale domestique : pratiques paysannes et points de vue d'éleveurs sur les obstacles et leviers d'action dans les dispositifs de gestion des races animales. mémoire de fin d'étude d'ingénieur, Montpellier, SupAgro Montpellier. 
BESSIS F., 2008. Quelques convergences remarquables entre l'économie des conventions et la théorie de la régulation. Revue française de socio-économie, 1, 9-25.

BEsSON Y., 2011. Les fondateurs de l'agriculture biologique. Albert Howard, Rudolf Steiner, Maria \& Hans Müller, Hans Peter Rush, Masanobu Fukuoka. Paris, Le sang de la Terre.

Bessy C., Chauvin P.-M., 2013. The Power of Market Intermediaries: From Information to Valuation Processes. Valuation Studies, 1 (1), 83-117.

Bezemer D., Headey D., 2006. Something of a Paradox: The Neglect of Agriculture in Economic Development. Gold Coast, Australia, In : International Association of Agricultural Economists Conference, 12-18 août, Queensland (Australia).

Bianco A., Zellner W., 2003. Is Wal-Mart Too Powerful? Business Week, 6 octobre, 100-104, 106, 108,110 .

Biggart N.W., Beamish T.D., 2003. The Economic Sociology of Conventions: Habit, Custom, Practice, and Routine in Market Order. Annual Review of Sociology, 29, 443-464.

Billaud J.-P., 1994. Le projet de l'ingénieur des Ponts et chaussées au XIX ${ }^{\mathrm{e}}$ siècle : rationalité technique et intégration sociale. Techniques, territoires et sociétés, 27, 115-123.

Billaudot B., 2009. Les institutions dans la théorie de la régulation : une actualisation. Revue de la régulation, 6 (2), revue en ligne : http://regulation.revues.org/7632 (consulté le 3 mai 2016).

Biofrac, 2006. Biofuels in the European Union - A Vision for 2030 and Beyond. Bruxelles, Commission européenne.

BioMat Net, 2006. 1st International Biorefinery Workshop.

Blanchet P., Dreyfus F., 2013. Conseiller autrement l'utilisation des pesticides pour produire autrement. Conseil général de l'alimentation, de l'agriculture et des espaces ruraux, Rapport 13057, Paris, La documentation française.

Block F.L., 1977. The Origins of International Economic Disorder: A Study of United States International Monetary Policy from World War II to the Present. Berkeley, University of California Press.

Bцок A., 2013. Pragmatic Sociology as Political Ecology On the Many Worths of Nature(s). European Journal of Social Theory, 16 (4), 492-510.

BloK A., 2015. Attachment to the Common-place: Pragmatic Sociology and the Aesthetic Cosmopolitics of Eco-house Design in Kyoto, Japan. European Journal of Cultural and Political Sociology, 2 (2), 122-145.

Blok A., Meilvang M.L., 2015. Picturing Urban Green Attachments: Civic Activists Moving between Familiar and Public Engagements in the City. Sociology, 49 (1), 19-37.

Board of Trade, 1917. The Food Supply of the United Kingdom. Londres, His Majesty's Stationery Office, 35 .

Boichard D., Bonatti B., Barbat A., 1993. Effet du croisement Holstein sur les caractères laitiers en population Pie Noir. Inra Productions animales, 6 (1), 25-30.

Boichard D., Maignel L., Verrier E., 1996. Analyse généalogique des races bovines laitières françaises. Inra Productions animales, 9 (5), 323-335.

Bornon J.-P., 2011. Les politiques foncières agricoles en France depuis 1945. Économie et statistiques, 444-445, 19-37.

Boltanski L., 2011. On Critique: A Sociology of Emancipation. Cambridge, Polity Press.

Boltanski L., Chiapello E., 1999. Le nouvel esprit du capitalisme. Paris, Gallimard (traduction en anglais : 2005. The New Spirit of Capitalism. Londres, Verso).

Boltanski L., ThÉvenot L., 1991. De la justification : les économies de la grandeur. Paris, Gallimard (traduction en anglais : 2006. On Justification: Economies of Worth. Princeton, Princeton University Press).

Bonanno A., Busch L., 2015. The international Political Economy of Agriculture and Food: An Introduction. In : Handbook of the International Political Economy of Agriculture and Food (Bonanno A., Busch L., dir.). New York, Edward Elgar Publishing, 1-15.

Bonnaud L., Coppalle J., 2008. La production de la sécurité sanitaire au quotidien : l'inspection des services vétérinaires en abattoir. Sociologie du travail, 50, 15-30.

Bonnaud L., Joly N., 2012. L'alimentation sous contrôle : tracer, auditer, conseiller. Versailles/ Dijon, Éditions Quæ/Educagri éditions. Seuil.

Bonneuil C., Fressoz J.B., 2013. L'événement anthropocène : la Terre, l'histoire et nous. Paris, Le

Bonneuil J.C., Thomas F., 2009. Gènes, pouvoirs et profits : recherche publique et régimes de production des savoirs de Mendel aux OGM. Versailles, Éditions Quæ. 
Bork H.R., Bork H., Dalchow C., Faust B., Piorr H.-P., Schatz T., 1998. Landschaftsentwicklung in Mitteleuropa. Gotha/Stuttgart, Klett-Perthes.

Bosc P.M., Sourisseau J.M., Bonnal P., Gasselin P., Valette E., Bélières J.F. (dir.), 2014. Diversité des agricultures familiales : exister, se transformer, devenir. Versailles, Éditions Quæ.

Boserup E., 1965. The Conditions of Agricultural Growth. The Economics of Agrarian Change under Population Pressure. Chicago, Aldine/Earthscan.

Boserup E., 1981. Population and Technological Change: A Study of Long-term Trends. Chicago, The University of Chicago Press.

Bosque Maurel J., 1984. Del INC al IRYDA: Análisis de los resultados obtenidos por la política de colonización posterior a la guerra civil. Agricultura y sociedad, 32, 153-191.

Boucher R., CARON J., Galas J. (dir.), 2012. Un service public de proximité démantelé : la statistique agricole départementale. Paris, Non Lieu éditions.

Boulet D., Touzard J.-M., 1995. Filière, territoire et construction sociale de la qualité : l'exemple du marché du vin à la production. In : Séminaire "Qualification des produits et des territoires ", 2-3 octobre, Montpellier, Inra.

Bourdieu P., 1997. Méditations pascaliennes. Paris, Seuil.

Bourdieu P., 2000. Les structures sociales de l'économie. Paris, Le Seuil.

Bourguignon F., Morrisson C., 2002. Inequality among World Citizens: 1820-1992. The American Economic Review, 92 (4), 727-744.

Boussard J.-M., 1987. Économie de l'agriculture. Paris, Economica.

Boussard J.-M., Gérard F, Piketty M.-G., 2008. Pourquoi les prix agricoles augmentent-ils ? Oléagineux, corps gras, lipides, 15 (2), 81-87.

Boussard J.-M., GÉRARd F., PIKETty M.-G., 2013. Stabilisation des prix des céréales : avantages et coûts du stockage public. Paris, MAAF-CEP/Cirad, https://agritrop.cirad.fr/572788/1/document_572788.pdf (consulté le 19 octobre 2016).

BOYER R., 1986. La flexibilité du travail en Europe. Paris, La Découverte.

Boyer R., 1989. Histoire des techniques et théories économiques. Vers un nouveau programme de recherche. Cahiers du Cepremap, 8903, consulté à l'adresse suivante : http://www.cepremap.fr/ depot/couv_orange/co8908.pdf (consulté le 13 octobre 2016).

Boyer R., 1990. Les problèmes de la régulation face aux spécificités sectorielles. Cahiers d'économie et de sociologie rurales, 17, 39-76.

BOYER R., 2000. Is a Finance-led Growth Regime a Viable Alternative to Fordism? A Preliminary Analysis. Economy and Society, 29 (1), 111-145.

BOYen R., 2002. Aux origines de la théorie de la régulation. In : Théorie de la régulation : l'état des savoirs (Boyer R., Saillard Y., dir.). Paris, La Découverte, 21-30.

BOYER R., 2015. Économie politique des capitalismes : théorie de la régulation et des crises. Paris, La Découverte.

Boyer R., Chavance B., Godard O., 1991. Les figures de l'irréversibilité en économie. Paris, Éditions de l'EHESS.

Boyer R., Durand J.P., 1993. L'après-fordisme. Paris, Syros.

Boyer R., Saillard Y. (dir.), 1995. Théorie de la régulation : l'état des savoirs. Paris, La Découverte.

Boyer R., SAILlard Y., 2002. Un précis de la régulation. In: Théorie de la régulation : l'état des savoirs (Boyer R., Saillard Y., dir.). Paris, La Découverte, 58-68.

Bozell J.J., Petersen G.R., 2010. Technology Development for the Production of Biobased Products from Biorefinery Carbohydrates-the US Department of Energy's "Top 10" Revisited. Green Chemistry, 12 (4), 539-554.

BRAUdel F., 1979. Civilisation matérielle, économie et capitalisme, $x v^{e}$-XVIII siècle. Tome 3 : Le temps du monde. Paris, Armand Colin.

Brautigam D., 2009. The Dragon's Gift: The Real Story of China in Africa. Oxford, Oxford University Press.

Brenner R., Glick M., 1991. The Regulation Approach: Theory and History. New Left Review, $188,45-119$.

Breslin S., 2005. Power and Production: Rethinking China's Global Economic Role. Review of International Studies, 31 (4), 735-753.

BresLin S., 2011. The "China Model" and the Global Crisis: From Friedrich List to a Chinese Mode of Governance? International Affairs, 87 (6), 1323-1343. 
Breviglieri M., Stavo-Debauge J., 2006. Sous les conventions. Accompagnement social à l'insertion : entre sollicitude et sollicitation. In : L'économie des conventions : méthodes et résultats. Tome 2. Développements (Eymard-Duvernay F., dir.). Paris, La Découverte, 129-144.

Bricas N., 2008. Nourrir le monde : retour aux fondamentaux de l'humanité. Diplomatie, 33, 58-62. Press.

Brown S.A., 1997. Revolution at the Checkout Counter. Cambridge (Mass.), Harvard University

Brun A., 1986. Aspects macro-économiques de la pluriactivité des familles agricoles. Économie rurale, $71,38-47$.

Brunsson N., Jacobsson B. (dir.), 2000. A World of Standards. Oxford, Oxford University Press.

Buchanan J.M., 1968. The Demand and Supply of Public Goods. Chicago, Rand McNally.

Buchs A., 2010. La construction sociale de la pénurie en eau à Almeria (Andalousie) ou l'échec de la normalisation « hydrauliciste ». Économie appliquée, 63 (3), 5-39.

Buchs A., 2014. Comprendre le changement institutionnel. Régimes et crises du mode d'usage de l'eau en Espagne ( $\mathrm{xIX}^{\mathrm{e}}-\mathrm{xx}^{\mathrm{e}}$ siècles). Revue de la régulation, 16 (2), revue en ligne : http://regulation. revues.org/10925 (consulté le 3 mai 2016).

Buchs A., 2016. La pénurie en eau est-elle inéluctable ? Une approche institutionnaliste de l'évolution du mode d'usage de l'eau en Espagne et au Maroc. Bruxelles, Peter Lang.

Buck D., Getz C., Guthman J., 1997. From Farm to Table: The Organic Vegetable Commodity Chain of Northern California. Sociologia Ruralis, 37 (1), 3-20.

Buller H., 2004. The "espace productif", the "théâtre de la nature" and the "territoires de développement local": The Opposing Rationales of Contemporary French Rural Development Policy. International Planning Studies, 9 (2-3), 101-119.

Bunker S.G., 1985. Underdeveloping the Amazon: Extraction, Unequal Exchange, and the Failure of the Modern State. Chicago, University of Chicago Press.

Burch D., Lawrence G., 2005. Supermarket Own-brands, Supply Chains and the Transformation of the Agri-food System. International Journal of Agriculture and Food, 13 (1) 1-16.

Burch D., Lawrence G., 2009. Towards a Third Food Regime: Behind the Transformation. Agriculture and Human Values, 26 (4), 267-279.

Burch D., Lawrence G., 2013. Financialization in Agri-Food Supply Chains: Private Equity and the Transformation of the Retail Sector. Agriculture and Human Values, 30 (2), 247-258.

Busch L. 1992. Metatheories and Better Theories: A Reply to Ruttan. International Journal of the Sociology of Agriculture and Food, 2, 44-49.

Busch L., 2000. The Moral Economy of Grades and Standards. Journal of Rural Studies, 16 (3), 273-283.

Busch L., 2007. Performing the Economy, Performing Science: From Neoclassical to Supply Chain Models in the Agrifood Sector. Economy and Society, 36 (3), 439-468.

Busch L., 2011. Standards: Recipes for Reality. Cambridge (Mass.), MIT Press.

Busch L., Bain C., 2004. New! Improved? The Transformation of the Global Agrifood System. Rural Sociology, 69 (3), 321-346.

Busch L., Tanaka K., 1996. Rites of Passage: Constructing Quality in a Commodity Subsector. Science, Technology and Human Values, 21 (1), 3-27.

Butault J.-.P, Bureau J.-C., Witzke H.-P., Heckelei T., 2012. Comparative Analysis of Agricultural Support within the Major Agricultural Trading Nations. étude pour le European Parliament's Committee on Agriculture and Rural Development, Bruxelles, European Parliament.

Buttel F.H., 2001. Some Reflections on Late Twentieth Century Agrarian Political Economy. Sociologia Ruralis, 41 (2), 165-181.

Buxton A., Campanale M., Cotula L., 2012. Farms and Funds: Investment Funds in the Global Land Rush. IIED Briefings Papers, en ligne http://pubs.iied.org/17121IIED/ (consulté le 10 octobre 2016).

BYÉ P., 1997. Productive Inertia and Technical Change. Science Technology and Society, 2 (1), 131-150.

Cadilhon J., Millemann A., 2011. Les politiques publiques de stabilisation du marché du riz en Asie. Centre d'études et de prospective, 30, Paris, Ministère de l'Agriculture.

CAE (Commission des affaires économiques, Assemblée nationale), 2013. Compte rendu de la séance du 10 décembre 2013. $14^{\mathrm{e}}$ législature, Paris, Assemblée nationale.

CaIn P.J., Hopkins A.G., 1986. Gentlemanly Capitalism and British Expansion Overseas I. The Old Colonial System, 1688-1850. The Economic History Review, 39 (4), 501-525. 
CAirncross A.K., 1953. Home and Foreign Investment 1870-1913. Studies in Capital Accumulation. Cambridge, Cambridge University Press.

Callon M. (dir.), 1998. The Laws of the Markets. Oxford, Basil Blackwell.

Callon M., Lascoumes P., Barthe Y., 2001. Agir dans un monde incertain : essai sur la démocratie technique. Paris, Le Seuil, Collection La couleur des idées.

Callon M., Meadel C., Rabeharisoa V., 2000. L'économie des qualités. Politix, 13 (52), 211-239.

Callon M., Millo Y., Muniesa F. (dir.), 2007. Market Devices. Oxford, Blackwell.

Cambon S., 1996. Services d'eau potable : de la logique d'offre à la maîtrise de la demande. Comparaison France-États-Unis. La place des usagers dans la gestion durable des services d'alimentation en eau placés sous contrainte environnementale. thèse de doctorat en sciences et techniques de l'environnement, Paris, ENPC/Latts.

CAPMa (CONSEJERÍA de AGRicultura, PESCA y MEdio AmBIENTE), 2013. Cartografía de invernaderos en el litoral de Andalucía Oriental. Campaña 2012. Malaga, Junta de Andalucía, 21 p.

CARon J., Toyre M., 2012. Les services départementaux sacrifiés sur l'autel du moins d'État. In : Un service public de proximité démantelé : la statistique agricole départementale (Boucher R., Caron J., Galas J., dir.). Paris, Non lieu éditions, 120-131.

Cartwright M.S., Walker F.O., Blocker J.N., Schulz M.R., Arcury T.A., Grzywacz J.G., Mora D., Chen H., Marín A.J., Quandt S.A., 2012. The Prevalence of Carpal Tunnel Syndrome in Latino Poultry Processing Workers and Other Latino Manual Workers. Journal of Occupational and Environmental Medicine, 54 (2), 198-201.

CashierLive. 2015. Grocery Store Point-of-Sale. Chicago, CashierLive, https://www.cashierlive. com/ (consulté le 9 mai 2015).

CASTEl R., 2008. La propriété sociale : émergence, transformations et remise en cause. Esprit, 8-9, 171-190.

Castree N., Braun B. (dir.), 2001. Social Nature: Theory, Practice and Politics. Malden, Blackwell Publishers.

Catton W.R., 1982. Overshoot: The Ecological Basis of Revolutionary Change. Champaign, University of Illinois Press.

Cerf M., Lenoir D., 1987. Le développement agricole. Paris, Presses universitaires de France, Collection Que sais-je ?

Centemeri L., Renou G., 2015. Métabolisme social et langages de valuation : apports et limites de l'économie écologique de Joan Martinez-Alier à la compréhension des inégalités environnementales. Hal : https://hal.archives-ouvertes.fr/hal-01163219/document (consulté le 13 octobre 2016).

Chakrabarty D., 2014. Quelques failles dans la pensée du changement climatique. In : De l'univers clos au monde infini (Hache E., dir.). Paris, Dehors, 107-146.

Chanteau J.P., Coriat B., Labrousse A., Orsi F., 2013. Autour d'Ostrom : communs, droits de propriété et institutionnalisme méthodologique. Introduction. Revue de la régulation, 14 (2), revue en ligne : https://regulation.revues.org/10516 (consulté le 28 mai 2016).

Chase-Dunn C., Jorgenson A.K., Reifer T.E., Lio S., 2005. The Trajectory of the United States in the World-System: A Quantitative Reflection. Sociological Perspectives, 48 (2), 233-254.

Chastel J.-M., 1995. Le rôle des institutions dans l'évolution de la filière canne à sucre à la Réunion. thèse de doctorat, Montpellier, Ensam.

Chatellier V., Delattre F., Rat-Aspert O., 2006. Le prix du lait en Savoie et les filières fromagères AOC : principales évolutions passées et perspectives. Rapport final GIS Alpes Jura.

Chaumet J.-M., 2012. Idele Chine $n^{\circ}$ 1. La lettre de veille de l'économie de l'élevage en Chine. Paris, Institut de l'élevage.

Chaumet J.-M., 2013. Idele Chine $n^{\circ}$ 5. La lettre de veille de l'économie de l'élevage en Chine. Paris, Institut de l'élevage.

Chaumet J.-M., Pouch T., 2012. La Chine au risque de la dépendance alimentaire. Oléagineux, corps gras, lipides, 19 (5), 290-298.

Chen S., Wilson W.W., Larsen R., Dahl B., 2013. Investing in Agriculture as an Asset Class. Agribusiness and Applied Economics Report 711, Department of Agribusiness \& Applied Economics, Fargo, North Dakota State University.

Chester L., 2010. Determining the Economic-environment Relation: A Regulationist Approach. International Journal of Green Economics, 4 (1), 17-42. 
Chevassus-Lozza E., Gallezot J., Galliano D., 1999. Les déterminants des échanges internationaux intra-firme : le cas de l'agro-alimentaire français. Revue d'économie industrielle, 87 (1), 31-44.

Cheyns E., 2011. Multi-stakeholder Initiatives for Sustainable Agriculture: Limits of the "Inclusiveness" Paradigm. In : Governing through Standards: Origins, Drivers and Limitations (Ponte S., Gibbon P., Vestergaard J., dir.). Basingstoke, Palgrave Macmillan, 318-354.

Cheyns E., 2014. Making "Minority Voices" Heard in Transnational Roundtables: The Role of Local NGOs in Reintroducing Justice and Attachments. Agriculture and Human Values, 31 (3), 409-423.

Cheyns E., Daviron B., Duama M., Fouilleux E., Guéneau S., 2016. La normalisation du développement durable par les filières agricoles insérées dans les marchés internationaux. In : Développement durable et filières tropicales (Estelle B., Alain R., Denis L., dir.). Versailles, Éditions Quæ, 275-294.

Cheyns E., Risgaard L., 2014. Introduction to the Symposium: The Exercise of Power through Multi-stakeholder Initiatives for Sustainable Agriculture and its Inclusion and Exclusion Outcomes. Agriculture and Human Values, 31 (3), 409-423.

ChiaPello E., 2009. Le capitalisme et ses critiques. In : $4^{e}$ congrès du Riodd : la RSE, une nouvelle régulation du capitalisme, 25-27 juin, Lille, Riodd.

Chiapello E., 2015. Financialisation of Valuation. Human Studies, 38 (1), 13-35.

Chiffoleau Y., Dreyfus F., Touzard J.-M., 2008. Nouvelles figures des marchés agroalimentaires : apports croisés de la sociologie, de l'économie, et de la gestion. Versailles, Éditions Quæ.

Chu J.M., 2013. Creating a Zambian Breadbasket: "Land Grabs" and Foreign Investments in Agriculture in Mkushi District. LDPI Working Paper, 33, 27 p.

Ciccantell P., 2009. China's Economic Ascent and Japan's Raw Material Peripheries. In : China and the Transformation of Global Capitalism (Hung H.-F., dir.). Baltimore, Johns Hopkins University Press, 109-129.

Cidell J.L., Alberts H.C., 2006. Constructing Quality: The Multinational Histories of Chocolate. Geoforum, 37 (6), 999-1007.

Clapp J., 2014. Financialization, Distance and Global Food Politics. The Journal of Peasant Studies, $41(5), 1-18$.

Claquin P., Lemeillet A., Delgoulet E., 2015. Flexibiliser les politiques de soutien aux biocarburants : éclairages théoriques et expérience américaine. Notes et études socioéconomiques, 39, 131-164, consultable en ligne sur : http://agriculture.gouv.fr/notes-et-etudes-socio-economiquesndeg39 (consulté le 17 octobre 2016).

Clarimont S., 2006. Partager les eaux de l'Ebre : la presse régionale aragonaise contre les projets de transfert. Mélanges de la Casa de Velázquez, 36 (2), 149-170.

Clark G., 2007. A Farewell to Alms: A Brief Economic History of the World. Princeton/Oxford, Princeton University Press.

Сосноу F., 2002. Une sociologie du packaging ou l'âne de Buridan face au marché. Paris, Presses universitaires de France.

Cосноy F., 2004. La captation des publics entre dispositifs et dispositions, ou le petit Chaperon rouge revisité. In : La captation des publics (Cochoy F., dir.). Toulouse, Presses universitaires du Mirail, 11-68.

Сосноу F., 2011. "Market-things Inside": Insights from Progressive Grocer (United States, 19291959). In : Inside Marketing (Cayla J., Zwick D., dir.). Oxford, Oxford University Press, 58-86.

Сосноу F., 2015. Myriam's “Adverteasing”: On the Performative Power of Marketing Promises. Journal of Marketing Management, 31 (1-2), 123-140.

Cochoy F., Grandclément C., 2005. Publicizing Goldilocks' Choice at the Supermarket: The Political Work of Product Packs, Carts and Talk. In : Making Things Public: Atmospheres of Democracy (Latour B., Weibel P., dir.). Cambridge (Mass.), The MIT Press, 646-659.

Cochoy F., Le Daniel L., Crave J., 2006. Le grand chevron rouge et les 282 petits chevreaux, ou l'emballage des cigarettes comme dispositif de captation. Terrains et travaux, 11, 179-201.

Codron J.M., Sterns P., Busch L., 2000. Questions de normes agro-alimentaires dans le contexte de globalisation. Cahiers d'économie et sociologie rurales, 55-56, 45-51.

Coнn T.H., 1993. The Changing Role of the United States in the Global Agricultural Trade Regime. In : World Agriculture and the GATT (Avery W.P., dir.). Londres, Lynne Rienner Publishers, 17-39. 
Colin S., 2012. Le défi rural du « rêve chinois ». Hérodote, 150, 9-26.

Colleau J., Tanguy D., 1984. Modélisation de la diffusion des gènes Holstein à l'intérieur de la population bovine Pie Noir Française. Génétique sélection évolution, 16 (3), 335-354.

Colonna P., 2013. La chimie du végétal et les nouveaux synthons accessibles par les biotechnologies. L'actualité chimique, 375-376, 56-64.

Colonna P., Fournier S., Touzard J.-M., 2013. Food Systems. In : Food Systems Sustainability (Esnouf C., Russel M., Bricas N., dir.). Cambridge, Cambridge University Press, 69-100.

Colonna P., TAyeb J., Valceschini E., 2014. Les nouveaux usages de la biomasse. Le déméter 2015, 275-305.

Colson F., 2006. L’État et les conseillers agricoles. Des États généraux du développement aux CTE : les enjeux politiques de l'encadrement technique. In : Conseiller en agriculture (Rémy J., Brives H., Lémery B., dir.). Versailles/Dijon, Inra éditions/Educagri éditions, 59-69.

Commission européenne, 2012a. Innovating for Sustainable Growth: A Bioeconomy for Europe. COM (2012) 60 final, Bruxelles, Commission européenne.

Commission européEnNe, 2012b. Impact Assessment Accompanying the Document Proposal or a Directive of the European Parliament and of the Council Amending Directive 98/70/EC Relating to the Quality of Petrol and Diesel Fuels and Amending Directive 2009/28/EC on the Promotion of the Use of Energy from Renewable Source. Bruxelles, Commission européenne.

Commission européEnNe, 2012c. Stratégie d'innovation au service d'une croissance durable : une bioéconomie pour l'Europe. Communication de la commission au Parlement européen, au conseil, au comité économique et social européen et au comité des régions. Bruxelles, Commission européenne.

Commons J.R., 1924. Legal Foundations of Capitalism. New York, Macmillan.

Commons J.R., 1925a. Law and Economics. Yale Law Journal, 34 (4), 371-382.

Commons J.R., 1925b. Marx To-day: Capitalism and Socialism. republié In : Journal of Institutional Economics, 2009, 5 (1), 117-136.

Commons J.R., 1931. Institutional Economics. American Economic Review, 21, 648-657.

Commons J.R., 1934. Institutional Economics: Its Place in Political Economy. New York/New Brunswick, Macmillan/Transaction Publishers.

Commons J.R., 2005 [1934]. Institutional Economics: Its Place in Political Economy. New Brunswick, Transaction Publishers, $3^{\mathrm{e}}$ édition.

Compagnone C., Auricoste C., Lémery B., 2009. Conseil et développement en agriculture. Quelles nouvelles pratiques? Dijon/Versailles, Educagri éditions/Éditions Quæ.

Compagnone C., Goulet F., Labarthe P. (dir.), 2015. Conseil privé en agriculture : acteurs, pratiques et marché. Dijon/Versailles, Educagri éditions/Éditions Quæ.

Coombes B., Campbell H., 1998. Dependent Reproduction of Alternative Modes of Agriculture: Organic Farming in New Zealand. Sociologia Ruralis, 38 (2), 127-145.

Cooper A. F., Flemes D., 2013. Foreign Policy Strategies of Emerging Powers in a Multipolar World: An Introductory Review. Third World Quarterly Review, 34 (6), 943-62.

Coq-Huelva D., García-Brenes M.D., Sabuco-I-Cantó A., 2012. Commodity Chains, Quality Conventions and the Transformation of Agro-ecosystems: Olive Groves and Olive Oil Production in Two Andalusian Case Studies. European Urban and Regional Studies, 19 (1), 77-91.

CoRiat B., 1979. L'atelier et le chronomètre : essai sur le taylorisme, le fordisme et la production de masse. Paris, Christian Bourgois.

Coriat B., Weinstein O., 2004. Institutions, échanges et marchés. Revue d'économie industrielle, 107 (1), 37-62.

Costa J., 1911. Política hidráulica (misión social de los riegos en España). Madrid, Biblioteca J. Costa/Biblioteca virtual universal, http://www.biblioteca.org.ar (consulté le 3 mai 2016).

Cotterill R.W., 1999. Continuing Concentration in Food Industries Globally: Strategic Challenges to an Unstable Status Quo. Food Marketing Policy Center, Department of Agricultural and Resource Economics, Storrs, University of Connecticut.

Cotton. 1922. Sixty-Six to Eleven. Cotton, janvier, 144, 150.

Cotula L., Blackmore E., 2014. Understanding Agricultural Investment Chains: Lessons to Improve Governance. Rome/Londres, FAO/IIED.

Cotula L., Vermeulen S., Leonard R., Keeley J., 2009. Land Grab or Development Opportunity? Agricultural Investment and International Land Deals in Africa. rapport de recherche, Londres/Rome, IIED/FAO/IFAD. 
Couharde C., Geronimi V., Taranco A., 2012. Les hausses récentes des cours des matières premières traduisent-elles l'entrée dans un régime de prix plus élevés ? Revue Tiers Monde, 211, 13-34.

Coulomb P., Delorme H., 1984. L'agriculture française à l'heure de la croissance zéro. Économie rurale, $163(1), 41-46$.

Coulomb P., Delorme H., Hervieu B., Jollivet M., Lacombe P., 1990. Les agriculteurs et la politique. Paris, Presses de Sciences Po.

Courdier M., Moureaux S., Mugnier S., Gerard A., Gaillard C., Verrier E., 2012. Extension des races bovines Montbéliarde et Simmental dans l'Ouest de la France : motifs et enjeux pour les éleveurs. Paris, J3R.

Cox A., 1999. Power, Value and Supply Chain Management. Supply Chain Management: An International Journal, 4 (4), 167-175.

CRA (CAJA RURAl de Almería), 1997. Gestión del regadío en el campo de Dalías: las comunidades Sol y Arena y Sol-Poniente. Almeria, Caja rural de Almería.

Crafts N., 1985. British Economic Growth During the Industrial Revolution. Oxford, Oxford University Press.

CRANNEY J., 1996. Inra. 50 ans d'un organisme de recherche. Versailles, Inra éditions.

Crosby A.W., 1973. The Columbian Exchange: Biological and Cultural Consequences of 1492. Westport, Greenwood Press.

Crosby A.W., 1986. Ecological Imperialism: The Biological Expansion of Europe, 900-1900. Cambridge, Cambridge University Press.

Crosby A.W., 2006. Children of the Sun: A History of Humanity's Unappeasable Appetite For Energys. New York, W.W. Norton \& Company.

Crouzet F., 1980. Toward an Export Economy: British Exports During the Industrial Revolution. Explorations in Economic History, 17 (1), 48-93.

Crouzet F., 1990. Angleterre-Brésil, 1697-1850: un siècle et demi d'échanges commerciaux. Histoire, économie et société, 9 (2), 288-317.

Cuitó Sabaté R., Martínez R.P., García Peña A., del Horno J.M., 2006. La recuperación del acuífero del Campo de Dalías. In : III Congreso de ingeniería civil, territorio y medioambiente, "Agua, biodiversidad e ingeniería », 25-27 octobre, Saragosse.

Cunfer G., 2005. On the Great Plains: Agriculture and Environment. College Station (Texas), A\&M University Press.

Cusso X., Garrabou R., Tello E., 2006. Social Metabolism in an Agrarian Region of Catalonia (Spain) in 1860 to 1870: Flows, Energy Balance and Land Use. Ecological Economics, 58 (1), 49-65.

Cwiertka K.J., 2006. Modern Japanese Cuisine: Food, Power and National Identity. Londres, Reaktion Books.

DA Costa I., 2010. L'institutionnalisme de John Commons et les origines de l'État providence aux États-Unis. Revue interventions économiques, revue en ligne : https://interventionseconomiques. revues.org/1283 (consulté le 19 octobre 2016).

Daly H.E., Совв J.B., Совв C.W., 1994. For the Common Good: Redirecting the Economy Toward Community, the Environment, and a Sustainable Future. Boston, Beacon Press.

Daniel S., 2012. Situating Private Equity Capital in the Land Grab Debate. The Journal of Peasant Studies, 39 (3-4), 703-729.

Darby H.C., 1956. The Clearing of the Woodland in Europe. In : Man's Role in Changing the Face of the Earth (Thomas Jr. W.L., dir.). Chicago, The University of Chicago Press, 183-216.

Darnhofer I., Lindenthal T., Bartel-Kratochvil R., Zollitsch W., 2010. Conventionalisation of Organic Farming Practices: from Structural Criteria towards an Assessment Based on Organic Principles: A Review. Agronomy for Sustainable Development, 30 (1), 67-81.

Darwin J., 2009. The Empire Project: The Rise and Fall of the British World-System, 1830-1970. Cambridge, Cambridge University Press.

Dasgupta P., Davi P., 1994. Towards a New Economics of Science. Research Policy, 23 (5), 487-521.

David P.A., Greenstein S., 1990. The Economics of Compatibility Standard: An Introduction to Recent Research. Economics of Innovation and New Technology, 1 (1-2), 3-41.

Daviron B., 2008. The Historical Integration of Africa in International Food Trade: A Food Regime Perspective. Globalization and Restructuring of African Commodity Flows (Fold N., Larson M., dir.). Uppsala, Nordika Afrikain Institutet, 44-79. 
Daviron B., 2014. Turning Organic Economies into Mineral Economies: Two Centuries of Oils and Fats Use and Supply in France. In : European Social Science History Conference, 23-26 avril, Vienne, ESSHC.

Daviron B., Doulllet M., 2013. Major Players of the International Food Trade and the World Food Security. Wageningen, LEI Wageningen UR.

Daviron B., Ponte S., 2005. The Coffee Paradox: Global Markets, Commodity Trade and the Elusive Promise of Development. Londres, Zed Books.

Daviron B., Vagneron I., 2012. Standards, risques et confiance dans le commerce à longue distance à destination de l'Europe : une lecture historique à partir de Giddens. In : Normaliser au nom du développement durable (Alphandery P., Djama M., Fortier A., Fouilleux E., dir.). Versailles, Éditions Quæ, 25-41.

Daviron B., Voituriez T., 2006. Quelle régulation des échanges agricoles internationaux ? Un éclairage par la théorie des régimes. In : La question politique en économie internationale (Berthaud P., Kebadjian G., dir.). Paris, La Découverte, 110-123.

Davis R., 1979. The Industrial Revolution and British Overseas Trade. Leicester, Leicester University Press.

Davis M., 2003. Génocides tropicaux. Catastrophes naturelles et famines coloniales : aux origines du sous-développement. Paris, La Découverte.

Davydova I., Franks J.R., 2006. Responses to Agrarian Reforms in Russia: Evidence from Novosibirsk Oblast. Journal of Rural Studies, 22 (1), 39-54.

Dawe D., Timmer P., 2012. Why Stable Food Prices Are a Good Thing: Lessons from Stabilizing Rice Price in Asia. Global Food Security, 1 (2), 127-133.

DeAne P., Cole W.A., 1967. British Economic Growth 1688-1959: Trends and Structure. Cambridge, Cambridge University Press.

Debailleul G., 1990. Évolution de la politique agricole américaine. thèse de docteur ingénieur, Paris, Inap-G.

DEBREF R., 2014. Le processus d'innovation environnementale face à ses contradictions : le cas du secteur des revêtements de sol résilients. thèse de doctorat en sciences économiques, Reims, Université de Reims-Champagne-Ardenne.

De Decker K., 2015. Medieval Smokestacks: Fossil Fuels in Pre-industrial Times. Low-Tech Magazine, consultable en ligne : http://www.lowtechmagazine.com/2011/09/peat-and-coal-fossil-fuelsin-pre-industrial-times.html (consulté le 16 novembre 2016).

Defalvard H., 1993. La méthodologie en sciences sociales : apport et limite de l'économie des conventions. Problèmes économiques, 2308, 1-7.

Deffeyes K.S., 2001. Hubbert's Peak, the Impending World Oil Shortage. Princeton, Princeton University Press.

Deffontaines G., 2013. Extension du domaine de la finance ? Partenariats public-privé (PPP) et « financiarisation » de la commande publique. Thèse de doctorat en sociologie, Université Paris-Est.

de Haen H. 2001. Première réunion d'experts sur la documentation et l'évaluation des rôles de l'agriculture dans les pays en développement. 19-21 mars, Rome, Projet ROA Publication No. 1, 1-4

Delgado Cabeza M., Aragón Mejías M.A., 2006. Los campos andaluces en la globalización. Almería y Huelva, fábricas de hortalizas, In : La agricultura española en la era de la globalización (Miren E., dir.). Madrid, Mapa, 424-474.

Delord B., Lacombe P., Touzard J.-M., 2000. Agricultural Systems and Agricultural Policy. In : Research on Agricultural Systems: Accomplishments, Perspectives and Issues (Colin J.P., Crawford E., dir.). Huntington (New York), Nova Science Publishers.

Delorme H., 2002. Vers une politique agricole commune multifontionnelle? Paris, Presses de Sciences Po.

DE los Llanos C., 1990. L'Andalousie dans l'Europe : l'essor du secteur fruitier et maraîcher. Madrid, Publications de la Casa de Velázquez.

Denis B., 2010. Races bovines : histoire, aptitudes, situation actuelle. Riaucourt, Castor \& Pollux.

Departament Prodovol'stvennyh resursov goroda Moscva, 2008. Moscow Food Security: Figures and Facts. Moscou, Departament Prodovol'stvennyh resursov goroda Moscva.

de Raymond A.B., 2013. En toute saison : le marché des fruits et légumes en France. Rennes, Presses universitaires de Rennes. 
Dervillé M., 2012. Territorialisation du secteur laitier et régimes de concurrence : le cas des montagnes françaises et de leur adaptation à l'après-quota. thèse de doctorat en sciences économiques et sociales, Paris, AgroParisTech.

Dervillé M., Allaire G., 2014a. Change of Competition Regime and Regional Innovative Capacities: Evidence from Dairy Restructuring in France. Food Policy, 49 (1), 347-360.

Dervillé M., Allaire G., 2014b. Quelles perspectives pour les filières laitières de montagne après la suppression des quotas laitiers ? Une approche en termes de régime de concurrence. Inra Productions animales, 27 (1), 17-30.

DE Schutter O., 2010. Rapport du Rapporteur spécial sur le droit à l'alimentation. New York, Nations Unies, consultable en ligne : http://www2.ohchr.org/english/issues/food/docs/A.HRC.16.49_ fr.pdf (consulté le 19 octobre 2016).

Desrosières A. 2008. La statistique, outil de gouvernement et outil de preuve. In : Pour une sociologie historique de la quantification (Desrosières A.). Paris, Presses de l'École des mines, 7-19.

Desrosières A., Mairesse J., Volle M., 1976. Les temps forts de l'histoire de la statistique française. Économie et statistique, 83, 19-28.

Devienne S., Bazin G., Charvet J.-P., 2005. Politique agricole et agriculture aux États-Unis : évolution et enjeux actuels. Annales de géographie, 641, 3-26.

de VRIes J., van der Woude A., 1997. The First Modern Economy: Success, Failure, and Perseverance of the Dutch Economy, 1500-1815. Cambridge, Cambridge University Press.

De Wit J., Verhoog H., 2007. Organic Values and the Conventionalization of Organic Agriculture. NJAS - Wageningen Journal of Life Sciences, 54 (4), 449-462.

DG Research, 2005A. New Perspectives on the Knowledge-Based Bio-Economy: Conference Report. Bruxelles, DG-Research, Commission of the European Communities.

DG ResEARCh/FAFB 2006. FP7 Theme 2: Food, Agriculture, Fisheries and Biotechnology. 2007 Work Programme.

DG Research/FAFB, 2011. FP7 Theme 2: Food, Agriculture, Fisheries and Biotechnology. 2012 Work Programme.

Diamond J.M., 2005. Collapse: How Societies Choose to Fail or Succeed. New York, Viking.

Diaz-Bone R., 2011. The Methodological Standpoint of the "économie des conventions". Historical Social Research/Historische Sozialforschung, 36 (4), 43-63.

Diaz-Bone R., 2012. Elaborating the Conceptual Difference between Conventions and Institutions. Historical Social Research, 37 (4), 64-75.

Diaz-Bone R., 2013. Discourse Conventions in the Construction of Wine Qualities in the Wine Market. Economic Sociology: European Electronic Newsletter, 14 (2), 46-53.

Diaz-Bone R., Salais R., 2011. Economics of Convention and the History of Economies. Towards a Transdisciplinary Approach in Economic History. Historical Social Research/Historische Sozialforschung, 36 (4), 7-39.

Dietrich M., 1994. Transaction Cost Economics and Beyond: Toward a New Economics of the Firm. Londres, Routledge.

Dixon M., 2013. The Land Grab, Finance Capital, and Food Regime Restructuring: The Case of Egypt. Review of African Political Economy, 41 (140), 232-248.

Dodier N., 2005. L'espace et le mouvement du sens critique. Annales. Histoire, sciences sociales, 60 (1), 7-31.

Donaldson J.L., 2005. Directory of National Accreditation Bodies. Gaithersburg (MD), National Institute of Standards and Technology.

Dore R., 1959. Land Reform in Japan. Oxford, Oxford University Press.

Dore R., 1978. Shinohata: Portrait of a Japanese Village. Londres, Allen Lane \& Pantheon.

Dosi G., Coriat B., 1995. Évolutionnisme et régulation : divergences et convergences. In : Théorie de la régulation : l'état des savoirs (Boyer R., Saillard Y., dir.). Paris, La Découverte, 500-510.

Dostaler G., Maris B., 2009. Capitalisme et pulsion de mort. Paris, Albin Michel.

Douai A., Montalban M., 2012. Institutions and the Environment: The Case for a Political SocioEconomy of Environmental Conflicts. Cambridge Journal of Economics, 36 (5), 1199-1220.

Dries L., Reardon T., van Kerckhove E., 2007. The Impact of Retail Investments in the Czech Republic, Slovakia, Poland and the Russian Federation. In : Global Supply Chains, Standards and the Poor: How the Globalization of Food Systems and Standards Affects Rural Development and Poverty (Swinnen J.F.M., dir.). Cambridge (Mass.), Cabi, 228-240. 
Drummond I., Marsden T., 1995. Regulating Sustainable Development. Global Environmental Change, 5 (1), 51-63.

Ducastel A., Anseeuw W., 2011. La libéralisation agricole post-apartheid en Afrique du Sud : nouveaux modèles de production et d'investissement. Afrique contemporaine, 237, 57-70.

Ducastel A., Anseeuw W., 2014. The Financialisation of South African Grain Cooperatives. What Room for the Agrarian Capital? In : 5th Annual Conference of the International Initiative for the Promotion of Political Economy "The Crisis: Scholarship, Policies, Conflicts and Alternatives", 16-18 septembre, Naples, IIPPE.

Ducastel A., Anseeuw W., 2015. Agriculture as an Asset Class: Reshaping the South African Farming Sector. Agriculture and Human Values, à paraître, 1-11, doi : http://dx.doi.org/10.1007/s10460016-9683-6 (consulté le 10 octobre 2016).

Duchâtel M., 2013. La politique étrangère de la Chine sous Xi Jinping. Hérodote, 150, 172-190.

du Gay P., Morgan G. (dir.), New Spirits of Capitalism? Crises, Justifications, and Dynamics. Oxford, Oxford University Press, 2013.

Dumont R., 1957. Révolution dans les campagnes chinoises. Politique étrangère, 22 (2), 187-202.

Dumont R., 1964. Les communes populaires rurales chinoises. Politique étrangère, 29 (4), 380-397.

Dupuy J.-P., Eymard-Duvernay F., Favereau O., Orléan A., Salais R., Thévenot L., 1989. Introduction. Revue économique, dossier L'économie des conventions, 40 (2), 141-145.

DuRAND C., 2014. Le capital fictif : comment la finance s'approprie notre avenir. Paris, Les prairies ordinaires.

Durand C., Cahen-Fourot L., 2016. La transformation de la relation sociale à l'énergie du fordisme au capitalisme néolibéral. Une exploration empirique et macro-économique comparée dans les pays riches (1950-2010). Revue de la régulation, 2.

Durand C., LéGé P., 2012. Regulation Beyond Growth. Capital \& Class, 37 (1), 111-126.

Duroselle M., 1980. La Holstein, miracle ou mirage? Puylaurens, M. Duroselle.

DU TERTRE C., 2002. Activités immatérielles et relationnelles : quels nouveaux enjeux de régulation pour les secteurs et les territoires ? Géographie économie société, 4 (2), 181-204.

EIA, 2010. International Energy Outlook 2010. Washington D. C., Energy Information Administration, Department of Energy (DOE).

EkBia H.R., Evans T.P., 2009. Regimes of Information: Land Use, Management, and Policy. The Information Society, 25 (5), 328-343.

Eквог J.M., 2003. Research and Technology Policies in Innovation Systems: Zero Tillage in Brazil. Research Policy, 32 (4), 573-86.

ELy R.T., 1914. Property and Contract in their Relations to the Distribution of Wealth, tome 1. New York, Macmillan.

Epoвio, 2006. Realising the Economic Potential of Sustainable Resources: Bioproducts from Nonfood Crops. Outputs from the Epobio Workshop « Products from Plants - The Biorefinery Future », Wageningen, Epobio.

EpsteIn G.A., 2005. Financialization and the World Economy. Northampton (Mass.), Edward Elgar Publishing.

Espagne C., 2014. La différenciation au sein des produits issus de l'agriculture biologique en France : standard public et standards privés. rapport de stage, Paris, AgroParisTech : https://esrcarto. supagro.inra.fr/intranet/carto_joomla/index.php/l-equipe-odr/menu-odr-theses (consulté le 4 octobre 2016).

European Commission, 2015. Systèmes de certification de la qualité des denrées alimentaires. Agriculture et développement rural, Bruxelles, European Commission.

European Council, 2000. Presidency Conclusions, 23-24 mars, Lisbonne, Lisbon European Council.

Ewald F., 1986. L'État providence. Paris, Grasset.

Eymard-Duvernay F., 1989. Conventions de qualité et formes de coordination. Revue économique, 40 (2), 329-359.

Eymard-Duvernay F., 1994. Coordination des échanges de l'entreprise et qualité des biens. In : Analyse économique des conventions (Orléan A., dir.). Paris, Presses universitaires de France, 307-334.

Eymard-Duvernay F., 1995. La négociation de la qualité. In : Agro-alimentaire : une économie de la qualité (Nicolas F., Valceschini E., dir.). Versailles/Paris, Inra éditions/Economica. 
Eymard-Duvernay F. (dir.), 2006a. L'économie des conventions : méthodes et résultats. Tome 1. Débats. Paris, La Découverte.

Eymard-Duvernay F. (dir.), 2006b. L'économie des conventions : méthodes et résultats. Tome 2. Développements. Paris, La Découverte.

Eymard-Duvernay F., Favereau O., Orléan A., Salais R., Thévenot L., 2006. Valeurs, coordination et rationalité : trois thèmes mis en relation par l'économie des conventions. In : L'économie des conventions : méthodes et résultats. Tome 1. Débats (Eymard-Duvernay F., dir.). La Découverte, Paris, 23-44.

FAIRbairn M., 2014. "Like Gold with Yield": Evolving Intersections between Farmland and Finance. The Journal of Peasant Studies, 41 (5), 777-795.

FAO, 2012. World Agriculture towards 2030/2050: The 2012 Revision. Rome, FAO, Agricultural Development Economics Division.

Faria N.R., Rambaut A., Suchard M.A., Baele G., Bedford T., Ward M.J., Tatem A.J., Sousa J.D., Arinaminpathy N., Pépin J., Posada D., Peeters M., Pybus O.G., Lemey P., 2014. The Hidden History of HIV-1: Establishment and Early Spread of the AIDS Pandemic. Science, 346, 56-61.

Farooki M., Kaplinsky R., 2013. The Impact of China on Global Commodity Prices: The Global Reshaping of the Resource Sector. Londres, Routledge.

FAVEREAu O., 1989. Marchés internes, marchés externes. Revue économique, 40 (2), 273-328.

FAVEREAU O., 1994. Règle, organisation et apprentissage collectif : un paradigme non standard pour trois théories hétérodoxes. In : Analyse économique des conventions (Orléan A., dir.). Paris, Presses universitaires de France, 113-137.

Favereau O., 1999. Salaire, emploi et économie des conventions. Cahiers d'économie politique, 34, 163-194.

Favereau O., Biencourt O., Eymard-Duvernay F., 2002. Where Do Markets Come From? From (Quality) Conventions! In : Conventions and Structures in Economic Organization: Markets, Networks and Hierarchies (Favereau O., Lazega E., dir.). Cheltenham, Edward Elgar, 253-282.

Favereau O., Thévenot L., 1991. Réflexion sur une notion d'équilibre utilisable dans une économie de marchés et d'organisations. ronéo, Paris, Ermes/EHESS, 40 p.

Federowicz M., 2000. Anticipated Institutions: The Power Of Path-Finding Expectations. In : Democratic and Capitalist Transitions in Eastern Europe: Lessons for the Social Science (Dobry M., dir.). Dordrecht, Kluwer Academic Publishers, 91-106.

Ferguson N., 2004. Empire: How Britain Made the Modern World. Londres, Penguin.

Fernández Lavandera O., Pizarro Checa A., 1981. Almería: la técnica del "enarenado" transforma un desierto. Revista de estudios agrosociales, 115, 31-70.

Ferretti M.P., 2007. Why Public Participation in Risk Regulation? The Case of Authorizing GMO Products in the European Union. Science as Culture, 16 (4), 377-395.

Fèvre C., Pouch T., 2013. L'affirmation des multinationales de l'agroalimentaire des pays émergents : le cas des firmes brésiliennes de la viande. Économie rurale, 334, 85-98.

Fischer-Kowalski M., 1998. Society's Metabolism. The Intellectual History of Material Flow Analysis, Part I: 1860-1970. Journal of Industrial Ecology, 2 (1), 61-78.

Fischer-Kowalski M., Haberl H., 1993. Metabolism and Colonization: Modes of Production and the Physical Exchange Between Societies and Nature. Innovation: The European Journal of Social Science Research, 6 (4), 415-442.

Fischer-Kowalski M., Haberl H., 1997a. Stoffwechsel und Kolonisierung: Konzepte zur Beschreibung des Verhältnisses von Gesellschaft und Natur. In : Gesellschaftlicher Stoffwechsel und Kolonisierung von Natur (Fischer-Kowalski M., Haberl H., Hüttler W., Payer H., Schandl H., Winiwarter V., Zangerl-Weisz H., dir.). Amsterdam, Gordon \& Breach Fakultas, 3-12.

Fischer-Kowalski M., Haberl H., 1997b. Tons, Joules and Money: Modes of Production and their Sustainability Problems. Society \& Natural Resources, 10, 61-85.

Fischer-Kowalski M., Haberl H., 1998. Sustainable Development: Socio-economic Metabolism and Colonization of Nature. International Social Science Journal, 50 (158), 573-587.

Fischer-Kowalski M., Krausmann F., Pallua I., 2014. A Sociometabolic Reading of the Anthropocene: Modes of Subsistence, Population Size and Human Impact on Earth. The Anthropocene Review, 1 (1), 8-33.

Fine B., 2012. La financiarisation en perspective. Actuel Marx, 51, 73-85.

Flamant J.-C., 2011. La sélection génomique : entre promesses et interrogations. Mission Agrobiosciences. 
Fligstein N., 1996. Markets as Politics: A Political Cultural Approach to Market Institutions. American Sociological Review, 61 (4), 656-673.

FonTe M, 2013. Reflexive Localism: Toward a Theoretical Foundation of an Integrative Food Politics. International Journal of the Sociology of Agriculture and Food, 10 (3), 397-402.

Food FOR LIFE, 2005. European Technology Platform Food for Life: Vision for 2020 and Beyond. Bruxelles, CIAA.

Food For Life, 2007. European Technology Platform Food for Life: Strategic Research Agenda. Bruxelles, CIAA.

FoOD FOR Life, 2008. European Technology Platform Food for Life: Implementation Action Plan. Bruxelles, CIAA.

Foster J.B., Clarck B., 2009. Ecological Imperialism and the Global Metabolic Rift: Unequal Exchange and the Guano/Nitrates Trade. International Journal of Comparative Sociology, 50 (3-4), 311-334.

Foster J.B., Clark B., York R., 2010. The Ecological Rift. Capitalism War on the Earth. New York, Monthly Review Press.

Foster J.B., Holleman H., 2014. The Theory of Unequal Ecological Exchange: A Marx-Odum Dialectic. The Journal of Peasant Studies, 41 (2), 199-233.

Fouilleux E., 2003. La politique agricole commune et ses réformes : une politique à l'épreuve de la globalisation. Paris, L'Harmattan.

Fouilleux E., 2008. Les politiques agricoles et alimentaires. In : Politiques publiques : la France dans la gouvernance européenne (Borraz O., Guiraudon V., dir.). Paris, Les Presses de Sciences Po, 113-146.

Fouilleux E., 2010. Standards volontaires : entre internationalisation et privatisation des politiques agricoles. In : Les mondes agricoles en politique : de la fin des paysans au retour de la question agricole (Mayer N., Hervieu B., Muller P., Purseigle F., Rémy J., dir.). Paris, Presses de Sciences Po, 371-396.

Fouilleux E, Loconto A., 2014. Du projet politique alternatif à la multiplication de services et de marchés. Les trajectoires régulatrices de l'agriculture biologique. In : Colloque Renouveler les approches institutionnalistes sur l'agriculture et l'alimentation : La "grande transformation » 20 ans après, 16-17 juin, Montpellier, Montpellier SupAgro.

Fouilleux E., Loconto A., 2016. Voluntary Standards, Certification and Accreditation in the Global Organic Agriculture Field. A Tripartite Model of Techno-politics. Agriculture and Human Values, DOI: 10.1007/s10460-016-9686-3.

Foureault F., 2014. Remodeler le capitalisme. Le jeu profond du Leverage Buy-Out en France, 2001-2009. thèse de doctorat en sociologie, Paris, Institut d'études politiques de Paris.

Fourquet F., 1980. Les comptes de la puissance. Histoire de la comptabilité nationale. Paris, Éditions Recherches.

Francks P., 1999. Japanese Economic Development: Theory and Practice. Londres, Routledge, 2 édition.

Frank A.G., 2006. Entropy Generation and Displacement. In : The World System and the Earth System (Hornborg A., Crumley C., dir.). Walnut Creek (California), Left Coast Press, 303-316.

Freibauer A., Mathiss E., Brunori G., Damianova Z., Faroult E., Gomis J.G., O'Brien L., Treyer S., 2011. Sustainable Food Consumption and Production in a Resource-constrained World. The 3rd SCAR (European Commission-Standing Committee on Agricultural Research) Foresight Exercise. Bruxelles, SCAR.

Freidberg S., 2003. Culture, Conventions and Colonial Constructs of Rurality in South-North Horticultural Trades. Journal of Rural Studies, 19 (1), 97-109.

Freidberg S., 2004. French Beans and Food Scares: Culture and Commerce in an Anxious Age. New York, Oxford University Press.

French S., Leyshon A., Wainwright T., 2011. Financializing Space, Spacing Financialization. Progress in Human Geography, 35 (6), 798-819.

Freund P., Martin G.T., 1993. The Ecology of the Automobile. Montréal, Black Rose Publishing.

Friedland W.H., Barton A., 1975. Destalking the Wily Tomato. Research Monograph No. 15, Department of Applied Behavioral Sciences, Davis, University of California.

Friedland R., Mohr J., Roose H., Gardinali P., 2014. The Institutional Logics of Love: Measuring Intimate Life. Theory and Society, 43 (3-4), 333-370. 
Friedmann H., 1978. World Market, State, and Family Farm: Social Bases of Household Production in the Era of Wage Labour. Comparative Studies in Society and History, 20 (4), 545-586.

Friedmann H., 1993. The Political Economy of Food: A Global Crisis. New Left Review, 1 (197), 29-57.

Friedman M., 2002 [1962]. Capitalism and Freedom. Chicago, University of Chicago Press.

Friedmann H., 2005a. From Colonialism to Green Capitalism: Social Movements and the Emergence of Food Regimes. In : New Directions in the Sociology of Global Development (Buttel F.H., McMichael P., dir.). Amsterdam, Elsevier, 229-267.

Friedmann H., 2005b. From Colonialism to Green Capitalism: Social Movements and Emergence of Food Regimes. Research in Rural Sociology and Development, 11, 227-264.

Friedmann H., 2009. Discussion: Moving Food Regimes Forward: Reflections on Symposium. Agricultural and Human Values, 26, 335-334.

Friedmann H., 2016. Commentary: Food Regime Analysis and Agrarian Questions: Widening the Conversation. The Journal of Peasant Studies, 43 (3), 671-692.

Friedmann H., Daviron B., Allaire G., 2016. Entretien avec Harriet Friedmann : « Political economists have been blinded by the apparent marginalization of land and food ». Revue de la régulation, 2 .

Friedmann H., McMichael P., 1989. Agriculture and the State System: The Rise and Decline of National Agricultures, 1870 to the Present. Sociologia Ruralis, 39 (2), 93-117.

Frischmann B.M., 2013. Two Enduring Lessons from Elinor Ostrom. Journal of Institutional Economics, 9 (4), 387-406.

Frontard R., 1994. Histoire de la norme. Culture technique, 29, 18-27.

Froud J., Sukhdev J., Williams K., 2002. Financialisation and the Coupon Pool. Capital \& Class, $26(3), 119-151$.

Funutake T., 1989. The Japanese Social Structure: Its Evolution in the Modern Century. Tokyo, University of Tokyo Press, $2^{\mathrm{e}}$ édition.

FulPoni L., 2006. Private Voluntary Standards in the Food System: The Perspective of Major Food Retailers in OECD Countries. Food Policy, 31 (1), 1-13.

FUNDACIÓN CAJAMAR, 2011-2013. Informes y monografías. Análisis de la campaña hortofrutícola de Almería. en ligne : http://www.publicacionescajamar.es (consulté le 3 mai 2016).

Galas J., 1997. Cinquante ans de statistique agricole. Courrier des statistiques, 83-84, 9-12.

Gale F., 2013. Growth and Evolution in China's Agricultural Support Policies. USDA-ERS Economic Research Report, 153, Washington D. C., USDA-ERS.

Gallezot P., 2010. Alternative Value Chains for Biomass Conversion to Chemicals. Topics in Catalysis, 53 (15), 1209-1213.

Galloway J.N., Townsend A.R., Erisman J.W., Bekunda M., Cai Z., Cai J., Freney L.A., Martinelli S.P., Seitzinger M., Sutton A., 2008. Transformation of the Nitrogen Cycle: Recent Trends, Questions and Potential Solutions. Science, 320 (5878), 889-892.

Galtier F., 2012. Gérer l'instabilité des prix alimentaires dans les pays en développement. Paris, Agence française de développement.

Garcia-PARPET M.-F., 2007. The Social Construction of a Perfect Market: The Strawberry Auction at Fontaines-en-Sologne. In : Do Economists Make Markets? On the Performativity of Economics (MacKenzie D., Muniesa F., Siu L., dir.). Princeton, Princeton University Press, 20-53.

Garcia Parpet M.-F., 2012. Le marché des certificateurs de l'agriculture biologique. In : L'alimentation sous contrôle : tracer, auditer, conseiller (Bonnaud L., Joly N., dir.). Dijon/Versailles, Educagri éditions/Éditions Quæ, 109-123.

García ToRrente R., 2005. El sector agrario. In : La economía de la provincia de Almería (Molina Herrera J., dir.). Almeria, Instituto Cajamar, 153-208.

Gaviria C., 2011. The Post-War International Food Order: The Case of Agriculture in Colombia. Lecturas de Economia, 74, 119-150.

GeELs F.W., 2002. Technological Transitions as Evolutionary Reconfiguration Processes: A Multi-level Perspective and a Case-study. Research Policy, 31 (8), 1257-1274.

Geels F.W., 2004. From Sectoral Systems of Innovation to Socio-technical Systems. Research Policy, 33 (6-7), 897-920.

Geels F.W., 2010. Ontologies, Socio-technical Transitions (to Sustainability), and the Multi-level Perspective. Research Policy, 39 (4), 495-510. 
Geiger S., Harrison D., KJellberg H., Mallard A. (dir.), 2015. Concerned Markets: Economic Ordering for Multiple Values. Cheltenham, Edward Elgar.

Genieys W., Smith A., 2001. Idées et intégration européenne : « la grande transformation » du midi viticole. Politique européenne, 1, 43-62.

Genus A., Coles A.-M., 2008. Rethinking the Multi-level Perspective of Technological Transitions. Research Policy, 37 (9), 1436-1445.

Georgescu-Roegen N., 1971. The Entropy Law and the Economic Process. Cambridge (Mass.), Harvard University Press.

Georgescu-Roegen N., 1975. Energy and Economic Myths. Southern Economic Journal, 41 (3), 347-381.

Gérard F, Piketty M.-G., Boussard J.-M., 2008. Analyse de l'impact de scénarios de libéralisation des échanges agricoles internationaux à partir $d u$ modèle ID3. Paris/Montpellier, Ministère de l'Agriculture/Cirad, consultable en ligne sur : http://agriculture.gouv.fr/ministere/analyse-de-limpactde-scenarios-de-liberalisation-des-echanges-agricoles-internationaux (consulté le 19 octobre 2016).

Gerbaux F., Muller P., 1984. La naissance du développement agricole en France. Économie rurale, $159,17-22$.

Gereffi G., Garcia-Johnson R., Sasser E., 2001. The NGO-Industrial Complex. Foreign Relations, 125 : 56-65.

Gereffi G., Humphrey J., Sturgeon T., 2005. The Governance of Global Value Chains. Review of International Political Economy, 12 (1), 78-104.

Gerschenkron A., 1989 [1943]. Bread and Democracy in Germany. Ithaca (New York), Cornell University Press.

Gervais M., Jollivet M., Tavernier Y., Duby G., 1977. Histoire de la France rurale. Tome 4. La fin de la France paysanne : de 1914 à nos jours. Paris, Seuil.

Gervais M., Servolin C., Weil J., 1965. Une France sans paysans. Paris, Seuil.

Ghiotтi S., 2007. Les territoires de l'eau : gestion et développement en France. Paris, CNRS éditions.

GiBbs D., 1996. Integrating Sustainable Development and Economic Restructuring: A Role for Regulation Theory? Geoforum, 27 (1), 1-10.

Gibbon P., 2008. An Analysis of Standards-based Regulation in the EU Organic Sector, 19912007. Journal of Agrarian Change, 8 (4), 553-582.

Gibbon P., Ponte S., 2005. Trading Down: Africa, Value Chains and the Global Economy. Philadelphie, Temple University Press.

Gibbon P., RiIsgaArd L., 2014. A New System of Labour Management in African Large-Scale Agriculture? Journal of Agrarian Change, 14 (1), 94-128.

Giddens A., 1994. Les conséquences de la modernité. Paris, L'Harmattan.

Giedion S., 1975 [1948]. Mechanization Takes Command. New York, W.W. Norton.

Gierlinger S., Krausmann F., 2012. The Physical Economy of the United States of America. Journal of Industrial Ecology, 16 (3), 365-377.

Gilbert C.L., 1996. International Commodity Agreements: An Obituary Notice. World Development, 24 (1), 24, 1-19.

Gilly J.-P., Wallet F., 2005. Enchevêtrement des espaces de régulation et gouvernance territoriale : les processus d'innovation institutionnelle dans la politique des Pays en France. Revue d'économie régionale et urbaine, 5, 699-722.

Giraud G., Kahraman Z., 2014. How Dependant is Growth from Primary Energy? Output Energy Elasticity in 50 Countries (1970-2011). The Shift Project, Paris School of Economics : http://www. parisschoolofeconomics.eu/IMG/pdf/article-pse-medde-juin2014-giraud-kahraman.pdf (consulté le 23 janvier 2015).

Giroud J., 2009. Semences et recherche : des voies du progrès. rapport au Conseil économique, social et environnemental, Paris, Conseil économique, social et environnemental.

Gislain J.-J., 2010. Pourquoi l'économie est-elle nécessairement instituée ? Une réponse commonsienne à partir du concept de futurité. Revue interventions économiques, 42, revue en ligne : http://interventionseconomiques.revues.org/1195 (consulté le 14 septembre 2016).

Global Footprint Network, 2006. Ecological Footprint and Biocapacity Data. http://www. footprintnetwork.org/en/index.php/GFN/page/footprint_for_nations/ (consulté le 11 octobre 2016).

Goldberg R., Segel A.I., Herrero G., Terris A., 2012. Farmland Investing: A Technical Note. Harvard Business School Background Note, 211-022. 
Golub P., 2013. From the New International Economic Order to the G20: How the "Global South" Is Restructuring Capitalism from Within. Third World Quarterly, 34 (6), 1000-1015.

Goodman D., 2004. Rural Europe Redux? Reflections on Alternative Agro-food Networks and Paradigm Change. Sociologia Ruralis, 44 (1), 3-16.

Goodman D., Dupuis M., Goodman M., 2011. Alternative Food Networks: Knowledge, Practice Politics. Londres, Routledge.

Goodman D., Goodman M.K., 2009. Food Networks, Alternative. In : International Encyclopedia of Human Geography (Kitchin R., Thrift N., dir.). Elsevier Science, 208-220.

Goodman D., Watts M., 1997. Globalising Food: Agrarian Questions and Global Restructuring. Londres, Routledge.

Goodwin M., Cloke P., Milbourne P., 1995. Regulation Theory and Rural Research: Theorising Contemporary Rural Change. Environment and Planning A, 27 (8), 1245-1260.

Gordon-Ashworth F., 1984. International Commodity Control, 1929 to 1977: A Contemporary History and Appraisal. Londres/New York, Croom Helm/St. Martin's Press.

Goulet F., 2008. L'innovation par retrait : reconfiguration des collectifs sociotechniques et de la nature dans le développement des techniques culturales sans labour. thèse de doctorat en sociologie, Grenoble, Université Pierre-Mendès-France.

GRAIN, 2010. Les nouveaux propriétaires fonciers : les sociétés d'investissement en tête de la course aux terres agricoles à l'étranger. rapport, Barcelone, Grain, 13 p.

Gramsci A., 1929. Américanisme et fordisme. Cahiers de prison 19 à 29, 211.

Granovetter M., 1985. Economic Action and Social Structure: The Problem of Embeddedness. American Journal of Sociology, 91 (3), 481-510.

Gras C., Hernández V., 2014. Agribusiness and Large-scale Farming: Capitalist Globalisation in Argentine Agriculture. Canadian Journal of Development Studies, 35 (3), 339-357.

Greffet P., Mauroux A., Ralle P., Randriambololna C., 2012. Définir et quantifier l'économie verte. In : L'économie française. Paris, Insee, 87-104

Griffon M., 1994. Rural Economy, Institutional Economics and Agriculture. Rome, Cirad/FAO.

GrifFon M., 2014. Y aura-t-il assez d'espace agricole pour produire de l'alimentation et de l'énergie ? Une exigence de discernement. Le déméter 2015, 255-274.

Grouiez P., 2010. Les stratégies des communautés et la régulation sectorielle et territoriale des configurations productives : le cas de l'agroalimentaire russe. thèse de doctorat en sciences économiques, Reims, Université Reims Champagne-Ardenne.

Grouiez P., 2013. Understanding the Puzzling Resilience of the Land Share Ownership in Russia: The Input of Ostrom's Approach. Revue de la régulation, 14 (2), revue en ligne : http://regulation. revues.org/10496 (consulté le 14 septembre 2016).

Grouiez P., 2014. Farming Strategies Regarding "Social Responsibility" in the Russian Agricultural Sector. East-West Journal of Economics and Business, 17 (1), 63-84.

GrüBler A., 1998. Technology and Global Change. Cambridge, Cambridge University Press.

GuÉRY A., 2001. Propriété, droit et institution dans l'institutionnalisme américain. Cahiers d'économie Politique/Papers in Political Economy, 40-41, 9-38.

GuilLaud J.-F., 1962. Rôle de l'Institut national de colonisation dans la mise en valeur agricole et hydro-agricole de l'Espagne. Revue de géographie alpine, 50 (4), 557-601.

Guillaume M., 1988. Les limites de l'utilitarisme. Revue européenne des sciences sociales, 26 (82), 99-108.

Guilleminot B., Ohana J.J., Оhana S., 2013. Les nouveaux modes d'investissement sur les marchés dérivés de matières premières agricoles : décryptage et impacts. étude commanditée par le Ministère de l'Agriculture/Riskelle/ESCP Europe, consultable en ligne sur : http://agriculture.gouv.fr/ministere/lesnouveaux-modes-dinvestissement-sur-les-marches-derives-de-matieres-premieres-agricoles (consulté le 19 octobre 2016).

Guinnane T.W., Harris R., Lamoreaux N.R., Rosenthal J.L., 2008. Pouvoir et propriété dans l'entreprise : pour une histoire internationale des sociétés à responsabilité limitée. Annales. Histoire, sciences sociales, 63 (1), 73-110.

Gunnoe A., 2014. The Political Economy of Institutional Landownership: Neorentier Society and the Financialization of Land. Rural Sociology, 9 (4), 478-504.

Guthey G.T., 2008. Agro-industrial Conventions: Some Evidence from Northern California's Wine Industry. The Geographical Journal, 174 (2), 138-148. 
Guthman J., 2004. Agrarian Dreams: The Paradox of Organic Farming in California. Berkeley, University of California Press.

GwYnNe R.N., 2006. Governance and the Wine Commodity Chain: Upstream and Downstream Strategies in New Zealand and Chilean Wine Firms. Asia Pacific Viewpoint, 47 (3), 381-395.

Haberl H., Winiwarter V., Andersson K., Ayres R.U., Boon C.G., Castillio A., Cunfer G., Fischer-Kowalski M., Freudenburg W.R., Furman E., Kaufmann R., Krausmann F., Langthaler E., Lotze-Campen H., Mirtl M., Redman C.A., Reenberg A., Wardell A.D., Warr B., Zechmeister H., 2006. From LTER to LTSER: Conceptualizing the Socioeconomic Dimension of Long-term Socioecological Research. Ecology and Society, 11 (2), 13, revue en ligne, http://www.ecologyandsociety.org/ vol11/iss2/art13/ (consulté le 11 octobre 2016).

Haberl H., Erb K.H., Krausmann F., Gaube V., Bondeau A., Plutzar C., Gingrich S., Lucht W., Fischer-Kowalski M., 2007. Quantifying and Mapping the Human Appropriation of Net Primary Production in Earth's Terrestrial Ecosystems. Proceedings of the National Academy of Sciences of the United States of America, 104 (31), 12942-12947.

Habermas J., 1973. La technique et la science comme idéologie. Paris, Gallimard.

Hairy D., Perraud D., 1985. Vers un nouveau mode de gestion des marchés ? In : Actes du colloque franco-québécois «Politiques agroalimentaires et développement rural», 7-10 octobre, Rimouski (Canada), Université du Québec, 19-29.

Hall D., 2015. The Role of Japan's General Trading Companies (Sogo Shosha) in the Global Land Grab. In : Conference Paper « Land Grabbing, Conflict and Agrarian-environmental Transformations: Perspectives from East and Southeast Asia », Chiang Mai University, Thailand.

Hall C.A.S., Cleveland C.J., Kaufmann R.K., 1986. Energy and Resource Quality. The Ecology of the Economic Process. New York, Wiley Interscience.

Hansen M.P., 2016. Non-normative Critique Foucault and Pragmatic Sociology as Practical Re-politicization. European Journal of Social Theory, 19 (1), 127-145.

Harada Y., 2011. TPP to Nihon nōgyō (TPP and Japanese Agriculture). Tokyo, The Tokyo Foundation : http://www.tkfd.or.jp/research/project/news.php?id=865 (consulté le 22 août 2012).

Harris M., Ross E., 1987. Death, Sex \& Fertility: Population Regulation in Pre-industrial and Developing Societies. New York, Columbia University Press.

Harvey D., 2006. The Limits to Capital. Londres/New York, Verso.

Harvey D., 2010. Le nouvel impérialisme. Paris, Les prairies ordinaires.

Hatanaka M., 2010. Certification, Partnership, and Morality in an Organic Shrimp Network: Rethinking Transnational Alternative Agrifood Networks. World Development, 38 (5), 706-716.

Hatanaka M., Busch L., 2008. Third-Party Certification in the Global Agrifood System: An Objective or Socially Mediated Governance Mechanism? Sociologia Ruralis, 48 (1), 73-91.

HAYEK F.A., 1973-1979. Law, Legislation and Liberty. 3 volumes, Chicago, University Of Chicago Press.

Hayek F.A., 2007 [1944]. The Road to Serfdom. Chicago, University Of Chicago Press.

Headrick D., 1988. Tentacles of Progress: Technology Transfer in the Age of Imperialism. Oxford, Oxford University Press.

Heller M.A., Eisenberg R.S., 1998. Can Patents Deter Innovation? The Anticommons in Biomedical Research. Science, 280 (5364), 698-701.

Heller M.C., Keoleian G.A., 2000. Life Cycle-Based Sustainability Indicators for Assessment of the U.S. Food System. Ann Arbor (Michigan), University of Michigan, Center for Sustainable Systems.

Henson S., Reardon T., 2005. Private Agri-food Standards: Implications for Food Policy and the Agri-food System. Food Policy, 30 (3), 241-253.

Hermitte M.-A., 2016. L'emprise des droits intellectuels sur le monde vivant. Versailles, Éditions Quæ.

Hervieu B., 2002. La multifonctionnalité de l'agriculture : genèse et fondements d'une nouvelle approche conceptuelle de l'activité agricole. Cahiers Agricultures, 11 (6), 415-419.

Hervieu B., Purseigle F., 2009. Pour une sociologie des mondes agricoles dans la globalisation. Études rurales, 183, 177-200.

Hervieu B., Purseigle F., 2013. Sociologie des mondes agricoles. Paris, Armand Colin.

Hess C., Ostrom E., 2003. Ideas, Artifacts, and Facilities: Information as a Common-pool Resource. Law and Contemporary Problems, 66 (1-2), 111-146. 
Hess C., Ostrom E., 2004. Studying Scholarly Communication. Can Commons Research and the IAD Framework Help Illuminate Complex Dilemmas? Libraries' and Librarians' Publications, 28, http:// surface.syr.edu/sul/28 (consulté le 19 octobre 2016).

Hiвоu B., 2012. La bureaucratisation du monde à l'ère néolibérale. Paris, La Découverte.

HighQuest Partners, 2010. Private Financial Sector Investment in Farmland and Agricultural Infrastructure. OECD Food, Agriculture and Fisheries Papers, 33, Paris, OECD Publishing.

HiLty L.M., 2008. Information Technology and Sustainability: Essays on the Relationship between Information Technology and Sustainable Development. Norderstedt, Books on Demand.

Hirschman A.O., 1967. The Principle of the Hiding Hand. The Public Interest, 6, 10-23.

Hirschman A.O., 1970. Exit, Voice, and Loyalty: Responses to Decline in Firms, Organizations, and States. Cambridge (Mass.), Harvard University Press.

Hirschman A.O, 1991. Deux siècles de rhétorique réactionnaire. Paris, Fayard.

HLPE, 2011. Price Volatility and Food Security: A Report by the High Level Panel of Experts on Food Security and Nutrition of the Commitee on World Food Security. Rome, FAO.

Hobsbawm E., 1968. Industry and Empire: An Economic History of Britain since 1750. Londres, Weidenfeld \& Nicolson.

Hobsвawm E.J., 1994. Age of Extremes: The Short Twentieth Century, 1914-1991. Londres, Michael Joseph.

Hochreiter C., 2011. Certified with Trust and Solidarity? Attitude, Benefits and Challenges of Organic Farmers in Participatory Guarantee Systems, Cacahoatán, Mexico. Vienne, University of Natural Resources and Life Sciences.

Hoeschele W., 2016. The Economics of Abundance: A Political Economy of Freedom, Equity, and Sustainability. Boca Raton (Floride), CRC Press.

Hohenberg P.M., 1967. Chemicals in Western Europe, 1850-1914. Chicago, Rand McNally \& Company.

Hokkaido Shitei SEINYũ SEISANSha Dantai, HokURen, 2012. Hokkaido rakunō no genjō ni tsuite (The Current State of Dairy Farming in Hokkaido). mimeo.

Holt Giménez E., Shattuck A., 2011. Food Crises, Food Regimes and Food Movements: Rumbling of Reform or Tides of Transformation. The Journal of Peasant Studies, 38 (1), 109-144.

Holt D., ReID T., BusCh L., 2007. Les normes en agriculture : du droit positif à « l'État évaluateur et auditeur ». Démeter 2007, 13, 89-116.

Holtz G., Brugnach M., Pahl-Wostl C., 2008. Specifying "Regime" - A Framework for Defining and Describing Regimes in Transition Research. Technological Forecasting and Social Change, 75 (5), 623-643.

Honma M., 2012. Nihon nōgyō 2020nen ni muketa seidō kaikaku no hōkō (The Direction of Reform Towards Japanese Agriculture in 2020). In : Nōgyō saisei no gurando dezain (Master Plan for Agricultural Reform). Tokyo, The $21^{\text {st }}$ Century Public Policy Institute/Éditions Tokyo, 106-123.

Hopkins R.F., Puchala D.J., 1980. Global Food Interdependance: Challenge to American Foreign Policy. New York, Columbia University Press.

Hornborg A., 2003. The Unequal Exchange of Time and Space: Toward a Non-normative Ecological Theory of Exploitation. Journal of Ecological Anthropology, 7 (1), 4-10.

Hornborg A., 2012. Accumulation: Land as a Medium of Domination. Ecology and Power: Struggles over Land and Material Resources in the Past, Present, and Future (Hornborg A., Clark B., Hermele K., dir.). Londres, Routledge, 13-22.

Hornborg A., 2013. Global Ecology and Unequal Exchange: Fetishism in a Zero-Sum World. Londres, Routledge.

Hornborg A., 2014. Ecological Economics, Marxism, and Technological Progress: Some Explorations of the Conceptual Foundations of Theories of Ecologically Unequal Exchange. Ecological Economics, 105, 11-18.

Hornborg A., Crumley C.L. (dir.), 2006. The World System and the Earth System. Walnut Creek (California), Left Coast Press.

Huang J., Yang J., Msangi S., Rozelle S., Weersink A., 2012. Biofuels and the Poor: Global Impact Pathways of Biofuels on Agricultural Markets. Food Policy, 37 (4), 439-451.

Huber M., 2013. Fueling Capitalism: Oil, the Regulation Approach, and the Ecology of Capital. Economic Geography, 89 (2), 171-194. 
Hueth B., Marcoul P., 2003. An Essay on Cooperative Bargaining in US Agricultural Markets. Journal of Agricultural \& Food Industrial Organization, 1 (1), 1-15.

Hugon P., 1993. Les trois temps de la pensée francophone en économie du développement. In : État des savoirs sur le développement (Choquet C., Dollfus O., Le Roy E., Vernières M., dir.). Paris, Karthala, 43-74.

IDELE, 2015. Lait en Europe du Nord: de grands écarts entre pays. dossier Économie de l'élevage, 460, $60 \mathrm{p}$.

IEA, 2007. Energy Statistics of Non-OECD Countries, 2004-2005. CD-Rom, édition 2007, Paris, International Energy Agency (IEA)/Organisation of Economic Co-Operation and Development (OECD).

IfoAm, 2005. PGS Case Studies 2005 in Brazil, France, India, New Zealand, USA. Ifoam studies, Bonn, Ifoam.

IfOAm, 2014. Membership Vote on Motions to the IFOAM Norms. consultable sur : http://www. ifoam.org/sites/default/files/ifoam_norms_motions_membership_vote_2014.pdf (consulté le 4 octobre 2016).

IfoAm-Europe, 2006. Principles of Organic Agriculture. Bonn, Ifoam.

ILC, à paraître. Commercial Pressures on Land. rapport de synthèse, Rome, ILC.

IlLich I., 1975a. Énergie et équité. trad. de l'anglais par Luce Giard, Paris, Seuil.

ILLich I., 1975b. Némésis médicale. Paris, Seuil.

INIKORI J., 2002. Africans and the Industrial Revolution in England: A Study in International Trade and Economic Development. Cambridge, Cambridge University Press.

Institut De L'élevage, InRa, 2011. La révolution génomique animale. Paris, France agricole.

Ioffe G., Nefedova T., 2001. Russian Agriculture and Food Processing: Vertical Cooperation and Spatial Dynamics. Europe-Asia Studies, 53 (3), 389-418.

IPCC, 2005. IPCC Special Report on Carbon Dioxide Capture and Storage. Prepared by Working Group III of the Intergovernmental Panel on Climate Change. Cambridge/New York, Cambridge University Press.

IPCC, 2007. Climate Change 2007 - Impacts, Adaptation and Vulnerability. Contribution of the Working Group II to the Fourth Assessment Report of the IPCC. Cambridge/New York/Melbourne, Cambridge University Press.

IsAKson S.R., 2014. Food and Finance: The Financial Transformation of Agro-Food Supply Chains. The Journal of Peasant Studies, 41 (5), 749-775.

JACKSON T., 2009. Prosperity without Growth: Economics for a Finite Planet. Londres, Earthscan.

JAFFEE D., Howard P., 2009. Corporate Cooptation of Organic and Fair Trade Standards. Agriculture and Human Values, 27 (4), 387-399.

JAGD S., 2011. Pragmatic Sociology and Competing Orders of Worth in Organizations. European Journal of Social Theory, 14 (3), 343-359.

Jahn G., Schramm M., Spiller A., 2005. The Reliability of Certification: Quality Labels as a Consumer Policy Tool. Journal of Consumer Policy, 28 (1), 53-73.

James D., 2014. Money from Nothing: Indebteness and Aspiration in South Africa. Stanford (Californie), Stanford University Press.

Jameson F., 2003. Future City. New Left Review, 21, 76.

JAS N., 2005. Déqualifier le paysan, introniser l'agronome, France 1840-1914. Écologie \& politique, 31, 45-55.

Jiménez DíAz J.F., 2011. Procesos de desarrollo en el Poniente Almeriense: Agricultores e inmigrados. Revista de estudios régionales, 90, 179-205.

Jobert B., Muller P., 1987. L'État en action : politiques publiques et corporatismes. Paris, Presses Universitaires de France.

Johnson T.G., Altman I., 2014. Rural Development Opportunities in the Bioeconomy. Biomass and Energy, 63, 341-344.

Joly P.-B., 2010. On the Economics of Techno-Scientific Promises. In : Débordements. Mélanges offerts à Michel Callon (Akrich M., Barthe Y., Muniesa F., dir.). Paris, Presses des Mines, 203-221.

Jones G., 2005. Multinationals from the 1930s to the 1980s. In : Leviathans/Multinational Corporations and the New Global History (Chandler A.D., Mazlich B., dir.). Cambridge, Cambridge University Press, 81-103. 
Jongeneel R., van Berkum S., Bont C., van Bruchem C., Helming J., Jage J., 2010. European Dairy Policy in the Years to Come: Quota Abolition and Competitiveness. La Hague, LEI, part of Wageningen UR.

Jorgenson A.K., 2012. The Sociology of Ecologically Unequal Exchange and Carbon Dioxide Emissions, 1960-2005. Social Science Research, 41 (2), 242-252.

Jorgenson A.K., Clark B., 2012. Are the Economy and the Environment Decoupling? A Comparative International Study, 1960-2005. American Journal of Sociology, 118 (1), 1-44.

Jorion P., 2007. La crise : des subprimes au séisme financier planétaire. Paris, Fayard.

Josuing T., 2006. The War on Terroir: Geographical Indications as a Transatlantic Trade Conflict. Journal of Agricultural Economics, 57 (3), 337-363.

Joss S. (dir.), 1999. Special Issue on Public Participation in Science and Technology. Science and Public Policy, 26 (5).

Kadtler J., Sperling H.J., 2002. The Power of Financial Markets and the Resilience of Operations: Argument and Evidence from the German Car Industry. Competition \& Change, 6 (1), 81-94.

Kander A., Malanima P., Warde P., 2014. Power to the People: Energy in Europe over the Last Five Centuries: Energy in Europe over the Last Five Centuries. Princeton, Princeton University Press.

KARPIK L., 1989. L'économie de la qualité. Revue française de sociologie, 30 (2), 187-210.

KARPIK L., 2007. L'économie des singularités. Paris, Gallimard.

KAUTSKY K., 1900. La question agraire : études sur les tendances de l'agriculture moderne. Paris, V. Giard \& E. Brière.

KAWASHIMA H., 2011. TPP o ki ni "sentaku" to "shūchū" Nihon wa Orandagata nogyo yushutsukoku ni nareru (With TPP as an Impetus "Selection and Focus" Japan can Become a Dutch-style Exporting Country). The Economist Report, mars, 97-99.

Kenney M., Lobao L.M., Curry J., Goe W.R., 1989. Midwestern Agriculture in US Fordism: From the New Deal to Economic Restructuring. Sociologia Ruralis, 29 (2), 131-148.

Keohane R.O., 1984. After Hegemony: Cooperation and Discord in the World Political Economy. Princeton, Princeton University Press.

Kerckhoffs T., van Os R., Vander Stichele M., 2010. Financing Food: Financialisation and Financial Actors in Agriculture Commodity Market. rapport Somo, Amsterdam, Somo.

Keynes J.M., 2002. La pauvreté dans l'abondance : recueil d'articles. Paris, Gallimard, Collection Tel.

Kindelberger C.P., 1973. The World in Depression, 1929-1939. Berkeley, University of California Press.

KIRWAN J., 2006. The Interpersonal World of Direct Marketing: Examining Conventions of Quality at UK Farmers' Markets. Journal of Rural Studies, 22 (3), 301-312.

KLeIn N., 2000. No Logo: Taking Aim at the Brand Bullies. New York, Picador.

Kobari M., 2012. Nōgyōhōjin ni okeru jinzai ikusei no torikumi (Measures to Nurture Human Resources in Agriculture Businesses). Nōrin kin'yū, juillet.

Kobayashi S., 2011. Rakunō nyūgyō no kiki to Nihon rakunō no shinro (The Crisis in the Dairy Industry and the Future Path of Japanese Dairy). Tokyo, Tsukuba shobo.

Korthals Altes W.K., van Ris E., 2013. Planning the Horticultural Sector: Managing Greenhouse Sprawl in the Netherlands. Land Use Policy, 31, 486-497.

Krausmann F., 2004. Milk, Manure and Muscular Power: Livestock and the Industrialization of Agriculture. Human Ecology, 32 (6), 735-773.

Krausmann F., Cunfer G., 2009. Agroecosystems on the American Frontier: Material and Energy Systems and Sustainability. In : World Congress of Environmental History, 4-8 août, Copenhague.

Krausmann F., Fischer-Kowalski M., Schandl H., Eisenmenger N., 2008a. The Global Sociometabolic Transition: Past and Present Metabolic Profiles and their Future Trajectories. Journal of Industrial Ecology, 12 (5-6), 637-656.

Krausmann F., Schandl H., Sieferle R.P., 2008b. Socio-ecological Regime Transitions in Austria and the United Kingdom. Ecological Economics, 65 (1), 187-201.

Krausmann F., Gingrich S., Eisenmenger N., Erb K.H., Haberl H., Fischer-Kowalski M., 2009. Growth in Global Materials Use, GDP and Population during the 20th Century. Ecological Economics, 68 (10), 2696-2705.

Kunn M., Pouch T., 2010. L'agriculture chinoise au milieu du gué. Monde chinois, 20, 52-64. 
LABARTHE P., 2006. La privatisation du conseil agricole en question : évolutions institutionnelles et performances des services de conseil dans trois pays européens (Allemagne, France, Pays-Bas). thèse de doctorat, Marne-la-Vallée, Université de Marne-la-Vallée.

LABARTHE P., 2006. La privatisation du conseil agricole en question : évolutions institutionnelles et performances des services de conseil dans trois pays européens (Allemagne, France, Pays-Bas). thèse de doctorat en sciences économiques, Marne-la-Vallée, Université de Marne-la-Vallée.

Labarthe P., 2009. Extension Services and Multifunctional Agriculture: Lessons Learnt from the French and Dutch Contexts and Approaches. Journal of Environmental Management, 90 (2), 193-202.

LABARTHE P., 2010. Services immatériels et verrouillage technologique : le cas du conseil technique aux agriculteurs. Économies et sociétés, 44 (2), 173-196.

LABARTHE P., 2014. AKIS and Advisory Services in France. Report for the AKIS Inventory (WP3) of the European Project PRO AKIS. Paris, Inra.

Labarthe P., Laurent C., 2013. Privatisation of Agricultural Extension Services in the EU: Towards a Lack of Adequate Knowledge for Small Scale Farms? Food Policy, 38, 240-252.

Labarthe P., Trouvé A., Laurent C., Perraud D., Berriet-Solliec M., Bonnafous P., Kirsch M., Corroyer P., RAmbaud C., 2009. L'accès aux connaissances scientifiques et leur mobilisation dans le débat politique : une application aux mesures réglementaires mettant en jeu l'agriculture et la préservation de la biodiversité. Rapport de recherche Ebp-Biosoc, Ensemble de travaux n 3, Inra/SAD.

Labatut J., 2013. Emerging Markets, Emerging Strategies under the Genomic Era. In : Annual Meeting of the European Association for Animal Production, Nantes, EAAP.

Labatut J., Aggeri F., Bibé B., Girard N., 2011. Construire l'animal sélectionnable. Revue d'anthropologie des connaissances, 5 (2), 302-336.

Labatut J., Allaire G., Aggeri F., 2013. Étudier les biens communs par les changements institutionnels : régimes de propriété autour des races animales face à l'innovation génomique. Revue de la régulation, 14 (2), revue en ligne : https://regulation.revues.org/10529 (consulté le 23 octobre 2016).

Labatut J., Astruc J.-M., Barillet F., Boichard D., Ducroce V., Griffon L., Lagriffoul G., 2014. Implications organisationnelles de la sélection génomique chez les bovins et ovins laitiers en France : analyses et accompagnement. Inra Productions animales, 27 (4), 303-316.

Labatut J., Bibé B., Aggeri F., Girard N., 2012. Coopérer pour gérer des races locales : conception, rôles et usages des instruments scientifiques de sélection. Natures sciences sociétés, 20, 143-156.

Labreuche J., de Tourdonnet S., Germon J.-C., Ouvry J.-F., Le Souder C., Castillon P., Real B., Félix I., Duval R., Galienne J., Quere L., 2007. Évaluation des impacts environnementaux des Techniques culturales sans labour (TCSL) en France. Évaluation collective, Ademe.

LAcombe P., 1987. Les exploitations agricoles : modèle et réalité. republié dans Problèmes économiques, 2012, 3-13Lacroix A., 1981. Transformation du procès de travail agricole : incidence de l'industrialisation sur les conditions de travail paysannes. thèse de doctorat en sciences économiques, Grenoble, Inra/Irep, 279 p.

Lacroix A., Mollard A., 1990. Pourquoi les agriculteurs travaillent-ils tant ? In : Les agriculteurs et la politique (Coulomb P., Delorme H., Hervieu B., Jollivet M., Lacombe P., dir.). Paris, Presses de Sciences Po, 282-288.

Lacroix A., Mollard A., Bel F., 1995. L'approche sectorielle de la régulation : une problématique à partir de l'agriculture. In : La grande transformation de l'agriculture : lectures conventionnalistes et régulationnistes (Allaire G., Boyer R., dir.). Versailles/Paris, Inra éditions/Economica, 259-191.

LAMANTHE A., 2007. Extension des marchés et normalisation : les systèmes agro-alimentaires dans la mondialisation. Géographie économie société, 9 (3), 257-270.

Lamarche T., Nieddu M., Grouiez P., Chanteau J.-P., Labrousse A., Michel S., Vercueil J., 2015. A Regulationist Method of Meso-analysis. In : Colloque "La théorie de la régulation à l'épreuve des crises », Paris, 9-12 juin, HAL, consulté à l'adresse https://halshs.archives-ouvertes.fr/hal-01163875/ document (consulté le 13 octobre 2016).

LAmbert B., 1970. Les paysans dans la lutte des classes. Paris, Seuil.

Lamine C., Bellon S., 2009. Conversion to Organic Farming: A Multidimensional Research Object at the Crossroads of Agricultural and Social Sciences. A Review. Agronomy for Sustainable Development, 29 (1), 97-112.

Landel P., 2015. Participation et verrouillage technologique dans la transition écologique en agriculture : le cas de l'agriculture de conservation en France et au Brésil. thèse de doctorat en sciences sociales, Paris, AgroParisTech. 
Langley P., 2008. The Everyday Life of Global Finance: Saving and Borrowing in America. Oxford, Oxford University Press.

LARSEN C.S., 2006. The Agricultural Revolution as Environmental Catastrophe: Implications for Health and Lifestyle in the Holocene. Quaternary International, 150 (1), 12-20.

Lascoumes P., Le Galès P. (dir.), 2004. Gouverner par les instruments. Paris, Les Presses de Sciences Po.

Lataste F., Berriet-Solliec M., Trouvé A., Lépicier D., 2012. Le second pilier de la Politique agricole commune : une politique à la carte. Revue d'économie régionale et urbaine, 3, 327-351.

Latour B., 1998. To Modernise or Ecologise? That Is the Question. In : Remaking Reality: Nature at the Millennium (Braun B., Castree N., dir.). Londres/New York, Routledge, 221-242.

Latour B., 2000. Factures/fractures : de la notion de réseau à celle d'attachement. In : Ce qui nous relie (Micoud A., Peroni M., dir.). La Tour d'Aigues, Éditions de l'Aube, 189-208.

Latour B., 2014. On Some of the Affects of Capitalism. Lecture à la Royal Academy de Copenhague. 26 février, Copenhague, Royal Academy.

Latour B., Weibel P. (dir.), 2005. Making Things Public: Atmospheres of Democracy. Cambridge (Mass.), The MIT Press.

LAURENT C., 1992. L'agriculture et son territoire dans la crise : analyse et démenti des prévisions sur la déprise des terres agricoles à partir d'observations réalisées dans le Pays d'Auge. thèse de doctorat de sciences économiques, Paris, Université Paris VII.

LAURENT C., 1995. La fin de l'hégémonie de l'agriculture professionnelle sur le territoire. In : La grande transformation de l'agriculture : lectures conventionnalistes et régulationnistes (Allaire G., Boyer R., dir.). Versailles/Paris, Inra éditions/Economica, 323-344.

LAURent C., 2002. Le débat scientifique sur la multifonctionnalité de l'activité agricole et sa reconnaissance par les politiques publiques. In : Colloque SFER «La multifonctionnalité de l'activité agricole et sa reconnaissance par les politiques publiques », 21-22 mars, Paris, SFER.

Laurent C., 2013. The Ambiguities of French Mediterranean Agriculture: Images of the Multifunctional Agriculture to Mask Social Dumping? Research in Rural Sociology and Development, $19,149-171$.

LAURENT C., 2015. L'agriculture méditerranéenne française entre multifonctionnalité et dumping social. Le courrier de l'environnement de l'Inra, 65, 123-134.

Laurent C., Baldi I., Bernadac G., Berthet A., Colosio C., Jas N., Jouzel J.-N., Garrigou A., Guichard L., Grimbuhler S., Lebailly P., Samuel O., Spinosi J., Wavreski P., 2016. Expositions professionnelles aux pesticides en agriculture. Expertise collective, 7 volumes, Maisons-Alfort, Anses.

Laurent C., Berriet-Solliec M., Labarthe P., Trouvé A., 2012. Evidence-based policy : de la médecine aux politiques agricoles? Les enjeux d'une approche méconnue en France. Notes et études socioéconomiques, 36, 79-101

Laurent C., Cartier S., Fabre C., Mundler P., Ponchelet D., Rémy J., 1998. L'activité agricole des ménages ruraux et la cohésion économique et sociale. Économie rurale, 244 (1), $12-21$.

Laurent C., du Tertre C. (dir.), 2008. Secteurs et territoires dans les régulations émergentes. Paris, L'Harmattan.

Laurent C., Giraud C. Ricroch A., Allsopp N., Bonnafous P., Carneiro M.-J., Matose F. (dir.), 2008. Difficultés d'accès aux connaissances scientifiques pour les décideurs publics chargés de concevoir les contenus techniques de mesures réglementaires mettant en jeu agriculture et préservation de la biodiversité. Rapport ANR EBP-Biosoc, Ensemble de travaux n 1 (ET1). Résultats des enquêtes réalisées en France, au Brésil et en Afrique du Sud.

Laurent C., Labarthe P., Trouvé A., Berriet-Solliec M., 2009. Les connaissances scientifiques, une ressource de plus en plus rare pour la décision publique ? In : Forum de la régulation, 1-2 décembre, Paris, Association Recherche et régulation.

Laurent C., Mouriaux M.F., 2008. Secteurs, territoires, rapport social d'activité. In : Secteurs et territoires dans les régulations émergentes (Laurent C., du Tertre C., dir.). Paris, L’Harmattan, 9-23.

Leach G., 1976. Energy and Food Production. Guildford, IPC Science and Technology Press.

Lecou P.-E., Courleux F., 2011. Vers la définition d'un nouveau cadre de régulation des marchés dérivés de matières premières agricole. Centre d'études et de prospective, 3, Paris, Ministère de l'Agriculture.

Le Galès P., Scott A., 2008. Une révolution bureaucratique britannique ? Autonomie sans contrôle ou « freer markets, more rules ». Revue française de sociologie, 49 (2), 301-330. 
Le Heron R., Lewis N., 2009. Discussion. Theorising Food Regimes: Intervention as Politics. Agriculture and Human Values, 26 (4), 345-349.

Lemeilleur S., Allaire G., 2014. Standardisation and Guarantee Systems: What Can Participatory Certification Offer? In : Conference IIPPE 2014: Fifth Annual Conference in Political Economy, "The Crisis: Scholarship, Policies, Conflicts and Alternatives », 16-18 septembre, Naples.

Lemeilleur S., N'Dao Y., Ruf F., 2015. The Productivist Rationality behind a Sustainable Certification Process: Evidence from the Rainforest Alliance in the Ivorian Cocoa Sector. International Journal of Sustainable Development, 18 (4), 310-328.

LÉMERY B., 2006. Nouvelle agriculture, nouvelles formes d'exercice et nouveaux enjeux du conseil aux agriculteurs. In : Conseiller en agriculture (Rémy J., Brives H., Lémery B., dir.). Versailles/Dijon, Inra éditions/Educagri éditions, 235-252.

LEROUX B., 2011. Les agriculteurs biologiques et l'alternative : contribution à l'anthropologie politique d'un monde paysan en devenir. thèse de doctorat en sociologie, Paris, EHESS.

Levenstein H.A., 1993. Paradox of Plenty: A Social History of Eating in Modern America. New York/Oxford, Oxford University Press.

Levidow L., 2015. European Transitions Towards a Corporate-environmental Food Regime: Agroecological Incorporation or Contestation? Journal of Rural Studies, 40, 76-89.

Levidow L., Marris C., 2001. Science and Governance in Europe: Lessons from the Case of Agricultural Biotechnology. Science and Public Policy, 28 (5), 345-60.

Levidow L., Birch K., Papaionnnou T, 2012. EU Agri-innovation Policy: Two Contending Visions of the Bio-economy. Critical Policy Studies, avril, consultable en ligne : http://www.tandfonline.com/loi/ rcps20 (consulté le 24 octobre 2016).

Levidow L., Birch K., Papaioannou T., 2013a. Divergent Paradigms of European Agro-Food Innovation: Knowledge-Based Bio-Economy (KBBE) as an R\&D Agenda. Science Technology Human Values, 38 (1), 94-125.

Levidow L., Papaioannou T., Borda-Rodriguez A., 2013b. Innovation Priorities for UK Bioenergy: Technological Expectations within Path Dependence. Science \& Technology Studies, 29 (3), 14-36.

Levidow L., Pimbert M., Vanloqueren G., 2014. Agroecological Research: Conforming - or Transforming the Dominant Agro-food Regime? Agroecology and Sustainable Food Systems, 38 (10), 1127-1155.

Lewontin R. C., Berlan J.-P., 1990. The Political Economy of Agricultural Research: The Case of Hybrid Corn. Agroecology (Caroll C.R., Vandermeyer J.H., Rosset P.M.P., dir.). New York, McGrawHill, 613-626.

Li G., 2016. Policy Developments of China Maize Production and Stock Holding. In : $9^{\mathrm{e}}$ Sessions du Global Food Market Information Group d'AMIS, communication, juin, Rome, AMIS.

Linder M., 1994. Projecting Capitalism: A History of the Internationalization of the Construction Industry. Westport, Greenwood Press.

LindKvist K.B., SÁNCHEZ J.L., 2008. Conventions and Innovation: A Comparison of Two Localized Natural Resource-based Industries. Regional Studies, 42 (3), 343-354.

Lines T, 2007. Les accords sur les produits tropicaux et les programmes d'ajustement structurel. In : La régulation des marchés agricoles internationaux, un enjeu décisif pour le développement (Boussard J-M., Delorme H., dir.). Paris, L'Harmattan, 183-196.

LinNÉR B.-O., 2003. The Return of Malthus: Environmentalism and Post-War Population-Resource Crises. Isle of Harris, The White Horse Press.

Lipietz A., 1995. Écologie politique régulationniste ou économie de l'environnement ? In: Théorie de la régulation : l'état des savoirs (Boyer R., Saillard Y., dir.). Paris, La Découverte, 350-356.

Lipton M., 1977. Why Poor People Stay Poor: Urban Bias in World Development. Cambridge (Mass.), Harvard University Press.

Livet P., Thévenot L., 1994. Les catégories de l'action collective. In : Analyse économique des conventions (Orléan A., dir.). Paris, Presses universitaires de France, 139-167.

Llamas Madurga M.R., Martínez-Santos P., 2005. Intensive Groundwater Use: Silent Revolution and Potential Source of Social Conflicts. Journal of Water Resources Planning and Management, 131 (5), 337-341.

Lloyd C., James S., 2008. Too Much Pressure? Retailer Power and Occupational Health and Safety in the Food Processing Industry. Work, Employment and Society, 22 (4), 713-730.

Loconto A., Busch L., 2010. Standards, Techno-economic Networks, and Playing Fields: Performing the Global Market Economy. Review of International Political Economy, 17 (3), 507-536. 
Loconto A., Stone J.V., Busch L., 2012. Tripartite Standards Regime. In : The Wiley-Blackwell Encyclopedia of Globalization (Rtizer G., dir.). Malden (Mass.), Blackwell Publishing Ltd., 2044-2051.

Lopez M., 2006. Regulation Redux, Regional Studies and the Sociology of Agriculture. In : Proceedings of the Rural Sociology Society, 10 août, Louisville (Kentucky), Rural Sociology Society.

López-Gunn E., 2009. Agua Para Todos: A New Regionalist Hydraulic Paradigm in Spain. Water Alternatives, 2 (3), 370-394.

LORRAIN D., 2008. Éditorial : les institutions de second rang. Entreprise et histoire, 1 (50), 6-18.

Losada A., López-Gálvez J., 1997. Gestión del regadío en el Campo de Dalías. In : La gestión del agua de riego (López-Gálvez J., Naredo J.M., dir.). Madrid, Fundación Argentaria-Visor, 33-72.

Losch B., 2000. La Côte d'Ivoire en quête d'un nouveau projet national. Politique africaine, 78, 5-25.

Losch B, 2007. Quel statut pour l'instabilité des prix dans les changements structurels des agricultures des Suds? In : La régulation des marchés agricoles internationaux, un enjeu décisif pour le développement (Boussard J.-M., Delorme H., dir.). Paris, L'Harmattan, 113-131.

Losch B., Fréguin-Gresh S., White E.T., 2012. Structural Transformation and Rural Change Revisited: Challenges for Late Developing Countries in a Globalizing World. Washington D. C., World Bank Publications.

LоткA A.J., 1922. Contribution to the Energetics of Evolution: Natural Selection as a Physical Principle. Proceedings of the National Academy of Sciences of the United States of America, 8 (6), 147151 et 151-154.

Love R.R., Hoey J.M., 1990. Management Science Improves Fast-Food Operations. Interfaces, $20(2), 21-29$.

Lubowski R.N., Vesterby M., Bucholtz S., Baez A., Roberts M.J., 2006. Major Uses of Land in the United States, 2002. USDA-ERS Economic Research Report, 14, Washington D. C., USDA-ERS.

Luhtakallio E., 2012. Practicing Democracy: Activism and Politics in France and Finland. Basingstoke, Palgrave Macmillan.

Luhtakallio E., Eliasoph N., 2014. Ethnography of Politics and Political Communication: Studies in Sociology and Political Science. In : Oxford Handbook of Political Communication (Hall Jamieson K, Kenski K, dir.). Oxford, Oxford University Press, publication en ligne : DOI: 10.1093/ oxfordhb/9780199793471.013.28

LuTz B., 1989. Der kurze Traum immerwährender Prosperität. Eine Neuinterpretation der industriellkapitalistischen Entwicklung im Europa des 20. Jahrhunderts. Francfort-sur-le-Main/New York, Campus Verlag.

MAAF (Ministère de L'Agriculture, de l'Agroalimentaire et de LA forêt), 2013. Écophyto. Réduire et améliorer l'utilisation des phytos. Note de suivi 2013. Tendances du recours aux produits phytosanitaires de 2008 à 2012. Paris, Maaf.

MAAF (Ministère de L'Agriculture, de L'AGRoAlimentaire et de LA Forêt), 2014. Écophyto. Réduire et améliorer l'utilisation des phytos. Note de suivi 2014. Tendances du recours aux produits phytosanitaires de 2008 à 2013. Paris, Maaf.

Maddison A., 2008. Historical Statistics for the World Economy: 1-2006 AD. Groningen (Pays-Bas), Maddison Project, http://www.ggdc.net/maddison/maddison-project/home.htm (consulté le 16 janvier 2017).

Madelrieux S., Nettier B., Dobremez L., 2010. L'exploitation agricole, la famille et le travail : nouvelles formes, nouvelles régulations? In : Journées d'étude Inra-Cirad: le travail en agriculture dans les sciences pour l'action, mars, Parent (France), Inra/Cirad.

Madison M.J., Frischmann B.M., Strandburg K.J., 2010. Constructing Commons in the Cultural Environment. Cornell Law Review, 95 (4), 657, 659.

Mahrane Y., Bonneuil C., 2014. Gouverner la biosphère : de l'environnement de la guerre froide à l'environnement néoliberal. In : Le gouvernement des technosciences : gouverner le progrès et ses dégâts depuis 1945 (Pestre D., dir.). Paris, La Découverte, 133-169.

Majone G., 1996. La Communauté européenne : un État régulateur. Paris, Montchrestien.

Malassis L., 1979. Traité d'économie agro-alimentaire. Tome I : Économie de la production et de la consommation. Paris, Cujas.

Malerba F., 2002. Sectoral Systems of Innovation and Production. Research Policy, 31 (2), 247-264.

Malm A., 2015. Fossil Capital: The Rise of Steam-Power and the Roots of Global Warming. Londres, Verso Books.

Manning J.G., 2002. Irrigation et État en Égypte antique. Annales. Histoire, sciences sociales, 57 (3), 611-623. 
MArié M., 1999. Introduction générale. L'eau, les conflits et les mots. In : Cultures, usages et stratégies de l'eau en Méditerranée occidentale : tensions, conflits et régulations (Marié M., Larcena D., Dérioz P., dir.). Paris, L'Harmattan, 15-38.

Markard J., Truffer B., 2008. Technological Innovation Systems and the Multi-level Perspective: Towards an Integrated Framework. Research Policy, 37 (4), 596-615.

Markowitz H. 1952. Portfolio Selection. Journal of Finance, 7 (1), 77-91.

Markunsen M.V., Ostergard H., 2013. Energy Analysis of the Danish Food Productin System: Food-EROI and Fossil Fuel Dependency. Energies, 6 (8), 4170-4186.

Marland G., Boden T.A., Andres R. J., 2007. Global, Regional, and National CO Emissions. In : In Trends: A Compendium of Data on Global Change (Oak Ridge National Laboratory, U.S. Department of Energy, dir.). Oak Ridge, Carbon Dioxide Information Analysis Center (CDIAC).

Marsden T., Banks J., Bristow G., 2000. Food Supply Chain Approaches: Exploring their Role in Rural Development. Sociologia Ruralis, 40 (4), 424-438.

Marsden T., Murdoch J., 2006. Between the Local and the Global: Confronting Complexity in the Contemporary Agrifood Sector. Wageningen, Elsevier.

Martínez-Alier J., 1987. Ecological Economics: Energy, Environment, and Society. Oxford, Basil Blackwell.

MARTíneZ-Alier J., 2014. L'écologisme des pauvres : une étude des conflits environnementaux dans le monde. Paris, Les petits matins.

Martínez-Alier J., Muradian R., 2015. Taking Stocks: The Keystones of Ecological Economics. In : Handbook of Ecological Economics (Martínez-Alier J., Muradian R., dir.). Londres, Edward Elgar Publishing, 1-25.

Marx K., 1973 [1867]. Le Capital, livre 1, tome III. Paris, Les éditions sociales.

MARZIN J., 2006. L'impact de la microfinance sur une communauté villageoise : le cas de Gandaogo au Ganzourgou. thèse de doctorat, Strasbourg, Université Louis Pasteur.

Mathews J.A., Tan H., 2011. Progress toward a Circular Economy in China: The Drivers (and Inhibitors) of Eco-industrial Initiative. Journal of Industrial Ecology, 15 (3), 435-457.

Mattalia S., Barbat A., Danchin-Burge C., Brochard M., Le Mezec P., Minery S., Jansen G., van Doormaal B., Verrier E., 2006. La variabilité génétique des huit principales races bovines laitières françaises : quelles évolutions, quelles comparaisons internationales ? In : 13 Rencontres recherches ruminants, 6-7 décembre, Paris, 239-246.

Maurel M.-C., 1980. La campagne collectivisée : société et espace rural en Russie. Paris, Anthropos.

Mazoyer M., Roudart L., Membrez J.H., 2006. A History of World Agriculture: From the Neolithic Age to the Current Crisis. Londres, Earth Scan.

McEntee J., 2010. Contemporary and Traditional Localism: A Conceptualisation of Rural Local Food. Local Environment, 15 (9-10), 785-803.

McInTYre B., 2009. International Assessment of Agricultural Knowledge, Science and Technology for Development. Washington D. C., Island Press.

McMichael P., 2005. Global Development and the Corporate Food Regime. New Directions in the Sociology of Global Development. Research in Rural Sociology and Development. Volume 11 (Buttel F.H., McMichael P., dir). Amsterdam, Elsevier, 265-299.

McMichael P., 2009a. A Food Regime Genealogy. The Journal of Peasant Study, 36 (1), 139-169.

McMichael P., 2009b. A Food Regime Analysis of the "World Food Crisis". Agriculture and Human Values, 26, 281-295.

McMichael P., 2012. The Land Grab and Corporate Food Regime Restructuring. The Journal of Peasant Studies, 39 (3-4), 681-701.

McMichael P., 2013. Food Regimes and Agrarian Questions. Halifax, Fernwood Publishing.

McMichael P., 2016. Commentary: Food Regime for Thought. The Journal of Peasant Studies, 43 (3), 648-670.

McNeILl W.H., 1992. The Global Condition: Conquerors, Catastrophes and Community. Princeton, Princeton University Press.

McNeill J.R., 1999. Ecology, Epidemics and Empires: Environmental Change and the Geopolitics of Tropical America, 1600-1825. Environment and History, 5 (2), 175-184.

McNeill J.R., 2000. Something New under the Sun: An Environmental History of the Twentieth Century. Londres, Allen Lane.

McNeill J.R., 2001. Something New under the Sun: An Environmental History of the TwentiethCentury World. New York, Norton. 
Meadows D.L., Meadows D.H., Randers J., 1972. Die Grenzen des Wachstums: Bericht an den Club of Rome. Stuttgart, DVA.

Merchant C., 2002. The Columbia Guide to American Environmental History. New York, Columbia University Press.

Middelberg S., 2014. Agricultural Land Valuation Methods Used by Financiers: The Case of South Africa. Agrekon, 53 (3), 101-115.

Mielniczur F., 2013. BRICS in the Contemporary World: Changing Identities, Converging Interests. Third World Quarterly, 34 (6), 1075-1090.

Millennium Ecosystem Assessment, 2005. Ecosystems and Human Well-being: Vol. 1. Current State and Trends. Washington D. C./Covelo/Londres, Island Press.

Ministère de l'Agriculture, 1999. Contribution française à la conférence OAA/FAO «The Multifunctional Character of Agriculture and Land », 12-17 septembre, Maastricht (Pays-Bas).

Ministry of Agriculture, Forests And Fisheries (MAFF), 2010a. Hōkatsuteki keizai renkei ni kansuru shiryō (Data on Trans-Pacific Strategic Economic Partnership Agreement). Tokyo, MAFF.

Ministry of Agriculture, Forests and Fisheries (MAFF), 2010b. 21 Seiki e no teigen: Solution (Proposal for the $21^{\text {st }}$ Century: Solution). Tokyo, MAFF.

Ministry of Agriculture, Forests and Fisheries (MAFF), 2011a. FY2010 Report on Food, Agriculture and Rural Areas in Japan - Summary. Tokyo, MAFF.

Ministry of Agriculture, Forests and Fisheries (MAFF), 2011b. Report on Results of 2010 World Census on Agriculture and Forests in Japan. Tokyo, MAFF : http://www.maff.go.jp/e/index.html (consulté le 31 juillet 2012).

Ministry of Agriculture, Forests and Fisheries (MAFF), 2011c. Kōsaku hōkichino genjō ni tsuite (The Current Situation on Idle Farmland). Tokyo, MAFF.

Missemer A., 2013. Nicholas Georgescu-Roegen, pour une révolution bioéconomique. Lyon, ENS éditions.

Mistral J., 1982. La diffusion internationale de l'accumulation intensive et sa crise. In : Économie et finance internationales (Reiffers J.L., dir.). Paris, Dunod, 205-237.

Mistral J., 1986. Régime international et trajectoires nationales. In : Capitalisme, fin de siècle (Boyer R., dir.). Paris, PUF.

Mitchell B.R., 2003. International Historical Statistics. New York, Palgrave McMillan.

MMAMRM (Ministerio de medio ambiente y medio rural y marino). Programa Agua, http://www. mma.es/secciones/agua/entrada.htm (page inactive depuis 2014).

Molle F., Mollinga P.P., Wester P., 2009. Hydraulic Bureaucracies and the Hydraulic Mission: Flows of Water, Flows of Power. Water Alternatives, 2 (3), 328-349.

Monni S., Pallottino M., 2015. Editorial. Buen Vivir: A New Toolbox for an Alternative to Neoliberal Dominance? International Journal of Environmental Policy and Decision Making, 1 (3), 184-204.

Montagne S., 2006. Les fonds de pension entre protection sociale et spéculation financière. Paris, Odile Jacob.

Moore J.W., 2003. The Modern World-System as Environmental History? Ecology and the Rise of Capitalism. Theory and Society, 32 (3), 307-377.

Moore J.W., 2010. "Amsterdam is Standing on Norway" Part I: The Alchemy of Capital, Empire and Nature in the Diaspora of Silver, 1545-1648. Journal of Agrarian Change, 10 (1), 33-68.

Moore J.W., 2015. Capitalism in the Web of Life. Londres, Verso Books.

Morgan K., 2000. Atlantic Trade and the British Economy, 1660-1800. Cambridge, Cambridge University Press.

Morgan K., Marsden T., Murdoch J., 2006. Worlds of Food: Place, Power, and Provenance in the Food Chain. Oxford, Oxford University Press.

Muchnik J., Requier-Desjardins D., Sautier D., Touzard J.-M., 2007. Systèmes agroalimentaires localisés. Économies et sociétés, 29, 1465-1484.

Mulgan A.G., 2006. Japan's Agricultural Policy Regime. Londres, Routledge.

Muller P., 1984. Le technocrate et le paysan. Paris, Les éditions ouvrières.

Muller P., 1990. Les politiques publiques entre secteurs et territoires. Politiques et management public, 8 (3), 19-33.

Muller P., 2000. La politique agricole française : l'État et les organisations professionnelles. Économie rurale, 255-256, 33-39. 
MulLer P., 2010a. Les changements d'échelles des politiques agricoles : introduction. In : Les mondes agricoles en politique : de la fin des paysans au retour de la question agricole (Hervieu B., Mayer N., Muller P., Purseigle F., Rémy J., dir.). Paris, Presses de Sciences Po, 339-350.

Muller P., 2010b. Secteur. In : Dictionnaire des politiques publiques (Boussaguet L., Jacquot S., Ravinet P., dir.). Paris, Les Presses de Sciences Po, 591-599.

Müller-Herold U., Sieferle R.P., 1997. Surplus and Survival: Risk, Ruin and Luxury in the Evolution of Early Forms of Subsistence. Advances in Human Ecology, 6, 201-220.

Mumford L., 1934. Technics and Civilization. New York, Harcourt.

Mummert A., Esche E., Robinson J., Armelagos G.J., 2011. Stature and Robusticity During the Agricultural Transition: Evidence from the Bioarchaeological Record. Economics \& Human Biology, 9 (3), 284-301.

MundLer P., 2006. Les combinaisons d'activités des agriculteurs rhônalpins. Agreste Rhône-Alpes : Coup d'œeil, 86.

Mundler P., Laurent C., 2003. Flexibilité du travail en agriculture : méthodes d'observation et évolutions en cours. Ruralia, 12-13, 239-257.

Murdoch J., 1998. The Spaces of Actor-Network Theory. Geoforum, 29 (4), 357-374.

Murdoch J., Marsden T., Banks J., 2000. Quality, Nature and Embeddedness: Some Theoretical Considerations in the Context of the Food Sector. Economic Geography, 76 (2), 107-125.

Murdoch J., Miele M., 1999. "Back to Nature": Changing "Worlds of Production" in the Food Sector. Sociologia Ruralis, 39 (4), 465-483.

Murdoch J., Miele M., 2004. Culinary Networks and Cultural Connections: A Conventions Perspective. In : Geographies of Commodity Chains (Hughes A., Reimer S., dir.). Londres, Routledge, 102-119.

Murphy S., Burch D., Clapp J., 2012. Cereal Secrets: The World's Largest Grain Traders and Global Agriculture. Oxford, Oxfam Research Reports.

Murphy A.M., van Moorsel D., Ching M., 2007. Agricutural Biotechnology to 2030: Steady Progress on Agricultural Biotechnology. Paris, OCDE.

National Industrial Conference Board, 1929. Industrial Standardization. New York, National Industrial Conference Board.

Naughton B., 2007. The Chinese Economy: Transitions and Growth. Cambridge (Mass.), The MIT Press.

NeFussi J., 1987. Les industries agro-alimentaires en France croissance et financement 1950-1985. Essai sur l'intégration financière et la dynamique industrielle. thèse de docteur ingénieur, Paris, Inap-G.

Nelson E., Tovar L.G., Rindermann R.S., Cruz M.A.G., 2010. Participatory Organic Certification in Mexico: An Alternative Approach to Maintaining the Integrity of the Organic Label. Agriculture and Human Values, 27 (2), 227-237.

Nesme T., Nowak B., David C., Pellerin S., 2016. L'agriculture biologique peut-elle se développer sans abandonner son principe d'écologie ? Le cas de la gestion des éléments minéraux fertilisants. Innovations agronomiques, 51, 57-66.

New S.J., 1997. The Scope of Supply Chain Management Research. Supply Chain Management, $2(1), 15-22$.

Nguyen G., Purseigle F., 2012. Les exploitations agricoles à l'épreuve de la firme : l'exemple de la Camargue. Études rurales, (190), 99-118.

Nicholson C., Young B., 2012. The Relationship Between Supermarkets and Suppliers: What Are the Implications for Consumers? Londres, Consumers International.

Nicolas F., Valceschini E. (dir.), 1995. Agro-alimentaire : une économie de la qualité. Versailles/ Paris, Inra éditions/Economica.

NicourT C., 2013. Etre agriculteur aujourd'hui : l'individualisation du travail des agriculteurs. Versailles, Éditions Quæ.

Nieddu M., 1998. Dynamiques de longue période dans l'agriculture productiviste et mutations du système agro-industriel français contemporain. thèse de doctorat en sciences économiques, Reims, Université de Reims.

Nieddu M., Gaignette A., 2000. L'agriculture française entre logiques sectorielles et territoriales (1960-1985). Cahiers d'économie et de sociologie rurales, 54, 48-87.

Nieddu M., Garnier E., Bliard C., 2010. L'émergence d'une chimie doublement verte. Revue d'économie industrielle, 132, 53-84. 
Nieddu M., Van Niel J., Youssef A., 2013. Novamont : un modèle de bioraffinerie sans biocarburants. Biofutur, 32 (344), 52-59.

Nieddu M., Vivien F.-D., 2015. La chimie verte, une fausse rupture ? Les trajectoires de la transition écologique. Revue française de socio-économie, 2, 139-153.

Nieddu M., Vivien F.-D., 2016a. La bioéconomie : entre enjeux économiques et projets de société. Biofutur, 35 (378), 60-61.

Nieddu M., Vivien F.-D., 2016b. La bioraffinerie comme objet transitionnel de la bioéconomie. Économie rurale, 349-350, 7-11.

Nielsen K., Jessop B., Hausner J., 1995. Institutional Change in Post-socialism. In : Strategic Choice and Path-dependency in Post-socialism: Institutional Dynamics in the Transformation Process (Hausner J., Jessop B., Nielsen K., dir.). Cheltenham, Edward Elgar, 3-34.

Niggli U., Anamarija S., Schmid O., Halberg N., Schlüter M., 2008. Vision for an Organic Food and Farming Research Agenda 2025 - Organic Knowledge for the Future. Bruxelles, Ifoam Regional Group European Union.

Nobunkyō (dir.), 2010. TPP hantai no taigi (The Just Cause Against TPP). Tokyo, Nobunkyō.

Nōrinsuisan chōKikin'yu kyōKai (Agriculture, Forestry and Fisheries Long-term Finance Association), 2005. Hokkaido ni okeru rakunō to megafuamu no tenbo ni kansuru chosa hokokusho (Survey Report on the Prospects for Hokkaido's Dairy and Mega-Farms). Sapporo, Nōrinsuisan chōkikin'yu Kyōkai.

Norman D.A., 1993. Les artefacts cognitifs. In: Les objets dans l'action, de la maison au laboratoire, (Conein B., Dodier N., L. Thévenot L., dir.). Paris, EHESS. Collection Raisons pratiques 4, 15-34.

North D., 1958. Ocean Freight Rates and Economic Development. Journal of Economic History, 18 (4), 537-555.

NoRTHRuP D., 1995. Indentured Labor in the Age of Imperialism, 1834-1922. Cambridge, Cambridge University Press.

Nowotny H., Scott P., Gibbons M., 2001. Re-Thinking Science: Knowledge and the Public in a Age of Uncertainty. Cambridge, Polity Press.

NRiagu J.O., 1994. Mercury Pollution from the Past Mining of Gold and Silver in the Americas. The Science of the Total Environment, 149 (3), 167-181.

NyBerg D., Wright C., 2013. Corporate Corruption of the Environment: Sustainability as a Process of Compromise. The British Journal of Sociology, 64 (3), 405-424.

O'Connor J., 1988. Capitalism, Nature, Socialism: A Theoretical Introduction. Capitalism, Nature, Socialism, 1 (1), 11-38.

O'Connor J., 1998. Natural Causes: Essays in Ecological Marxism. New York/Londres, The Guilford Press.

OCDE, 1998. Les technologies du XXI siècle. Promesses et périls d'un futur dynamique. Paris, OCDE.

OCDE, 2002. Distributive Public Governance: Agencies, Authorities and other Government Bodies. Paris, OCDE.

OCDE, 2005. OECD Review of Agricultural Policies: China 2005. Paris, OCDE.

OCDE, 2006a. OECD Economic Surveys: Japan. Paris, OCDE.

OCDE, 2006b. The Bioeconomy to 2030: Designing a Policy Agenda Scoping Paper. Paris, OCDE.

OCDE, 2009. The Bioeconomy to 2030: Designing a Policy Agenda. Paris, OCDE.

OCDE, 2011. Agricultural Policy Monitoring and Evaluation 2011. Paris, OCDE.

OCDE, 2013. Agricultural Policy Monitoring and Evaluation 2013. Paris, OCDE.

Oddy D. J., 2003. From Plain Fair to Fusion Food. Woodbridge, Boydell Press.

OrlÉAn A., 1989. Pour une approche cognitive des conventions économiques. Revue économique, 40 (2), 241-272.

OrléAn A., 1994. Analyse économique des conventions. Paris, Presses universitaires de France.

OrLÉAN A., 2000. L'individu, le marché et l'opinion : réflexions sur le capitalisme financier. Esprit, novembre 2000, 51-75.

OrLÉAN A., 2004. L'économie des conventions : définitions et résultats. In : Analyse économique des conventions (Orléan A., dir.). préface de la $4^{\mathrm{e}}$ édition, Paris, Presses universitaires de France, 9-48.

ORLÉAN A., 2011. L'empire de la valeur : refonder l'économie. Paris, Seuil.

ORSI F., 2013. Elinor Ostrom et les faisceaux de droits : l'ouverture d'un nouvel espace pour penser la propriété commune. Revue de la régulation, 14 (2), revue en ligne : https://regulation.revues. org/10471 (consulté le 8 octobre 2016). 
Ortiz H., 2008. Anthropologie politique de la finance contemporaine : évaluer, investir, innover. thèse de doctorat en anthropologie, Paris, EHESS.

Ortiz H., 2014. Financial Valuation and Investment: Techniques, Organizations, Politics. In : Finance, Food and Farming Workshop. 25 janvier, La Hague, International Institute of Social Studies (ISS).

Ostrom E., 2005. Understanding Institutional Diversity. Princeton, Princeton University Press.

Ostrom E., 2010. Beyond Markets and States: Polycentric Governance of Complex Economic Systems. American Economic Review, 100 (3), 1-33.

Ouma S., 2014. Situating Global Finance in the Land Rush Debate: A Critical Review. Geoforum, $57,162-166$.

Overbeek H., Dingwerth K., Pattber P., Compagnon D., 2010. Forum: Global Governance. Decline or Maturation of an Academic Concept? International Studies Review, 12 (4), 696-719.

Padel S., Niggli U., Pearce B., Schlüter M., Schimd O., Cuoco E., Willer E., Huber M., Halberg N., Micheloni C., 2010. TP Organics, Implementation Action Plan for Organic Food and Farming Research. Bruxelles, Ifoam-EU Group.

Painter D., 1984. Oil and the Marshall Plan. Business History Review, 58 (3), 359-383.

Palpacuer F., Pérez R., Tozanl S., Brabet J., 2006. Financiarisation et globalisation des stratégies d'entreprise : le cas des multinationales agroalimentaires en Europe. Finance, contrôle, stratégie, 9 (3), 165-189.

Parrott N., Wilson N., Murdoch J., 2002. Spatializing Quality: Regional Protection and the Alternative Geography of Food. European Urban and Regional Studies, 9 (3), 241-261.

Parthasarathi P., 2011. Why Europe Grew Rich and Asia Did Not: Global Economic Divergence, 1600-1850. Cambridge, Cambridge University Press.

PASSET R., 1979. L'économique et le vivant. Paris, Economica.

Pecqueur B., 2001. Gouvernance et régulation : un retour sur la nature du territoire. Géographie, économie, société, 3 (2), 229-245.

Pecqueur B., Zimmermann J.B. (dir.), 2004. Économie de proximités. Paris, Hermes.

Pellegrini P., 1999. De l'idée de race animale et de son évolution dans le milieu de l'élevage. Ruralia, 5, revue en ligne : http://ruralia.revues.org/112 (consulté le 10 mai 2014).

Pérez Picazo M.T., Lemeunier G., 2000. Formation et mise en cause du modèle de gestion hydraulique espagnol de 1780 à 2000. Économies et sociétés, 37, 71-98.

Pernet F., 1982. Résistances paysannes. Grenoble, Presses universitaires de Grenoble.

Perraud D., 1985. Crise laitière et transformation des modes de régulation sectoriels : conclusions provisoires. In : Actes du colloque franco-québécois "Politiques agroalimentaires et développement rural », 7-10 octobre, Rimouski (Québec), Université du Québec, 43-49.

Perraud D., 1995. PAC, États, régions : l'articulation des niveaux de politique agricole dans l'UE. Économie rurale, 227, 2-10.

Perrier-Cornet P., Sylvander B., 2000. Firmes, coordinations et territorialité : une lecture économique de la diversité des filières d'appellation d'origine. Économie rurale, 258 (1), 79-89.

Perrot C., Chatellier V., Gouin D.M., 2015. Les exploitations laitières françaises sont-elles compétitives? In : $23^{e}$ journée Rencontres recherches ruminants $(3 R), 8 \mathrm{p}$.

Pestre D., 2003. Regimes of Knowledge Production in Society: Towards a More Political and Social Reading. Minerva, 41 (3), 245-61.

Pestre D., 2013. À contre-science : politiques et savoirs des sociétés contemporaines. Paris, Seuil.

Petit P., 1998. Formes structurelles et régimes de croissance de l'après fordisme. Recherches \& Régulation Working Papers, K 1998-1, consultable à l'adresse suivante : https://www.researchgate. net/profile/Pascal_Petit3/publication/4749139_Formes_structurelles_et_regimes_de_croissance_ de_l'apres_fordisme/links/56b5e08c08aebbde1a79b5e5.pdf (consulté le 13 octobre 2016).

Pezet A., Morales J., 2010. Les contrôleurs de gestion, « médiateurs » de la financiarisation. Comptabilité contrôle audit, 16 (1), 101-132.

Pfister C., 2003. Energiepreis und Umweltbelastung. Zum Stand der Diskussion über das "1950er Syndrom”. In : Umweltgeschichte Themen und Perspektiven (Siemann W., dir.). Munich, C.H. Beck, 61-86.

PiketTy T., 2013. Le capital au xxie siècle. Paris, Seuil.

Pimentel D., Pimentel M., 1979. Food, Energy and Society. Londres, Edward Arnold. 
PIRIOU S., 2002. L'institutionnalisation de l'agriculture biologique (1980-2000). thèse de doctorat, Rennes, École nationale supérieure agronomique de Rennes.

Plumecoce G., 2014. The Second Generation of Ecological Economics: How Far Has the Apple Fallen from the Tree? Ecological Economics, 107, 457-468.

PodobNik B., 1999. Toward a Sustainable Energy Regime, a Long-wave Interpretation of Global Energy Shifts. Technological Forecasting and Social Change, 62 (3), 155-172.

Polanyi K., 1957 [1944]. The Great Transformation. Boston, Beacon Press.

POLANYI K., 1983 [1944]. La grande transformation : aux origines politiques et économiques de notre temps. Paris, Gallimard.

Poméon T., Desquilbet M., Monier-Dilhan S., 2014. Les standards privés dans le développement de l'agriculture biologique. In : Colloque Renouveler les approches institutionnalistes sur l'agriculture et l'alimentation : La "grande transformation » 20 ans après, 16-17 juin, Montpellier, Montpellier SupAgro.

Pomeranz K., 2000. The Great Divergence: China, Europe and the Making of the Modern World Economy. Princeton, Princeton University Press.

Pomeranz K., 2010. Une grande divergence : la Chine, l'Europe et la construction de l'économie mondiale. Paris, Albin Michel.

Ponte S., 2009. Governing through Quality: Conventions and Supply Relations in the Value Chain for South African Wine. Sociologia Ruralis, 49 (3), 236-257.

Ponte S., Cheyns E., 2013. Voluntary Standards and the Governance of Sustainability Networks. Global Networks, 13 (4), 459-477.

Ponte S., Daviron B., 2011. Creating and Controlling Symbolic Value. In : The Cultural Wealth of Nations (Bandelj N., Wherry F., dir.). Stanford (Californie), Stanford University Press, 197-221.

Ponte S., Gibbon P., 2005. Quality Standards, Conventions and the Governance of Global Value Chains. Economy and Society, 34 (1), 1-31.

Ponte S., Sturgeon T., 2014. Explaining Governance in Global Value Chains: A Modular Theorybuilding Effort. Review of International Political Economy, 21 (1), 195-223.

Power M., 1997. The Audit Society: Rituals of Verification. Oxford, Oxford University Press.

Prigogine I., 1969. Structure, Dissipation and Life. In: Theoretical Physics and Biology. Amsterdam, North-Holland Publication Company, 23-52.

Puech D., Boisson J.-M., 1995. Eau-ressource et eau-milieu : une interdépendance croissante impliquant une évolution des modalités de gestion. In : Eau-ressource et eau-milieu. Vers une gestion durable. Les cahiers de l'économie méridionale, 1, 5-47.

Pulido Bosch A. (dir.), 2005. Recarga en la Sierra de Gádor e hidrogeoquímica de los acuíferos del Campo de Dalías. Almeria, Estación experimental Cajamar.

Quemia M., 2001. Théorie de la régulation et développement : trajectoires latino-américaines. L'année de la régulation, 5, 57-103.

Quetglás G.M., Grau B.C., 2002. Aspects of University Research and Technology Transfer to Private Industry. Journal of Business Ethics, 39 (1), 51-58

Raikes P., Jensen M.F., Ponte S., 2000. Global Commodity Chain Analysis and the French Filière Approach: Comparison and Critique. Economy and Society, 29 (3), 390-417.

Ramaux C., 2012. L'État social : pour sortir du chaos néolibéral. Paris, Fayard/Mille et une nuits.

RAstoin J.-L., Ghersi G., 2010. Le système alimentaire mondial. Versailles, Éditions Quæ.

Raynolds L.T., 2002. Consumer/Producer Links in Fair Trade Coffee Networks. Sociologia Ruralis, 42 (4), 404-424.

RaYnolds L.T., 2004. The Globalization of Organic Agro-Food Networks. World Development, $32(5), 725-743$.

RAYNolds L.T., 2012a. Fair Trade Flowers: Global Certification, Environmental Sustainability, and Labor Standards. Rural Sociology, 77 (4), 493-519.

RAYNOLDS L.T., 2012b. Fair Trade: Social Regulation in Global Food Markets. Journal of Rural Studies, 28 (3), 276-287.

Raynolds L.T., Murray D., Heller A., 2007. Regulating Sustainability in the Coffee Sector: A Comparative Analysis of Third-party Environmental and Social Certification Initiatives. Agriculture and Human Values, 24 (2), 147-163. 
Reardon T., Berdegue J., Flores L., Balsevich F., Hernandez R., 2007. Supermarkets, Horticultural Supply Chains, and Small Farmers in Central America. FAO Commodities and Trade Proceedings, 95-104.

Reardon T., Chen K.Z., Minten B., Adriano L., The Anh D., Wang J., Gupta S. D., 2014. The Quiet Revolution in Asia's Rice Value Chains. Annals of the New York Academy of Sciences, 1331, 106-118.

Redon M., 2014. L'influence des Directeurs administratifs et financiers dans le processus de financiarisation. mémoire de master en gestion, Paris, Université Paris-Dauphine.

Rees W., Wackernagel M., 1996. Our Ecological Footprint: Reducing Human Impact on the Earth. Gabriola Island (B. C.), New Society Publishers.

Reganold J.P., Wachter J.M., 2016. Organic Agriculture in the Twenty-First Century. Nature Plants, 2, en ligne : doi:10.1038/nplants.2015.221.

Reinert E., 2007. How Rich Countries Got Rich. Why Poor Countries Stay Poor. Londres, Constable.

Reiter E., 1991. Making Fast Food: From the Frying Pan into the Fryer. Montréal, McGill-Queens University Press.

RémY J., 1982. Distinction, promotion et sélection des agriculteurs : le rôle des organismes de développement. Économie rurale, 152, 67-71.

Renard M.C., 2003. Fair Trade: Quality, Market and Conventions. Journal of Rural Studies, 19 (1), 87-96.

Reynaud J.-D., 1989. Les règles du jeu : l'action collective et la régulation sociale. Paris, Armand Colin.

RicARD D., Rieutort L., 1995. Filières agro-alimentaires et moyennes montagnes françaises. Revue de géographie alpine, 83 (3), 101-114.

Richards J., 2003. The Unending Frontier. An Environmental History of the Early Modern World. Berkeley/Los Angeles, University of California Press.

Richard-Ferroudi A., Barreteau O., 2012. Assembling Different Forms of Knowledge for Participative Water Management: Insights from the Concert'eau Game. In : Environmental Democracy Facing Uncertainty (Claeys C., Jacqué M., dir.), 19 p., http://hal.ird.fr/hal-00777847/document (consulté le 13 octobre 2016).

Risgaard L., Gibbon P., 2014. Labour Management on Contemporary Kenyan Cut Flower Farms: Foundations of an Industrial-Civic Compromise. Journal of Agrarian Change, 14 (2), 260-285.

Rivera MenÉndez J., 2000. La política de colonización agraria en el Campo de Dalías (1940-1990). Cajamar/Almeria, Instituto de estudios Almerienses.

Robertson T., 2008. This is the American Earth: American Empire, the Cold War, and American Environmentalism. Diplomatic History, 32 (4), 561-584.

RoBidel J.P., 2014. Quantifier et cartographier l'agriculture biologique des années 1980-90 en France. In : Dynamiques des agricultures biologiques : effets de contexte et appropriations (Cardona A., Chrétien F., Leroux B., Ripoll F., Thivet D., dir.). Dijon/Versailles, Educagri éditions/Éditions Quæ, 45-56.

Roddier F., 2012. Thermodynamique de l'évolution : un essai de thermo-bio-sociologie. Artignoscsur-Verdon, Éditions Parole.

Rosin C., 2008. The Conventions of Agri-environmental Practice in New Zealand: Farmers, Retail Driven Audit Schemes and a New Spirit of Farming. GeoJournal, 73 (1), 45-54.

Rosin C., Campbell H., 2009. Beyond Bifurcation: Examining the Conventions of Organic Agriculture in New Zealand. Journal of Rural Studies, 25 (1), 35-47.

Rosset P.M., Altieri M.A., 1997. Agroecology Versus Input Substitution: A Fundamental Contradiction of Sustainable Agriculture. Society \& Natural Resources, 10 (3), 283-295.

Rousseau S., 2002. Économie et environnement : une analyse régulationniste de la rente environnementale. thèse de doctorat en économie, Lille, Université Lille 1.

Roux B., 2006. Agriculture, marché du travail et immigration : une étude dans le secteur des fruits et légumes méditerranéens. Mondes en développement, 134, 103-117.

Roux B., 2010. Les modalités du développement des cultures intensives sous abri en Andalousie. In : Agricultures et paysanneries du monde (Wolfer B., dir.). Versailles, Éditions Quæ, 103-119.

Ruet F., 2004. De la vache machine en élevage laitier. Quaderni, 56 (1), 59-69.

RuF T., 2010. Dynamismes comparés et contrastés des sociétés paysannes méditerranéennes et de leurs territoires hydrauliques. In : Agricultures et paysanneries du monde (Wolfer B., dir.). Versailles, Éditions Quæ, 145-184. 
RugGIE J.G., 1982. International Trade, Transactions, and Change: Embedded Liberalism in the Postwar Economic Order. International Organization, 36 (2), 379-415.

Rylko D., Jolly R.W., 2005. Russia's New Agricultural Operators: Their Emergence, Growth and Impact. Comparative Economic Studies, 47 (1), 115-126.

SAGE C., 2013. The Interconnected Challenges for Food Security from a Food Regimes Perspective: Energy, Climate and Malconsumption. Journal of Rural Studies, 29, 71-80.

SAHLins M. D., 1976. Âge de pierre, âge d'abondance: l'économie des sociétés primitives. Paris, Gallimard.

Sakuyama T., 2014. The Grand Design for Japan's Agriculture, Forestry and Fisheries Policies, en ligne : http://ap.fftc.agnet.org/ap_db.php?id+295\&print=1 (consulté le 6 janvier 2015).

SAlais R., Storper M., 1992. The Four "Worlds" of Contemporary Industry. Cambridge Journal of Economics, 16 (2), 169-193.

SALAis R., ThÉVEnot L. (dir.). 1986. Le travail : marché, règles, conventions. Paris, Insee/Economica.

SÁnchez-Hernández J.L., 2011. The Food Value Chain as a Locus for (dis) Agreement: Conventions and Qualities in the Spanish Wine and Norwegian Salted Cod Industries. Geografiska Annaler: Series B, Human Geography, 93 (2), 105-119.

Sánchez-Hernández J.L., Aparicio-Amador J., Alonso-Santos J.L., 2010. The Shift between Worlds of Production as an Innovative Process in the Wine Industry in Castile and Leon (Spain). Geoforum, 41 (3), 469-478.

SÁNCHEZ Picón A., 2005. De frontera a milagro. La conformación histórica de la economía almeriense. In : La economía de la provincia de Almería (Molina Herrera J., dir.). Almeria, Instituto Cajamar, 43-85.

SANJUAn EstRADa J.F., 2007. Detección de la superficie invernada en la provincia de Almería a través de imágenes ASTER. Almeria, Fiapa.

SaUlais L., 2015. Foodservice, Health and Nutrition: Responsibility, Strategies and Perspectives. In : The Routledge Handbook of Sustainable Food and Gastronomy (Sloan P., Legrand W., Hindley C., dir.). New York/Londres, Routledge, 256-263.

SCAR (Standing Committee on Agricultural Research), 2015. Sustainable Agriculture, Forestry and Fisheries in the Bioeconomy. A Challenge for Europe. $4^{\text {th }}$ SCAR Foresight Exercise, Bruxelles, European Commission.

SCAR FEG, 2007. Foresight Expert Group, FFRAF Report: Foresight Food, Rural and Agri-futures. Standing Committee on Agricultural Research, Bruxelles, Consultative Expert Group.

Schaffartzik A., Mayer A., Gingrich S., Eisenmenger N., Loy C., Krausmann F., 2014. The Global Metabolic Transition: Regional Patterns and Trends of Global Material Flows. 1950-2010. Global Environmental Change, 26, 87-97.

Schandl H., Krausmann F., 2007. The Great Transformation: A Socio-metabolic Reading of the Industrialization of the United Kingdom. In : Socioecological Transitions and Global Change: Trajectories of Social Metabolism and Land Use (Fischer-Kowalski M., Haberl H., dir.). Cheltenham/ Northampton, Edward Elgar, 83-115.

Schandl H., Schulz N., 2002. Changes in the United Kingdom's Natural Relations in Terms of Society's Metabolism and Land-Use from 1850 to the Present Day. Ecological Economics, 41 (2), 203-221.

Schieb P.-A, Philip J.C., 2014. Biorefining Policy Needs to Come of Age. Trends in Biotechnology, $32(10), 496-500$.

Schlager E., Ostrom E., 1992. Property Rights Regime and Natural Resources: A Conceptual Analysis. Land Economics, 68 (3), 249-262.

Schneider M., Sharma S., 2014. China's Pork Miracle? Agribusiness and Development in China's Pork Industry. La Hague, Institute of Agriculture and Trade Policy.

Schonhardt-Bailey C., 2006. From the Corn Laws to Free Trade. Cambridge (Mass.), The MIT Press.

Sснотт J., 2009. America, Europe and the New Trade Order. Business and Politics, 11 (3), 1-22.

Schulman J.P., 1978. Analyse énergétique de l'agriculture française. mémoire de DEA, Paris, Université Paris I.

Scнwoов M.-H., 2015. The Political Dimension of Agricultural Markets Information: Views from within China. Working Papers $\mathrm{N}^{\circ} 07 / 15$, Paris, Iddri.

Scott A., Pasqualoni P.P., 2014. The Making of a Paradigm. Exploring the Potential of Economy of Conventions and Pragmatic Sociology. In : The Oxford Handbook of Sociology, Social Theory and 
Organization Studies (Adler P.S., du Gay P., Morgan G., Reed M.). Oxford, Oxford University Press, 64-87.

SEGRestin D., 1997. L'entreprise à l'épreuve des normes de marché : les paradoxes des nouveaux standards de gestion dans l'industrie. Revue française de sociologie, 38 (3), 553-585.

SÉGUY L., 2014. De la nutrition à l'étiquetage nutritionnel : une histoire de la domestication marchande et politique des nutriments. thèse de doctorat en sociologie, Toulouse, Université Toulouse Jean Jaurès.

SGard F., Harayama Y., 2013. La bioéconomie aujourd'hui et ses perspectives de développement. Réalités industrielles, 1, février, dossier La bioéconomie, élément clé des transitions énergétiques et écologiques, 5-11.

Sharma S., 2014. The Need for Feed. China's Demand for Industrial Meat and its Impacts. Global Meat Complex: The China Series, La Hague, Institute of Agriculture and Trade Policy, consultable en ligne : http://www.iatp.org/documents/the-need-for-feed-china\%E2\%80\%99s-demand-for-industrializedmeat-and-its-impacts (consulté le 16 janvier 2017).

Sharma S., Rou Z., 2014. China's Dairy Dilemma: The Evolution and Future Trends of China's Dairy Industry. La Hague, Institute of Agriculture and Trade Policy, consultable en ligne : http:// www.iatp.org/documents/china $\% \mathrm{E} 2 \% 80 \% 99 \mathrm{~s}$-dairy-dilemma-the-evolution-and-future-trends-ofchina\%E2\%80\%99s-dairy-industry (consulté le 16 janvier 2017).

Shogensi S., 2010. Nihon no nōsei kaikaku: genba shiten no nōsei tenkai (Reform of Japanese Agriculture Policy: Changes in Agriculture Policy from the Viewpoint of the Field). Tokyo, Tokyo zaidan kenkyūsho.

Shove E., Walker G., 2007. Caution! Transitions Ahead: Politics, Practice, and Sustainable Transition Management. Environment and Planning A, 39 (4), 763-770.

Sieferle R.P., 2001. The Subterranean Forest: Energy Systems and the Industrial Revolution. Cambridge, The White Horse Press.

SiefERLE R.P., 2003. Nachhaltigkeit in universalhistorischer Perspektive. In : Umweltgeschichte Themen und Perspektiven (Siemann W., dir.). Munich, C.H. Beck, 39-60.

Silber I.F., 2003. Pragmatic Sociology as Cultural Sociology. European Journal of Social Theory, 6 (4), 427-449.

Silva-Castañeda L., 2012. A Forest of Evidence: Third-party Certification and Multiple Forms of Proof: A Case Study of Oil Palm Plantations in Indonesia. Agriculture and Human Values, 29 (3), 361-370.

Silva-Castañeda L., 2015. What Kind of Space? Multi-stakeholder Initiatives and the Protection of Land Rights. International Journal of Sociology of Agriculture and Food, 22 (2), 67-83.

Silva-CastañEda L., 2016. In the Shadow of Benchmarks: Normative and Ontological Issues in the Governance of Land. Environment and Planning A, 48 (4), 681-698.

Singh S.J., Haberl H., Gaube V., Grünbühel C.M., Lisievici P., Lutz J., Matthews R., Mirtl M., Vadineanu A., Wildenberg M., 2010. Conceptualising Long-term Socio-ecological Research (LTSER): Integrating the Social Dimension. In : Long-term Ecological Research, between Theory and Application (Müller F., Baessler C., Schubert H., Klotz S., dir.). Dordrecht/Heidelberg/Londres/New York, Springer, 377-398.

Slicher Van Bath N.H., 1963. The Agrarian History of Western Europe 500-1850. Londres, Edward Arnold Ltd.

Smil V., 2001. Enriching the Earth: Fritz Haber, Carl Bosch, and the Transformation of World Food Production. Cambridge (Mass.)/Londres, MIT Press.

Smil V., 2003. Energy at the Crossroads: Global Perspectives and Uncertainties. Cambridge (Mass.)/ Londres, MIT Press.

Smil V., Kobayashi K., 2012. Japan's Dietary Transition and its Impacts. Cambridge (Mass.), The MIT Press.

Schmid O., Padel S., Halberg N., Huber M., Darnhofer I., Micheloni C., Koopmans C., Bügel S., Stopes C., Willer H., Schlüter M. Cuoco E., 2009. Strategic Research Agenda for Organic Food and Farming. Bruxelles, Ifoam-EU Group.

Sмiтн T., 1989. Native Sources of Japanese Industrialization, 1750-1920. Berkeley, University of California Press.

Sмith G., 2009. Interaction of Public and Private Standards in the Food Chain. OECD Food, Agriculture and Fisheries Working Papers, No. 15, Paris, OECD Publishing. 
Smith A., Costa O., Maillard J., 2007. Vin et politique : Bordeaux, la France, la mondialisation. Paris, Presses de Sciences Po.

Smith A., Raven R., 2012. What Is Protective Space? Reconsidering Niches in Transitions to Sustainability. Research Policy, 41 (6), 1025-1036.

Smith A., Stirling A., Berkhout F., 2005. The Governance of Sustainable Socio-technical Transitions. Research Policy, 34 (10), 1491-1510.

Smith A., Voss J.-P., Grin J., 2010. Innovation Studies and Sustainability Transitions: The Allure of the Multi-level Perspective and its Challenges. Research Policy, 39 (4), 435-448.

Solow B., 1985. Caribbean Slavery and British Growth: The Eric Williams Hypothesis. Journal of Development Economics, 17 (1-2), 99-115.

Sombart W., 1928. Der moderne Kapitalismus. Munich/Leipzig, Duncker/Humblot.

Soussana J.-F., 2013. S'adapter au changement climatique. Versailles, Éditions Quæ.

Spash C.L., 1999. The Development of Environmental Thinking in Economics. Environmental Values, 8 (4), 413-435.

SPINDLER F., 2002. Les races bovines en France au XIX siècle, spécialement d'après l'enquête agricole de 1862. Ethnozootechnie, dossier Éléments d'histoire des races bovines et ovines en France, hors-série 3, 17-57.

Staffas L., Gustavsson M., McCormick K., 2013. Strategies and Policies for the Bioeconomy and Bio-Based Economy: An Analysis of Official National Approaches. Sustainability, 5 (6), 2751-2769.

Stark D., 2011. The Sense of Dissonance: Accounts of Worth in Economic Life. Princeton, Princeton University Press.

Stassart P.M., Jamar D., 2009. Agriculture biologique et verrouillage des systèmes de connaissances : conventionnalisation des filières agroalimentaires bio. Innovations agronomiques, 4, 313-328.

Steel C., 2008. Hungry City: How Food Shapes Our Lives. Londres, Vintage.

Steffen W., Crutzen P.J., McNeill J.R., 2007. The Anthropocene: Are Humans Now Overwhelming the Great Forces of Nature. Ambio, 36 (8), 614-621.

Steiner P. (dir.), 2014. Les marchés contestés. Toulouse, Presses universitaires du Mirail.

Storper M., Salais R., 1997. Worlds of Production: The Action Frameworks of the Economy. Cambridge (Mass.), Harvard University Press.

Storz C., Amable B., Caspar S., Lechevalier S. (dir.), 2013. Bringing Asia into the Comparative Capitalist Perspective. Socio-Economic Review, 11 (2), 217-232.

StRÆte E.P., 2004. Innovation and Changing "Worlds of Production": Case-studies from Norwegian Dairies. European Urban and Regional Studies, 11 (3), 227-241.

Strange S., 2011. China's Post-listian Rise: Beyond Radical Globalisation Theory and the Political Economy of Neoliberal Hegemony. New Political Economy, 16 (5), 539-559.

Swart W., Donno L., 1981. Simulation Modeling Improves Operations, Planning, and Productivity of Fast Food Restaurants. Interfaces, 11 (6), 35-47.

Swyngedouw E., 2007. Technonatural Revolutions: The Scalar Politics of Franco's Hydro-social Dream for Spain, 1939-1975. Transactions of the Institute of British Geographers, 32 (1), 9-28.

Sylvander B., 1995. Convention de qualité, concurrence et coopération : cas du «Label rouge » dans la filière volaille. In : La grande transformation de l'agriculture : lectures conventionnalistes et régulationnistes (Allaire G., Boyer R., dir.). Versailles/Paris, Inra éditions/Economica, 73-96.

Sylvander B., Allaire G., Belletti G., Marescotti A., Barjolle D., Thevencod-Mottet E., TREgear A., 2006. Qualité, origine et globalisation : justifications générales et contextes nationaux, le cas des Indications géographiques. Canadian Journal of Regional Science, 29 (1), 43-54.

Sylvander B., Barjolle D., Arfini F., 2000. The Economics of Origin Labelled Products in Agrifood Supply Chains: Spatial, Institutional and Coordination Aspects. Inra Actes et communications, 17.

TAinter J.A., 1988. The Collapse of Complex Societies. Cambridge, Cambridge University Press.

TAllontiRe A., 2007. CSR and Regulation: Towards a Framework for Understanding Private Standards Initiatives in the Agri-food Chain. Third World Quarterly, 28 (4), 775-791.

TAVERNIER Y., 1967. Une nouvelle administration pour l'agriculture : la réforme du ministère. Revue française de science politique, 17 (5), 889-917.

TAYLor F.W., 1911. The Principles of Scientific Management. New York, Harper.

TeIL G., 2013. Le label AB, dispositif de promesse ou de jugement? Natures sciences sociétés, 21 (2), 213-222. 
Thaler R.H., Sunstein C.R., 2008. Nudge: Improving Decisions about Health, Wealth and Happiness. New Haven/Londres, Yale University Press.

The World Bank Group, 2007. World Development Indicators 2007. CD-Rom, Washington D. C., The World Bank.

ThÉRet B., 2001. Saisir les faits économiques : la méthode Commons. Cahiers d'économie politique, 40-41, 79-137.

ThÉRET B., 2005. Économie, éthique et droit : la contribution de l'économie institutionnelle de John R. Commons à la compréhension de leurs (cor)relations. In : Éthique médicale et politique de santé (Batifoulier P., Gadreau M., dir.). Paris, Economica, 63-91.

ThÉRET B., 2013. Dettes et crise de confiance dans l'euro : analyse et voies possibles de sortie par le haut. Revue française de socio-économie, 12, 91-124.

ThÉvenot L., 1989a. Équilibre et rationalité dans un univers complexe. Revue économique, 40 (2), 147-197.

Thévenot L., 1989b. Économie et politique de l'entreprise ; économies de l'efficacité et de la confiance. In : Justesse et justice dans le travail (Boltanski L., Thévenot L., dir.). Cahiers du Centre d'études de l'emploi, 33, Paris, Presses universitaires de France, 135-207.

Thévenot L., 1995. Des marchés aux normes. In : La grande transformation de l'agriculture : lectures conventionnalistes et régulationnistes (Allaire G., Boyer R., dir.). Versailles/Paris, Inra éditions/ Economica, 33-51.

Thévenot L., 2006. L'action au pluriel : sociologie des régimes d'engagement. Paris, La Découverte.

ThÉvenot L., 2007. The Plurality of Cognitive Formats and Engagements: Moving between the Familiar and the Public. European Journal of Social Theory, 10 (3), 413-427.

Thévenot L., 2009. Governing Life by Standards: A View from Engagements. Social Studies of Science, 39 (5), 793-813.

Thévenot L., 2012. Convening the Company of Historians to Go into Conventions, Powers, Critiques and Engagements. Historical Social Research, 37 (4), 22-35.

Thévenot L., 2015a. Certifying the World: Power Infrastructures and Practices in Economies of Conventional Forms. In : Re-Imagining Economic Sociology (Aspers P., Dodd N., dir.). Oxford, Oxford University Press, 195-223.

Thévenot L., 2015b. Vous avez dit « capital »? Extension de la notion et mise en question d'inégalités et de pouvoirs de domination. Annales, Histoire, sciences sociales, 70 (1), 69-80.

ThÉvenot L., 2015c. Autorités à l'épreuve de la critique. Jusqu'aux oppressions du « gouvernement par l'objectif ». In : Le tournant de la théorie critique (Frère B., dir.). Paris, Desclée de Brouwer, 216-235.

Thévenot L., 2016. Le pouvoir des conventions. In : Dictionnaire des conventions (Batifoulier P., Bessis F., de Larquier G., Remillon D., dir.). Villeneuve d'Ascq, Presses universitaires du Septentrion, 203-207.

Thomas F., 2015. Droits de propriété industrielle et «communs » agricoles. Comment repenser l'articulation entre domaine public, biens collectifs et biens privés ? In : Repenser la propriété, essai de politique écologique (Vanuxem S., Guibet Lafaye C., dir.). Marseille, Presses universitaires d'AixMarseille, 171-190.

Tordjman H., 2008. La construction d'une marchandise : le cas des semences. Annales. Histoire, sciences sociales, 63 (6), 1341-1368.

Tordjman H., 2011. La crise contemporaine, une crise de la modernité technique. Revue de la régulation, en ligne, 10 (2), revue en ligne : http://regulation.revues.org/9456 (consulté le 3 mai 2016).

Torre A., 2002. Les AOC sont-elles des clubs? Réflexions sur les conditions de l'action collective localisée, entre coopération et règles formelles. Revue d'économie industrielle, 100 (1), 39-62.

Tout D., 1990. The Horticulture Industry of Almeria’s Province, Spain. The Geographical Journal, 156, 304-312.

Touzard J.-M., 1994. Crises sectorielles et dynamiques régionales : les recompositions de l'agriculture en Languedoc-Roussillon. thèse de doctorat en économie agroalimentaire, Montpellier, Ensam.

TouzARD J.-M., 1995. Régulation sectorielle, dynamique régionale et transformation d'un système productif localisé : l'exemple viticole languedocien. In : La grande transformation de l'agriculture : lectures conventionnalistes et régulationnistes (Allaire G., Boyer R., dir). Versailles/Paris, Inra éditions/ Economica, 293-322. 
Touzard J.-M., 1998. From Mass to Quality Production: Radical Change in Wine Co-operatives in Languedoc. In : Actes du colloque «Trajectories in Innovation in Agriculture », 23-26 avril, Berkeley (Californie).

TouzARD J.-M., 2000. Coordinations locales, innovation et régulation : l'exemple de la transition en Languedoc-Roussillon. Revue d'économie régionale et urbaine, 3, 589-604.

TOUZARD J.-M., 2008. Construction des marches et actions publiques : l'exemple de la reconversion viticole en Languedoc Roussillon. Les cahiers du Cevipof, 48, 113-140.

Touzard J.-M., 2016. Agroalimentaire : les voies contrastées de l'innovation. Paris/Lille, L’Harmattan/Université de Lille.

TouZARD J.-M., Fournier S., 2014. La complexité des systèmes alimentaires : un atout pour la sécurité alimentaire ? VertigO, 14 (1), revue en ligne https://vertigo.revues.org/14840 (consulté le 13 octobre 2016).

Touzard J.-M., Temple L., Faure G., Triomphe B., 2014. Systèmes d'innovation et communautés de connaissances dans le secteur agricole et agroalimentaire. Innovations, Cahiers d'économie et de management de l'innovation, 43, 13-38.

TP Organics, 2011. TP Organics Response to the Consultation on the "Green Paper on a Common Strategic Framework for Future EU Research and Innovation Funding". TP Organics Technology Platform.

Trabalzi F., 2007. Crossing Conventions in Localized Food Networks: Insights from Southern Italy. Environment and Planning A, 39 (2), 283-300.

Tracy M., 1982. Agriculture in Western Europe: Challenge and Response, 1880-1980. Londres, Granada.

Trostle R., 2008. Global Agricultural Supply and Demand: Factors Contributing to the Recent Increase in Food Commodity Prices. WRS-0801, Washington D. C., USDA-ERS.

Trouvé A., 2007. Le rôle des régions européennes dans la redéfinition des politiques agricoles. thèse de doctorat en sciences économiques, Dijon, Université de Bourgogne.

Trouvé A., 2009. Les régions, porteuses de nouveaux compromis pour l'agriculture ? Revue de la régulation, 5, revue en ligne : https://regulation.revues.org/7550 (consulté le 13 octobre 2016).

Trouvé A., Berriet-Solliec M., 2010. Regionalization in European Agricultural Policy: Institutional Actualities, Issues and Prospects. Regional Studies, 44 (8), 1005-1017.

Trouvé A., Dervillé M., Gouin D.M., Pouch T., Fink-Kessler A., Kroll J.F., Rat-Aspert O., Briot X., Lambaré P., 2016. Étude sur les mesures contre les déséquilibres de marché. Quelles perspectives pour l'après quotas dans le secteur laitier européen ? Rapport Marché référencé SSP-DGPAAT-2014-027, Paris, Ministère de l'Agriculture, de l'agroalimentaire et de la forêt.

Truninger M., 2011. Cooking with Bimby in a Moment of Recruitment: Exploring Conventions and Practice Perspectives. Journal of Consumer Culture, 11 (1), 37-59.

Tubiana L., 1984. Le commerce mondial de produits agricoles : de la régulation globale au fractionnement des marchés. Économies et sociétés, 28, 125-156.

Tucker R.P., 2000. Insatiable Appetite. The United States and the Ecological Degradation of the Tropical World. Berkeley/Los Angeles, University of California Press.

Tully J., 2009. A Victorian Ecological Disaster: Imperialism, the Telegraph, and Gutta-Percha. Journal of World History, 20 (4), 559-579.

Turner F.J., 1893. The Significance of the Frontier in American History. In : Frederick Jackson Turner: Wisconsin's Historian of the Frontier (Ridge M., dir.). Madison, State Historical Society of Wisconsin.

Twede D., 2012. The Birth of Modern Packaging: Cartons, Cans and Bottles. Journal of Historical Research in Marketing, 4 (2), 245-272.

UNCTAD, 2008. Private-Sector Standards and National Schemes for Good Agricultural Practices: Implications for Exports of Fresh Fruit and Vegetables from Sub-Saharan Africa: Experiences of Ghana, Kenya, and Uganda. New York/Genève, United Nations.

United Nations Departments of Economic and Social Affairs, 2004. Statistical Yearbook, 48. New York, United Nations.

United States Bureau of the Census, 1976. The Statistical History of the United States, from Colonial Times to the Present/Historical Statistics of the United States, Colonial Times to 1970. New York, Basic Books.

Valceschini E., Saulais L., (avec la collaboration de Barrey S.), 2005. Articulation entre réglementation, normalisation et référentiels privés dans les industries agroalimentaires. rapport final, 
Ministère de l'Agriculture et de la pêche, Direction des politiques économique et internationale (DPEI).

Valin H., Peters D., van den Berg M., Frank S., Havlik F.P., Forsell N., Hamelinck C., Pirker J., Mosnier A., Balkovic J., Schmid E., Dürauer M., Fulvio di Fulvio F., 2015. The Land Use Change Impact of Biofuels Consumed in the EU. Quantification of Area and Greenhouse Gas Impacts. Project number: BIENL13120, IIASA/E4Tech/Ecofys, Utrecht, Ecofys.

van Apeldoorn B., 2004. Theorizing the Transnational: A Historical Materialist Approach. Journal of International Relations and Development, 7 (2), 142-176.

van Dam D., Streith M., Nizet J., Stassart P., 2012. Agroécologie : entre pratiques et sciences sociales. Dijon, Educagri éditions.

VAN DER AKKer J., 2009. Convergence entre les Systèmes participatifs de garantie et les Systèmes de contrôle interne dans un projet pilote européen d'Ifoam. Innovations agronomiques, 4, 441-446.

van der Ploeg J.D., Jingzhong Y., Schneider S., 2012. Rural Development Through the Construction of New, Nested, Markets: Comparative Perspectives from China, Brazil and the European Union. The Journal of Peasant Studies, 39 (1), 133-173.

VANKeERberghen A., 2012. "Agriculteurs bio »: de l'institutionnalisation d'un groupe à une diversité de parcours professionnels. Uzance, 2, 1-13.

VAnlerberghe C. 2014. Paquets de cigarettes neutres : les leçons de l'expérience australienne. Le figaro.fr, 25 septembre, http://sante.lefigaro.fr/actualite/2014/09/25/22820-paquets-cigarettes-neutreslecons-lexperience-australienne (consulté le 2 octobre 2015).

Vanloqueren G., Baret P.V., 2009. How Agricultural Research Systems Shape a Technological Regime that Develops Genetic Engineering but Locks out Agro-ecological Innovations. Research Policy, 38 (6), 971-983.

van Tielhof M, 2002. The "Mother of all Trades": The Baltic Grain Trade in Amsterdam from the Late 16th to the Early 19th Century. Boston, Brill.

Varela Ortega C., Hernández-Mora N., 2009. Institutions and Institucional Reform in Spanish Water Sector: A Historical Perspective. In : Water Policy in Spain (Garrido A., Llamas Madurga R., dir.). Leiden, CRC Press/Balkema, 117-130.

VAtin F., 1996. Le lait et la raison marchande. Rennes, Presses universitaires de Rennes.

Vatin F., 2013. Valuation as Evaluating and Valorizing. Valuation Studies, 1 (1), 31-50.

Veblen T., 1908. On the Nature of Capital: Investment, Intangible Assets, and the Pecuniary Magnate. The Quarterly Journal of Economics, 23 (1), 104-136.

VerhaEgen E., 2012. Les réseaux agroalimentaires alternatifs : transformations globales ou nouvelle segmentation du marché. In : Agroécologie : entre pratiques et sciences sociales (Van Dam D., Michel Streith M., Nizet J., Stassart P.M., dir.). Dijon, Educagri éditions, 265-279.

Verhoest K., van Thiel S., Bouckaert G., Laegried P., 2012. Government Agencies: Practices and Lessons from 30 Countries. Londres, Palgrave Macmillan.

Vidal J.-F., 2002. Les régimes internationaux. In : Théorie de la régulation : l'état des savoirs (Boyer R., Saillard Y., dir.). Paris, La Découverte, 171-179.

VIEL J.-M., 1979. L'agriculture biologique, une réponse? Paris, Éditions Entente.

Vissac B. (avec le concours de LeClerc B.), 2002. Les vaches de la République : saisons et raisons d'un chercheur citoyen. Versailles, Éditions Quæ.

Vissac B., 2009. Une seconde révolution de l'élevage. In : Dans les pas de Bertrand Vissac, un bâtisseur : de la génétique animale aux systèmes agraires (Inra, dir.). Paris, Inra, 136.

Visser O., Mamonova N., Spoor M., 2012. Oligarchs, Megafarms and Land Reserves: Understanding Land Grabbing in Russia. The Journal of Peasant Studies, 39 (3-4), 899-931.

Visser O., Spoor M., Mamonova N., 2014. Is Russia the Emerging Global "Breadbasket"? Re-Cultivation, Agroholdings and Grain Production. Europe-Asia Studies, 66 (10), 1589-1610.

VIVIEN F.-D., 1998. Bioeconomic Conceptions and the Concept of Sustainable Development. In : Sustainable Development: Concepts, Rationalities, Strategies (Faucheux S., O'Connor M., van der Straaten J., dir.). Dordrecht, Kluwer Academic Publishers, 57-68.

Vivien F.-D., 1999. From Agrarianism to Entropy: Georgescu-Roegen's Bioeconomics from a Malthusian Viewpoint. In : Bioeconomics and Sustainability: Essays in Honour of Nicholas GeorgescuRoegen (Mayumi K., Gowdy J.M., dir.). Cheltenham, Edward Elgar, 155-172.

Vogl C.R., Kilcher L., Schmidt H., 2005. Are Standards and Regulations of Organic Farming Moving Away from Small Farmers' Knowledge? Journal of Sustainable Agriculture, 26 (1), 5-26. 
Voigt P., Wolz A., 2014. Agro-holdings in Russia: Temporary Phenomenon or a Prevailing Business Form? In : Agri-Food and Rural Innovations for Healthier Societies, EAAE 2014 Congress, 26-29 août, Ljubljana (Slovénie), EAAE.

von Elsner B., Briassoulis D., WaAijenberg D., Mistriotis A., von Zabeltitz C., Gratraud J., Russo G., SuAY-CORTES R., 2000a. Review of Structural and Functional Characteristics of Greenhouses in European Union Countries: I. Design Requirements. Journal of Agricultural Engineering Research, 75 (1), 1-16.

von Elsner B., Briassoulis D., Waaijenberg D., Mistriotis A., von Zabeltitz C., Gratraud J., Russo G., SuAY-CORTES R., 2000b. Review of Structural and Functional Characteristics of Greenhouses in European Union Countries: II. Typical Designs. Journal of Agricultural Engineering Research, 75 (2), 111-126.

von GotTl-Ottlilienfeld F., 1924. Fordismus: Über Industrie und Technische Vernunft. Jena, Fischer. Voz de Almeria ( La a), 2000. Anuario de la agricultura almeriense. Almeria, Novotécnica.

Wallerstein I., 1974. Capitalist Agriculture and the Origins of the European World-economy in the Sixteenth Century. New York, Academic Press.

Wallerstein I., 1983a. The Three Instances of Hegemony in the History of the Capitalist World Economy. International Journal of Comparative Sociology, 24 (1-2), 100-108.

Wallerstein I., 1983b. Crises: The World-Economy, the Movements, and the Ideologies. In : Crises in the World-System (Bergesen A., dir.). Beverly Hills, Sage, 21-36.

Wallerstein I., 1985. Le capitalisme historique. Paris, La Découverte, 1985 (nouvelle édition 2002).

Wallerstein I., 2006. Comprendre le monde : introduction à l'analyse des systèmes Monde. Paris, La Découverte.

Wandel J., 2011. Business Groups and Competition in Post-Soviet Transition Economies: The Case of Russian "Agroholdings". The Review of Austrian Economics, 24 (4), 403-450.

WARdE P., 2007. Energy Consumption in England \& Wales, 1560-2000. Napoli, Consiglio nazionale delle ricerche.

Waring P., LeWer J., 2004. The Impact of Socially Responsible Investment on Human Resource Management: A Conceptual Framework. Journal of Business Ethics, 52 (1), 99-108.

Weatherspoon D.D., Reardon T., 2003. The Rise of Supermarkets in Africa: Implications for Agrifood Systems and the Rural Poor. Development Policy Review, 21 (3), 333-356.

Webi W.P., 1964. The Great Frontier. Austin, University of Texas Press.

Weber M., 1995 [1921]. Économie et société : les catégories de la sociologie. Paris, Pocket.

WeIzsäcKer E.U., Lovins A.B., Lovins H.L., 1995. Faktor Vier - Doppelter Wohlstand, halbierter Naturverbrauch. Der neue Bericht an den Club of Rome. Munich, Droemer Knaur.

Wells P., ZaPATA C., 2012. A New Frontier for Industrial Ecology? Journal of Industrial Ecology, $16(5), 665-668$.

Wezel A., Bellon S., Doré T., Francis C., Vallod D., David C., 2009. Agroecology as a Science, a Movement and a Practice. Agronomy for Sustainable Development, 29 (4), 503-515.

Whatmore S., Thorne L., 1997. Nourishing Networks: Alternative Geographies of Food. In : Globalizing Food, Agrarian Questions and Global Restructuring (Goodman D., Watts M., dir.). Londres, Routledge, 287-304.

White H.C., 1992. Identity and Control: A Structural Theory of Social Action. Princeton, Princeton University Press.

Whatmore S., Thorne L., 1997. Nourishing Networks. Alternative Geographies of Food. In : Globalising Food. Agrarian Questions and Global Restructuring (Goodman D., Watts M., dir). Londres, Routledge, 287-304.

White C., 2004. Strategic Management. New York, Palgrave Macmillan.

Whittaker D.H., Sturgeon T., Song L., 2016. Compressed Development, Business Systems, and Innovation. In : Changing Asian Business Systems: Globalization, Socio-Political Change, and Economic Organisation (Whitley R., Zhang X., dir.). Oxford, Oxford University Press Oxford, 283-305.

Whyte K.P., List M., Stone J.V., Grooms D., Gasteyer S., Thompson P.B., Busch L., Buskirk D., Giorda E., Bouri H., 2014. Uberveillance, Standards, and Anticipation: A Case Study on Nanobiosensors in U.S. Cattle. In : Uberveillance and the Social Implications of Microchip Implants: Emerging Technologies (Michael M.G., Michael K., dir.). Hershey (Pennsylvanie), IGI Global, 251-269.

Wilkinson R.G., 1973. Poverty and Progress: An Ecological Model of Economic Development. Londres, Methuen. 
WiLkinson J., 1997. A New Paradigm for Economic Analysis. Economy and Society, 26 (3), 305-339.

WiLkinson J., 2014. Challenges to the Dominant Food System. Unpublished paper prepared for QUNU, Genève, QUNU.

WiLl P.-É., 1983. Le stockage public des grains en Chine à l'époque des Qing, 1644-1911. Problèmes de gestion et problèmes de contrôle. Annales. Économies, sociétés, civilisations, 38 (2), 259-278.

Willer H., Lernoud J., 2016. The World of Organic Agriculture - Statistics and Emerging Trends 2016. Bonn/Frick (Suisse), Research Institute of Organic Agriculture (FiBL)/Ifoam-Organics International.

Williams M., 2002. Deforesting the Earth: From Prehistory to Global Crisis. Chicago/Londres, University of Chicago Press.

Williams M., 2008. A New Look at Global Forest Histories of Land Clearing. Annual Review of Environment and Resources, 33, 345-367.

Williams J.W., 2014. Feeding Finance: A Critical Account of the Shifting Relationships between Finance, Food and Farming. Economy and Society, 43 (3), 401-431.

Williamson O.E., 1975. Markets and Hierarchies. New York, Free Press.

Williamson O.E., 1996. The Mechanisms of Governance. Oxford, Oxford University Press.

Wittfogel K.A., 1957. Oriental Despotism: A Comparative Study of Total Power. New Haven, Yale University Press.

World BANK, 2009. World Development Report 2008: Agriculture for Development. Washington D. C., World Bank Publications.

World Bank, 2010. Rising Global Interest in Farmland. Can it Yield Sustainable and Equitable Benefits? rapport de recherche, Washington D. C., World Bank.

World Economic Forum, 2010. The Future of Industrial Biorefineries. Genève, World Economic Forum.

Woo W.T., Lu M., SAchs J.D., Chen Z., 2012. A New Economic Growth Engine for China: Escaping the Middle-income Trap by not Doing more of the Same. Singapour, World Scientific Publishing Co. Pte. Ltd.

Wrigley E.A., 2010. Energy and the English Industrial Revolution. Cambridge, Cambridge University Press.

Yamashita K., 2008a. The Issues in the Farmland System, Tokyo. Tokyo, The Tokyo Foundation, en ligne : http://www.tokyofoundation.org/en/articles/2008/the-issues-in-the-farmland-system (consulté le 8 décembre 2012).

Yamashita K., 2008b. The Perilous Decline of Japanese Agriculture. Tokyo, The Tokyo Foundation, en ligne : http://www.tokyofoundation.org/en/articles/2008/the-perilous-decline-ofjapanese-agriculture-1 (consulté le 8 décembre 2012).

Yamashita K., 2009. The Agricultural Cooperatives and Farming Reform in Japan (1). Tokyo, The Tokyo Foundation.

YANG W., 2005. Réformes, ajustements structurels et revenu rural en Chine. Perspectives chinoises, 92, 29-35.

Yoshimatsu H., 1998. Japan's Keidanren and Political Influence on Market Liberalization. Asian Survey, 38 (3), 328-345.

Zelizer V.A., 1988. Beyond the Polemics on the Market: Establishing a Theoretical and Empirical Agenda. Sociological Forum, 3 (4), 614-634.

Zhang Q., Pierce F.J., 2013. Agricultural Automation: Fundamentals and Practices. Boca Raton (Floride), CRC Press.

ZuINDEAU B., 2001. L'analyse des externalités environnementales : éléments pour un programme de recherche régulationniste. Géographie, économie, société, 3 (1), 71-92.

Zuindeau B., 2007. Régulation School and Environment: Theoretical Proposals and Avenues of Research. Ecological Economics, 62 (2), 281-290.

Zukang S., 2009. Overview. In : Promoting Development, Saving the Planet (World Economic and Social Survey 2009). Department of Economic and Social Affairs, New York, United Nations. 


\section{Liste des auteurs}

Allaire Gilles, économie institutionnelle Directeur de recherche honoraire Inra, 19 rue Bellegarde, 31000 Toulouse Allaire.gilles@wanadoo.fr

BÉfORT Nicolas, sciences économiques

Laboratoire Regards, Université de Reims Champagne-Ardenne UFR de Sciences éco., sociales et de gestion 57, bis rue Pierre Taittinger, 51096 Reims Cedex, France befort.n@gmail.com

Boisvert Valérie, économie écologique Professeure ordinaire Université de Lausanne, Faculté des géosciences et de l'environnement Institut de géographie et durabilité CH-1015 Lausanne, Suisse valerie.boisvert@unil.ch

Bonneuil Christophe, histoire Chargé de recherche CNRS Centre Alexandre Koyré (UMR 8560, Cnrs-Ehess-Mnhn) 27 rue Damesme, 75013 Paris, France christophe.bonneuil@cnrs.fr

Buchs Arnaud, socioéconomie de l'environnement Maître de conférences Université Toulouse Jean Jaurès, LISST-Dynamiques rurales (CNRS-EHESS-ENFA)

FR-31058 Toulouse Cedex 9, France arnaud.buchs@univ-tlse2.fr

\section{Busch Lawrence}

University distinguished prof. of sociology

Michigan State University

509 E. Circle Drive, East Lansing,
MI 48824, USA

Lbusch@msu.edu

Cheyns Emmanuelle, sociologie Cirad, UMR Moisa

TA C-99/15, 73 rue Jean-François Breton, 34398 Montpellier Cedex 5, France emmanuelle.cheyns@cirad.fr

Cochoy Franck, sociologie

Professeur

CERTOP, Université Toulouse Jean-Jaurès, 5 allée Antonio Machado, 31058 Toulouse Cedex, France cochoy@univ-tlse2.fr

Colonna Paul, bioéconomie Directeur scientifique adjoint Bioéconomie Inra, 147 rue de l'université 75338 Paris cedex 07. France paul.colonna@inra.fr

Courleux Frédéric, agroéconomiste Cabinet Carles et Associés, Think-tank Momagri, vice-président de la SFER frederic.courleux@momagri.org

DAVIron Benoit, économie politique Cirad, UMR Moisa

73 rue Jean-François Breton 34398 Montpellier Cedex 5, France daviron@cirad.fr

DePeyrot Jean-Noël, agroéconomie Chargé de mission Régulation économique et marchés agricoles

Centre d'études et de prospective, Ministère de l'Agriculture, de l'agroalimentaire et de la forêt 3 rue Barbet de Jouy 75349 Paris 07 SP, France jean-noel.depeyrot@agriculture.gouv.fr 
Dervillé Marie, économie

Maître de conférences

LEREPS, université de Toulouse, ENSFEA, IEP de Toulouse, France marie.derville@educagri.fr

Ducastel Antoine, économie politique Cirad, UMR Art-Dev

TA C-113/15, 73 rue Jean-François Breton 34398 Montpellier Cedex 5, France antoine.ducastel@cirad.fr

Fischer-KowALSKi Marina Prof. emeritus of social ecology Alpen Adria University Klagenfurt, Wien, Graz Institute of Social Ecology Vienna 1070 Wien, Schottenfeldgasse 29, Autriche Marina.fischer-kowalski@aau.at http://www.uni-klu.ac.at/socec/eng/ inhalt/876.htm

Foullleux Éve, science politique Directrice de recherches CNRS, université de Montpellier Chercheure associée Cirad, UMR Moisa TA C-99/15, 73 rue Jean-François Breton 34398 Montpellier Cedex 5, France eve.fouilleux@cirad.fr

Fressoz Jean-Baptiste, historien Chargé de recherche CNRS

Centre Alexandre Koyré, CNRS-EHESS-MNHN

27 rue Damesme, 75013 Paris, France jean-baptiste.fressoz@cnrs.fr

Goodman David

Prof. emeritus, environmental studies University of California, High Street Santa Cruz, CA. 95060, USA. hatters@ucsc.edu goodmande38@icloud.com

Grouiez Pascal, économie

Maître de conférences Université Paris Diderot 5 rue Thomas Mann 75202 Paris Cedex 13, France pascal.grouiez@gmail.com

Krausmann Fridolin

Prof. of sustainable resource use, vice Dean for research

Alpen Adria University Klagenfurt, Wien, Graz Institute of Social Ecology Vienna 1070

Wien, Schottenfeldgasse 29, Autriche

Fridolin.krausmann@aau.at http://www.uni-klu.ac.at/socec/inhalt/882.htm

\section{Labarthe Pierre}

Inra, Sad-APT, 16, rue Claude Bernard

75231 Paris cedex 05, France

pierre.labarthe@agroparistech.fr

LABATUT Julie, sciences de gestion

Inra, UMR-Agir

Université de Toulouse,

INRA, INPT, INP- EI PURPAN,

Castanet-Tolosan, France

julie.labatut@inra.fr

LANDel Pauline, science politique

AgroParisTech, 16 rue Claude Bernard 75231 Paris Cedex 5, France

landel.pauline@gmail.com

Laurent Catherine, économie politique

Directrice de recherche

Inra-Sad, 16 rue Claude Bernard, 75231

Paris Cedex 5, France

catherine.laurent@inra.fr

LemeILleur Sylvaine, économie, Cirad, UMR Moisa

TA C-99/15, 73 rue Jean-François Breton, 34398 Montpellier Cedex 5, France sylvaine.lemeilleur@cirad.fr

LEvidow Les, science and technology studies, rural sociology, human geography Senior research fellow

Development Policy and Practice

Open University, Milton Keynes MK7 6AA, UK

L.Levidow@open.ac.uk

Loconto Allison Marie, sociologie

Chargée de recherche

Laboratoire interdisciplinaire sciences innovations sociétés (Lisis), CNRS-ESIEE Paris-INRA-UPEM, université Paris-Est Cité Descartes, 5, boulevard Descartes Champs-sur-Marne 
77454 Marne-la-Vallée cedex, 02, France allison-marie.loconto@inra.fr

Nieddu Martino, économie

Professeur des universités, dir. du laboratoire Regards UFR des Sciences économiques, sociales et de gestion, université de Reims Champagne Ardenne 57 bis, rue Pierre Taittinger 51096 Reims cedex, France martino.nieddu@univ-reims.fr

PomÉOn Thomas, socioéconomie Ingénieur de recherches Inra US-ODR, Inra Toulouse thomas.pomeon@inra.fr

PonTE Stefano, international political economy Professor

Copenhagen Business School, Department of Business and Politics Steen Blichersvej 22, 2000 Frederiksberg, Denmark

Sp.dbp@cbs.dk

SAulais Laure, économie

Chargée de recherche

Institut Paul Bocuse,

Château du Vivier

BP 25, 69131 Écully Cedex, France

laure.saulais@institutpaulbocuse.com

SCOLLAy Robert, economics

Associate professor

Faculty of Business and Economics,

University of Auckland

r.scollay@auckland.ac.nz

Tesnière Germain, sciences de gestion Inra, université de Toulouse,

UMR Agir

Chemin de Borde Rouge

F-31326 Castanet-Tolosan, France

germain.tesniere@inra.fr
Touzard Jean-Marc, économie de l'innovation Directeur de recherche Inra Inra UMR Innovation, 2 place Viala, 34060 Montpellier touzard@montpellier.inra.fr

VAlCESChini Égizio

Directeur de recherche Inra

Représentant pour la France au Standing

Committee for Agricultural Research

Inra, 147 rue de l'université

75338 Paris Cedex 07, France

egizio.valceschini@inra.fr

Vivien Franck-Dominique, économie

Professeur des universités

Laboratoire Regards

Université de Reims Champagne Ardenne 57 bis, rue Pierre Taittinger, 51096 Reims

Cedex, France

fd.vivien@univ-reims.fr

WARD Anseeuw, économie politique

UMR Art-Dev

Fonds international de Développement Agricole FIDA -

Via Paolo di Dono, 44-00142 Roma, Italie ward.anseeuw@cirad.fr

Whittaker D. Hugh, economic sociology

Director

Nissan Institute of Japanese Studies

University of Oxford, UK

hugh.whittaker@nissan.ox.ac.uk

WiLKINSON John, sociologue

professeur associé

Centre Développement Agriculture

et Société

CPDA/DDAS,

Universidade Federale Rurale

Av Presidente Vargas, 417/6 Centro

20071-003, Rio de Janeiro, Brésil

jhn.wlknsn@gmail.com 
Édition

Yann Lézénès

Mise en page

DESK

Impression

ISIPrint

Dépôt légal Février 2017 
À l'heure des robots et du numérique, la terre (habitat, agriculture, paysage, planète) et la nourriture (du corps et de l'âme) sont parmi les préoccupations majeures dans les espaces médiatiques et politiques; le pétrole et l'abondance qui l'a accompagné nous avaient fait oublier qu'elles sont au fondement des sociétés humaines. La " crise alimentaire » de 2008, qui a secoué plusieurs continents, a rappelé aux gouvernements l'enjeu de la sécurité alimentaire.

Après des décennies d'excédents, de baisse du prix des produits agricoles de base, la question de la valeur de la terre et de l'agriculture est de retour. La question de la santé et celle des droits humains prennent une place élargie tant dans les politiques publiques que dans la production de normes alimentaires. Des mouvements sociaux transnationaux s'emparent de la question de l'avenir de l'agriculture et de l'alimentation, et de celle de la «bonne vie».

Pour contribuer à cette réflexion sur l'avenir de la terre et de la nourriture, cet ouvrage étudie la socialisation de l'agriculture, c'est-à-dire sa prise en charge tant par les politiques agricoles (essentiellement nationales) que par l'organisation des marchés dans un cadre national et international. Il le fait en prenant un large recul et mobilise trois temporalités. La première est celle de la planète. La seconde, celle des régimes métaboliques, façons dont l'humanité à différents stades de développement, mobilise matériaux et énergie. La troisième est celle du capitalisme, avec la succession de systèmes hégémoniques (ce qui n'exclut pas de multiples polarités).

Cet ouvrage réunit des recherches récentes d'économistes, de sociologues, d'historiens et d'agronomes, de différents pays, recherches qui ont en commun de concerner la place de l'agriculture dans l'évolution des capitalismes.

Gilles Allaire est économiste, directeur de recherches honoraire à l'Inra. Ses principaux thèmes de recherche concernent les institutions, les marchés et les politiques agricoles.

Benoit Daviron est économiste au Cirad. Ses domaines de compétences sont l'organisation du commerce international de produits tropicaux, les accords de produit et les normes internationales dans le secteur agricole.

En couverture : cargo-palette, acrylique sur papier marouflé sur toile (C) Tina Kambani, artiste peintre, 2010.

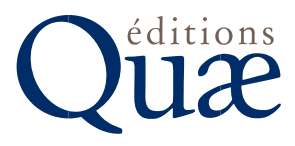

Éditions Cirad, Ifremer, Inra, Irstea www.quae.com

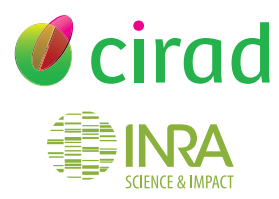

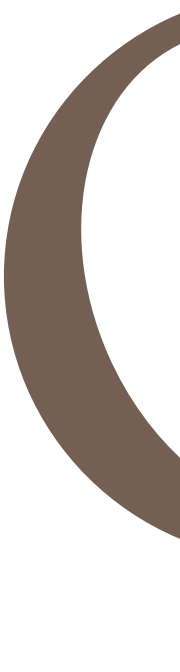

